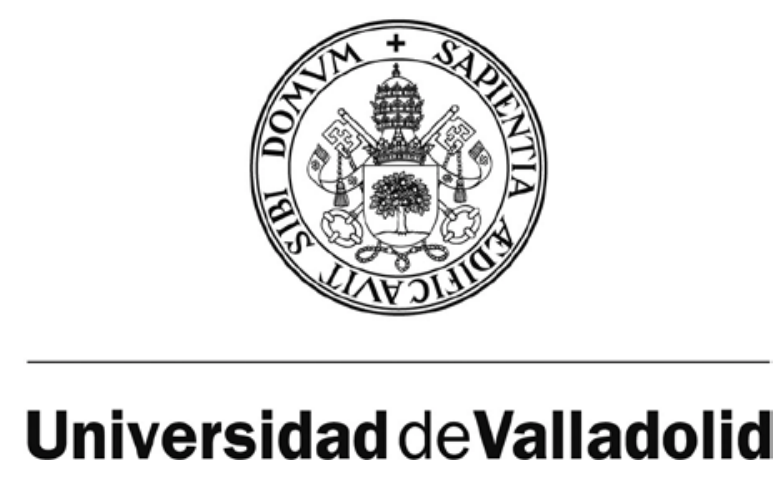

ESCUELA DE INGENIERÍAS INDUSTRIALES

DEPARTAMENTO DE INGENIERÍA ENERGÉTICA Y FLUIDOMECÁNICA

TESIS DOCTORAL:

\title{
“REDUCCIÓN DEL CONSUMO ENERGÉTICO Y EMISIONES DE ANHÍDRIDO CARBÓNICO EN EDIFICIOS COMBINANDO ENFRIAMIENTO EVAPORATIVO, ENFRIAMIENTO GRATUITO Y RECUPERACIÓN DE ENERGÍA EN SISTEMAS TODO AIRE"
}

Presentada por Ana Tejero González para optar al grado de doctora por la Universidad de Valladolid

\author{
Dirigida por: \\ Dr. Eloy Velasco Gómez \\ Dr. Francisco Javier Rey Martínez
}





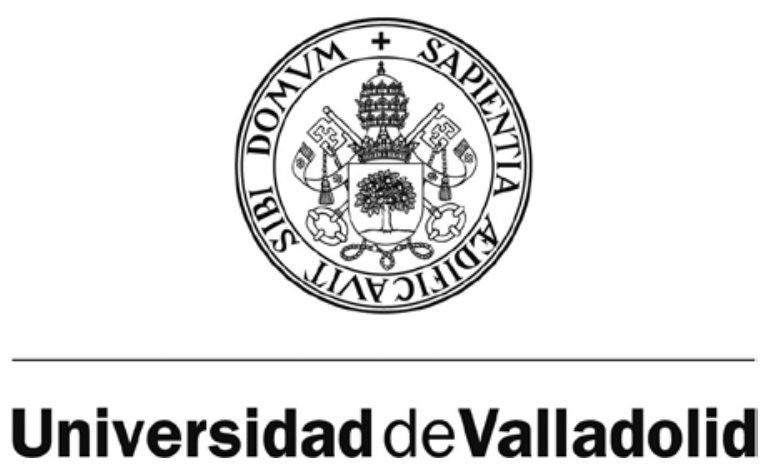

\author{
SCHOOL OF ENGINEERING \\ DEPARTMENT OF ENERGY AND FLUIDMECHANICS
}

PHD THESIS:

\title{
"REDUCTION OF THE ENERGY CONSUMPTION AND $\mathrm{CO}_{2}$ EMISSIONS IN BUILDINGS, COMBINING EVAPORATIVE COOLING, FREE-COOLING AND ENERGY RECOVERY IN AIR-TO-AIR SYSTEMS"
}

Submitted by Ana Tejero González in support of candidature for the Ph.D. degree (European Mention) by the University of Valladolid

\author{
Directed by: \\ Dr. Eloy Velasco Gómez \\ Dr. Francisco Javier Rey Martínez
}



A los cuatro espejos

en los que me miro 



\section{AGRADECIMIENTOS}

Este trabajo no existiría si mis tutores, Eloy Velasco y Francisco Javier Rey, no me hubieran embarcado en él, enseñado tanto, y guiado y revisado cada paso dado.

Y hubiera sido todavía más arduo si Sergio no se hubiera manchado las manos, o mi hermano no me hubiera echado una dejándose los ojos con la portada.

Aún así, mi familia ha tenido que aguantarme con toda la paciencia del mundo las consecuencias del agobio. Incluso aunque mis compañeros de entrenamiento me hayan permitido descargarlas en ellos, recordándome lo importante de Perseverar...

En cualquier caso, siempre ha sido más ameno de llevar teniendo al lado al puñado de amigos que aún quedan por la Escuela, y el apoyo de los que ya marcharon pero siguen cerca estando en otra ciudad o en otro continente.

Sobre todo cuando fui yo quien estuvo fuera, y todas esas personas siguieron próximas. $Y$ cuando regresé, lo hice habiendo ganado otras nuevas.

Sin aquéllos a los que menciono en esta única hoja del trabajo, no existiría el resto de ellas.

Gracias a todos. 



\section{ÍNDICE/ INDEX}

AGRADECIMIENTOS

PARTE I: INTRODUCCIÓN/

PART I: INTRODUCTION

Capítulo I: Problemática energética en la climatización/ Chapter I: Energy problems in Air-conditioning ......................3

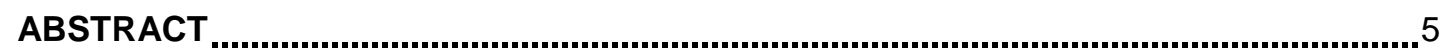

I.1. ENERGÍA: NECESIDAD Y PROBLEMÁTICA. ................................................. 7

DEPENDENCIA DE RECURSOS

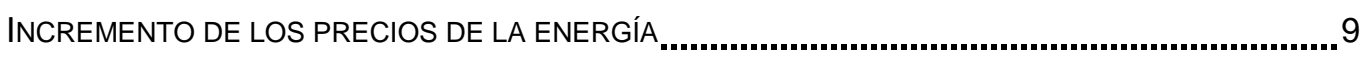

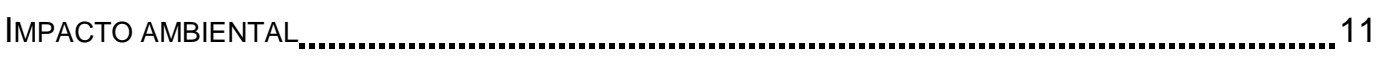

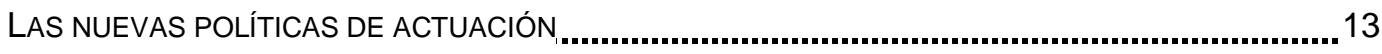

I.2. PROBLEMÁTICA ENERGÉTICA EN LA EDIFICACIÓN............................................14

CONSUMO ENERGÉTICO EN LAS INSTALACIONES DE CLIMATIZACIÓN.....................................16

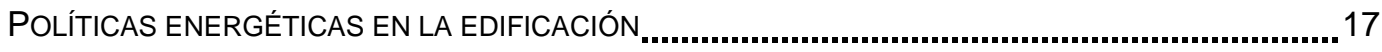

Certificación energética ...........................................................................17

Código Técnico de la Edificación (CTE) ............................................................18

Reglamento de Instalaciones Térmicas en Edificios (RITE) .................................19

I.3. MÉTODOS DE REDUCCIÓN DEL CONSUMO ENERGÉTICO EN LA CLIMATIZACIÓN DE EDIFICIOS. 
DISMINUCIÓN DE LAS NECESIDADES ENERGÉTICAS. 22

SUSTITUCIÓN DE LAS FUENTES CONVENCIONALES DE ENERGÍA POR OTRAS FUENTES SOSTENIBLES... 22

OPTIMIZACIÓN DE LA EFICIENCIA DE UTILIZACIÓN.

\section{Capítulo II: Calidad del Clima Interiorl Chapter II: Indoor Climate Quality}

ABSTRACT

II.1. CALIDAD DE AMBIENTES INTERIORES IEQ (INDOOR ENVIRONMENTAL QUALITY) .....35

INTRODUCCIÓN 35

FACTORES QUE INTERVIENEN EN EL BIENESTAR EN ESPACIOS INTERIORES 36

II.2. CALIDAD DEL CLIMA INTERIOR ICQ (INDOOR CLIMATE QUALITY). 37

CONFORT TÉRMICO 37

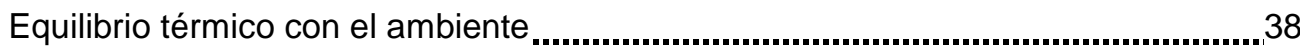

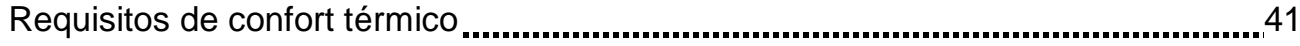

Normativa

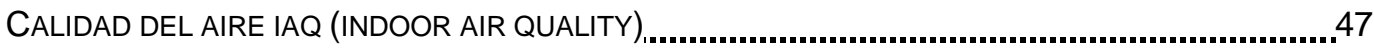

Introducción

Evolución temporal de la concentración de un contaminante: ecuaciones..............48

Percepción sensorial de la calidad del aire: evaluación subjetiva .........................49

Normativa

II.3. CLASIFICACIÓN DE AMBIENTES INTERIORES EN CONFORT TÉRMICO Y CALIDAD DEL AIRE. 53

CLASIFICACIÓN DEL AMBIENTE TÉRMICO: CRITERIOS DE ACEPTABILIDAD............................53

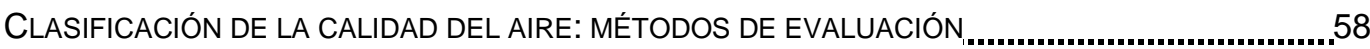

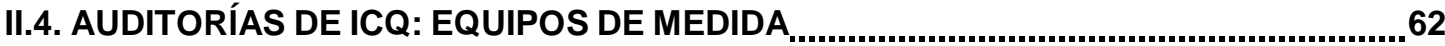

INTRODUCCIÓN

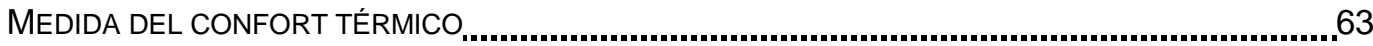

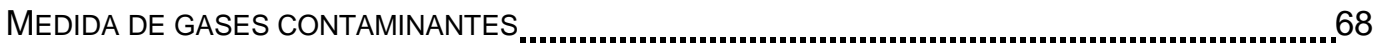




\section{Capítulo III: Estado actual de las tecnologías de estudiol} Chapter III: State of the art of studied technologies

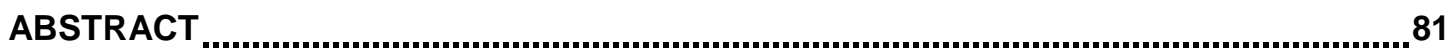

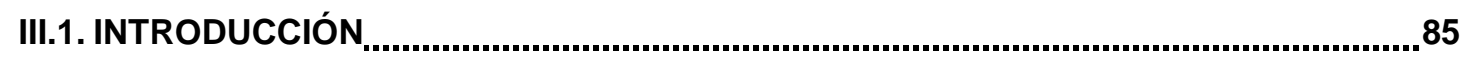

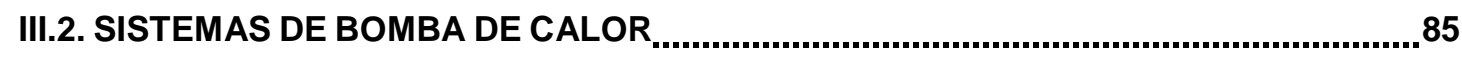

FUNDAMENTOS

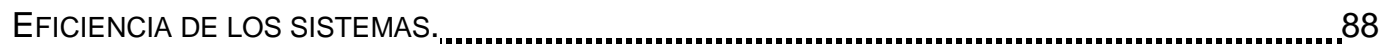

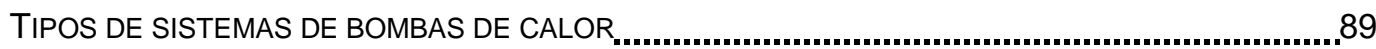

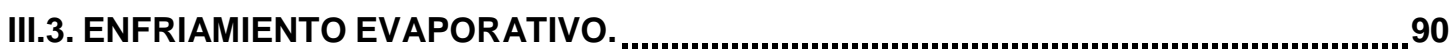

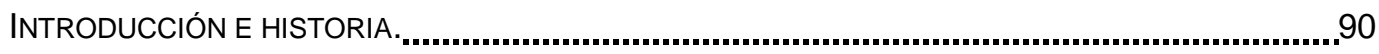

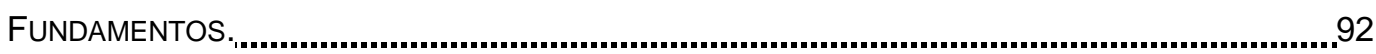

SISTEMAS DE ENFRIAMIENTO EVAPORATIVO CONVENCIONALES..........................................95

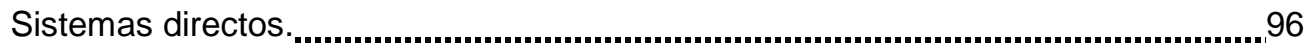

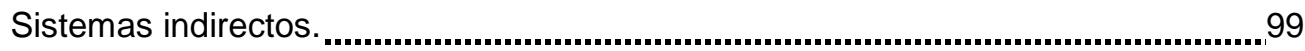

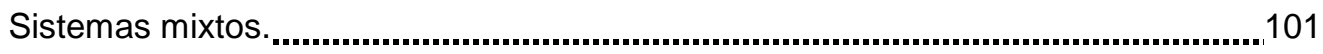

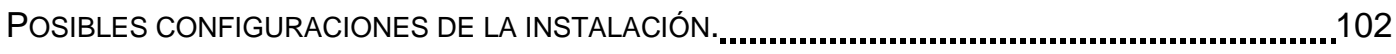

LEGIONELOSIS: RIESGOS Y CONTROL.......................................................................

III.4. ENFRIAMIENTO GRATUITO (FREE-COOLING) ...................................................104

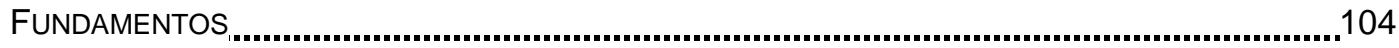

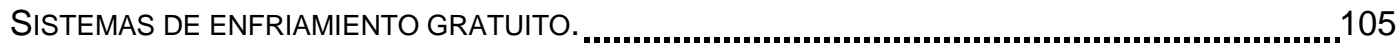

Sistemas de enfriamiento gratuito por aire exterior ............................................105

Sistemas de enfriamiento gratuito por agua .......................................................109

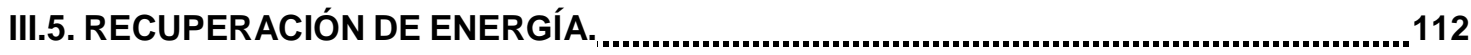

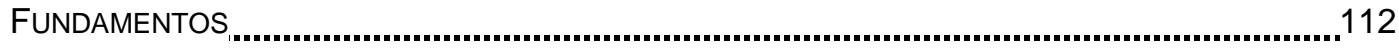

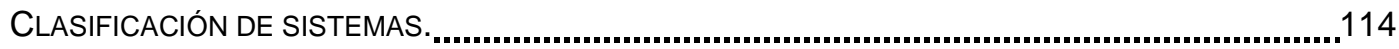

Intercambiadores de Placas ...........................................................................

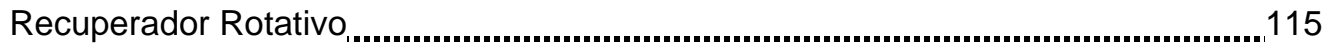

Recuperador de dos baterías con bomba .........................................................116

Recuperadores evaporativos........................................................................117 
Recuperadores con tubos de calor 118

Bomba de Calor como recuperador 119

\section{PARTE II: CARACTERIZACIÓN EXPERIMENTAL DE LOS SISTEMASI}

PART II: EXPERIMENTAL CHARACTERIZATION.

\section{Capítulo IV: Dispositivo experimentall}

Chapter IV: Experimental facility

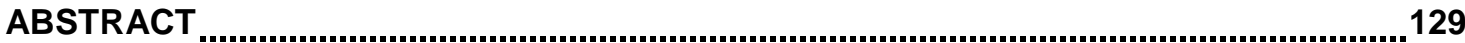

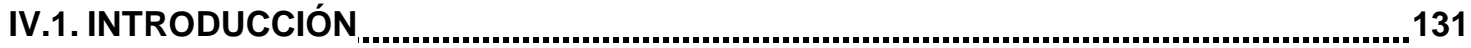

IV.2. ELEMENTOS DEL BANCO DE ENSAYOS .............................................................

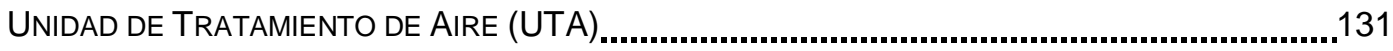

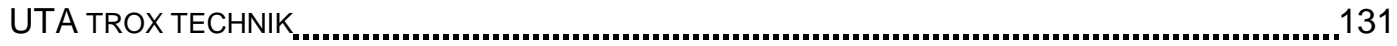

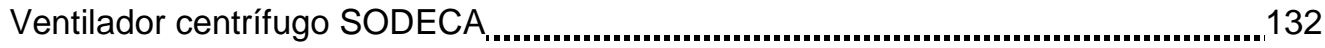

Humidificador HumiSteam X-Plus (CAREL) ...................................................... 133

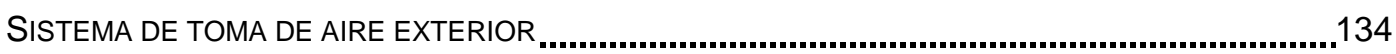

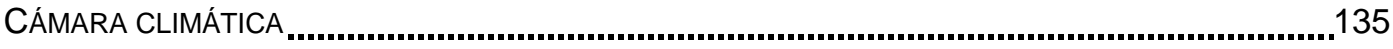

Bomba de Calor Aire-aire ......................................................................................136

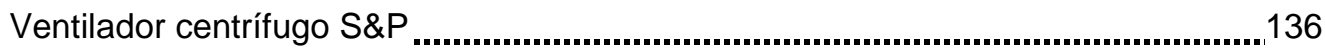

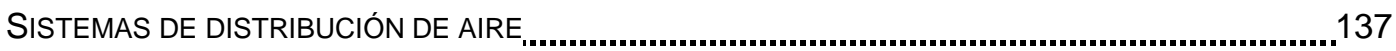

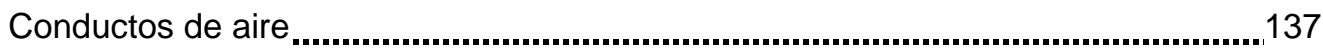

Plenums de distribución y conexión....................................................................138

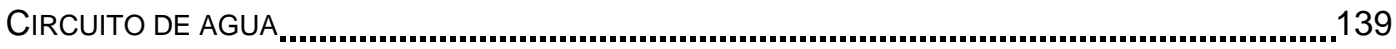

Bombas de agua

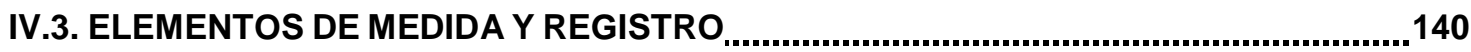

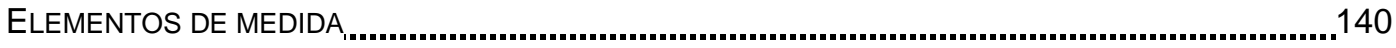

Sensores de medida de temperatura .................................................................140

Sensores de medida de humedad .....................................................................141

Medida de la presión diferencial y caudal volumétrico: Placa orificio......................141

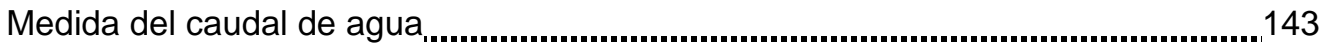

SISTEMA DE ADQUISICIÓN Y SOFTWARE DE MONITORIZACIÓN DE DATOS .................................143

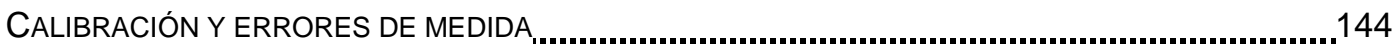

Calibración de las sondas de temperatura ......................................................145

Calibración de las sondas de humedad relativa ..................................................146 
Capítulo V: Caracterización de los enfriadores evaporativos indirectos de placas de policarbonatol

Chapter V: Characterization of the polycarbonate plate indirect evaporative coolers

ABSTRACT 157

V.1. INTRODUCCIÓN 161

V.2. DISEÑO Y CONSTRUCCIÓN DE LOS ENFRIADORES EVAPORATIVOS INDIRECTOS DE POLICARBONATO.

V.3. INSTALACIÓN EXPERIMENTAL. 165

V.4. DISEÑO DE EXPERIMENTOS. METODOLOGÍA DE ENSAYOS 167

V.5. ANÁLISIS DE RESULTADOS. 169

PARÁMETROS CONSIDERADOS EN LA CARACTERIZACIÓN EXPERIMENTAL, 169

RESULTADOS DEL EEI DE POLICARBONATO DE PASO ESTRECHO 170

RESULTADOS DEL EEI DE POLICARBONATO DE PASO ANCHO. 174 COMPARACIÓN DE RESULTADOS ENTRE EQUIPOS. 178

V.6. ANÁLISIS DE VARIANZA 181

Capítulo VI: Caracterización de equipos de Enfriamiento Evaporativo Directos/

Chapter VI: Characterization of the Direct Evaporative Coolers.

VI.1. INTERÉS Y PROBLEMÁTICA DE LOS EQUIPOS DE ENFRIAMIENTO EVAPORATIVO DIRECTOS 201

VI.2. EED DE PULVERIZACIÓN 202

APLICACIONES DE LOS SISTEMAS DE PULVERIZACIÓN 202

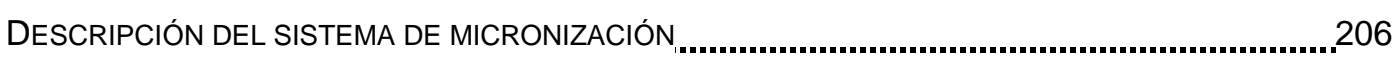

CARACTERIZACIÓN DEL SISTEMA DE MICRONIZACIÓN ......................................................208 Instalación experimental....................................................................................208

Metodología de ensayos

Análisis de resultados..........................................................................2 211

APLICACIÓN AL REFRESCAMIENTO DE UN ESPACIO EXTERIOR............................................215 
APLICACIÓN AL REFRESCAMIENTO DE UN ESPACIO INTERIOR

Instalación experimental

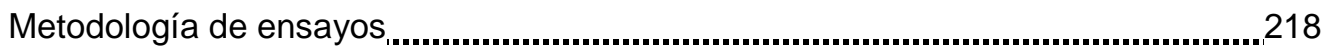

Cálculo teórico del flujo másico de agua........................................................219

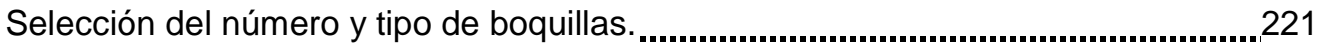

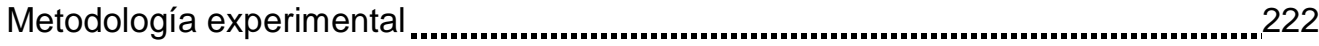

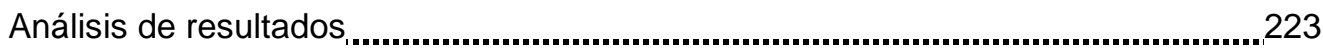

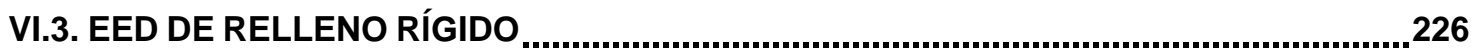

DESCRIPCIÓN DEL SISTEMA COMERCIAL DE RELLENO RÍGIDO FA6......................................227

INSTALACIÓN EXPERIMENTAL.,........................................................................... 230

METOdOLOGÍA DE ENSAYOS. ....................................................................................232

ANÁLISIS DE RESULTADOS. ...........................................................................232

EVOLUCIÓN PSICROMÉTRICA DEL AIRE TRATADO...........................................................236

VI.4. COMPARACIÓN ENTRE LOS DOS SISTEMAS DE EED

Capítulo VII: Caracterización del sistema de enfriamiento gratuito por agual

Chapter VIl: Characterization of the Free cooling by water system

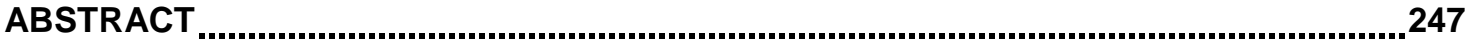

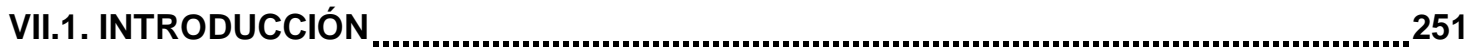

VII.2. DESCRIPCIÓN DEL SISTEMA DE TORRE CON BATERÍA.....................................251

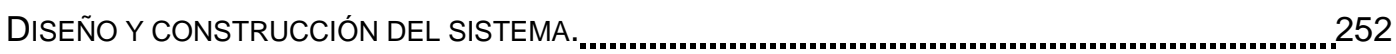

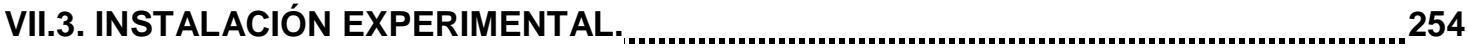

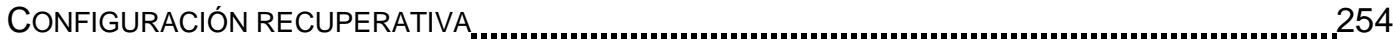

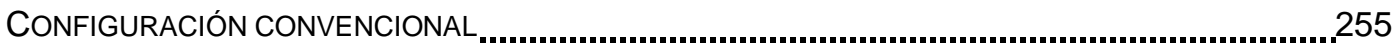

DiSEÑO DE EXPERIMENTOS. METODOLOGÍA DE ENSAYOS...........................................256

VII.4. ANÁLISIS DE RESULTADOS.

PARÁMETROS CONSIDERADOS EN LA CARACTERIZACIÓN EXPERIMENTAL............................258

RESULTADOS DE LA CONFIGURACIÓN RECUPERATIVA ......................................................260

RESULTADOS DE LA CONFIGURACIÓN CONVENCIONAL............................................266

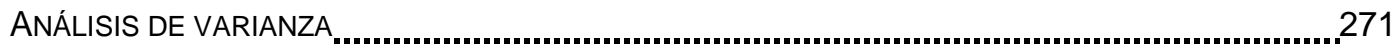

ANOVA - C-R: Resultados ..........................................................................271 
Capítulo VIII: Caracterización del sistema de recuperación de energía mediante dos baterías con bombal

Chapter VIII: Characterization of the Run-around loop heat recovery system. 289

ABSTRACT 291

VIII.1. INTRODUCCIÓN 295

VIII.2. DISEÑO Y CONSTRUCCIÓN DEL SISTEMA 295

VIII.3. DISEÑO DE EXPERIMENTOS. METODOLOGÍA DE ENSAYOS. 299

VIII.4. ANÁLISIS DE RESULTADOS 301

PARÁMETROS CONSIDERADOS EN LA CARACTERIZACIÓN EXPERIMENTAL 301 RESULTADOS DE LOS PARÁMETROS CONSIDERADOS 303 ANÁLISIS DE VARIANZA 306

PART III: RESULTS AND CONCLUSIONS 315

Chapter IX: Practical analysis of results obtained 317

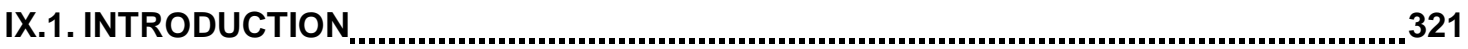

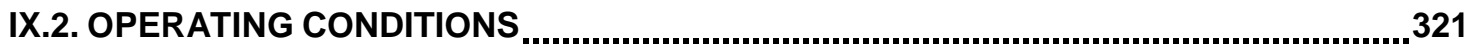

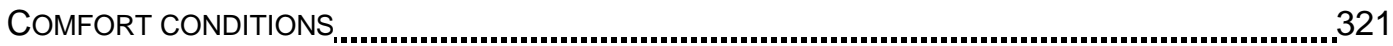

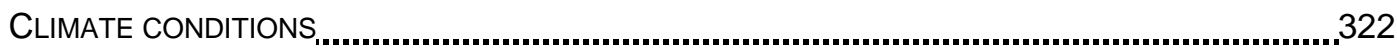

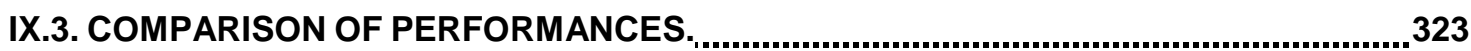

PERFORMANCE OF SYSTEMS OPERATING IN NATURALLY CONDITIONED SPACES ......................323

COOLING CAPACITIES OF SYSTEMS OPERATING INTO A HEAT RECOVERY MODE ......................324

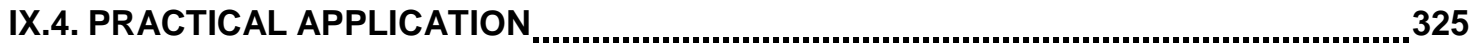

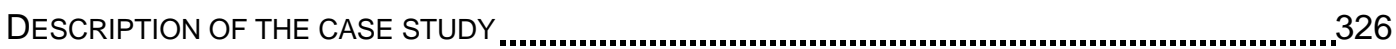

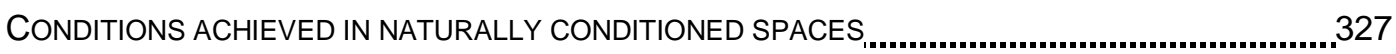

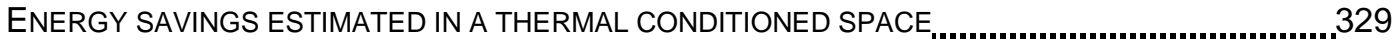

$\mathrm{CO}_{2}$ EMISSIONS REDUCTION ESTIMATED IN A THERMAL CONDITIONED SPACE $\ldots . . . \ldots \ldots \ldots \ldots . . . . . . . . .334$

Chapter X: Conclusions and future work .......................................341

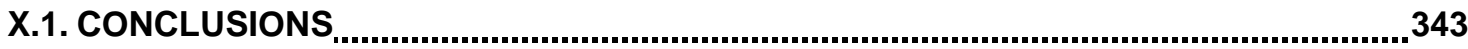


POLYCARBONATE INDIRECT EVAPORATIVE COOLERS 343

DIRECT EVAPORATIVE COOLERS 344

FREE-COOLING BY WATER. 345

RUN-AROUND LOOP HEAT RECOVERY, 346

X.2. FUTURE WORK 346

ANEXosl ANNEXES

Anexo A: Procedimiento de diseño de experimentos y análisis de varianzal

Annex A: Design of Experiments and Analysis of Variance Proceedings 351

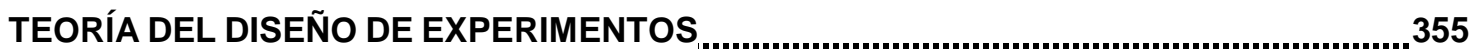

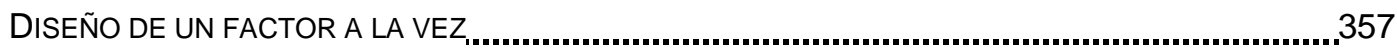

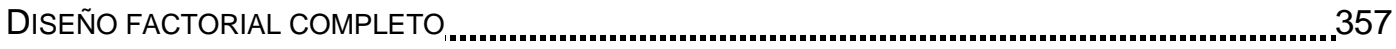

DISEÑO ORTOGONAL FRACCIONAL Y ARREGLOS ORTOGONALES..........................................358

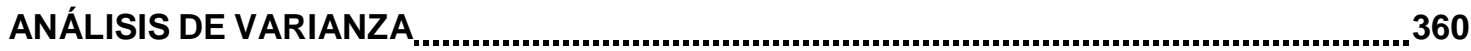

\section{Anexo B: Calibraciones/}

Annex B: Calibrations

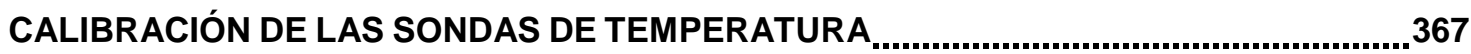

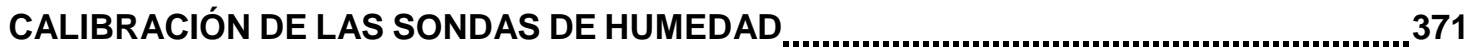

CALIBRACIÓN DE LOS MANÓMETROS DE PRESIÓN ...................................................372

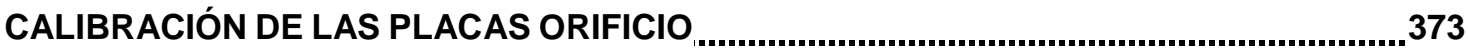




\section{RESUMEN \\ ABSTRACT}




\section{RESUMEN}

El presente trabajo de Tesis Doctoral se focaliza en la caracterización experimental de diversos sistemas de acondicionamiento de aire, así como en el diseño y construcción original de varios de estos sistemas, destinados a reducir la demanda energética de climatización de los edificios en período estival, a fin de modelar su comportamiento ante las diversas condiciones de funcionamiento esperables.

La justificación del estudio de este tipo de sistemas de bajo consumo energético, se basa en el preacondicionamiento del aire de ventilación impulsado a los locales para cumplir los requisitos establecidos de Calidad del Aire Interior IAQ, dentro del contexto de conciencia global sobre eficiencia energética orientada a combatir la extinción de recursos y el impacto medioambiental, manteniendo las prestaciones exigidas a las instalaciones de acondicionamiento de aire. Por este motivo, se introducen los conceptos más relevantes sobre confort térmico y calidad del aire, a fin de definir con claridad los objetivos últimos de la operación de los sistemas.

Los sistemas analizados se tratan en su mayor parte de prototipos diseñados y construidos en el laboratorio de Termotecnia de la Universidad de Valladolid; si bien los sistemas de enfriamiento evaporativo directos son equipos comerciales. Para la caracterización experimental, se construye un banco de ensayos en el laboratorio que permita la regulación y control de los factores de ensayo considerados de interés en base a un diseño de experimentos realizado sobre cada estudio particular, y orientando los resultados obtenidos a la definición de una serie de parámetros de eficiencia que permitan describir su funcionamiento. Para la comprobación de resultados en cuanto a relevancia de los factores considerados, se plantea posteriormente para cada equipo un análisis de varianza ANOVA.

Finalmente, se propone un análisis conjunto de los sistemas en base a su aplicabilidad a un caso práctico común de un local sencillo, concebido como referencia en la normativa española para la validación de métodos alternativos de cálculo de demandas; supuesto térmicamente acondicionado o meramente con ventilación natural, en función de las posibilidades de aplicación características de cada sistema.

De los resultados obtenidos a partir de la caracterización individual de cada equipo, así como de la comparativa realizada en conjunto, se derivarán una serie de conclusiones y trabajos futuros considerados de importancia para asentar la relevancia científica del trabajo desarrollado. 


\section{ABSTRACT}

The present $\mathrm{PhD}$ work focuses on the experimental characterization of various airconditioning systems, as well as on the design and manufacturing of many of them, all aimed at reducing the energy demand required for air-conditioning buildings during summer period, in order to determine their behaviour in different operational conditions expected.

The study on these low-energy consumption devices is justified in base of the possibility of preconditioning ventilation airstreams supplied inside spaces to accomplish with the requirements established for Indoor Air Quality IAQ, within the current global framework of environmental awareness and avoiding extinction of energy sources; without forgetting maintaining the levels of Indoor Climate and Air Quality (ICQ, IAQ) expected indoors. For this reason, concepts concerning ICQ and IAQ are introduced, with the aim of clearly defining the final objectives of the system's installation.

Systems studied are in the most part prototypes designed and manufactured at the Thermal Engineering Laboratory of the University of Valladolid. However, the two direct evaporative coolers are commercial systems. For the characterization, an experimental facility is constructed and acquired to enable regulation and control of the test factors considered of interest with respect to the results derived from a Design of Experiments; and results are used for the determination of some parameters that permit defining the system's beaviour. To check the relevance on the behaviour of the factors considered, an analysis of variance ANOVA has been developed afterwards.

Finally, a global analysis of the results is proposed to study the applicability of the systems for a particular case study of a simple indoor space, defined by the Spanish norm as a reference for the validation of alternative methods of cooling demand calculus. This space is supposed to be thermally conditioned or naturally ventilated, depending on the possibilities of application of each system.

From the results obtained through the individual characterizations, as well as from their application in the case study, some conclusions and future work are derived as important issues to set the scientific relevance of the study. 


\section{ANTECEDENTES \\ BACKGROUND}




\section{ANTECEDENTES}

El grupo de Termotecnia de la Universidad de Valladolid viene realizando históricamente un extenso y dedicado trabajo sobre el estudio de las prestaciones requeridas en la climatización de espacios, y en particular sobre alternativas de climatización de bajo consumo energético. Algunos de los trabajos de tesis doctorales precedentes al presente y de importancia para su desarrollo son los mentados a continuación:

Trabajo de tesis doctoral del Dr. Don Julio San José Alonso titulado "Estudio energético de un Refrigerador Evaporativo Indirecto con Recuperación de Energía en Sistemas de Aire Acondicionado", y presentado en el año 1994. El dispositivo estudiado consistió en un enfriador evaporativo indirecto fabricado con placas de aluminio como superficie de intercambio, el cual se trata de un material bastante convencional para este tipo de sistemas.

El trabajo de tesis doctoral con título: "Estudio Energético y Desarrollo de un Recuperador Tipo Heat Pipes (Tubos de Calor) para Climatización" fue presentado por el investigador Eloy Velasco Gómez en el año 1998, tutor del presente trabajo de tesis doctoral. En ese trabajo de investigación se estudiaba una alternativa de recuperación de energía basada en la tecnología heat-pipes.

El siguiente trabajo doctoral realizado en el grupo corresponde al del doctor ingeniero industrial Mario Álvarez-Guerra Plasencia, también presentado en el año 1998, y titulado "Recuperación de Energía en Sistemas de Climatización Mediante Sistema Mixto Evaporativo Indirecto y Tubos de Calor", en la que se caracterizó el comportamiento conjunto del sistema Heat Pipe y del refrigerador evaporativo indirecto, presentados en los dos trabajos de tesis doctoral anteriores, verificando que la principal contribución al ahorro de energía se debe a la presencia del sistema que utiliza la refrigeración evaporativa.

La cuarta tesis doctoral presentada en este campo tiene por título "Recuperación de Energía en Instalaciones de Acondicionamiento de Aire Mediante Sistemas Evaporativos con Tubos Cerámicos", la cual fue presentada por el Doctor Ingeniero Industrial Mario Javier Molina Leyva en el año 2002. Esta consistió en fabricar, construir y caracterizar un recuperador evaporativo con tubos cerámicos, operando dentro de la configuración de ensayo como sistema recuperativo. En este trabajo se observó que, además del calor sensible intercambiado por la pared de los tubos (similar a un refrigerador evaporativo indirecto) utilizando un medio poroso, el sistema podía trabajar como refrigerador evaporativo directo cuando la humedad del aire de impulsión es baja. Por lo tanto, dependiendo de las condiciones de operación, el sistema podía operar como refrigerador evaporativo directo o indirecto.

En la tesis doctoral de la Dra. Ruth Herrero Martín, titulada "Recuperación de Energía Residual a Baja Temperatura Según un Sistema Combinado Mixto RESIHP" y presentada en el año 2006, se analiza el comportamiento del sistema evaporativo cerámico junto con una 
batería de tubos Heat Pipe, analizando las contribuciones de manera individual y conjunto de los diferentes equipos que intervienen.

El Doctor Fernando Enrique Flores Murrieta presentó en el 2008 su tesis titulada "Fabricación, Monitorización y Caracterización de un Equipo de Are Acondicionado de Bajo Impacto Ambiental, Utilizando un Sistema Combinado: Refrigerador Evaporativo Cerámico y Tubos de Calor REC-TC". En dicho estudio se continuó trabajando sobre las posibilidades de recuperación de energía de los tubos de calor, pero en ese caso apoyando a un sistema evaporativo, aun también cerámico como el analizado en trabajos anteriores, que presentaba una mayor porosidad y consecuentemente mayores posibilidades de evaporación de agua y consecuente enfriamiento del aire tratado.

Además de los trabajos anteriores, en donde interviene la refrigeración evaporativa y la recuperación de energía, se han desarrollado en el seno del grupo de Termotecnia de la Universidad de Valladolid otros proyectos de tesis doctoral orientados al estudio de los requerimientos de Calidad de los Ambientes Interiores y de Eficiencia Energética en edificios.

Entre estos trabajos se encuentra el del Dr. Rafael Díez Vega, de título "Estudio Experimental de la Calidad de Ambiental (IEQ) en Edificios", presentada en el año 2006; el del Dr. Fernando Varela Díez, con título "Estudio de Eficiencia Energética en Edificios", presentado en el año 2008; y la más reciente tesis doctoral de la Dr. Cristina Cano Herrador, titulada "Estudio de la Sostenibilidad Energética en Diferentes Tipos de Edificios de un Campus Universitario", presentada en el año 2010.

Adicionalmente, se han realizado numerosos proyectos de fin de carrera: 6 de ellos relacionados con la tecnología Heat Pipe; 9 con la climatización y calidad del ambiente interior de espacios industriales y edificios; 13 relacionados con auditorías energéticas, análisis de parámetros energéticos y ahorro energético en la industrial; y 7 sobre sistemas de enfriamiento evaporativo. 


\section{BACKGROUND}

The Thermal Engineering Group of the University of Valladolid has being working extensively on the study of the requirements established for air-conditioning spaces, and particularly on alternatives of low-energy consumption air-conditioning. Some of the doctoral thesis which constitute the background of the one presented here, are the ones mentioned following:

Doctoral thesis of Dr. Julio San José Alonso, entitled "Energy Study of an Indirect Evaporative Cooler with Heat Recovery in Air-Conditioning Systems", defended in 1994. The device studied was an Indirect evaporative cooler made of aluminum plates, thus being a quite conventional material for such systems.

The doctoral thesis defended in 1998 by Dr. Eloy Velasco Gómez, whose title was "Energy Study and Development of a Heat Recovery System made of Heat Pipes for Air-Conditioning", introduced an alternative for Heat Recovery based on the technology of Heat Pipes.

The next thesis defended in the same year 1998 was that of Dr. Mario Álvarez-Guerra Plasencia, entitled "Heat Recovery in Air Conditioning Through a Combined System of an Indirect Evaporative Cooler and Heat Pipes", in which it was characterized the behaviour of the two previous devices operating together. It was verified that the main contribution to energy savings was due to the evaporative cooling.

The fourth doctoral thesis defended in this field is entitled "Heat Recovery in AirConditioning Systems through Evaporative Coolers with Heat Pipes", developed by Dr. Mario Javier Molina Leyva in 2002. That work consisted in manufacturing and characterizing a ceramic evaporative cooler which operated as a heat-recovery system. It was observed that not only sensible heat was transferred through the porous surface of the ceramic tubes (similar to indirect evaporative coolers), but also the system could operate as a direct evaporative cooler when relative humidity of supplied air was low. Thus, depending on the operating conditions, the system could behave as either an indirect or a direct evaporative cooler.

In the PhD thesis of Dr. Ruth Herrero Martín, entitled "Low-temperature Heat Recovery of Residual Energy Through a Combined System RESIHP", defended in 2006, the same ceramic evaporative cooler is analyzed together with the Heat Pipe system, studying the individual behaviour of the systems, as well as combined.

Dr. Fernando Enrique Flores Murrieta defended his thesis in 2008, titled "Manufacturing, Monitoring and Characterization of an Air Conditioning System of Low-Environmental Impact, Using a Combined System: Ceramic Evaporative Cooler and Heat Pipes REC-TC". Here, further work was developed on the possibilities of the Heat Pipes for heat-recovery, though in this case supporting another ceramic evaporative cooler made of hollow bricks, characterized by a higher porosity, and consequently higher potentials of humidification and thus cooling of treated air. 
Additionally to the previous doctoral thesis, in which evaporative cooling and heat recovery are studied as alternatives for air conditioning, it has also been developed in the Thermal Engineering Group of the University of Valladolid further projects focused on Indoor Environmental Quality requirements and Energy Efficiency in buildings.

Among these works is the thesis defended by Dr. Rafael Díez Vega in 2006, titled "Experimental Study of Indoor Environmental Quality in Buildings"; the thesis "Study of Energy Efficiency in Buildings", defended by Dr. Fernando Varela Díez in 2008; and the most recent doctoral thesis defended in 2010 by Dr. Cristina Cano Herrador, whose title is "Study of Energy Sustainability in Different Sort Buildings of a University Campus".

Moreover, numerous Final Projects have been developed on these issues: 6 concerning Heat Pipe technology; 9 related to air-conditioning and IEQ in the residential and industrial sector; 13 in relation with energy audits, analysis of energy parameters and energy savings in the industry; and 7 concerning evaporative cooling. 


\section{OBJETIVOS OBJECTIVES}


OBJETIVOS - OBJECTIVES 


\section{OBJETIVOS}

El objetivo principal de este trabajo de Tesis Doctoral, es proporcionar información útil sobre el funcionamiento de los sistemas propuestos, a través principalmente de su caracterización experimental, para justificar el interés de su utilización en el contexto de conciencia global sobre eficiencia energética en la climatización de los edificios. Para ello, será necesario seguir un proceso largo y complejo, en su mayor parte específico para cada sistema.

Previamente a su comienzo, es necesaria una evaluación inicial del interés y potencial de la idea del proyecto, para su justificación en el contexto energético actual (capítulo l), e identificación de diversas alternativas de posible estudio. Las alternativas escogidas son las siguientes:

- Enfriamiento evaporativo indirecto, mediante intercambiadores de plástico. Particularmente se usará policarbonato, y se abordarán dos tamaños de superficie de intercambio.

- Enfriamiento evaporativo directo, mediante pulverización de agua y evaporación desde superficie húmeda (relleno rígido), por ser las dos tecnologías más extendidas.

- Enfriamiento gratuito o free-cooling por agua, contemplando la posibilidad de recuperación de energía.

- Recuperación de energía, mediante dos baterías con bomba para mayor versatilidad en la instalación de aire.

Una vez determinadas las tecnologías de trabajo, cada sistema debe diseñarse en base a los requerimientos de confort buscados y a los conocimientos existentes sobre la tecnología actual. Sobre este diseño, se procederá a realizar el estudio de cada alternativa, siguiendo los pasos enumerados a continuación:

- Construcción o adquisición del equipo comercial adecuado a las condiciones de diseño, según el caso.

- Planteamiento de las condiciones de ensayo apropiadas para la caracterización experimental, utilizando la técnica de Diseño de Experimentos.

- Consecución del procedimiento experimental de caracterización y registro de datos.

- Estudio de los resultados experimentales, y determinación de los patrones de comportamiento a través de la definición de ciertos parámetros de interés.

- Comprobación de la repercusión, en dichos parámetros de funcionamiento, de los distintos factores ensayados, mediante un análisis de varianza ANOVA.

Finalmente, se pretende hacer uso de los resultados obtenidos para presentar brevemente un caso práctico que permita plantear, de forma meramente orientativa, la posibilidad real de instalación de los diversos sistemas en un local, tanto para mejorar las condiciones de confort 
suponiéndolo no acondicionado (con ventilación natural), como para actuar de apoyo a los sistemas de acondicionamiento existentes, suponiendo el local como acondicionado térmicamente.

De todos los resultados así obtenidos, y en base a estudios previos realizados y mentados en los antecedentes, se buscará perfilar las líneas de trabajo futuras que continúen el desarrollo realizado históricamente por el grupo de Termotecnia de la Universidad de Valladolid sobre sistemas de acondicionamiento de aire de bajo consumo energético. 


\section{OBJECTIVES}

The main aim of this work is giving useful information about the behaviour of the proposed systems, mainly through their experimental characterization, in order to justify the interest on their use within the framework of global awareness on energy efficiency for air-conditioning in buildings. It is thus necessary to follow a wide and complex process, mostly specific for each system.

Previously, it is required an initial discussion on the interest and potential of the aim of the project, to justify it within the current energy framework (chapter I). Also the possible alternatives are identified. Among these, the ones selected for the study are:

- Indirect evaporative cooling through plastic heat exchangers. Particularly, polycarbonate is used. Two heat-exchange areas are conceived.

- Direct evaporative cooling. Misting and Rigid Media Pad technologies are considered for their widespread use.

- Free-cooling by water. It is also conceived the possibility of introducing heat recovery.

- Energy recovery through a Runaround-Loop system made of two coils and a pump, which offers great flexibility in air installations.

Once determined the technologies to be considered in the study, each system needs to be designed based on the comfort requirements indoors, and on the actual knowledge about current technologies. From this design, each alternative is studied independently, according to the following steps:

- Construction or acquisition of the commercial devices that fits to the design conditions.

- Determination of the appropriate test conditions to characterize the system, using the technique of Design of Experiments.

- Development of the experimental process, and data registration.

- Study of the experimental results, and definition of the models of behaviour through the introduction of certain useful parameters.

- Checking of the weight of the different factors tested on the results of the parameters obtained, with the aid of an analysis of variance ANOVA.

Finally, results obtained are used to briefly analyze a simple case study that enables proposing the actual possibility of installing the different devices in a particular space, either to improve climate conditions indoors (provided it is a naturally-ventilated space) or to support the conventional systems to reduce energy consumption (if the space is thermally conditioned).

From all results obtained, and based on the previous work mentioned in the Background section, it is aimed to determine the possible future work that stretches the research labour developed by the Thermal Engineering Group of the University of Valladolid on low-energy consumption air-conditioning devices. 
OBJETIVOS - OBJECTIVES 


\section{CONTENIDOS CONTENTS}


CONTENIDOS - CONTENTS 


\section{CONTENIDOS}

El desarrollo del estudio que ha derivado de los objetivos del proyecto presentados en la sección anterior, y que constituye el contenido del presente trabajo de tesis doctoral, se ha estructurado en tres partes, englobando respectivamente los siguientes contenidos:

Parte I: Introducción. Engloba los conocimientos actuales sobre el contexto energético mundial presentado como base justificativa, los requerimientos de confort y calidad del aire exigidos a los sistemas, y el estado actual de las tecnologías consideradas en el proyecto. Queda constituida por los tres primeros capítulos del trabajo:

Capítulo I: Problemática energética en la climatización.

Capítulo II: Calidad del clima interior.

Capítulo III: Estado actual de las tecnologías de estudio.

Parte II: Caracterización experimental de los sistemas. Desarrolla la descripción del banco de ensayos y dispositivos del laboratorio utilizados o construidos para la caracterización de los sistemas; además del estudio abordado sobre cada sistema en particular, presentando tanto sus características constructivas, como el diseño de experimentos realizado, los resultados experimentales obtenidos y el análisis de varianza. A esta parte corresponden los capítulos:

Capítulo IV: Dispositivo experimental.

Capítulo V: Enfriadores evaporativos indirectos de placas planas de policarbonato

Capítulo VI: Enfriadores evaporativos directos

Capítulo VII: Caracterización del sistema de enfriamiento gratuito por agua.

Capítulo VIII: Caracterización del recuperador de dos baterías con bomba

Parte III: Resultados y Conclusiones. Este último apartado se encuentra redactado en inglés. En él se recopilan los resultados obtenidos sobre el funcionamiento de los sistemas, abordados en un sencillo caso práctico para plantear su aplicabilidad. Finalmente, se recopilan las conclusiones derivadas del estudio, globales y particulares de los distintos sistemas; así como los desarrollos futuros que resultarían de interés para la continuación de la línea de trabajo. Los capítulos que conforman esta tercera parte son:

Capítulo IX: Estudio práctico de los resultados obtenidos.

Capítulo X: Conclusiones y desarrollos futuros. 
Al final del texto y tras los capítulos, se incluye un anexo en el que se describe la técnica de Diseño de Experimentos y Análisis de Varianza seguidos en el planteamiento y tratamiento de los resultados.

Cada capítulo no redactado en lengua inglesa, está introducido por un breve resumen del mismo en dicho idioma. Asimismo, para favorecer la claridad y simplicidad de búsqueda, se proporcionan las referencias, relación de simbología o nomenclatura utilizada, el índice de figuras y el índice de tablas por capítulo. De esta forma, el contenido de cada capítulo está estructurado como sigue:

- Índice de contenidos del capítulo.

- Resumen del capítulo en inglés, si procede.

- Simbología utilizada en el capítulo.

- Contenidos desarrollados en el capítulo.

- Índice de referencias a bibliografía, normativa y páginas web.

- Relación de figuras.

- Relación de tablas.

La numeración seguida para este contenido es la siguiente:

- En cuanto a las referencias, se hace distinción entre las bibliográficas, referencias a normativa y accesos a páginas web, y su numeración es independiente entre capítulos.

Las referencias bibliográficas se introducen en el texto entre corchetes, indicando el número de orden de aparición en el capítulo, el nombre del autor o autores, y el año de publicación:

[9, Pérez et al., 2007]

En la lista de referencias, se identifican a través del orden de aparición en el texto, entre corchetes; seguido nombre de los autores, título de la publicación; nombre, número y páginas de la revista en su caso, y año de publicación. En el ejemplo:

[9] Pérez-Lombard L., Ortiz J., Pout C., "A review on buildings energy consumption information", Energy and Buildings (40) pp.: 394-398. 2008.

Las referencias a normativas se identifican en el texto entre corchetes, mediante el número de orden de éstas antepuesto por la letra "N". Por ejemplo: [N-2]

[N-2] Ministerio de Vivienda de España, "Real Decreto 315/2006 de 17 de marzo: Código Técnico de la Edificación: Parte 1". 2006.

Análogamente, las referencias a accesos a páginas web se introducen en orden consecutivo y encabezadas por la letra "W", también entre corchetes: [W-3] 
En el índice de referencias a páginas web se indica la fecha de última consulta:

[W-3] Energy Performance of Buildings Directive, Concerted Action. http://www.epbdca.org/ (Día de consulta: 14 de marzo de 2011).

- La numeración de las figuras se realiza de forma consecutiva por capítulo, mediante numeración arábiga antecedida por el número del capítulo en números romanos. Por ejemplo:

Figura III.5.- Posibles evoluciones psicrométricas del aire en contacto con agua.

- $\quad$ Las tablas se numeran de forma análoga a las figuras. Por ejemplo:

Tabla II.5.- Rangos límites de variación de los parámetros de consideración en el confort térmico.

Finalmente, las ecuaciones se enumeran también por capítulo, en este caso entre paréntesis, indicando el número de capítulo y de orden de aparición de la ecuación, encabezados por la letra "E". Por ejemplo:

$$
C_{\mathrm{int}}=C_{e x t}+\frac{G}{Q} \times \frac{1}{\varepsilon_{v}}
$$

Las figuras, tablas y ecuaciones en los anexos se referencian de forma análoga, pero antepuestas por la letra "A" para el Anexo A, y "B" para el Anexo B, en vez de por el número de capítulo en números romanos. 
CONTENIDOS - CONTENTS 


\section{CONTENTS}

The study developed from the objectives previously mentioned has been structured into three parts, including the following contents:

Part I: Introduction. It includes the analysis of the nowadays framework on energy issues as a justification for the present study, as well as the current knowledge on comfort and indoor air quality to be achieved by the systems, and the state of the art of the technologies considered in the project. It is constituted by the first three chapters:

Chapter I: Energy problems in Air-conditioning.

Chapter II: Indoor Climate Quality.

Chapter III: State of the art of the technologies.

Part II: Experimental characterization of the systems. In this part, it is described the experimental facility mounted on the laboratory for the characterization. It is also dealt here the analysis of each particular device, describing their characteristics, the Design of Experiments developed to determine the tests needed, the experimental results obtained and the analysis of variance performed. To this part belong the following chapters:

Chapter IV: Experimental facility.

Chapter V: Characterization of the Indirect Evaporative Coolers made of Polycarbonate.

Chapter VI: Characterization of the Direct Evaporative Coolers.

Chapter VII: Characterization of the Free-Cooling by Water system.

Chapter VIII: Characterization of the Runaround-Loop Heat Recovery system.

Part III: Results and Conclusions. Here, results obtained about the behaviour of the systems are gathered, and a simple case study is proposed to study their applicability. Finally, both global and particular conclusions for each device are reminded. Moreover, future work which would be of interest for pursuing the study is noted. Chapters in this part are:

Chapter IX: Practical study of results obtained.

Chapter X: Conclusions and future work.

At the end, besides the chapters, there is an annex describing the technique of the Design of Experiments and the Analysis of Variance followed in the approach and analysis of the results.

Chapters not written in English are introduced by a brief abstract in this language, summarizing contents developed on it. Furthermore, to enhance clarity and simplicity, references, nomenclature, list of figures and list of tables are given individually for each chapter. Then, content in each chapter is structured as follows: 
- Index of contents.

- $\quad$ Abstract in English.

- Nomenclature employed in the chapter.

- Contents developed in the chapter.

- Index of references (bibliography, norms, websites).

- $\quad$ List of figures.

- $\quad$ List of tables.

References, figures, tables and equations are numbered as follows:

- $\quad$ Concerning references, it is distinguished between bibliography, norms and websites; and they are numbered independently among chapters.

References to bibliography are introduced in the text between square brackets, giving the order number of mention in the chapter, name of main author/s and year of publication:

[9, Pérez et al., 2007]

References listed are identified through their order of mention in the text, in square brackets, followed by the names of the authors, title of the publication; name, number and pages of the journal, if concerning, and year of publication. E.g.:

[9] Pérez-Lombard L., Ortiz J., Pout C., "A review on buildings energy consumption information", Energy and Buildings (40) pp.: 394-398. 2008.

References to norms are identified by the letter "N" followed by the corresponding number of appearance, as for example: [N-2]

[N-2] Ministerio de Vivienda de España, "Real Decreto 315/2006 de 17 de marzo: Código Técnico de la Edificación: Parte 1". 2006.

Similarly, references to websites are introduced consecutively and identified by letter "W". For example: [W-3]

In the corresponding index, date of last search is given:

[W-1] Instituto para la Diversificación y Ahorro Energético (IDAE) http://www.idae.es/ Date of last search: 11th March 2011.

- $\quad$ Numbering of figures is given consecutively by chapter, with Arabic numbers preceded by the number of the chapter. E.g.:

Figure IX.3.- General scheme of the building subject (geometry of cases 600 and 900). 
- $\quad$ Tables are numbered similarly to figures. For example:

Table IX.8.- Annual total operating hours of the systems in the four cities studied.

Finally, equations are also numbered by chapter. In this case numbering is given in brackets, showing the number of the chapter and that of mentioning in the text, preceded by letter "E". E.g.:

$$
C_{\text {int }}=C_{e x t}+\frac{G}{Q} \times \frac{1}{\varepsilon_{v}}
$$

References to figures, tables and equations in the annex are given similarly, but preceded by letter "A" for Annex A, and "B" for Annex B, instead of the corresponding roman numeral of the chapter. 
CONTENIDOS - CONTENTS 


\section{PARTE I: INTRODUCCIÓN}

CAPÍtulo I: Problemática energética en la Climatización.

CAPÍTULO II: CALIDAD DE AMBIENTES INTERIORES.

CAPÍtulo III: Estado Actual de las TeCnologías DE ESTUDIO. 



\section{CAPÍTULO I PROBLEMÁTICA ENERGÉTICA EN LA CLIMATIZACIÓN}

ABSTRACT

I.1. ENERGÍA: NECESIDAD Y PROBLEMÁTICA ....................................................... 7

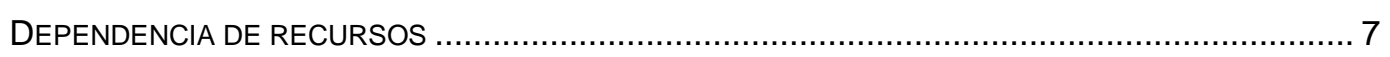

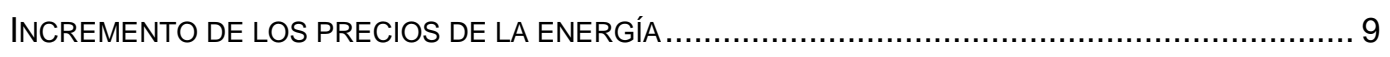

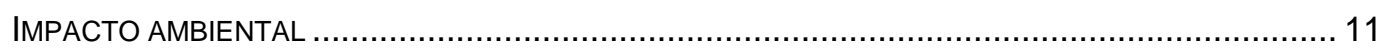

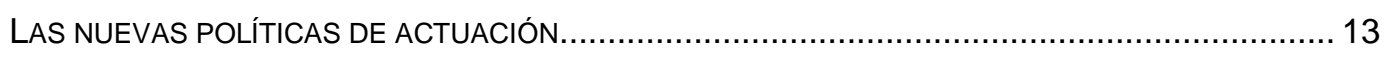

I.2. PROBLEMÁTICA ENERGÉTICA EN LA EDIFICACIÓN ............................................. 14

Consumo ENERgÉtico EN LAS INSTALACIONES DE CLIMATIZACIÓN............................... 16

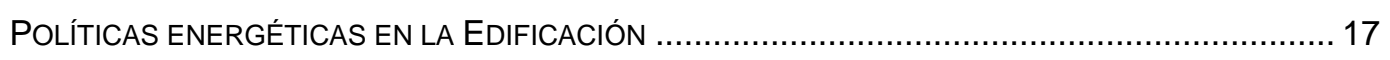

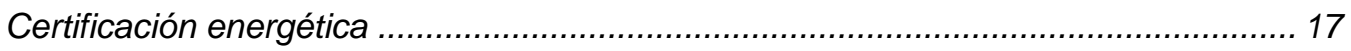

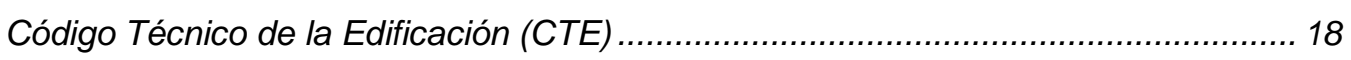

Reglamento de Instalaciones Térmicas en Edificios (RITE) ...................................... 19

I.3. MÉTODOS DE REDUCCIÓN DEL CONSUMO ENERGÉTICO EN LA CLIMATIZACIÓN

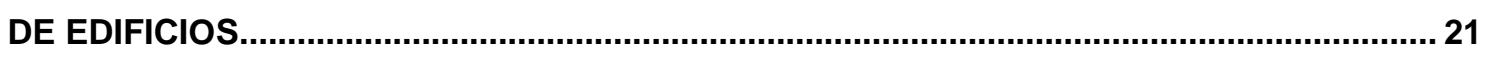

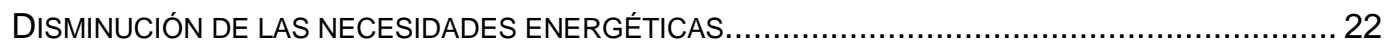

SUSTITUCIÓN DE LAS FUENTES CONVENCIONALES DE ENERGÍA POR OTRAS FUENTES

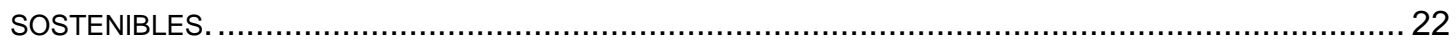

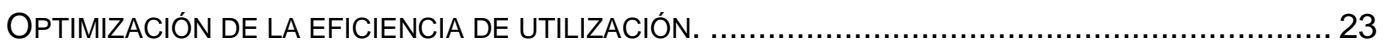




\section{CHAPTER I:}

\section{ENERGY PROBLEMS IN AIR-CONDITIONING}

\section{ABSTRACT}

Energy has become essential for human life, and thus it is necessary to ensure its availability at affordable prices. However, nowadays current problems associated to resources location and exhaustion enhance the efforts aiming for energy saving.

This chapter deals with the current energy framework worldwide, focusing on the European Union and particularly in Spain. Problems such as dependency on certain resources, price rising and environmental impact are described, and promoted politics for a sustainable energy provision are introduced.

As the specific sector of interest in the present PhD project, and due to its great potential of improvement, energy consumption in buildings is analyzed. Here, the main Spanish norms concerning energy efficiency in buildings are presented. On this basis, several alternatives for reducing energy consumption required in air-conditioning in the building sector are presented. These are grouped into three categories: the ones whose objective is reducing the energy demand itself; the substitution of conventional sources by other more sustainable alternatives; and finally those options which are aimed at optimizing system's performance. 


\section{I.1. ENERGÍA: NECESIDAD Y PROBLEMÁTICA.}

Desde el descubrimiento del fuego, la energía puede considerarse un bien vital más para el ser humano. Esta nueva dependencia ha venido imponiéndose a lo largo de la historia, hasta convertirse en los últimos siglos en un recurso indispensable para la actividad económica y social en todo el mundo, siendo además necesaria en abundancia en los países más desarrollados. Esto incurre en una nueva preocupación para la humanidad: asegurar su disponibilidad.

Sin embargo, esta realidad que resulta ahora natural hasta el punto de no cuestionarse, supone una gran problemática cuya solución no se muestra tan obvia. La situación energética actual es una realidad en la que quedan lejos los días en los que la provisión de fuentes de energía podía considerarse barata y segura, debido tanto al incremento de la demanda con el desarrollo económico e industrial, como al agotamiento de los mismos recursos y por lo tanto aumento de la dependencia de las importaciones y de los precios asociados.

A este problema se le suma la preocupación por las consecuencias del impacto medio ambiental del uso y transformación de la energía, del que la concienciación generalizada empieza a temer suponga una destrucción del mismo planeta que nos provee de las fuentes por las que se lo necesita.

Es por ello que, para garantizar un suministro de energía sostenible, seguro y competitivo, hay que decantarse por unas nuevas políticas de actuación [1, EC, 2010], [2, OECD/IEA, 2005], [3, OECD/IEA, 2009].

\section{Dependencia de recursos}

A pesar del concienciado fomento durante las últimas décadas de las energías renovables y residuales a fin de diversificar las fuentes energéticas, los combustibles fósiles siguen constituyendo el principal recurso de energía primaria a nivel mundial, y en particular en España dentro del contexto europeo, como puede verse en las figuras I.1, I.2 y I.3. [W-1].

No obstante las políticas de actuación orientadas a la limitación del consumo de combustibles fósiles para frenar el impacto ambiental derivado de su uso y reducir la dependencia de los principales países exportadores, el incremento en la demanda energética asociada al aumento del nivel de vida deriva en un aumento inevitable de estos consumos a nivel mundial (figura I.3). Este hecho, menos notorio como puede verse en la figura 1.2 en países ya desarrollados como es el caso de la Europa constituyente de la OECD (Organisation for Economic Co-operation and Development), es especialmente destacable en los países en vías de desarrollo, y en particular para el caso de España a partir de las últimas décadas del siglo pasado.

La energía nuclear se presenta asimismo como una fuente de gran peso actual, alcanzado éste durante las últimas décadas del siglo XX y bastante estable desde entonces, dadas las 
políticas de moratoria seguidas en algunos países ante los riesgos derivados de su explotación y la generalizada postura pública desfavorable al respecto. A pesar de encontrarse en el punto de mira de las propuestas de control de emisiones, el uranio no deja de ser un combustible con unas reservas limitadas en el planeta Tierra, y su explotación intensiva tornaría los datos actuales favorables en cuanto a duración esperada de las mismas en nuevas fechas preocupantes de próximo agotamiento del recurso.

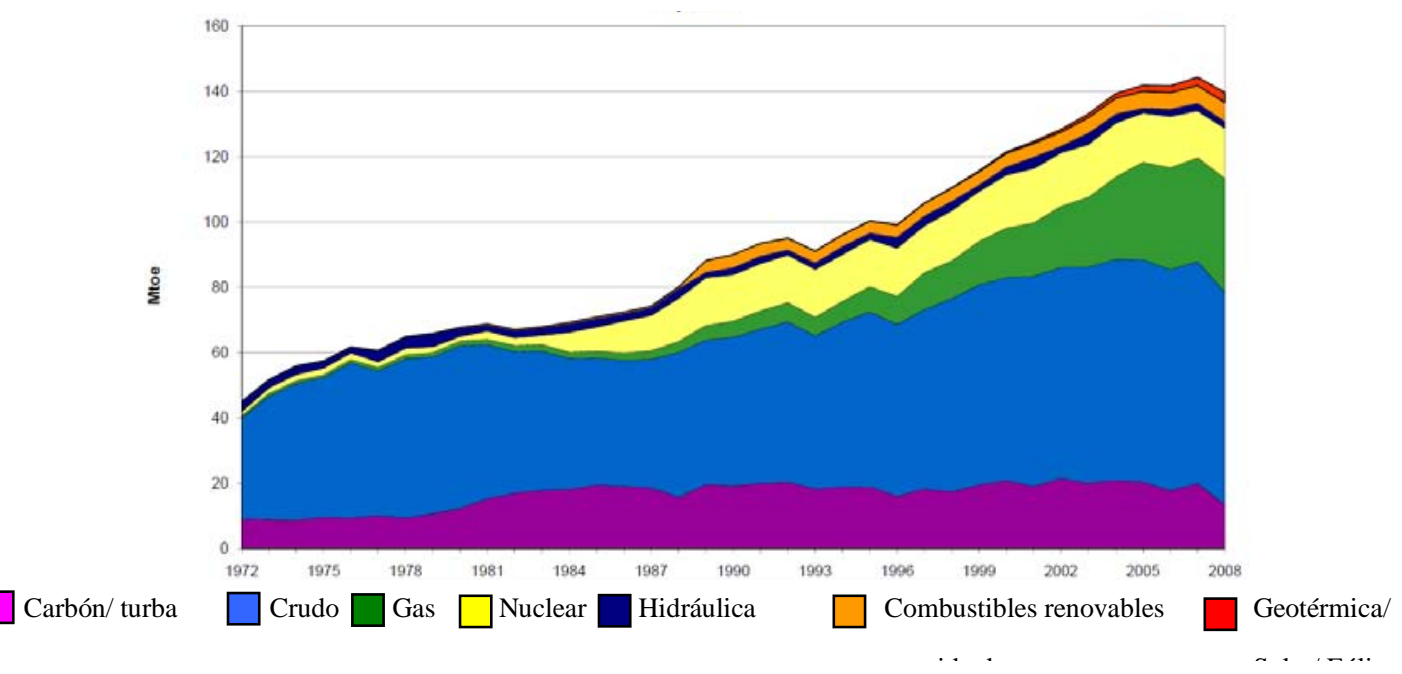

Figura I.1.- Provisión de energía primaria en España (traducido de la fuente: IEA Energy Statistics () OECD/IEA, 2010).

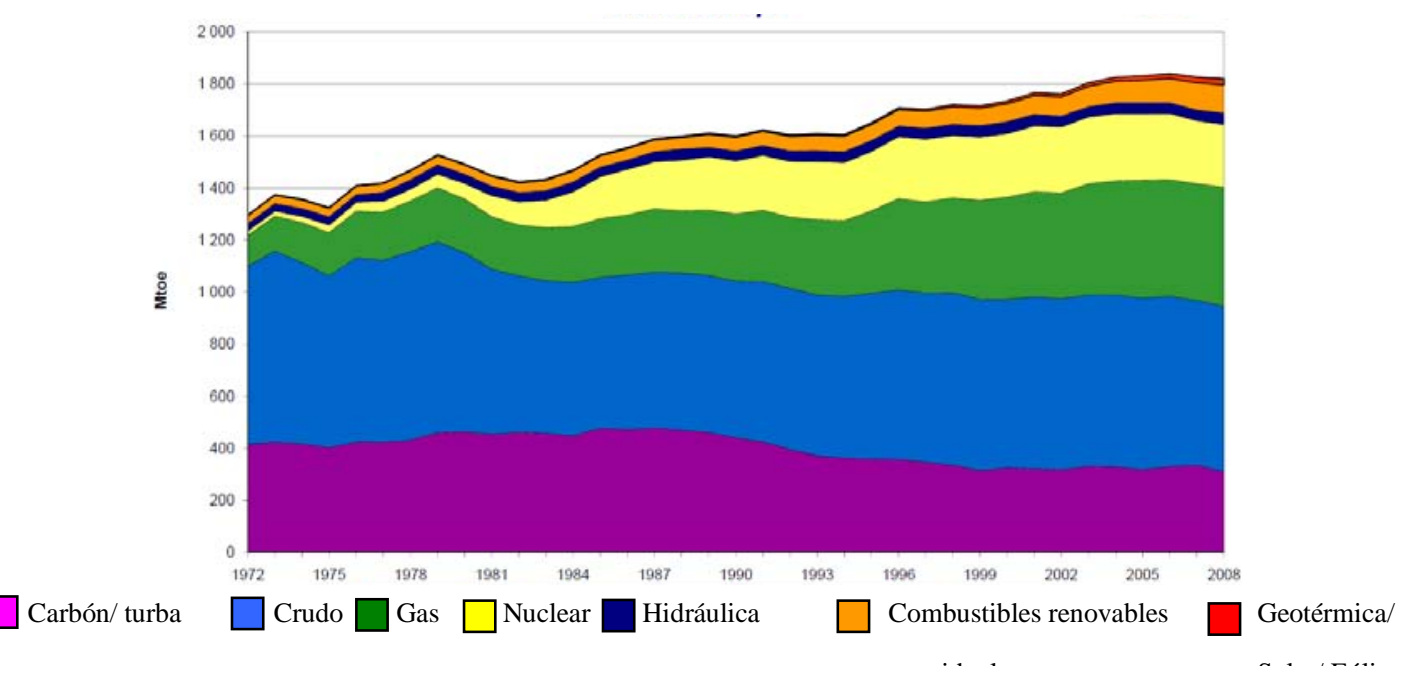

Figura I.2.- Provisión de energía primaria en Europa (OECD) (traducido de la fuente: IEA Energy Statistics (C) OECD/IEA, 2010). 


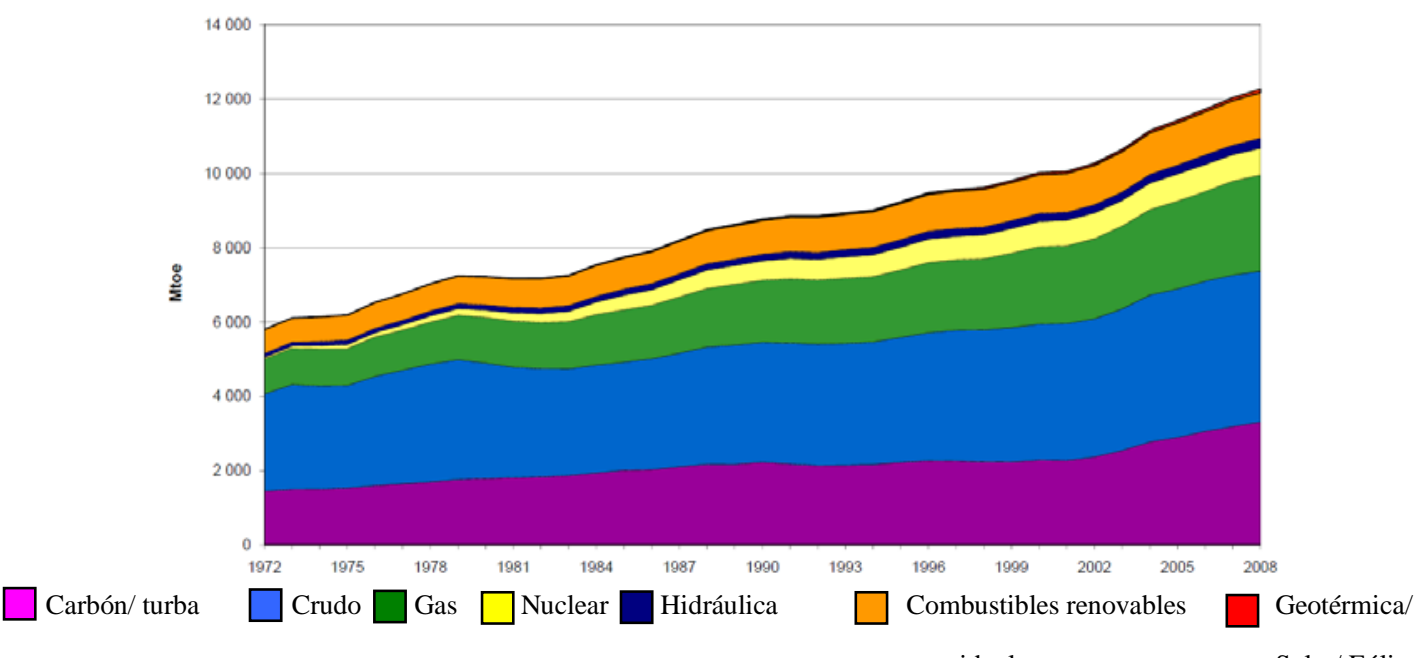

Figura I.3.- Provisión de energía primaria en el Mundo (traducido de la fuente: IEA Energy Statistics (C) OECD/IEA, 2010).

Dos problemas esenciales derivan de la dependencia energética de los combustibles fósiles: en primer lugar, existe una limitación de las reservas, no sólo por la detención geológica en el proceso de generación de las fuentes sino también por las limitaciones tecnológicas para su actual extracción de forma viable, aunque todavía se espera que éstas puedan aprovisionarnos energéticamente más allá del 2030; y en segundo lugar, la localización geográfica de estas reservas, concentrándose en algunos países cuya inestabilidad política pone en riesgo la seguridad del aprovisionamiento energético. Ambos problemas derivan tanto en un aumento continuado de los precios de estos combustibles como en aumentos puntuales de los mismos, debidos estos últimos a menudo a inestabilidades de la situación política mundial.

\section{Incremento de los precios de la energía}

Como puede observarse en las figuras I.4, 1.5 y I.6, los precios del crudo, carbón y gas natural han sufrido un incremento muy importante durante la última década, después de haberse mantenido dentro de unos márgenes bastante estables durante las dos décadas inmediatamente anteriores. La variabilidad más acusada del precio del crudo frente a la más suave producida en los precios del carbón o gas natural es principalmente debida a la mayor localización de las reservas de este recurso, frente a la mayor dispersión de las reservas de los otros dos combustibles y por lo tanto menor dependencia de las importaciones. 


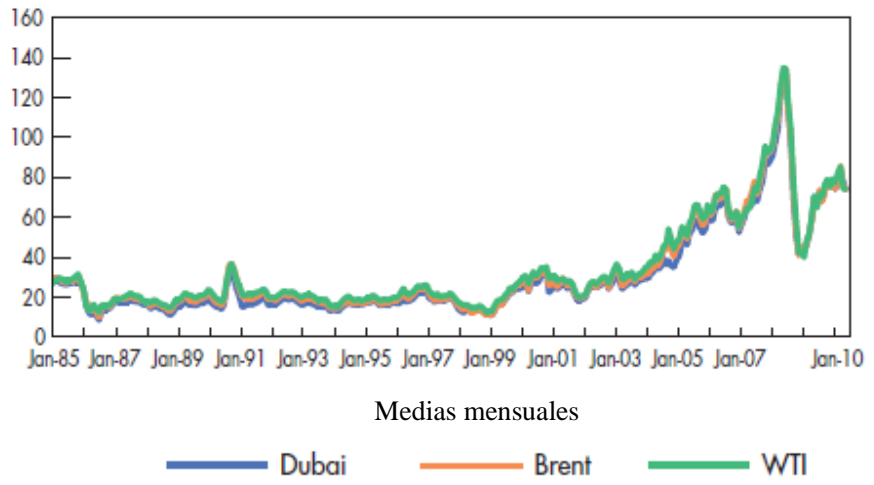

Figura I.4.- Precios spot del crudo en dólares americanos/barril (traducido de la fuente: Key World Energy Statistics 2010 ๑ OECD/IEA, p. 40).

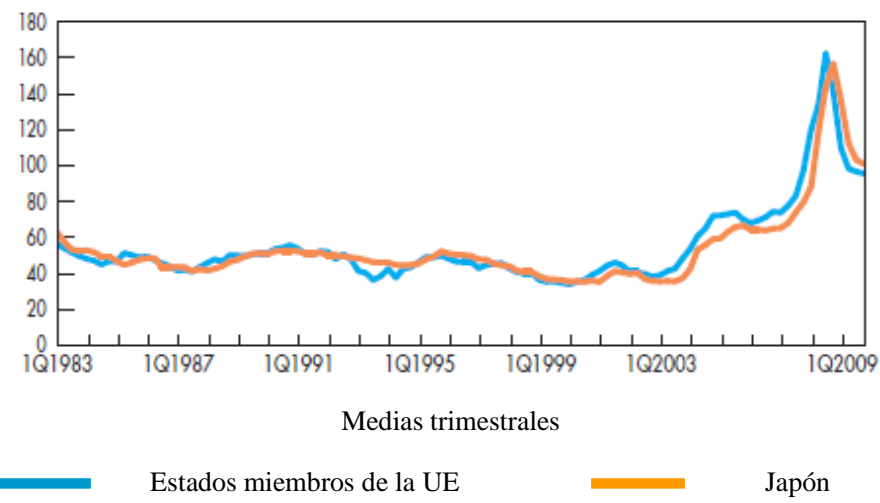

Figura I.5.- Precios del carbón térmico en dólares americanos/ tonelada (traducido de la fuente: Key World Energy Statistics 2010 @ OECD/IEA, p. 41).

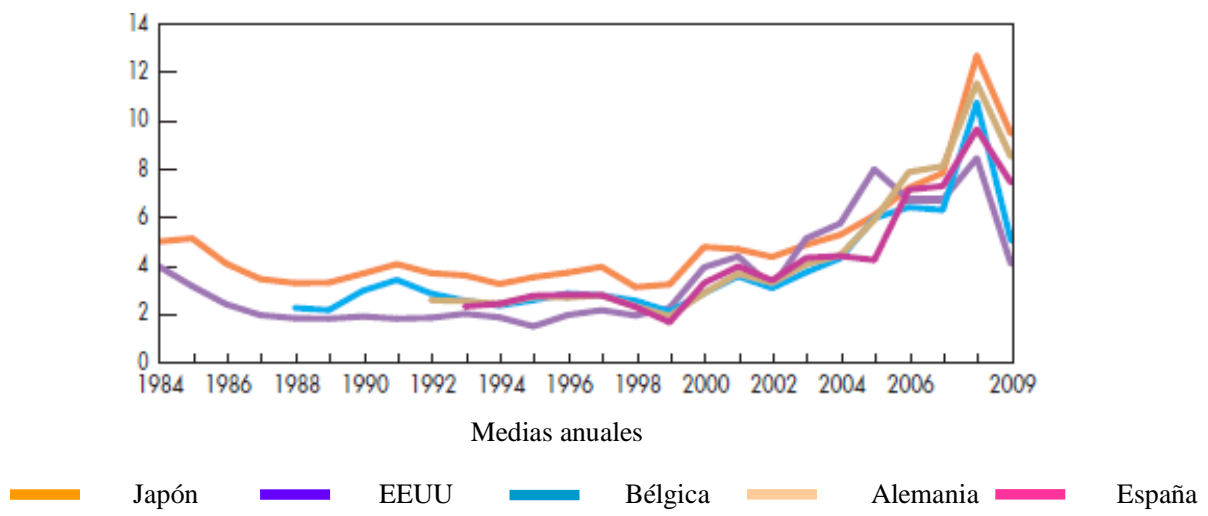

Figura l.6.- Precios de importación del gas natural en dólares americanos/ MBtu (traducido de la fuente: Key World Energy Statistics 2010 ๑ OECD/IEA, p. 41).

Por su parte, la provisión de electricidad a nivel mundial procede también en su mayor parte de centrales térmicas convencionales, y por lo tanto de combustibles fósiles. Además su demanda está en continuo aumento, como se muestra en la figura I.7. De manera particular, la 
dependencia nacional de las importaciones de combustibles fósiles es especialmente alarmante, considerando las escasas fuentes localizadas en la península, limitándose prácticamente a minas de carbón.

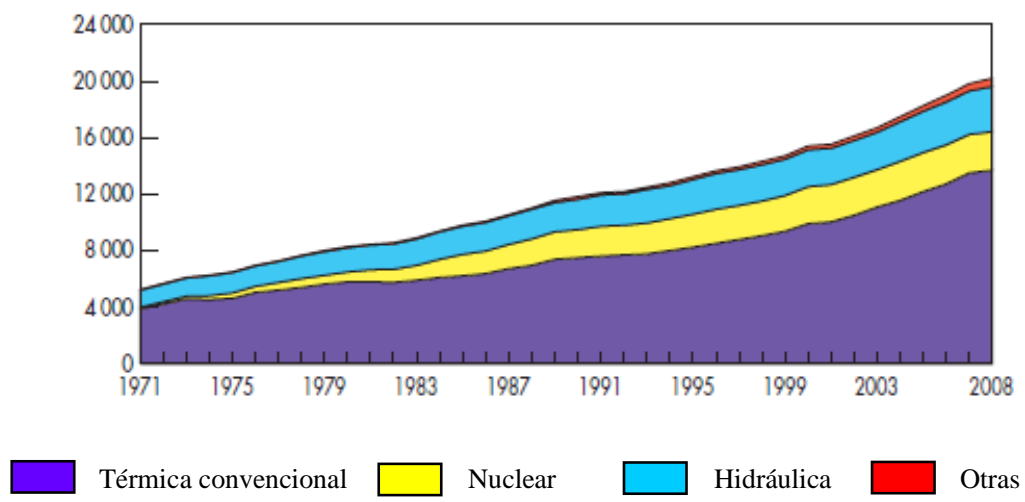

Figura I.7.- Evolución de la generación de electricidad por tipo de fuente en TWh (traducido de la fuente: Key World Energy Statistics 2010 @ OECD/IEA, p. 24).

\section{Impacto ambiental}

En lo que concierne a la incidencia en el cambio climático, la energía juega un papel clave en cuanto a las emisiones de gases de efecto invernadero derivadas del uso y transformación de la energía, cuya demanda se ha visto que está en imparable aumento. De mantenerse la tendencia actual, se prevé que las emisiones a nivel mundial en el 2020 se vean aumentadas en un $20 \%$, lo cual demostraría el hecho de que las políticas energéticas actuales no son sostenibles. Es por ello que las distintas organizaciones mundiales en la materia estudian la incidencia que distintos escenarios alternativos en función de la aplicación de las nuevas actuaciones energéticas promulgadas tendrían en un futuro a medio plazo [4, OECD/IEA, 2010].

Esta situación crítica del aumento continuado de emisiones a nivel mundial (figuras I.8 y 1.9) ha conducido a establecer unas limitaciones a las emisiones de los gases, o familias de gases, de efecto invernadero $\left(\mathrm{CO}_{2}, \mathrm{CH}_{4}, \mathrm{~N}_{2} \mathrm{O}, \mathrm{PFC}\right.$ 's, HCFC's y $\left.\mathrm{SF}_{6}\right)$, firmándose el Protocolo de Kioto, en vigor desde 2005, dentro de la Convención Marco de las Naciones Unidas sobre el Cambio Climático. Sucesivas conferencias de la ONU sobre el cambio climático derivan en la XIII Cumbre del Clima en Bali en el 2007, y finalmente en la XV Conferencia sobre el Cambio Climático (Cumbre de Copenhague) en diciembre de 2009, orientada a establecer futuros objetivos para reemplazar los del Protocolo de Kioto, que termina en 2012.

En España, las consecuencias del compromiso de Kioto son especialmente delicadas. Como puede comprobarse por el índice de evolución (figura l.10) respecto al año base del Protocolo de Kioto (1990), las emisiones totales se sitúan en 2008 en un 40,0\% por encima, valor que se eleva a un 46,8\% cuando se compara la media del último quinquenio, 2004-2008 
con el mismo año base [5, MITC, 2006]. Considerando el compromiso de España de limitar el aumento de emisiones a un 15\% durante el primer período, los objetivos establecidos quedan lejos de ser cumplidos para el 2012, con las consiguientes penalizaciones que puedan imponérsele.

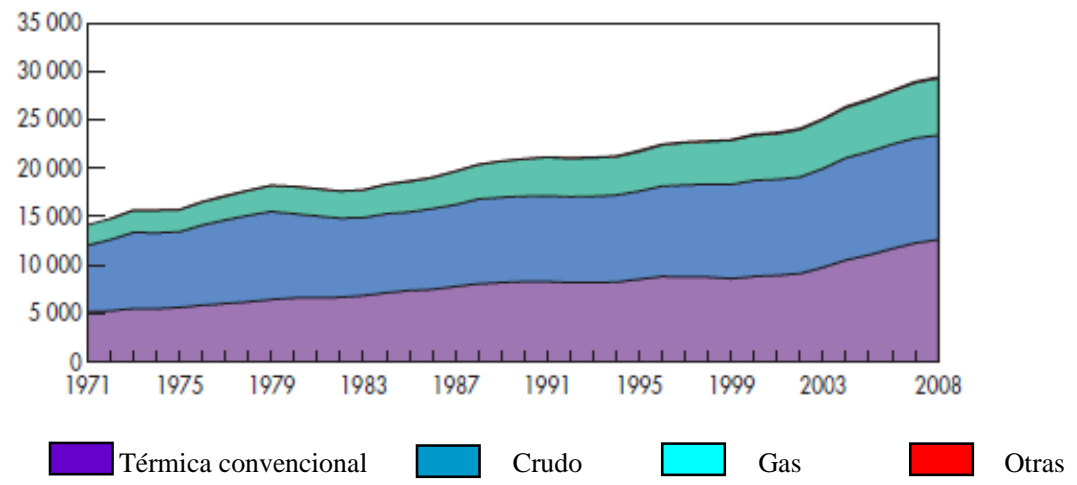

Figura I.8.- Emisiones mundiales de $\mathrm{CO}_{2}$ por combustible en $\mathrm{Mt}$ de $\mathrm{CO}_{2}$ (traducido de la fuente: Key World Energy Statistics 2010 (C) OECD/IEA, p. 44).

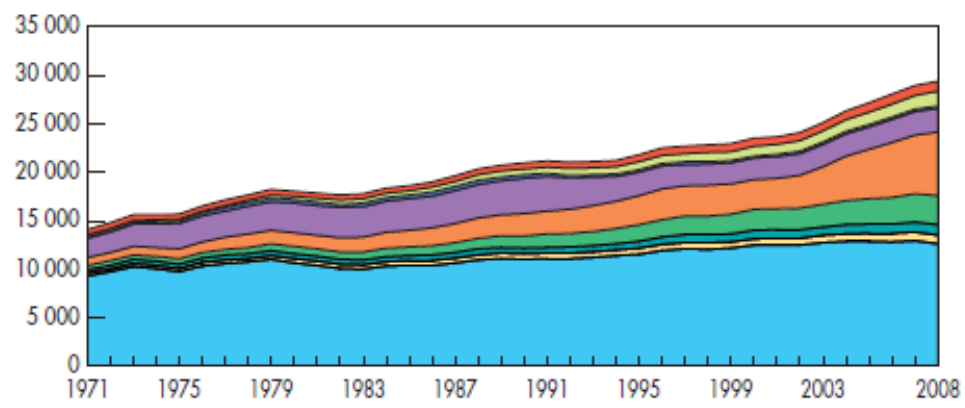
OECD
$\square$ Africa
$\square$ Sudamérica
$\square$ Asia China
Antigua URSS
Europa no OECD
Oriente próximo
Carboneras

Figura 1.9.- Emisiones mundiales de $\mathrm{CO}_{2}$ por región en $\mathrm{Mt}$ de $\mathrm{CO}_{2}$ (traducido de la fuente: Key World Energy Statistics 2010 ○ OECD/IEA, p. 45).

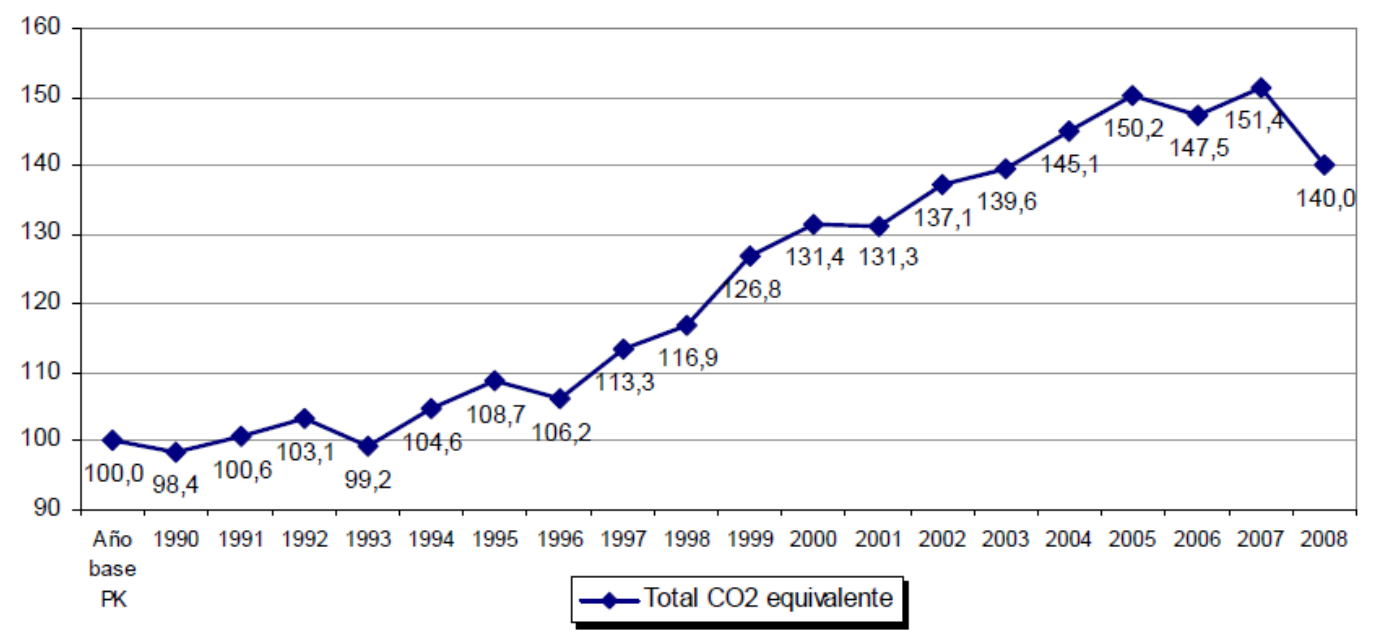

Figura I.10.- Índice de evolución de $\mathrm{CO}_{2}$ total equivalente (fuente: Ministerio de Industria, Turismo y Comercio de España). 
Sin embargo, no sólo las emisiones de gases de efecto invernadero son preocupantes para la atmósfera terrestre. También en cuanto a la calidad del aire es importante tener presente la limitación de ciertos compuestos al ambiente, lo cual ha supuesto el desfavorecimiento del uso de ciertos combustibles fósiles, en especial el carbón, por los compuestos generados en su combustión causantes de la lluvia ácida. Considerando las ventajas que presenta el carbón en cuanto a dispersión y abundancia de recursos en el planeta, se están desarrollando alternativas para su explotación sostenible, como puede ser la gasificación; o técnicas más simples de lavado, purificación y filtrado de humos, considerando el coste energético adicional de estas alternativas [6, WCl, 2005].

Un problema medioambiental de gran resonancia hace unos años, pero en aparente relegación a un plano secundario para la opinión pública ante las emisiones de anhídrido carbónico, es la actividad de los compuestos clorados en la destrucción de la capa de ozono. Esta problemática es de la incumbencia de este trabajo, debido a que a pesar de las normativas destinadas a la supresión de los compuestos fluoro-clorados (CFCs) e hidrógenofluoro-clorados (HCFCs) en los sistemas de refrigeración derivadas del Protocolo de Montreal [7, UNEP, 2006], aún existen equipos en la cadena de frío mundial que trabajan con este tipo de fluidos frigoríficos. Aunque estos sistemas trabajan con ciclos cerrados de los fluidos, las posibles fugas de refrigerante son un riesgo no sólo como agentes del efecto invernadero sino especialmente en cuanto al deterioro de la capa de ozono, inadmisible este último ante la dimensión del problema.

\section{Las nuevas políticas de actuación}

Como ya se ha comentado, los países desarrollados están reorientando sus políticas energéticas buscando un suministro de energía seguro, sostenible y competitivo; objetivo para el cual se establecen medidas destinadas a la diversificación de fuentes energéticas y su procedencia, un aumento de la eficiencia en el uso y conservación de la energía, investigación y desarrollo de nuevas tecnologías y finalmente a fomentar la cooperación entre países. Trabajando sobre estos puntos se puede luchar contra la subida de precios de la energía asociada a la dependencia ya mentada, contribuyendo a mantener la competitividad y el empleo en las economías europeas. Es esta idea la que ha movido a la UE a establecer un Plan de Acción con el que pretende convertirse en referencia mundial en el campo [W-2].

En lo que a fomentar la eficiencia energética se refiere, deben garantizarse unas exigencias de eficiencia mínima de los equipos de uso final de la energía, en particular en edificios, transporte y transformación de ésta, ya que se estima que más del $20 \%$ del consumo actual podría ahorrarse. Es por ello que la nueva estrategia recoge el objetivo cuantitativo de mejorar la eficiencia energética en un 20\% con vistas al 2020 [8, MITyC, 2006].

Esta idea queda implantada a nivel europeo con la directiva 2006/32/EC de fomento de la eficiencia en el uso final de la energía y servicios energéticos, en la cual se establecen los objetivos, así como las medidas, incentivos, y estructura financiera y legal para eliminar las 
barreras del mercado existente que impiden el uso eficiente de la energía. Los países miembros deben implantar la normativa necesaria para alcanzar las metas convenidas.

En España, este objetivo de mejora de la eficiencia energética queda recogido en el conocido como Plan de Acción 2008-2012 de la Estrategia de Ahorro y Eficiencia energética (E4), aprobado el 20 de julio de 2007. El Plan espera generar un ahorro de 87,9 millones de toneladas equivalentes de petróleo (el equivalente al 60\% del consumo de energía primaria en España durante 2006) así como permitir una reducción de emisiones de $\mathrm{CO}_{2}$ a la atmósfera de 238 millones de toneladas [W-2].

Dicho plan concentra sus esfuerzos en 7 sectores: Industria; Transporte; Edificación; Servicios Públicos; Equipamiento residencial y ofimático; Agricultura; y, Transformación de la Energía; para cada uno de los cuales especifica medidas concretas. En lo que al objeto del presente trabajo concierne, puede destacarse la medida dentro del sector edificación de mejorar la eficiencia energética de las instalaciones térmicas de los edificios existentes, mediante la sustitución de equipos de producción de frío e incorporación de sistemas de enfriamiento gratuito y de recuperación térmica; manteniendo un adecuado nivel de confort térmico en los espacios acondicionados.

\section{I.2. PROBLEMÁticA ENERGÉTICA EN LA EDIFICACIÓN}

El consumo de energía final suele dividirse en tres grandes sectores: industria, transporte y otros, que incluye, a su vez, el sector primario (agricultura, ganadería y pesca), el sector servicios y el sector residencial. La evolución del consumo energético por sectores en España y Europa se muestra en las figuras siguientes (figuras I.11 y I.12).

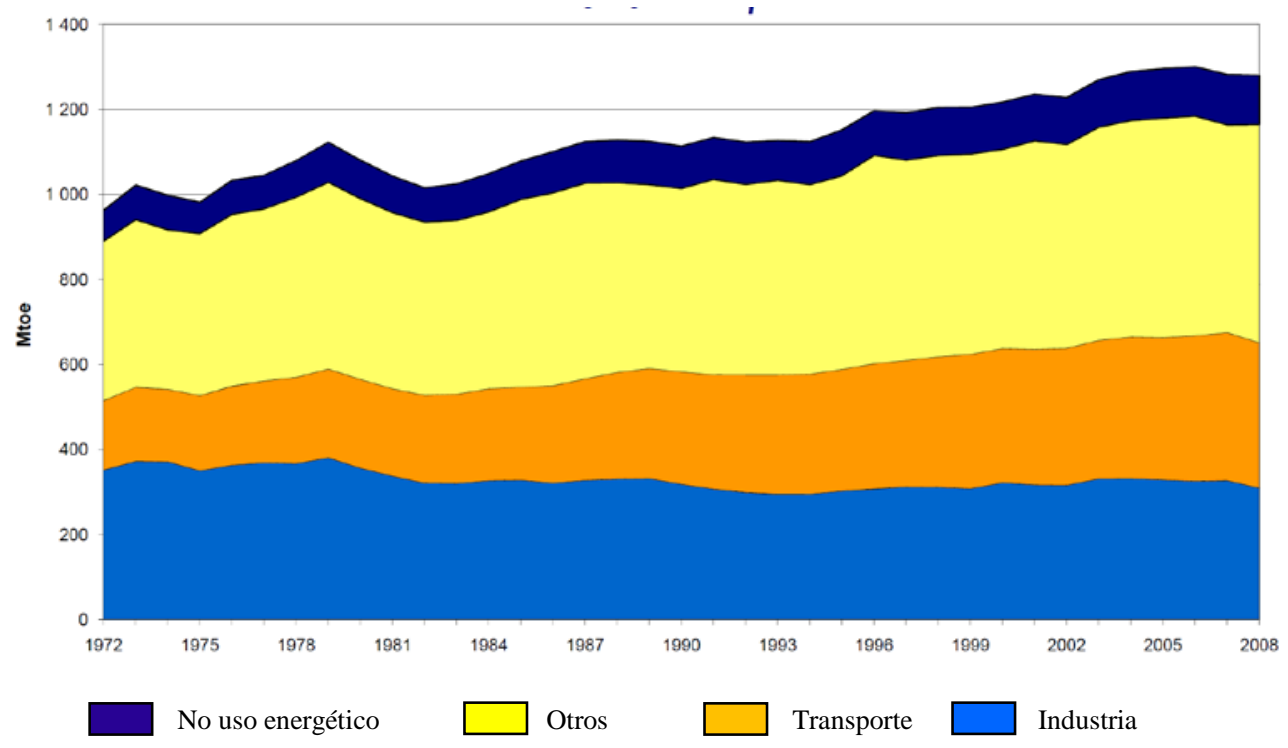

Figura I.11.- Evolución del consumo final de energía por sectores en Europa (OECD) Mtoe (traducido de la fuente: IEA Energy Statistics @ OECD/IEA, 2010). 


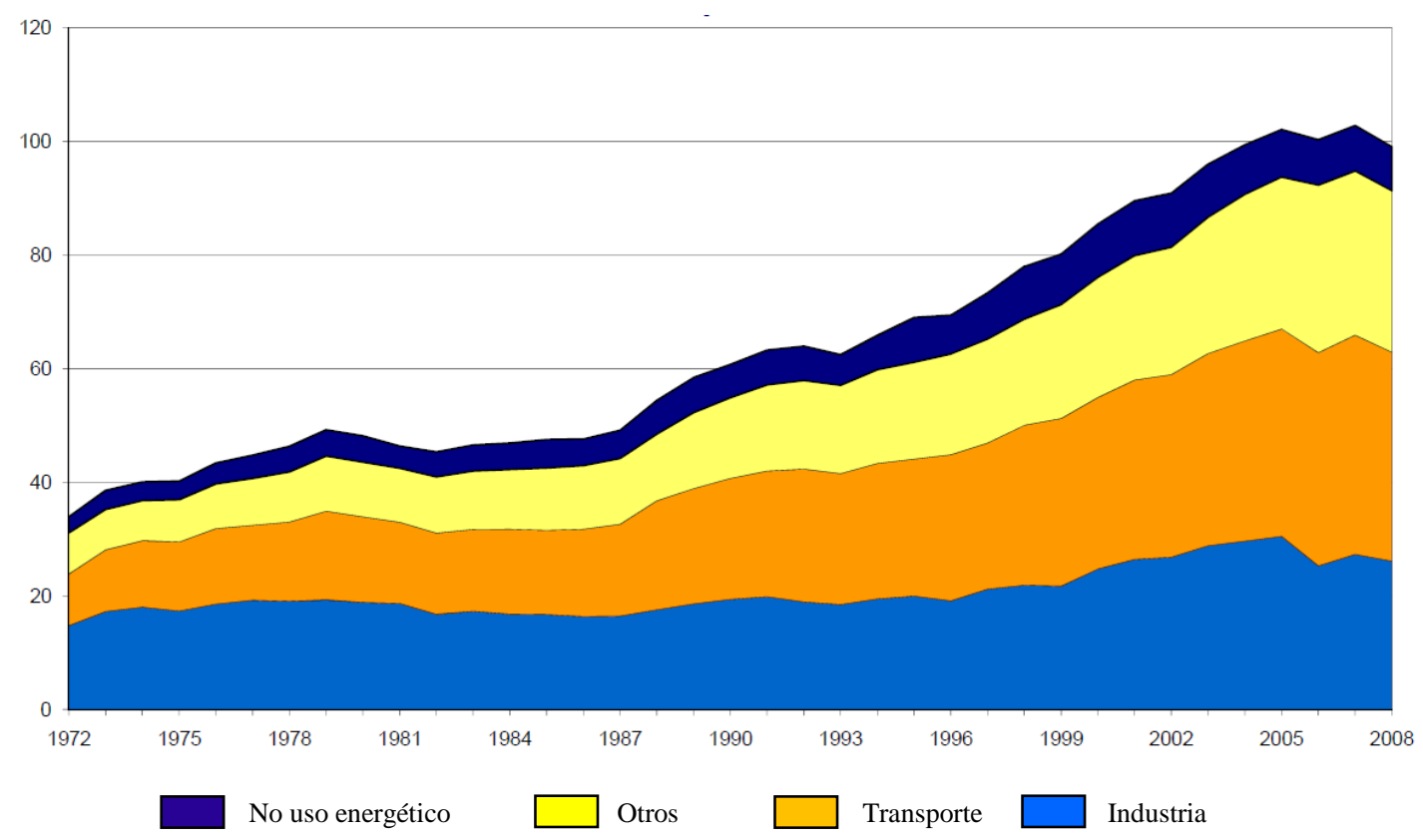

Figura I.12.- Evolución del consumo final de energía por sectores en España (OECD) Mtoe (traducido de la fuente: IEA Energy Statistics (C) OECD/IEA, 2010).

De este modo, aunque se observa un importante peso del resto de sectores englobados en "otros", y su creciente relevancia particularmente en España, no resulta fácil obtener información sobre el consumo en edificios de forma independiente, pues al consumo en viviendas (sector residencial) hay que añadir la fracción del consumo del sector servicios que se produce en edificios no residenciales.

El sector de la edificación debe destacarse entre los objetivos de las nuevas políticas de actuación como el sector con mayor potencial de ahorro energético, debido por un lado a que lleva asociado entre un $20 \%$ y un $40 \%$ del consumo de energía final en Europa, dependiendo de la climatología; y por otro a que se estima que un $20 \%$ de dicho consumo podría ahorrarse [8, MITyC, 2006]. Además, se presenta como uno de los sectores con mayor incremento en el consumo de energía final en los últimos años en países desarrollados, alcanzando a sectores con mayor peso históricamente en cuanto a consumo energético, como el industrial o el de transportes. Este incremento se explica atendiendo al crecimiento económico y bienestar social, la expansión del sector de la edificación así como del de servicios derivado de éste, especialmente en lo concerniente a climatización; junto con el hecho de que las personas pasan cada vez más parte de su vida diaria en espacios interiores [9, Pérez et al., 2007].

Por todo ello, un estudio estricto del ahorro energético en este sector debería abordarse de forma independiente, desglosando el mismo al menos en dos subsectores: edificios residenciales y no residenciales (terciarios). Estos últimos engloban aquellos edificios de carácter público o comercial, entre los que se incluyen hospitales, escuelas, restaurantes, etc., distinguiéndose en estos una gran variedad de usos y servicios energéticos (climatización, ACS, iluminación, refrigeración, preparación de alimentos, etc.). 
En el sector residencial, el tamaño y la climatología son factores determinantes para el consumo energético. Las viviendas pequeñas necesitan menos energía al tener menor superficie acondicionada y de transferencia y menor ocupación. La cantidad y el tipo de energía consumida en una vivienda dependen fundamentalmente del clima, el diseño arquitectónico, la infraestructura energética y el nivel económico de sus ocupantes. En general, los hogares de naciones desarrolladas consumen más energía y se espera que su consumo continúe creciendo con la instalación de nuevos equipos (acondicionadores de aire, electrodomésticos, ordenadores, etc.).

\section{Consumo Energético en las Instalaciones de Climatización.}

La demanda de energía en los edificios residenciales deriva de una amplia variedad de usos y servicios, como la provisión de agua caliente sanitaria (ACS), climatización (sistemas HVAC), refrigeración, iluminación, cocina, etc. En lo que concierne a los equipos de climatización, incluyendo tanto calefacción como ventilación y acondicionamiento de aire, comprenden el mayor consumo energético tanto en el sector residencial, como se muestra en la figura I.13, como en el no residencial, cuando no tiempo atrás podían considerarse un lujo.

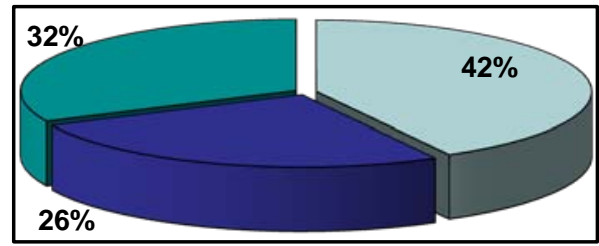

$\square$ Acondicionamiento térmico $\square \mathrm{ACS}$

口lluminación y aparatos eléctricos

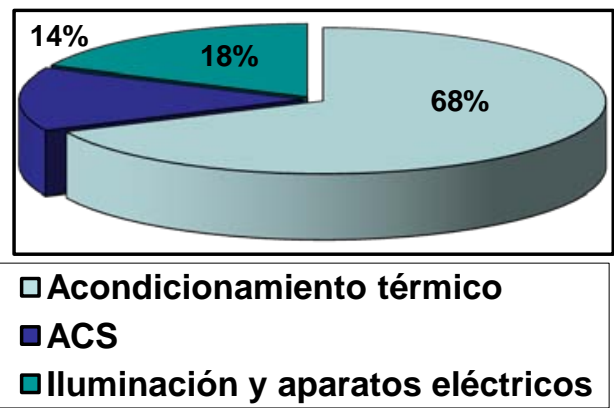

口lluminación y aparatos eléctricos

\section{Figura I.13.- Principales usos energéticos en edificios en España (izquierda) y Europa} (derecha) (fuente: IDAE).

Asimismo, y en función de la climatología local, el aumento en el número de instalaciones de sistemas de acondicionamiento en verano supone en los países desarrollados un incremento anual importante de demanda de electricidad, que no sólo implica las consecuencias conocidas derivadas de la producción, transformación y transporte, sino además la existencia de demandas punta que pueden saturar la red eléctrica (especialmente en los países meridionales; sólo España e Italia representan más del 50\% del mercado europeo).

De forma aproximada, para naciones desarrolladas, la climatización representa la mitad de la energía consumida en los edificios y entre la décima y la quinta parte de la energía total. Además, los pronósticos indican un fuerte crecimiento del consumo y la superficie climatizada en la UE que aumentará un 50\% en los próximos 15 años [9, Pérez et al., 2007]. 


\section{Políticas energéticas en la Edificación}

Este aumento en el consumo energético y emisiones de dióxido de carbono asociadas al sector de la edificación, ha convertido los conceptos de eficiencia y ahorro energético en estrategias prioritarias de las políticas energéticas en la mayoría de los países, como es el caso de la normativa europea conocida como EPBD (Energy Performance of Buildings Directive) [N1].

Con objeto de favorecer la deseada cooperación entre los Estados miembro se establece la Aplicación Conjunta de dicha Directiva Europea [W-3], potenciando el intercambio de información y experiencia entre los países de la UE-27 además de Noruega y Croacia. De esta forma se fomenta la implantación de la legislación comunitaria específica y políticas energéticas asociadas a la eficiencia energética en edificios.

A nivel nacional, dicha directiva europea queda transpuesta al ordenamiento jurídico español a través del Real Decreto 47/2007 de 19 de enero, por el que se aprueba el procedimiento básico para la certificación de eficiencia energética de edificios de nueva construcción; así como del Código Técnico de la Edificación [N-2], introducido por la Ley de Ordenación de la Edificación (LOE) 38/1999 de 5 de Noviembre. Asimismo ha sido necesaria una revisión del antiguo Reglamento de Instalaciones Térmicas en Edificios con el Real Decreto 1027/2007 [N-3] para implantar estas nuevas normativas. En los subapartados siguientes se resumen brevemente estas normativas nacionales.

\section{Certificación energética}

Desde su puesta en vigor el 1 de noviembre de 2007, es obligatorio poner a disposición de los compradores o usuarios de los edificios un Certificado de Eficiencia Energética; en el cual, y mediante una etiqueta de eficiencia energética, se asigna a cada edificio una Clase Energética de eficiencia, que variará desde la clase A, para los energéticamente más eficientes, a la clase G, para los menos eficientes. Estos certificados son documentos técnicos sin carácter reglamentario, destinados a facilitar el cumplimiento del Procedimiento básico descrito en el Real Decreto; y han de estar recogidos en el Registro general de documentos reconocidos para la certificación energética de edificios, adscrito a la Secretaría General de Energía del Ministerio de Industria, Turismo y Comercio, como prueba de su reconocimiento por dicho ministerio y del Ministerio de Vivienda existente en el momento de su implantación.

Todo lo dispuesto por la certificación energética de la Directiva no tiene otro objetivo que, limitando las emisiones de $\mathrm{CO}_{2}$ mediante la mejora de la eficacia energética, conservar la calidad del medio ambiente y garantizar una utilización prudente y racional de los recursos naturales, a fin de favorecer una mayor transparencia del mercado inmobiliario que fomente las inversiones en ahorro de energía, mediante la aportación de una información objetiva de las características energéticas de los edificios [W-2]. 


\section{Código Técnico de la Edificación (CTE)}

Por su parte, el Código Técnico de la Edificación transpone parcialmente la Directiva europea 2002/91/CE en lo que se refiere a los requisitos mínimos de eficiencia energética que deben cumplir los edificios nacionales para que se ajusten a los requisitos básicos, establecidos en la Ley de Ordenación de la Edificación (LOE) 38/1999 de 5 de Noviembre, que garanticen ciertas necesidades de las personas en cuestiones de seguridad y habitabilidad (acústicas, térmicas, estructurales, etc.) [N-2].

EI CTE está planteado bajo un enfoque semejante al adoptado a nivel europeo y al propugnado por las principales organizaciones internacionales en este campo, a fin de fomentar la innovación y el desarrollo tecnológico: los códigos basados en prestaciones u objetivos.

La asistencia y asesoramiento para la aplicación del CTE, su desarrollo y actualización, corren a cargo del Consejo para la Sostenibilidad, Innovación y Calidad de la Edificación, creado por Real Decreto 315/2006 de 17 de marzo.

El código se divide en dos partes, ambas de carácter reglamentario, en la primera de las cuales se prescriben los objetivos a alcanzar y las exigencias a satisfacer para lograr estos. La segunda parte está constituida por 6 módulos que proporcionan las reglas técnicas, procedimientos y ejemplos de soluciones que permiten determinar si el edificio cumple los niveles de prestación establecidos. Estos módulos dan cabida a la aplicación de otros medios alternativos, y además se presentan, oficialmente reconocidos pero sin carácter reglamentario, los llamados Documentos de Referencia como complemento externo al Código de utilidad por facilitar su aplicación.

Los seis documentos básicos que conforman la segunda parte del CTE son los indicados a continuación:

- DB-SE: Seguridad Estructural

- DB-SI: Seguridad en caso de incendio

- DB-SU: Seguridad de Utilización

- DB-HS: Salubridad

- DB-HR: Protección frente al ruido

- DB-HE: Ahorro de energía

Dentro del Documento Básico HE de ahorro de energía se encuentran las siguientes secciones:

- HE.1: Limitación de demanda energética (calefacción y refrigeración)

- HE.2: Rendimiento de las instalaciones térmicas.

- HE.3: Eficiencia energética de las instalaciones de iluminación.

- HE.4: Contribución solar mínima de agua caliente sanitaria. 
- HE.5: Contribución fotovoltaica mínima de energía eléctrica.

De esta forma, el Código Técnico de la edificación ha permitido transponer las reglas comunitarias en este campo, pero además establece una seguridad estructural no abordada previamente, así como nuevas exigencias acústicas. En el aspecto ambiental, se da respuesta igualmente, mediante nuevas y bastante más estrictas exigencias energéticas, a los compromisos de Kyoto relativos a la reducción de emisiones de $\mathrm{CO}_{2}$.

\section{Reglamento de Instalaciones Térmicas en Edificios (RITE)}

La necesidad de transponer la Directiva europea 2002/91/CE, así como la coherencia con el "Documento Básico de Ahorro de energía" del CTE, implicaba la incorporación de nuevas exigencias de ahorro y eficiencia energética de las instalaciones térmicas en los edificios, lo que convergió en la revisión del Reglamento de Instalaciones Térmicas en Edificios, derogándose el anterior con el Real Decreto 1027/2007. Además, dicha revisión permitía introducir en el nuevo documento la experiencia acumulada de la aplicación del viejo RITE desde su puesta en vigor. Este Real Decreto ha sido elaborado conjuntamente por el Ministerio de Industria, Turismo y Comercio y el antiguo Ministerio de Vivienda; aunque con posterioridad se publicó una corrección de errores [N-3].

Sin embargo, para la aplicación de este Real Decreto se debe desarrollar a nivel autonómico la reglamentación complementaria correspondiente, introduciendo los requisitos adicionales a cumplir por las instalaciones dispuestas en su territorio.

Este reglamento establece las condiciones que deben cumplir las instalaciones destinadas a atender la demanda de bienestar térmico e higiene a través de las instalaciones de calefacción, climatización y agua caliente sanitaria, para conseguir un uso racional de la energía.

Las mayores exigencias en eficiencia energética que establece el RITE, se concretan en:

- Mayor Rendimiento Energético en los equipos de generación de calor y frío, así como los destinados al movimiento y transporte de fluidos.

- Mejor aislamiento en los equipos y conducciones de los fluidos térmicos.

- Mejor regulación y control para mantener las condiciones de diseño previstas en los locales climatizados.

- Utilización de energías renovables disponibles, en especial la energía solar y la biomasa.

- Incorporación de subsistemas de recuperación de energía y el aprovechamiento de energías residuales.

- Sistemas obligatorios de contabilización de consumos en el caso de instalaciones colectivas. 
- Desaparición gradual de combustibles sólidos más contaminantes.

- Desaparición gradual de equipos generadores menos eficientes.

Existen unos documentos reconocidos de carácter técnico pero no reglamentario, destinados a facilitar el cumplimiento de las exigencias de este Reglamento y recogidos en el Registro general de documentos reconocidos del RITE, adscrito a la Secretaría General de Energía del Ministerio de Industria, Turismo y Comercio, como prueba de su reconocimiento por parte de este ministerio y del entonces Ministerio de Vivienda.

Además, el Reglamento impone la obligación de revisar y actualizar las exigencias de eficiencia energética en períodos de al menos 5 años; tarea encargada a la Comisión Asesora del RITE, la cual elabora las propuestas conforme a la evolución de la técnica y la política energética nacional.

El Reglamento de Instalaciones Térmicas en Edificios está conformado por dos partes: una primera en la que se describen las disposiciones generales y una segunda en la que se desarrollan las instrucciones técnicas relativas a su aplicación. Dentro de esta segunda, existe un apartado dedicado a las exigencias de eficiencia energética de las instalaciones (IT 1.2.), para cuya correcta aplicación se establecen la necesidad de un procedimiento de verificación.

El RITE plantea dos posibles procedimientos de verificación: uno simplificado y prescriptivo, y otro alternativo que deja abierta la posibilidad de innovación (procedimiento prestacional). El primero de ellos consiste en la adopción de soluciones basadas en la limitación indirecta del consumo de energía de la instalación, mediante el cumplimiento de valores límite y soluciones especificadas en el propio reglamento para cada sistema o subsistema diseñado, y cuyo cumplimiento asegura la superación de la exigencia de eficiencia energética. Por su parte, el segundo procedimiento plantea la posibilidad de recurrir a propuestas ajenas a lo establecido en el texto, siempre y cuando estas sean válidas; es decir, que cumplan o mejoren los requerimientos de eficiencia establecidos, en $\mathrm{kg}$ de $\mathrm{CO}_{2}$ emitidos por el sistema.

La metodología seguida para la caracterización de la eficiencia energética sigue una serie de pasos que concluyen en la determinación de la energía primaria consumida y las emisiones de $\mathrm{CO}_{2}$ asociadas. Para ello se parte de la obtención de la demanda térmica del sistema, a partir de la cual se obtiene el valor del consumo solicitado al mismo. Una vez realizada la simulación de las instalaciones térmicas a fin de obtener el rendimiento medio de las mismas, se procede a calcular los consumos como el cociente entre la demanda y dicho rendimiento. Obtener las emisiones de $\mathrm{CO}_{2}$ ocasionadas por ese consumo resulta ya inmediato, recurriendo al correspondiente valor del coeficiente de paso para la energía primaria, o en su caso para la energía eléctrica consumida. Estos coeficientes de paso deberán ser suministrados por la Administración con frecuencia anual (tabla I.1). 
Tabla I.1.- Emisión de $\mathrm{CO}_{2}$ de la electricidad (mix para España). (Fuente: IDAE).

\begin{tabular}{|c|c|c|c|}
\hline \multirow{2}{*}{\multicolumn{2}{|c|}{ ENERGÍA }} & \multicolumn{2}{|c|}{ COEFICIENTES DE PASO } \\
\hline & & $\begin{array}{c}\text { kWh/ kWh energía } \\
\text { primaria }\end{array}$ & $\mathrm{g} \mathrm{CO}_{2} / \mathrm{kWh}(\mathrm{t} \circ \mathrm{e})$ \\
\hline \multirow{7}{*}{$\begin{array}{l}\text { Energía } \\
\text { Térmica }\end{array}$} & Gas Natural & 1,011 & 204 \\
\hline & Gasóleo-C & 1,081 & 287 \\
\hline & GLP & 1,081 & 244 \\
\hline & Carbón (doméstico) & 1,000 & 347 \\
\hline & Biomasa & Neutro (0) & Neutro (0) \\
\hline & Biocarburantes & Neutro (0) & Neutro $(0)$ \\
\hline & Solar térmica & 0 & 0 \\
\hline \multirow{5}{*}{$\begin{array}{l}\text { Energía } \\
\text { eléctrica }\end{array}$} & Convencional peninsular & 2,603 & 649 \\
\hline & Convencional insular & 3,347 & 981 \\
\hline & Solar fotovoltaica & 0 & 0 \\
\hline & Horas valle peninsular & 2,022 & 517 \\
\hline & Horas valle insular & 3,347 & 981 \\
\hline
\end{tabular}

\section{I.3. MÉtOdOS DE REDUCCIÓN DEL CONSUMO ENERGÉTICO EN LA CLIMATIZACIÓN DE EDIFICIOS}

Una vez adquirida consciencia de la relevancia del impacto medio ambiental de las instalaciones de climatización en edificios, resulta obvia la conveniencia de los sistemas recuperadores de energía que permitan utilizar un calor residual, que de lo contrario se desperdiciaría simplemente. Estos equipos reducen el consumo de energía de adecuación y, por tanto, el de energía primaria, que está ejerciendo un efecto tan desastroso sobre el equilibrio ecológico del planeta.

En general es posible señalar tres métodos diferentes para reducir el consumo energético de los edificios, como muestra la figura I.14 [10, Rey et al., 2000].

Estos tres métodos son:

- Disminución de las necesidades energéticas.

- Sustitución de las fuentes convencionales de energía por fuentes gratuitas.

- Optimización de la eficiencia de utilización. 


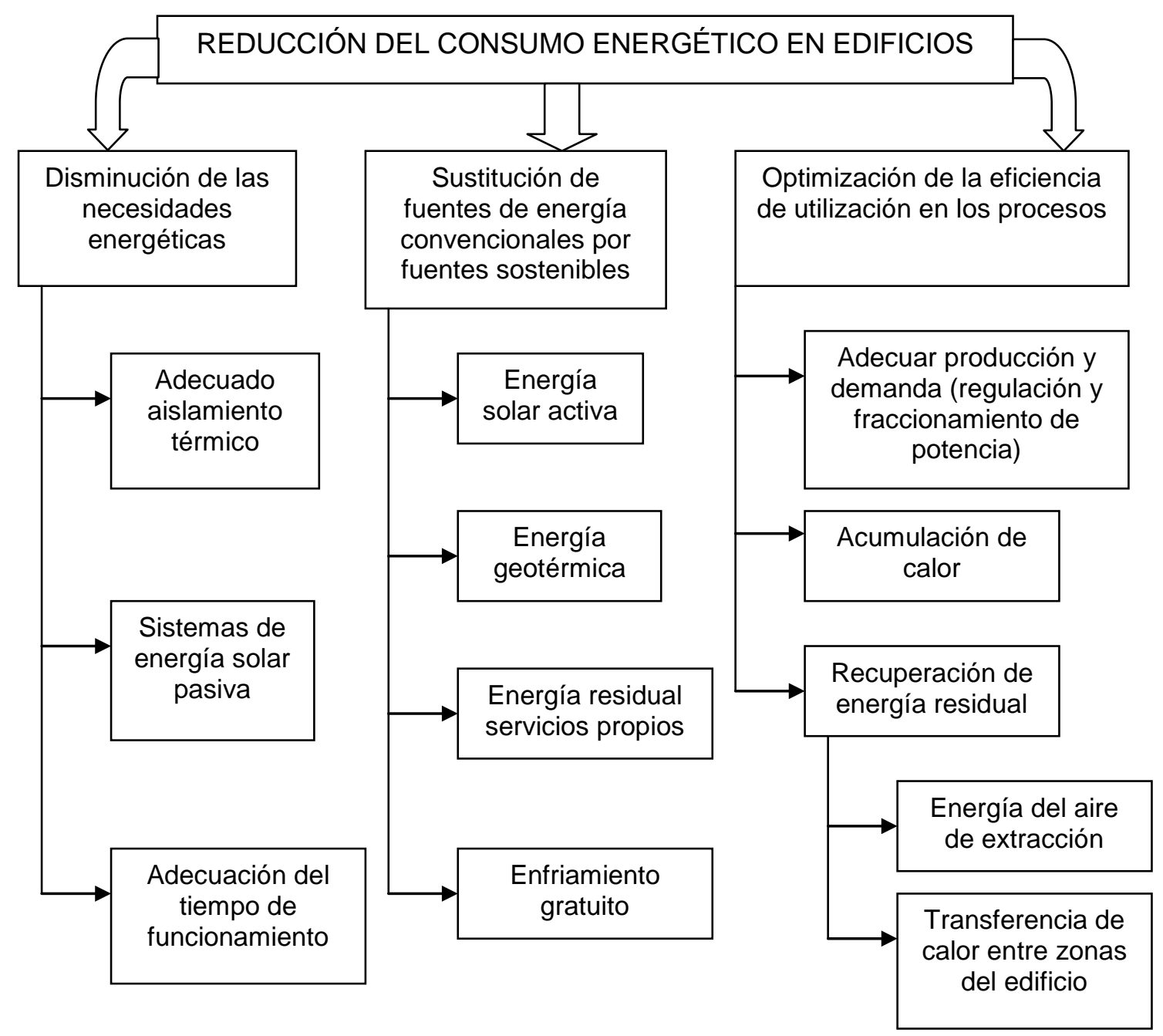

Figura I.14.- Esquema de los procesos más utilizados en la reducción del consumo energético en edificios.

\section{Disminución de las necesidades energéticas.}

Para lograr esto se puede actuar por tres vías distintas:

- Elección de un adecuado aislamiento térmico.

- Utilización de arquitectura y sistemas pasivos.

- Adecuación del tiempo de funcionamiento de las instalaciones con sistemas de regulación.

\section{Sustitución de las fuentes convencionales de energía por otras fuentes sostenibles.}

Es evidente que un procedimiento que permite un importante ahorro energético es el empleo de energías alternativas, como la energía solar activa, la geotérmica, energías residuales de otros procesos o el denominado enfriamiento gratuito o "free cooling". 


\section{Optimización de la eficiencia de utilización.}

Una vez que se ha reducido al mínimo imprescindible la demanda energética de un edificio, cualquier disminución posterior de los consumos requiere el empleo de procesos más eficientes como:

- Adecuar la producción de frío o calor a la demanda del edificio, mediante un adecuado fraccionamiento de la potencia instalada y una correcta regulación de la misma.

- Empleo de acumuladores de agua fría o caliente que permita atender puntas de consumo con un funcionamiento continuo de equipos de forma más eficiente al mismo tiempo que posibilita la utilización de tarifas especiales, lo que puede generar además un ahorro en términos económicos.

- La recuperación de energías residuales, reutilizando energías que normalmente son desaprovechadas en las instalaciones térmicas de la edificación y, en la mayoría de los casos, se evacuan al exterior perdiéndose totalmente.

Consecuentemente, las ya mentadas políticas de actuación desarrolladas en torno al sector edificación se focalizan no sólo en la mejora de la eficiencia de utilización de los procesos, sino también en la reducción de la demanda energética y diversificación de fuentes a favor de la implantación de fuentes gratuitas.

Este trabajo se enmarca por lo tanto dentro del panorama energético presentado, planteando el estudio de alternativas de climatización orientadas a la explotación de estas tres vías de actuación: reducción de la demanda energética a soportar por los sistemas y aprovechamiento de recursos energéticos gratuitos, mediante sistemas de recuperación energética, free-cooling y de enfriamiento evaporativo; así como la optimización de la eficiencia de los sistemas precisando la combinación óptima de funcionamiento de los mismos. Por lo tanto el estudio se focaliza en la optimización de la operación de una instalación de climatización que favorezca la reducción del consumo energético y de las emisiones de anhídrido carbónico. 


\section{REFERENCIAS}

[1] "Energy 2020 - A strategy for competitive, sustainable and secure energy", Communication from the Commission to the European Parliament, the Council, the European Economic and Social Committee and the Committee of the Regions. http://eurlex.europa.eu/LexUriServ/LexUriServ.do?uri=COM:2010:0639:FIN:EN:PDF2010

[2] OECD/ International Energy Agency, "30 Key Energy Trends in the IEA \&Worldwide. 30th anniversary of the International Energy Agency", Paris, 2005.

[3] OECD/ International Energy Agency, "WEO 2009 Special Early Excerpt: How the Energy Sector Can Deliver on a Climate Agreement in Copenhagen", Bangkok, 2009.

[4] OECD/ International Energy Agency, "Key World Energy Statistics 2010", 2010.

[5] Ministerio de Medio Ambiente, y Medio Rural y Marino, Secretaría de Estado de Cambio Climático. Dirección General de Calidad y Evaluación Ambiental. Unidad de Información Ambiental Estratégica, "Inventarios nacionales de emisiones a la atmósfera 1990-2008, documento resumen". Julio 2010.

[6] World Coal Institute, "The Coal Resource: a Comprehensive Overview of Coal", Londres, 2005.

[7] United Nations Environment Programme (UNEP), Ozone Secretariat, "Handbook for the Montreal Protocol on Substances that Deplete the Ozone Layer", 8ª edición, Kenya, 2006.

[8] Ministerio de Industria, Turismo y Comercio: secretaría general de energía, "La energía en España 2006", Centro de publicaciones del Ministerio de Industria, Turismo y Comercio. ISBN 13: 978-84-96275-52-2. Madrid, 2006.

[9] Pérez-Lombard L., Ortiz J., Pout C., "A review on buildings energy consumption information", Energy and Buildings (40) pp.: 394-398. 2008.

[10] Rey Martínez, F.J., San José Alonso, J.F., Velasco Gómez, E., Álvarez-Guerra Plasencia, M.A., "Recuperación de energía en sistemas de climatización. Documentos Técnicos de Instalaciones en la Edificación, DTIE 8.01". Edición a cargo de ATECYR. Editorial: El Instalador. ISBN: 84-921270-5-8. 2000. 


\section{Normativa}

[N-1] Directive 2002/91/CE of the European Parliament and of the Council of 16 December 2002 on the energy performance of buildings, 2002. (Energy Performance of Buildings Directive). http://www.epbd-ca.org/

[N-2] Ministerio de Vivienda de España, "Real Decreto 315/2006 de 17 de marzo: Código Técnico de la Edificación: Parte 1". 2006.

[N-3] Ministerio de Industria, Turismo y Comercio y Ministerio de Vivienda de España, "Real Decreto 1027/2007: Reglamento de Instalaciones Térmicas en Edificios".

\section{Páginas Web}

[W-1] OECD/ International Energy Agency, "IEA Energy Statistics 2010". http://www.iea.org/stats/ (Día de consulta: 10 de febrero de 2011).

[W-2] Instituto para la Diversificación y Ahorro Energético (IDAE) http://www.idae.es/ Día de consulta: 11 de marzo de 2011.

[W-3] Energy Performance of Buildings Directive, Concerted Action. http://www.epbd-ca.org/ (Día de consulta: 14 de marzo de 2011). 


\section{RELACIÓN DE FiguRAS}

- Figura I.1.- Provisión de energía primaria en España (traducido de la fuente: IEA Energy Statistics $\odot$ OECD/IEA, 2010).

- Figura I.2.- Provisión de energía primaria en Europa (OECD) (traducido de la fuente: IEA Energy Statistics (C) OECD/IEA, 2010).

- Figura I.3.- Provisión de energía primaria en el Mundo (traducido de la fuente: IEA Energy Statistics (C) OECD/IEA, 2010).

- Figura I.4.- Precios spot del crudo en dólares americanos/barril (traducido de la fuente: Key World Energy Statistics 2010 @ O OECD/IEA, p. 40).

- Figura 1.5.- Precios del carbón térmico en dólares americanos/ tonelada (traducido de la fuente: Key World Energy Statistics 2010 ๑ OECD/IEA, p. 41).

- Figura 1.6.- Precios de importación del gas natural en dólares americanos/ MBtu (traducido de la fuente: Key World Energy Statistics 2010 ๑ OECD/IEA, p. 41).

- Figura I.7.- Evolución de la generación de electricidad por tipo de fuente en TWh (traducido de la fuente: Key World Energy Statistics 2010 ๑ OECD/IEA, p. 24).

- Figura I.8.- Emisiones mundiales de $\mathrm{CO}_{2}$ por combustible en $\mathrm{Mt}$ de $\mathrm{CO}_{2}$ (traducido de la fuente: Key World Energy Statistics 2010 (c) OECD/IEA, p. 44).

- Figura 1.9.- Emisiones mundiales de $\mathrm{CO}_{2}$ por región en $\mathrm{Mt}$ de $\mathrm{CO}_{2}$ (traducido de la fuente: Key World Energy Statistics 2010 @ OECD/IEA, p. 45).

- Figura I.10.- Índice de evolución de $\mathrm{CO}_{2}$ total equivalente (fuente: Ministerio de Industria, Turismo y Comercio de España).

- Figura I.11.- Evolución del consumo final de energía por sectores en Europa (OECD) Mtoe (traducido de la fuente: IEA Energy Statistics (C) OECD/IEA, 2010).

- Figura I.12.- Evolución del consumo final de energía por sectores en España (OECD) Mtoe (traducido de la fuente: IEA Energy Statistics @ OECD/IEA, 2010).

- Figura I.13.- Principales usos energéticos en edificios en España (izquierda) y Europa (derecha) (fuente: IDAE).

- Figura I.14.- Esquema de los procesos más utilizados en la reducción del consumo energético en edificios. 


\section{RELACIÓN DE TABLAS}

- Tabla I.1.- Emisión de $\mathrm{CO}_{2}$ de la electricidad (mix para España). (Fuente: IDAE). 


\section{CAPÍTULO II \\ CALIDAD DEL CLIMA INTERIOR}

ABSTRACT

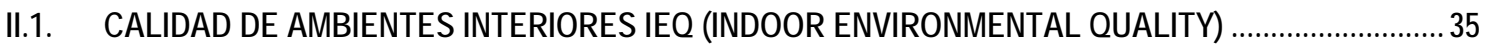

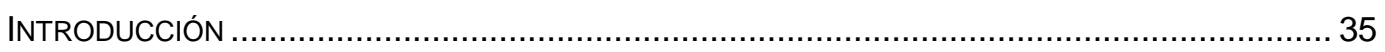

FACTORES QUE INTERVIENEN EN EL BIENESTAR EN ESPACIOS INTERIORES ......................... 36

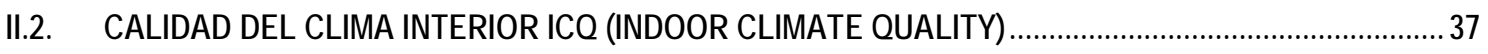

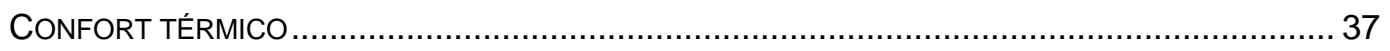

Equilibrio térmico con el ambiente ....................................................... 38

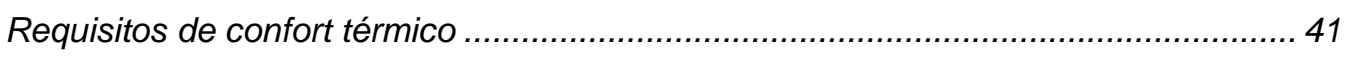

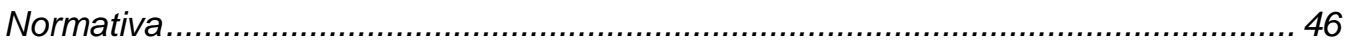

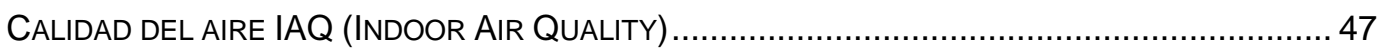

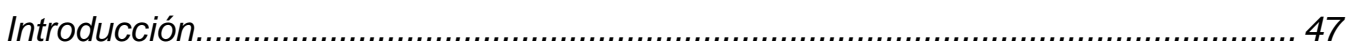

Evolución temporal de la concentración de un contaminante: ecuaciones................. 48

Percepción sensorial de la calidad del aire: evaluación subjetiva............................. 49

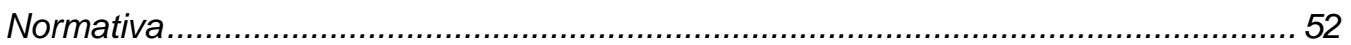

II.3. CLASIFICACIÓN DE AMBIENTES INTERIORES EN CONFORT TÉRMICO Y CALIDAD DEL AIRE.........53

CLASIFICACIÓN DEL AMBIENTE TÉRMICO: CRITERIOS DE ACEPTABILIDAD ............................ 53

CLASIFICACIÓN DE LA CALIDAD DEL AIRE: MÉTODOS DE EVALUACIÓN................................ 58

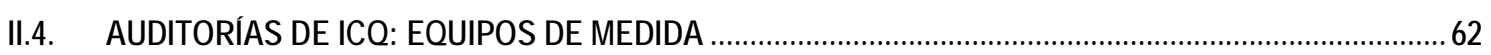

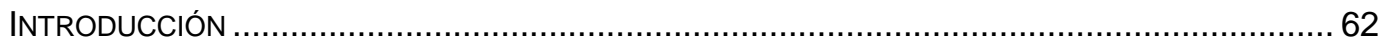

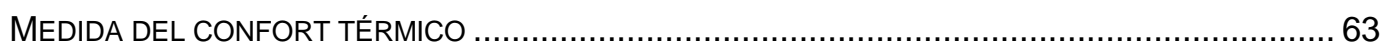

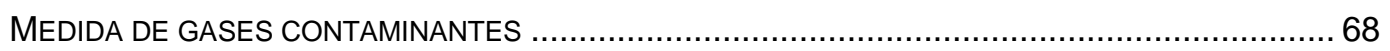




\section{CHAPTER II: \\ INDOOR CLIMATE QUALITY}

\section{ABSTRACT}

Air- conditioning systems are aimed at consuming the minimum amount of energy, maintaining the levels of Indoor Environmental Quality established. Consequently, it must be considered in every moment the requirements of thermal comfort and Air Quality expected indoors.

In the present chapter, the main factors affecting indoor environments are presented. Thermal comfort is achieved when human body is in thermal equilibrium with the surroundings. Consequently, several factors such as clothing, activity, etc. will affect this state. On the other hand, the presence of certain compound on breathing air could affect human health or even wellbeing. Then, requirements of thermal comfort and IAQ are introduced here, as well as the current norms where they are regulated.

Concerning these requirements, indoor environments can be classified in terms of thermal comfort and IAQ achieved. Due to the complexity of this characterization, criteria related to subjective personal judgment are introduced. Thus, categories are established in terms of indexes based on average votes and percentages of people that find the environment unacceptable.

Finally, a brief introduction to the main equipment use for characterizing indoor spaces is given. These techniques are aimed at evaluating some of the factors affecting thermal comfort, and determining the presence of some substances that spoil air quality. 


\section{SiMBOLOGÍA DEL CAPÍTULO}

S: tasa de calor retenido por el cuerpo $\left[\mathrm{W} / \mathrm{m}^{2}\right]$

M: tasa de producción de calor por metabolismo corporal $\left[\mathrm{W} / \mathrm{m}^{2}\right]$

W: tasa de trabajo útil realizado $\left[\mathrm{W} / \mathrm{m}^{2}\right]$

$R$ : tasa de calor intercambiado con el entorno por radiación $\left[\mathrm{W} / \mathrm{m}^{2}\right]$

C: tasa de calor intercambiado con el entorno por convección $\left[\mathrm{W} / \mathrm{m}^{2}\right]$

K: tasa de calor intercambiado con el entorno por conducción $\left[\mathrm{W} / \mathrm{m}^{2}\right]$

E: tasa de calor perdido por evaporación $\left[\mathrm{W} / \mathrm{m}^{2}\right]$

RES: tasa de calor intercambiado con el ambiente por la respiración $\left[\mathrm{W} / \mathrm{m}^{2}\right]$

Sup: superficie de piel corporal $\left[\mathrm{m}^{2}\right]$

m: masa corporal [kg]

h: altura de la persona [m]

$K_{c l}:$ Transferencia de calor por conducción a través de la ropa $\left[\mathrm{W} / \mathrm{m}^{2}\right]$

$R_{c l}:$ Resistencia a la evaporación de la vestimenta

$I_{c l}:$ Resistencia de la vestimenta a la transferencia de calor $\left[\mathrm{m}^{2} \cdot \mathrm{K} / \mathrm{W}\right]$

$P v_{a}:$ Presión parcial del vapor de agua en el aire [Pa]

$t_{0}$ : temperatura operativa $\left[{ }^{\circ} \mathrm{C}\right]$

$t_{\mathrm{a}}$ : temperatura seca del aire $\left[{ }^{\circ} \mathrm{C}\right]$

$t_{\text {rad: }}$ : temperatura radiante media del entorno $\left[{ }^{\circ} \mathrm{C}\right]$

$h_{c}$ : coeficiente del intercambio de calor por convección $\left[W /\left(m^{2} K\right)\right]$

$h_{r}$ : coeficiente del intercambio de calor por radiación $\left[W /\left(m^{2} K\right)\right]$

$P_{T a}$ : presión del vapor de agua a la temperatura del aire del ambiente [ $\mathrm{kPa}$ ]

$P_{\text {SatTe }}$ es la presión parcial del vapor a saturación a la temperatura efectiva [kPa]

$t_{\text {eq }}$ : temperatura equivalente $\left[{ }^{\circ} \mathrm{C}\right]$

$v_{a}:$ velocidad del aire $[\mathrm{m} / \mathrm{s}]$

H: Pérdidas de calor sensible.

$C_{\text {res: }}$ Calor intercambiado por convección en la respiración $\left[\mathrm{W} / \mathrm{m}^{2}\right]$. 
$E_{\text {res }}$ : Calor intercambiado por evaporación en la respiración $\left[\mathrm{W} / \mathrm{m}^{2}\right]$.

PMV: Voto Medio Previsto (Predicted Mean Vote)

PPD: Porcentaje de Personas Insatisfechas (Percentage of People Dissatisfied)

X: media instantánea de la concentración del contaminante $\left(\mathrm{mg} / \mathrm{m}^{3}\right)$

G: tasa de generación del contaminante en el interior del local ( $\mathrm{mg} / \mathrm{h})$

V: volumen del local $\left(\mathrm{m}^{3}\right)$

A: tasa de renovación de aire (h-1)

$X_{\text {ext }}$ : concentración del contaminante en el aire exterior de ventilación $\left(\mathrm{mg} / \mathrm{m}^{3}\right)$

$v_{d}$ : tasa de deposición del contaminante $\left(\mathrm{mg} / \mathrm{h} \cdot \mathrm{m}^{2}\right)$

A: superficie de deposición del contaminante $\left(\mathrm{m}^{2}\right)$

$Q_{a c}$ : flujo de aire tratado por el purificador $\left(\mathrm{m}^{3} / \mathrm{h}\right)$

$\varepsilon_{a c}:$ eficiencia del purificador.

$X_{\text {equi: }}$ concentración de equilibrio del contaminante $\left(\mathrm{mg} / \mathrm{m}^{3}\right)$

$X_{\text {ini: }}$ : concentración inicial del contaminante en el local $\left(\mathrm{mg} / \mathrm{m}^{3}\right)$

$C_{\text {int }}$ : calidad del aire interior percibida [olf]

$C_{\text {ext }}$ : calidad del aire exterior de renovación, percibida [olf]

PI: Índice de rendimiento [\%]

FI: Índice de fracaso [\%]

$\mathrm{Fl}_{C}$ : Índice de fracaso por frío [\%]

$F I_{W}$ : Índice de fracaso por calor [\%]

$\mathrm{Fl}_{\mathrm{C}-\mathrm{w}}$ : Índice ponderado de fracaso por frío [\%]

$F I_{W-w}:$ Índice ponderado de fracaso por calor [\%]

wf: factor de ponderación de los índices por fracaso.

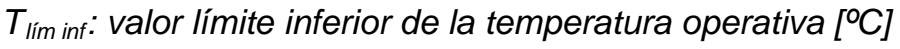

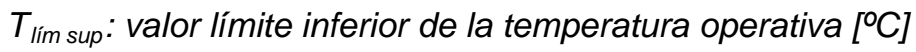

r: tiempo [h]

$X_{\mathrm{CO} 2}$ : concentración inicial de $\mathrm{CO}_{2}$ en el espacio ocupado [ppm]

Q: caudal de ventilación aportado [ $\mathrm{m}^{3} / \mathrm{h} /$ persona] 


\section{II.1. CALIDAD DE AMBIENTES INTERIORES IEQ (INDOOR ENVIRONMENTAL QUALITY)}

\section{Introducción}

El constante avance de los países desarrollados hacia mejores niveles de vida, junto con el también cada vez mayor porcentaje de tiempo pasado por las personas en el interior de edificios (estimado en aproximadamente un $90 \%$ en la actualidad), genera la necesidad de asegurar unas ciertas condiciones ambientales en los espacios interiores, consideradas como aceptables. Estos requisitos esperados en el interior de los edificios constituyen, por lo tanto, una necesidad relativamente actual, que además irá evolucionando en el futuro a la par del desarrollo de los conocimientos sobre las repercusiones asociadas así como del propio nivel de vida de las personas que los ocupan.

Unas adecuadas condiciones ambientales en un determinado local no son, sin embargo, necesarias exclusivamente en términos de confort de sus ocupantes. Son además especialmente relevantes las repercusiones que la presencia de ciertos contaminantes en el aire respirado [N-1], [N-2], un excesivo ruido, iluminación insuficiente o niveles extremos de humedad relativa [N-3], a modo de ejemplo, pueden tener sobre la salud de las personas.

Asimismo, existe un interés adicional en el mantenimiento de unos niveles satisfactorios de la calidad del ambiente interior: la productividad de las personas en sus lugares de trabajo o estudio. Se ha comprobado que este efecto, el cual comienza a ser tenido en cuenta más recientemente, puede llegar a tener un peso relevante en los costes asociados al personal, ya que no sólo su bienestar puede suponer un aumento de un $1 \%$ en su productividad, sino que también se reducen los costes debidos a afecciones de su salud o a daños y averías en los equipos manipulados por ellos [1, Corgnati\&Gameiro, 2011].

Sin embargo, la búsqueda de unas condiciones ambientales óptimas que aseguren tanto el confort como la salud y productividad de sus ocupantes, no debe suponer en ningún caso una ruptura con la eficiencia del comportamiento energético del edificio, cuya importancia se destacó en el capítulo I [2, EC, 1996] [3, Rey\&Velasco, 2000]. La evaluación de la calidad de los espacios interiores debe orientarse, por lo tanto, a compatibilizar estos requisitos con los de eficiencia energética establecidos por las distintas normativas, derivadas a nivel europeo de la ya mentada Directiva sobre Eficiencia Energética en Edificios (Energy Performance of Buildings Directive 2002/91/EC) [N-4]. De esta forma, un edificio y sus instalaciones deberán proporcionar un adecuado ambiente para las personas, teniendo asignada a la vez una categoría aceptable en la escala de Certificación Energética establecida, la cual se determina abarcando sus consumos energéticos destinados a la calefacción y climatización de espacios, aprovisionamiento de agua caliente e iluminación.

No obstante, los consumos energéticos no van a verse afectados sólo por los niveles de calidad buscados en el espacio interior, sino también por las acciones llevadas a cabo por sus 
ocupantes para controlar dichos niveles, su actividad y horarios desarrollados en esos locales, y la operación de los sistemas de climatización. Un adecuado estudio o auditoría realizada sobre el comportamiento del edificio permite caracterizar detalladamente los consumos energéticos, además de proporcionar asesoramiento sobre alternativas de mejora.

La calidad de ambientes interiores, por lo tanto, representa un papel clave en el estudio de la sostenibilidad de un edificio. En consecuencia, un adecuado estudio de la CAI comprende tres grandes etapas, como se muestra en la figura II.1: un cuidado diseño de la instalación de los sistemas HVAC, la certificación energética del edificio en base a la normativa en vigor, y finalmente la realización de las debidas auditorías ambientales.

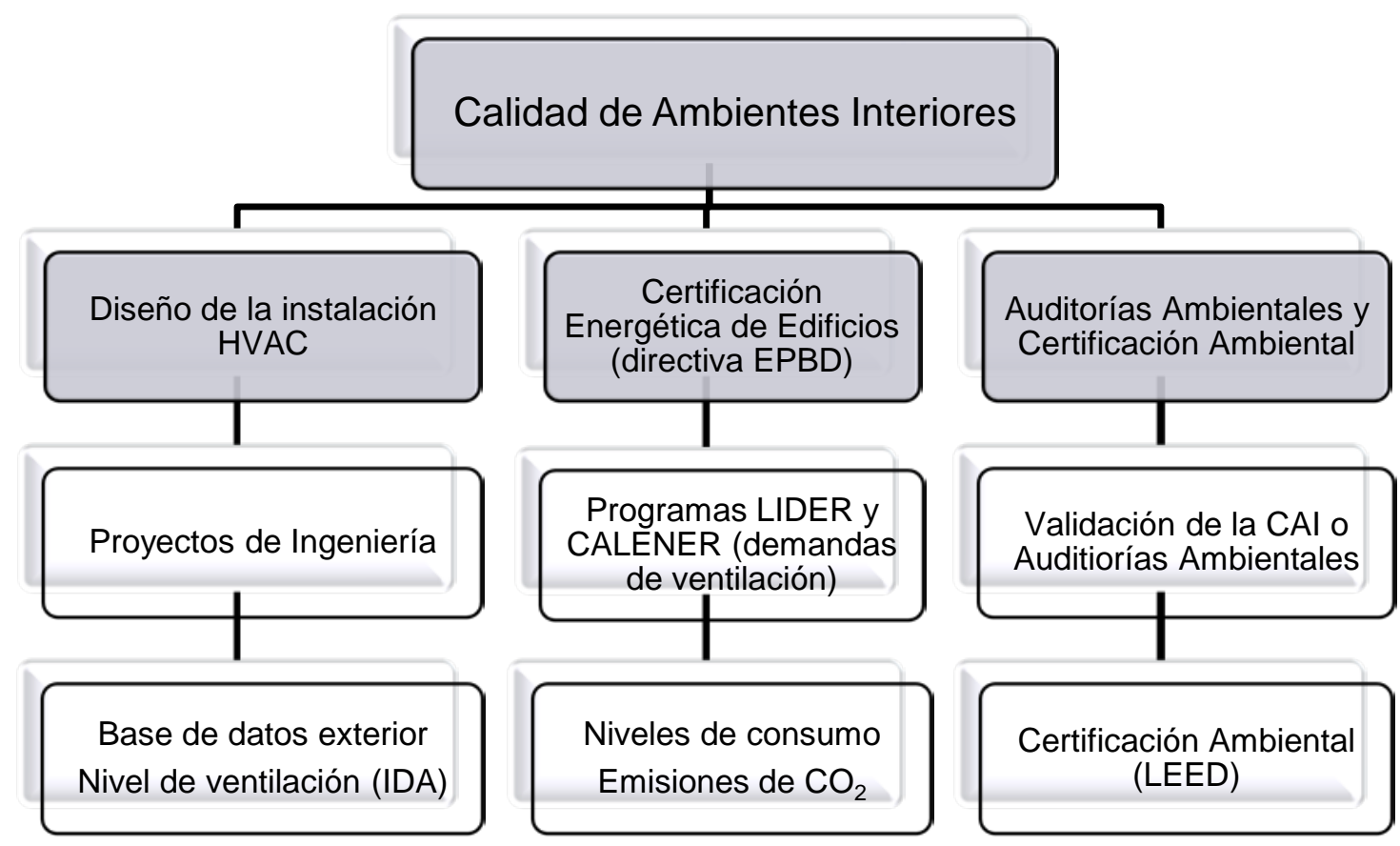

Figura II.1.- Relevancia de la Calidad de Ambientes Interiores en la sostenibilidad de edificios.

Por todo ello, siempre se buscará alcanzar un compromiso entre los niveles deseados de calidad del aire, de confort térmico, y acústicos; y los consumos de energía y costes de la instalación y construcción asociados al edificio y sus instalaciones.

\section{Factores que intervienen en el bienestar en espacios interiores}

Resta no obstante presentar qué parámetros o factores deben ser considerados para adecuar convenientemente un determinado ambiente interior. A nivel global, se estudia la calidad de un ambiente o espacio interior IEQ (Indoor Environmental Quality) abarcando no sólo los niveles de temperatura, radiación y humedad que afectan al confort térmico de sus ocupantes, sino también la calidad del aire que respiran IAQ (Indoor Air Quality), los niveles de ruidos y vibraciones percibidos, la iluminación y su fuente de procedencia, y otros factores visuales y ergonómicos [N-3]. 
Se habla de Calidad del Clima Interior ICQ (Indoor Climate Quality) en referencia a los factores asociados a la calidad del aire, IAQ, y al confort térmico. Estos serán los parámetros estudiados en este trabajo de tesis doctoral, al ser los afectados más directamente por los sistemas de climatización (si bien no deben ignorarse los niveles de ruido y vibraciones generados por las instalaciones) [1, Corgnati\&Gameiro, 2011].

A continuación se presentan más detalladamente los criterios a considerar para alcanzar una adecuada calidad del clima interior ICQ, ya que deberán ser tenidos en cuenta durante toda la caracterización de los sistemas de climatización, a fin de poder analizar si los equipos estudiados garantizan estos requisitos con un consumo energético aceptable.

También se introduce más adelante en este capítulo la clasificación de espacios a la que estos criterios dan lugar, además de las principales ideas de la auditoría de edificios en cuestión de ICQ y de los métodos instrumentales empleados.

\section{II.2. Calidad DEL Clima INTERIOR ICQ (INDOOR CLIMATE QUALITY)}

\section{Confort térmico}

Las condiciones óptimas de confort, incluido el confort térmico, deben plantearse como aquéllas satisfactorias para el mayor porcentaje posible de personas. Esto es así porque las condiciones de neutralidad térmica puede variar entre individuos, e incluso estos pueden preferir cierto distanciamiento de las mismas respecto a dicha neutralidad, en función de las diferencias en las actividades desarrolladas, vestimenta y también particularidades fisiológicas y psicológicas personales.

El propio cuerpo humano va a poseer de hecho de los mecanismos más efectivos para alcanzar la neutralidad térmica, y consecuentemente una situación lo más cercana posible al confort. Dado que la temperatura interior en éste debe mantenerse entorno a $37^{\circ} \mathrm{C}$, con apenas ligeras variaciones entre personas y hora del día, el organismo va a requerir sistemas de termorregulación que controlen el balance de calor producido y liberado al ambiente. Por su parte, la temperatura media de la piel es de $33^{\circ} \mathrm{C}$, variando $1^{\circ} \mathrm{C}$ entre personas y desde 24 a $34^{\circ} \mathrm{C}$ entre distintas zonas, ya que por ejemplo la temperatura en las extremidades siempre es menor. El cuerpo detecta las variaciones en la temperatura de la piel a través de los sensores localizados bajo ésta, y envía esta información al hipotálamo, desde donde se controlan los mecanismos de regulación. Estos mecanismos son [1, Corgnati\&Gameiro, 2011].

- Regulación del flujo sanguíneo hacia la piel: es el proceso más común, y permite aumentar el flujo de calor liberado al ambiente, si el balance es positivo (ganancia de calor corporal) a través de la vasodilatación de los capilares sanguíneos de la piel; mientras que si el 
balance es negativo (pérdida de calor corporal), se produce la vasoconstricción de los capilares, conservando el calor.

- Incremento de la tensión muscular para ganar calor adicional.

- Incremento de la producción de calor en estado de reposo mediante escalofríos.

- Aumento de la sudoración corporal para aumentar las pérdidas de calor y reducir la temperatura de la piel.

Es importante tener en cuenta que, si las condiciones ambientales no son favorables a la evaporación del sudor, éste se extenderá por la piel para aumentar el área de evaporación. Si la fracción de piel humedecida por el sudor es muy alta, derivará en una situación desagradablemente cálida, incrementándose además la fricción con las prendas de vestir y agravándose cuando esta está en contacto con superficies lisas o no higroscópicas.

Es por lo tanto a través de todos estos mecanismos que el cuerpo humano tiende por sí mismo a mantenerse en equilibrio térmico con el ambiente, de forma que su temperatura permanezca estable. A continuación se describe el balance energético del cuerpo con el ambiente.

\section{Equilibrio térmico con el ambiente}

Según el método desarrollado por Fanger [4, Fanger, 1973], en un ambiente térmico estable, la temperatura corporal se mantiene constante si se alcanza el balance entre el calor producido por el mismo y las pérdidas generadas, el calor retenido por el cuerpo es nulo $(S=0)$ :

$$
S=M \pm W \pm R \pm C \pm K-E-R E S
$$

M representa el calor producido por el cuerpo por su propio metabolismo. Su valor dependerá de la superficie corporal, dada por la ecuación de DuBois (ecuación E-II.2) y su valor para distintos tipos de actividades viene recogido en tablas, dado en met ( 1 met $=58,15$ $\mathrm{W}$ por $\mathrm{m}^{2}$ de área de piel desnuda). Algunos ejemplos son los dados en la tabla II.1 [N-5], [N-6].

$$
\text { Sup }=0,202 \cdot m^{0,425} \cdot h^{0,725}
$$

El trabajo útil realizado por el organismo, $\mathbf{W}$, viene generalmente dado en términos de eficiencia mecánica, W/M; valor que por otro lado nunca excede de 0,05 o 0,1, siendo para la mayor parte de las actividades próximo a cero, ya que el rendimiento del cuerpo humano es muy pequeño.

En cuanto al calor involucrado en la evaporación de la humedad corporal, E, constituye siempre de una pérdida de calor ya que el sudor toma energía del cuerpo para cambiar de estado; y puede deberse bien a difusión de éste a través de la piel por la diferencia entre la presión parcial de vapor en ésta respecto a la del ambiente; o por la evaporación directa del sudor desde la piel, el cual se ha presentado ya como un mecanismo corporal de regulación térmica, cuya intensidad variará con el tipo de actividad realizada. 
Tabla Il.1.- Tasas metabólicas [N-6]

\begin{tabular}{|l|c|c|}
\hline \multicolumn{1}{|c}{ Actividad } & \multicolumn{3}{c|}{ Tasa } \\
& \multicolumn{2}{c|}{ metabólica } \\
\hline Reposo, tendido & 46 & Met \\
\hline Reposo, sentado & 58 & 1,0 \\
\hline Actividad sedentaria (oficina, domicilio, escuela, laboratorio) & 70 & 1,2 \\
\hline $\begin{array}{l}\text { Actividad ligera, de pie (de compras, laboratorio, industria ligera) } \\
\text { Actividad media, de pie (dependiente de comercio, tareas domésticas, trabajo } \\
\text { con máquinas) }\end{array}$ & 93 & 1,6 \\
\hline Caminar en llano: & & \\
\hline $2 \mathrm{~km} / \mathrm{h}$ & 110 & 1,9 \\
\hline $3 \mathrm{~km} / \mathrm{h}$ & 140 & 2,4 \\
\hline $4 \mathrm{~km} / \mathrm{h}$ & 165 & 2,8 \\
\hline $5 \mathrm{~km} / \mathrm{h}$ & 200 & 3,4 \\
\hline
\end{tabular}

Por su parte, $\mathbf{R}$ es la tasa de calor intercambiado por radiación entre la piel y la ropa y el entorno. Este mecanismo de transferencia de calor tiene un papel clave en el confort. El área radiante efectiva es menor que la total, pues existe intercambio entre algunas partes del cuerpo, por lo que se corrige con un factor de 0,71. Por otro lado, la emitancia media de la piel (cercana a $1 \mathrm{~W} / \mathrm{m}^{2}$ ) y de la vestimenta (de media $0,95 \mathrm{~W} / \mathrm{m}^{2}$ ), se estima en $0,97 \mathrm{~W} / \mathrm{m}^{2}$. [1, Corgnati\&Gameiro, 2011]

El calor intercambiado por convección, C, es suma de dos componentes: el debido a la convección natural generada usualmente por el contacto del aire, a menor temperatura, con la piel, más cálida; y la posible convección forzada.

La componente de calor intercambiado por conducción a través de la vestimenta, $\mathbf{K}$, es más complicada de determinar, puesto que es función de la temperatura media de la piel, la conductividad térmica y la temperatura de la ropa, siendo esta última en principio desconocida, por lo que será necesario recurrir a métodos iterativos para la determinación del balance energético planteado [W-1]. En el término de transmisión por conducción se considera la transferencia de calor a través de la vestimenta. La fracción transferida al terreno través del calzado puede considerarse insignificante, mientras que la conducción por el contacto con sofás u otros elementos se aborda asemejándolo a la vestimenta. Algunos ejemplos de datos dados por la normativa para distintas vestimentas y asientos se proporcionan en la tablas II.2 y II.3, en unidades clo [N-5], [N-6].

Finalmente, el término RES se corresponde con la energía intercambiada en la respiración, tanto sensible como latente, y que en la mayoría de los casos constituye una pérdida, por lo que se expresa como tal. 
Tabla II.2.- Rangos de aislamiento térmico y cambios de temperatura operativa óptima para algunas prendas [N-6]

\begin{tabular}{|l|c|c|c|}
\multicolumn{1}{c}{ Prenda } & \multicolumn{2}{c}{$\mathrm{I}_{\text {clu }}$} & $\begin{array}{c}\text { Cambio de temperatura } \\
\text { operativa óptima, }{ }^{\circ} \mathrm{C}\end{array}$ \\
\hline Bragas, calzoncillos & 0,03 & 0,005 & 0,2 \\
\hline Camisetas manga corta & 0,09 & 0,014 & 0,6 \\
\hline Camisa manga corta & 0,15 & 0,023 & 0,9 \\
\hline Camisa normal, manga larga & 0,25 & 0,039 & 1,6 \\
\hline Pantalones cortos & 0,06 & 0,009 & 0,4 \\
\hline Pantalones normales & 0,25 & 0,039 & 1,6 \\
\hline Falda ligera (verano) & 0,15 & 0,023 & 0,9 \\
\hline Falda gruesa (invierno) & 0,25 & 0,039 & 1,6 \\
\hline Vestido ligero & 0,4 & 0,062 & 2,5 \\
\hline Chaleco & 0,12 & 0,019 & 0,8 \\
\hline Jersey & 0,28 & 0,043 & 1,7 \\
Cazadora & 0,55 & 0,085 & 3,4 \\
\hline Chaquetón & 0,6 & 0,093 & 3,7 \\
\hline Calcetines gruesos, largos & 0,1 & 0,016 & 0,6 \\
\hline Medias nylon & 0,03 & 0,005 & 0,2 \\
\hline Zapatos suela gruesa & 0,04 & 0,006 & 0,3 \\
\hline Guantes & 0,05 & 0,008 & 0,3 \\
\hline
\end{tabular}

Tabla II.3.- Valores de aislamiento térmico para asientos [N-6]

\begin{tabular}{|c|c|c|c|}
\hline \multicolumn{1}{|c|}{ Tipo de asiento } & \multicolumn{2}{c|}{$\mathrm{I}_{\mathrm{cl}}$} \\
\hline Silla metálica con asiento de rejilla & 0,00 & 0,00 \\
\hline Taburete de madera & 0,01 & 0,002 \\
\hline Silla normal de oficina & 0,1 & 0,016 \\
\hline Sillón de ejecutivo & 0,15 & 0,023 \\
\hline
\end{tabular}

La figura II.2 muestra en esquema de estos flujos de calor con el ambiente.

Si la ecuación II.1 se replantea considerando el balance relativo a la ropa, ésta queda de la forma:

$$
M \pm W-E-R E S=K c l= \pm R \pm C
$$




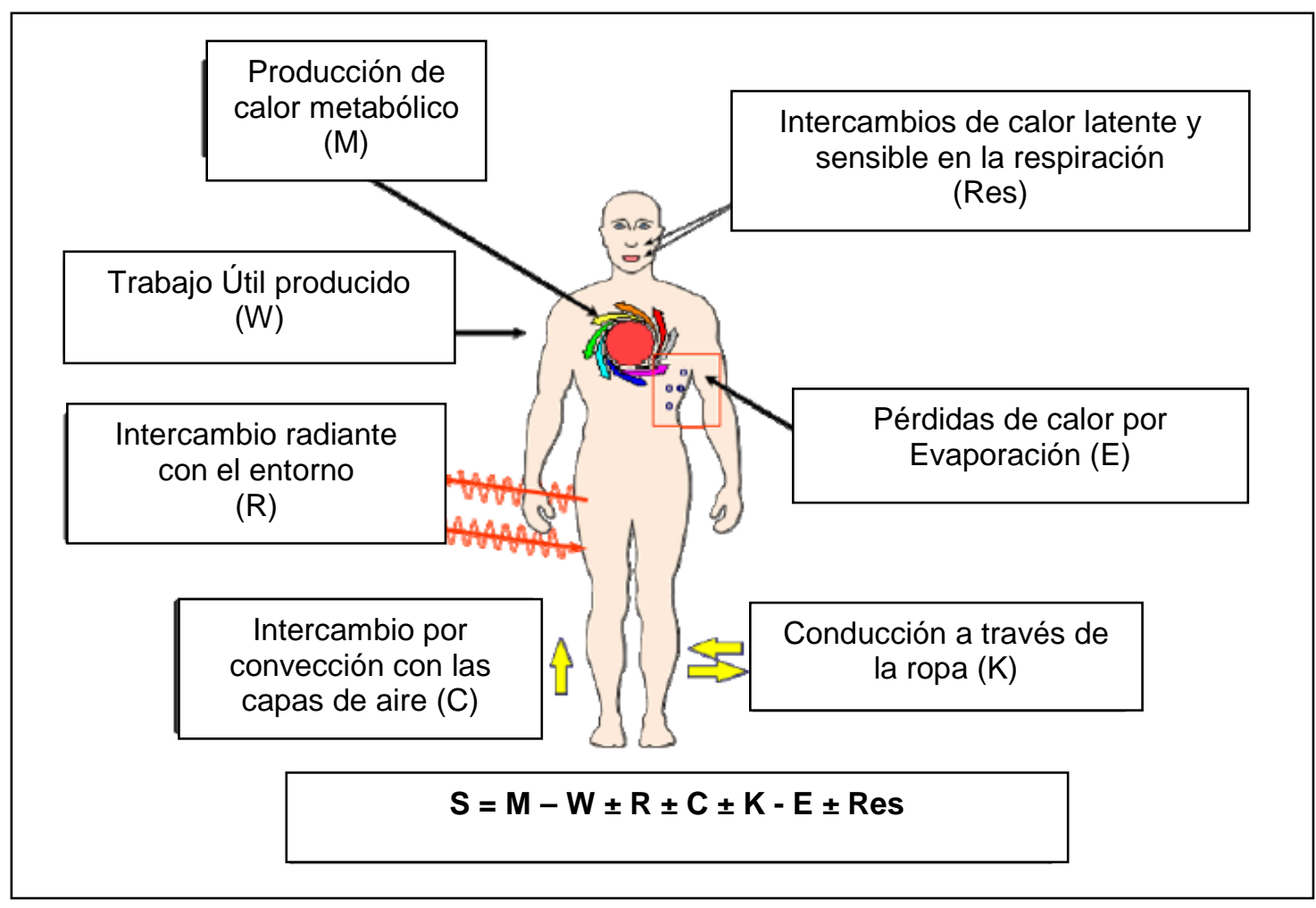

Figura II.2.- Balance térmico del cuerpo humano con el entorno.

\section{Requisitos de confort térmico}

Como ya se ha planteado, las condiciones óptimas de confort térmico no siempre serán tales para todas las personas, debiéndose plantear siempre bajo el objetivo de satisfacer al máximo porcentaje posible de individuos. De hecho, existen sensibles diferencias en las preferencias de confort térmico entre distinto género, edades, climatología del lugar de origen o incluso entre distintos días.

A la hora de definir el confort térmico, deben considerarse dos factores personales, asociados a la actividad metabólica y a la vestimenta; y cuatro factores ambientales: temperatura del aire, temperatura radiante media, velocidad del aire y humedad relativa. La tabla II.4 de la norma ISO 7726 [N-7], [N-8], indica los términos del balance térmico en los que afectan las variables relacionadas con esos factores. A pesar de que el balance energético del organismo con el entorno puede alcanzarse con numerosas combinaciones de los 6 factores anteriores, el confort térmico del individuo sólo se alcanzará en un determinado rango de las condiciones ambientales, debido a las restricciones en la temperatura de la piel y sudoración. Los límites de estos parámetros son los indicados en la tabla II.5. La ecuación de Fanger proporciona la combinación de factores personales y ambientales que permiten alcanzar las condiciones de confort térmico, definidas para el mayor porcentaje de personas posible. Esta ecuación está definida a partir de las relaciones entre la temperatura media de la piel y la tasa metabólica, y entre las pérdidas de calor por evaporación y la tasa metabólica [4, Fanger, 1973]. 
Tabla II.4.- Principales magnitudes independientes que intervienen en el análisis del balance térmico entre el hombre y el ambiente térmico

\begin{tabular}{|c|c|c|c|c|c|c|c|c|}
\hline \multirow{2}{*}{$\begin{array}{c}\text { Elementos del balance } \\
\text { térmico }\end{array}$} & \multicolumn{8}{|c|}{ Magnitudes } \\
\hline & $\mathrm{t}_{\mathrm{a}}$ & $t_{r}$ & $\mathrm{v}_{\mathrm{a}}$ & $P v_{a}$ & $I_{c l}$ & $\mathrm{R}_{\mathrm{cl}}$ & M & W \\
\hline $\begin{array}{l}\text { Producción de calor } \\
\text { interno, M-W }\end{array}$ & & & & & & & $x$ & $x$ \\
\hline $\begin{array}{c}\text { Transferencia de calor por } \\
\text { radiación, } \mathrm{R}\end{array}$ & & $\mathrm{x}$ & & & $\mathrm{x}$ & & & \\
\hline $\begin{array}{c}\text { Transferencia de calor por } \\
\text { convección, } C^{(1)}\end{array}$ & $x$ & & $x$ & & $x$ & & & \\
\hline \multicolumn{9}{|l|}{$\begin{array}{l}\text { Pérdidas de calor por } \\
\text { evaporación: }\end{array}$} \\
\hline A través de la piel, E & & & $x$ & $x$ & & $x$ & & \\
\hline Por la respiración, $E_{\text {res }}$ & & & & $x$ & & & $\mathrm{x}$ & \\
\hline $\begin{array}{l}\text { Convección por } \\
\text { respiración }\end{array}$ & $X$ & & & & & & $x$ & \\
\hline
\end{tabular}

(1) La transferencia de calor por convección también depende de los movimientos del cuerpo. La velocidad del aire resultante en las proximidades de la piel se denomina velocidad relativa del aire (var).

La conducción de calor (temperatura superficial) sólo tiene una influencia limitada en el balance de calor total.

Tabla II.5.- Rangos límites de variación de los parámetros de consideración en el confort térmico.

\begin{tabular}{|l|c|c|}
\hline \multicolumn{1}{|c|}{ PARÁMETRO } & LÍMITES & UNIDAD \\
\hline Actividad metabólica & 0,8 a 4 & met \\
\hline Grado de vestimenta & 0 a 2 & clo \\
\hline Temperatura seca del aire & 10 a 30 & ${ }^{\circ} \mathrm{C}$ \\
\hline Temp. radiante media de los cerramientos & 10 a 40 & ${ }^{\circ} \mathrm{C}$ \\
\hline Velocidad del aire en la zona ocupada & 0 a 1 & $\mathrm{~m} / \mathrm{s}$ \\
\hline Humedad relativa & 30 a 70 & $\%$ \\
\hline
\end{tabular}

Dentro de estas combinaciones de parámetros, debe notarse que la humedad tan sólo tiene un efecto reducido en la sensación térmica, al igual que en la calidad del aire percibida, de los ocupantes del local en actividad sedentaria. Por lo tanto, generalmente no es estrictamente necesario humidificar el aire interior. No obstante, humedades extremas continuadas pueden resultar problemáticas para la salud, como puede ser el caso del crecimiento de bacterias en espacios con humedades relativas altas, o la sequedad e irritación de los ojos y de las vías respiratorias en el caso de ambientes muy secos (HR <15-20\%); pero su control puede ser también de importancia para evitar condensaciones $u$ hongos en los 
edificios, y en especial en algunos edificios en particular (históricos, museos...). Los posibles requerimientos de humidificación o deshumidificación a considerar en el diseño por las especificaciones de confort, salud o del edificio, afectarán a la energía consumida finalmente por el sistema. En la tabla II.6 se recogen los valores de humedad recomendados como criterio de diseño para los espacios en los que se realice control de la humedad ambiental. No obstante, en todo caso se recomienda que esta no exceda nunca de los $12 \mathrm{gH} 2 \mathrm{O} / \mathrm{kg}$ aire seco [N-3].

Tabla II.6.- Ejemplo de criterios de diseño recomendados para control de la humedad en espacios ocupados con sistemas de humidificación o deshumidificación.

\begin{tabular}{|c|c|c|c|}
\hline \multicolumn{1}{|c}{$\begin{array}{c}\text { Tipo de edificio/ } \\
\text { espacio }\end{array}$} & Categoría & $\begin{array}{c}\text { Humedad relativa de } \\
\text { diseño para } \\
\text { deshumidificación [\%] }\end{array}$ & $\begin{array}{c}\text { Humedad relativa de } \\
\text { diseño para } \\
\text { humidificación [\%] }\end{array}$ \\
\hline $\begin{array}{c}\text { Espacios donde se } \\
\text { establecen criterios de } \\
\text { humedad por la ocupación } \\
\text { humana. }\end{array}$ & I & 50 & 30 \\
$\begin{array}{c}\text { Pueden diferir en el caso } \\
\text { de edificios especiales } \\
\text { (museos, iglesias, etc.) }\end{array}$ & II & 60 & 25 \\
\hline
\end{tabular}

Para simplificar el estudio del confort térmico en espacios interiores, se recoge la información sobre los parámetros personales y ambientales a través de la definición de distintos índices: [N-1], [N-2]

- Temperatura operativa: se define como la temperatura uniforme de un recinto negro ideal en el que el intercambio de calor por convección y radiación entre éste y sus ocupantes fuera idéntico al del entorno no-uniforme real. Se trata por lo tanto de una ponderación de las temperaturas radiantes medias y temperaturas del aire, en función de sus respectivos coeficientes de transmisión de calor, según expresa la ecuación II.4. Como puede deducirse, engloba información sobre tres variables físicas: dos de ellas de forma explícita (temperatura del aire y temperatura media radiante), y una tercera implícita a través del coeficiente de convección (velocidad del aire).

$$
t_{0}=\left(h_{c} t_{a}+h_{r} t_{r a d}\right) /\left(h_{c}+h_{r}\right)
$$

El coeficiente hr es casi constante y su valor es aproximadamente $4,7 \mathrm{~W} /\left(\mathrm{m}^{2} \mathrm{~K}\right)$. En cambio el coeficiente hc varía entre 3 y $6 \mathrm{~W} /\left(\mathrm{m}^{2} \mathrm{~K}\right)$ dependiendo, sobre todo, del movimiento del aire. Para un valor medio de 4,5 W / $\left(\mathrm{m}^{2} \mathrm{~K}\right)$ resulta, que al ser muy próximos los valores de los coeficientes, la temperatura operativa es casi la media aritmética entre la temperatura seca del aire y la temperatura radiante media, y se podría concluir que sobre la temperatura operativa poseen la misma contribución la temperatura del aire que la de los cerramientos.

Resulta sin embargo más estricto trabajar con la temperatura eficaz o efectiva. Este parámetro incluye la contribución de la humedad al intercambio energético, y es la temperatura 
de un ambiente con el $50 \%$ de humedad relativa que provoca el mismo intercambio de calor con el ambiente que el local objeto de estudio. La temperatura eficaz tiene también en consideración las pérdidas de calor latente y está definida por la siguiente ecuación:

$$
t_{e}=t_{o}+c \cdot\left\lfloor P_{T_{a}}-0,5 \cdot P_{\text {sat Te }}\right\rfloor
$$

Siendo :

c el producto de la fracción de piel mojada, por la eficiencia de permeabilidad al paso de vapor de la vestimenta y la capa de aire cerca de la piel, y por la relación de Lewis entre los coeficientes de transferencia de calor evaporativo y convectivo.

$\mathrm{P}_{\mathrm{Ta}}$ es la presión del vapor de agua a la temperatura del aire del ambiente (en $\mathrm{kPa}$ )

$\mathrm{P}_{\text {SatTe }}$ es la presión parcial del vapor a saturación (en $\mathrm{kPa}$ ) a la temperatura efectiva

El valor del índice $t_{e}$ depende del porcentaje de superficie de piel mojada y de la permeabilidad de la vestimenta. Si el porcentaje de piel mojada es pequeño, la humedad del aire tiene poca importancia. Ésta es la condición que se da en locales acondicionados, cuando sus condiciones están próximas a las de neutralidad térmica. Por esta razón, es mejor normalmente emplear el índice temperatura operativa al índice temperatura efectiva.

- Temperatura equivalente: es la temperatura uniforme de un recinto imaginario con velocidad del aire nula en el que una persona intercambiaría las mismas pérdidas de calor sensible por radiación y convección que en el recinto no-uniforme real.

$$
t_{e q}=0,55 \cdot t_{a}+0,45 \cdot t_{r}+0,24-0,75 \cdot \sqrt{v_{a}}+I_{c l} \cdot\left(36,5-t_{a}\right)
$$

En esta expresión, $v_{\mathrm{a}}$ hace referencia a la velocidad del aire, e $I_{c l}$ a la resistencia a la transferencia de calor que presenta la vestimenta, en un recinto caracterizado por una temperatura radiante media $t_{r}$ y una temperatura seca del aire $t_{a}$.

- Voto Medio Previsto PMV (Predicted Mean Vote): relaciona, a través de los principios del balance térmico, los seis parámetros con la respuesta media esperada de las personas en función de una escala subjetiva de sensaciones térmicas.

$$
P M V=\left(0,303 \cdot e^{-2,100 \cdot M}+0,028\right) \cdot\left[(M-W)-H-E-C_{r e s}-E_{\text {res }}\right]
$$

En esta expresión se introducen los términos de pérdidas de calor sensible $\mathrm{H}, \mathrm{y}$ de calor intercambiado en la respiración por convección, $\mathrm{C}_{\text {res }}$, y evaporación, $\mathrm{E}_{\text {res }}$.

- Porcentaje de Personas Insatisfechas PPD (Percentage of Persons Dissatisfied): este índice proporciona una idea del éxito alcanzado en la implantación de las condiciones de confort, en referencia a la fracción de personas satisfechas o no.

$$
P P D=100-95 \cdot e^{-\left(0,03353 \cdot P M V^{4}+0,2179 \cdot P M V^{2}\right)}
$$


Los indices PMV y PPD están relacionados entre sí, relación que queda representada para distintas categorías del ambiente térmico a través de curvas similares a una distribución Gaussiana invertida, suponiendo que el PPD es simétrico entorno a un PMV neutro. Las condiciones para un $\mathrm{PMV}=0$ se consideran las óptimas, y puede observarse que sin embargo no se alcanza un porcentaje de satisfechos del 100\% (Figura II.3) [N-5], [N-6]. Por ello, se considera un ambiente térmico ideal el correspondiente a un PPD del 5\%.

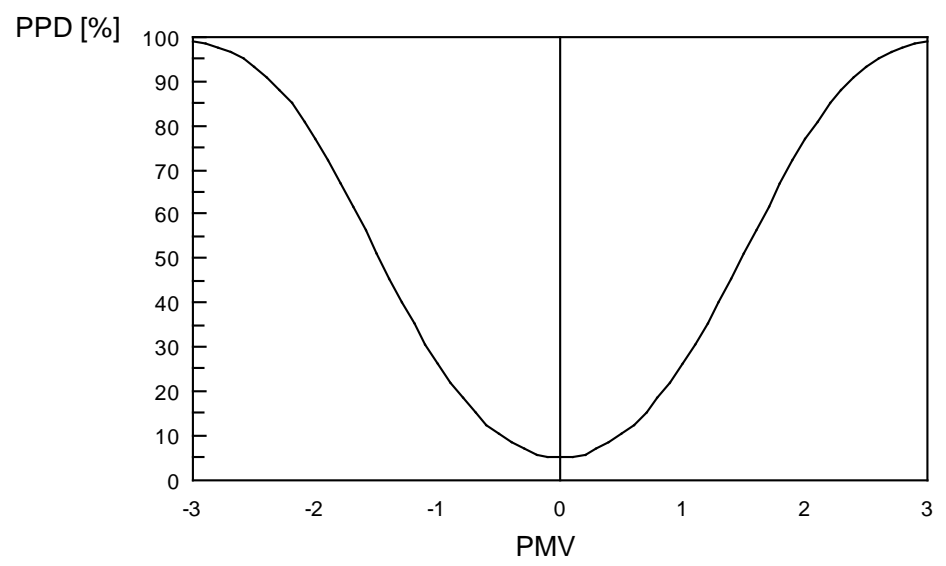

Figura II.3.- Porcentaje de Personas Insatisfechas (PPD) en función del Voto Medio Previsto (PMV).

Sin embargo, los índices PMV y PPD proporcionan una idea del confort térmico alcanzado sólo a nivel global, mientras que pueden producirse igualmente situaciones de disconfort local por:

- Existencia de corrientes de aire indeseadas, relacionadas con la velocidad, turbulencia y temperatura del aire, y más graves en caso de afectar al nivel de la nuca a personas realizando actividades sedentarias

- Acusados gradientes verticales de temperatura: especialmente relevantes si la temperatura es mayor en la zona de la cabeza.

- Temperaturas del suelo extremas, tanto muy frías como muy cálidas.

- Asimetría radiante entre cerramientos muy acusada (de especial relevancia en aplicaciones con cerramientos activos) (Figura II.4).

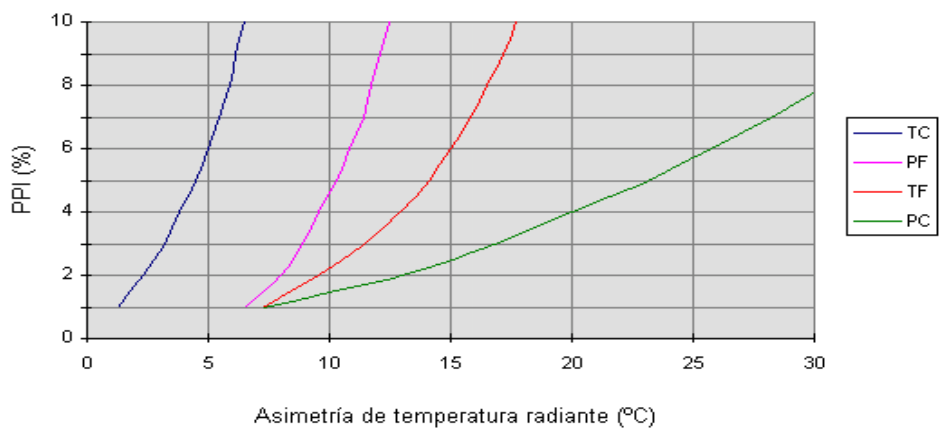

Figura II.4.- Relación entre el PPI y los distintos casos de asimetría radiante. 
Lo más usual es, sin embargo, que el ambiente no se encuentre en unas condiciones térmicas estacionarias, sino que sufra variaciones transitorias, lo cual cuestiona la validez de los planteamientos anteriores. Estas condiciones no estacionarias pueden ser debidas a:

- Ciclos de temperatura en el recinto, debidos al control de la misma. Si estas son menores de $1 \mathrm{~K}$, no afectan al bienestar y el estudio del ambiente puede abordarse desde la concepción estacionaria.

- Derivas o rampas de temperatura: debe considerarse no obstante como no estacionario el caso anterior, si las variaciones se producen con una frecuencia igual o superior a $2 \mathrm{~K} / \mathrm{h}$.

- Fluctuaciones transitorias: un salto de temperatura operativa se percibe instantáneamente, si bien un ascenso en la misma lleva a nuevos estados de bienestar predecibles de forma ajustada e inmediata por los índices PMV y PPD, mientras que un descenso en la misma genera condiciones no identificables mediante éstos hasta pasado más tiempo, dependiente éste de las condiciones iniciales.

Debe distinguirse además a la hora de determinar las condiciones de confort, aquéllos casos en los que los edificios no disponen de instalaciones de climatización y ventilación mecánica, ya que los rangos de temperatura operativa, la cual varía con la media de la temperatura del ambiente exterior, deben ser más amplios. Además, sus ocupantes tienen control directo sobre los medios disponibles de adecuación del ambiente interior (apertura de ventanas, elementos de intercepción de la radiación solar, etc.), así como capacidad de adaptación modificando la vestimenta o el nivel de actividad. De esta forma, las personas responden a sus necesidades de confort dependiendo del clima exterior, y por lo tanto de forma distinta a aquéllos ocupantes de edificios climatizados mecánicamente. Adicionalmente, las personas no perciben la misma sensación de confort para un ambiente en las mismas condiciones cuando se cambia de estación. En verano se soporta mejor el calor que en invierno, manteniéndose todo el resto de condiciones constantes [N-3], [N-5], [N-6].

\section{Normativa}

Todos los criterios de confort térmico aquí presentados, así como su campo de aplicación y la definición de los índices introducidos para su caracterización en función de los parámetros de relevancia, están recogidos en diversas normativas internacionales [N-3], [N-5], a su vez traspuestos a nivel nacional a través de la normativa correspondiente [N-6].

La norma CEN 15251 abarca de forma general todos los aspectos de calidad de espacios interiores IEQ, por lo que no sólo se limita a regular el ámbito del confort térmico sino que también aborda la calidad del aire, iluminación o ruido. En este documento se proporcionan criterios de dimensionamiento de los edificios y sus sistemas de climatización, además de aquéllos requeridos sobre los parámetros ambientales para el cálculo energético establecido en la EPBD, y los de evaluación, clasificación e inspección de los ambientes interiores. Asimismo recopila en los anexos una amplia relación de recomendaciones e indicaciones sobre los distintos criterios. 
El estándar europeo ISO 7730, y análogamente su correspondiente normativa Española UNE-EN ISO 7730, se centra en consideraciones sobre el bienestar térmico, indicando qué condiciones son precisas para alcanzar dicho estado de confort y estableciendo las vías de categorización en función de la evaluación subjetiva prevista por los propios ocupantes.

\section{Calidad del aire IAQ (Indoor Air Quality)}

\section{Introducción}

La calidad del aire respirado es, como se ha visto, factor clave no sólo para el bienestar sino también para la salud e incluso para la productividad de las personas. La caracterización de la IAQ es un proceso complejo y puede abordarse desde diversas perspectivas, unas objetivas y otras subjetivas, pero en cualquier caso atiende a la posible existencia de ciertas sustancias contaminantes en el aire y a su concentración durante un determinado período de tiempo, en función de cómo afectan a la percepción sensorial del aire y a los posibles riesgos que puedan suponer para la salud [5, Rey et al., 1999], [6, Vaquero, 2011]. El proceso de caracterización y mejora de la calidad del aire interior se abordará más adelante, buscando como ya se ha argumentado alcanzar un nivel satisfactorio precisando el mínimo consumo energético posible.

La carga contaminante presente en un determinado ambiente puede proceder de fuentes muy diversas, bien del interior del edificio o bien del ambiente exterior.

Los contaminantes provenientes del propio interior del edificio no sólo son debidos a sus ocupantes, sino que también tienen su origen en los materiales de construcción del edificio, mobiliario etc. o incluso en el propio sistema de ventilación, si ésta es mecánica. Las cargas contaminantes emitidas por los revestimientos, sustancias absorbidas por los materiales o simplemente contenidas en éstos, o asociadas a los propios equipos de climatización, son principalmente partículas suspendidas, bacterias, $\mathrm{CO}, \mathrm{O}_{3}$, VOCs y radón. La carga asociada a los bioefluentes derivados de la actividad humana es en su mayor parte $\mathrm{CO}_{2}$, vapor de agua, metano, aldehídos, esteres y alcoholes, bacterias, partículas, etc., pero también puede deberse al humo de tabaco y presencia de $\mathrm{CO}$ en aquellos espacios donde hay presencia de fumadores [7, Fanger et al., 1988], [1, Corgnati\&Gameiro, 2011].

Por su parte, la calidad del aire exterior es fundamental, dado que el aire de renovación del interior, bien por ventilación o por las propias infiltraciones, procede del exterior. Sin embargo, a la hora de abordar el problema de determinación y dilución de la carga contaminante, este origen de la polución no se considera, previéndose que la contaminación contenida en el aire de renovación es retenida por los filtros de la instalación.

Cabe anunciar ya, por lo tanto, que la ventilación requerida para asegurar una cierta IAQ se calculará en función de la ocupación (por persona) yl o del espacio (por unidad de área), siempre con el objetivo de determinar el mínimo caudal que cumpla los requisitos establecidos, a fin de minimizar la energía precisa para mover y acondicionar el volumen de aire de 
renovación. Dicha ventilación podrá ser natural, asegurándose la renovación del aire interior por el propio flujo del aire debido a las diferencias de densidades; o bien puramente mecánica, si su aporte es forzado a través de sistemas de ventilación. Si se implanta una combinación de las anteriores, se habla de ventilación híbrida [N-3].

No obstante, los requisitos de IAQ no serán los mismos según el ambiente de estudio sea industrial o no. En ambientes industriales, la probablemente más alta concentración de contaminantes puntuales exigirá del tradicional análisis componente por componente para su comparación con los valores límites de referencia establecidos para evitar riesgos, siendo dichas concentraciones fáciles de medir, por tan altas, con los instrumentos disponibles actualmente. Además puede ser necesario en estos casos la instalación de sistemas de extracción localizada que evite el transporte de contaminantes al espacio ocupado por las personas. Por otro lado, en ambientes no industriales suelen presentarse una extensa variedad de componentes contaminantes en concentraciones bajas que incluso pueden modificarse en el tiempo por la interacción entre sustancias, ante lo cual un estudio detallado por componente no sería factible. En este último caso, y dada la escasa información disponible sobre el efecto en el ser humano de cada uno de los múltiples componentes posibles en tan baja concentración, puede recurrirse a procesos subjetivos de caracterización del ambiente, aunque sólo en términos de bienestar (para asegurar la ausencia de riesgos para la salud, es necesario plantear métodos objetivos de caracterización del aire respirado). [8, Fanger, 1988].

Evolución temporal de la concentración de un contaminante: ecuaciones.

La concentración de un cierto contaminante en el ambiente no será un factor constante, sino que sufrirá variaciones temporales a causa de su fuente de proveniencia, su absorción o depósito sobre las superficies, o incluso debido a la posible existencia de sistemas de purificación de aire, además de por la propia ventilación. Sin embargo, la determinación de su evolución en el tiempo es complicada, ya que todos estos factores (fuente, ventilación...) también tienden a fluctuar en el tiempo [1, Corgnati\&Gameiro, 2011].

$$
\frac{d X}{d t}=\frac{G}{V}+\lambda \cdot X_{e x t}-\lambda \cdot X-v_{d} \cdot \frac{A}{X}-\frac{Q_{a c}}{V} \cdot X \cdot \varepsilon_{a c}
$$

Donde:

X es la media instantánea de la concentración del contaminante $\left(\mathrm{mg} / \mathrm{m}^{3}\right)$

G la generación del mismo en el interior del local ( $\mathrm{mg} / \mathrm{h})$

$\vee$ el volumen de dicho local $\left(\mathrm{m}^{3}\right)$

$\lambda$, la tasa de renovación de aire (h-1), por ejemplo, el flujo de aire impulsado por volumen del local

$X_{\text {ext }}$, la concentración del contaminante en el aire exterior de ventilación $\left(\mathrm{mg} / \mathrm{m}^{3}\right)$ 
$\mathrm{v}_{\mathrm{d}}$, la tasa de deposición $\left(\mathrm{mg} / \mathrm{h} \cdot \mathrm{m}^{2}\right)$

A, la superficie de deposición $\left(\mathrm{m}^{2}\right)$

$\mathrm{Q}_{\mathrm{ac}}$, el flujo de aire tratado por el purificador $\left(\mathrm{m}^{3} / \mathrm{h}\right)$

$\varepsilon_{\mathrm{ac}}$, la eficiencia del purificador.

Esta expresión puede no obstante simplificarse asemejando el filtrado, eliminación, absorción y depositado de partículas a una eventual disminución de la emisión por parte de la fuente, quedando la expresión II.10:

$$
X(t)=X_{\text {equi }}+\left(X_{\text {ini }}-X_{\text {equi }}\right) \cdot e^{-\lambda \cdot t}
$$

Esta ecuación sería válida tanto para incrementos como para decrementos de la concentración, cambiando los términos $X_{\text {equi }}$ y $X_{\text {ini }}$ entre sí. Donde la concentración de equilibrio, $X_{\text {equi }}$, se corresponde con aquélla una vez alcanzado el estado estacionario, y por lo tanto puede obtenerse de igualar a cero la variable temporal en la expresión E-II.9:

$$
X_{\text {equi }}=X_{\text {ini }}+\frac{G}{V \cdot \lambda}
$$

Y reexpresando, sabiendo que $\lambda_{v}=Q / V$

$$
X_{\text {equi }}=X_{\text {ini }}+\frac{G}{Q}
$$

Se denomina edad media local del aire al parámetro de ventilación que define el tiempo medio que el aire localizado en un determinado espacio ha permanecido en el interior del edificio. En ocasiones, la evolución temporal de la concentración de un contaminante es más complicada de determinar y no puede modelarse mediante ecuaciones debido a los intercambios de aire entre locales adyacentes, en los cuales la concentración del mismo varía respecto a la del exterior.

\section{Percepción sensorial de la calidad del aire: evaluación subjetiva}

La calidad del aire IAQ puede expresarse en términos de éxito en el alcance de los requerimientos establecidos, pero al igual que en el caso de las condiciones de confort térmico óptimas, pueden existir diferencias muy importantes entre la sensibilidad de los distintos individuos. Se introduce por lo tanto el concepto de evaluación subjetiva de las condiciones del aire respirado.

No existen aún instrumentos de medida que permitan determinar cómo es percibido el aire por las personas, ya que tampoco se ha identificado una interrelación clara entre la calidad del 
aire percibida y la presencia de contaminantes típicos en cierta concentración. De hecho, ni el $\mathrm{CO}_{2}, \mathrm{CO}$, partículas y VOCs, ni siquiera la tasa de renovación de aire, resultan ser buenos índices de predicción del juicio sobre la calidad del aire dado por las personas, por lo que en la actualidad dicho testimonio directo es el único medio de calificación. Estos juicios deben ser dados por los individuos de forma independiente, y proporcionarse de forma inmediata a la entrada en contacto con el ambiente a evaluar [7, Fanger et al., 1988], [8, Fanger, 1988].

Aunque queda demostrado por lo anterior que los sensores olfativos y químicos nasales son más precisos que los propios análisis químicos a la hora de identificar la presencia de olores y componentes irritantes, y a pesar de que su sentido olfativo puede en muchos casos proporcionar una primera indicación de existencia de sustancias en el ambiente de posible riesgo, dado que algunos contaminantes peligrosos para la salud no son perceptibles por el ser humano (como es el caso del CO o del radón) el estudio de la calidad del aire en términos de salud debe considerarse separadamente, siendo este proceso subjetivo de evaluación sensorial sólo admisible para la caracterización del IAQ en términos de bienestar [7, Fanger et al., 1988], [8, Fanger, 1988].

En cualquier caso, la percepción humana se va a ver influida por un lado por la humedad y temperatura del aire inhalado (generalmente, aire frío y seco genera menos porcentaje de personas insatisfechas), y por otro la duración de la exposición al mismo. En este último caso, debe considerarse que la sensibilidad a los olores se reduce con el tiempo de exposición al producirse una adaptación sensorial a éstos, mientras que aumenta en el caso de sustancias irritantes. De esta forma, se produce una adaptación considerable del sentido olfativo a los bioefluentes humanos, siendo algo menor en el caso del tabaco y nula para las sustancias emitidas por los materiales de los edificios.

Se define un índice olfativo como la relación entre la concentración de un componente respecto a su perceptibilidad olfativa (mínima concentración de un componente aislado a la cual es detectado por un $50 \%$ de los humanos). De esta forma, es posible proporcionar un valor de la probabilidad de que un cierto olor sea detectado por las personas que respiran el aire analizado. No obstante, debe tenerse cuidado en el uso de este índice por las limitaciones que implica en cuanto a su reducida fiabilidad en la detección precisa de componentes, así como a causa de la posible interacción entre éstos, etc. Puede utilizarse una escala de intensidad de olores, pero teniendo especial cuidado en relación al tiempo de exposición (si existe o no adaptación en la respuesta). [1, Corgnati\&Gameiro, 2011].

El nivel de calidad del aire percibido por los humanos depende de la tasa de ventilación $(Q)$, la eficiencia de dicha ventilación $\left(\varepsilon_{v}\right)$, la calidad del aire de renovación $\left(C_{\text {ext }}\right)$, y la intensidad de las fuentes de polución interior $(G)$. De esta forma, puede plantearse un modelo generalizado de confort en relación a la IAQ percibida a partir de la expresión matemática:

$$
C_{\mathrm{int}}=C_{e x t}+\frac{G}{Q} \times \frac{1}{\varepsilon_{v}}
$$


La intensidad de de las fuentes emisoras de las sustancias contaminantes, G, está tabulada en "olf", equiparándolas al número de personas que generarían una cantidad equivalente de bioefluentes que causaran la misma sensación de discomfort. La intensidad sensorial total de un conjunto de fuentes puede aproximarse por la suma de la generada por todas estas. Algunos ejemplos vienen dados en la tabla II.7.

Tabla II.7.- Intensidad percibida, en olf, de las fuentes contaminantes en espacios no industriales.

\begin{tabular}{|c|c|}
\hline Fuente contaminante & $\begin{array}{l}\text { Intensidad } \\
\text { percibida }\end{array}$ \\
\hline Ocupante adulto en actividad sedentaria (1-1,2 met) & 1 olf \\
\hline Ocupante adulto, realizando actividad física ligera (3 met) & 4 olf \\
\hline Ocupante adulto, realizando actividad física media (6 met) & 10 olf \\
\hline Ocupante adulto, realizando actividad física elevada, atletas (10 met) & 20 olf \\
\hline Niño (guarderías), 3-6 años (2,7 met) & 1,2 olf \\
\hline Niño (colegio), 14-16 años (1-1,2 met) & 1,3 olf \\
\hline Humo de tabaco, presencia entre los ocupantes de $20 \%$ fumadores & 2 olf \\
\hline Humo de tabaco, presencia entre los ocupantes de $40 \%$ fumadores & 3 olf \\
\hline Humo de tabaco, presencia entre los ocupantes de $100 \%$ fumadores & 6 olf \\
\hline Humo de tabaco, fumando & 25 olf \\
\hline PC con monitor CRT, 50 h de operación & 2,7 olf \\
\hline PC con monitor CRT, 400 h de operación & 1,8 olf \\
\hline PC con monitor CRT, 600 h de operación & 1,4 olf \\
\hline PC con monitor TFT, 50h, 400h, 600h de operación & Imperceptible \\
\hline TV, 50h de operación & 1 olf \\
\hline TV, 400h, 600h de operación & Imperceptible \\
\hline Edificio*: oficinas y salas de reuniones (permitido fumar) & $0,23 \mathrm{olf} / \mathrm{m}^{2}$ \\
\hline Edificio*: oficinas (prohibido fumar) & $0,11 \mathrm{olf} / \mathrm{m}^{2}$ \\
\hline Edificio*: colegios & $0,06 \mathrm{olf} / \mathrm{m}^{2}$ \\
\hline Edificio*: guarderías & 0,06 olf $/ \mathrm{m}^{2}$ \\
\hline Edificio*: grandes almacenes & $0,15 \mathrm{olf} / \mathrm{m}^{2}$ \\
\hline
\end{tabular}

*Engloba los materiales de construcción, mobiliario y sistemas de climatización.

Si bien la intensidad sensorial se mide en "olf", la calidad del aire percibida se mide en "pol", aunque resulta más conveniente en la práctica el uso de "decipols". Ambas unidades fueron definidas por Fanger [8, Fanger,1988]. Esta calidad del aire, C, puede concebirse como la concentración de contaminantes que puede ser percibida por los humanos, definiéndose como la concentración de bioefluentes humanos que causaría el mismo nivel de insatisfacción que la polución real. 
Por otro lado, la calidad del aire no se verá mejorada simplemente asegurando una cierta tasa de ventilación, $\mathrm{Q}$, sino también dependiendo de la eficiencia de ésta, la cual puede variar entre 0,9 - 1, si hay recirculación, y hasta 1,2 -1,4 si hay renovación completa; y de la calidad del aire de renovación, que variará en función de la localización del edificio $(<0,1$ dp en ciudades con buena calidad del aire exterior, $y>0,5 \mathrm{dp}$ en ciudades con baja calidad del aire exterior). Si existen datos disponibles sobre la calidad del aire del entorno del edificio, estos deberían utilizarse [N-1], [N-2].

\section{Normativa}

Los aspectos citados en cuanto a calidad del aire vienen especificados y regulados en diversa normativa internacional y los correspondientes documentos que trasponen dichas directrices a nivel nacional, referenciados a lo largo del texto anterior. Las normas internacionales orientadas a la calidad del aire de espacios interiores son, en EEUU, la norma ASHRAE 62 [N-9]; y en Europa la norma CR 1752 [N-1], traspuesta en España directamente a través de la PN CR 1752 [N-2], y la más reciente EN 15251 [N-3].

La norma 62 de ASHRAE (American Society of Heating, Refrigeration and Air Conditioning Engineers) sobre "Ventilación para una Calidad del Aire Interior Aceptable" es una de las normas de ventilación existentes desde hace más tiempo (primera edición datada del 1973). Actualmente está en vigor la revisión de 2010. En ella se establece un método prescriptivo de determinación de los requisitos de ventilación de los espacios interiores, basado en el cálculo, en función de la carga contaminante por ocupación y debida al propio edificio, de los caudales de ventilación necesarios para mantener las concentraciones de contaminantes bajo los valores límites.

Por su parte, la norma CR 1752 de la Comisión Europea de Normalización (CEN), y su equivalente a nivel nacional PN CR 1752, establecen un conjunto de criterios para la clasificación de los edificios en términos de calidad ambiental proporcionada en su interior. Adopta la utilización de tres clases de aceptación de los ambientes interiores - A, B y C según varios aspectos respecto a los cuales pueden ser evaluados los ambientes interiores (ambiente térmico, calidad del aire interior, ruido e iluminación). Esta norma plantea la introducción de la posibilidad de utilización de criterios subjetivos basados en la percepción sensorial humana para el estudio de la calidad ambiental interior. A partir de evaluaciones de ambientes interiores realizados, la norma establece los porcentajes de personas insatisfechas en función del caudal de aire de ventilación aportado al espacio. También esta considera el efecto tanto de la carga contaminante debida a ocupación como la del propio edificio

La norma europea EN 15251 es una norma elaborada más recientemente por la Comisión Técnica TC 156 - Ventilación para Edificios de CEN la cual, dentro del hecho de que aborda como se ha visto todos los ámbitos de la calidad de espacios interiores IEQ, adopta los mismos criterios que la CR 1752 en cuanto a la calidad del aire interior y a los requisitos de ventilación. Esta norma suele resultar en valores de caudal de ventilación más elevados que la norma 
ASHRAE 62, ya que considera la evaluación subjetiva por sensación de aire viciado realizada por un ocupante que llega a un determinado ambiente.

La semejanza que presentan las normas europeas CR 1752 y EN 15251 con la norma ASHRAE 62, es que consideran la posibilidad de definir los caudales de aire de ventilación necesarios para la dilución de los contaminantes en base a un método analítico. También está contemplada la posibilidad de utilizar sistemas de control de la tasa de ventilación en función de las necesidades ("demand controlled ventilation") controlados por medidores de calidad de aire interior, particularmente sensores de concentración de dióxido de carbono.

\section{II.3. CLASIFICACIÓN DE AMBIENTES INTERIORES EN CONFORT TÉRMICO Y CALIDAD DEL AIRE.}

En este apartado se introducen los criterios considerados en la clasificación del clima de los espacios interiores, de acuerdo con los estándares y normativas actuales. La especificación de criterios es necesaria tanto para el diseño de los ambientes interiores, como para el estudio y cálculo energético y de eficiencia en la operación del edificio, así como para abordar el análisis subjetivo del IEQ.

Es en el estándar EN 15251 donde se aborda la metodología y la propia clasificación de todos los aspectos comprendidos en la calidad de ambientes interiores IEQ, estableciendo los criterios desde la misma etapa de diseño. En dicha normativa, se presentan los principales parámetros a considerar en el cálculo energético del edificio y en su evaluación a largo plazo, identificándose también aquellos de especial interés para su monitorizado y publicación junto con la información sobre la clasificación ambiental del espacio. La clasificación, bien requerida o ya verificada, se presenta en cuatro categorías (I, II, III, y IV), indicando los valores recomendados de los distintos parámetros para cada una de ellas, y en función de ciertos factores como el tipo de edificio y las expectativas de sus ocupantes; el tipo de clima, la estación y las posibles diferencias nacionales, etc.

A continuación se describen más en detalle los criterios establecidos para cada categoría en el campo del ambiente térmico y de la calidad del aire, dentro del estudio del ICQ.

\section{Clasificación del ambiente térmico: criterios de aceptabilidad}

El parámetro estudiado para la determinación de las distintas categorías en las que puede clasificarse el ambiente térmico es el Voto Medio Previsto (PMV), y por extensión el Porcentaje de Personas Insatisfechas (PPD). Como queda reflejado en la tabla II.8, la categoría óptima se obtendrá cuando la proporción de personas que se encuentren en disconfort térmico sea inferior a un 6\%; y las categorías II y III se corresponderán con ambientes térmicos ante los 
cuales el porcentaje de ocupantes insatisfechos no exceda el 10 y el 15\%, respectivamente. El resto de casos quedarían englobados en la categoría IV, la cual no es recomendable.

Tabla II.8.- Clasificación por categorías del ambiente térmico en función del PMV y PPD.

\begin{tabular}{|c|c|c|}
\hline \multicolumn{2}{|c|}{ Categoría } & \multicolumn{2}{c|}{ Estado térmico del cuerpo (global) } \\
\multicolumn{1}{|c|}{ PPD [\%] } & PMV \\
\hline I & $<6$ & $-0,2<\mathrm{PMV}<+0,2$ \\
II & $<10$ & $-0,5<\mathrm{PMV}<+0,5$ \\
III & $<15$ & $-0,7<\mathrm{PMV}<+0,7$ \\
IV & $>15$ & $\mathrm{PMV}<-0,7$ o PMV $>+0,7$ \\
\hline
\end{tabular}

Sin embargo, la categoría asignada puede diferir en función del tipo de estudio perpetuado para la clasificación del espacio. De esta forma, el análisis del ambiente térmico puede resultar en una mejor o peor categoría según se base en criterios de diseño realizados para el cálculo energético del edificio (de ser este un edificio de nueva construcción); en la simulación anual de su funcionamiento (tanto para nuevos edificios como para ya existentes); medición, a largo plazo, de ciertos parámetros seleccionados sobre el ambiente interior de edificios ya existentes; o a partir de la respuesta subjetiva de ocupantes encuestados en el edificio, también necesariamente existente. Por lo tanto, el método utilizado en la clasificación debe ser especificado, al proporcionar resultados cuya interpretación debe ser completamente diferente. Además, en particular para la segunda y tercera posibilidades de estudio, se presenta especialmente interesante la determinación del tiempo durante el cual se han alcanzado los requisitos establecidos en cada categoría.

Asimismo, el estándar también proporciona indicaciones sobre la evaluación del edificio completo, ponderando la importancia relativa de sus distintos pisos o zonas definidas, a su vez categorizadas a partir de las de los espacios que las constituyen, y en relación al tiempo durante el cual se alcanzan los requisitos de dichas categorías.

Los criterios de aceptabilidad del ambiente térmico vienen determinados en los estándares $[\mathrm{N}-5][\mathrm{N}-6],[\mathrm{N}-10]$.

Asumiendo que la sensación térmica está determinada principalmente por el balance energético corporal con el ambiente ya planteado, y que este está influido por 4 parámetros ambientales (temperatura seca, temperatura radiante, humedad relativa y velocidad del aire) y dos personales (vestimenta y actividad metabólica), se puede predecir a través del Voto Medio Previsto PMV. En cualquier caso, la sensación térmica y consecuentemente el porcentaje de personas insatisfechas PPD, puede verse modificado gracias a la adaptación de los ocupantes y las posibilidades de control sobre su situación que puedan tener.

La norma indica que el índice PMV sólo debe utilizarse en espacios ventilados mecánicamente, ya que en los espacios con ventilación natural es preciso considerar rangos 
más amplios de tolerancia, al variar estos con la variación de la temperatura exterior, y tener los ocupantes mayor control sobre los modos de acondicionamiento térmico. En las figuras II.5.a y II.5.b. se muestran los diagramas elaborados por Dear y Brager, representando los rangos de aceptabilidad de la temperatura operativa en dos tipos de espacios radicalmente opuestos [9, deDear\&Brager, 1998].

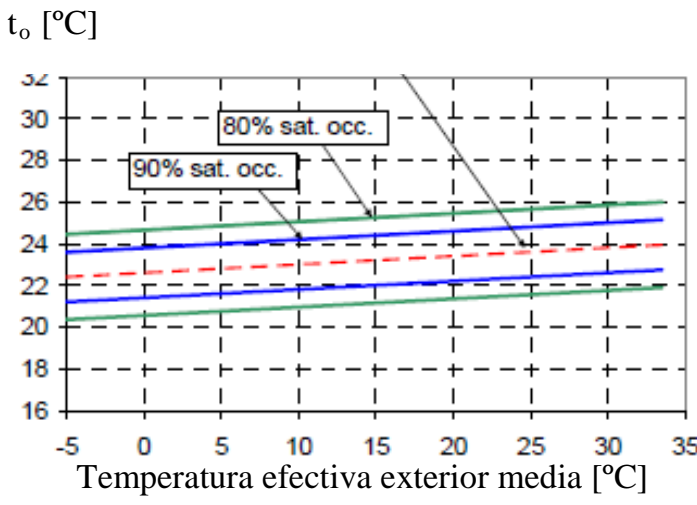

Figura II.5.a- Rangos de aceptabilidad de la temperatura operativa en espacios ventilados mecánicamente, con escasas opciones de adaptación por los ocupantes. $\mathrm{t}_{\mathrm{o}}\left[{ }^{\circ} \mathrm{C}\right]$

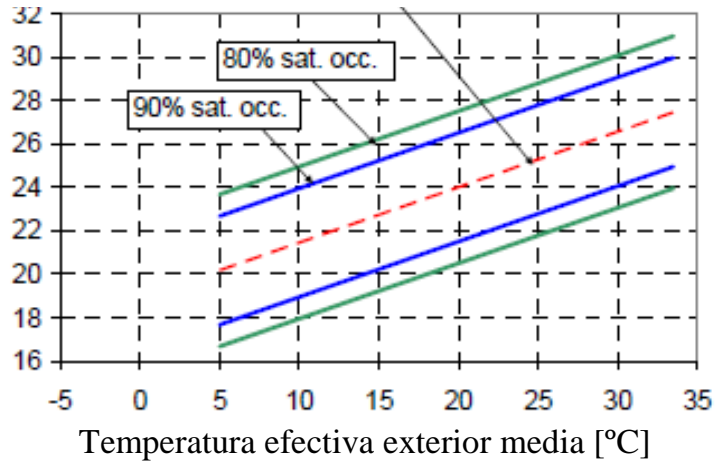

Figura II.5.b.- Rangos de aceptabilidad de la temperatura operativa en espacios con ventilación natural, sin equipos de climatización, y con amplias posibilidades de adaptación por los ocupantes.

Para los espacios con ventilación natural sin equipos de climatización, y en los que sus ocupantes, en actividad sedentaria, tienen amplio control sobre los métodos de regulación del ambiente térmico mediante apertura o cierre de ventanas y modificación de la vestimenta, las distintas normas proponen modelos adaptativos de evaluación. El diseño en estos casos debe considerar métodos alternativos o soluciones pasivas para controlar la temperatura interior en verano, como la orientación de superficies acristaladas o la disposición de elementos de sombra regulables. En las figuras II.6.a y II.6.b se muestran los rangos de aceptabilidad de estos modelos para los estándares internacionales EN 15251 y ASHRAE-55 [N-3] [N-10], [10, deDear\&Brager, 2002].

$$
\mathrm{t}_{\mathrm{o}}\left[{ }^{\mathrm{o}} \mathrm{C}\right]
$$

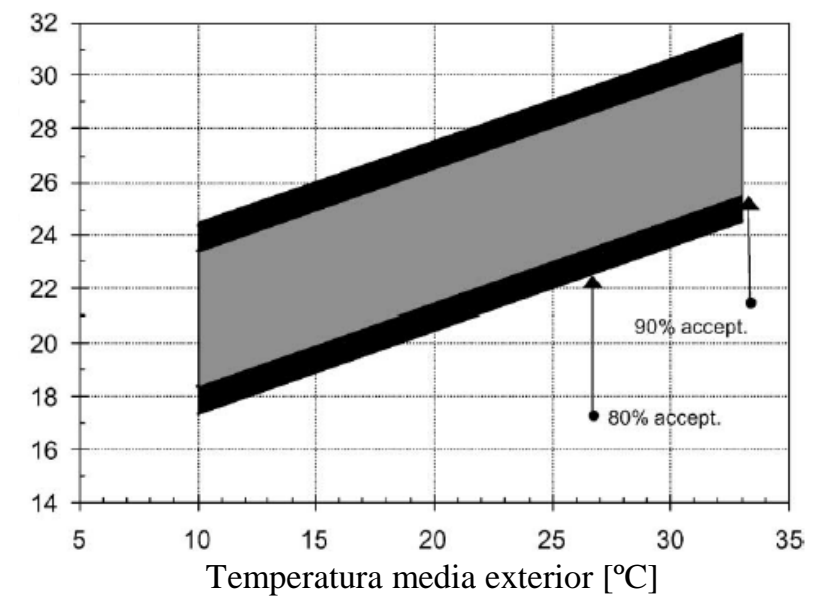

Figura II.6.a- Diagrama del modelo adaptativo propuesto en el estándar ASHRAE-55. 


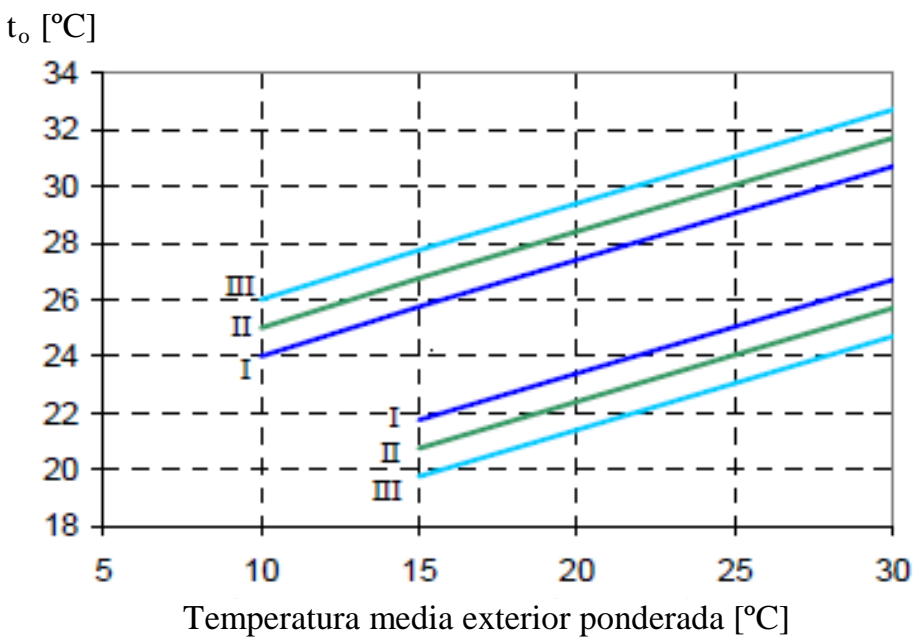

Figura II.6.b- Diagrama del modelo adaptativo propuesto en el estándar EN 15251 [N-3].

Puede observarse cómo el estándar europeo introduce dos diferencias respecto al americano: en primer lugar, comprende tres rangos de aceptabilidad del ambiente térmico; y segundo, propone dichos rangos en relación a la temperatura media exterior ponderada respecto a la temperatura de los días precedentes, ya que las condiciones de los días anteriores influye, por ejemplo, en la vestimenta escogida por las personas para el día en cuestión.

Por su parte, el estándar europeo EN ISO 7730 no proporciona ningún diagrama adaptativo, pero asume la ampliación de las condiciones de aceptabilidad en el caso de espacios con ventilación natural controlados principalmente por los ocupantes [N-5] [N-6].

Un punto adicional introducido por los estándares es el hecho de que también proporcionan indicaciones sobre la evaluación de los cuatro tipos posibles de disconfort térmico local, en función del Porcentaje de Personas Insatisfechas en cada caso. Sin embargo, el disconfort local se considera sólo cuando los ocupantes se encuentran realizando actividades sedentarias, ya que para mayores niveles de actividad las personas resultan ser menos sensibles a éste. En la tabla II.9, se muestran las consideraciones establecidas en términos de porcentaje de insatisfechos sobre las categorías definidas para disconfort global y local [N-5] $[\mathrm{N}-6][\mathrm{N}-3]$.

Tabla II.9.- Categorías de los espacios en términos de IAQ [N-1] [N-2] [N-3]

\begin{tabular}{|c|c|}
\hline Categoría & Descripción \\
\hline A, I & $\begin{array}{l}\text { Elevado nivel de expectativa. Es recomendada para espacios ocupados por personas muy } \\
\text { sensibles o que precisan de cuidados especiales, enfermos, niños o personas mayores. }\end{array}$ \\
\hline B, II & $\begin{array}{c}\text { Nivel normal de expectativas. Es el requerido en edificios de nueva construcción o } \\
\text { renovados. }\end{array}$ \\
\hline C, III & Nivel moderado de expectativa, aceptable. Es la requerida en edificios existentes. \\
\hline $\mathrm{D}, \mathrm{IV}$ & $\begin{array}{l}\text { Se corresponde con valores fuera de los criterios de las categorías anteriores. Sólo es } \\
\qquad \text { admisible durante períodos limitados. }\end{array}$ \\
\hline
\end{tabular}

Clases A, B, C, D - CR 1752; Clases I, II, III, IV - Norma EN 15251 
Debe notarse que la temperatura operativa óptima va a ser siempre la misma, correspondiente a un $\mathrm{PMV}=0$, sea cual sea la categoría establecida como requisito del ambiente. La única diferencia reside en los rangos de tolerancia permitidos en ese caso particular. El principal problema reside en que el ambiente térmico puede variar sustancialmente durante un período de tiempo largo, y por lo tanto a la hora de clasificarlo puede resultar que no se mantenga dentro de los límites establecidos en la categoría definida durante todo el tiempo de operación. Por lo tanto, los estándares proponen una evaluación aproximada a través de índices a largo plazo:

- Índice de rendimiento $(P I)$ : refleja el porcentaje de tiempo durante el cual el parámetro evaluado o medido queda comprendido dentro de los rangos de tolerancia establecidos:

$$
P I[\%]=\left(\frac{\sum \tau_{\text {(tiempodentrodelrango det olerancia) }}}{\sum_{0}^{\text {tiempototaldeocupación }} \tau}\right) \cdot 100
$$

- Índice defracaso (FI): se define como el concepto opuesto al PI; es decir, como el porcentaje de tiempo durante el cual el valor del parámetro cae fuera del rango de tolerancia:

$$
F I[\%]=100-P I
$$

Para poder realizar un estudio más detallado de las causas de ese fracaso, se definen dos índices de fracaso parciales:

- Índice de fracaso por frío (FIc): se corresponde con el porcentaje de tiempo durante el cual el valor del parámetro cae por debajo del límite inferior de tolerancia:

$$
F I_{c}[\%]=\left(\frac{\sum \tau_{(\text {tiempobajoel limite inf erior })}}{\sum_{0}^{\text {tiempototaldeocupación }} \tau}\right) \cdot 100
$$

- Índice de fracaso por calor (Flw): se corresponde con el porcentaje de tiempo durante el cual el valor del parámetro queda sobrepasa el límite superior de tolerancia:

$$
F I_{w}[\%]=\left(\frac{\sum \tau_{(\text {tiemposobreel lim ite sup erior })}}{\sum_{0}^{\text {tiempototaldeocupación }} \tau}\right) \cdot 100
$$


La información recogida puede ser más amplia incluso, redefiniendo los dos índices parciales anteriores ponderando mediante un factor en función de la dimensión de la desviación del parámetro estudiado respecto los límites establecidos.

- Índice ponderado de fracaso por frío (Flc-w)

$$
F I_{c-w}[\%]=\left(\frac{\sum \tau_{(\text {tiempobajoellimiteinf erior) }} \cdot w f}{\sum_{0}^{\text {tiempototaldeocupación }} \tau}\right) \cdot 100
$$

- Índice ponderado de fracaso por calor (Flw-w)

$$
F I_{W-w}[\%]=\left(\frac{\sum \tau_{(\text {tiemposobreel limite sup erior })} \cdot w f}{\sum_{0}^{\text {tiempototaldeocupación }} \tau}\right) \cdot 100
$$

De ser la temperatura operativa el parámetro de estudio, el factor viene definido en porcentaje de "grados-hora", y será igual al módulo de la diferencia entre el valor real y el límite respecto al que se desvía, y cero cuando se mantenga dentro del rango establecido:

$$
\begin{aligned}
& \text { wf }=0 \text { si } T_{\text {lim inf }} \leq T \leq T_{\text {lim sup }} \\
& \text { wf }=1 \text { si } T_{\text {lim sup }}<T \leq\left(T_{\text {lim sup }}+1^{\circ} \mathrm{C}\right), o\left(T_{\text {lim inf }}-1^{\circ} \mathrm{C}\right) \leq T<T_{\text {lim inf }} \\
& \text { wf }=\left|T-T_{\text {lim }}\right| \text { para }\left|T-T_{\text {lim }}\right|>1^{\circ} \mathrm{C}
\end{aligned}
$$

\section{Clasificación de la calidad del aire: métodos de evaluación}

La calidad del aire interior, como en el caso del resto de factores en consideración en la calidad de ambientes, puede expresarse en función del porcentaje de personas que lo encuentran inaceptable. En base a este criterio, las clases recomendadas de calidad de aire interior vienen definidas como A, B, C y D, según la norma CR 1752, o análogamente I, II, III y IV según la norma EN 15251, y correspondientes a niveles de insatisfacción inferiores a 15\%, $20 \%$ y $30 \%$ y superiores al $30 \%$, respectivamente. La definición cualitativa, en función de las distintas expectativas en los espacios, está definida en la tabla II.9. [N-1] [N-2] [N-3].

Como puede verse en la Figura II.7, categorías superiores requieren de mayores caudales de ventilación. Sin embargo, debe tenerse presente que la categoría I implica un tratamiento muy cuidadoso por parte de los sistemas de distribución de aire, a fin de garantizar una buena uniformidad de la distribución espacial de velocidades del aire en la zona ocupada, para evitar generar sensación de disconfort térmico localizado a causa de corrientes de aire. 


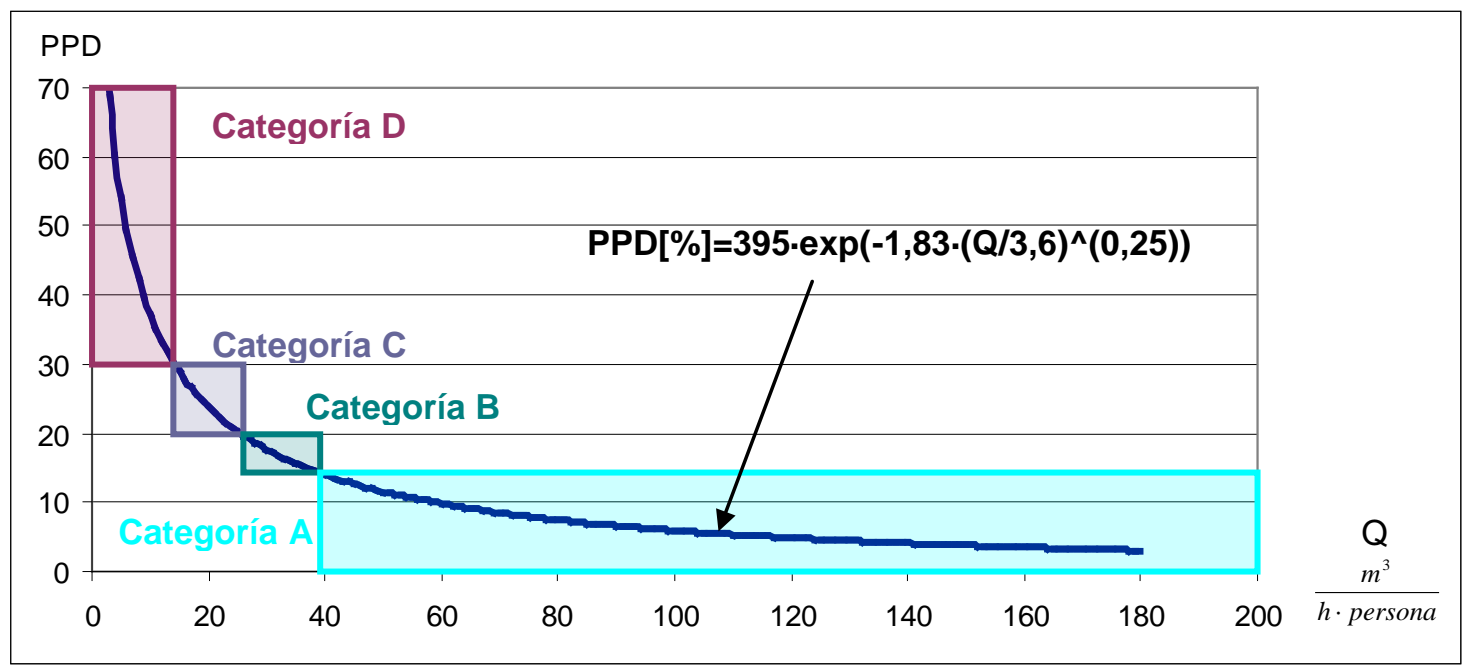

Figura II.7.- Porcentaje de personas insatisfechas PPD, cuando llegan a un espacio, en función del caudal de ventilación ( $\mathrm{m}^{3} / \mathrm{h} /$ persona).

Aunque no se puede caracterizar el nivel de calidad percibido en el aire a partir de la medida de la concentración de ningún componente, como demostró Fanger [7, Fanger et al., 1988], y dado que, como se verá en el apartado siguiente, la caracterización experimental subjetiva es muy complicada, la norma CR 1752 plantea la posibilidad de clasificar un ambiente en términos de IAQ en función de las concentraciones medidas de $\mathrm{CO}_{2}$ [N-1] [N-2]. La concentración de $\mathrm{CO}_{2}$ en un determinado espacio interior en relación a la concentración en el aire atmosférico exterior es, en la mayor parte de los casos, un buen indicador de la tasa de ventilación. $\mathrm{Si}$ el $\mathrm{CO}_{2}$ presente en el ambiente interior del edificios es de origen casi exclusivamente metabólico, y es posible estimar la intensidad de las fuentes de contaminantes en función del número de ocupantes y de su tipo de actividad, los valores medidos de $\mathrm{CO}_{2}$ permiten una buena estimación en los casos en que la mayor parte de la carga contaminante se debe a ocupación humana [11, Gameiro, 2009]. El porcentaje de insatisfechos en función de la concentración de $\mathrm{CO}_{2}$, así como la consecuente clasificación, se muestran en la Figura II.8.

Los dos requerimientos básicos del IAQ son que no exista riesgo importante para la salud por la exposición a dicho aire, y que éste sea percibido como aceptable en términos de confort. Por lo tanto, el objetivo de la norma es mantener los niveles de concentración de las sustancias contaminantes dentro de unos valores de referencia, a través de diversas estrategias (dilución, filtrado, eliminación de fuentes, purificado del aire, etc.), para que no sean perjudiciales para la salud ni produzcan malestar [N-11].

Existen tres métodos de evaluación del IAQ: uno directo, a través de la misma medida de las concentraciones de contaminantes; y dos indirectos, uno a través de la evaluación de las consecuencias de la exposición a dicho aire de personas, animales, etc., y el otro a través del estudio de los parámetros de operación del sistema de tratamiento de aire (por ejemplo, la tasa de ventilación exterior sería el criterio de evaluación en una estrategia de control por dilución de contaminantes en aire fresco). Estos tres métodos se encuentran interrelacionados, como se 
indica en la Figura II.9 Para cerrar este triángulo, asegurando que se cumplen los dos objetivos buscados en el IAQ en cuanto a riesgos y confort, la mayoría de los estándares proporcionan datos sobre la evaluación subjetiva de la calidad del aire percibida por los ocupantes y de las tasas de ventilación requeridas, correspondientes ambas a ciertos valores de referencia de concentraciones de los contaminantes presentes en el espacio interior [N-11] [N-9], [N-1] [N-2] [N-12] [N-13].

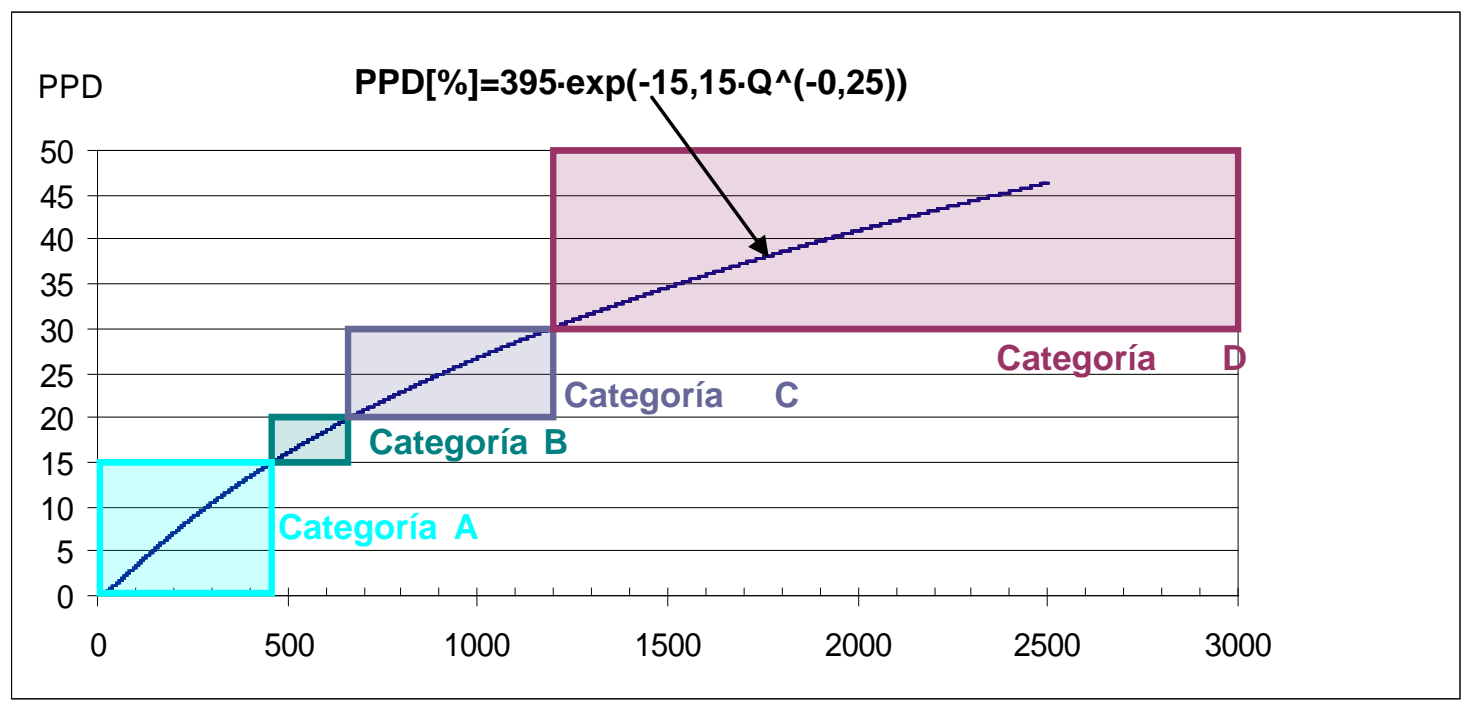

Figura II.8.- Porcentaje de personas insatisfechas PPD, cuando llegan a un espacio, en función del exceso de concentración respecto al exterior de $\mathrm{CO}_{2}$.

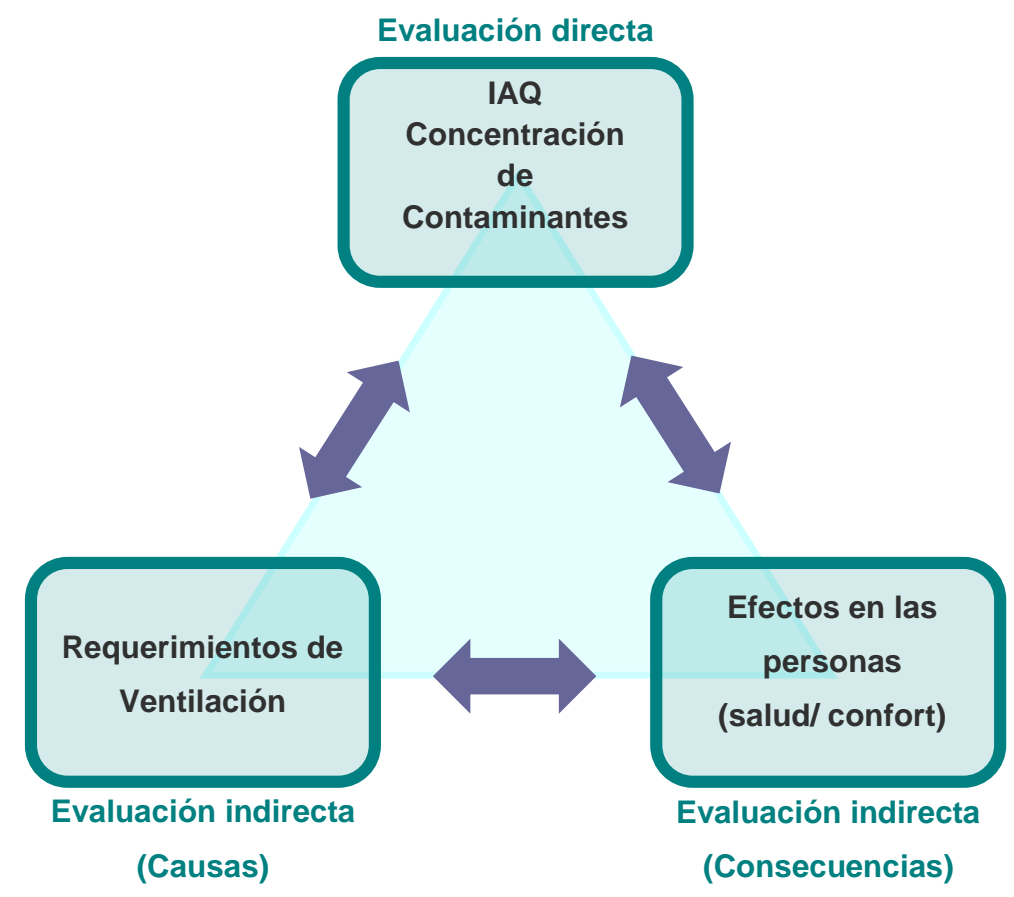

Figura II.9.- Métodos de evaluación de la calidad del aire interior IAQ. 
Las figuras II.7 y II.8 representan dos de las tres relaciones bidireccionales existentes entre los tres métodos presentados en el triángulo de la Figura II.9. La tercera relación bidireccional quedaría reflejada en la Figura II.10.

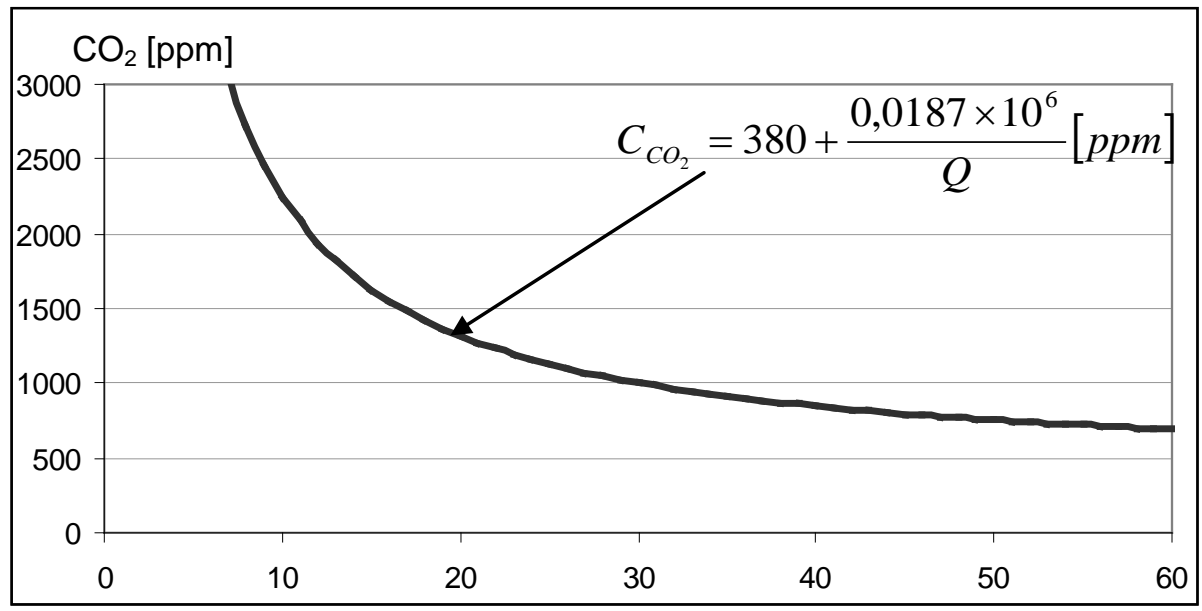

Figura II.10.- Concentración de equilibrio del $\mathrm{CO}_{2}$ metabólico como función del flujo de aire de ventilación, para una persona en actividad sedentaria ( $M=1,2$ met).

El cálculo de la tasa de ventilación instantánea que permita asegurar un cierto nivel de calidad del aire interior es complejo, y requiere ciertas simplificaciones, como la consideración de unas tasas fijas de emisión de contaminante y de aire de renovación aportado y la uniformidad de la distribución espacial de los contaminantes, que permitan obtener una ecuación que relacione ésta con la concentración de un cierto contaminante a diluir.

Como se ha visto, el $\mathrm{CO}_{2}$ puede ser un buen indicador de la tasa de ventilación. Desarrollando la expresión II.12 en el caso del $\mathrm{CO}_{2}$, para una cierta eficiencia de ventilación y considerando una generación de $0,0187 \mathrm{~m}^{3}$ por hora y metro cuadrado de local, y una concentración de $\mathrm{CO}_{2}$ en el aire exterior de 380 ppm, la ecuación final obtenida resulta de la forma [12, Gameiro et al., 2011]:

$$
Q=\frac{0,0187 \times 10^{6}}{X_{\mathrm{CO}_{2}}-380} \Rightarrow X_{\mathrm{CO}_{2}}=380+\frac{0,0187 \times 10^{6}}{Q}[\mathrm{ppm}]
$$

Esta relación entre la concentración inicial de $\mathrm{CO}_{2}, \mathrm{X}_{\mathrm{CO} 2}$, y el caudal de ventilación preciso para su dilución, Q, se muestra representada en la Figura II.10.

Como ya se ha indicado en apartados anteriores, la contaminación del aire interior puede originarse, bien en el interior del propio edificio por su ocupación o por las propias emisiones de los materiales e incluso los sistemas de ventilación, o bien por la contaminación presente en el aire exterior. Dado que la contaminación exterior no se considera por esperarse solventada con el filtrado de los sistemas de tratamiento del aire, la tasa de ventilación debe calcularse en función de la ocupación y/ o del espacio; es decir: por persona y/ o por unidad de superficie. Los distintos estándares nacionales e internacionales describen los procesos para determinar 
la tasa de ventilación como suma de los dos aportes anteriores, o por consideración del máximo entre ellos, no existiendo consenso aún en el procedimiento. Por ejemplo, ambas posibilidades quedan propuestas en la norma EN 15251 [1, Corgnati\&Gameiro, 2011].

Existen dos metodologías propuestas alternativamente para determinar la tasa de aire de ventilación necesaria a fin de asegurar una cierta calidad del aire en un compartimento interior, en función de la dilución de contaminantes en el volumen de aire fresco impulsado: uno prescriptivo y otro analítico. El método prescriptivo recurre a valores de ventilación tabulados en función de la clase requerida y de, bien la ocupación a través del tipo de actividad desarrollada en el local, o bien del edificio en sí por su tipo de construcción. Por su parte, el método analítico proporciona los valores de ventilación requeridos en función de los límites fijados hasta los cuales hay que diluir el contaminante considerado [12, Gameiro et al., 2011].

\section{II.4. AUdITORÍAS DE ICQ: EQUIPOS DE MEDIDA}

\section{Introducción}

Todas las fases del ciclo de vida de un edificio son fundamentales a la hora de evaluarlo: tanto el diseño, como su proceso de construcción, y el período de ocupación. Esta última etapa está adquiriendo una importancia crucial, derivando en la necesidad de monitorizar y testear la eficiencia del edificio, a fin de facilitar su optimización. Dicha optimización está encaminada a "cumplir las necesidades de sus ocupantes de una forma más fiable y eficiente".

En particular, la auditoría sobre el clima interior va a permitir no sólo evaluar el nivel de confort térmico de sus ocupantes (identificando los posibles problemas y proponiendo soluciones a los mismos), sino también proponer alternativas para introducir mejoras operacionales e incluso proporcionar feedback para casos futuros, en relación a las acciones correctivas llevadas a cabo.

Los objetivos de un estudio del ICQ pueden ser, por lo tanto, diversos: puede orientarse a la obtención de feedback sobre los sistemas de climatización, a verificar la consecución de objetivos establecidos; obtener un diagnóstico rápido de las causas de fallos o quejas de los ocupantes, u obtener una propuesta de mejora del funcionamiento del edificio. Es posible también determinar la correlación existente entre el consumo energético y las condiciones de confort térmico alcanzadas. De esta forma, dependiendo del objetivo particular del estudio, este se focalizará en la medición detallada y puntual de unas ciertas condiciones espaciotemporales, o en una visión más amplia y dinámica, pero menos precisa, de su evolución durante un cierto período.

Un análisis del funcionamiento del edificio resulta, consecuentemente, en una mejora del confort en el espacio interior, un aumento de la eficiencia energética, y una reducción en los costes de mantenimiento, además de extender la vida útil tanto del edificio en sí como de sus sistemas. 


\section{Medida del confort térmico}

Las condiciones de confort térmico de los ocupantes de un cierto local se caracterizan a través de los índices ya definidos de temperatura operativa, temperatura efectiva, PMV y PPD, para cuya determinación es requerido conocer 6 factores, dos de los cuales están relacionados con aspectos personales (vestimenta, dada en clo, y actividad, en met), y los otros 4 con parámetros ambientales. Son estos últimos a cuyos métodos e instrumentos de medida hace referencia la normativa ISO 7726, traspuesta a nivel nacional a través de la UNE EN ISO 7726, donde se especifican los intervalos de medida, precisión requerida y recomendada, y el tiempo de respuesta, entre otros [N-7] [N-8].

Estos 4 parámetros ambientales de interés se describen a continuación, junto con unas escuetas indicaciones sobre las especificaciones de la normativa en referencia a los instrumentos y métodos de medida. En todo caso, cualquier dispositivo de medida o método de cálculo propuesto como alternativa a los descritos en la norma es admisible si se ajusta a las especificaciones de exactitud requeridas en ésta.

- Temperatura seca del aire, Ta: Es la temperatura del aire que rodea al cuerpo,

cuyo valor es necesario para determinar la transferencia de calor por convección entre éste y el ambiente.

Los instrumentos de medida de la temperatura seca precisan estar debidamente protegidos de la radiación, así como mantener los niveles de precisión requeridos incluso ante elevadas diferencias respecto a la temperatura radiante. Estos instrumentos pueden basarse en diferentes principios, pero siempre atendiendo a los efectos radiantes, por lo que debe tratarse de sensores pequeños y protegidos pero permitiendo la circulación de aire. Además, deben ser fácilmente desmontables para calibración, y la conductividad térmica entre el sensor y el resto de elementos de soporte debe minimizarse para reducir pérdidas.

En las figuras II.11.a y II.11.b se muestran un esquema de este sensor y una imagen de uno real.

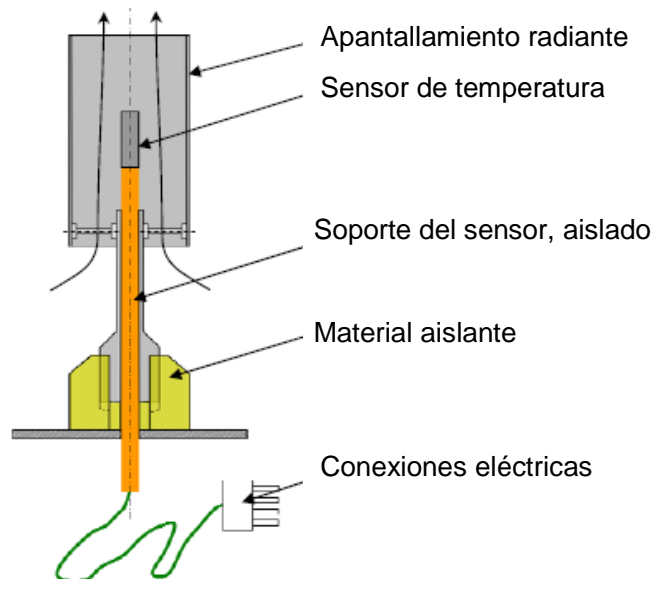

Figura II.11.a.- Esquema de una sonda de temperatura seca del aire.

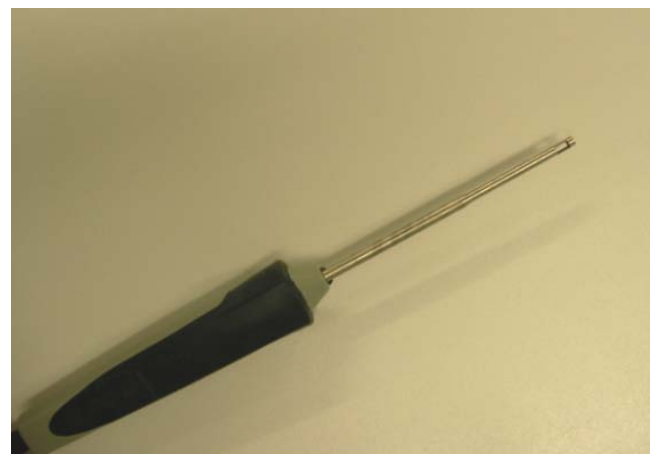

Figura II.11.b.- Imagen de una sonda de temperatura seca del aire. 
- Temperatura media radiante, Tr: es la temperatura uniforme de un recinto

imaginario en el que la transferencia de calor radiante desde el cuerpo humano es igual a la efectuada en un recinto real no uniforme.

Para la medida de este parámetro se recurre a instrumentos que permiten "integrar" en un valor medio la radiación, generalmente heterogénea, emitida por las paredes de un recinto real.

Uno de los dispositivos de medida frecuentemente empleado es el termómetro de globo negro (Figura II.12.b), obteniéndose un valor aproximado de la temperatura radiante media a partir de los valores de la temperatura de globo y de la temperatura y velocidad del aire que lo rodea. Estos instrumentos son generalmente una esfera negra de diámetro 0,15 m (Figura II.12.a), por lo que su respuesta es muy lenta. La forma esférica supone una aproximación razonable a la forma de una persona sentada, aunque los sensores elipsoidales la aproximan mejor. Esferas de menor tamaño proporcionan respuestas más rápidas, pero pueden no ser suficientemente precisas. Además, la precisión también depende de la temperatura y velocidad del aire. Si la precisión disponible no alcanza la especificada en la norma, debe indicarse claramente la real.

En este caso también es de vital importancia a la conductividad a través del soporte del sensor, así como a la facilidad de acceso para la recalibración.

La temperatura radiante media también puede calcularse a partir de valores medidos de la temperatura de las pareces circundantes, del tamaño de éstas y de su disposición respecto a la persona. Otra opción es estimarla a partir de la temperatura radiante plana, como se indica más adelante, entre otras.

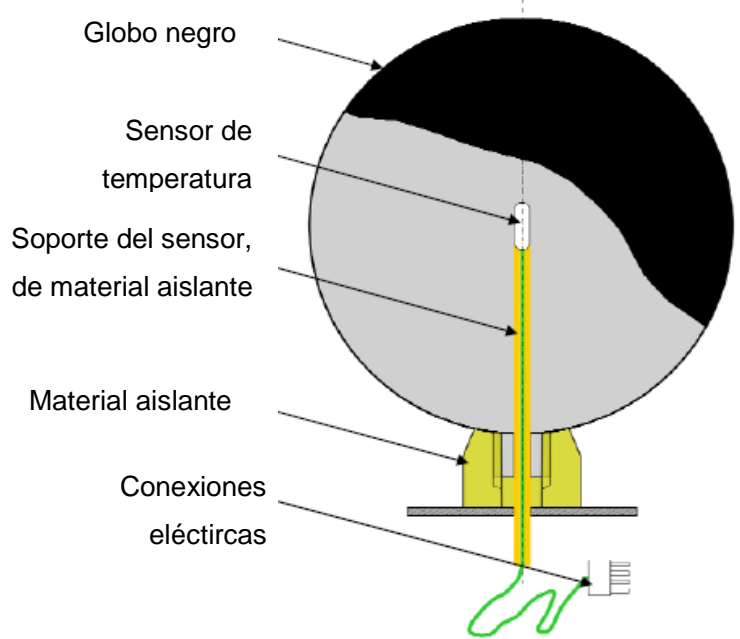

Figura II.12.a.- Esquema de una sonda de globo para medida de temperatura radiante media.

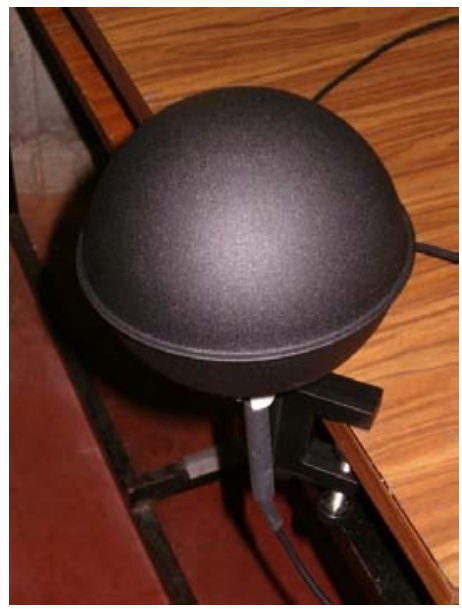

Figura II.12.b.- Imagen de una sonda de globo para medida de temperatura radiante media.

- Humedad específica del aire: Hace referencia a cualquier magnitud que indique la cantidad real de vapor de agua presente en el aire, tales como la humedad relativa o el 
grado de saturación, aunque también puede hacerse referencia a la presión parcial de vapor de agua.

La humedad específica del aire puede determinarse directamente, mediante equipos de condensación o dispositivos electrolíticos; o indirectamente, mediante la medida simultánea de diversas magnitudes como la humedad relativa y la temperatura del aire o la temperatura húmeda psicrométrica y la temperatura del aire. Para este último caso, con frecuencia se emplean psicrómetros.

En las imágenes II.13.a y II.13.b se muestran tanto el esquema como una imagen real de un sensor de humedad relativa.

a)

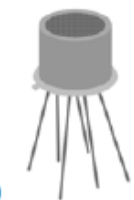

b)

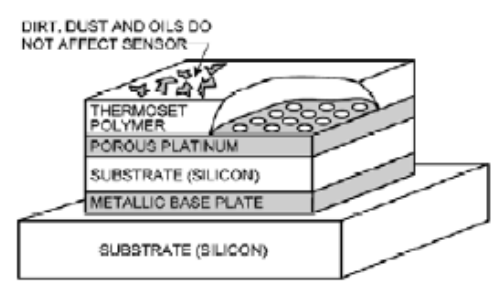

Fig. 6.4 Thermoset polymer-based capacitive RH sensor; a) sensor in TO-5 housing with a hydrophobic sintered stainless steel filter, b) sensor construction - a planar capacitor with a polymer layer to protect against dirt, dust, oils and other hazards.

Figura II.13.a.- Esquema de una sonda de medida de

\section{Humedad Relativa.}

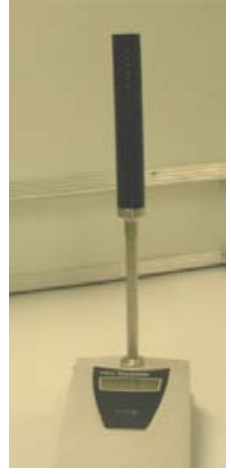

Figura Il.13.b.- Sonda de Humedad Relativa.

- Velocidad del aire, $v$ : el vector velocidad del aire caracteriza el movimiento de éste, a través tanto de su magnitud como de su dirección. Sin embargo, los estándares sólo consideran la magnitud de dicho vector velocidad del flujo en el punto de medida considerado. Dado que el valor velocidad en cualquier punto del espacio fluctúa en el tiempo, es recomendable registrar dichas fluctuaciones, y describirse el flujo de aire por su velocidad media en un intervalo de tiempo correspondiente con el período de medida, y por la desviación típica. Las figuras II.14.a y II.14.b muestran respectivamente un esquema y una fotografía de una sonda para medida de la magnitud de la velocidad del aire en un determinado punto.

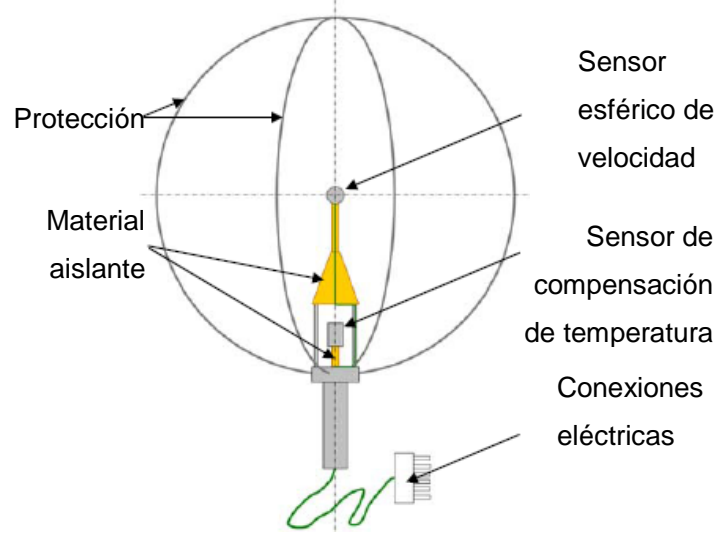

Figura II.14.a.- Esquema de una sonda de medida de la magnitud de la velocidad del aire.

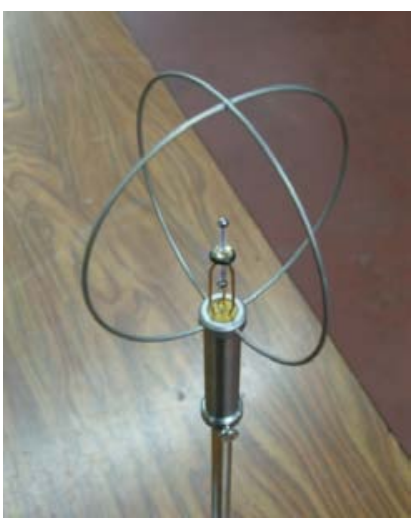

Figura II.14.b.- Sonda de medida de la magnitud de la velocidad del aire. 
Además de estos cuatro parámetros, puede ser necesario o interesante medir dos parámetros extra:

- Temperatura radiante plana, Tpr: Se define como la temperatura uniforme de un recinto en el que la irradiación sobre un lado de un pequeño elemento plano es la misma que en un ambiente real no uniforme.

El concepto de asimetría de temperatura radiante atiende a la diferencia entre las temperaturas radiantes planas de los dos lados opuestos de un pequeño elemento plano, y se emplea cuando la temperatura media radiante por sí misma no permite describir debidamente el entorno radiante.

Permite además proporcionar una estimación de la temperatura radiante media, a partir de su valor en seis direcciones opuestas y ponderadas en función de los factores de superficie proyectada para una persona.

En la figura II.15 se muestra el esquema de un sensor de medida de este tipo.

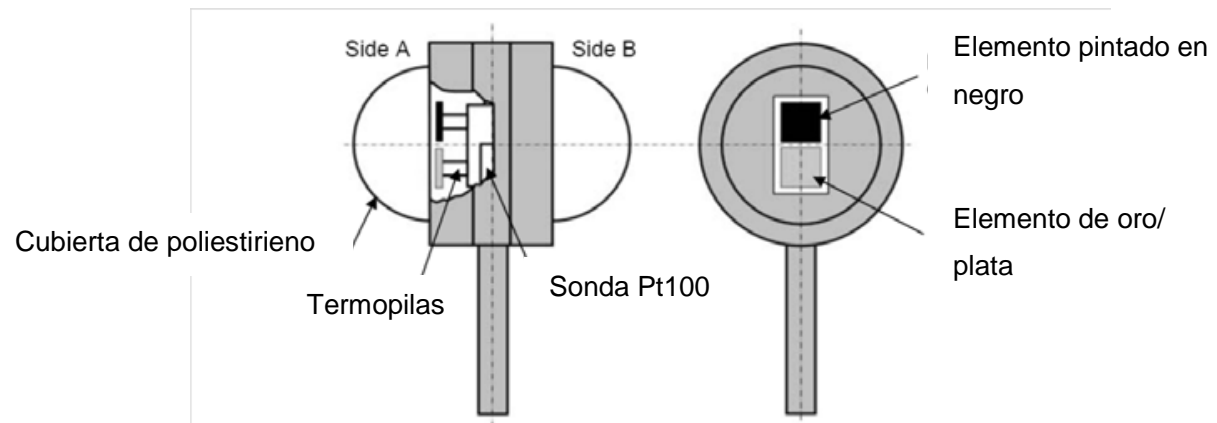

Figura II.15.- Esquema de un sistema de medida de asimetría radiante.

- Temperatura superficial, Ts: Es la temperatura de una superficie dada. Se utiliza para evaluar el intercambio radiante en el cuerpo humano por medio de la temperatura radiante media o la temperatura radiante plana. También se emplea para evaluar el efecto del contacto directo entre dicho cuerpo una determinada superficie.

Su medida puede realizarse utilizando un termómetro de contacto, cuando el sensor está en contacto con la superficie, aunque puede modificar el flujo térmico en el punto de medida y consecuentemente influir en el resultado; o un sensor de infrarrojos, mediante el que se mide el flujo de calor radiante emitido por la superficie para luego traducirlo a temperatura, aunque los resultados pueden verse influidos en este caso por la emisividad de la superficie, la cual puede ajustarse en el termómetro.

En las figuras II.16.a y II.16.b pueden verse el esquema y una imagen de estos sistemas de medida. 

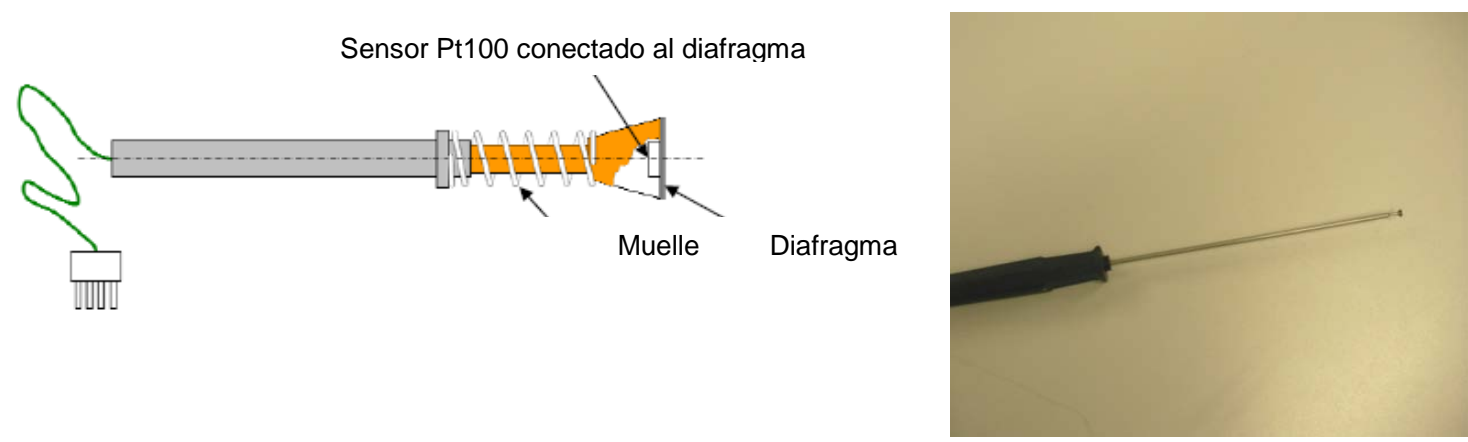

Figura II.16.a.- Esquema de un sistema de medida de la temperatura de superficie.

Figura II.16.b.- Vista de un sistema de medida de la temperatura de superficie.

La norma también concibe la posibilidad de medir directamente temperaturas operativas. Uno de los requisitos para un sensor de medida directa de temperatura operativa es que la relación entre sus coeficientes de pérdida de calor por radiación y convección sea la misma que para una persona, restringiéndose por lo tanto el diámetro del sensor. Un diámetro óptimo depende de la velocidad del aire, estando comprendido entre 0,04 $\mathrm{m}$ y 0,1 $\mathrm{m}$. También deben tenerse en consideración su forma, de estar en ambientes de radiación no uniforme; y su color, si está expuesto a radiación de onda corta. En la Figura II.17 se muestra una imagen de una sonda de medición de temperatura operativa, la cual puede reclinarse para aproximar más fielmente la postura de una persona en pie, sentada o tumbada.

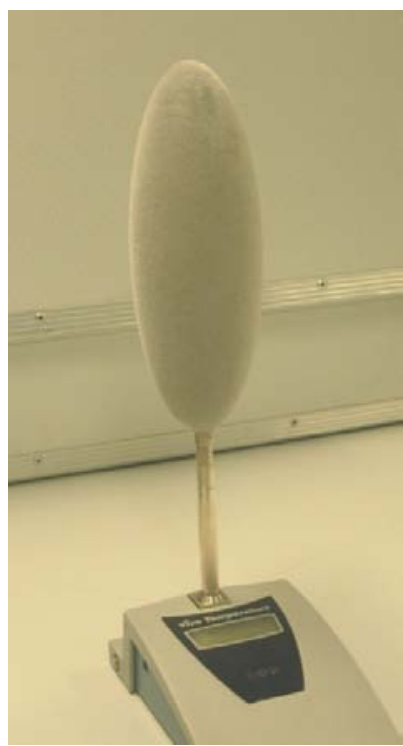

Figura II.17.- Sonda de medición directa de la temperatura operativa

Todos estos parámetros pueden variar tanto en el espacio (homogéneo o heterogéneo) y el tiempo (estacionario o no-estacionario). La normativa propone un método para reconocer los casos estacionarios y homogéneos, pero además proporciona indicaciones sobre la disposición de los sensores tanto para estos casos como para los no homogéneos; y recomendando, para los casos no estacionarios, el registro de medidas durante todo el período de ocupación. 


\section{Medida de gases contaminantes}

Aunque en términos de calidad del aire percibido el propio sentido olfativo humano es mucho más preciso que cualquier análisis, se ha visto que en cuestiones de salud es preciso medir y controlar la presencia de ciertos gases contaminantes.

Generalmente, los componentes con posible presencia en el ambiente de especial consideración en los distintos estándares son el monóxido de carbono (CO), formaldehído $\left(\mathrm{CH}_{2} \mathrm{O}\right)$, plomo $(\mathrm{Pb})$, dióxido de nitrógeno $\left(\mathrm{NO}_{2}\right)$, ozono $\left(\mathrm{O}_{3}\right)$, radón $(\mathrm{Ra})$, dióxido de azufre $\left(\mathrm{SO}_{2}\right)$ y compuestos orgánicos volátiles (VOCs). Sin embargo, esta lista se está ampliando con otros compuestos, entre los cuales merecen particular atención los provenientes de fuentes del propio edificio y que pueden aparecer en concentraciones considerables, suponiendo por lo tanto posibles riesgos para la salud, como son el benceno, naftaleno, los hidrocarburos aromáticos policíclicos, el tricloroetileno y el tetracloroetileno.

Los procedimientos de determinación de los gases contaminantes deben ser tanto cualitativos como cuantitativos, y por lo tanto pueden resultar extremadamente complejos, ya que pueden requerir mediciones de concentraciones instantáneas o ponderadas durante un cierto período de tiempo, e incluso la monitorización constante durante períodos largos. Por ejemplo, en casos estacionarios de medición in situ de contaminantes, el proceso deberá realizarse durante un cierto período para no dar lugar a interpretaciones erróneas.

Para la selección de los instrumentos de medida adecuados debe considerarse, en primer lugar, qué contaminantes tipo y en qué niveles de concentración se esperan; si los resultados deben registrarse para su lectura in situ o enviarse para su posterior análisis; la precisión requerida en las medidas, probablemente relacionada con la propia calibración del sensor utilizado; y finalmente evitar en lo posible errores en la repetibilidad de medidas.

No cabe duda por lo tanto de que se trata de un campo muy amplio, por lo que sólo se presentarán aquí de forma introductoria los instrumentos más usuales para el análisis de gases contaminantes [1, Corgnati\&Gameiro, 2011], [13, Rey\&Velasco, 2007].

\section{Sensores electroquímicos de laboratorio:}

Estos instrumentos varían entre fabricantes y entre los diversos gases a medir, pero siempre se basan en el mismo principio de operación: el gas en cuestión reacciona, reduciéndose u oxidándose, en un electrolito seleccionado en función de la reactividad química del gas objeto, produciendo un impulso eléctrico que depende de su concentración.

Estos sistemas necesitan tiempo para estabilizarse, además de ser especialmente sensibles a cambios de temperatura, por lo que necesitan un sistema de compensación de temperatura. Además su tiempo de vida es también corto. 


\section{Semi-conductores o sensores de estado sólido:}

El principio de medición se basa en la variación en la conductividad de un semi-conductor en función de la concentración del gas, el cual es adsorbido por dicho semi-conductor mantenido a alta temperatura. Este dispositivo tiene una vida útil más larga, pero no es muy selectivo, pudiendo interferir en la medición la presencia de otros gases.

En la figura II.18 se muestra un esquema de la composición de los tubos de semiconductores de estado sólido para el muestreo de gases a través de adsorción a alta temperatura.
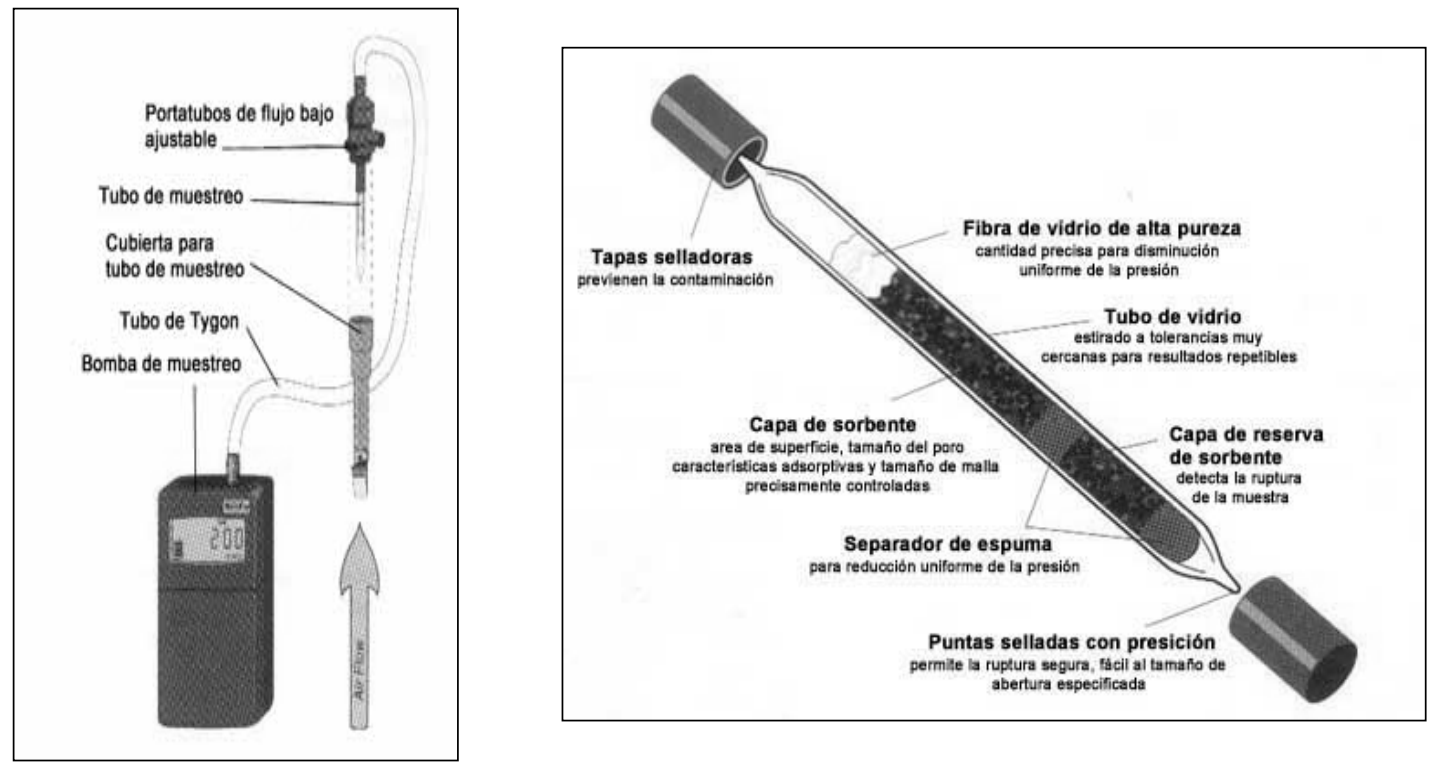

Figura II.18.- Composición y funcionamiento de los tubos de semiconductores de estado sólido adsorbentes para el muestreo.

\section{Sensores de combustión catalítica:}

Este tipo de sensores se utiliza para gases inflamables. La concentración del gas es medida a través del cambio en la resistencia de un elemento de platino debido a la ganancia de calor, y por lo tanto incremento de su temperatura, cuando actúa como agente catalítico en la combustión del gas. Sin embargo, la lectura puede no ser muy precisa de existir presencia de algunos gases en particular.

\section{Espectroscopía:}

Esta metodología comprende diversos métodos de medición de concentración de gases a través de su emisión, absorción o desviación de la luz. Algunos instrumentos típicos se basan en radiación infrarroja, pudiendo ser dispersivos (para uso en laboratorio) o no dispersivos (portátiles, para mediciones de campo), los cuales se basan en el principio de absorción por parte de las moléculas de la radiación recibida a frecuencia igual a su frecuencia natural, provocando un aumento de su vibración y consecuentemente de su temperatura. 


\section{- Espectroscopía en el infrarrojo cercano (NIRS):}

Estos sensores son de tipo no-dispersivo, que utilizan la región del espectro del infrarrojo cercano para caracterizar cuantitativamente $\mathrm{CO}, \mathrm{CO}_{2}, \mathrm{SO}_{2}$ o gases combustibles. Constan de dos celdas, una con la muestra de aire y otra llena del gas de referencia, puro.

\section{o Espectroscopía fotoacústica:}

Esta metodología es utilizada para detectar y analizar un amplio rango de contaminantes gaseosos. Se basa en la detección mediante micrófonos de variaciones de presión, debidas a ganancias de calor en una cámara donde la muestra de gas absorbe radiación infrarroja emitida a la longitud de onda característica de su enlace. En la figura II.19 se muestra una imagen de un equipo de detección y análisis de gases basado en este principio.

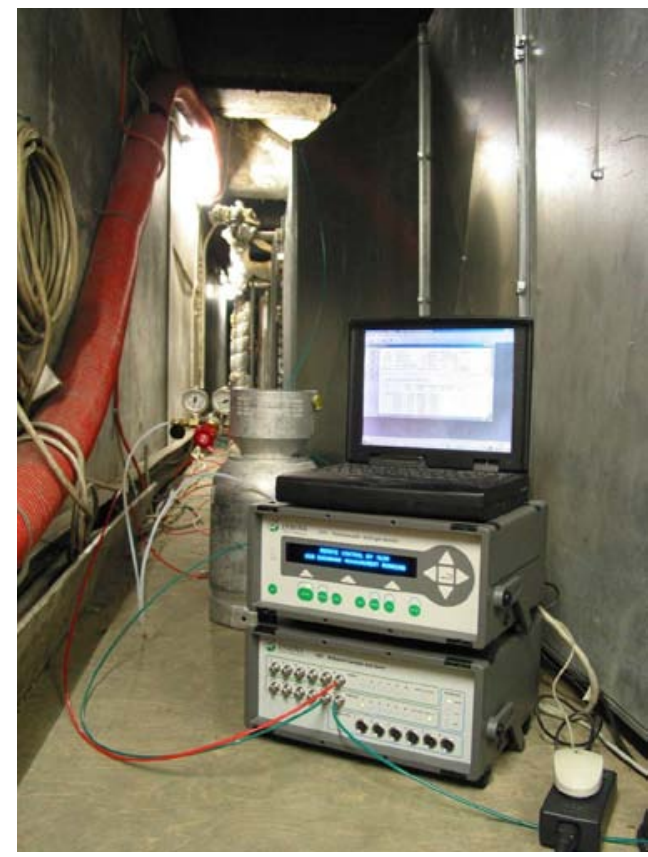

Figura II.19.- Equipo de medida de concentración de gases por espectroscopía fotoacústica.

\section{- Cromatografía gaseosa:}

Es utilizada para compuestos volátiles (por ejemplo, orgánicos), pero no es adecuada para compuestos con puntos de ebullición altos o inestables a temperaturas elevadas. La muestra de aire es inyectada en la corriente de un cierto gas portador que circula por una columna con un material sólido, donde se produce la separación de componentes. Cada componente es transportado hacia la salida de la columna tras un determinado tiempo de retención asociado a las condiciones de operación constantes, donde es detectado. La sensibilidad a los contaminantes particulares viene determinada por el tipo de detector utilizado.

\section{- Espectroscopía Másica:}

Es uno de los métodos cuantitativos más fiable para el análisis de contaminantes tanto orgánicos como inorgánicos, aunque también permite el análisis cualitativo. A menudo se utiliza 
junto con la cromatografía gaseosa, como detector del gas saliente de la columna. Para ello, ioniza y acelera el gas mediante un fuerte campo eléctrico, tras lo cual lo separa en función del ratio masa-carga en un fuerte campo magnético.

\section{Partículas:}

Este análisis se realiza proporcionando el número de partículas en el volumen de aire, o la concentración másica de partículas en una muestra de aire.

\section{- Medida gravimétrica:}

La medida gravimétrica suele utilizarse en espacios interiores con grandes cantidades de partículas en suspensión (por ejemplo, ambientes industriales). Consiste en extraer el polvo y hacerlo atravesar un filtro para recoger la muestra (se requiere de una indicación media de la concentración másica en el tiempo de la muestra de polvo).

\section{o Instrumentos de partículas ópticos.}

Son los más frecuentemente utilizados para determinar el número y la concentración másica de partículas en el aire interior. Un detector de luz mide tanto la cantidad de luz, de densidad energética conocida, obstruida por la partícula, como la cantidad de luz desviada de la dirección original (obscuración y desvío del haz de luz). Las partículas pueden contarse y medirse simultáneamente. Por partículas pequeñas $(<1 \mu \mathrm{m})$, se precisa aumentar el tamaño de éstas mediante condensación de vapores.

La figura II.20 muestra un equipo analizador de partículas óptico.

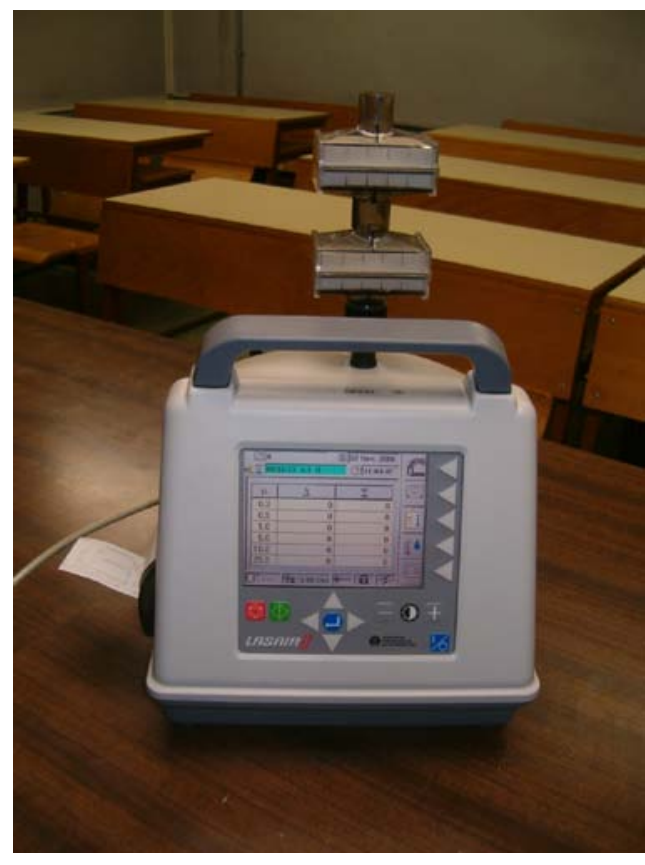

Figura II.20.- Analizador de partículas óptico. 


\section{REFERENCIAS}

[1] Corgnati, S.P.; Gameiro da Silva, M.C.; Ansaldi, R.; Asadi, E.; Costa, J.J.; Filippi, M.; Kaczmarczyk, J.; Melikov, A.K.; Olesen, B.W.; Popiolek, Z.; Wargocki, P.; "Indoor Climate Quality Assessment", REHVA Guidebook No.14. Finlandia, 2011.

[2] European Comission, Joint Research Centre, Environment Institute, Working Group 12. Report EUR 16367 EN: "Report No. 17: Indoor Air Quality and the Use of Energy in Buildings". European Collaborative action. Luxemburgo, 1996.

[3] Rey Martínez, F.J.; Velasco Gómez, E.; "Experimental study of indoor air quality, energy saving and analysis of ventilation norms in climatised areas". Revista: Energy and Buildings, 33, pp.:57-67. 2000.

[4] Fanger, P.O.; "Thermal comfort: analysis and applications in environmental engineering". Ed.: McGraw-Hill. Nueva York, 1973.

[5] San José Alonso, J.F; Velasco-Gómez, E.; Rey Martínez, F.J.; Álvarez-Guerra, M.; Gallego Peláez, C.; "Study on environmental quality of a surgical block". Revista: Energy and Buildings, 29, pp.: 179-187. 1999.

[6] Vaquero de la Hoz, M.T.. Tesis Doctoral: "Calidad del Aire Interior (IAQ) en las Edificaciones Hospitalarias". Valladolid, 2011.

[7] Fanger, P. O.; Lauridsen, J.; Bluyssen, P.; Clausen, G.; "Air Pollution Sources in Offices and Assembly Halls, Quantified by the olf Unit". Revista: Energy and Buildings, 12, pp.: 7 - 19. 1988.

[8] Fanger, P.O.; "Introduction of the olf and the decipol Units to Quantify Air Pollution Perceived by Humans Indoors and Outdoors". Revista: Energy and Buildings, 12, pp.:1 -6. 1988.

[9] deDear, R. J.; Brager, G. S.; "Developing an Adaptive Model of Thermal Comfort and Preference", RP-884. ASHRAE Transactions: Research. 1998.

[10] deDear, R. J.; Brager, G. S.; "Thermal comfort in naturally ventilated buildings: revisions to ASHRAE Standard 55". Revista: Energy and Buildings, vol 34, pp549-561. 2002.

[11] Gameiro da Silva, M.C.; "Requisitos de Ventilação em Edifícios Escolares", Informe Técnico elaborado por el departamento de Ingeniería Mecánica del Instituto ADAI para Parque Escolar EPE. Coimbra, 2009. 
[12] Gameiro da Silva, M.C.; Costa J.J.; Peixeiro Ramos E.; "On the definition of ventilation requirements in IAQ standards - A method based on emission rates of pollutants"; actas del congreso CLIMAMED Madrid 2011.

[13] Rey Martínez, F.J.; Velasco Gómez, E.; "Calidad de Ambientes Interiores". Ed. Thomson. Madrid, 2007.

\section{Normativa}

[N-1] CR 1752:1998. Ventilation for Buildings: Design Criteria for the Indoor Environment. CEN.

[N-2] PNE-CR 1752:1998 Norma Española: Ventilación de edificios: Criterios de diseño para el ambiente interior.

[N-3] EN 15251: 2008. Criteria for the indoor environment including thermal, indoor air quality, light and noise.

[N-4] DIRECTIVE 2002/91/EC OF THE EUROPEAN PARLIAMENT AND OF THE COUNCIL of 16 December 2002 on the Energy Performance of Buildings. Official Journal of the European Communities, 4.1.2003, pp L1/65 - L1/71.

[N-5] ISO 7730:2005 Moderate thermal environment- Determination of the PMV and PPD indices and specification of the conditions for thermal comfort. International Organization for Standardization.

[N-6] UNE-EN ISO 7730:2006 Ergonomía del ambiente térmico. Determinación analítica e interpretación del bienestar térmico mediante el cálculo de los índices PMV y PPD y los criterios de bienestar térmico local.

[N-7] ISO 7726:1998. International Standard: Ergonomics of the thermal environment Instruments for measuring physical quantities. International Organization for Standardization.

[N-8] UNE-EN ISO 7726:2002 Norma Española: Ergonomía de los ambientes térmicos. Instrumentos de medida de las magnitudes físicas

[N-9] ANSI/ASHRAE Standard 62.1-2010. "Ventilation for Acceptable Indoor Air Quality", American Society of Heating and Air-Conditioning Engineers Inc., Atlanta.

[N-10] ANSI/ASHRAE Standard 55-2004, Thermal environmental conditions for human occupancy, Atlanta: American Society of Heating, Refrigerating and Air-Conditioning Engineers, Inc. 
[N-11] ISO 16814:2008 Building environment design - Indoor air quality - Methods of expressing the quality of indoor air for human occupancy. Geneva. International Standardization Organization.

[N-12] EN 13779:2005. Ventilation for non-residential buildings. Performance requirements for ventilation and room conditioning systems.

[N-13] UNE-EN 13779:2005 Norma Española: Ventilación en edificios no residenciales. Requisitos de prestaciones de los sistemas de ventilación y acondicionamiento de recintos.

\section{Páginas Web}

[W-1] Gameiro da Silva, M.C.; "Spreadsheets for the calculation of thermal comfort indices PMV and PPD". https://woc.uc.pt/efs/getFile.do?tipo=2\&id=277 (Día de consulta: 1 agosto 2011). 


\section{RELACIÓN DE FIGURAS}

- Figura II.1.- Relevancia de la Calidad de Ambientes Interiores en la sostenibilidad de edificios.

- Figura II.2.- Balance térmico del cuerpo humano con el entorno.

- Figura II.3.- Porcentaje de Personas Insatisfechas (PPD) en función del Voto Medio Previsto (PMV).

- Figura II.4.- Relación entre el PPI y los distintos casos de asimetría radiante.

- Figura II.5.a- Rangos de aceptabilidad de la temperatura operativa en espacios ventilados mecánicamente, con escasas opciones de adaptación por los ocupantes.

- Figura II.5.b.- Rangos de aceptabilidad de la temperatura operativa en espacios con ventilación natural, sin equipos de climatización, y con amplias posibilidades de adaptación por los ocupantes.

- Figura II.6.a- Diagrama del modelo adaptativo propuesto en el estándar ASHRAE-55.

- Figura II.6.b- Diagrama del modelo adaptativo propuesto en el estándar EN 15251 [N-3].

- Figura II.7.- Porcentaje de personas insatisfechas PPD, cuando llegan a un espacio, en función del caudal de ventilación ( $\mathrm{m}^{3} / \mathrm{h} /$ persona).

- Figura II.8.- Porcentaje de personas insatisfechas PPD, cuando llegan a un espacio, en función del exceso de concentración respecto al exterior de $\mathrm{CO}_{2}$.

- Figura II.9.- Métodos de evaluación de la calidad del aire interior IAQ.

- Figura II.10.- Concentración de equilibrio del $\mathrm{CO}_{2}$ metabólico como función del flujo de aire de ventilación, para una persona en actividad sedentaria ( $M=1,2$ met).

- Figura II.11.a.- Esquema de una sonda de temperatura seca del aire.

- Figura II.11.b.- Imagen de una sonda de temperatura seca del aire.

- Figura II.12.a.- Esquema de una sonda de globo para medida de temperatura radiante media.

- Figura II.12.b.- Imagen de una sonda de globo para medida de temperatura radiante media.

- Figura II.13.a.- Esquema de una sonda de medida de Humedad Relativa.

- Figura II.13.b.- Sonda de Humedad Relativa.

- Figura II.14.a.- Esquema de una sonda de medida de la magnitud de la velocidad del aire.

- Figura II.14.b.- Sonda de medida de la magnitud de la velocidad del aire.

- Figura II.15.- Esquema de un sistema de medida de asimetría radiante.

- Figura II.16.a.- Esquema de un sistema de medida de la temperatura de superficie.

- Figura II.16.b.- Vista de un sistema de medida de la temperatura de superficie.

- Figura II.17.- Sonda de medición directa de la temperatura operativa.

- Figura II.18.- Analizador de partículas óptico.

- Figura II.19.- Equipo de medida de concentración de gases por espectroscopía fotoacústica.

- Figura II.20.- Composición y funcionamiento de los tubos de semiconductores de estado sólido adsorbentes para el muestreo. 


\section{RELACIÓN DE TABLAS}

- Tabla II.1.- Tasas metabólicas [N-6]

- Tabla II.2.- Rangos de aislamiento térmico y cambios de temperatura operativa óptima para algunas prendas $[\mathrm{N}-6]$

- Tabla II.3.- Valores de aislamiento térmico para asientos [N-6]

- Tabla II.4.- Principales magnitudes independientes que intervienen en el análisis del balance térmico entre el hombre y el ambiente térmico

- Tabla II.5.- Rangos límites de variación de los parámetros de consideración en el confort térmico.

- Tabla II.6.- Ejemplo de criterios de diseño recomendados para control de la humedad en espacios ocupados con sistemas de humidificación o deshumidificación.

- Tabla II.7.- Intensidad percibida, en olf, de las fuentes contaminantes en espacios no industriales.

- Tabla II.8.- Clasificación por categorías del ambiente térmico en función del PMV y PPD.

- Tabla II.9.- Categorías de los espacios en términos de IAQ [N-1] [N-2] [N-3]. 


\section{CAPÍTULO III Estado Actual de LAS TECNOLOgías DE ESTUDIO}

ABSTRACT 81

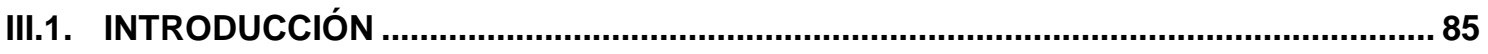

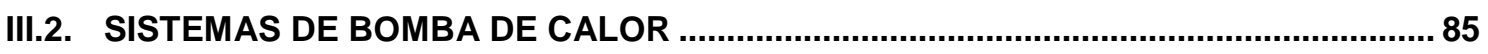

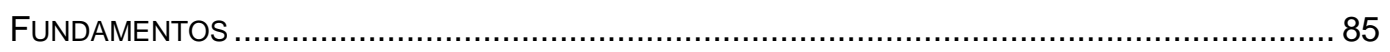

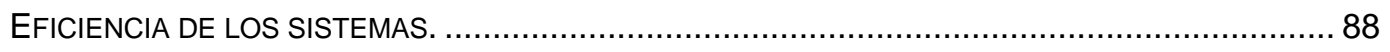

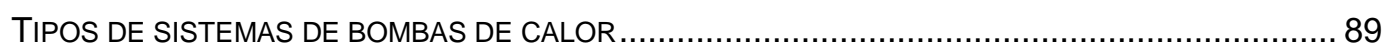

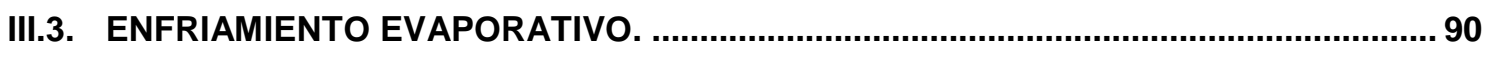

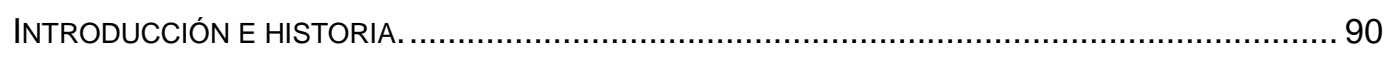

FUNDAMENTOS.

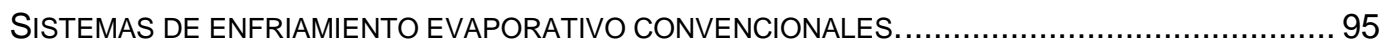

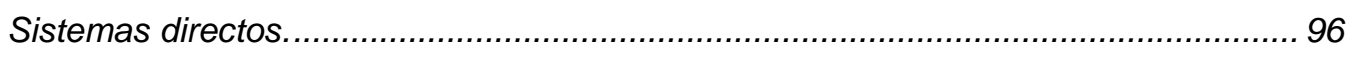

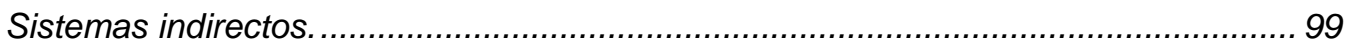

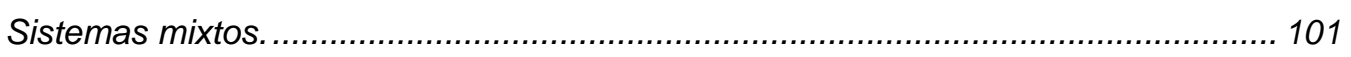

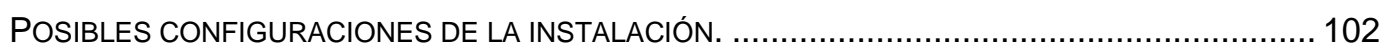

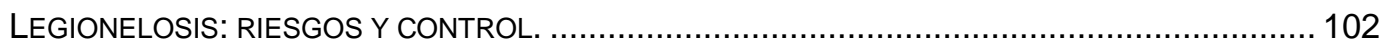

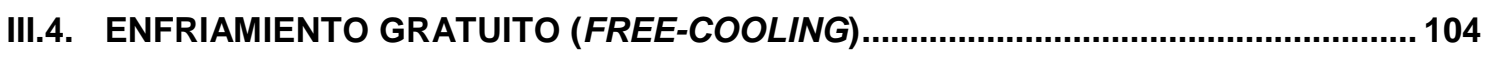

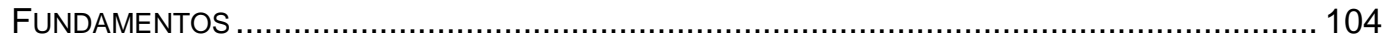

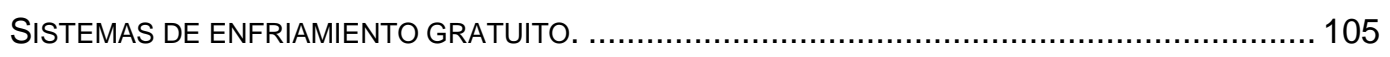

Sistemas de enfriamiento gratuito por aire exterior ................................................. 105

Sistemas de enfriamiento gratuito por agua ....................................................... 109

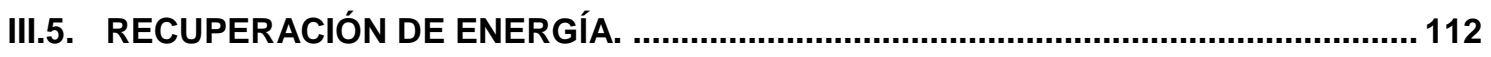

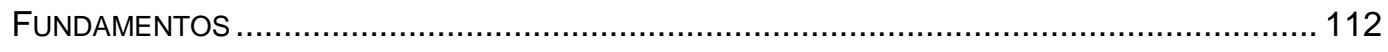

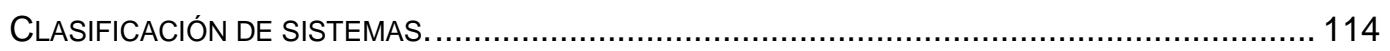

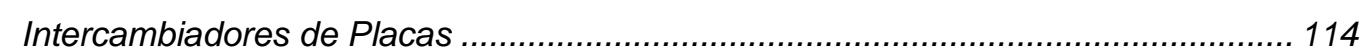


Recuperador Rotativo

Recuperador de dos baterías con bomba

Recuperadores evaporativos. 117

Recuperadores con tubos de calor. 118

Bomba de Calor como recuperador. 119 


\section{CHAPTER III: \\ STATE OF THE ART OF STUDiED TECHNOLOGIES}

\section{ABSTRACT}

Several alternatives for air-conditioning indoor spaces are tackled in the present Thesis. It appears thus necessary to briefly introduce the State of the Art of the related technologies, previously to thoroughly describe the characteristics and operation of the devices and solutions suggested.

In this third chapter, the last among the ones grouped as "introductory" to the body of the present project, this current knowledge on the technology is introduced in order to set the basis of the future design of the devices studied.

For being the most widely installed solution for air-conditioning, and consequently the one considered to be supporting the thermal loads on our cases of study, the operation principles of a Heat Pump are presented firstly.

Afterwards, it is described the three low-energy consumption alternatives considered in the project as ways to reduce the energy demand to air-condition the spaces, and consequent decrease on the energy consumption of the conventional Heat Pumps installed. These alternatives are: Evaporative Cooling, Free Cooling, and Heat Recovery. In these subsections, not only the specific technologies tackled in the following chapters are presented, but also every option based on these three principles, in order to justify the selections made. Thus, the different existing direct, indirect and mixed evaporative cooling systems are presented. On the other hand, the main two options of Free-Cooling by outdoor air and by water are described. Finally, the various alternatives of heat recovery in air-conditioning, composed by simple Plate Heat - Exchangers, Rotary recovery systems, Runaround Loop heat recovery systems, Heat Pipes and Heat Pumps operating in a heat recovery configuration are presented. 


\section{SiMBOLOGÍA DEL CAPÍTULO}

$\dot{Q}_{F}$ : Flujo de calor absorbido en el evaporador de la bomba de calor.

$\dot{Q}_{C}$ : Flujo de calor cedido por el condensador de la bomba de calor.

$\dot{W}$ : Trabajo aportado en el compresor de la bomba de calor.

$T_{F}$ : Temperatura del foco frío con el que trabaja la bomba de calor.

$T_{C}$ : Temperatura del foco caliente con el que trabaja la bomba de calor.

$S_{1}$ : Entropía del refrigerante a la entrada del compresor.

$S_{2}$ : Entropía del refrigerante a la salida del compresor.

$T_{o}:$ Temperatura del ambiente exterior.

$T^{*}$ : Temperatura de consigna considerada en el control del free-cooling.

$T_{r}:$ Temperatura del aire recirculado.

E : Energía recuperada.

$\rho:$ densidad del aire.

$C_{p}:$ Calor específico a presión constante del aire.

$\dot{V}$ : Caudal volumétrico del aire tratado.

$\Delta T$ : Salto de temperaturas entre las corrientes de expulsión y renovación.

t: tiempo de operación. 


\section{III.1. INTRODUCCIÓN}

En el capítulo I se ha visto que existen múltiples recursos para reducir el consumo energético destinado a la climatización de edificios, de entre los cuales se abordan en este trabajo de Tesis Doctoral varias alternativas orientadas al aprovechamiento de fuentes gratuitas para el acondicionamiento de aire en verano, como son el enfriamiento evaporativo y el enfriamiento gratuito (o free cooling); así como a la recuperación de la energía residual del aire de expulsión de los locales derivado de los requerimientos de ventilación. La adecuada aplicación de estas tres alternativas va a permitir, en su combinación u operación de forma individualizada según las condiciones particulares de trabajo en período estival, disminuir la demanda energética requerida por los sistemas convencionales para adecuar el ambiente interior a los parámetros de confort deseados, pudiéndose incluso llegar a anular en ciertos casos.

En el capítulo presente se va a proceder a introducir las tecnologías utilizadas en la adecuación de los locales; no sólo de los sistemas presentados como alternativas de bajo consumo (enfriadores evaporativos, sistemas free cooling y recuperadores de aire), sino también aquellos sistemas convencionales cuyo consumo energético se busca minimizar, y que estarán siempre presentes en la instalación como equipos auxiliares a fin de poder asegurar de forma general las condiciones de confort deseadas en el interior de los locales a acondicionar: los sistemas de bomba de calor.

\section{III.2. SistemAS DE BOMBA DE CALOR}

\section{Fundamentos}

Una bomba de calor es esencialmente una máquina termodinámica que trabaja siguiendo un ciclo frigorífico clásico (compresor, condensador, sistema de expansión y evaporador), dimensionada para aprovechar la energía calorífica cedida por el condensador (aire caliente o agua caliente que sale del condensador) y no la que se absorbe en el evaporador (fuente fría) del aire ambiente, del agua de un pozo o de un río, o del propio terreno. De esta forma, se produce un flujo de calor desde el ambiente exterior, más frío, al espacio calefactado del interior del local. Sin embargo, es posible la reversión del flujo de calor producido para su aplicación en verano, de tal forma que la unidad encargada de extraer calor (evaporador) sea la situada en el interior del espacio que se desea climatizar, realizándose la cesión de calor desde el condensador al ambiente exterior, más cálido. Hablamos en este caso de bomba de calor reversible. En la figura III.1 se observa el esquema del principio de funcionamiento de una bomba de calor, trabajando con una válvula de 4 vías para revertir el sentido del flujo de calor según el sistema funcione en período invernal o estival [1, Rey\&Velasco, 2005].

En estos intercambios intervienen los calores latentes de evaporación y de condensación del fluido refrigerante utilizado. En la evaporación, este fluido absorbe energía del ambiente en 
forma de calor, pasando del estado líquido al estado gaseoso a temperatura y presión constantes. Por su parte, en la condensación se libera la energía al medio que se pretende calentar, mediante el paso del refrigerante del estado vapor al estado líquido a temperatura constante. Por lo tanto, se requiere que el refrigerante sea un fluido de elevado calor latente cuyo punto de ebullición a presiones bajas se produzca a las bajas temperaturas a las que trabaje el evaporador. Para cerrar el ciclo será necesario por lo tanto licuar de nuevo el fluido de trabajo, para lo cual se eleva su presión una vez en estado gaseoso mediante un compresor. Tras la compresión se conduce al condensador, refrigerado por aire o por agua, y finalmente un sistema de expansión retornará el fluido al estado de baja presión en forma de vapor húmedo a la entrada del evaporador, cerrándose así el ciclo frigorífico. El calor total cedido por el condensador será igual al calor absorbido por el evaporador en el foco frío más el calor resultante de la transformación del trabajo mecánico realizado por el compresor que se transforma en calor.

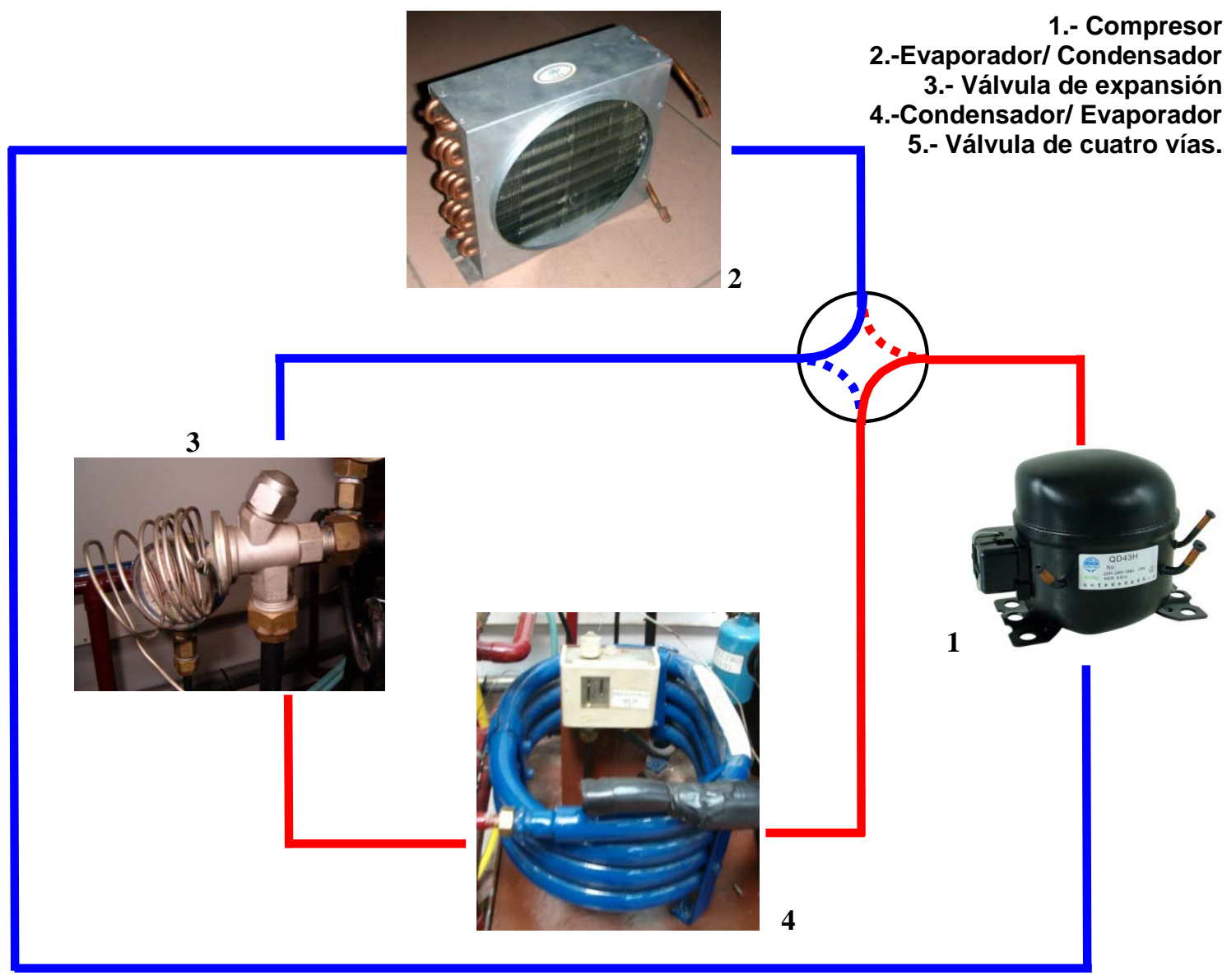

Figura III.1.- Esquema de funcionamiento de una bomba de calor reversible.

Se requieren por lo tanto para su funcionamiento cuatro elementos básicos: dos intercambiadores de calor que actúen como evaporador y condensador respectivamente, un sistema que permita llevar el vapor de refrigerante a los niveles de presión de condensación y que generalmente se tratará de un compresor mecánico (en el caso de las máquinas de 
absorción, se tratará de un compresor térmico), y un sistema de expansión que permita su retorno a los niveles de presión del evaporador. Sin embargo, para la aplicación práctica de este ciclo serán necesarios numerosos dispositivos auxiliares que permitan el funcionamiento real, como el arrastre de aceite desde el compresor que pueda ensuciar el sistema y reducir la eficacia del intercambio, para lo cual se dispone un separador de aceite a la salida del mismo; o eliminación de agua e impurezas que puedan existir en el refrigerante, mediante filtros y deshidratadores; elementos de amortiguación de las vibraciones y silenciador de ruidos asociados al funcionamiento del compresor; etc. Además de los accesorios anteriores, en bombas de calor reversibles es necesaria la función de una válvula de cuatro vías, que permita dirigir el flujo de refrigerante desde la descarga del compresor hacia la denominada batería exterior o hacia la batería interior para que actúen una u otra como unidad condensadora según se requiera, pudiendo impulsar calor en cualquier dirección (exterior en verano e interior en invierno).

Dado que se busca producir un flujo de calor desde un foco frío a otro foco a mayor temperatura, proceso que según el segundo principio de la termodinámica no podría producirse de forma natural, será necesario realizar un aporte de energía que se traduce a efectos prácticos en el trabajo aportado en la compresión del refrigerante en estado gaseoso. Normalmente se dispone de una fuente de corriente eléctrica, siendo el caso más habitual el de conexión a red. Sin embargo, los compresores y aparatos auxiliares también pueden funcionar mediante un motor a gas, gasolina o diesel, con la ventaja suplementaria, en este caso, de poder recuperar el calor perdido residual desprendido en las camisas de los cilindros, en el aceite de refrigeración y en los gases de escape como foco frío de operación de la máquina.

En el ciclo simple por compresión de vapor, o ciclo de refrigeración saturado simple, denominado ciclo inverso de Rankine, el fluido recorre el ciclo en sentido contrario a como lo haría en una máquina térmica funcionando como ciclo Rankine. La figura III.2 muestra el ciclo de refrigeración simple en el diagrama P-h (Presión - entalpía). El punto 3 representa la aspiración o salida del evaporador (estado de vapor saturado); el punto 4 la salida del compresor (estado de vapor recalentado); el punto 1 la salida del condensador (estado de líquido saturado) y finalmente el 2 la entrada del evaporador [1, Rey\&Velasco, 2005].

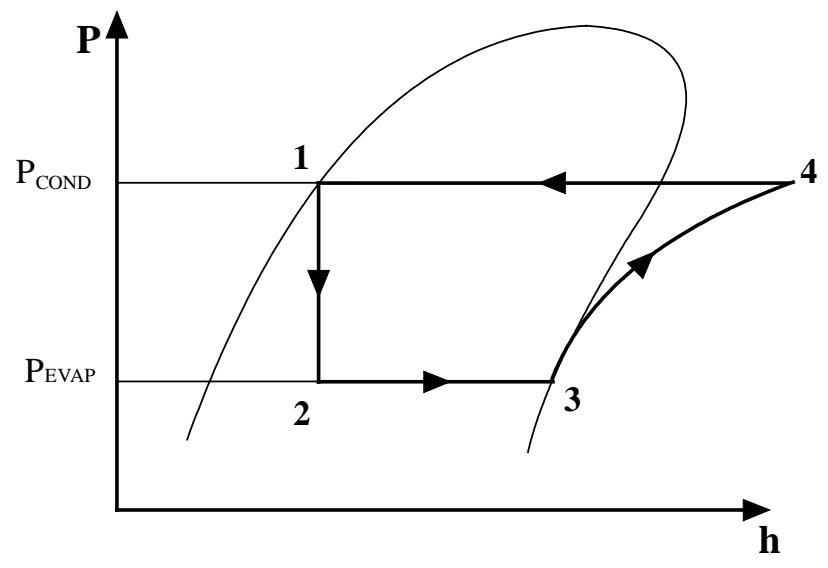

Figura III.2.- Diagrama P-h del ciclo de refrigeración simple de Rankine. 
En la realidad las máquinas de producción de frío o las bombas de calor (poseen esquemas de operación iguales), no funcionan como ciclo simple, pues el compresor no es isentrópico, siempre hay subenfriamiento a la salida del condensador y sobrecalentamiento del gas a la entrada del compresor, se producen pérdidas de carga al circular el refrigerante por el condensador y el evaporador, etc. El ciclo real es por lo tanto irreversible, y su diagrama P-h puede ser representado como el que se expone en la figura III.3.

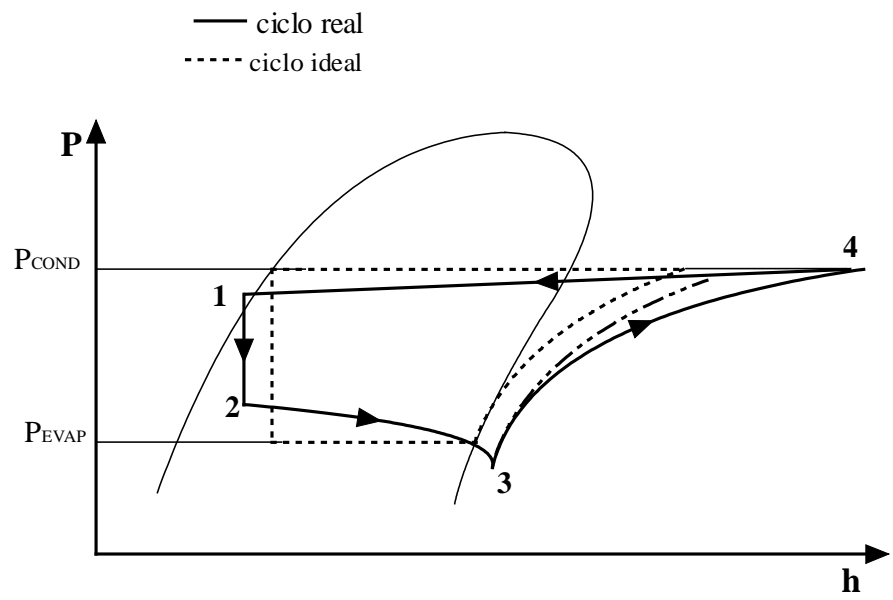

Figura III.3.- Diagrama P-h del ciclo de refrigeración real de Rankine.

\section{Eficiencia de los sistemas.}

A la eficiencia de las máquinas frigoríficas y de las bombas de calor lo denominaremos de forma abreviada COP o coeficiente de prestaciones (Coefficient Of Performance), factor con el cual deben compararse los consumos de energía para el funcionamiento de las diferentes alternativas de calefacción o refrigeración.

Para la aplicación en período estival de los sistemas de bomba de calor, estos trabajan como máquina frigorífica aprovechando el calor extraído en el evaporador para proporcionar un fluido frío (aire, agua o el propio refrigerante del circuito frigorífico) que sirva para refrigerar los locales. En este caso, es cuando la bomba de calor opera en "modo refrigeración", y el COP $\mathrm{REF}$ (o Energy Efficiency Ratio EER) se define como:

$$
C O P_{R E F}=\frac{\text { Efecto útil }}{\text { Trabajo aportado }}=\frac{\dot{Q_{F}}}{\dot{W}}=\frac{\dot{Q_{F}}}{\dot{Q_{C}}-\dot{Q_{F}}}=\frac{\dot{m_{F}} \cdot\left(h_{3}-h_{2}\right)}{\dot{m_{F}} \cdot\left(h_{4}-h_{3}\right)}
$$

Para el ciclo inverso de Carnot (ciclo teórico) el COP máximo (COP REF IDEAL $)$ viene dado por la siguiente expresión:

$$
C O P_{R E F ~ I D E A L}=\frac{\dot{Q_{F}}}{\dot{Q_{C}}-\dot{Q}_{F}}=\frac{T_{F} \cdot\left(s_{2}-s_{1}\right)}{\left(T_{C}-T_{F}\right) \cdot\left(s_{2}-s_{1}\right)}=\frac{T_{F}}{T_{C}-T_{F}}
$$

Donde $T_{C}$, es temperatura del foco caliente y $T_{F}$ la del foco frío. 
De este resultado se deduce que:

- El COP para el caso del ciclo inverso de Carnot, COP REF IDEAL, sólo depende de las temperaturas de los focos.

- Será tanto más elevado cuanto menor sea la diferencia entre las dos isotermas $T_{C}$ y $T_{F}$.

- El COP será mayor cuanta más alta es la temperatura del foco frío $T_{F}$.

Según el segundo Principio de la Termodinámica, ninguna máquina frigorífica puede tener un COP superior al establecido por el ciclo inverso de Carnot, $C O P_{R E F} \leq C O P_{R E F ~ I D E A L}$. Por tanto, la producción de frío será tanto más difícil de conseguir cuanto menor sea la temperatura a la que se debe producir. También es importante observar que la disipación de calor del condensador en una máquina frigorífica, será peor en un ambiente cálido que en uno frío. Por ello, para tener un $\mathrm{COP}_{\mathrm{REF}}$ alto en época estival, la temperatura ambiente, que en esta situación será la del foco caliente $\left(T_{C}\right)$ debe ser lo más baja posible; es decir, el COP será más alto para una temperatura ambiente de $20^{\circ} \mathrm{C}$ que para el caso de una temperatura ambiente de $40{ }^{\circ} \mathrm{C}$. Este último punto puede mejorarse recurriendo al aprovechamiento de fuentes de energía residuales que actúen como foco frío; por ejemplo, aprovechando un nivel térmico más adecuado de la corriente de aire de expulsión del local, mejorando así el rendimiento de la máquina. Se habla en este caso de bomba de calor trabajando en modo recuperación o recuperación activa, siendo un recurso especialmente interesante en términos de eficiencia energética.

La relación entre el COP de una máquina frigorífica determinada y el de una de Carnot que operase entre los mismos focos, se denomina grado de reversibilidad o coeficiente económico de la instalación. El grado de reversibilidad expresa, en tanto por uno, la aproximación del comportamiento de una máquina dada al modelo ideal, constituido por la máquina frigorífica totalmente reversible.

\section{Tipos de sistemas de bombas de calor}

Existen muchas posibilidades de clasificar las bombas de calor pero, dentro de las más interesantes en el campo de la edificación, la clasificación que hace referencia al medio de donde se capta y al que se cede la energía es la que nos permite obtener una tipología que obedece a su posible utilización constructiva propiamente dicha. Según este criterio, encontramos cinco tipos de sistemas [1, Rey\&Velasco, 2005]:

$$
\begin{aligned}
& \text { - Aire - Aire } \\
& \text { - Aire - Agua } \\
& \text { - Agua - Aire } \\
& \text { - Agua - Agua }
\end{aligned}
$$




$$
\begin{aligned}
& \text { - Tierra - Agua } \\
& \text { - Tierra - Aire } \\
& \text { - Tierra - Tierra }
\end{aligned}
$$

Seguramente, la tipología Aire - Aire es la más utilizada, ya que la fuente fría de donde se toma el calor es inagotable y su instalación es muy sencilla. En invierno se toma calor del aire exterior y es bombeado al interior del edificio a la temperatura deseada gracias al cambio de fase del refrigerante, según el funcionamiento ya descrito. En verano, toma calor del interior y lo transporta y expulsa al ambiente exterior. Por su parte, las tres últimas están asociadas a instalaciones geotérmicas.

Para minimizar los consumos energéticos del sistema convencional de bomba de calor, deben considerarse, junto a los objetivos de mejora de eficiencia de la propia operación del sistema, el abanico de opciones asociadas a la disminución de la demanda y el aprovechamiento de fuentes gratuitas. Este análisis se abordará para las opciones presentadas para instalaciones de climatización por aire.

\section{III.3. ENFRIAMIENTO EVAPORATIVO.}

\section{Introducción e historia.}

En el contexto energético actual ya planteado, en el que el aumento del consumo de energía hace cada vez más urgente la integración de aspectos medioambientales y el desarrollo sostenible en la política energética, se presenta como una alternativa de especial interés el uso racional de los sistemas evaporativos, por su repercusión a nivel social y medioambiental positiva. Asimismo, son una tecnología segura considerando oportunamente el adecuado mantenimiento tanto mecánico como sanitario (prevención de la legionelosis, tan dañina para la expansión de estos sistemas).

El efecto conocido como enfriamiento evaporativo es el fenómeno natural originado cuando agua y aire entran en contacto, en el que se produce un descenso en la temperatura del aire al producirse en su seno la evaporación del agua. Se trata por lo tanto de un proceso de transferencia de calor y masa, en el cual tiene lugar una conversión de calor sensible a calor latente. El carácter natural del fenómeno y el elevado calor latente de vaporización del agua involucrado hacen de este tipo de procesos una base de trabajo interesante dentro del panorama de potenciación de la eficiencia energética en el acondicionamiento de aire.

Sin embargo, precisamente por tratarse de un fenómeno natural, su aplicación no es una novedad de nuestra época actual. Obviando el aprovechamiento que la misma naturaleza hace de este fenómeno, como es el caso de la regulación metabólica de la temperatura del cuerpo gracias a la evaporación del sudor desde la piel, o el hecho de que muchos animales embadurnen de barro su cuerpo para refrescarse, existen muchos otros ejemplos de su 
utilización práctica por el ser humano, cuyos primeros vestigios se remontan a las civilizaciones de la Antigüedad.

De hecho, los primeros indicios identificativos de la aplicación de este fenómeno proceden de frescos del Antiguo Egipto, datados entorno al 2500 A.C., los cuales prueban que ya entonces se enfriaba agua abanicando vasijas cuya porosidad mantenía húmeda la superficie (figura III.4). Parece previsible que sea precisamente una civilización asentada en un clima árido y caliente la primera en hacer uso del enfriamiento evaporativo, ya que en estas condiciones puede aprovecharse de forma óptima el efecto descrito [2, Bowen, 1981]. Otro indicio de su aplicación es un fresco datado del 70 D.C. en una pared de Herculano, Italia, en el que se muestra esta misma aplicación con vasijas de piel. También las tiendas de campaña de los antiguos persas o algunos indios americanos se mantenían húmedas para favorecer su refrigeración. Asimismo, existen aplicaciones más actuales del enfriamiento evaporativo similares a las históricas ya mentadas, como es el caso de las vasijas cubiertas de lona húmeda de los soldados, y los recipientes tradicionalmente conocidos como "botijos", que permiten disponer de agua para consumo a una temperatura inferior a la del ambiente.

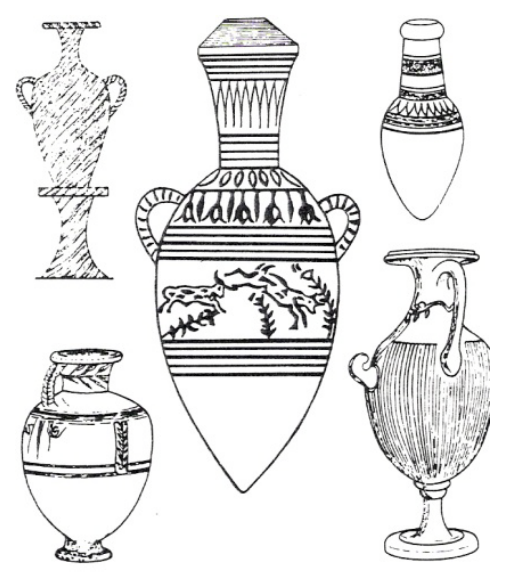

Figura II.4.- Vasijas cerámicas utilizadas para refrescamiento de ambientes.

En la Edad Media el Islam difunde estas técnicas por Occidente, adoptándose sistemas de refrigeración evaporativa, principalmente en las zonas mediterráneas. Aunque probablemente fue Leonardo da Vinci el primero en construir un enfriador mecánico de aire, constituido por una rueda hueca donde el aire era enfriado y purificado al ser impulsado axialmente a través de diferentes cámaras por las que se hace caer el agua [3, Shakerin, 2000].

En la industria, el principio de enfriamiento evaporativo se ha venido aplicando desde hace más de 100 años. El primer análisis riguroso de los sistemas evaporativos directos e indirectos, presentando sus ventajas y desventajas, indicando aplicaciones y estableciendo unas consideraciones sobre su diseño, lo realizó el Dr. John R. Watt en 1963 en su texto "Evaporative Air Conditioning Handbook" [4, Watt, 1986]. Watt construyó y evaluó cuatro prototipos de enfriadores evaporativos de placas (uno de ellos de dos etapas) así como uno de 
torre de enfriamiento y serpentín, determinando tanto su eficacia como la capacidad de enfriamiento del dispositivo.

Ya contemporáneamente, los trabajos del Dr. Donald Pescod recogen diferentes estudios acerca de enfriadores evaporativos indirectos de placas, siendo los pioneros en la utilización de placas de materiales plásticos y en crear turbulencias artificiales para minimizar el estancamiento de la película de aire [5, Pescod, 1974]. No obstante, la teoría de la Refrigeración Evaporativa debe mucho al Dr. Willis $\mathrm{H}$. Carrier, que estableció la teoría de la saturación adiabática y desarrolló su diagrama psicrométrico, de gran utilidad para la compresión de la técnica.

En la década de los años 80, el interés por estos sistemas se incrementa notablemente como lo demuestra el número de artículos y comunicaciones aparecidos en publicaciones científicas, [6, Maclain-Cross\&Banks, 1983], [7, Shoda et al., 1990]; desarrollándose diferentes aplicaciones de esta técnica, como el aprovechamiento del potencial existente en el aire procedente de la corriente de retorno de los locales, para el desarrollo de sistemas de recuperación de energía mediante esta tecnología. Sin embargo, actualmente la injustificada vinculación de diferentes brotes de legionella a los equipos evaporativos [8, Puckorious et al., 1995], así como la existencia de una legislación restrictiva en este campo, están propiciando el desuso de los mismos a favor de sistemas de producción de frío con condensación por aire que, sin embargo, son mucho menos eficientes. Por lo tanto, se debe hacer una reconsideración de los sistemas evaporativos, dada su importancia en relación con el ahorro y uso eficiente de la energía.

\section{Fundamentos.}

El enfriamiento evaporativo es un proceso de transferencia de calor y masa basado en la conversión del calor sensible en latente. Cuando esta transformación sigue un proceso adiabático, la temperatura seca del aire no saturado disminuye a medida que aumenta su humedad, al proporcionar el aire el calor sensible que se convertirá en latente para que se produzca la evaporación del agua. Este intercambio de calor sensible y latente tiene lugar hasta que el aire se satura y la temperatura del aire y el agua se igualan alcanzando un valor denominado "temperatura de saturación adiabática", siendo por lo tanto el proceso conocido como "saturación adiabática" [9, Pinazo, 2000], [10, Pizzetti, 1991].

La temperatura de bulbo húmedo en los intervalos habitualmente utilizados en los sistemas de climatización es muy próxima a la temperatura de saturación adiabática; si bien ambas temperaturas son conceptos distintos, la ventaja de la primera frente a la segunda reside en la facilidad de ser medida, por lo que a menudo se trabajará con ésta indistintamente.

El funcionamiento de la mayoría de los enfriadores evaporativos se basa en procesos de saturación adiabática, ya que este tipo de procesos se producen cuando el valor de la temperatura del agua se aproxima a la de bulbo húmedo del aire a la entrada del sistema, y al 
recircularse continuamente el agua en el sistema se favorece el cumplimiento de esta condición. En teoría, esta temperatura del agua recirculada permanece constante, según lo cual toda la evaporación serviría para enfriar el aire, no el agua. En la práctica, sin embargo, el agua usualmente gana algunas cargas sensibles externas en el depósito y tuberías por el trabajo de bombeo, siendo por lo tanto su temperatura mayor que la de saturación adiabática del aire de entrada. Además, el agua de reposición adicionada para cubrir la parte evaporada se encuentra a la temperatura de red, que generalmente es inferior a la temperatura de bulbo húmedo. Por tanto, la "saturación adiabática" en el proceso de enfriamiento evaporativo es únicamente un límite teórico que establece hasta dónde se podría enfriar idealmente el agua o el aire que intervienen en el proceso. Cuando el agua está considerablemente más caliente que la temperatura de saturación adiabática del aire, el proceso se asemeja al de una torre de enfriamiento.

Existen limitaciones al enfriamiento alcanzado por saturación adiabática. De hecho, la cantidad de calor sensible eliminado no puede ser superior al calor latente necesario para saturar el aire. Es por ello que las posibilidades de enfriamiento varían inversamente con el contenido en humedad del aire. Si el aire está muy saturado de humedad, sólo podrá ser enfriado de manera sensible por el intercambio de calor consecuencia de la diferencia de temperaturas aire/agua, no por el calor latente necesario para la evaporación del agua en aire. Estos son por lo tanto algunos de los puntos que deben tenerse en cuenta a la hora de estudiar la operabilidad, en función de las condiciones climáticas y de confort requeridas, estudiadas estas últimas en el capítulo II, de los sistemas de enfriamiento evaporativos abordados en el presente estudio para optimizar la eficiencia energética de las instalaciones de acondicionamiento de aire.

Para una correcta comprensión de las posibilidades del enfriamiento evaporativo, va a ser necesario analizar los procesos ideales y reales de la refrigeración evaporativa, los cuales se abordan para mayor claridad sobre el diagrama psicrométrico.

Como se ha indicado, el proceso ideal es adiabático, siguiendo la correspondiente línea de entalpía constante, pudiéndose lograr el máximo enfriamiento posible por este método si se alcanza el punto de saturación.

En el proceso de humidificación del aire por contacto con el agua recirculada a la temperatura de saturación adiabática, la temperatura de bulbo seco del aire disminuye a medida que este cede calor sensible para permitir la evaporación del agua, compensándose al transformarse en calor latente por la absorción de vapor, aumentando así simultáneamente su humedad específica.

Sin embargo, como ya se ha indicado, debido a causas como la ganancia de cargas externas por parte del agua, o la menor temperatura del agua de red de reposición, la mayoría de los enfriadores evaporativos siguen procesos desviados del adiabático. Por lo tanto habrá que tener en cuenta la posibilidad de encontrarse trabajando en alguno de los casos de 
evolución representados en la figura III.5 y descritos a continuación, en todos los cuales se considera que la temperatura del agua aportada permanece constante:

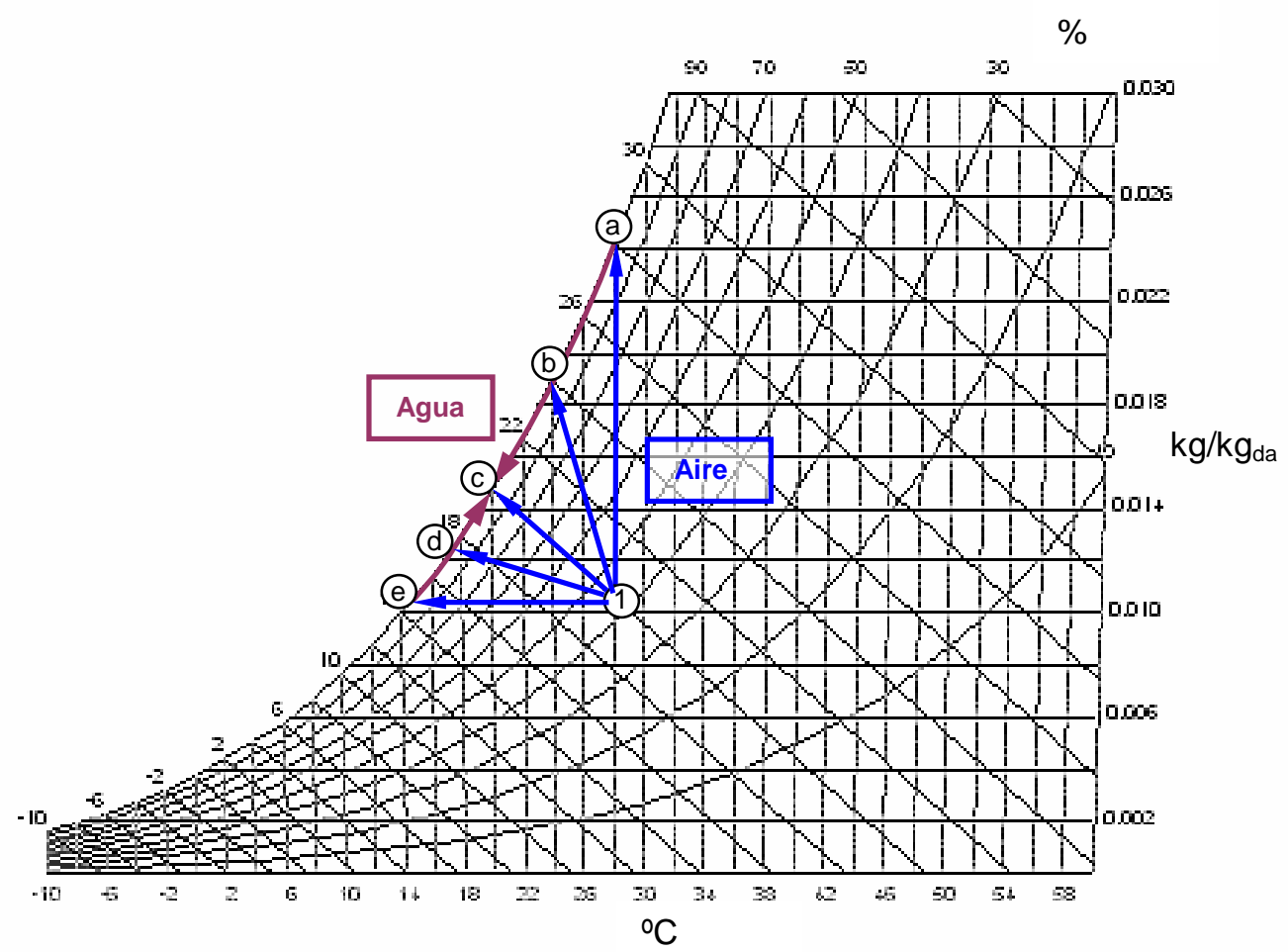

Figura III.5.- Posibles evoluciones psicrométricas del aire en contacto con agua.

a- Si la temperatura del agua es superior a la de bulbo seco del aire.

El aire se calienta y humidifica ganando entalpía, aumentando tanto la temperatura de bulbo húmedo como la de bulbo seco del aire. Esta ganancia de entalpía se compensa energéticamente con la pérdida de la misma por parte del agua, que se enfría al entrar en contacto con aire a menor temperatura.

b- La temperatura del agua está entre las de bulbo seco y saturación adiabática del aire.

El aire se enfría y humidifica ganando entalpía. Esto puede deberse a la ligera ganancia de cargas externas por parte del agua a su paso por bombas, depósitos o tuberías durante su recirculación. En este caso, la temperatura de bulbo húmedo del aire a la salida del sistema habrá aumentado ligeramente, pero la temperatura de bulbo seco será menor.

c- La temperatura del agua está a la temperatura de saturación adiabática.

El aire se enfría y humidifica manteniendo su entalpía constante, de forma que el fenómeno actúa plenamente enfriando el aire, no el agua. Este caso se corresponde con el ideal, y por lo 
tanto alcanzando la saturación se lograría el máximo enfriamiento posible del aire haciendo uso del fenómeno de enfriamiento evaporativo.

d- La temperatura del aqua está entre la temperatura de saturación adiabática y la temperatura de rocío del aire.

Esto puede producirse cuando se usa agua fría para la reposición de la cantidad evaporada. En este caso, el aire se enfría y humidifica perdiendo entalpía. Por lo tanto, no sólo disminuye la temperatura de bulbo seco del aire, sino también la de bulbo húmedo, con respecto a las correspondientes al aire a la entrada.

e- La temperatura del agua está por debajo de la temperatura de rocío del aire.

El aire se enfría y deshumidifica perdiendo entalpía, ya que se produce condensación de parte del vapor de agua contenido en la corriente de aire original.

\section{Sistemas de enfriamiento evaporativo convencionales.}

Dadas las características ya descritas del fenómeno, el enfriamiento evaporativo se puede aplicar en la mejora de muchos procesos industriales, ya que resulta más fácil enfriar con agua o aire frío que con aire caliente. En particular, en las instalaciones de climatización y acondicionamiento de aire se suele utilizar para reducir o eliminar la demanda energética de adecuación térmica en edificios. Asimismo, es adecuado en aplicaciones en las que se requieren tanto enfriamiento como humidificación en verano.

Los equipos cuyo funcionamiento se basa en el fenómeno del enfriamiento evaporativo, dentro del mercado actual de las instalaciones de climatización y acondicionamiento de aire, pueden englobarse en dos grandes grupos:

- Sistemas utilizados en procesos destinados al acondicionamiento del aire de locales, cuyo principal objetivo será reducir o eliminar la demanda energética de adecuación térmica de los edificios. Dentro de este grupo se encuentran los refrigeradores y los recuperadores evaporativos.

- Sistemas de refrigeración de equipos, como torres de refrigeración y condensadores evaporativos. Estos dispositivos permiten optimizar el consumo energético de las instalaciones condensadas por agua, y que por diferentes problemas como la Legionella, en algunos casos están siendo remplazadas por unidades enfriadas por aire [11, Adnot et al., 2003].

Sin embargo, el problema de la legionelosis no debe ser impedimento para el uso de los sistemas evaporativos, si se aseguran los procesos adecuados de limpieza y desinfección pertinentes; permitiéndose de esa forma rentabilizar cada vez más el uso de estos sistemas.

Dentro del primer grupo de sistemas, existen diversos equipos diferenciados por la corriente de aire en la que realizan el enfriamiento evaporativo. Podremos clasificarlos por lo tanto en sistemas directos, indirectos, o como una combinación multietapa de ambos, conocida 
como sistemas mixtos, según se describe a continuación [12, ASHRAE, 2000], [13, Rey et al., 2000], [14, Velasco et al., 2005].

\section{Sistemas directos.}

En este tipo de sistemas el agua se evapora directamente en el aire de impulsión al local, logrando el enfriamiento de éste con el consiguiente aumento de su contenido de humedad, siguiendo un proceso idealmente adiabático, según se ha descrito en los fundamentos del fenómeno. El aire cede calor sensible al agua, disminuyendo su temperatura de bulbo seco, a la vez que se incrementa la humedad presente en él, de forma que la cantidad de calor sensible cedida por el aire iguala a la cantidad de calor latente absorbida por la evaporación del agua. (figura III.6).

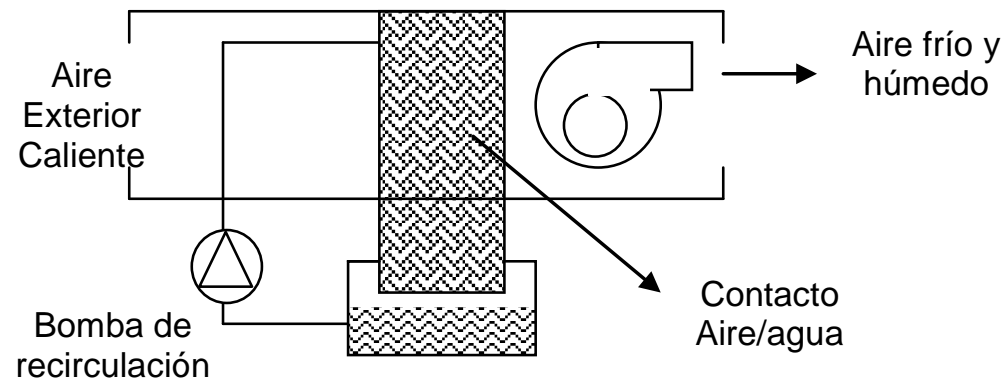

Figura III.6.- Esquema de un enfriador evaporativo directo

Dado que el flujo de masa de vapor de agua en el aire involucrado en la refrigeración evaporativa es proporcional a la superficie de contacto entre ambos medios, el principal problema de diseño de los sistemas evaporativos directos, independientemente de si trabajan desde una superficie húmeda o desde un sistema de atomización, se focaliza en maximizar la superficie de intercambio másico superficie húmeda / aire.

Como unidades independientes para suministrar aire frío a locales climatizados, los refrigeradores evaporativos directos están compuestos por al menos un elemento de humectación, un ventilador (generalmente centrífugo para suministrar la presión necesaria y un bajo nivel de ruido), un depósito inferior y una carcasa exterior. En los sistemas con atomización es necesario también disponer de una bomba de circulación que proporcione suficiente presión para la pulverización, así como sus correspondientes tuberías y boquillas de pulverización o toberas.

El principal problema de estos sistemas reside en que existe riesgo de contaminación por legionelosis en la corriente primaria, en la que se produce el enfriamiento evaporativo, que es además la corriente de aire de impulsión al local. Para minimizar el riesgo de generación de aerosoles que puedan transportar la bacteria, será imprescindible siempre disponer de un separador de gotas eficaz en los sistemas de pulverización. No obstante hay que poner especial cuidado en asegurar el correcto mantenimiento de todos los sistemas que utilicen 
refrigeración evaporativa, se basen en pulverización o no, para evitar contaminaciones bacteriológicas. Algunas de estas consideraciones son el siempre recomendable vaciado del depósito de agua durante los períodos de no operación, evitar la exposición a la radiación solar del agua estancada, así como llevar el relleno hasta sequedad en la parada del sistema al final del día, y realizar el debido tratamiento bacteriológico en el agua de aporte, por ejemplo mediante radiación ultravioleta.

De acuerdo con las características del medio de humectación, los enfriadores evaporativos directos pueden clasificarse en:

- De paneles evaporativos: Están compuestos por paneles, generalmente de fibras tratadas químicamente para prevenir el crecimiento de microorganismos, que son montados en marcos de metal o plástico removibles. (Figura III.7).

- De medio rígido: Estos están conformados por placas rígidas y corrugadas hechas de plástico, celulosa impregnada, fibra de vidrio, etc. El equipo sería similar al presentado anteriormente de paneles evaporativos, sustituyendo el relleno de fibra por los paneles rígidos y prescindiendo de marcos de soporte, además de presentar frente a los anteriores unas menores resistencias hidráulicas y una limpieza más sencilla. Las corrientes de aire y agua se disponen usualmente en flujo cruzado de modo que los canales horizontales correspondan al aire y los verticales al agua (figuras III.8.a y III.8.b). Sin embargo, son también recurribles otros materiales para conformar el relleno de sistemas que operen de esta forma, como es el caso del prototipo desarrollado por la Universidad Nacional de Asunción de la República de Paraguay mostrado en la figura III.9, construido a base de esponja vegetal [15, Silva\&Albertini,2010].

- Rotativos: Estos sistemas disponen de un medio de humectación en forma de rueda rotativa, de material resistente a la corrosión, accionada por un motor eléctrico acompañado del correspondiente reductor para permitir obtener velocidades muy bajas, del orden de 1 ó 2 r.p.m. La parte inferior de la rueda se sumerge en un depósito con agua y por ello no requieren dispositivos de distribución (figura III.9.).

- Pulverización directa: En estos dispositivos la humectación se consigue pulverizando agua en la corriente de aire primario. Aunque la eficacia de los dispositivos de pulverización es muy elevada, existen problemas asociados a su funcionamiento que pueden derivar en riesgos de contaminación bacteriológica como la legionelosis. Algunos de estos problemas son la formación de gotas por coalescencia de dos aerosoles o por mala operación de las boquillas, la necesidad de drenaje de todo el sistema con boquillas de autovaciado, necesidad de renovación de aire para favorecer la evaporación del agua pulverizada, además de la necesidad de un adecuado mantenimiento, al igual que para el resto de los sistemas. Es por ello que el uso de estos sistemas se reduce prácticamente a aplicaciones en espacios abiertos. 


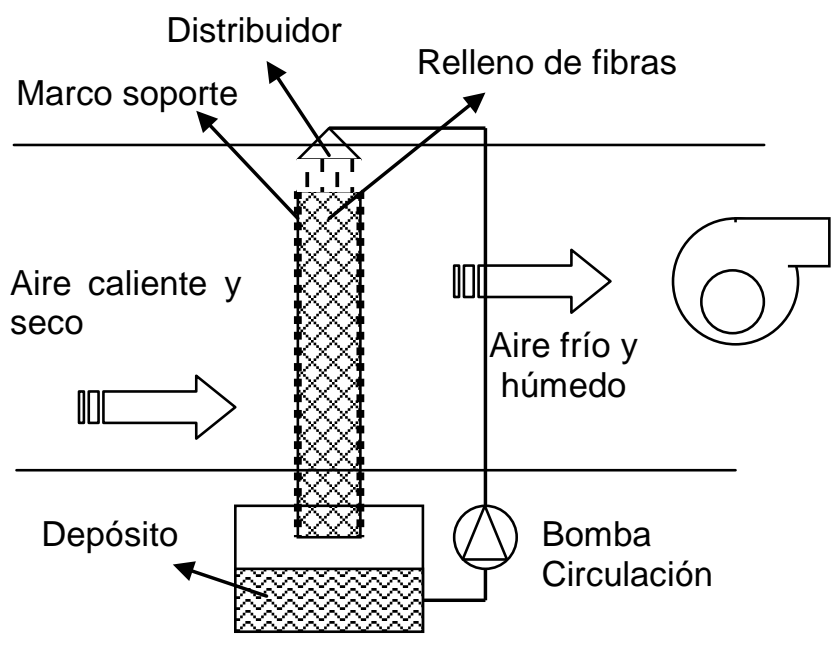

Figura III.7.- Esquema de un refrigerador directo de paneles evaporativos.

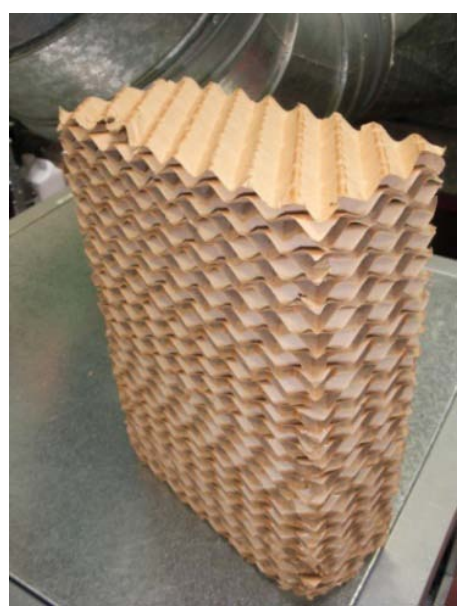

Figura III.8.a.- Vista de un relleno rígido.

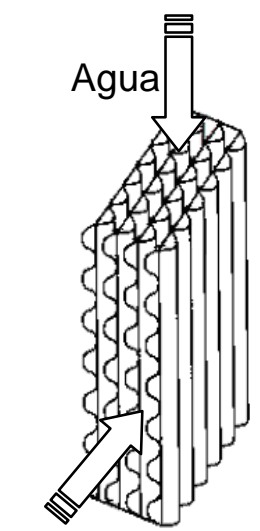

Aire
Figura III.8.b.- Esquema de la operación de un panel rígido.

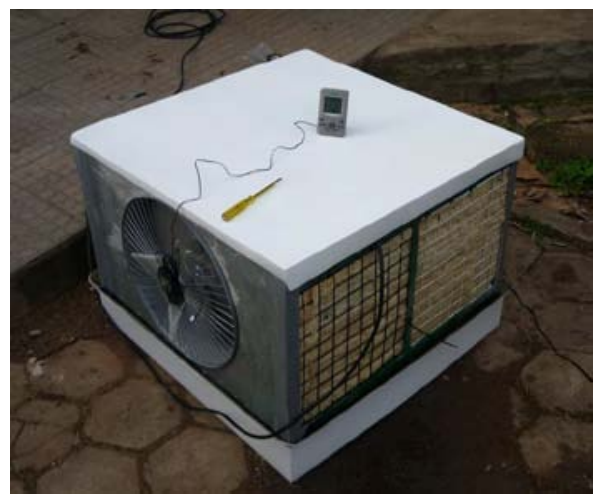

Figura III.9.- Enfriador evaporativo de medio rígido fabricado en esponja vegetal. 


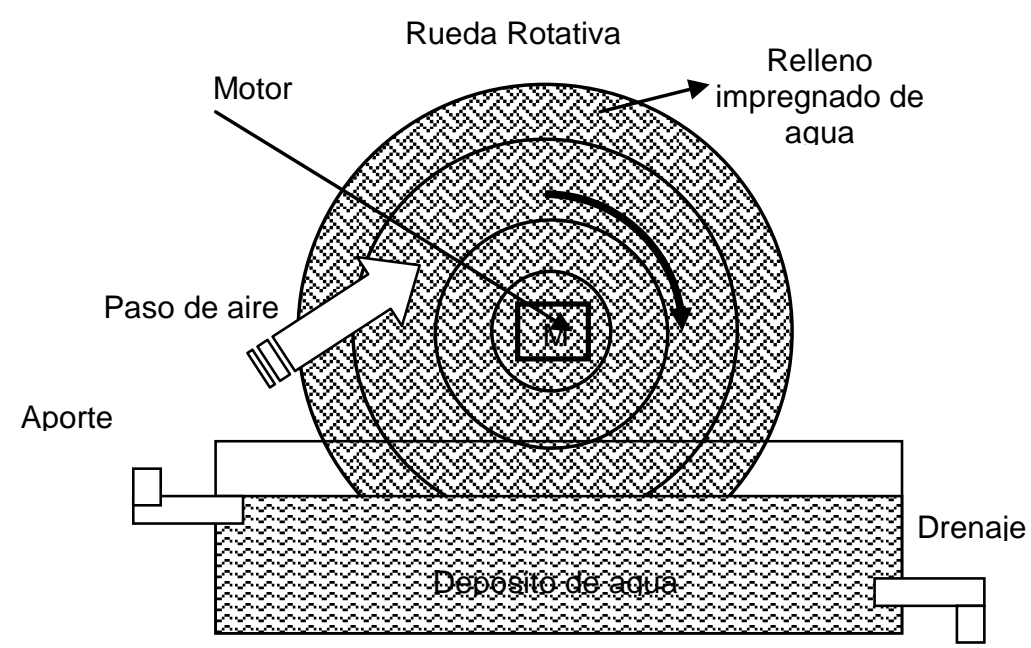

Figura III.10.- Esquema de un refrigerador directo rotativo

\section{Sistemas indirectos.}

En el caso del enfriamiento evaporativo indirecto la evaporación del agua se efectúa en una corriente secundaria de aire, que intercambia sensiblemente calor con la corriente de aire primario (impulsión) a través de un intercambiador. De este modo la superficie de transferencia de calor es enfriada por contacto con este aire secundario, mientras simultáneamente al otro lado del intercambiador la corriente de aire primario experimenta un proceso de enfriamiento sensible (su contenido en humedad no se ve modificado). Por ello el proceso es llamado indirecto, y se utiliza especialmente en aquellas aplicaciones donde no se permite la adición de humedad en el aire de renovación. Además salva los riesgos de contaminación del aire de impulsión, puesto que no hay intercambio directo entre las corrientes de aire. No obstante, en todo caso el circuito secundario de aire necesita tratamientos adecuados para evitar la proliferación de la legionela (figura III.11.).

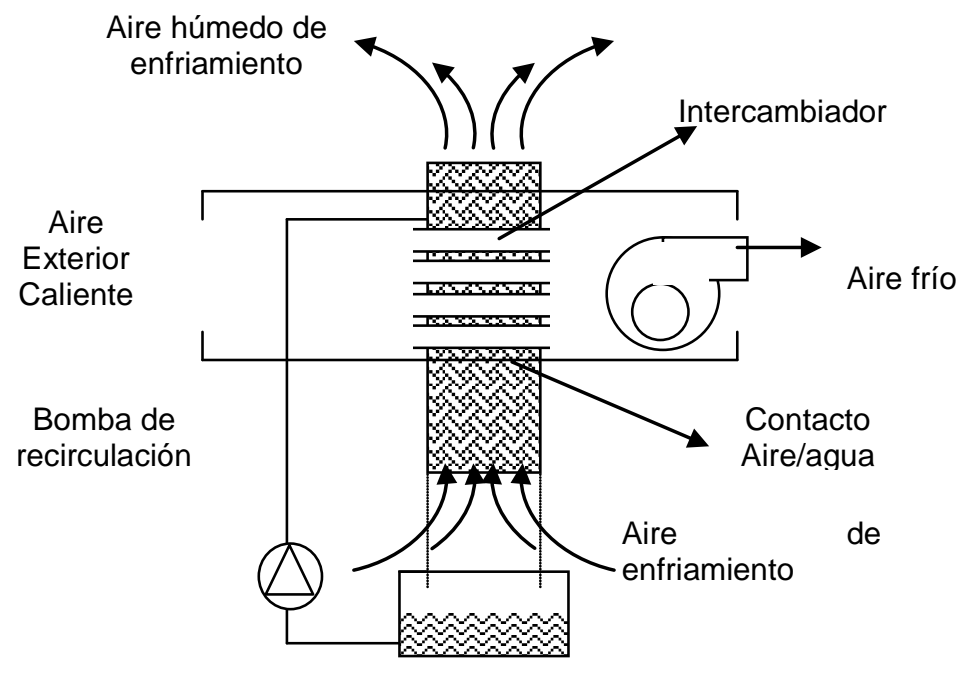

Figura III.11.- Esquema de un refrigerador evaporativo indirecto 
Al igual que en el caso del enfriador evaporativo directo, en el sistema indirecto el parámetro fundamental de diseño es la superficie de transferencia de calor que separa las corrientes de aire y agua a evaporar; las cuales pueden ser de metal o plástico y deben conducir fácilmente el calor, mantener las dos corrientes separadas y resistir la corrosión.

Dentro de este grupo podemos hacer referencia a los modelos con intercambiadores tubulares o de placas.

- Sistema indirecto con intercambiador tubular: Los modelos actuales están constituidos por un enfriador de ventana, que permite tomar aire exterior y dirigirlo a través de un banco de tubos horizontales finos y lisos de plástico mediante un ventilador, mientras unos sistemas de pulverización humedecen el lado exterior de los tubos, por donde también circula el aire de expulsión. En la figura III.12 se muestra un esquema de operación de este tipo de dispositivos.

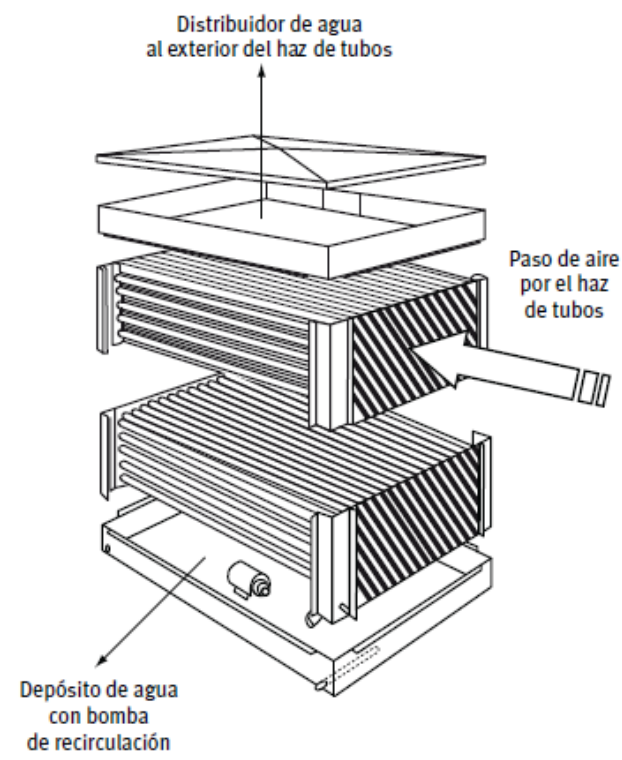

Figura III.12.- Sistema evaporativo indirecto con intercambiador tubular

- Sistema indirecto con intercambiador de placas: Es el sistema de refrigeración evaporativa indirecta más utilizado. El principio de funcionamiento de este sistema se basa en dos etapas: un enfriamiento inicial del aire de retorno de locales en dos lavadores de aire de tipo spray (enfriamiento evaporativo directo), tras lo cual el aire frío se utiliza para enfriar aire exterior mediante intercambiadores de placas, que luego será utilizado para impulsar a los locales, mientras que el aire húmedo se elimina al exterior. Una de las ventajas de este sistema es que, como el agua no entra en contacto con la superficie de intercambio, no aparecen incrustaciones. Sin embargo, como inconveniente cabe destacar lo voluminoso de estos equipos y la necesidad de grandes superficies de transferencia para el intercambio térmico aire-aire, por lo que su desarrollo se orienta hacia sistemas más compactos y económicos (figura III.13). 


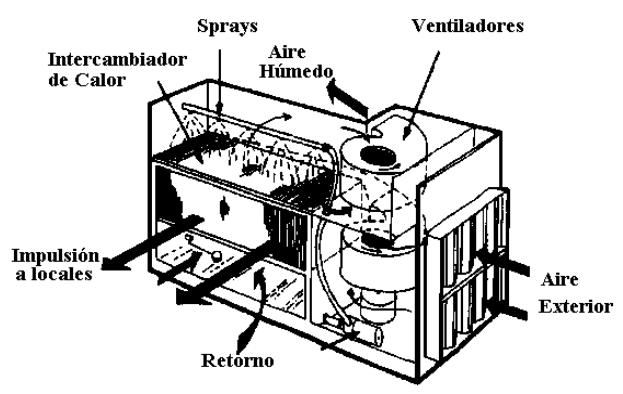

Figura III.13.- Refrigerador evaporativo indirecto de placas desarrollado por Pescod.

En este equipo, el aire exterior entra por un lateral atravesando una serie de filtros y se impulsa con el ventilador hacia los pasos del intercambiador de placas dispuestos en dirección horizontal, donde se enfría. El aire de retorno, aspirado por el ventilador superior, atraviesa los pasos verticales, correspondientes a la zona húmeda del intercambiador en la que se está pulverizando el agua, y a su salida se expulsa al exterior. El agua pulverizada no vaporizada se recircula con la bomba desde el depósito inferior hasta las boquillas de pulverización dispuestas en la zona superior.

\section{Sistemas mixtos.}

Los sistemas mixtos pretenden combinar los dos casos básicos anteriores (directo e indirecto) mediante una serie de módulos secuenciales, permitiendo compatibilizar las ventajas e inconvenientes de ambos sistemas y así mejorar el rendimiento y ampliar las posibilidades de aplicación en climas húmedos. La figura III.14 muestra un esquema del equipo y la evolución seguida en el diagrama psicrométrico. Como puede verse en la evolución seguida por el aire expulsado, en azul, la energía que gana este es la involucrada en el enfriamiento evaporativo en el proceso indirecto.

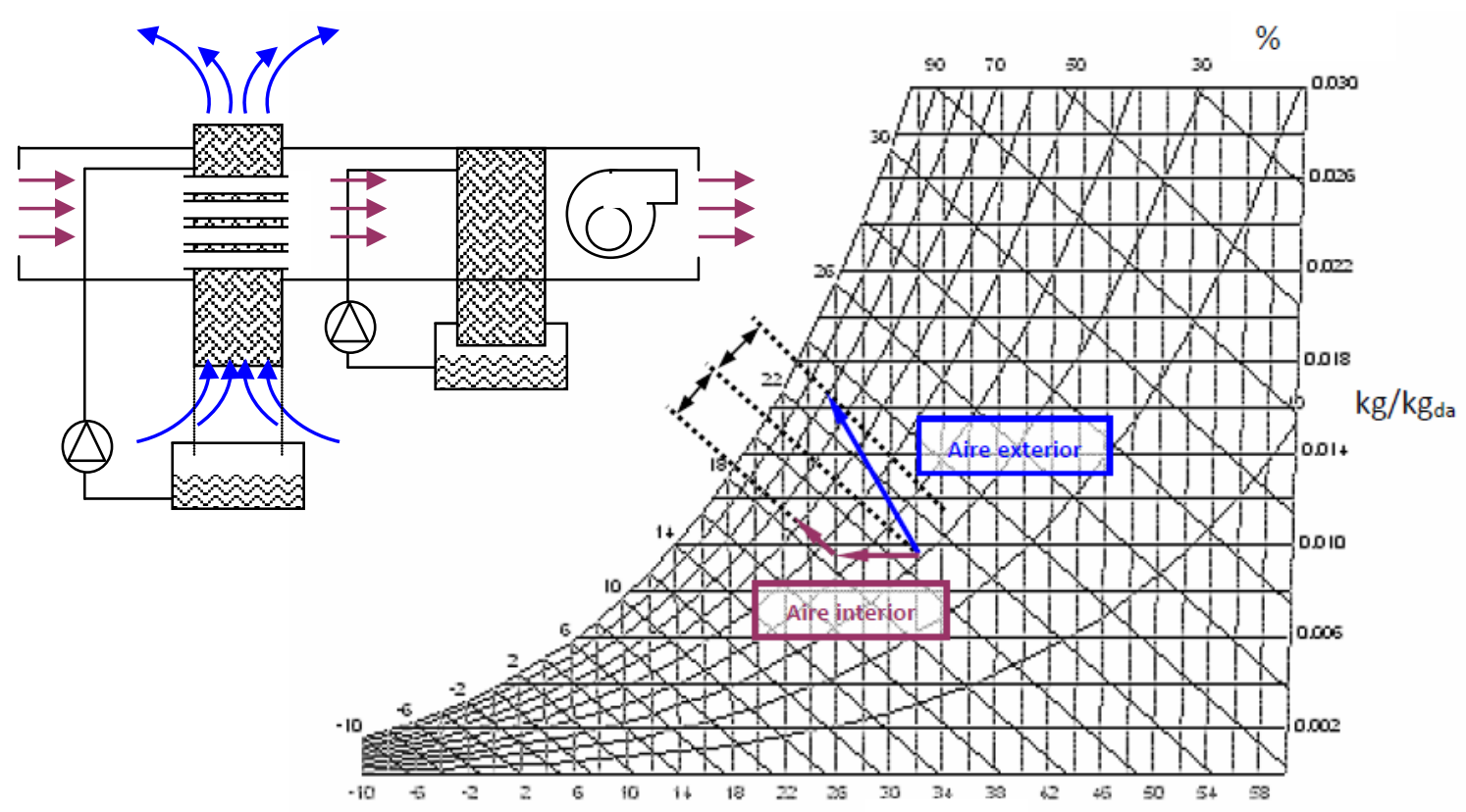

Figura III.14.- Esquema y evolución del proceso seguido en un sistema mixto 


\section{Posibles configuraciones de la instalación.}

Los sistemas de enfriamiento evaporativo pueden considerarse como recuperadores de energía siempre que utilicen el aire de retorno de los locales climatizados como aire secundario para el proceso de enfriamiento evaporativo, aprovechando su menor temperatura yl o humedad, o bien una mezcla de éste y aire exterior. Así algunos autores hablan de ciclos regenerativos o recuperativos de acuerdo con los siguientes esquemas:

a) Sistema evaporativo indirecto convencional. Presentado ya anteriormente, combina un intercambiador de calor y un humidificador hasta saturación adiabático, empleando únicamente aire exterior tanto para el circuito primario como para el secundario. El enfriamiento del aire primario se realiza a través de un intercambiador.

b) Sistema regenerativo evaporativo indirecto: Consistente en un refrigerador evaporativo indirecto en el cual parte del aire primario enfriado en el intercambiador es utilizado como secundario, lo que permite aumentar el efecto de refrigeración del sistema al reducir la temperatura de bulbo húmedo de la corriente de aire secundario.

c) Sistema evaporativo recuperativo indirecto: Consistente en un refrigerador evaporativo indirecto, en el cual como aire secundario se emplea aire de expulsión procedente del local, aprovechando las características de menor temperatura y humedad específica de esta corriente de aire, en condiciones de confort, que permiten enfriar hasta temperaturas inferiores a las alcanzadas utilizando aire del exterior.

\section{Legionelosis: riesgos y control.}

A pesar de la elevada eficiencia energética que caracteriza a los sistemas de enfriamiento evaporativo, su uso no está tan extendido principalmente debido al riesgo de posible contaminación bacteriológica, especialmente por Legionella. Este es precisamente el mayor inconveniente tanto de las torres de enfriamiento como de los condensadores evaporativos o este tipo de sistemas, ya que aunque un debido mantenimiento permite eliminar estos riesgos de contaminación bacteriológica, los costes asociados hacen que estas alternativas se desechen a favor de sistemas menos eficientes. No obstante, estas decisiones siempre deben ser consecuencia de un adecuado análisis económico [11, Adnot et al., 2003].

A menudo se suele recurrir a sistemas de enfriamiento evaporativo indirectos en sustitución a los directos, ya que en el caso de estos últimos la posible contaminación bacteriológica se produce en la misma corriente de aire primario usada en el acondicionamiento higrotérmico del local; mientras que los indirectos, aún incurriendo en una menor eficiencia, al trabajar con un intercambiador de calor se evita la contaminación del aire de impulsión, aunque esto no exime de requerirse mantenimiento en el circuito secundario donde se produce el enfriamiento evaporativo. 
Parece por lo tanto necesario estudiar esta problemática a fin de tener presente su repercusión en la instalación y funcionamiento de los sistemas que nos incumben.

La Legionella está formada por un grupo de bacterias del tipo bacilo con formas alargada o esférica según las condiciones en las que se encuentre. Ya estaba en la tierra antes de la aparición del hombre, e incluye más de 42 especies, no todas ellas virulentas, siendo el serogrupo 1 de la Legionella Pneumophila el que causa mayor número de infecciones y el más frecuente en el agua de las instalaciones. Sin embargo, no fue descubierta hasta el año 1977, a causa de un brote de neumonía declarado en 1976 en Philadelphia, entre los asistentes ana reunión de militares veteranos de la legión estadounidense [16, Velasco et al., 2009].

A pesar de tratarse de un riesgo importante, para que se produzca el contagio es necesario que se dé la conjunción de una serie de condiciones, mostradas en la cadena de acontecimientos presentados en la figura III.15.

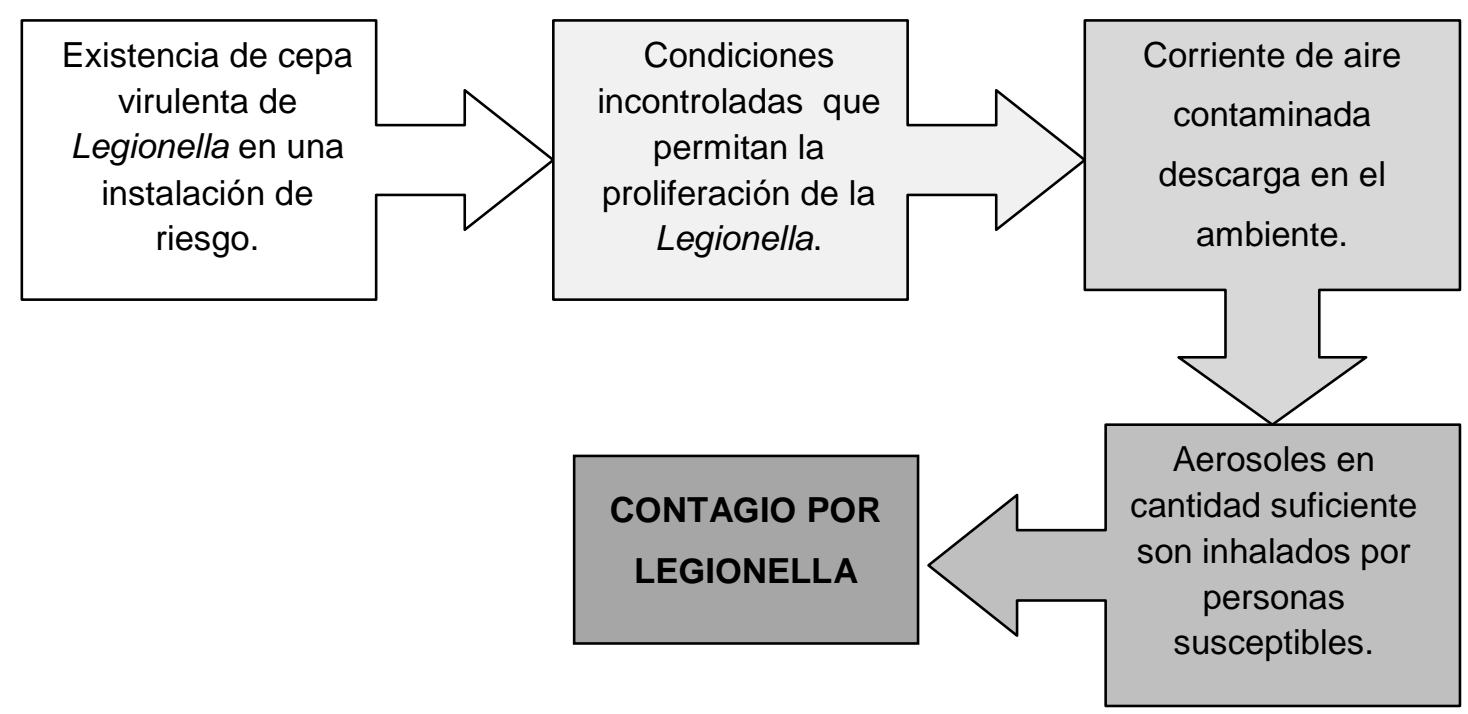

Figura III.15.- Etapas necesarias para la contaminación por legionella.

La existencia de una cepa virulenta en la instalación puede proceder del agua de aporte o por aerosoles de instalaciones próximas contaminadas.

Pueden darse condiciones incontroladas en las instalaciones a consecuencia de un defecto en el mantenimiento. Las bacterias utilizan la materia orgánica presente en el agua (suciedad) como alimento y las incrustaciones o biofilm sirven como refugio. Unas malas condiciones de incrustaciones y suciedad unidas a rangos de temperatura favorables para el desarrollo de la bacteria, pueden hacer que ésta prolifere en el medio acuoso hasta concentraciones elevadas.

Cuando el funcionamiento de los equipos como torres de refrigeración, condensadores evaporativos, sistemas de humidificación adiabática, etc., producen aerosoles en suficiente concentración y de dimensiones suficientemente grandes para transportar la bacteria pero a la vez suficientemente pequeñas como para poder ser inhaladas (entorno a $5 \mu \mathrm{m}$ ), y dichos 
aerosoles contaminados pasan al tracto respiratorio de personas inmunodeprimidas (ancianos, fumadores, enfermos del aparato respiratorio, etc.), se produce un contagio por la bacteria que debe ser tratado clínicamente. Sólo en algunos casos provoca la muerte del enfermo.

Si se rompiera un eslabón de la cadena anterior, como el hecho de que no exista una fuente de bacterias, que el mantenimiento sea correcto y no haya suciedad ni incrustaciones; que el nivel térmico no sea el adecuado para la proliferación bacteriana; o no se generen aerosoles en el aire impulsado, etc. no se produciría legionelosis.

De hecho, las condiciones particulares de los sistemas de enfriamiento evaporativo no van a favorecer el contagio por legionelosis, precisamente por no cumplir alguno o varios de estos requerimientos [8, Puckorious et al., 1995]. Aun así, la existencia de riesgo de contaminación hace necesario asegurar un debido mantenimiento de estos sistemas, debidamente regulado por normativa [N-1].

\section{III.4. ENFRIAMIENTO GRATUITO (FREE- COOLING)}

\section{Fundamentos}

A pesar de que el caso más habitual es aquél en el que las condiciones requeridas para que el aire de impulsión sea capaz de vencer las cargas internas de los locales son más próximas a las que posee el aire del retorno que a las del aire exterior, presentándose por lo tanto necesaria la recirculación de aire en cuestión de eficiencia energética, pueden darse a lo largo del año diferentes situaciones que pueden hacer más conveniente la utilización de aire del exterior que no recircular aire, lo que reduce los consumos energéticos y a la calidad del aire interior que se consigue en los locales [17, ATECYR, 2010], [18, Ghiaus\&Allard, 2006].

Es precisamente en esta idea en la que se basa el concepto de enfriamiento gratuito por aire exterior, comúnmente conocido como "free-cooling". Esta aplicación es sin duda el líder del ahorro energético, ya que consiste simplemente en utilizar aire del exterior, normalmente sólo filtrado, en vez de recircular aire del retorno, por tener unas características energéticas que le hacen más eficiente energéticamente que el aire procedente del interior. El objetivo de un sistema de enfriamiento gratuito es por lo tanto reducir la energía necesaria para la adecuación higrotérmica del aire impulsado por los sistemas de acondicionamiento. Pero además de ser más económico utilizar aire frío del exterior para disipar las cargas internas, al aumentar el caudal de aire exterior, repercutirá en una mejora de la calidad del aire interior (IAQ).

Por lo tanto, los aspectos más relevantes que se pueden destacar de este dispositivo son:

- El ahorro de energía en períodos interestacionales o en climatologías suaves.

-La reducción del impacto medioambiental referido a emisiones de $\mathrm{CO}_{2}$ como consecuencia de la reducción del consumo energético. 
- Mejora de la calidad del aire interior (IAQ), al aumentar el caudal de renovación.

El reglamento RITE obliga al uso de enfriamiento gratuito por aire exterior para aquellos sistemas de climatización de tipo "todo aire" cuya potencia térmica nominal sea mayor de 70 kW en régimen de refrigeración [N-2].

Cuando se aplica el enfriamiento gratuito o free-cooling en un ciclo de acondicionamiento de aire para alcanzar las condiciones de confort térmico en un espacio interior, hablamos de "ciclo economizador". Este recurso se puede aplicar de dos formas: directamente utilizando aire exterior, lo cual se presenta como la aplicación más directa o evidente; o aprovechando el aire exterior para enfriar agua en una torre de enfriamiento, en lugar de enfriarla mediante un sistema convencional de producción de frío por compresión mecánica, y utilizar esta agua fría para adecuar térmicamente la corriente de aire de impulsión al interior mediante un intercambiador de calor, similar a lo que anteriormente se ha denominado como enfriador evaporativo indirecto convencional.

\section{Sistemas de enfriamiento gratuito.}

Como se acaba de presentar, existen básicamente dos tipos de sistemas para poder aprovechar las condiciones energéticas del aire exterior, bien utilizar directamente el aire exterior, o bien utilizar el aire exterior para enfriar agua en una torre de enfriamiento, utilizando el agua fría para enfriar a su vez el aire que se impulsará al interior de los locales [17, ATECYR, 2010].

\section{Sistemas de enfriamiento gratuito por aire exterior}

Estos sistemas consiguen utilizar la capacidad de enfriamiento gratuito del aire exterior en sustitución de un sistema convencional de enfriamiento por refrigeración mecánica, utilizando hasta un $100 \%$ de aire exterior, de manera que sea capaz incluso de disipar el total de la carga térmica del local.

Sin embargo, resulta evidente que para poder utilizar un sistema de enfriamiento gratuito por aire, es necesario que los sistemas de climatización de los locales sean por aire y que las unidades de tratamiento de aire estén equipadas con los adecuados sistemas de compuertas, ventiladores y control, necesarios para realizar un control adecuado de la instalación. Este control es especialmente relevante, ya que la opción de free-cooling debe habilitarse y regularse en función de las diferentes situaciones que se pueden plantear de cargas internas y condiciones climáticas exteriores, actuando sobre las compuertas de aire y los equipos que deben estar en operación, para conseguir que el aire de impulsión alcance las condiciones higrotérmicas adecuadas con el menor coste energético.

El dispositivo consta por lo tanto de un sistema con tres compuertas de aire colocadas de manera que la compuerta de aire de retorno está en serie con los ventiladores de aire de retorno e impulsión, mientras que las otras dos compuertas están en paralelo, la de expulsión en el circuito del ventilador de retorno y la de aire exterior en el circuito del ventilador de 
impulsión, como se puede ver en la figura III.16. Este sistema de compuertas deberá permitir regular el caudal de aire exterior en función de los requisitos establecidos por el sistema de control.

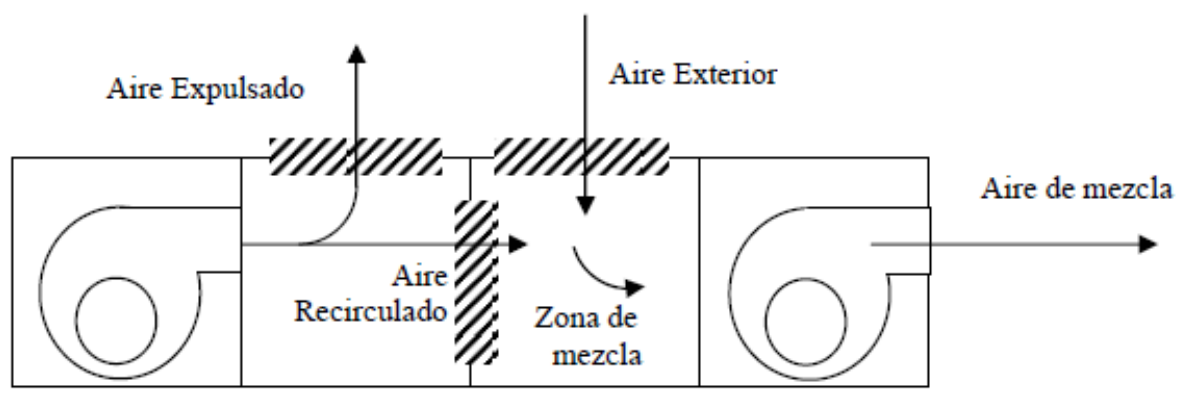

Figura III.16.- Esquema básico de un sistema de enfriamiento gratuito por aire.

El control puede realizarse por criterio de entalpía o por temperatura. Cuando la entalpía del aire exterior o en su caso la temperatura, dependiendo del sistema de control utilizado, sea inferior a la entalpía o temperatura del aire procedente del local, será más eficiente energéticamente utilizar aire exterior que no recircular aire de retorno del local. Los sistemas se pueden dividir por lo tanto en dos grandes grupos atendiendo al tipo control.

En el primer tipo de control, por comparación de entalpías, se miden las condiciones exteriores de temperatura seca y humedad relativa, parámetros a partir de los cuales el sistema puede calcular la entalpía del aire exterior. Si la entalpía del aire exterior es superior a la de retorno del local, las compuertas de aire de renovación y expulsión se mantendrán cerradas en la mínima posición que permita proporcionar el caudal de aire de renovación mínimo requerido, y manteniéndose abierta en su máxima posición la compuerta que regula la recirculación de aire de retorno. Por el contrario, si las condiciones energéticas del aire exterior resultan ser más adecuadas que las del retorno, la compuerta de recirculación se mantendrá cerrada y las de aire exterior y expulsión abiertas en su máxima posición.

Pueden darse sin embargo casos intermedios. Existe por lo tanto para la regulación una sonda de temperatura adicional que mide la temperatura del aire de mezcla. Cuando la temperatura exterior sea inferior a la temperatura establecida como consigna del aire de impulsión, $T o \leq T^{*}$, entonces el regulador del equipo modula la posición de las compuertas de aire (exterior, expulsión y recirculado) de manera que se mantenga la temperatura de la mezcla del aire en el valor establecido en la consigna $T^{\star}$. En esta situación, el sistema de producción de frío convencional estará parado.

En las figuras III.17 y III.18 se muestran los esquemas de operación y el sistema de control por entalpía, así como la identificación en el diagrama psicrométrico de las condiciones exteriores adecuadas en este caso. 


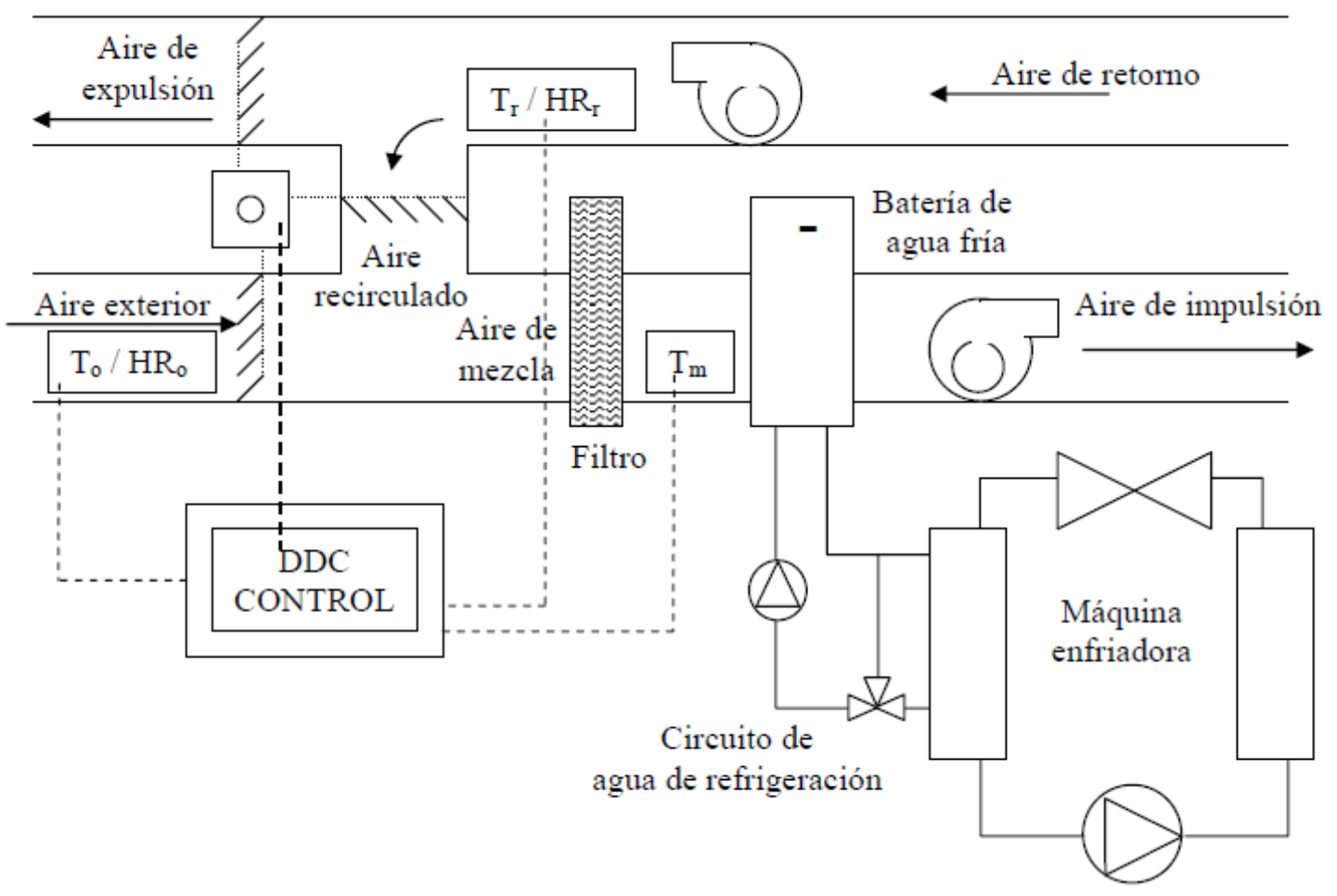

Figura III.17.- Esquema del proceso de refrigeración por aire utilizando control por entalpía

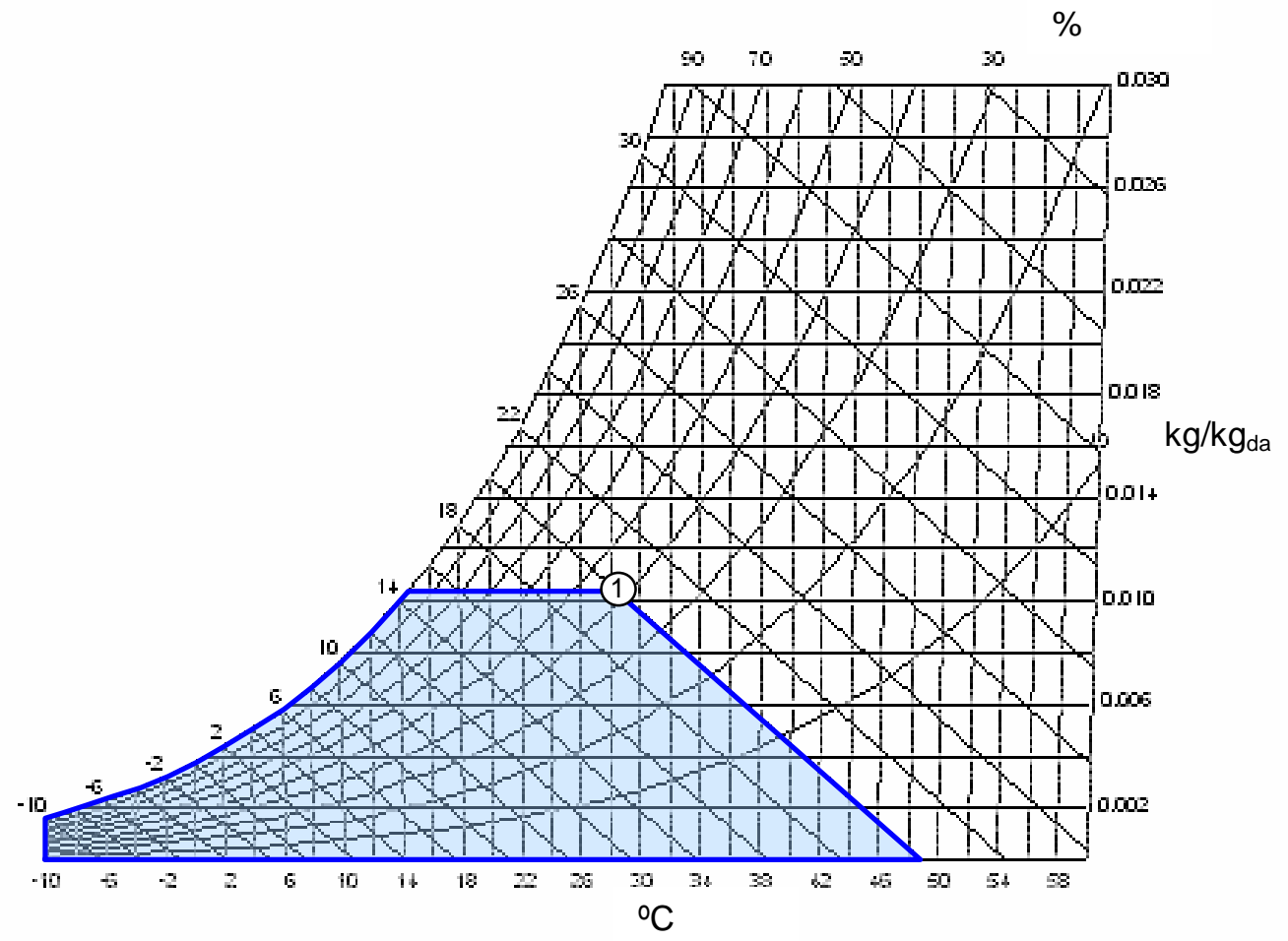

Figura III.18.- Representación en el diagrama psicrométrico de la zona de aire exterior donde sería adecuado utilizar enfriamiento gratuito con control de entalpía. 
Teóricamente, se consigue más eficiencia energética con el control de entalpía que con el control de temperatura, pero en muchas ocasiones el enfriamiento del aire precisa de un enfriamiento adiabático cuando la humedad es muy baja. Sin embargo, para poder comparar los valores de entalpía se precisan sondas de temperatura y humedad, por lo que desde un punto de vista práctico, dado que las sondas de humedad pueden proporcionar errores (incluso del $10 \%)$ como consecuencia de una baja precisión o de derivaciones de la calibración en cortos periodos de tiempo que hacen dificultoso su mantenimiento, y adicionalmente su precio es relativamente elevado, hacen que el sistema más utilizado de control de enfriamiento gratuito sea el de temperatura.

Este segundo método de control por temperatura resulta por otra parte más sencillo, ya que se comparan solamente temperaturas secas utilizando una única sonda de temperatura. La comparación se realiza entre la temperatura del aire exterior To con la temperatura del aire recirculado $\operatorname{Tr}$ (o con el valor de un punto de consigna predeterminado). En este caso, las compuertas de aire de renovación y de expulsión se mantendrán en la mínima posición y la de aire de retorno totalmente abierta cuando la temperatura exterior exceda la de retorno o la de consigna; mientras que se interrumpirá la recirculación de aire permitiendo entrada de aire exterior cuando la temperatura exterior sea inferior a la de retorno, regulándose las posiciones intermedias en relación a la medida adicional de una sonda de temperatura de mezcla, al igual que se planteaba para el caso de control por entalpía.

El esquema de operación y el sistema de control serían los representados en la figura III.19, mientras que la zona de condiciones climáticas de interés en este caso sería la reflejada en el diagrama psicrométrico de la figura III.20.

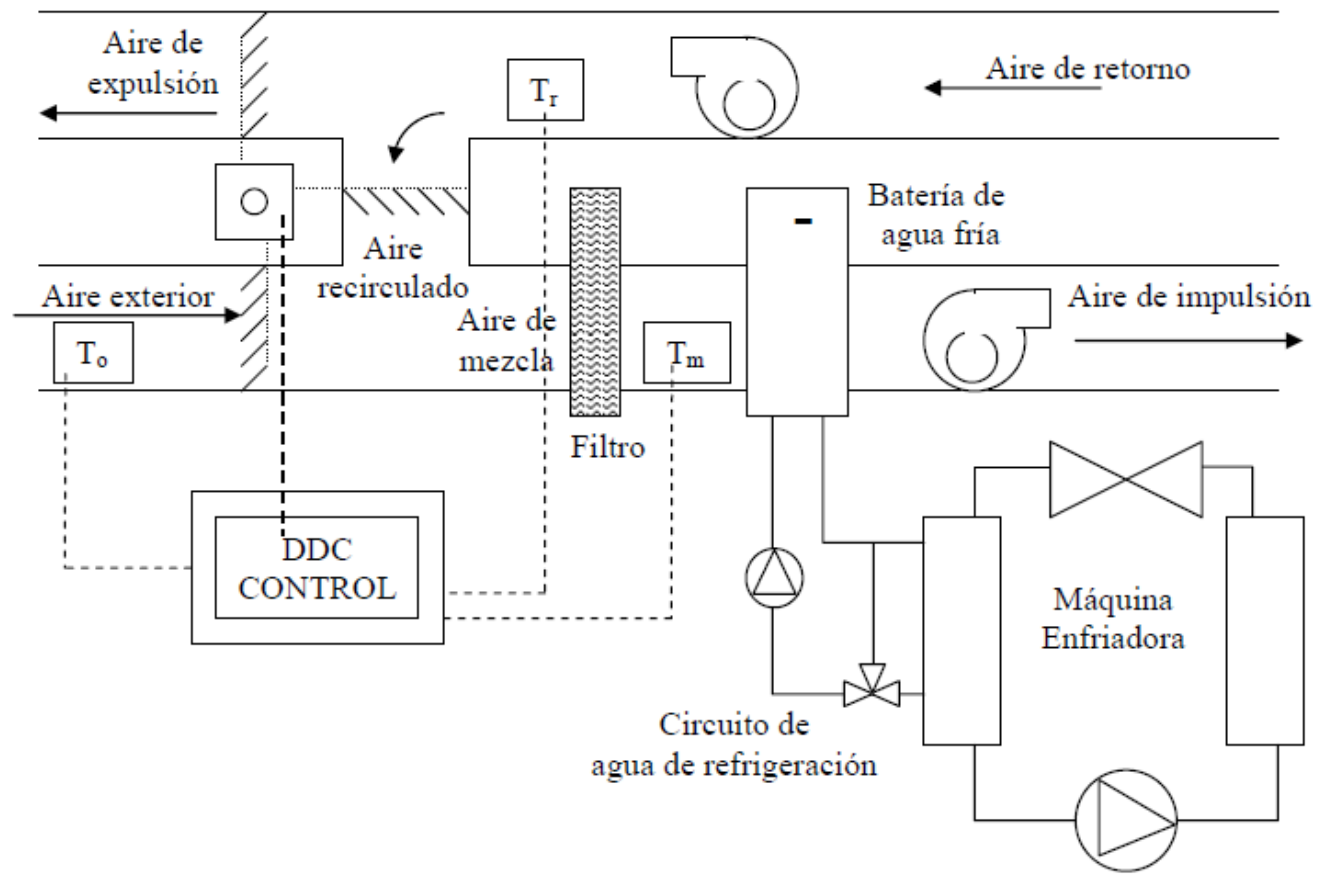

Figura III.19.- Esquema del proceso de refrigeración por aire utilizando control por temperatura 


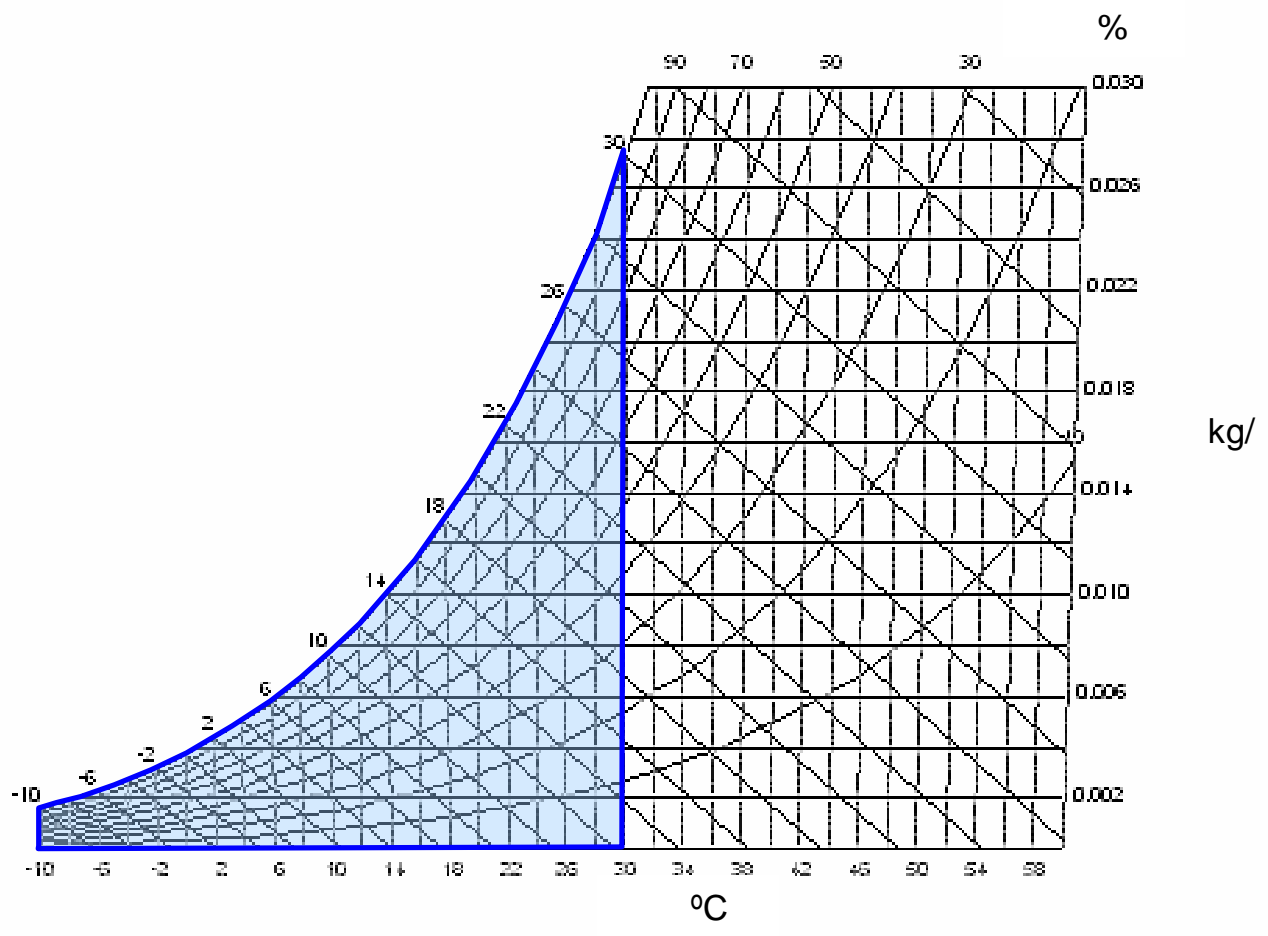

Figura III.20.- Representación en el diagrama psicrométrico de la zona de aire exterior donde sería adecuado utilizar enfriamiento gratuito con control de temperatura.

\section{Sistemas de enfriamiento gratuito por agua}

Por otro lado, como ya se ha indicado, cabe también la posibilidad de utilizar el agua procedente de una torre de enfriamiento, que idealmente puede ser enfriada hasta la temperatura de saturación adiabática del aire exterior que circula por dicha torre, para enfriar el aire enviado a la unidad de tratamiento, reduciendo de esta forma el consumo energético de la misma respecto al que requeriría utilizando un sistema convencional para enfriar el agua de la batería de la UTA. No obstante, si es necesario utilizar las dos baterías para alcanzar las condiciones deseadas en el aire de impulsión, estas se conectan siempre en serie y primero la que utiliza free cooling por agua. La disposición esquemática de esta instalación es la que se presenta en la figura III.21.

En lo que concierne a este modo de enfriamiento gratuito, las condiciones climáticas pueden ser divididas en tres zonas en función de la temperatura de bulbo húmedo del aire exterior, según se muestra en el diagrama psicrométrico de la figura III.22, y consecuentemente quedarán distinguidos tres modos de funcionamiento del sistema:

En la Zona I la torre de refrigeración está parada.

En la Zona II, la torre trabaja reemplazando parte de la refrigeración mecánica.

En la Zona III la torre sola soporta totalmente la demanda energética. 


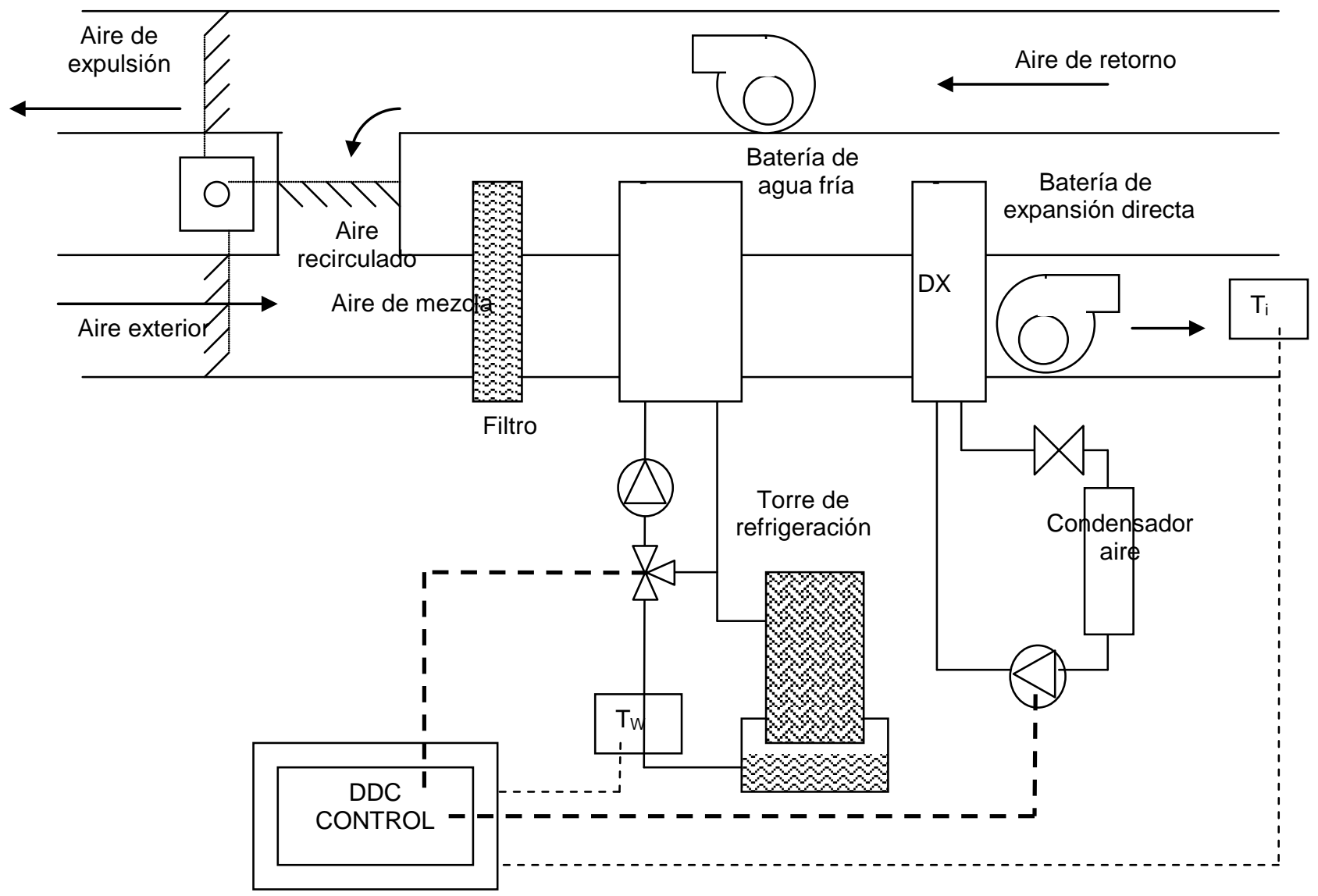

Figura III.21.- Esquema básico del enfriamiento gratuito por agua.

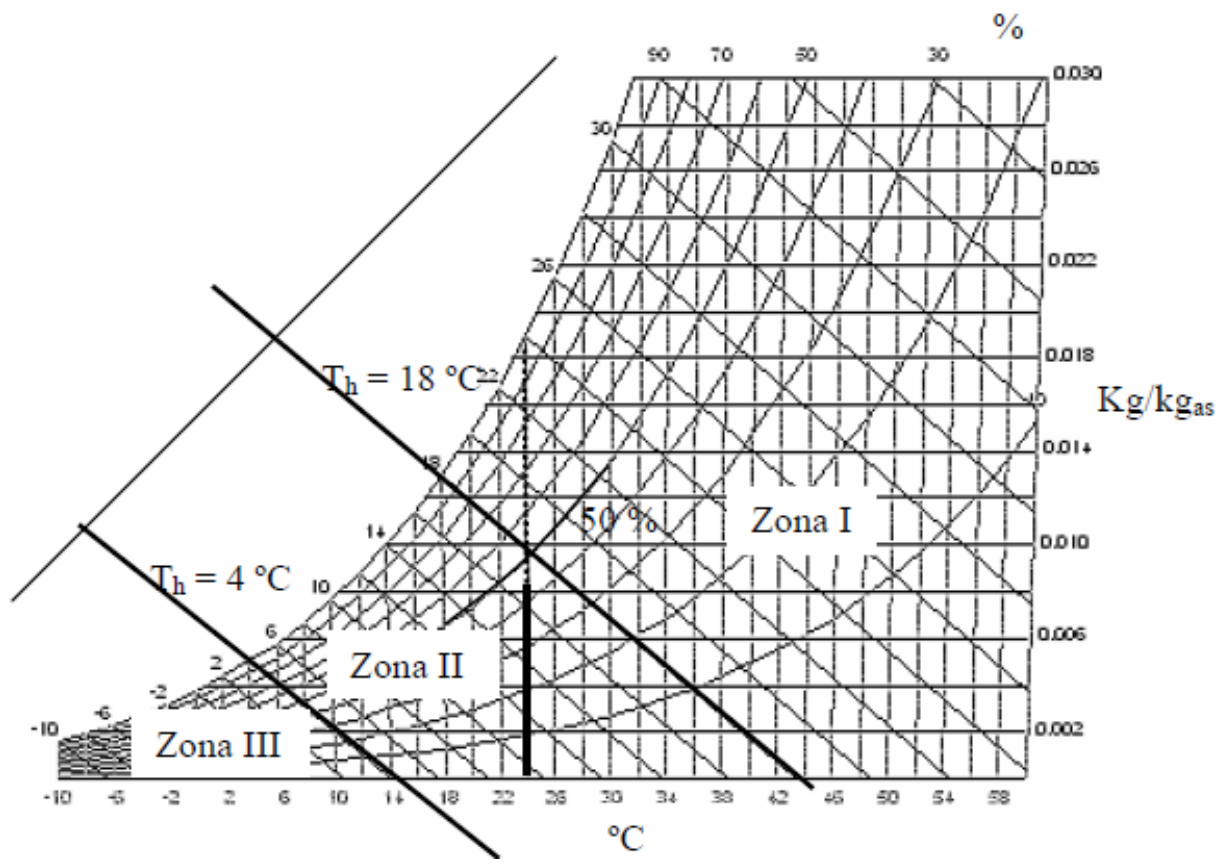

Figura III.22.- Zonas de control del proceso de free-cooling por agua. 
Puede observarse que la división de las zonas I y II está caracterizada por la línea de temperatura húmeda, que para las condiciones particulares del local supuestas en el diagrama correspondería a $18{ }^{\circ} \mathrm{C}$. Por debajo de este valor el enfriamiento de aire utilizando agua enfriada en una torre de refrigeración puede operar de manera efectiva. La división entre las zonas II y III está caracterizada por la temperatura húmeda, que en esta situación se ha supuesto de $4{ }^{\circ} \mathrm{C}$, que determina las condiciones exteriores límite que permitirían compensar por enfriamiento gratuito por agua todas las cargas de refrigeración del sistema de climatización. Por debajo de ese valor la máquina de producción de frío por compresión mecánica estaría parada.

En el control del funcionamiento de estos sistemas, se toman como variables la temperatura del agua a la salida de la torre, y la temperatura de impulsión del aire tras atravesar la batería, siendo los valores de consigna considerados respectivamente la temperatura húmeda del interior del local y la temperatura establecida en la impulsión para soportar las cargas internas del local. La torre de enfriamiento estará en funcionamiento mientras la temperatura alcanzada por el agua sea inferior a la temperatura húmeda del local, y siempre que esta no descienda por debajo de los $2^{\circ} \mathrm{C}$, caso en el que existiría riesgo de congelación. Para temperaturas alcanzadas por agua suficientemente bajas (generalmente establecidas en $10^{\circ} \mathrm{C}$ ), el sistema de enfriamiento gratuito por agua bastará para adecuar la corriente de aire; pero en otro caso la temperatura de impulsión del aire resultaría superior a la requerida, y habría que recurrir al apoyo de un sistema de refrigeración auxiliar. Si por el contrario el sistema de enfriamiento gratuito por agua puede soportar toda la carga y la temperatura de impulsión del aire registrada es igual o menor que el valor de consigna, un regulador controlará el caudal de paso de agua por la batería a fin de ajustar dicha temperatura. El esquema de funcionamiento y control se puede observar en la figura III.23.

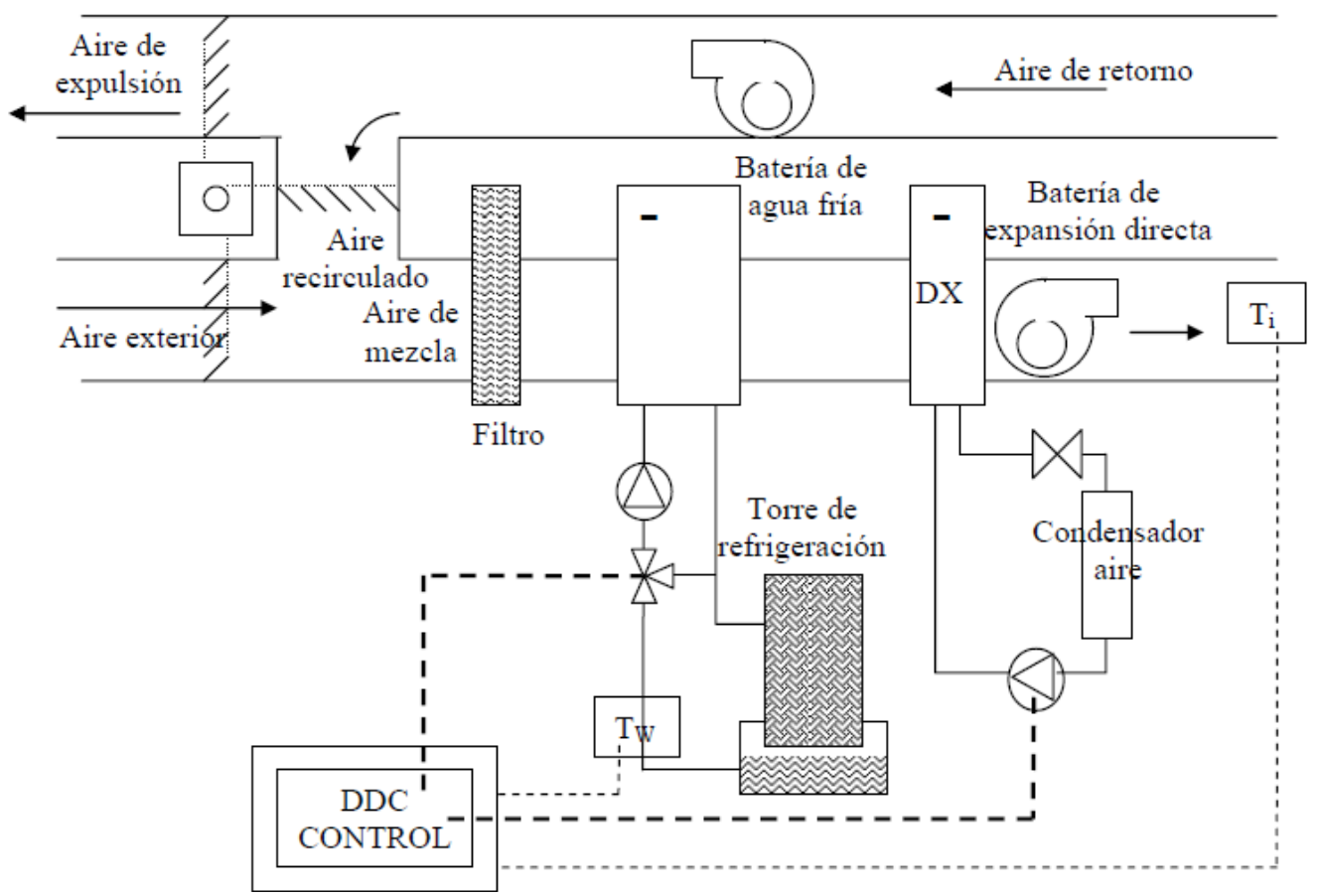

Figura III.23.- Enfriamiento gratuito utilizando enfriamiento evaporativo de agua. 
Resulta evidente la limitación del aprovechamiento de este recurso respecto a las circunstancias particulares del clima exterior, lo que restringe su periodo de funcionamiento. Se presenta por lo tanto interesante su combinación con otros sistemas y aplicaciones, como puede ser la recuperación de energía. En estos sistemas el control regulará la utilización del recuperador de energía cuando sea necesario utilizar aire exterior aunque posea unas características energéticas peores que el aire de retorno. En estas condiciones el recuperador permitirá reducir la energía eliminada en el aire de expulsión, aportándosela al aire exterior. No obstante, las opciones de la recuperación de energía se desarrollan más exhaustivamente a continuación.

\section{III.5. Recuperación de EnERgía.}

\section{Fundamentos}

Los recuperadores de energía en los sistemas de climatización van a conciliar calidad del aire interior con ahorro energético, ya que permiten aportar los caudales de ventilación requeridos para renovación de aire sin penalizar energéticamente los sistemas de acondicionamiento higrotérmico, simplemente preacondicionando este flujo de aire mediante el aprovechamiento de la energía residual del aire extraído para la renovación. Por lo tanto, se puede definir un recuperador de energía como aquel dispositivo que permite reutilizar el calor residual de un sistema con el objetivo final de alcanzar la máxima eficiencia en el funcionamiento global de la instalación [17, ATECYR, 2010], [19, Rey et al., 1996].

Los equipos de recuperación del calor residual son generalmente intercambiadores térmicos más o menos complejos, pudiendo darse en ellos tanto flujos de calor como de masa. Sin embargo, estos sistemas no dejan de estar integrados dentro de un proceso de acondicionamiento más global, por lo que deben plantearse como medios de reducción del consumo energético de esta instalación suponiendo unos costes económicos aceptables de inversión en la misma. Estos sistemas deben por lo tanto dimensionarse como intercambiadores térmicos, pero bien concebidos como parte integrante del sistema para alcanzar los objetivos perseguidos para la aplicación particular; atendiendo siempre a si la energía residual aprovechada podría, en primer caso, evitarse; buscando dónde y de qué formas se puede realizar el aprovechamiento de la misma, en otro caso, de forma óptima; y comprobando que el ahorro generado compensa el incremento en la inversión producido. Debe tenerse en cuenta que estos sistemas son costosos; sin embargo, en muchos casos su instalación no será una opción sino un requisito impuesto por la normativa [N-1]. Aún así, no debe pasarse por alto el hecho de que un sistema de recuperación permite no sólo reducir costes energéticos durante el funcionamiento, sino también en la inversión de la instalación de acondicionamiento higrotérmico, ya que se reduce la demanda a soportar por ésta. 
En cualquier caso, la recuperación de energía residual permite reducir tanto el consumo como los costes energéticos. La energía reutilizada se correspondería con la ecuación siguiente:

$$
E=\rho \cdot C p \cdot \dot{V} \cdot \Delta T \cdot t
$$

Según esta ecuación, la cual presenta el calor que sería recuperado, es previsible que en el ámbito de la climatización de edificios, el interés energético y económico de esta opción recaiga especialmente en aquellas aplicaciones que, bien trabajen con altos caudales de ventilación o bien requieran instalaciones de ventilación y extracción funcionando durante largos periodos de tiempo; así como aquellos casos en los que los saltos térmicos entre el aire exterior y el interior en condiciones de confort sean muy elevados durante largos periodos tanto invernales (grados-día) como estivales (temperaturas de bulbo seco y bulbo húmedo muy elevadas).

Por otro lado, la eficiencia de este tipo de sistemas va a estar referida al calor sensible asociado a la corriente de aire de renovación, estando definida como la relación entre el salto térmico sufrido por el aire de ventilación al atravesar el intercambiador y el máximo salto que podría darse, siendo este último la diferencia de temperaturas a la entrada del sistema de las dos corrientes de aire entre las que se produce el intercambio energético. Sin embargo, algunos tipos de recuperadores de energía permiten también aprovechar el calor latente residual de la corriente de expulsión para acondicionar en humedad la corriente de aire de renovación.

No obstante, como intercambiadores de calor van a generar una cierta pérdida de carga adicional que incurrirá en un aumento en el consumo energético de los ventiladores para mantener los mismos caudales en circulación en la instalación que si no se hubiera dispuesto de un sistema de recuperación de energía, lo cual debe tenerse presente a la hora de estudiar la eficacia de la instalación global.

A pesar de las complicaciones existentes a la hora de establecer una clasificación de los sistemas de recuperación de energía al deberse tenerse tanto los modos de funcionamiento, como los medios entre los que se produce la transferencia energética, separación de los mismos, etc., se recopilan a continuación los principales sistemas utilizados en climatización por aire para la recuperación del calor residual, o en algunos casos también la humedad, del aire de expulsión. 


\section{Clasificación de sistemas.}

\section{Intercambiadores de Placas}

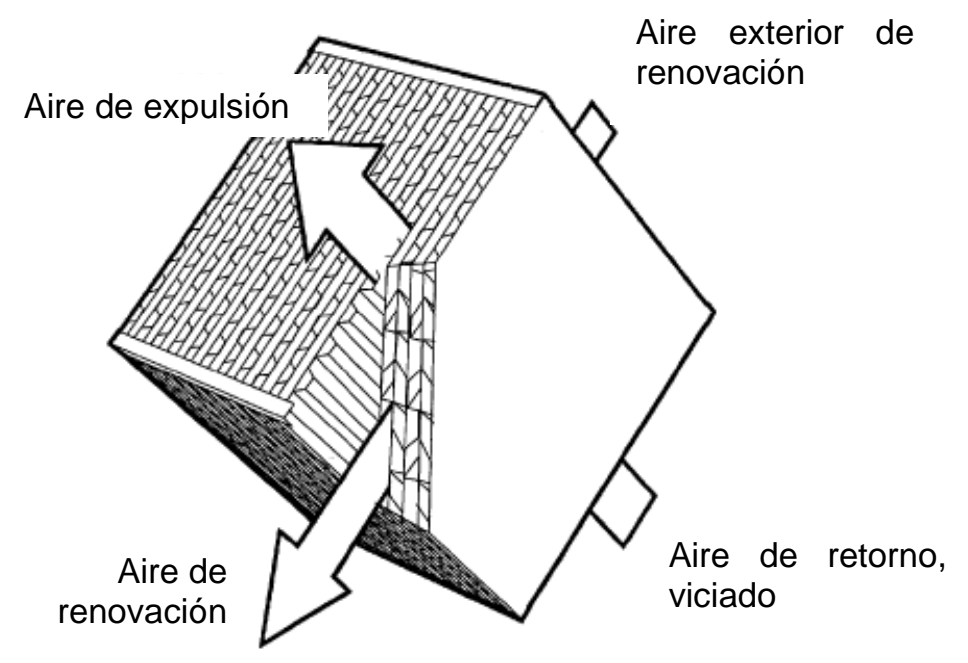

Figura III.24.- Esquema de funcionamiento de un intercambiador de placas.

Al igual que existen diversas configuraciones, tamaños y patrón de flujo en función de la aplicación particular, también puede recurrirse a diversos tipos de materiales, por ejemplo en función de si el sistema permite recuperación en entalpía o tan sólo de calor sensible [20, ASHRAE, 2000], [21, Mardiana-Idayu\&Riffat, 2011]. Introduciendo la recuperación del calor latente produciendo condensación de la humedad de una de las corrientes, disminuida su temperatura por debajo de la de rocío, se consigue una mejora sustancial del rendimiento gracias al aprovechamiento del calor latente del cambio de fase; sin embargo para esta operación se requerirá la existencia de una bandeja de recogida de condensados así como un cuidado mantenimiento de la limpieza del sistema. En estos casos se deberá recurrir a materiales que soporten los efectos del agua de condensación, como corrosión, deterioro del material, etc. Sin embargo, para el resto de casos y en función de si el objetivo es la transferencia de entalpía o sólo de calor sensible, se podrán recurrir a múltiples materiales como medio de separación, desconsiderando los posibles criterios de diseño que podrían plantearse en un primer estudio en cuanto a conductividad de los materiales, factor que no sería tan determinantes como podría parecer previsible, tal y como se ha comprobado [5, Pescod, 1974].

Los requerimientos de tamaño y eficiencia determinan el número de placas. Un número superior de placas, aunque supone un aumento en la superficie de fricción de los fluidos en circulación, proporciona mayor sección de paso con la consecuente reducción de velocidad. Por lo tanto, de forma global al aumentar el número de placas se logra una disminución en la pérdida de carga introducida por el intercambiador. 
El control de estos equipos se realiza simplemente actuando sobre una serie de compuertas que permitan by-pasar el sistema, en caso de necesidad como por ejemplo por riesgo de formación de hielo en el intercambiador operando en climatologías muy frías, o en caso de ser conveniente el trabajo en modo free-cooling.

Frente a la existencia en algunos casos de riesgo de congelación de las posibles condensaciones, así como de la elevada pérdida de carga introducida por el equipo, estos sistemas presentan interesantes ventajas como son su compacidad y la ausencia de contacto directo entre las corrientes de intercambio, aunque para asegurar esto debe cuidarse la disposición de las tomas de aire y de expulsión para que no se produzca mezcla de las corrientes.

\section{Recuperador Rotativo}

Al igual que los de placas, los recuperadores rotativos son sistemas aire-aire, que pueden bien intercambiar calor sensible, o calor sensible y latente (recuperador entálpico o de energía total) si las características higroscópicas del rotor lo permiten. Puesto que las corrientes de aire entre las que se efectúa el intercambio de calor circulan por el mismo espacio físico, se dice que estos sistemas de recuperación son regenerativos.

Estos dispositivos están formados por una carcasa en cuyo interior gira una rueda o tambor construido con un material permeable al aire con una gran superficie de contacto resistente a la abrasión. Los flujos de aire exterior y de expulsión están separados por dos sectores (adyacente y en contracorriente) [21, Mardiana-Idayu\&Riffat, 2011].

Para la recuperación de la energía del aire de extracción, la rueda o tambor gira, siendo por lo tanto atravesado alternativamente por las dos corrientes de aire con un período función de la velocidad de rotación. La figura III.25 muestra una imagen del aspecto y el esquema de funcionamiento de estos equipos. En cada rotación, el material de relleno del tambor se calienta absorbiendo calor del flujo de aire más caliente, y lo cede a la corriente de aire más fría. Este calentamiento y enfriamiento sucesivo permite transportar energía sensible entre las dos corrientes de aire que circulan a través del recuperador. Si el material con el que está construido el rotor está tratado con una sustancia higroscópica (una sal con capacidad de captar y ceder la humedad del aire cuando varía la temperatura), en la rotación absorbe no sólo calor sino también humedad de la corriente más caliente y húmeda, transfiriendo por lo tanto calor sensible y latente desde ésta a la corriente más fría.

Por lo tanto, aunque los materiales más utilizados la construcción de este tipo de recuperadores son metales (generalmente capas alternativas de aluminio corrugado y aluminio plano) por su elevada densidad y calor específico; en los casos en los que se busca la posibilidad de tratar las superficies con sustancias higroscópicas para permitir el intercambio de calor latente, se recurre a fibras inorgánicas o polímeros sintéticos y orgánicos [17, ATECYR, 2010]. 

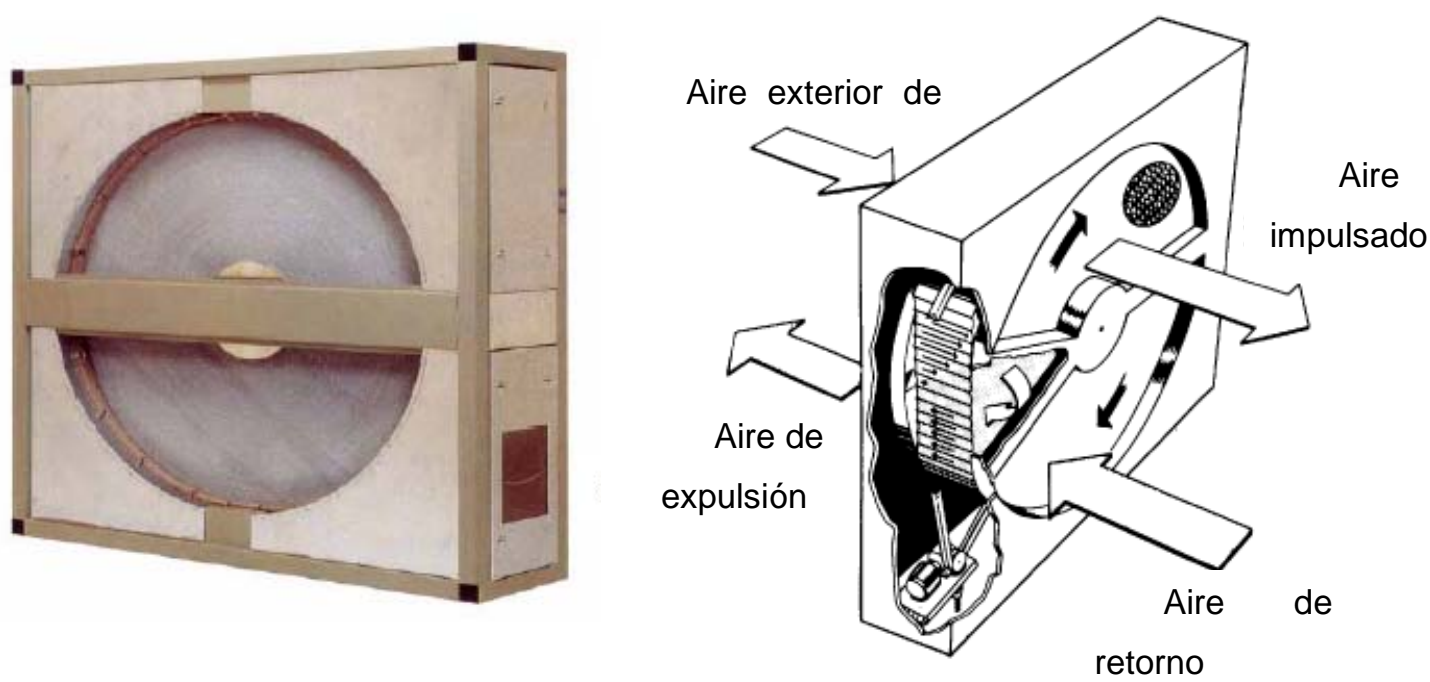

Figura III.25.- Configuración de las placas de un recuperador.

El control de la temperatura de impulsión del aire lograda con estos sistemas puede realizarse, bien regulando el caudal de aire de renovación tratado, by-pasando el resto del caudal para su impulsión directa; bien modificando la velocidad de rotación del tambor.

Estos sistemas presentan altas eficiencias, además de amplias posibilidades de regulación en función de las condiciones de operación. Sin embargo, su eficiencia se ve reducida por la necesidad de disponer de una zona de purga que evite el principal problema de estos equipos, que es la contaminación de la corriente de aire de impulsión con la de extracción, ya que puede llegar a alcanzarse un 1 ó $2 \%$ de mezcla entre ellas. Además, se da la limitación debida a la necesidad de que los conductos de aire se ajusten al espacio del recuperador [20, ASHRAE, 2000].

\section{Recuperador de dos baterías con bomba}

Estas instalaciones, también llamadas run-around, permiten la transferencia energética entre las corrientes de extracción y renovación gracias a la circulación de un líquido caloportador que intercambia generalmente sólo calor sensible con éstas.

Para permitir esto, están constituidas por dos baterías aleteadas (tubos de cobre con aletas normalmente de lámina de aluminio al ser menor su coste, o aletas de cobre en el caso de ambientes salinos para evitar la corrosión por par galvánico) unidas entre sí mediante un circuito de transferencia de la energía térmica recuperada por el cual circula el líquido portador de calor (normalmente agua o una solución acuosa de etilenglicol cuando hay peligro de congelación) gracias a una bomba hidráulica, atravesando las dos baterías. El fluido absorbe calor en la batería que es atravesada por la corriente de aire con temperatura más elevada y lo cede al flujo de aire con temperatura más baja a través de la otra batería. Un esquema del 
funcionamiento se muestra en la figura III.26 [17, ATECYR, 2010], [21, Mardiana-Idayu\&Riffat, 2011].

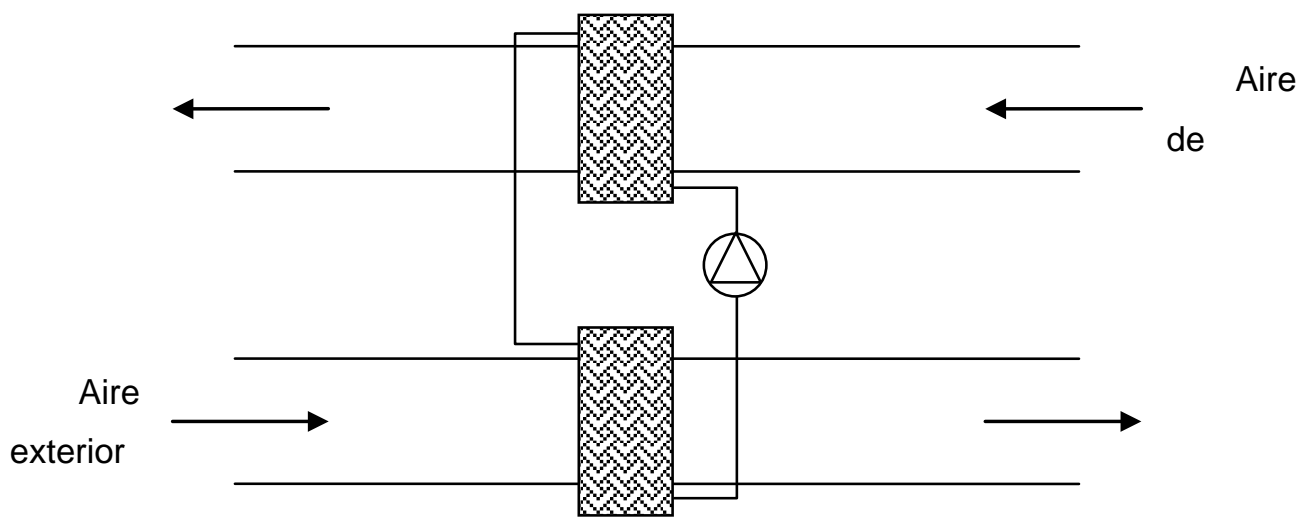

Figura III.26.- Esquema de un recuperador de dos baterías con bomba.

Tanto el control sobre la temperatura del aire impulsado como sobre el riesgo de congelación en invierno se realiza simplemente actuando sobre el caudal de fluido circulante. Asimismo, para amortiguar las variaciones de volumen por los cambios en la densidad del líquido debidas a sus cambios de temperatura, es necesario disponer del correspondiente vaso de expansión [20, ASHRAE, 2000].

Este tipo de sistemas es muy flexible, puesto que puede ser utilizada también si las tomas de aire exterior y de extracción están distantes entre sí, o cuando existen más tomas de aire exterior y/o de extracción. Sus principales inconvenientes son, sin embargo, la limitación de la eficiencia por el doble intercambio térmico aire-líquido-aire, así como los riesgos de corrosión u oxidación de los sistemas.

Este sistema será el seleccionado como opción de recuperación energética para el análisis de recursos de ahorro energético planteado en el presente trabajo.

\section{Recuperadores evaporativos}

Como ya se ha introducido con anterioridad, existe la posibilidad de disponer enfriadores evaporativos bien directos, indirectos o combinando varias etapas de los mismos, trabajando con corrientes de aire de retorno de los locales climatizados como aire secundario del proceso, aprovechando sus mejores condiciones energéticas de temperatura y humedad para el proceso. Tendremos en este caso una aplicación combinada del recurso del enfriamiento evaporativo con la recuperación energética residual, mejorando por lo tanto la capacidad de refrigeración del primero, al depender esta de las condiciones psicrométricas del aire utilizado en el proceso.

En esta opción puede recurrirse a la utilización de sólo aire de retorno como corriente secundaria, o bien una mezcla de ésta con aire exterior. En aplicaciones en las que se utilice como corriente secundaria parte del aire tratado en el proceso de enfriamiento evaporativo, se 
hablará de sistema regenerativo en vez de recuperativo [17, ATECYR, 2010], [22, Shibuola, 1997].

Estas opciones de combinación de modos de ahorro energético también serán consideradas a la hora de abordar la optimización del uso de recursos para reducir la demanda energética en la climatización de edificios en período estival desarrollada en el presente trabajo de tesis doctoral.

\section{Recuperadores con tubos de calor}

En este tipo de sistemas, la transferencia energética entre las corrientes es siempre únicamente sensible, y se realiza por medio de una batería de tubos aleteados llamados tubos de calor. Estos dispositivos consisten en tubos metálicos sellados en cuyo interior se hace vacío y los cuales se han cargado con un líquido de trabajo, y que trabajan según se muestra en la figura III.27 [17, ATECYR, 2010], [20, ASHRAE, 2000] [21, Mardiana-Idayu\&Riffat, 2011], [23, Rey et al., 2003]. Como puede observarse, el extremo de los tubos en contacto con la corriente más caliente actúa como evaporador, produciéndose en él el paso a estado gaseoso del líquido interior. El volumen de gas encerrado en cada tubo atraviesa este y se condensa en el otro extremo, el cual está en contacto con la corriente de aire frío. El líquido condensado circula hasta el extremo evaporador, bien por gravedad en los sistemas tipo termosifón, o bien a través de un relleno capilar (dispositivos heat-pipe), cerrando el ciclo y perpetuando así el sentido de transferencia energética. El principal inconveniente de los tubos tipo termosifón es que para su operación por gravedad sólo permiten la transferencia de calor en un sentido, teniéndose que intercambiar el paso de las corrientes de expulsión y renovación por los conductos de una estación a otra.

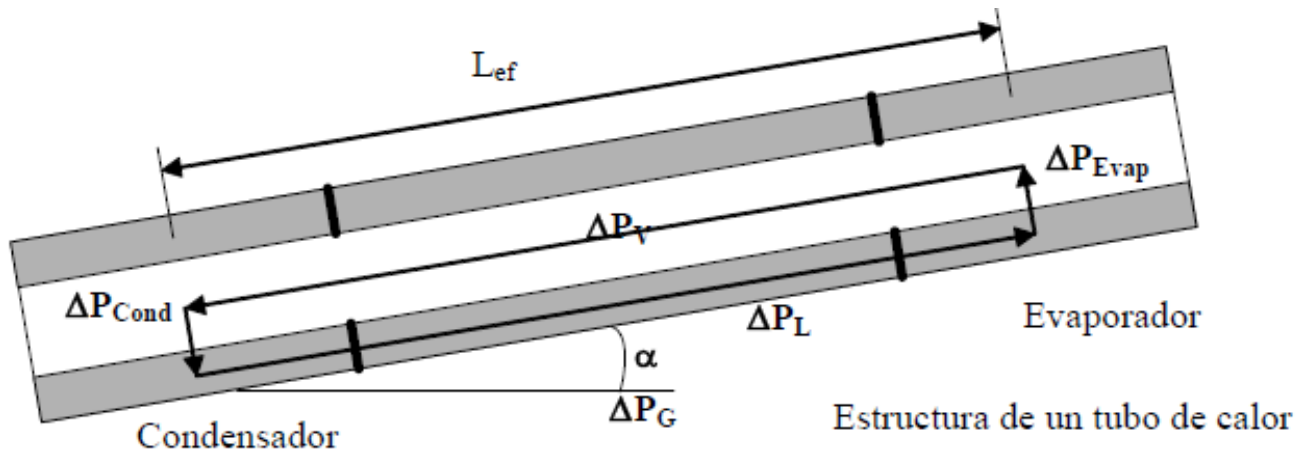

Figura III.27.- Esquema de funcionamiento de un tubo de calor.

Los materiales de construcción empleados deben ser aptos para las condiciones de trabajo que estén previstas. En el campo del aire acondicionado es normal utilizar bastidores de acero galvanizado, tubos de cobre, tabiques de cobre poroso y aletas de aluminio o cobre. Por su parte, los posibles fluidos de trabajo son muy diversos: metanol, agua, acetona, amoníaco, etc., teniendo como único requisito la compatibilidad con el material utilizado para construir la carcasa y el relleno. 
Estos sistemas son especialmente interesantes en aplicaciones en las que debe evitarse toda mezcla de corrientes. Además, presentan otras ventajas como su baja inercia térmica o la no necesidad de energía eléctrica para su funcionamiento. Sin embargo, su diseño es complicado y su coste elevado.

\section{Bomba de Calor como recuperador}

Ya se ha introducido en este mismo capítulo el funcionamiento de una bomba de calor, definida como un sistema que transfiere energía de una fuente fría a una caliente, por la circulación de un fluido que absorbe o cede calor al recorrer un ciclo de compresión mecánica, permitiendo este gracias al aporte de trabajo mediante un compresor. Si los focos frío, desde el que se extrae calor, y el caliente, al que se cede, son las corrientes de aire de extracción y de renovación, se tiene una bomba de calor trabajando como sistema de recuperación de energía. De esta forma se aprovecha el más adecuado nivel térmico de la corriente de aire de expulsión frente al del ambiente exterior en cuanto al rendimiento del funcionamiento de la máquina.

Por lo tanto, el principal interés de estos sistemas de acondicionamiento de aire actuando como recuperadores de calor reside en el hecho de que permiten revalorizar energías residuales, o transvasar energía de zonas calientes a zonas frías de un mismo edificio, pudiendo adaptarse a las fuentes de bajo nivel térmico que en cada caso estén disponibles, formando la base de los denominados sistemas integrales de recuperación de energía.

No obstante, presentan el inconveniente del mayor coste de inversión asociado, el cual puede sin embargo verse compensado por el ahorro en los costes de operación introducido; además del inconveniente generalizado en cuanto a limitaciones espaciales de la mayoría de los recuperadores de energía ya vistos, que se traduce en este caso en la necesidad de disponer de un conducto de aire de retorno donde colocar la unidad exterior de la bomba de calor, no existiendo además conducción alguna del retorno en muchas instalaciones de pequeño tamaño [17, ATECYR, 2010]. 


\section{REFERENCIAS}

[1] Rey Martínez, F.J.; Velasco Gómez, E. "Bombas de Calor y Energías Renovables en Edificios". Editorial Thomson. ISBN: 84-9732-395-5. Madrid, 2005.

[2] Bowen, A.B.; "Cooling achievement in the gardens of Moghul India". Proceedings of the International Passive and Hybrid Cooling Conference, Miami Beach, Florida 1981.

[3] Shakerin, S.; "Water and fountains in history". ASME Fluids Engineering Division Conference. Boston, 2000.

[4] Watt, J.R.; " Evaporative Air Conditioning Handbook", Editorial Chapman \& Hall. Nueva York, 1986.

[5] Pescod, D.; "An Evaporative Air Cooler using a Plate Heat Exchanger", CSIRO Division of Mechanical Engineering Transactions. Victoria, Australia, 1974.

[6] Maclaine-Cross, I.L.; Banks, P.J.; "A General Theory of Wet Surface Heat Exchangers and its Aplication to Regenerative Evaporative Cooling". Revista: Journal of Heat Transfer, no103 (pp.579-583). 1983.

[7] Sodha, M.S.; Singh, S.P.; Sawhney, R.L. "Evaluation of Discomfort in a Room with Desert Cooler". Revista: International Journal of Energy Research, Vol 14 (pp.745-756). 1990.

[8] Puckorious, P.R., Thomas, P.T., Augspurger, R.L., Why evaporative coolers have not caused Legionnaires' disease. ASHRAE Journal, January 1995, (рp.: 29-33).

[9] Pinazo Ojer, J.M. "Psicrometría. Documentos Técnicos de Instalaciones en la Edificación, DTIE 3.01". Edición a cargo de ATECYR. Editorial: El Instalador. ISBN: 84-921270-5-8. 2000.

[10] Pizzetti, C. "Acondicionamiento del aire y refrigeración. Teoría y cálculo de las instalaciones". 2a Edición. Editorial: Bellisco. 1991.

[11] Adnot, J. et al.; "Energy Efficiency and Certification of Central Air Conditioners (EECCAC) FINAL REPORT - APRIL 2003", Volumen 3. Paris, 2003.

[12] ASHRAE, "Systems and Equipment. Chapter 19: Evaporative air cooling equipment". Handbook. 19.1-19.8. 2000.

[13] Rey Martínez, F.J.; Velasco Gómez, E.; Álvarez Guerra, M.; Molina Leyva, M.; "Refrigeración Evaporativa". Suplemento de la revista El Instalador, n³60, enero 2000. 
[14] Velasco, E.; Rey, F.J.; Varela, F.; Molina, M.J.; Herrero R.. "Description and experimental results of a semi-indirect ceramic evaporative cooler." International Journal of Refrigeration 28 (pp. 654-662). 2005.

[15] Silva, C.; Albertini, J.; "Fabricación de un Prototipo de Enfriador Evaporativo con Paneles de Esponja Vegetal". Trabajo Final de Grado, Universidad Nacional de Asunción. San Lorenzo, Paraguay, 2010.

[16] Velasco Gómez, E.; Rey Martínez, F.J.; Tejero González, A.; Flores Murrieta, F.E. "Legionela y mantenimiento de sistemas de enfriamiento evaporativo". Revista: Mundo HVAC\&R, marzo 2009, (pp. 34-35), NLG Editoriales. México, 2009.

[17] Asociación Técnica Española de Climatización y Refrigeración (ATECYR), "Guía técnica de ahorro y recuperación de energía en instalaciones de climatización". Serie: "Ahorro y Eficiencia Energética en la Climatización", Guía n ${ }^{\circ}$. Instituto para la Diversificación y Ahorro de la Energía (IDAE), Madrid, 2010.

[18] Ghiaus, C.; Allard, F.; "Potential for free-cooling by ventilation". Revista: Solar Energy, n80 (pp.402-413). 2006.

[19] Rey Martínez, F.J.; San José Alonso, J.F.; Velasco Gómez, E.; Álvarez-Guerra Plasencia, M.A.; "Recuperación de Energía en Sistemas de Climatización". Documentos Técnicos de instalaciones en la Edificación DTIE 8.01. Madrid, 1996.

[20] ASHRAE "Systems and Equipment. Chapter 44: Air-to-air Energy Recovery". Handbook. 44.1-44.18. 2000.

[21] Mardiana-Idayu, A.; Riffat, S.B.; "Review on heat recovery technologies for building applications". Revista: Renewable and Sustainable Energy Reviews, 2011 (publicación aceptada).

[22] Schibuola, L.; "High-efficiency recovery for air-conditioning applications in a mild climate: a case study". Revista: Applied Thermal Engineering 17, №5 (pp.: 447-454). 1997.

[23] Rey Martínez F.J.; Álvarez-Guerra Plasencia, M.A.; Velasco Gómez, E.; Varela Díez, F.; Herrero Martín, R.; "Design and experimental study of a mixed energy recovery system, heat pipes and indirect evaporative equipment for air conditioning". Revista: Energy and Buildings, $\mathrm{n}^{\circ}$ 35 (pp.: 1021-1030). 2003. 


\section{Normativa}

[N-1] Real Decreto 865/2003, de 4 de julio, por el que se establecen los criterios higiénicosanitarios para la prevención y control de la legionelosis. 2003

[N-2] Ministerio de Industria, Turismo y Comercio y Ministerio de Vivienda de España, "Real Decreto 1027/2007: Reglamento de Instalaciones Térmicas en Edificios". 


\section{RELACIÓN DE FiguRAS}

- Figura III.1.- Esquema de funcionamiento de una bomba de calor reversible.

- Figura III.2.- Diagrama P-h del ciclo de refrigeración simple de Rankine.

- Figura III.3.- Diagrama P-h del ciclo de refrigeración real de Rankine.

- Figura II.4.- Vasijas cerámicas utilizadas para refrescamiento de ambientes.

- Figura III.5.- Posibles evoluciones psicrométricas del aire en contacto con agua.

- Figura III.6.- Esquema de un enfriador evaporativo directo

- Figura III.7.- Esquema de un refrigerador directo de paneles evaporativos.

- Figura III.8.a.- Vista de un relleno rígido.

- Figura III.8.b.- Esquema de la operación de un panel rígido.

- Figura III.9.- Equipo enfriador evaporativo de medio rígido fabricado con esponja vegetal.

- Figura III.10.- Esquema de un refrigerador directo rotativo

- Figura III.11.- Esquema de un refrigerador evaporativo indirecto

- Figura III.12.- Sistema evaporativo indirecto con intercambiador tubular

- Figura III.13.- Refrigerador evaporativo indirecto de placas desarrollado por Pescod.

- Figura III.14.- Esquema y evolución del proceso seguido en un sistema mixto

- Figura III.15.- Etapas necesarias para la contaminación por legionella.

- Figura III.16.- Esquema básico de un sistema de enfriamiento gratuito por aire.

- Figura III.17.- Esquema del proceso de refrigeración por aire utilizando control por entalpía

- Figura III.18.- Representación en el diagrama psicrométrico de la zona de aire exterior donde sería adecuado utilizar enfriamiento gratuito con control de entalpía.

- Figura III.19.- Esquema del proceso de refrigeración por aire utilizando control por temperatura

- Figura III.20.- Representación en el diagrama psicrométrico de la zona de aire exterior donde sería adecuado utilizar enfriamiento gratuito con control de temperatura.

- Figura III.21.- Esquema básico del enfriamiento gratuito por agua.

- Figura III.22.- Zonas de control del proceso de free-cooling por agua.

- Figura III.23.- Enfriamiento gratuito utilizando enfriamiento evaporativo de agua.

- Figura III.24.- Esquema de funcionamiento de un intercambiador de placas.

- Figura III.25.- Configuración de las placas de un recuperador.

- Figura III.26.- Esquema de un recuperador de dos baterías con bomba.

- Figura III.27.- Esquema de funcionamiento de un tubo de calor. 


\section{PARTE II: CARACTERIZACIÓN DE LOS SISTEMAS}

CAPÍtulo IV: Dispositivo Experimental.

CAPÍTULO V: CARACTERIZACIÓN DE LOS ENFRIADORES EVAPORATIVOS INDIRECTOS DE PLACAS PLANAS dE POLICARBonato

CAPÍTULO VI: CARACTERIZACIÓN DE LOS ENFRIADORES EVAPORATIVOS DIRECTOS

CAPÍtulo Vil: CARACTERIZACIÓN DEL Sistema dE ENFRIAMIENTO GRATUITO POR AgUA.

CAPÍtulo Vili: CARActerización del RECUPERAdor de Dos baterías con BOMba 



\section{CAPÍTULO IV \\ DISPOSITIVO EXPERIMENTAL}

ABSTRACT

IV.1. INTRODUCCIÓN

IV.2. ELEMENTOS DEL BANCO DE ENSAYOS.

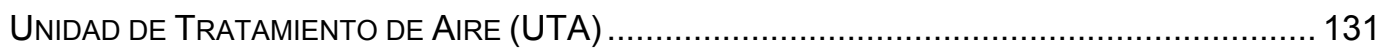

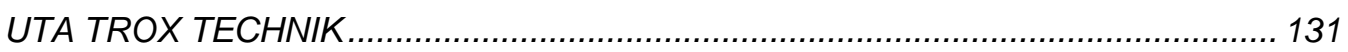

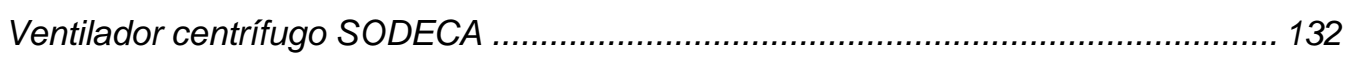

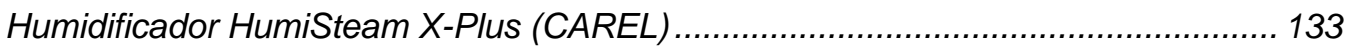

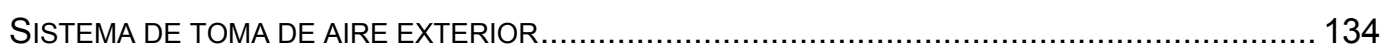

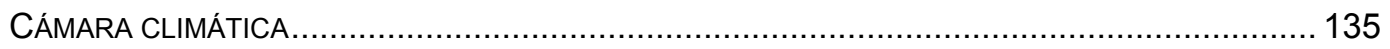

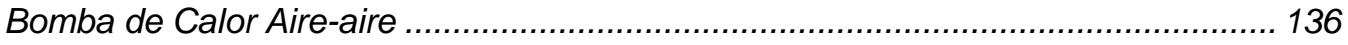

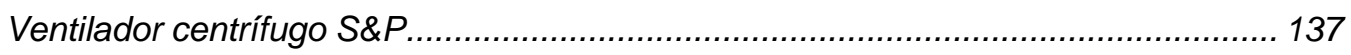

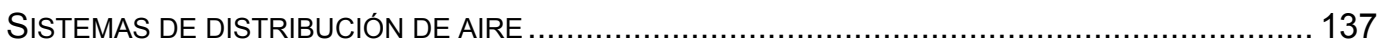

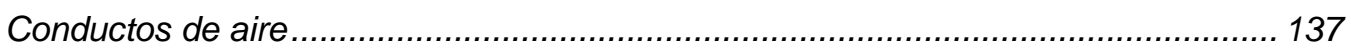

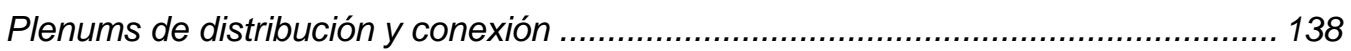

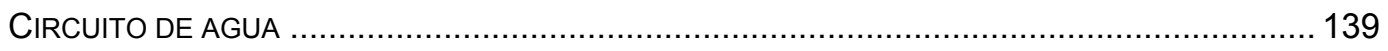

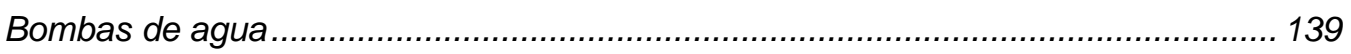

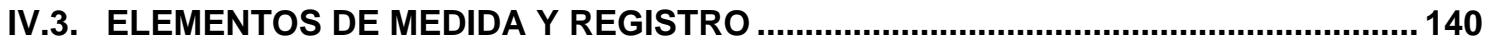

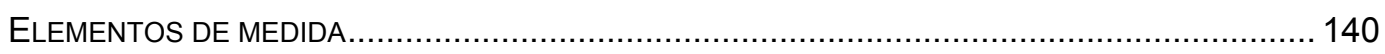

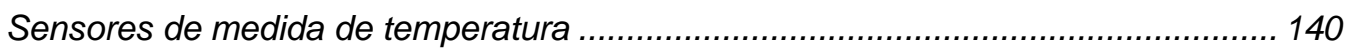

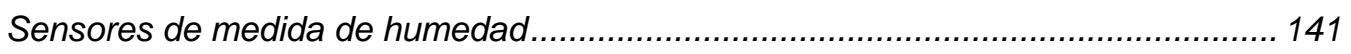

Medida de la presión diferencial y caudal volumétrico: Placa orificio. ........................ 141

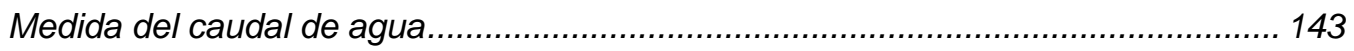

SISTEMA DE ADQUISICIÓN Y SOFTWARE DE MONITORIZACIÓN DE DATOS ................................ 143

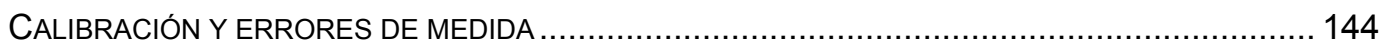

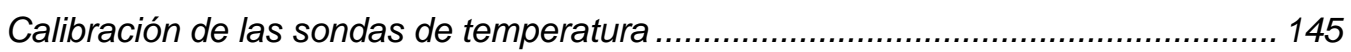

Calibración de las sondas de humedad relativa...................................................... 146

Calibración de la placa orificio para la medida del caudal....................................... 147

Calibración de los manómetros de presión para la medida del caudal...................... 149 


\section{CHAPTER IV: \\ EXPERIMENTAL FACILITY}

\section{ABSTRACT}

For the experimental characterization of the various systems acquired or, in most cases, designed and constructed in the laboratory, a complex and flexible experimental setup has been required. To construct such a complete facility, a number of differently dimensioned devices were needed. In the following chapter, these devices, both the ones required for the installation itself and the ones for measuring and acquisition of data, are thoroughly described.

Among the first group is the element permitting the provision of the required airstreams in the conditions at which the studied systems are to be tested. The different components of these devices are presented separately.

Another key component is the Climate Chamber where the due comfort climate conditions are required. This one is also described, together with the air fan that permits air renovation, and the heat pump installed to ensure that thermal loads are achieved indoors.

The rest of the facility aimed at installing the system is composed by the connecting ducts, distribution systems, and the water circuits when needed.

Moreover, the characteristics of the temperature, humidity, air volume flow and water flow measurement elements are described, as well as the acquisition data system. Finally, probes calibration and measurement errors estimated are described. 


\section{IV.1. INTRODUCCIÓN}

En el capítulo III se ha visto el estado actual de las tecnologías de acondicionamiento de aire en las que están basados los equipos, tanto prototipos como comerciales, estudiados en el presente proyecto de tesis doctoral. En particular, los sistemas de interés se corresponden con las tecnologías específicas de: enfriamiento evaporativo indirecto mediante intercambiadores de placas; enfriamiento evaporativo directo de medio rígido; enfriamiento evaporativo directo por pulverización; enfriamiento gratuito por agua y recuperación de energía mediante dos baterías con bomba.

La caracterización del funcionamiento de sistemas tan diversos requiere de un banco de ensayos muy versátil que disponga de múltiples recursos, siendo por lo tanto la instalación experimental necesaria para la realización de los ensayos sobre cada sistema específica de cada uno de estos. No obstante, en el capítulo actual se presentan y describen algunos de los dispositivos comunes necesarios para toda caracterización, si bien no todos ellos serán recurridos en el estudio de cada sistema.

\section{IV.2. Elementos DEL BANCO DE ENSAyOS}

A continuación se describen los distintos recursos disponibles en el laboratorio para conformar el banco de ensayos que permita en cada caso realizar la caracterización experimental de los sistemas abordados en capítulos posteriores.

Principalmente va a ser necesario disponer de unos elementos básicos que son, en primer lugar, una Unidad de Tratamiento de Aire que proporcione los caudales de aire de ventilación requeridos, reproduciendo las condiciones climáticas exteriores establecidas para cada ensayo; o un sistema de toma de aire exterior de ventilación si las condiciones climáticas ya cumplen los requisitos del ensayo. También es necesario un espacio cerrado que haga la función del local cuyo ambiente sería necesario acondicionar según los requerimientos de calidad del ambiente interior establecidos. Se precisa además de los elementos de distribución del aire que permitan conectar los distintos sistemas canalizando las corrientes de aire de impulsión y extracción en las diversas configuraciones posibles. Asimismo, en los casos pertinentes, se requerirá de sistemas de circulación y distribución de agua.

\section{Unidad de Tratamiento de Aire (UTA)}

\section{UTA TROX TECHNIK}

El sistema experimental debe ser capaz de simular las condiciones climáticas que pueden presentarse a lo largo de todo el año. Para reproducir las diferentes condiciones de temperatura del aire que se desean ensayar, se empleará una unidad de tratamiento de aire (UTA), modelo TKM-30 de la casa TROX TECHNIK (figura IV.1) [1,TROX,2000],[W-1] Este equipo dispone de un filtro para filtrar el aire a tratar, tomado del laboratorio; 2 baterías 
eléctricas que permitirán acondicionar térmicamente este flujo de aire y otra batería de tubos aleteados unidos a una bomba de calor reversible; un sistema de humidificación con control de humedad mediante dardo de vapor; y un sistema de impulsión.

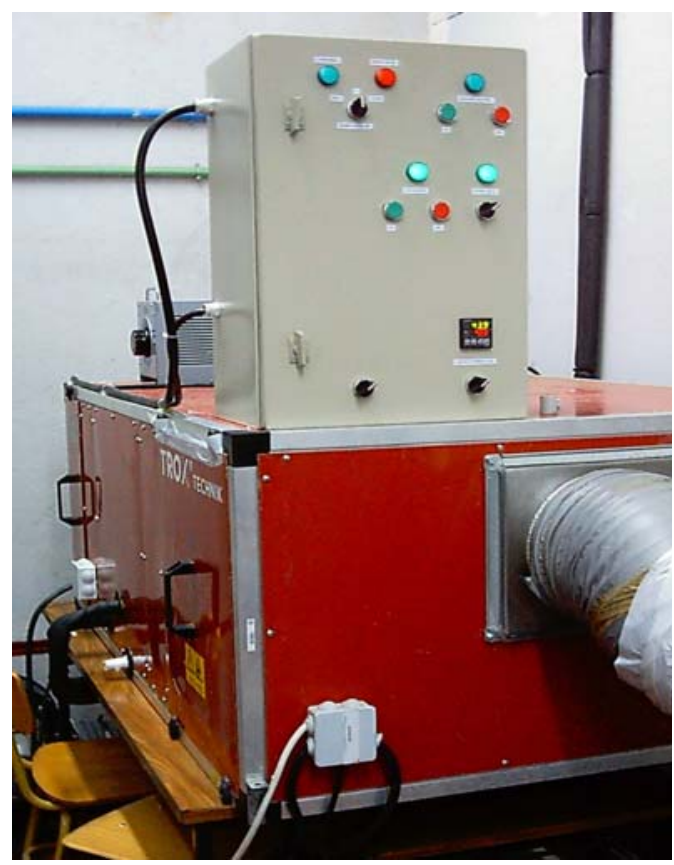

Figura IV.1.- Unidad de Tratamiento de Aire TROX serie TKM-30.

Algunas de las características generales del climatizador son:

- Potencia frigorífica: $20035 \mathrm{Frig} / \mathrm{h}$.

- Potencia calorífica: $20 \mathrm{~kW}$.

- Caudal de aire de impulsión: $2500 \mathrm{~m}^{3} / \mathrm{h}$.

- Potencia motor: 0,55 kW.

- Alimentación: 230 V.

\section{Ventilador centrífugo SODECA}

El sistema de impulsión de aire primario está constituido por un equipo ventilador acoplado a un regulador variable que permite modificar los caudales de aire impulsado (figura IV.2). Sin embargo, no es posible establecer valores muy precisos del caudal, ya que dicho elemento de regulación no dispone de posiciones determinadas, y dado que el caudal proporcionado para cada posición del regulador dependerá de las pérdidas de carga de la instalación particular que esté conectada a la UTA en ese ensayo, precisa en cada caso específico de una posición determinada diferente para proporcionar el caudal de aire más aproximado al nivel especificado para el ensayo en particular. Por lo tanto, será previsible cierta disparidad en los valores de caudal ensayados para los distintos sistemas. 


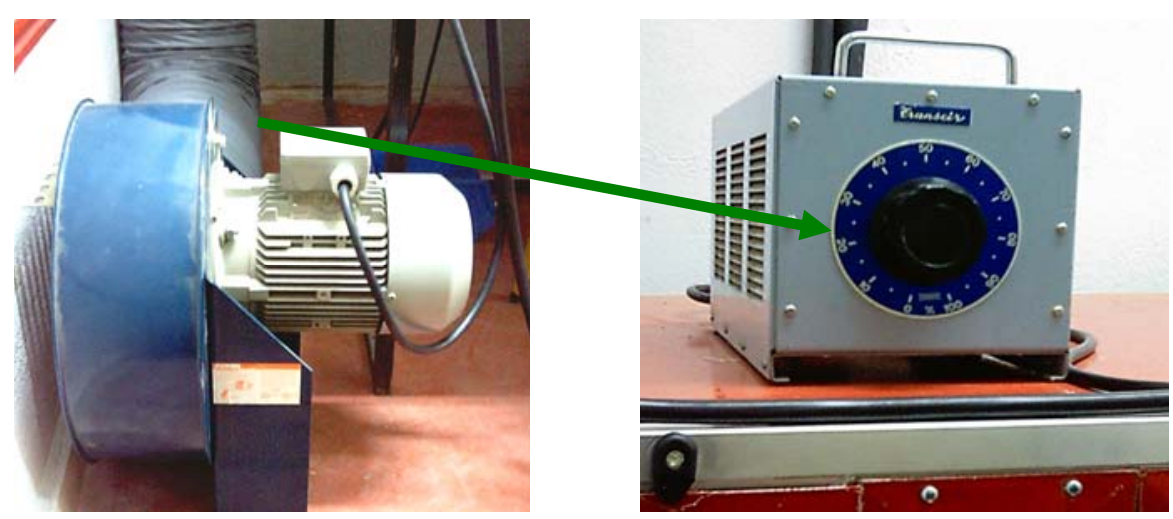

Figura IV.2.- Izquierda: ventilador de la casa SODECA. Derecha: Variador de frecuencia TELEMECANIC

El ventilador centrífugo utilizado es el modelo CMP-922-2T-3 de la casa SODECA [2, SODECA,2009], [W-2], cuyas características son:

- Velocidad de giro: $2845 \mathrm{rpm}$.

- Voltaje: $230 \mathrm{~V}$.

- Intensidad máxima admisible (400 V): 4,6 A.

- Potencia instalada: 2,2 kW.

- Caudal máximo: $2900 \mathrm{~m}^{3} / \mathrm{h}$.

- Peso aproximado: $2,5 \mathrm{~kg}$.

\section{Humidificador HumiSteam X-Plus (CAREL)}

Para poder ensayar distintos niveles de humedad relativa, la UTA original se ha combinado con un equipo humidificador, en concreto uno por electrodos sumergidos de la casa CAREL, modelo humiSteam x-plus (figura IV.3) [3, CAREL, 2007], [W-3]. Este sistema permite producir vapor a razón de hasta $10 \mathrm{~kg} / \mathrm{h}$, modulable desde el $20 \%$ hasta el $100 \%$ mediante un controlador que puede trabajar en distintos modos (todo o nada, proporcional, o modulante, en función de distintas señales externas y limitaciones de seguridad). El vapor producido se inyecta en la última etapa de la UTA con ayuda de una lanza distribuidora de vapor.

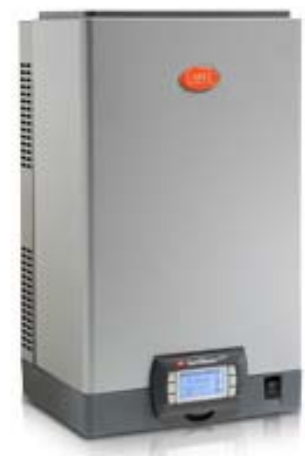

Figura IV.3.- Humidificador por electrodos sumergidos modelo humiSteam x-plus de la casa CAREL. 


\section{Sistema de toma de aire exterior}

Gracias a las adecuadas condiciones climáticas de Valladolid durante el período de ensayo, la caracterización de algunos equipos es posible haciéndolos trabajar directamente con el mismo aire exterior disponible. En estos casos es por lo tanto necesario tan sólo un sistema de toma de aire de ventilación del exterior del laboratorio. Este sistema constará simplemente de una conducción de aire desde una toma exterior equipada con un ventilador y un filtro de tipo filtrante fibroso seco, formado por un fieltro de asbesto, para retener en la medida de lo posible las impurezas que arrastra el aire.

El ventilador, mostrado en la figura IV.4, es de la marca ATLAS tiene las siguientes características:

- Revoluciones máximas: 1800 rpm

- Potencia máxima absorbida al eje: $2,5 \mathrm{~kW}$.

- Velocidad tangencial: rpmx0,0141 m/s.

- Dimensiones de la boca de aspiración: $221 \mathrm{~mm}$.

- Dimensiones de la boca de impulsión: 326x292 mm.

- Dimensiones del rodete: $275 \mathrm{~mm}$ de diámetro y $271 \mathrm{~mm}$ de ancho.

- Momento de inercia: PD/4 0,067 $\mathrm{kg} \cdot \mathrm{m}^{3}$.

- Peso de ventilador: $13 \mathrm{~kg}$.
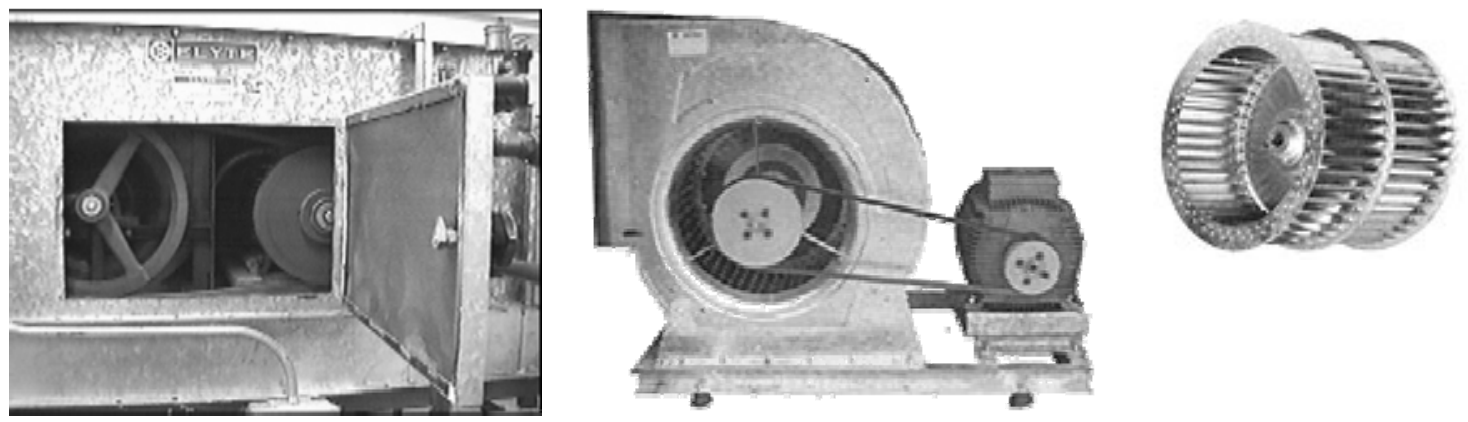

Figura IV.4.- Ventilador ATLAS utilizado para toma de aire exterior (centro); montado (izquierda), y vista del rodete (derecha).

La red de conductos de aire que constituyen la toma de aire de ventilación consta del propio conducto de toma directa de aire exterior, (marca KOOLAIR, mod. 20-45-H, 750 $\times 300$ $\mathrm{mm})$, y el conducto de impulsión con una derivación por la que podemos dirigir todo el aire de impulsión conduciéndolo por un tubo flexible con el fin de poder hacer una utilización directa del aire (figura IV.5). 

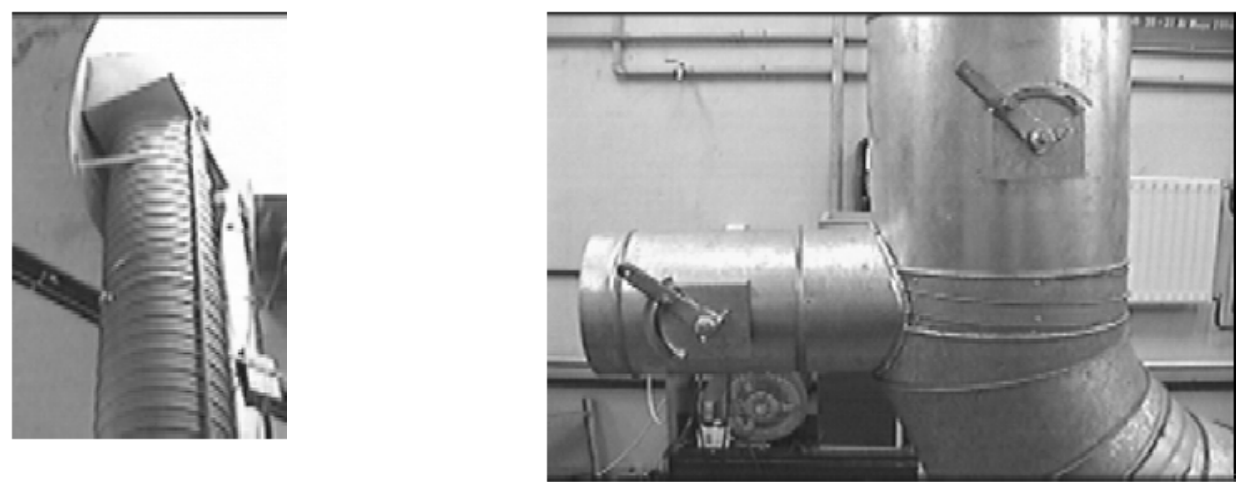

Figura IV.5.- Vista de la toma de aire exterior (izquierda) y derivación del conducto de impulsión (derecha).

\section{Cámara climática}

La cámara climática utilizada en el banco de ensayo experimental para la ejecución de los diferentes experimentos tiene de dimensiones aproximadas $4 \times 4 \times 3 \mathrm{~m}$, con techo variable en altura, equipada con 4 difusores rotacionales, donde se miden las condiciones higrotérmicas y de confort del acondicionamiento del aire (figura IV.6). Se encuentra elevada sobre el suelo apoyada sobre una serie de soportes, y dispone de una única puerta y una superficie total acristalada de $6,7 \mathrm{~m}^{2}$.

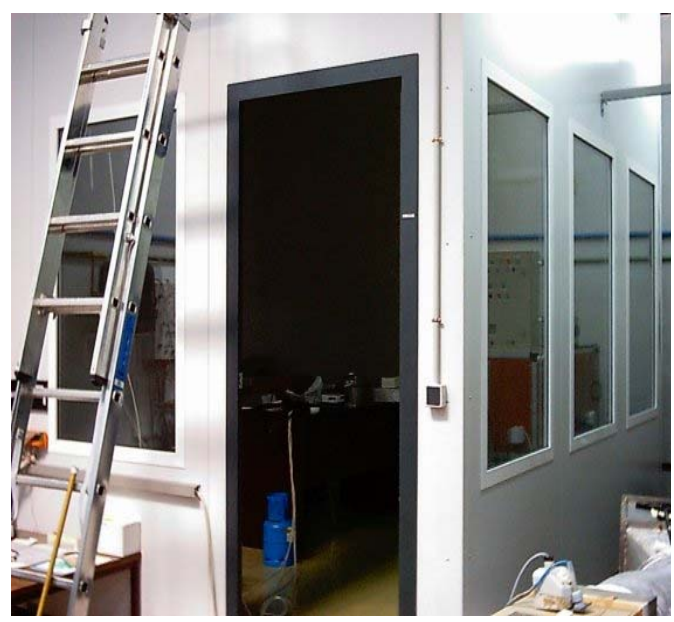

Figura IV.6.- Vista de la Cámara Climática del laboratorio.

En el capítulo II se describían detalladamente las condiciones requeridas para mantener un cierto nivel de calidad de los ambientes interiores, y cuáles eran las especificaciones establecidas en la normativa vigente con ese mismo fin. Para reproducir de forma válida las condiciones de funcionamiento de los sistemas en algunos ensayos en los que se hace uso de las condiciones del aire de extracción, va a ser necesario asegurar que el espacio acondicionado se encuentra dentro de dichos requisitos. Según lo establecido en el RITE (Reglamento de Instalaciones Térmicas en Edificios), las condiciones interiores de diseño en verano para personas con actividad metabólica sedentaria (1,2 met) y vestimenta de 0,5 clo, asegurando un PPD entre el $10 \%$ y el $15 \%$, están comprendidas entre 23 y $25{ }^{\circ} \mathrm{C}$ de 
temperatura operativa, y entre 40 y $60 \%$ de humedad relativa; parámetros en consideración para edificios de nueva construcción o en reformas de edificios ya existentes [N-1].

En el particular, las condiciones ambientales alcanzadas en la cámara se mantienen entre 20 y $23^{\circ} \mathrm{C}$ de temperatura seca, y entre un 35 y un $65 \%$ de humedad relativa. Estas condiciones se adecuan a los requisitos de confort térmico y salubridad estudiados en el capítulo II, puesto que valores de temperatura seca más relajados están orientados simplemente a un ahorro energético, y por lo tanto valores menores alcanzados con equipos de consumo energético casi nulo serían admisibles. Dichas condiciones serán además las del aire de retorno dirigido al paso secundario del sistema.

\section{Bomba de Calor Aire-aire}

Con el objetivo de conseguir que la temperatura y humedad relativa de la sala estén próximas a las condiciones de confort requeridas, es necesario situar un dispositivo adicional con el que podremos aportar o extraer calor del recinto cuando la temperatura seca del aire se encuentre por debajo o por encima de la temperatura de confort. Para ello se dispone de una bomba de calor tipo Split Aire-Aire con la que se alcanza la temperatura adecuada en la cámara antes de iniciar el ensayo programado (figura IV.7).
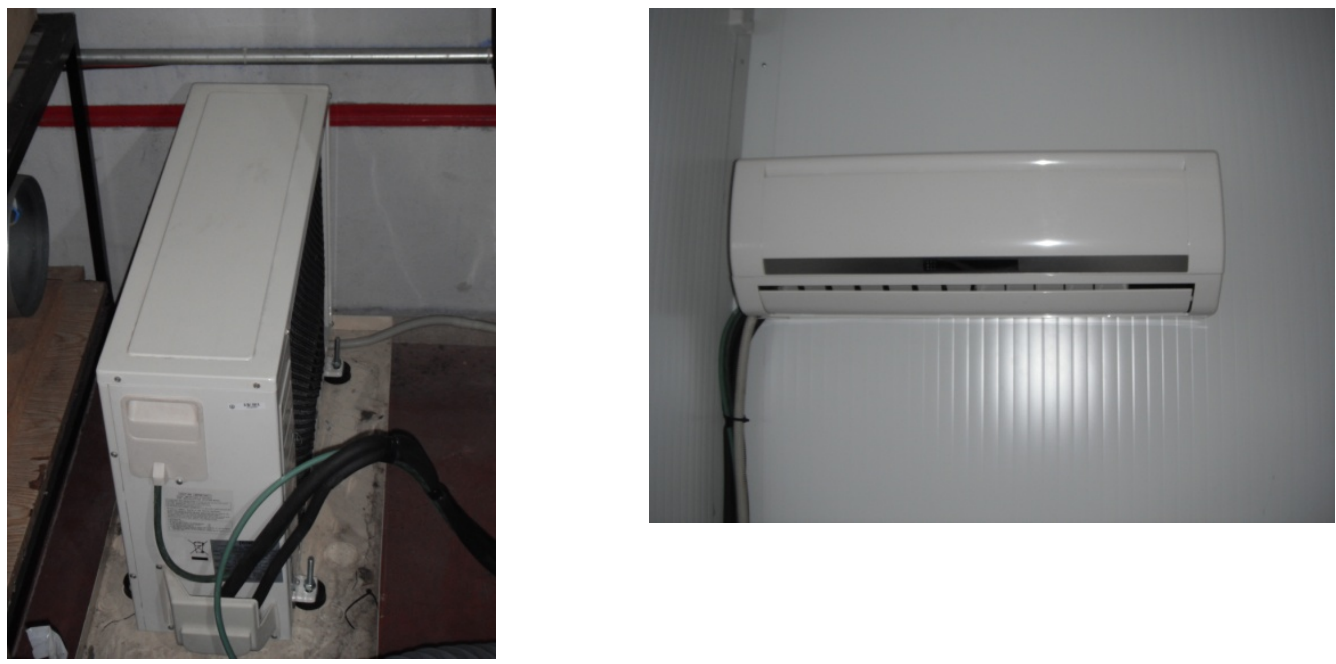

Figura IV.7.- Unidades exterior (izquierda) e interior (derecha) de la Bomba de Calor aireaire de marca Ferroli instalada en la cámara climática.

El equipo disponible es un acondicionador modelo Diamond 9000 de la casa Ferroli [4, Ferroli, 2007] [W-4], algunas de cuyas características generales son:

- Refrigerante: R410A.

- Potencia frigorífica: $2,6 \mathrm{~kW}$ (a $35^{\circ} \mathrm{C}$ de temperatura seca exterior y $27^{\circ} \mathrm{C} / 19^{\circ} \mathrm{C}$ de temperatura seca/ de bulbo húmedo en el ambiente).

- Potencia calorífica: $3,2 \mathrm{~kW}\left(a 7^{\circ} \mathrm{C} / 6^{\circ} \mathrm{C}\right.$ de temperatura seca/ de bulbo húmedo exterior y $20^{\circ} \mathrm{C}$ de temperatura seca en el ambiente).

- Alimentación: 230 V/ $50 \mathrm{~Hz}$. 


\section{Ventilador centrífugo $S \& P$}

Además, será también necesario disponer de un ventilador en el interior de la cámara climática para impulsar el aire de retorno hacia el sistema. El ventilador instalado se muestra en la figura IV.8.

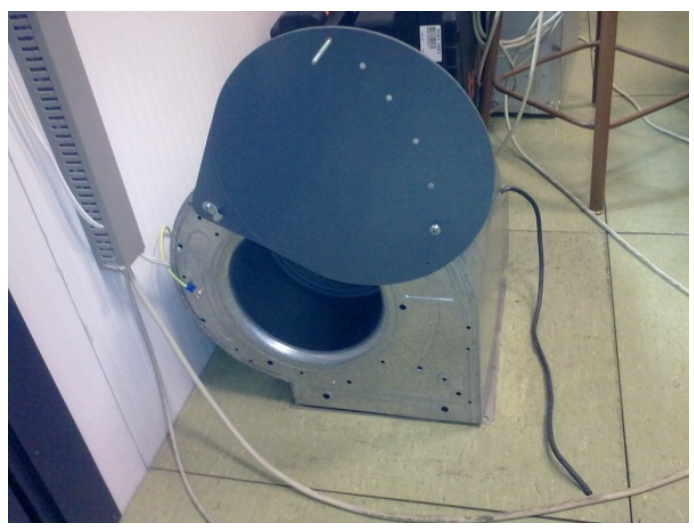

Figura IV.8.- Ventilador instalado en la cámara climática.

Se trata de un ventilador centrífugo tipo CBM/4-240/240 T3/4 CV de la casa Soler\&Palau [5,Soler\&Palau], [W-5], de características:

- Potencia: 0,55 kW.

- Velocidad de giro: $1320 \mathrm{rpm}$.

- Alimentación: 230 V/ $50 \mathrm{~Hz}$.

\section{Sistemas de distribución de aire}

\section{Conductos de aire}

Se han empleado conductos de aire flexibles de diámetro de $250 \mathrm{~mm}$ para conectar los elementos disponibles en el banco de ensayos según los requerimientos de las distintas configuraciones a ensayar. Un detalle de estos conductos se muestra en la figura IV.9:

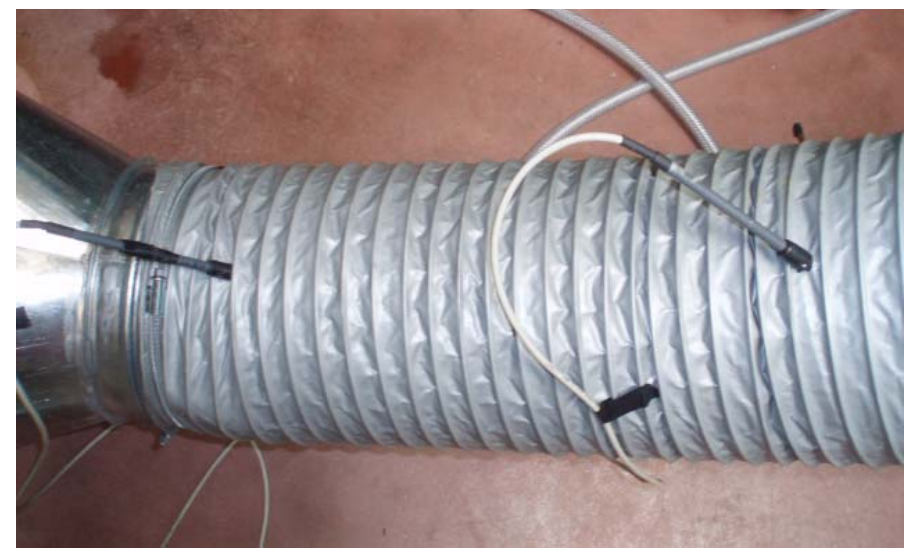

Figura IV.9.- Detalle de un conducto de aire flexible.

Estos conductos van a permitir la conducción de las corrientes de aire de retorno de la cámara climática y las proporcionadas por las UTAs, así como las procedentes del sistema ensayado en cada caso particular. Sin embargo, para ello va a ser también necesario disponer de elementos que permitan realizar la conexión de los conductos a los distintos elementos. 


\section{Plenums de distribución y conexión}

En las figuras IV.10 y IV.11 se muestran los plenums de distribución de aire desde la UTA y hacia la cámara climática.

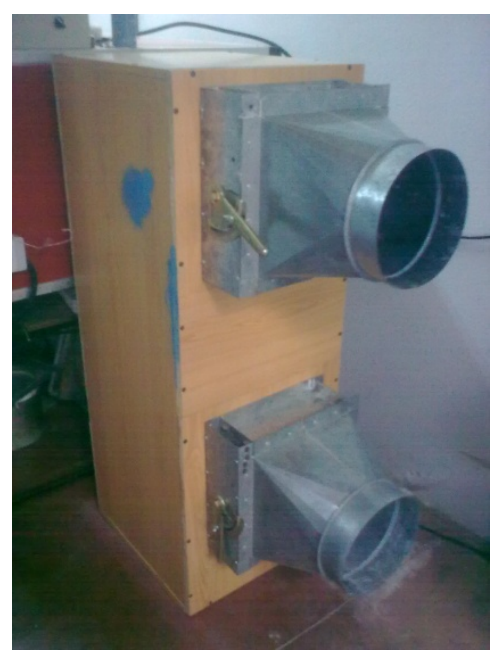

Figura IV.10.- Vista del plénum de distribución conectado a la UTA.

El plénum instalado a la salida de la UTA va a permitir dividir en dos la corriente de aire tratado hasta las condiciones del ensayo, para su canalización hacia diversos objetivos, en las configuraciones en las que se precisan varias tomas de aire exterior.

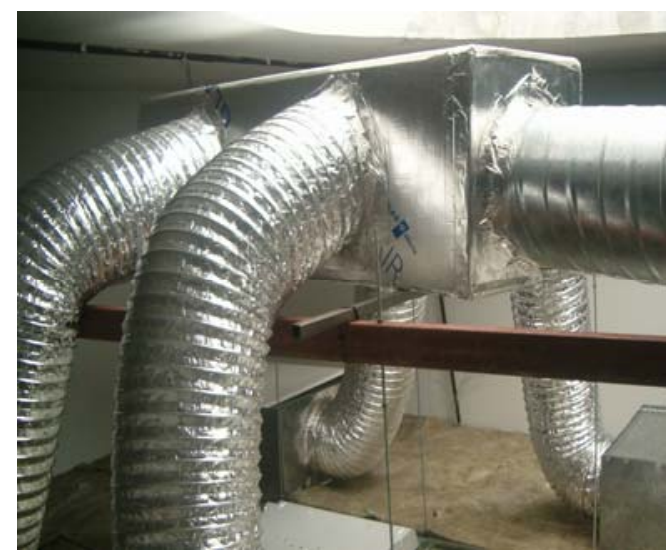

Figura IV.11.- Vista de la conexión del plénum de distribución a la cámara climática.

Por su parte, es necesario también disponer de un plénum a la entrada de la cámara climática para la distribución del aire hacia las 4 entradas de aire disponibles en ésta, correspondientes a los 4 difusores rotacionales ya descritos en el apartado anterior.

Finalmente, la conexión de los conductos de aire a las admisiones y salidas de los distintos sistemas tiene que realizarse disponiendo unos colectores que se ajusten a cada dispositivo en particular. En la figura IV.12 se muestran algunas vistas de los colectores utilizados con este objeto. 

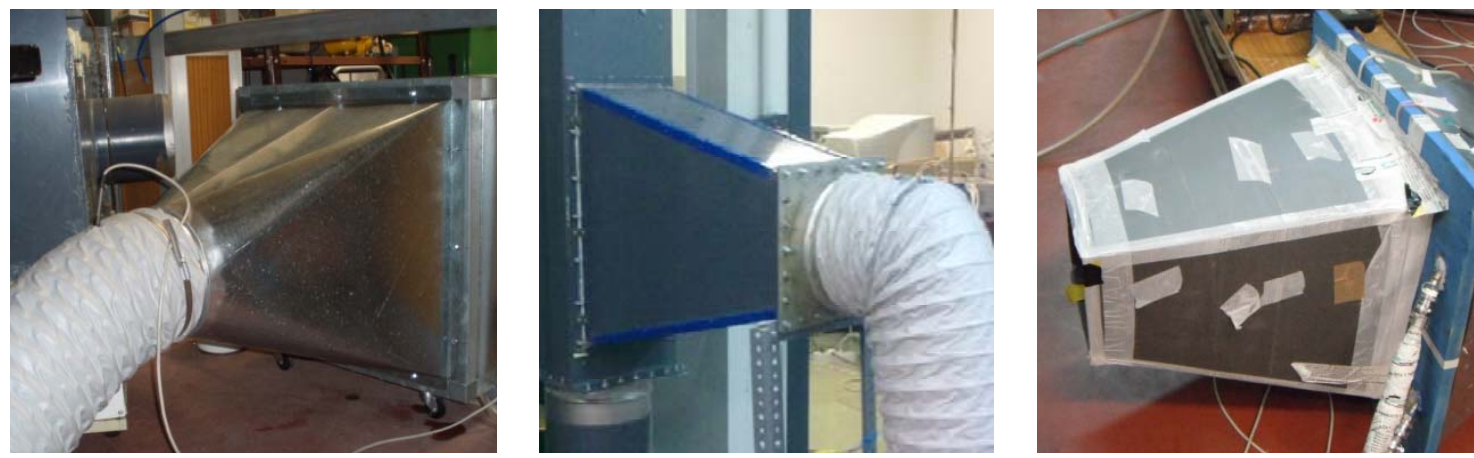

Figura IV.12.- Colectores empleados en la conexión de los conductos a los sistemas, de material metálico (izquierda), PVC (centro) y plástico (derecha).

\section{Circuito de agua}

En algunas de las configuraciones de ensayo de ciertos sistemas es necesario realizar un aporte de agua. Para la canalización del agua se emplean mangueras de PVC transparentes reforzadas, de características:

- Diámetro exterior de tubo: $27 \mathrm{~mm}$.

- Diámetro interior de tubo: $20 \mathrm{~mm}$.

- Presión máxima de funcionamiento: 7 bar.

- Rango de temperaturas: $-15 \mathrm{a}+60^{\circ} \mathrm{C}$

\section{Bombas de agua}

Como elementos de circulación, se emplean bombas de agua de pequeño tamaño, como las mostradas en la figura IV.13, de distinta potencia en función de la pérdida de carga específica de la instalación de agua en cada sistema.
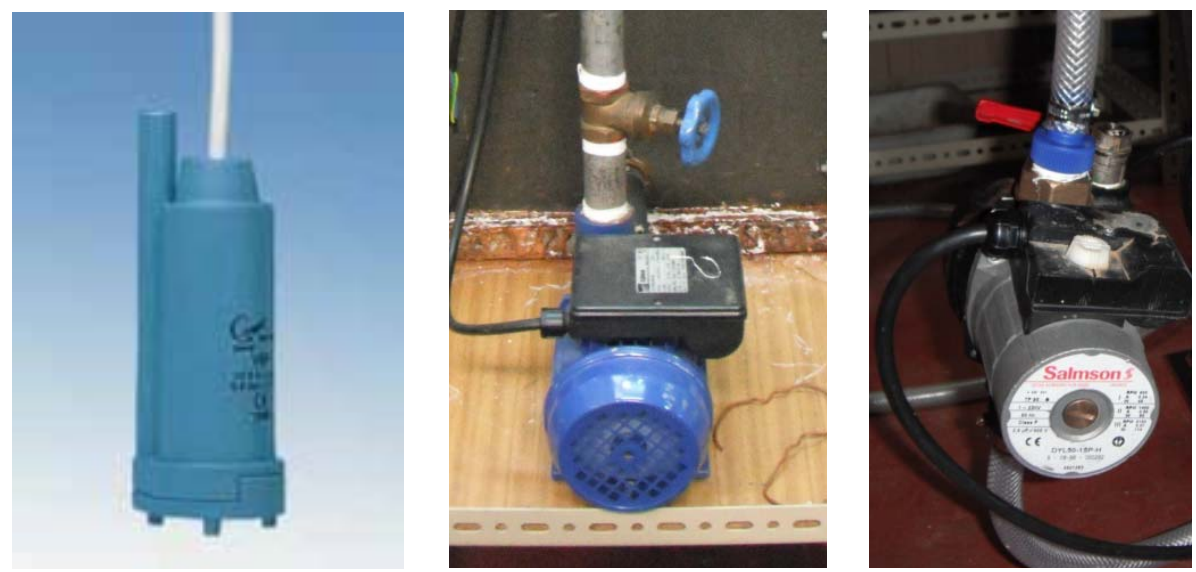

Figura IV.13.- Bombas de agua disponibles en el banco de ensayos, Comet sumergible (izquierda), EBARA periférica (centro), y Salmson (derecha).

La figura de la izquierda se corresponde con una bomba sumergible de la casa Comet, modelo VIP [6,Comet,2011], [W-6], de características: 
- Potencia consumida: 10 a 20 W.

- Caudal máximo: 16 l/min.

- $\quad$ Altura máxima: 6,5 m.

También se dispone de una electrobomba periférica de arrabio de la casa EBARA, modelo PRA 050 M [W-7], de $37 \mathrm{kWcaudal} \mathrm{mínimo} 0,3 \mathrm{~m}^{3} / \mathrm{h}$ y altura máxima $88 \mathrm{~m}$.

- Potencia consumida: 370 W.

- Caudal mínimo: $0,3 \mathrm{~m}^{3} / \mathrm{h}$.

- $\quad$ Altura máxima: 88 m (65 bar).

La bomba de la derecha se corresponde con una bomba Salmson modelo DY L50-15P-H, [W-8]:

- Potencia consumida: 46 a 93 W.

- Caudal máximo: $3,2 \mathrm{~m}^{3} / \mathrm{h}$.

- $\quad$ Altura máxima: 6 m.

\section{IV.3. ELEMENTOS DE MEDIDA Y REGISTRO}

Finalmente, será necesario disponer de dispositivos de medida de las múltiples variables de interés sobre las condiciones de los fluidos de trabajo, así como de los elementos que permitan el registro de dichas medidas.

\section{Elementos de medida}

\section{Sensores de medida de temperatura}

Para la medida de la temperatura en todos los puntos de la instalación, se ha optado por sensores Pt100 a 4 hilos cerámicos (figura IV.14) de la casa RS [W-9]. Aunque su coste es alto, es el material más idóneo y con mejores características para emplearlo como sensor de temperatura por su alto grado de linealidad y estabilidad así como por su elevada precisión, llegando a ser esta del orden de $0,1^{\circ} \mathrm{C}$. El rango de temperaturas de trabajo abarca de -50 a $+250^{\circ} \mathrm{C}$.

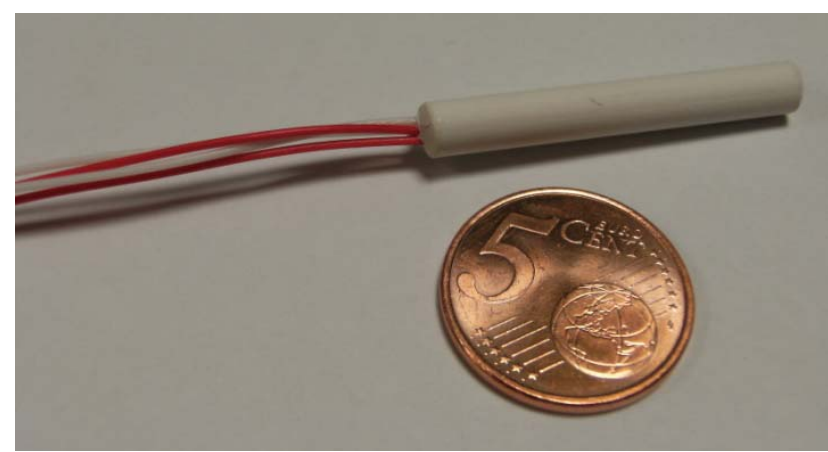

Figura IV.14.- Sonda cerámica de temperatura. 


\section{Sensores de medida de humedad}

Como sondas de medida de la humedad relativa se emplean sensores capacitivos de detección fabricados en polímero termoestable (figura IV.15), de la casa Honeywell [W-10].

En algunos casos, como por ejemplo en los instrumentos situados en el conducto de impulsión, en un mismo tubo de protección se incorporan dos sensores: temperatura y humedad relativa.

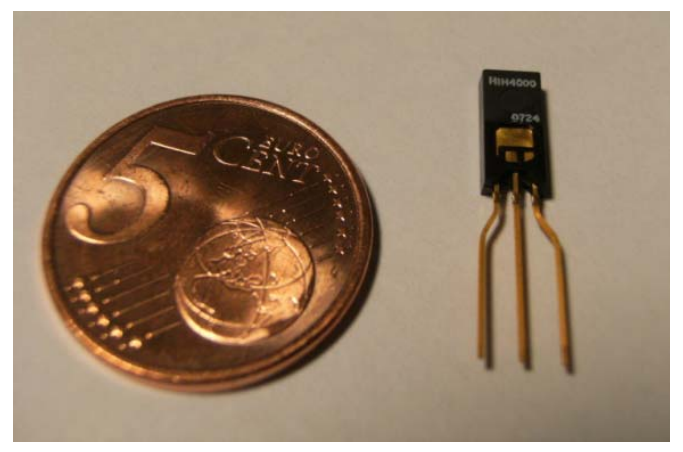

Figura IV.15.- Higrómetro capacitivo Honeywell.

Sus principales características son:

- Tensión de alimentación: 5 Vcc

- Escala de medida: de 0 a $100 \%$ de HR.

- Precisión del instrumento: $+/-2 \%$.

- Estabilidad: +/- 1\% HR.

- Tiempo de respuesta: $15 \mathrm{~s}$.

- Salida de tensión: de 0,8 a 3,9 Vcc

- Temperatura de funcionamiento: de $-40^{\circ} \mathrm{C}$ a $+85^{\circ} \mathrm{C}$.

Medida de la presión diferencial y caudal volumétrico: Placa orificio.

Para la medida del caudal volumétrico, se parte de las medidas de presión diferencial obtenidas a partir de los valores proporcionados por los manómetros dispuestos a entrada y salida de una placa orificio de $10 \mathrm{~cm}$ de diámetro, como la mostrada en la figura IV.16. Un ejemplo de cálculo de caudales realizado mediante este procedimiento es el registrado para la placa orificio numerada 1, proporcionado en la figura IV.17.

Para la medida de la caída de presión en la placa orificio, se emplean sensores de diferencia de presión ultrabaja como el mostrado en la figura IV.18, que proporcionan una salida de tensión proporcional a la presión aplicada. 


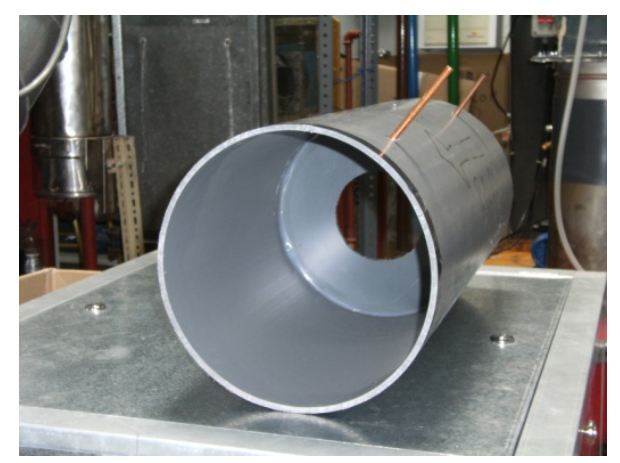

Figura IV.16.- Vista de una de las placas orificio utilizadas en la medición del caudal de aire.

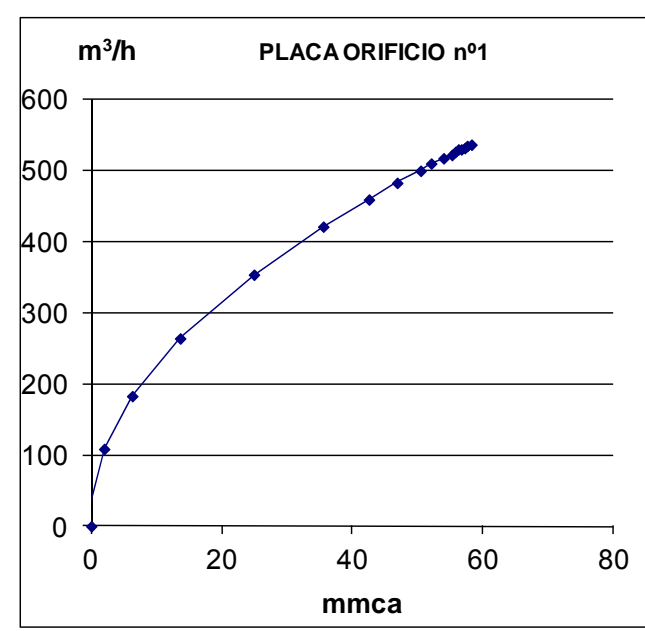

Figura IV.17.- Curva de caudales medidos con la placa orificio $n^{\circ} 1$.

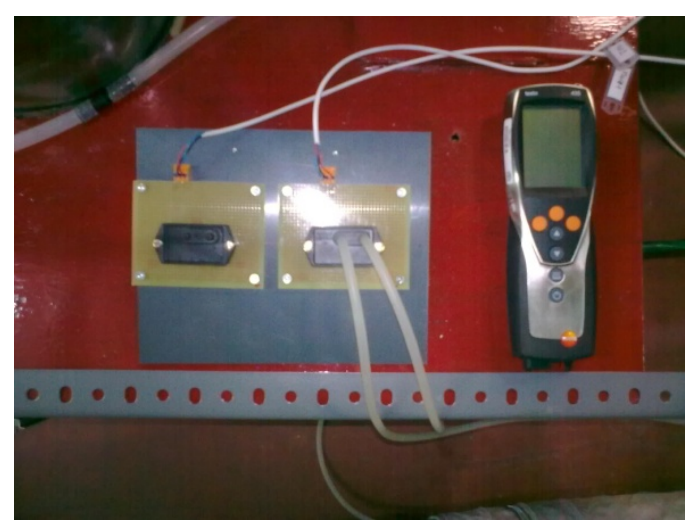

Figura IV.18.- Sensores de presión manométrica utilizados.

Las especificaciones técnicas de los sensores de presión manométrica son [W-9]:

- FSO (Salida a Fin de Escala: Diferencia algebraica entre puntos extremos de salida de presión nula y máxima): mín 4.85 típ 5.00 máx $5.15 \mathrm{~V}$

- Desplazamiento del cero: mín 0.95 típ 1.00 máx $1.05 \mathrm{~V}$

- Excitación: mín 3.45 típ 3.5 máx $3.55 \mathrm{~V}$

- Excitación: mín 6.0 típ 8.00 máx 16.0 Vcc

- Corriente de salida: Fuente $10.0 \mathrm{~mA}$, Sumidero 5.0

- Corriente de alimentación (carga 10k1/2) 8.0 20.0 mA

- Sobrepresión 5 p.s.i.

- Temperatura de operación $-40^{\circ} \mathrm{C}$ to $+85^{\circ} \mathrm{C}$

- Temperatura de almacenaje $-55^{\circ} \mathrm{C}$ to $+125^{\circ} \mathrm{C}$ 


\section{Medida del caudal de agua}

En las configuraciones de ensayo en las que es necesario disponer de un circuito de agua, se recurre a un caudalímetro de bola, de la marca Parker [W-11], para la medida del flujo volumétrico de agua circulante. Se trata de indicadores de caudal variable con un flotador dentro de una escala graduada exterior de caudal en la funda de visión. Utilizan la técnica de la presión diferencial a través de un pistón que, a medida que el caudal aumenta, mueve el pistón contra un resorte calibrado; y requieren ser instalados en posición perfectamente vertical para asegurar la máxima precisión. Se utilizan distintos modelos en función del rango de caudales requeridos en el ensayo particular. Estos dispositivos se corresponden con el mostrado en la figura IV.19:
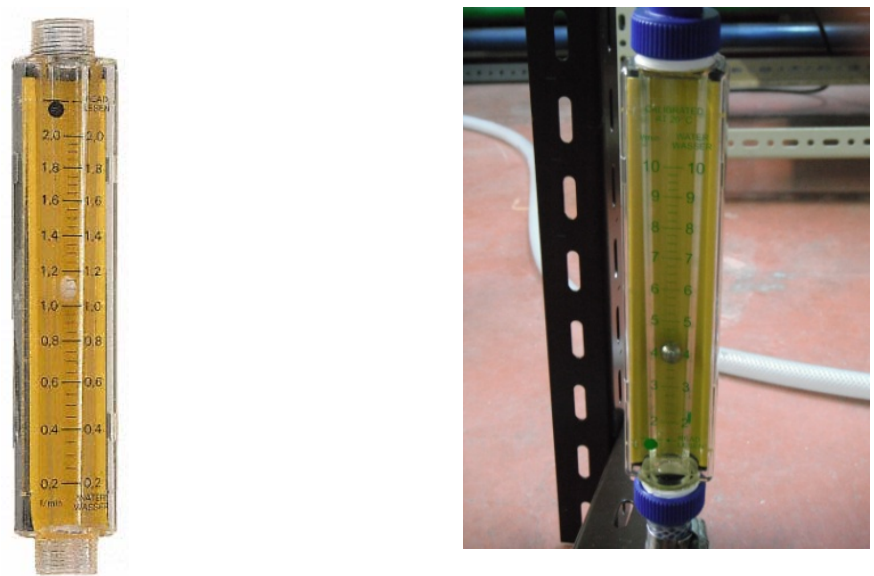

Figura IV.19.- Caudalímetro de bola de la marca Parker.

Las características de estos caudalímetros son:

- Precisión $\pm 2 \%$

- $\quad$ Repetitividad $\pm 1 \%$

- Presión de funcionamiento 10 bar

- Temperatura de funcionamiento máxima $60^{\circ} \mathrm{C}$

- Rango de velocidad de flujo: 1,5 a $10 \mathrm{l} / \mathrm{min}$ y de 4 a $22 \mathrm{l} / \mathrm{min}$.

\section{Sistema de adquisición y software de monitorización de datos}

El sistema de instrumentación y adquisición de datos ha de posibilitar la medida del mayor número de variables posible con la precisión adecuada, además de controlar las interacciones y relaciones entre las variables estudiadas. Para ello se requiere el uso de instrumentos potentes y flexibles que adquieran toda la información, la registren y la traten, a la vez que efectúan decisiones y controlan el sistema. En particular se emplea un adquisidor de datos «Agilent 34972A» como el mostrado en la figura IV.20 [7, Agilent, 2010], [W-12]. 


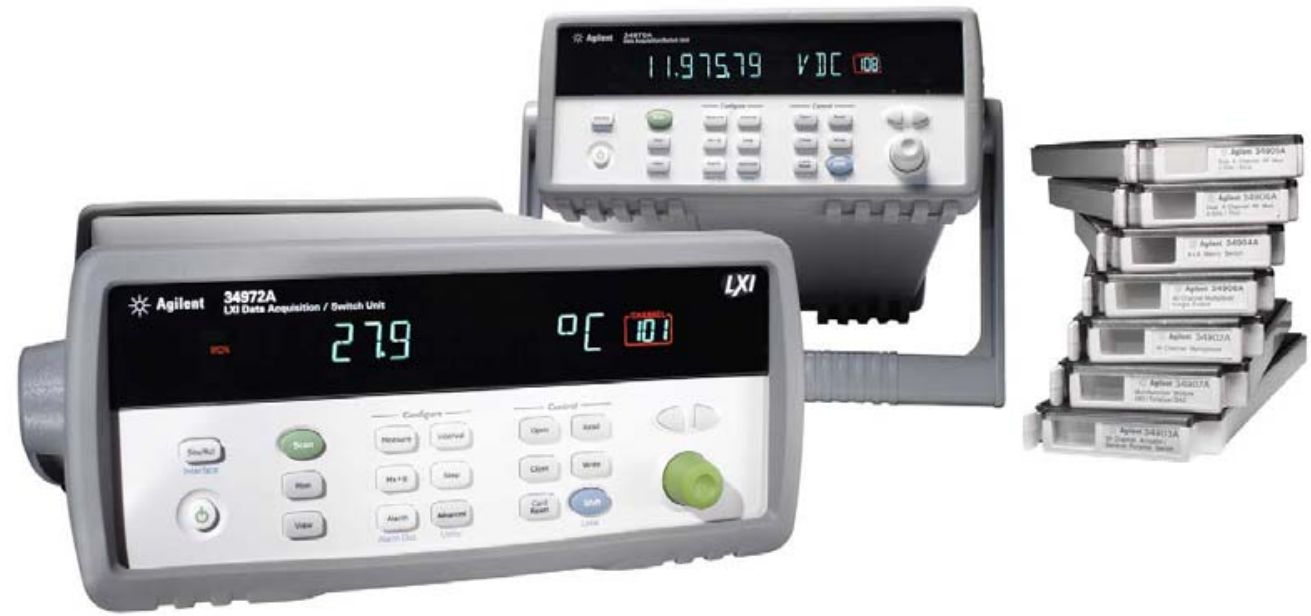

Figura IV.20.- Adquisidor de datos Agilent 34972A.

El sistema de adquisición de datos (SAD) sirve de interfaz entre el computador digital y el sistema físico. Permite capturar, acondicionar, procesar y generar señales, transformando las señales de tensión procedentes de sensores de presión, termorresistencias, sensores de humedad, etc. en valores numéricos para su posterior representación gráfica y análisis numérico. Para ello constará de distintos elementos, como son un ordenador, transductores, actuadores, acondicionamiento de la señal, circuitería de adquisición de datos, circuitería de análisis de los datos, control y software.

\section{Calibración y errores de medida}

Para reducir la incertidumbre de una medida, es necesario determinar los límites entre los que se comprende el error de medida del instrumento utilizado, lo que requiere de una calibración adecuada de éste. De esta forma, se dice que un instrumento estará bien calibrado cuando en todos los puntos de su campo de medida, la diferencia entre el valor real de la variable y el valor transmitido esté comprendida entre los límites determinados por la precisión del instrumento.

El objetivo de la calibración de los equipos de medida es poder efectuar su confirmación metrológica, es decir, determinar a través de los resultados obtenidos en las calibraciones si el equipo está en condiciones de medir o si es adecuado para garantizar la precisión requerida en las medidas. Los equipos a verificar se contrastarán con patrones de referencia debidamente reconocidos por los organismos competentes.

Las sondas de medida de temperatura, humedad relativa y los manómetros de medida de presión utilizados para el cálculo del caudal de aire, se han calibrado previamente a su uso según se describe a continuación. 


\section{Calibración de las sondas de temperatura}

Las sondas de temperatura cerámicas se han calibrado con la ayuda de un horno de calibración FLUKE 9103 (rango de calibración entre -25 hasta $140^{\circ} \mathrm{C}$ ) utilizado como patrón primario (figura IV.21). El rango de calibración de las sondas está comprendido entre -5 y $45^{\circ} \mathrm{C}$, el cual cubre las condiciones de trabajo ensayadas. Para la calibración, la temperatura del horno se ha variado desde el valor mínimo al máximo y, una vez alcanzado éste, manteniendo constante la temperatura en dicho valor durante un período mínimo de 1 hora. Tras esto, se disminuye de nuevo la temperatura hasta el valor inferior, a fin de reflejar la histéresis de la medida.

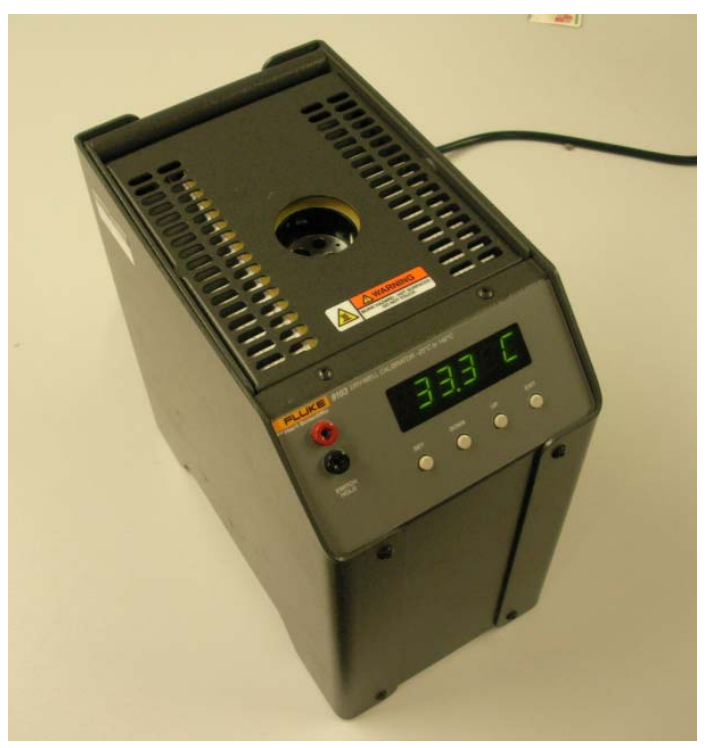

Figura IV.21.- Horno de calibración FLUKE 9103.

La tabla IV.1 recoge las regresiones obtenidas para las curvas de calibración de las diferentes sondas utilizadas.

Tabla IV.1.- Regresiones de las rectas de calibración de las sondas de temperatura.

\begin{tabular}{|c|c|c|c|}
\hline $\mathrm{T}_{\text {medida }}=\mathrm{a} \cdot \mathrm{T}_{\text {horno }}+\mathrm{b}$ & $\mathrm{a}$ & $\mathrm{b}$ & $\mathrm{R}^{2}$ \\
\hline $\mathrm{T} 1$ & 1,03 & $-0,5716$ & 0,9997 \\
$\mathrm{~T} 2$ & 1,0949 & $-2,3401$ & 0,9994 \\
$\mathrm{~T} 3$ & 1,0195 & $-0,2901$ & 1 \\
$\mathrm{~T} 4$ & 1,061 & $-0,9978$ & 0,9998 \\
$\mathrm{~T} 5$ & 0,9245 & $-3,6188$ & 0,8168 \\
$\mathrm{~T} 6$ & 1,027 & $-0,4408$ & 0,9999 \\
$\mathrm{~T} 7$ & 1,0091 & $-0,2464$ & 1 \\
\hline $\mathrm{T} 8$ & 1,0137 & $-0,5062$ & 0,9999 \\
\hline
\end{tabular}

La sonda de temperatura T5 se desconsideró en la realización de los ensayos, debido a los malos resultados registrados en la calibración, como puede observarse por la baja 
regresión. El resto de las sondas se consideraron válidas para la realización de medidas, dado que la regresión es superior a 0,999. La figura IV.22 muestra a modo de ejemplo una de las gráficas de estas regresiones.

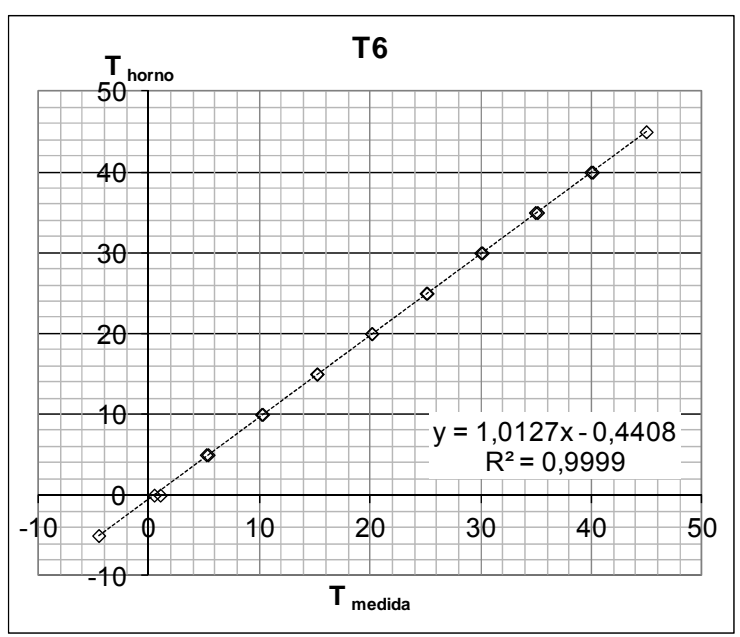

Figura IV.22.- Regresión de la calibración de la sonda de temperatura T6.

Estas regresiones se programaron en el adquisidor de datos para obtener de forma directa los valores corregidos de temperatura, ya aplicado el ajuste de calibración.

\section{Calibración de las sondas de humedad relativa}

La calibración de las sondas de humedad se ha realizado de forma simultánea, y utilizando como referencia la sonda de humedad relativa TESTO [W-14], según se muestra en la figura IV.23: se proporciona un caudal de aire a humedad relativa determinada, y en un cierto punto de su canalización se disponen todas las sondas de humedad relativa junto con la sonda patrón. Se realiza el registro de las medidas en comparación a la referencia para un rango de humedades de entre el $20 \%$ y el $90 \%$.
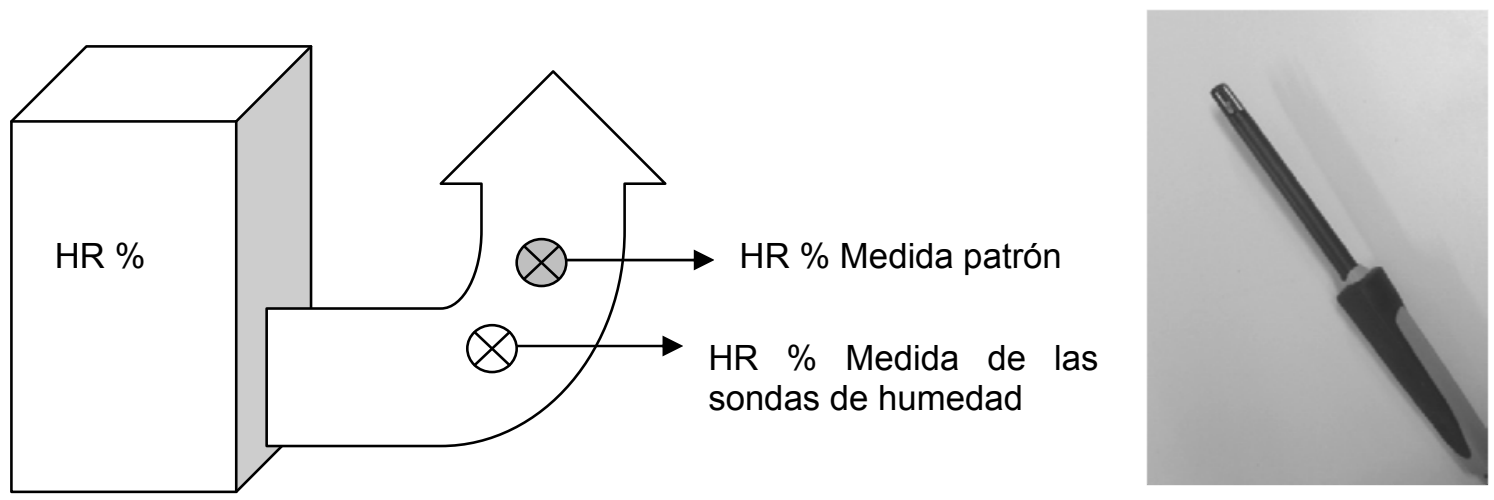

Figura IV.23.- Esquema del dispositivo de calibración de las sondas de humedad relativa, y sonda TESTO utilizada de patrón de referencia (derecha). 
En la tabla IV.2 se recogen las regresiones obtenidas para las 4 sondas de humedad relativa empleadas.

Tabla IV.2.- Regresiones de las rectas de calibración de las sondas de humedad relativa.

\begin{tabular}{|c|c|c|c|}
\hline Dif $_{\text {medida }}=\mathrm{a} \cdot \mathrm{HR}_{\text {horno }}+\mathrm{b}$ & $\mathrm{a}$ & $\mathrm{b}$ & $\mathrm{R}^{2}$ \\
\hline Sonda 1 & 0,0396 & 0,1422 & 0,9344 \\
Sonda 2 & 0,026 & 0,629 & 0,8629 \\
Sonda 3 & 0,029 & 0,5249 & 0,935 \\
\hline Sonda 4 & 0,0269 & 0,5899 & 0,8861 \\
\hline
\end{tabular}

Aunque las regresiones no son óptimas, los resultados de la calibración serían aceptables, ya que los rangos en los que varía la humedad relativa real para medidas iguales, debidos a la histéresis de las sondas, aunque elevados, no suponen diferencias importantes en las humedades específicas asociadas.

Estos resultados se programan directamente en el adquisidor de datos para la obtención directa de los valores de humedad relativa. A modo de ejemplo, se muestra en la figura IV.24 la gráfica de la regresión obtenida para una de éstas.

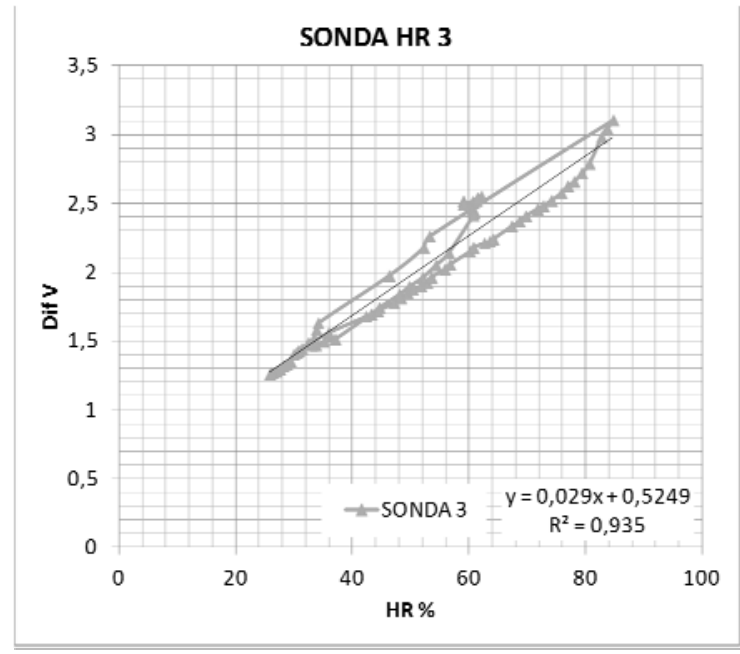

Figura IV.24.- Regresión obtenida en la calibración de la sonda de humedad relativa n³.

\section{Calibración de la placa orificio para la medida del caudal}

Las placas orificio utilizadas en la medición del caudal de aire en la instalación, han sido previamente calibradas mediante una tobera de acero inoxidable de la casa TECNER Ingeniería [W-13], modelo TG50 (figura IV.25), con rango de trabajo entre 3200 I/min y 13000 I/h, y con pérdida de carga conocida. 

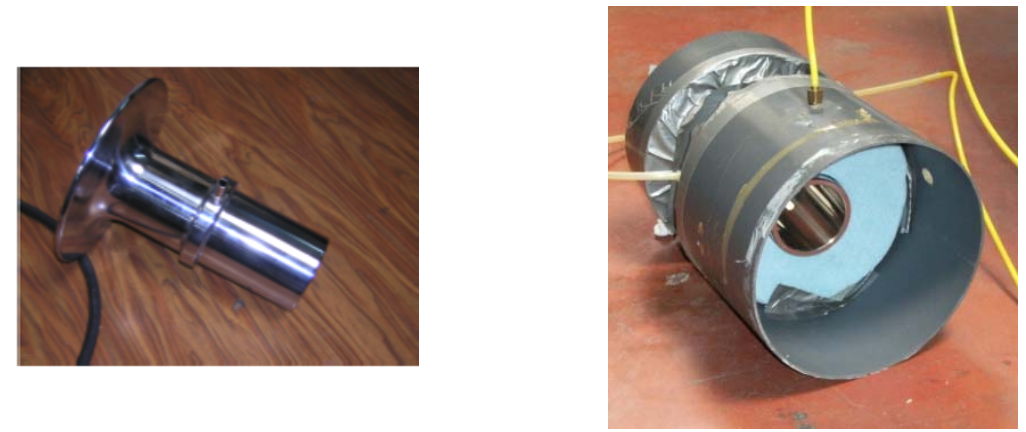

Figura IV.25.- Tobera de referencia para calibración. Derecha: tobera montada.

En su instalación intercalada en un conducto para la calibración, hay que prever una longitud recta equivalente a 6 diámetros aguas arriba de la tobera, y a 3 diámetros aguas debajo de la tobera (figura IV.26).

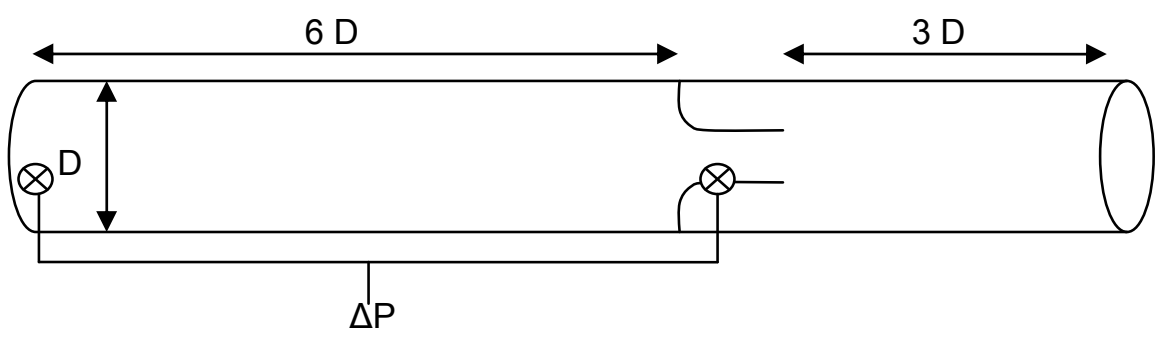

Figura IV.26.- Esquema de la instalación de la tobera para la calibración

Las especificaciones dadas para la tobera por el fabricante se proporcionan en los anexos (Anexo B).

Con el caudal calculado a partir de las medidas de caída de presión registradas en la tobera, se procede a calibrar las placas orificio. Los resultados de estas calibraciones se proporcionan en los anexos. La figura IV.27 muestra la calibración de una de las placas orificio, a modo de ejemplo.
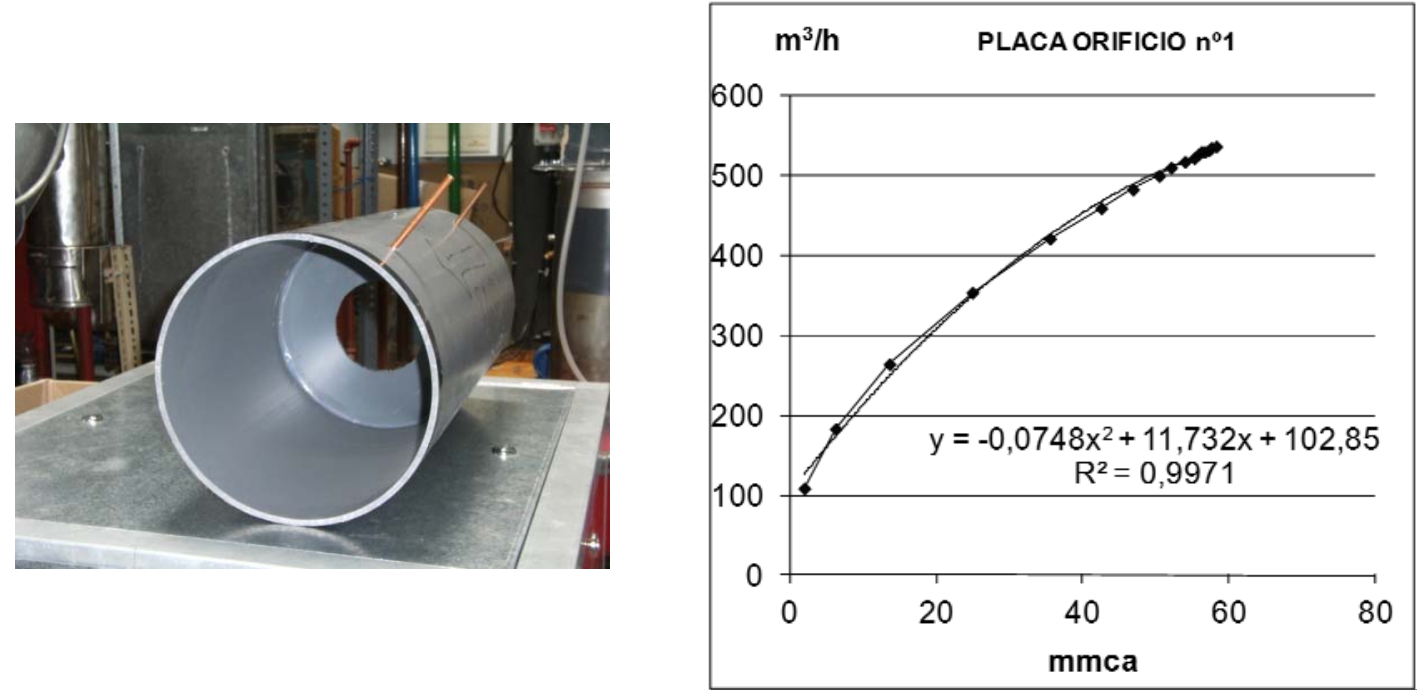

Figura IV.27.- Placa orificio n¹ y gráfica de calibración. 


\section{Calibración de los manómetros de presión para la medida del caudal}

Los manómetros de presión (figura IV.18), utilizados en la determinación del caudal de aire circulante por los distintos canales mediante la medición de la diferencia de presión generada en la tobera también calibrada a su vez, se han calibrado registrando su respuesta ante presiones manométricas del aire comprendidas entre 0 y 90 mmca. La recta de regresión de uno de estos manómetros se muestra a modo de ejemplo en la figura IV.28. (véase Anexo B).

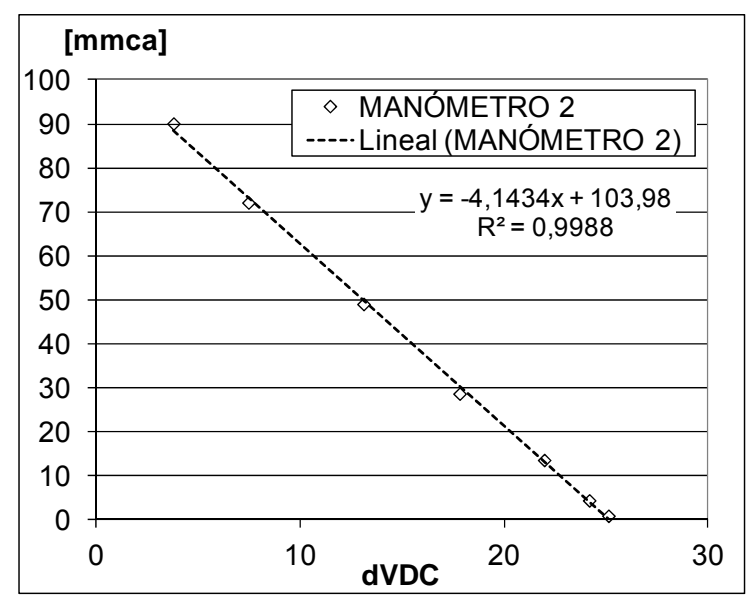

Figura IV.28.- Rectas de calibración de los manómetros de presión. 


\section{REFERENCIAS}

[1] TROX TECHNIK. Climatizadores serie TKM-30. Información del producto (2002).

[2] Catálogo de ventiladores SODECA. Tarifa de precios 2009.

[3] Humidificador por electrodos sumergidos CAREL humiSteam x-plus. Manual del Usuario (2007)

[4] Acondicionador de Ambiente DIAMOND, Ferroli. Manual del Instalador (2007).

[5] Extractores centrífugos de baja presión, gama CBM Grande. Catálogo. Soler\&Palau.

[6] Catálogo de productos Comet Germany (2011).

[7] Agilent 34970A Data Acquisition/Switch Unit Family, Product Overview 34970A 34972A. Agilent Technologies Inc., USA (2010).

\section{Normativa}

[N-1] Ministerio de Industria, Turismo y Comercio y Ministerio de Vivienda de España, "Real Decreto 1027/2007: Reglamento de Instalaciones Térmicas en Edificios".

\section{Páginas web}

[W-1] http://www.trox.es Página del fabricante Trox Technik en España donde se puede descargar la información técnica sobre los climatizadores de la serie TKM. (Consultada en octubre de 2011).

[W-2] http://www.sodeca.com Página del fabricante SODECA, donde se puede descargar la información técnica sobre los ventiladores centrífugos de la gama CMP. (Consultada en octubre de 2011).

[W-3] http://www.carel.com Página del fabricante CAREL, donde se puede descargar la información técnica sobre los humidificadores de electrodos HumiSteam X-plus. (Consultada en octubre de 2011).

[W-4] http://www.ferroli.es Página del fabricante Ferroli en España, donde se puede descargar la información técnica sobre los acondicionadores de ambiente de los modelos Diamond. (Consultada en octubre de 2011).

[W-5] http://www.soler-palau.com Página del fabricante Soler\&Palau, donde se puede descargar la información técnica sobre los ventiladores centrífugos CBM. (Consultada en octubre de 2011). 
[W-6] http://www.comet-pumpen.de Página del fabricante Comet Germany, donde se puede descargar la información técnica sobre las bombas de inmersión modelo VIP. (Consultada en octubre de 2011).

[W-7] http:// http://www.ebaraeurope.com Página del fabricante EBARA en Europa, donde se puede consultar la información técnica sobre las electrobombas periféricas de arrabio modelo PRA. (Consultada en octubre de 2011).

[W-8] http://www.salmson.com Página del fabricante SALMSON, donde se puede consultar y descargar información técnica sobre los circuladores domésticos modelo DYL. (Consultada en octubre de 2011).

[W-9] http://es.rs-online.com Página del fabricante y proveedor RS, donde se puede consultar y descargar información técnica sobre los productos. (Consultada en octubre de 2011).

[W-10] http://sensing.honeywell.com Página de los productos de control y medida del fabricante Honeywell, donde se puede consultar y descargar información técnica sobre las sondas de humedad relativa capacitivas. (Consultada en octubre de 2011).

[W-11] http://www.parker.com/ Página del fabricante PARKER, donde se puede acceder a información sobre los caudalímetros de bola. (Consultada en octubre de 2011).

[W-12] http://www.agilent.com Página del fabricante AGILENT, de donde se puede descargar información sobre los SAD. (Consultada en octubre de 2011).

[W-13] http://www.tecner.com/ Página del fabricante TECNER ingeniería. (Consultada en octubre de 2011).

[W-14] http://www.testo.es/online/abaxx-?\$part=PORTAL.ESP.HomeDesk\&\$event=go-home Página del fabricante TESTO (Consultada en octubre de 2011). 


\section{RELACIÓN DE FIGURAS}

- Figura IV.1.- Unidad de Tratamiento de Aire TROX serie TKM-30.

- Figura IV.2.- Izquierda: ventilador de la casa SODECA. Derecha: Variador de frecuencia TELEMECANIC

- Figura IV.3.- Humidificador por electrodos sumergidos modelo humiSteam x-plus

- de la casa CAREL.

- Figura IV.4.- Ventilador ATLAS utilizado para toma de aire exterior (centro); montado (izquierda), y vista del rodete (derecha).

- Figura IV.5.- Vista de la toma de aire exterior (izquierda) y derivación del conducto de impulsión (derecha).

- Figura IV.6.- Vista de la Cámara Climática del laboratorio.

- Figura IV.7.- Unidades exterior (izquierda) e interior (derecha) de la Bomba de Calor aireaire de marca Ferroli instalada en la cámara climática.

- Figura IV.8.- Ventilador instalado en la cámara climática.

- Figura IV.9.- Detalle de un conducto de aire flexible.

- Figura IV.10.- Vista del plénum de distribución conectado a la UTA.

- Figura IV.11.- Vista de la conexión del plénum de distribución a la cámara climática.

- Figura IV.12.- Colectores empleados en la conexión de los conductos a los sistemas, de material metálico (izquierda), PVC (centro) y plástico (derecha).

- Figura IV.13.- Bombas de agua disponibles en el banco de ensayos, Comet sumergible (izquierda), EBARA periférica (centro), y Salmson (derecha).

- Figura IV.14.- Sonda cerámica de temperatura.

- Figura IV.15.- Higrómetro capacitivo Honeywell.

- Figura IV.16.- Vista de una de las placas orificio utilizadas en la medición del caudal de aire.

- Figura IV.17.- Curva de caudales medidos con la placa orificio n¹.

- Figura IV.18.- Sensores de presión manométrica utilizados.

- Figura IV.19.- Caudalímetro de bola de la marca Parker.

- Figura IV.20.- Adquisidor de datos Agilent 34972A.

- Figura IV.21.- Horno de calibración FLUKE 9103.

- Figura IV.22.- Regresión de la calibración de la sonda de temperatura T6.

- Figura IV.23.- Esquema del dispositivo de calibración de las sondas de humedad relativa, y sonda TESTO utilizada de patrón de referencia (derecha).

- Figura IV.24.- Regresión obtenida en la calibración de la sonda de humedad relativa n³.

- Figura IV.25.- Tobera de referencia para calibración. Derecha: tobera montada.

- Figura IV.26.- Esquema de la instalación de la tobera para la calibración

- Figura IV.27.- Placa orificio $n^{\circ} 1$ y gráfica de calibración.

- Figura IV.28.- Rectas de calibración de los manómetros de presión. 


\section{RELACIÓN DE TABLAS}

- Tabla IV.1.- Regresiones de las rectas de calibración de las sondas de temperatura.

- Tabla IV.2.- Regresiones de las rectas de calibración de las sondas de humedad relativa. 


\section{CAPÍTULO V \\ CARACTERIZACIÓN DE LOS \\ ENFRIADORES EVAPORATIVOS \\ INDIRECTOS DE PLACAS PLANAS DE POLICARBONATO}

ABSTRACT.

V.1. INTRODUCCIÓN

V.2. DISEÑO Y CONSTRUCCIÓN DE LOS ENFRIADORES EVAPORATIVOS INDIRECTOS DE POLICARBONATO.

V.3. INSTALACIÓN EXPERIMENTAL 165

V.4. DISEÑO DE EXPERIMENTOS. METODOLOGÍA DE ENSAYOS. 167

V.5. ANÁLISIS DE RESULTADOS 169

PARÁMETROS CONSIDERADOS EN LA CARACTERIZACIÓN EXPERIMENTAL 169

RESULTADOS DEL EEI DE POLICARBONATO DE PASO ESTRECHO 170

RESULTADOS DEL EEI DE POLICARBONATO DE PASO ANCHO 174

COMPARACIÓN DE RESULTADOS ENTRE EQUIPOS. 178

V.6. ANÁLISIS DE VARIANZA 181 
Capítulo V: Caracterización de los Enfriadores EVaporativos INDiRectos de Placas Planas de POLICARBONATO 


\section{CHAPTER V: \\ CHARACTERIZATION OF THE \\ POLYCARBONATE PLATE INDIRECT \\ EVAPORATIVE COOLERS}

\section{ABSTRACT}

The present chapter aims to describe the design, manufacturing and experimental characterization of two indirect evaporative cooling systems made of polycarbonate panels; as well as introduce the main results obtained.

The prototypes are designed with a total heat exchange area of $5.6 \mathrm{~m}^{2}$ and $3 \mathrm{~m}^{2}$ respectively, and are installed in a heat-recovery cycle in the laboratory, thanks to the available experimental facility already described in chapter IV. The experimental setup required for the particular tests mainly consists of: an Air Handling Unit to simulate the outdoor airstream conditions, a conditioned climate chamber, and a water circuit to provide the water supply required

Two operating modes are performed. In the first one, exhaust air from the climate chamber, in comfort conditions, goes through one side of the heat-exchanger made of polycarbonate, producing a heat transfer from the outdoor air stream through the plastic walls of the system. In the second case, an evaporative cooling process is implemented by supplying water to the exhaust airstream.

The parameters studied for the different conditions performed are: temperature drop, thermal effectiveness and wet-bulb thermal effectiveness; cooling capacity and thermal conductance. Results are then analysed considering how heat-exchange area (by comparing both systems), outside airstream volume flow rate and temperature, as well as mode of operation (whether evaporative cooling improves heat recovery or not) influence in the performance obtained.

Finally, an Analysis of Variance is proposed in order to determine which among these factors actually have influence in the process, through the study of the parameters proposed. 
Capítulo V: Caracterización de los Enfriadores EVaporativos INDiRectos de Placas Planas de POLICARBONATO 


\section{SiMBología dEL CAPÍTULO}

$\varepsilon_{T}:$ Efectividad térmica.

$\varepsilon_{T B H}$ : Efectividad térmica de Bulbo Húmedo.

$T_{v 1}:$ Temperatura de bulbo seco del aire exterior de ventilación a la entrada del sistema $\left[{ }^{\circ} \mathrm{C}\right]$

$T_{v 2}:$ Temperatura de bulbo seco del aire exterior de ventilación a la salida del sistema [ ${ }^{\circ} \mathrm{C}$ ]

$T_{r 1}$ : Temperatura de bulbo seco del aire de retorno desde la cámara climática, a la entrada del sistema $\left[{ }^{\circ} \mathrm{C}\right]$

$T_{r 2}$ : Temperatura de bulbo seco del aire de retorno desde la cámara climática, a la salida del sistema $\left[{ }^{\circ} \mathrm{C}\right]$

$\Delta T$ : salto térmico de temperaturas alcanzado en la corriente de aire de ventilación [ $\left.{ }^{\circ} \mathrm{C}\right]$

$T_{B H v 1}$ : Temperatura de bulbo húmedo del aire exterior de ventilación a la entrada del sistema $\left[{ }^{\circ} \mathrm{C}\right]$

$T_{B H v 2:}$ Temperatura de bulbo húmedo del aire exterior de ventilación a la salida del sistema [ $\left.{ }^{\circ} \mathrm{C}\right]$

$E_{C c}$ : Capacidad de enfriamiento [W]

$\dot{m}$ : Flujo másico de aire seco $\left[\mathrm{kg}_{\mathrm{as}} / \mathrm{s}\right]$

$h_{v 1:}$ entalpía del aire de ventilación a la entrada del sistema $\left[\mathrm{kJ} / \mathrm{kg}_{\text {as }}\right]$

$h_{\mathrm{v} 2}$ : entalpía del aire de ventilación a la salida del sistema $\left[\mathrm{kJ} / \mathrm{kg}_{\mathrm{as}}\right]$

$C p_{a}:$ Calor específico del aire a presión constante $[\mathrm{kJ} / \mathrm{kgC}]$

U: Coeficiente Global de Transmisión de Calor $\left[\mathrm{W} / \mathrm{m}^{2} \mathrm{~K}\right]$

A: Área $\left[\mathrm{m}^{2}\right]$

$\Delta T_{L M}$ : Diferencia Media Logarítmica de Temperaturas [K]

$\mathrm{SS}_{p}:$ Porcentaje de contribución de la suma de cuadrados del factor "prototipo" [\%]

$\mathrm{SS}_{\mathrm{M}}$ : Porcentaje de contribución de la suma de cuadrados del factor "modo de operación" [\%]

SS $S_{v}$ Porcentaje de contribución de la suma de cuadrados del factor "caudal volumétrico" [\%]

$\mathrm{SS}_{T}$ : Porcentaje de contribución de la suma de cuadrados del factor "temperatura seca exterior" [\%]

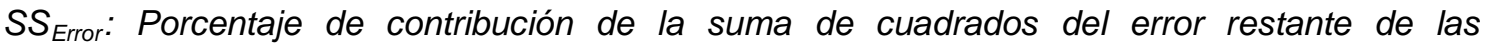
contribuciones de los factores [\%] 
$S_{P M}$ : Porcentaje de contribución de la suma de cuadrados de la interacción prototipo - modo de operación [\%]

$S_{P V}$ : Porcentaje de contribución de la suma de cuadrados de la interacción prototipo - caudal volumétrico[\%]

$S_{S_{P T}}$ : Porcentaje de contribución de la suma de cuadrados de la interacción prototipo temperatura[\%]

$\mathrm{SS}_{\mathrm{MV}}$ : Porcentaje de contribución de la suma de cuadrados de la interacción modo de operación - caudal volumétrico [\%]

$\mathrm{SS}_{M T}$ : Porcentaje de contribución de la suma de cuadrados de la interacción modo de operación - temperatura [\%]

$\mathrm{SS}_{V T}$ : Porcentaje de contribución de la suma de cuadrados de la interacción caudal volumétrico - temperatura [\%]

$S_{\text {RError: }}$ Porcentaje de contribución de la suma de cuadrados del error restante de las contribuciones de los factores y sus interacciones [\%] 


\section{V.1. INTRODUCCIÓN}

El aprovechamiento del potencial de enfriamiento del aire expulsado para la renovación del aire interior constituye un recurso clave en el ahorro de energía destinado al acondicionamiento de los caudales de ventilación. Entre las numerosas alternativas de recuperación de calor en el acondicionamiento térmico de edificios, existe la posibilidad de implantar un proceso de enfriamiento evaporativo en la corriente de extracción para optimizar este aprovechamiento del potencial de enfriamiento del aire viciado pero en condiciones de confort, a lo cual se ha llamado "recuperación evaporativa" [1, Schibuola, 1997], [2, Rey et al., 2000]. Además, estas alternativas son en la actualidad preceptos establecidos por la normativa Española [N-1].

Como se ha visto en el capítulo III, la principal ventaja de los sistemas indirectos es que operan sin que se produzca contacto directo entre las corrientes de intercambio, de forma que no se ve alterado el contenido de humedad de la corriente de aire de impulsión ni existen riesgos de contaminación de la misma, lo cual puede ser de gran interés para aquéllas aplicaciones que presenten estos dos requisitos.

Sin embargo, el efecto del enfriamiento evaporativo se ve en este caso limitado por el proceso de transferencia de calor entre la corriente a tratar y aquélla en contacto directo con el agua, siendo por lo tanto la superficie de intercambio entre corrientes y el coeficiente global de intercambio de calor los parámetros clave en el diseño del sistema.

Por otro lado, es también de vital importancia en el diseño el material utilizado como superficie de intercambio, no sólo por sus propiedades térmicas sino por su comportamiento en presencia de agua. En trabajos realizados con anterioridad por Grupo de Termotecnia de la Universidad de Valladolid, se ha abordado este problema de recuperación de energía con enfriamiento evaporativo mediante sistemas cerámicos, que además permitían el funcionamiento como sistemas indirectos o directos en función de las condiciones de operación [3, Rey et al., 2003], [4, Velasco et al., 2005], [5, Velasco et al., 2009], [6, Velasco et al., 2010], [7, Rey et al., 2004].

No obstante, los sistemas con intercambiador de placas se han introducido como los enfriadores evaporativos indirectos más utilizados. Este tipo de sistemas requiere de la búsqueda de una máxima compacidad que asegure grandes áreas de intercambio en equipos poco voluminosos. Como consecuencia del interés hacia el estudio de estos equipos en particular, dentro del presente proyecto de Tesis Doctoral el Grupo de Termotecnia de la Universidad de Valladolid ha diseñado y construido dos prototipos de enfriadores evaporativos indirectos de placas de policarbonato, los cuales se describen y caracterizan en el capítulo actual. 


\section{V.2. DISEÑO Y CONSTRUCCIÓN DE LOS ENFRIADORES EVAPORATIVOS INDIRECTOS DE POLICARBONATO.}

Se han diseñado y construido en el laboratorio dos prototipos de Enfriador Evaporativo Indirecto de Placas Planas utilizando paneles de policarbonato, referidos a partir de ahora como "de paso ancho" y "de paso estrecho" en referencia a la anchura de los paneles de este material empleados en cada caso. Dado que tanto el diseño de la configuración operativa como el proceso de manufacturación y su instalación y caracterización experimental fueron idénticos, se presenta aquí su descripción de forma conjunta, tras lo cual se abordarán los respectivos resultados experimentales obtenidos de forma comparativa.

La configuración en tipo placas planas se ha realizado a partir de la propia geometría del material empleado para la fabricación: paneles huecos de policarbonato. En la figura V.1 se muestran los dos tipos de paneles de policarbonato empleados, cuyas dimensiones geométricas se detallan en la tabla V.1.

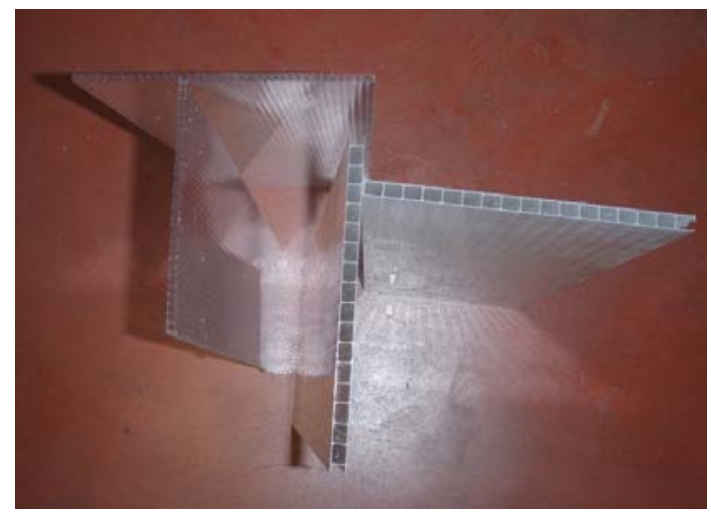

Figura V.1.- Paneles de policarbonato de paso ancho y estrecho utilizados en la fabricación de los prototipos.

Como se extrae de la tabla de datos, el sistema de paso ancho se construyó con un total de 15 paneles de policarbonato de $9 \mathrm{~mm}$ de espesor, consiguiéndose un sistema de área de intercambio próxima a $3 \mathrm{~m}^{2}$. Por su parte, el diseño del sistema de paso estrecho compuesto por 28 paneles de $4 \mathrm{~mm}$ duplica el valor del área de intercambio, concebido para estudiar cómo afecta un aumento en este factor determinante.

A pesar de no tratarse de una solución muy extendida para la fabricación de intercambiadores de calor, la elección de un material plástico para la construcción del sistema se fundamentó en las interesantes ventajas que presentaba en cuanto a ligereza y bajo coste, además de su buen comportamiento en presencia de agua sin necesidad de recibir tratamiento especial alguno. Sin embargo, el uso de sistemas de materiales plásticos no es novedoso, siendo ya abordado por Pescod en los años 70 [8, Pescod, 1974], demostrándose que la menor conductividad térmica de este material frente a la de un material metálico, por ejemplo, 
no es un factor determinante para espesores de intercambio tan reducidos [9, Zhao et al., 2008]. Este resultado ha potenciado numerosos trabajos posteriores sobre la aplicabilidad de materiales plásticos en intercambiadores de calor [10, Joen et al., 2009]. Estudios más recientes han probado también su viabilidad e interés en combinación con otros sistemas para preacondicionar aire [11, Delfani et al., 2010], [12, Heidarinejad et al., 2009].

Tabla V.1.- Características geométricas de los dos prototipos de policarbonato.

\begin{tabular}{|c|c|c|}
\hline $\begin{array}{c}\text { Dimensión } \\
\text { característica }\end{array}$ & $\begin{array}{c}\text { Sistema de paso } \\
\text { ancho }\end{array}$ & $\begin{array}{c}\text { Sistema de paso } \\
\text { estrecho }\end{array}$ \\
\hline $\begin{array}{c}\text { Espesor "e" de los } \\
\text { paneles }\end{array}$ & $9 \mathrm{~mm}$ & $4 \mathrm{~mm}$ \\
\hline $\begin{array}{c}\text { Anchura "a" del } \\
\text { panel }\end{array}$ & $0,18 \mathrm{~m}$ & $0,62 \mathrm{~m}$ \\
\hline $\begin{array}{c}\text { Largura "L" del panel } \\
\text { Espesor de la pared } \\
\text { de policarbonato }\end{array}$ & $0,62 \mathrm{~m}$ & $1 \mathrm{~mm}$ \\
\hline $\begin{array}{c}\text { Número de paneles } \\
\text { Ancho de la sección } \\
\text { transversal del } \\
\text { equipo }\end{array}$ & $0,23 \mathrm{~m}$ & $0,23 \mathrm{~m}$ \\
\hline $\begin{array}{c}\text { Área total de } \\
\text { intercambio }\end{array}$ & $3 \mathrm{~m}^{2}$ & $5,6 \mathrm{~m}^{2}$ \\
\hline
\end{tabular}

La figura V.2.a muestra una imagen esquemática de la disposición de los paneles para la configuración del sistema, mientras que en las figuras V.2.b y V.2.c se puede observar una vista real del prototipo de paso ancho y de paso estrecho, respectivamente, durante su construcción.

El principio de funcionamiento del sistema queda reflejado en la figura V.3. Como se aprecia, el sistema actúa como un intercambiador de calor de flujo cruzado entre la corriente de aire de renovación que será impulsada al local, la cual fluye horizontalmente entre paneles, y la corriente extraída del local en condiciones de confort y por lo tanto con alto potencial de enfriamiento, que sigue un flujo ascendente por el interior de los paneles, en contracorriente con el aire de expulsión. Para implantar el proceso de enfriamiento evaporativo en la corriente secundaria o de extracción, se aporta agua desde un distribuidor superior para que entre en contacto directo con dicha corriente a su paso por el interior de los paneles.

Para realizar un análisis más profundo sobre el comportamiento del sistema como enfriador evaporativo indirecto, se realiza su caracterización en dos modos de funcionamiento: uno primero en el cual tan sólo opera como simple recuperador de calor entre corrientes, al que se 
denominará "modo seco"; y uno segundo en el que se efectúa el proceso evaporativo aportando agua a la corriente secundaria del intercambio, llamado "modo húmedo".

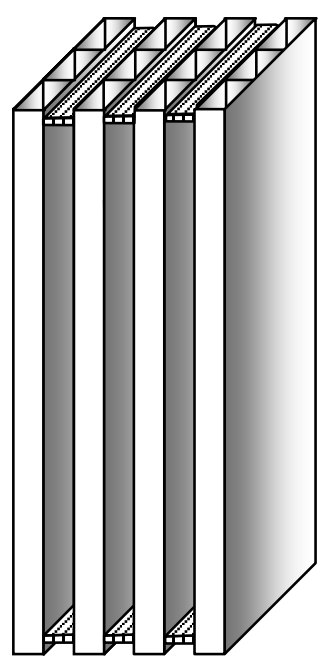

Figura V.2.a.- Esquema de la disposición de los paneles de policarbonato.

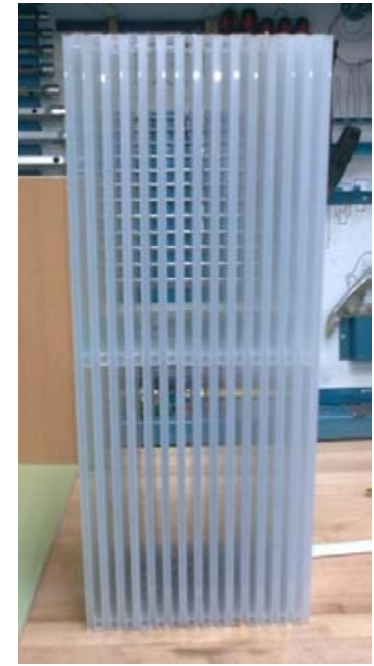

Figura V.2.b.- Vista del prototipo de paso ancho durante su construcción.

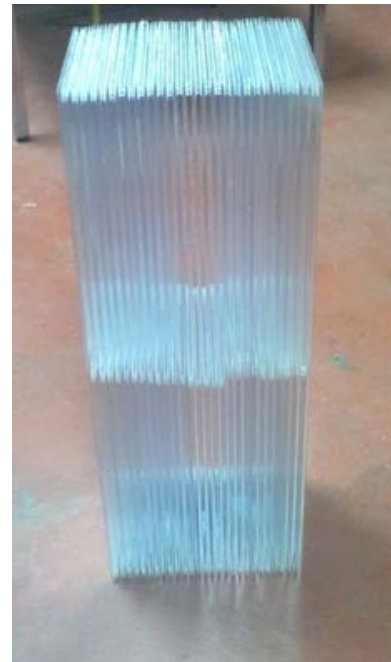

Figura V.2.c.- Vista del prototipo de paso estrecho durante su construcción.

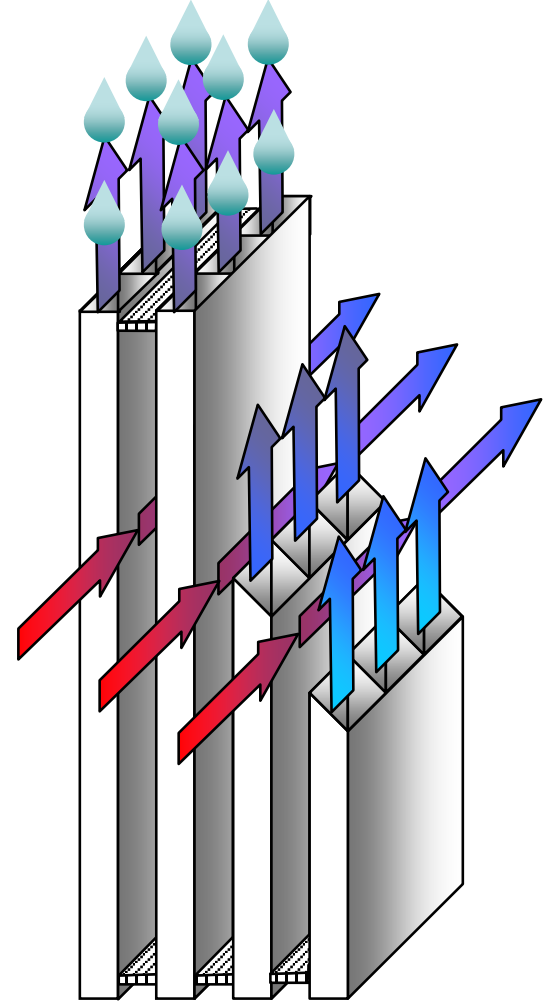

Figura V.3.- Vista esquemática del funcionamiento del prototipo de policarbonato en modo húmedo. 


\section{V.3. INSTALACIÓN EXPERIMENTAL}

Una vez construidos los prototipos, para su caracterización experimental se dispusieron en una estructura especialmente adaptada para su conexión en el conjunto de la instalación experimental disponible en el laboratorio y descrita en el capítulo IV. En la figura V.4 se muestra una vista de uno de los dos equipos adaptado a dicha estructura.

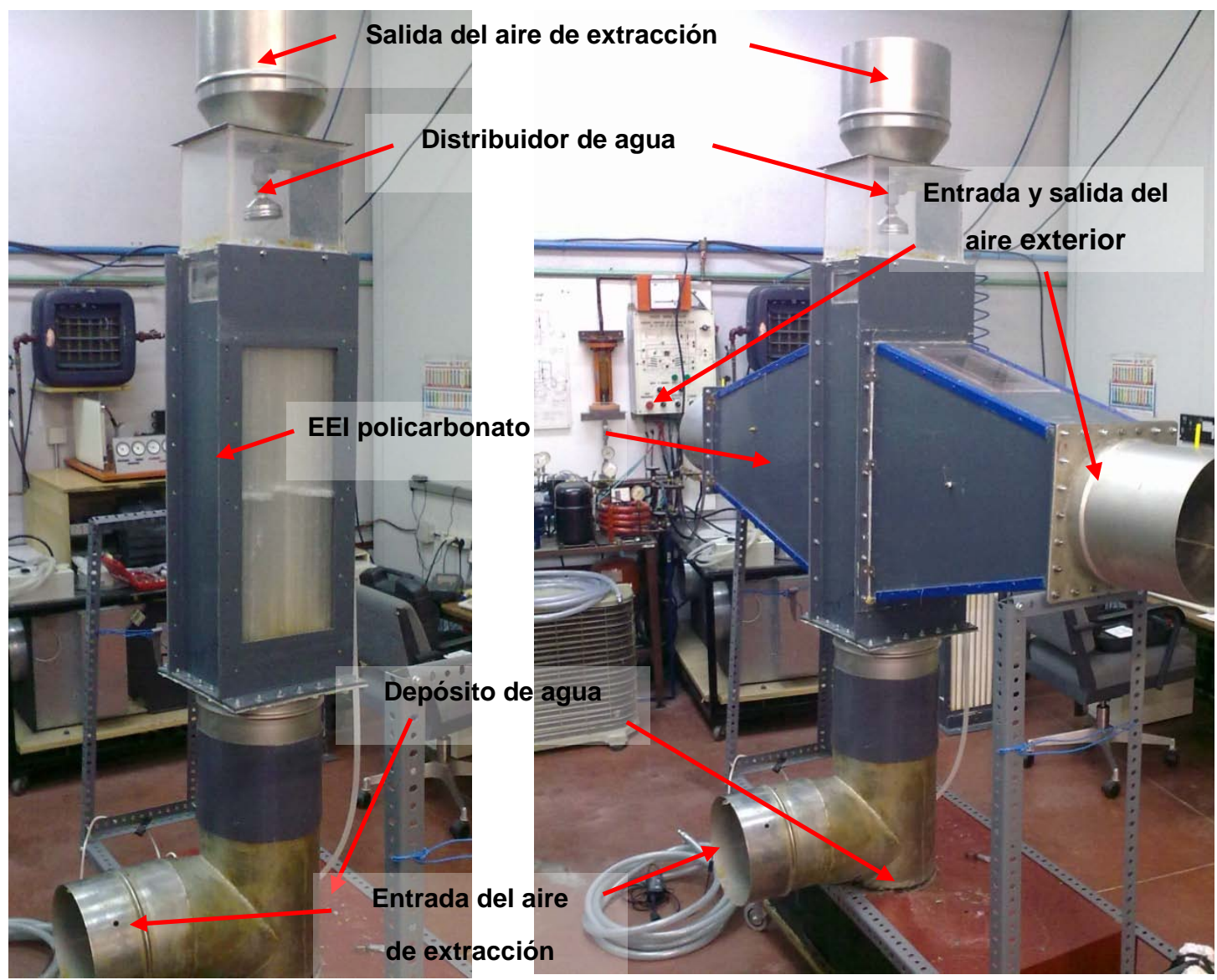

Figura V.4.- Adaptación del sistema a la estructura de conexión a la instalación.

Además de permitir la conducción de los flujos de aire, esta estructura dispone de un sistema de distribución superior, acumulación inferior y recirculación de agua que permite el funcionamiento en modo húmedo; así como de un separador de gotas a la salida de la corriente de aire de extracción del espacio acondicionado, que evita el arrastre de aerosoles en la corriente a expulsar al ambiente.

Para la caracterización de los equipos en particular, el banco de ensayos configurado a partir de los recursos del laboratorio, descritos en el capítulo IV, va a disponer de la cámara climática como espacio en condiciones de confort; y de una UTA que proporcione el caudal de aire en condiciones exteriores. El equipo a ensayar, dentro de la estructura de soporte y conexión, se conecta a estos dos elementos en configuración recuperativa, según se muestra en la figura V.5, siguiendo el esquema de la figura V.6. 


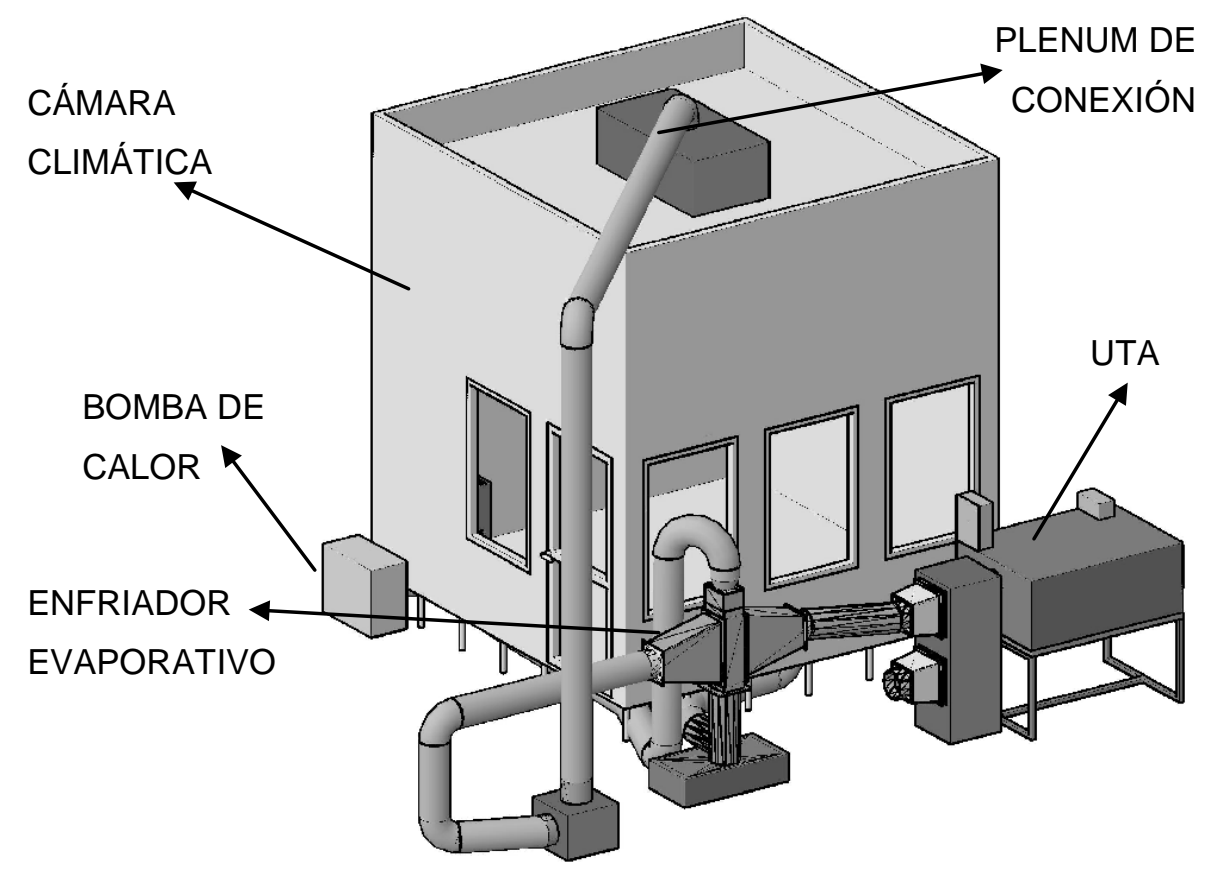

Figura V.5.- Conexión de la estructura al dispositivo experimental del laboratorio.

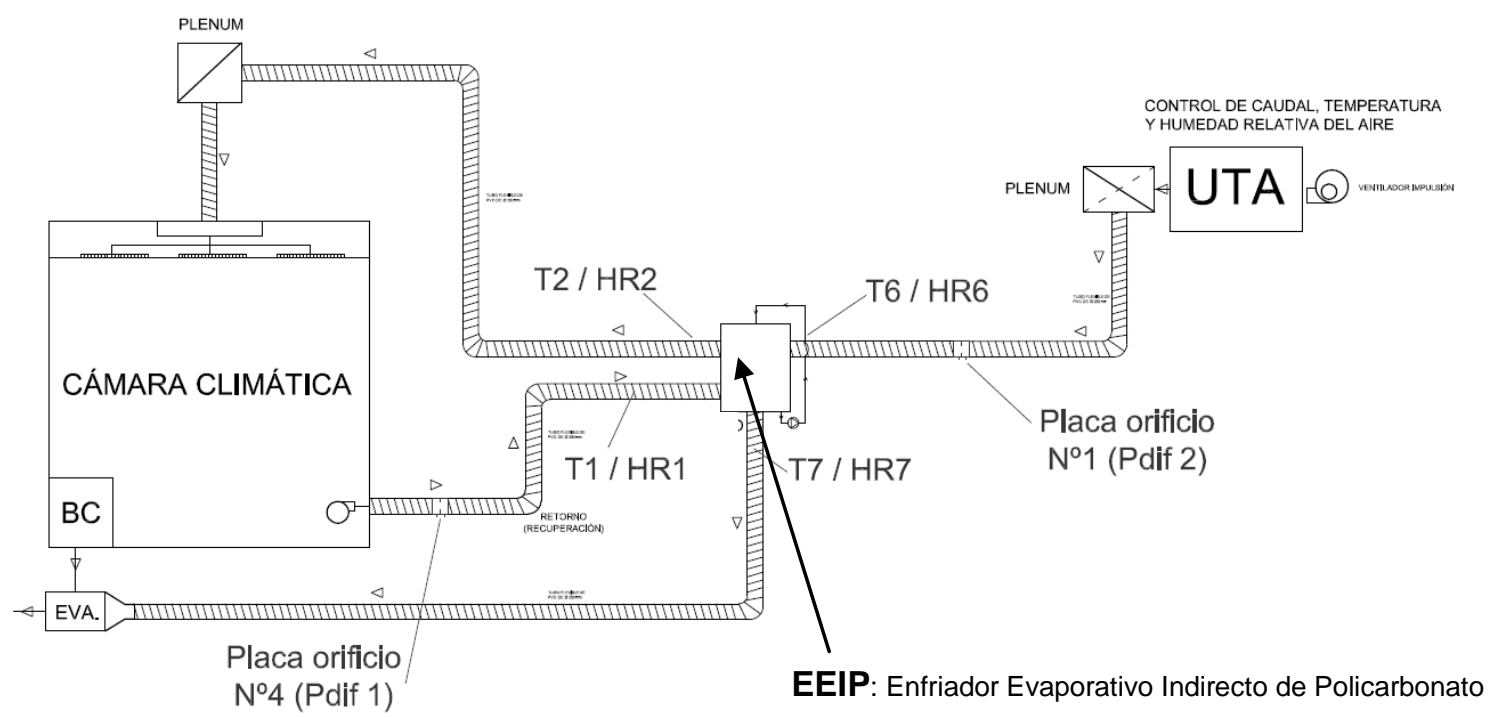

Figura V.6.- Esquema del dispositivo experimental completo. 


\section{V.4. Diseño de eXPERIMENTOS. METOdología DE ENSAYOS}

Para realizar la caracterización experimental de los dos prototipos construidos en policarbonato operando como meros intercambiadores de calor o como enfriadores evaporativos indirectos, se planteó un Diseño de Experimentos (apéndice A), según el cual se decidió considerar dos parámetros como factores determinantes del comportamiento del sistema, ambos relacionados con la corriente de aire de renovación: la temperatura de bulbo seco y el caudal de dicho aire exterior. Ambos parámetros se variaron en 4 niveles, dentro de un rango de entre 125 y $400 \mathrm{~m}^{3} / \mathrm{h}$ de caudal y 25 y $40^{\circ} \mathrm{C}$ de temperatura seca. Los niveles de los factores planteados en el diseño de experimentos se recogen en la tabla V.2.

Tabla V.2.- Diseño de Experimentos planteado para la caracterización de los dos prototipos de policarbonato.

\begin{tabular}{|c|c|c|}
\hline Modos de operación & $\begin{array}{l}\text { Caudal de aire exterior } V \\
\qquad\left[\mathrm{~m}^{3} / \mathrm{h}\right]\end{array}$ & $\begin{array}{c}\text { Temperatura de bulbo seco del } \\
\text { aire exterior } \mathrm{T}\left[{ }^{\circ} \mathrm{C}\right]\end{array}$ \\
\hline M1- modo "seco" & $\begin{array}{l}\text { V1- } 125 \\
\text { V2- } 200\end{array}$ & $\begin{array}{l}\text { T1- } 25 \\
\text { T2- } 30\end{array}$ \\
\hline $\begin{array}{c}\text { M2- modo "húmedo" } \\
\text { (enfriador evaporativo } \\
\text { indirecto) }\end{array}$ & $\begin{array}{l}\text { V3- } 300 \\
\text { V4- } 400\end{array}$ & $\begin{array}{l}\text { T3- } 35 \\
\text { T4- } 40\end{array}$ \\
\hline
\end{tabular}

Inicialmente se planteó abarcar un mayor rango de temperaturas, alcanzando los $40^{\circ} \mathrm{C}$. Sin embargo, las condiciones teóricas determinadas por el Diseño de Experimentos original no resultaron factibles en el momento de ensayo, viéndose limitadas a las recogidas en la tabla V.2, ya que, en el caso del menor nivel de caudal, no resultó posible ensayar valores de temperatura seca superiores a $30^{\circ} \mathrm{C}$. Esto fue debido a las limitaciones de las resistencias de la Unidad de Tratamiento de Aire, las cuales sufrían sobrecalentamiento, interrumpiéndose por seguridad el funcionamiento del sistema, al no ser suficientemente refrigeradas con caudales tan bajos de aire.

En cuanto a la humedad relativa de operación del equipo, esta no ha sido regulada a pesar de ser posible la humidificación de la corriente de aporte gracias al humidificador instalado en la UTA. Sin embargo sí ha sido registrada, dado su interés como factor determinante en el proceso de enfriamiento evaporativo.

Por su parte, los parámetros de interés a registrar en el desarrollo experimental son la temperatura seca y humedad relativa del aire tratado por el equipo e impulsado al espacio acondicionado, así como estas mismas condiciones a la entrada y salida del sistema de la corriente de retorno proveniente de la cámara climática. El funcionamiento de la bomba de calor instalada en ésta permite establecer las condiciones del espacio climatizado en los 
valores de confort deseados $\left(22^{\circ} \mathrm{C}\right.$ y $50 \%$ de humedad relativa), los cuales serán por lo tanto las condiciones de entrada al equipo en configuración recuperativa de la corriente de retorno.

El equipo a caracterizar se ha instalado en el banco de ensayos descrito en el apartado anterior, debidamente conectado en configuración recuperativa a los elementos que constituyen este mediante los conductos de conexión disponibles. Los sensores de medida de temperatura y humedad relativa se disponen a la entrada y salida de las corrientes primaria y secundaria (retorno) del equipo, según se ha indicado en el esquema de la figura V.6.

Al comienzo de cada ensayo, previo a la lectura de datos, se establecen los parámetros de temperatura seca y caudal volumétrico de operación del equipo en el ensayo correspondiente mediante la UTA, tras lo cual ya se procede a registrar los valores de temperatura seca y humedad relativa a la entrada y salida del equipo, tanto en la corriente de aire primario como en la corriente de aire de retorno, una vez alcanzado el régimen estacionario de funcionamiento del equipo.

Los datos registrados mediante el sistema de adquisición de datos han sido exportados a formato Excel para su tratamiento. A partir de estos datos se han obtenido distintos parámetros de utilidad para la caracterización del funcionamiento de los equipos. Los resultados de estos parámetros obtenidos para cada sistema y el estudio de caracterización y comparación derivado de los mismos se muestran en los apartados siguientes.

El gráfico de la figura V.7 se muestra como ejemplo del registro de datos de las sondas de temperatura durante la realización de uno de los ensayos en modo húmedo sobre el equipo de paso estrecho. Los valores medios obtenidos de las variables adquiridas se recogen como recopilación de resultados de los ensayos, los cuales se proporcionan en los subapartados siguientes.

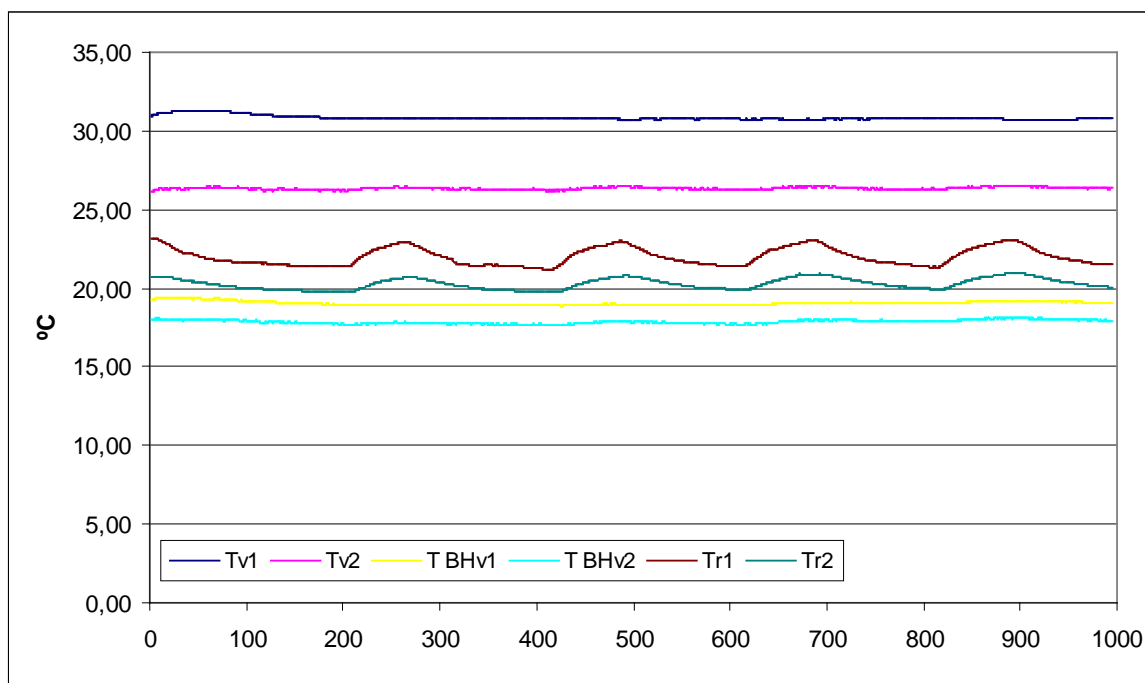

Figura V.7.- Evolución registrada de las medidas de las sondas de temperatura durante la realización del ensayo del sistema estrecho en modo húmedo, a $300 \mathrm{~m}^{3} / \mathrm{h}$ de caudal y $30^{\circ} \mathrm{C}$ de temperatura seca a la entrada. 


\section{V.5. ANÁLISIS DE RESULTADOS}

\section{Parámetros considerados en la caracterización experimental}

Para el estudio de la operación del sistema en las distintas condiciones indicadas en el Diseño de Experimentos, se ha trabajado con los resultados experimentales obtenidos del registro de medidas consideradas de interés para determinar una serie de factores que permitan caracterizar el funcionamiento.

En un primer lugar se analizan los resultados obtenidos directamente en salto de temperaturas logrados por el equipo en los distintos casos (ecuación V.1).

$$
\Delta T=T_{v 1}-T_{v 2}
$$

Quizás el parámetro de consideración más inmediata sea habitualmente la efectividad térmica del equipo enfriador. Este parámetro viene definido como la relación entre el salto térmico en el equipo frente al máximo salto térmico que podría alcanzar, definido por la diferencia de temperatura seca respecto a la de la corriente de aire a la entrada. Dicho cociente queda reflejado como indica la expresión (V.2) [13, Wang, 1994]:

$$
\varepsilon_{T}=\frac{T_{v 1}-T_{v 2}}{T_{v 1}-T_{r 1}}
$$

Sin embargo, esta expresión no resulta especialmente acertada para el equipo operando en el aquí denominado "modo húmedo", ya que el aire tratado podría en este caso enfriarse, teóricamente, hasta la temperatura de saturación adiabática de entrada del aire de retorno que circula por el lado secundario del intercambiador, si tanto el proceso de enfriamiento adiabático en este lado del equipo como el intercambio de calor a través de las paredes del mismo fueran ideales. En base a esta idea, se presenta más interesante abordar el estudio del rendimiento del sistema a través de otra definición del parámetro anterior, expresado por la ecuación (V.3): la eficiencia térmica de bulbo húmedo [13, Wang, 1994].

$$
\varepsilon_{T B H}=\frac{T_{v 1}-T_{v 2}}{T_{v 1}-T_{B H r 1}}
$$

Se presenta interesante por otro lado introducir un índice en el que quede reflejada la cantidad de aire que es tratada por el sistema. Con este objeto, se plantea el estudio de la Capacidad de Enfriamiento, según se define en la ecuación (V.4). Será de esperar por lo tanto que este parámetro proporcione información en términos de cantidad de energía involucrada en el proceso.

$$
E_{C C}=\dot{m} \cdot\left(h_{v 1}-h_{v 2}\right)
$$


Para el cálculo de este parámetro en el caso particular que se plantea, dado que sólo existe intercambio de calor sensible entre corrientes su expresión puede simplificarse según la ecuación (V.5):

$$
E_{C C}=\dot{m} \cdot C p_{a} \cdot\left(T_{v 1}-T_{v 2}\right)
$$

Finalmente, la bondad del sistema como intercambiador de calor puede expresarse a través del coeficiente global de transmisión característico, dado por la ecuación (V.6):

$$
U=\frac{E_{C C}}{A \cdot \Delta T_{L M}}
$$

Donde la diferencia media logarítmica de temperaturas queda como:

$$
\Delta T_{L M}=\frac{\left(T_{v 1}-T_{r 2}\right)-\left(T_{v 2}-T_{r 1}\right)}{\ln \left(\frac{\left(T_{v 1}-T_{r 2}\right)}{\left(T_{v 2}-T_{r 1}\right)}\right)}
$$

En la caracterización se habla no obstante de Conductancia Térmica, en referencia al Coeficiente Global de Transmisión por el área de intercambio del sistema.

\section{Resultados del EEI de policarbonato de paso estrecho}

El análisis de resultados se ha focalizado, con la definición de los parámetros de interés ya indicados, en la efectividad del tratamiento de la corriente de aire de ventilación tomada del ambiente exterior, en condiciones estivales para el caso de interés. En una primera confrontación con los datos obtenidos, y como estudio previo de los parámetros indicadores del comportamiento del sistema, se ha abordado el descenso logrado en la temperatura de la corriente exterior a su paso por el sistema. La visión previa que nos da este indicador queda reflejada en las figuras V.8.a y V.8.b.

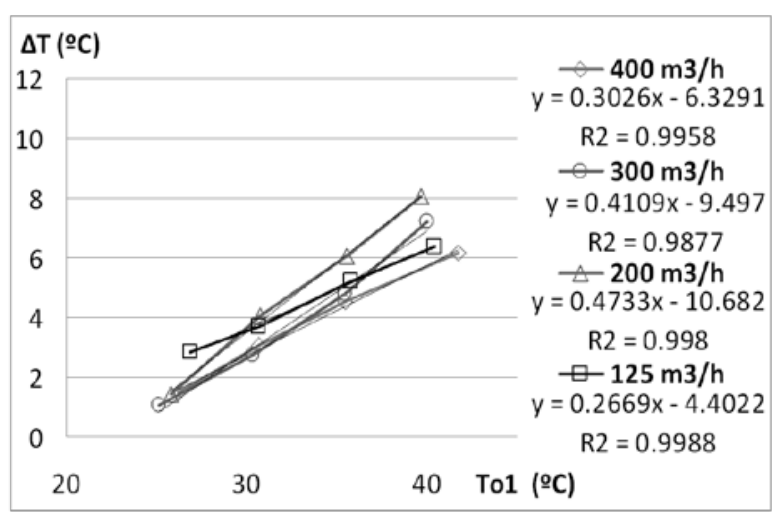

Figura V.8.a.- Salto térmico de temperaturas logrado con el prototipo de paso estrecho en modo seco.

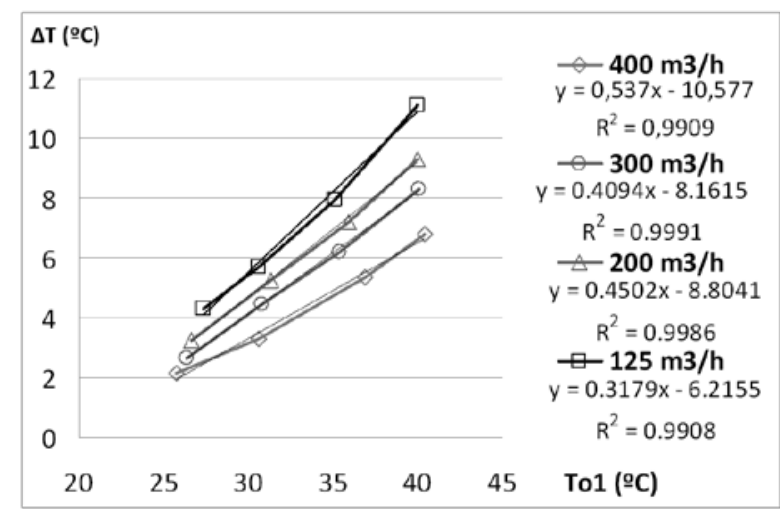

Figura V.8.b.- Salto térmico de temperaturas logrado con el prototipo de paso estrecho en modo húmedo. 
Como puede observarse, el salto de temperaturas alcanzado es mayor cuando se trabaja con mayores temperaturas exteriores. Este es un resultado obvio ya que, previendo que la corriente de aire de extracción que atraviesa el sistema por el otro lado del intercambiador se encontrará siempre en condiciones constantes de temperatura seca correspondientes a las de confort establecidas en el espacio acondicionado, la mayor diferencia de temperaturas alcanzada entre ambos lados del intercambiador debida a condiciones más cálidas del ambiente exterior, derivará en un mayor intercambio sensible de calor a través de las paredes de éste, y consecuentemente un mayor enfriamiento de la corriente a preacondicionar. Esta conclusión es además común a ambos modos de funcionamiento, y sean cuales sean los caudales tratados. Por otro lado, mayores caudales de impulsión suponen un menor enfriamiento en los mismos, como también cabría de esperar dado el menor tiempo de residencia del aire en el sistema.

Un resultado interesante es el incremento en los saltos térmicos alcanzados cuando el sistema opera como enfriador evaporativo indirecto. Esto se debe a que la temperatura seca del aire de extracción en la corriente secundaria no se corresponde en este caso con la del aire de la cámara climática en condiciones de confort, sino que se aproxima a la temperatura adiabática del aire en dichas condiciones, al verse sometido a un proceso de enfriamiento adiabático por evaporación del agua aportada.

Puede notarse no obstante una desviación, respecto a la tendencia general observada, de los resultados del equipo en los ensayos realizados en modo seco con el mínimo caudal de impulsión. Atendiendo a los caudales de aire de retorno registrados durante dichos ensayos, se observa que estos disminuyeron notablemente por debajo del nivel de retorno establecido. Esto supone que los resultados de dichos ensayos en particular no puedan considerarse representativos del funcionamiento del equipo, como podrá comprobarse también en el análisis del resto de parámetros considerados.

En cuanto a la relación de este salto térmico alcanzado con el máximo que podría alcanzarse, definida como efectividad térmica, los resultados son los mostrados en las figuras V.9.a y V.9.b. En este caso también se produce una mejora del parámetro de estudio a menores caudales tratados, por la misma explicación que la planteada anteriormente. Sin embargo, no se observa variación notable con la temperatura seca de entrada del aire exterior.

Por otro lado, el sistema operando en modo húmedo también presenta en términos de este parámetro un mejor comportamiento, mostrando similares tendencias con la temperatura de entrada y el caudal de aire tratado, pero con mejores rendimientos. La causa es en este caso la misma que la presentada para el salto de temperaturas, ya que este se ve mejorado por las razones expuestas mientras que el máximo salto obtenible es en todo caso un valor de referencia fijo.

Nótese no obstante que los resultados obtenidos para la menor temperatura de ensayo no se han mostrado en las gráficas. Esto es debido a que, dada la proximidad de este valor, $25^{\circ} \mathrm{C}$, 
al de confort en la cámara climática y por lo tanto a la temperatura de la corriente de extracción, por la propia definición de la expresión de la efectividad térmica, esta adquiere valores muy altos que no se corresponden en absoluto con una representación realista del comportamiento del sistema.

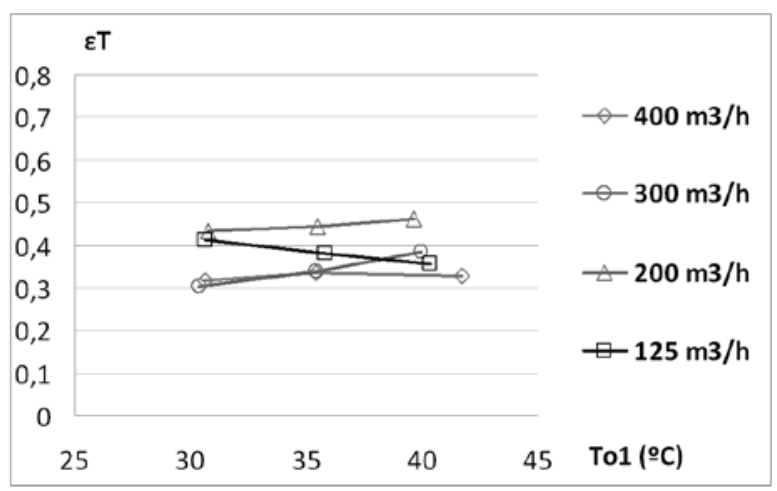

Figura V.9.a.- Efectividad térmica del prototipo de paso estrecho en modo seco.

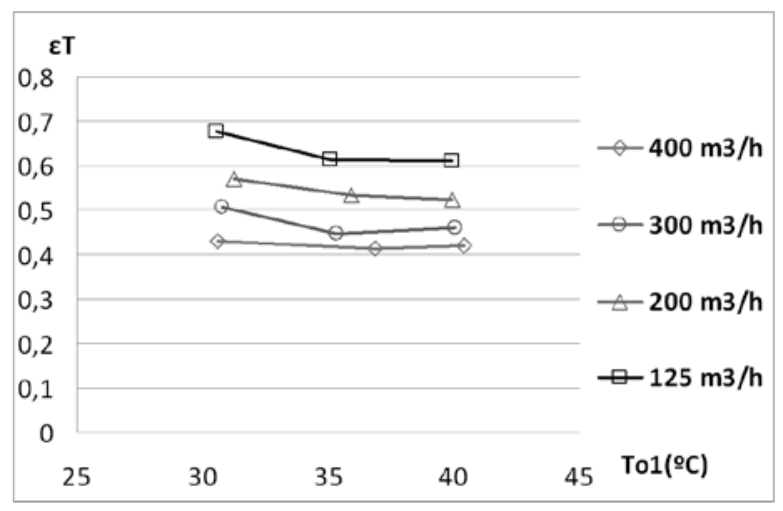

Figura V.9.b.- Efectividad térmica del prototipo de paso estrecho en modo húmedo.

Sin embargo, para el modo húmedo no sería estrictamente apropiado trabajar con la expresión dada para la efectividad térmica, ya que el máximo salto de temperaturas obtenible realmente no sería la diferencia entre las temperaturas secas de entrada del aire exterior y del aire de retorno de la cámara, sino la diferencia entre la primera y la temperatura de saturación adiabática (aproximada por la de bulbo húmedo) del aire de retorno, al evolucionar éste de forma adiabática a estados de menor temperatura seca y mayor contenido de humedad. En base a esta idea se había introducido el parámetro de efectividad térmica de bulbo húmedo. Los resultados para el sistema operando en modo húmedo y tratados según esta definición se representan en la figura V.10. Como puede verse, la variación de este parámetro con el caudal volumétrico tratado muestra igual tendencia, si bien parece presentar una ligera tendencia ascendente con la temperatura de entrada, aunque no notable, como puede observarse en las reducidas pendientes de las rectas de regresión obtenidas. Lo que sí es interesante es el hecho de que, comparando ambos modos de operación en términos de efectividad térmica de bulbo seco en un caso y de bulbo húmedo en el otro, no se refleja especial mejora entre los valores de los correspondientes parámetros al implementar un enfriamiento evaporativo. Es destacable por lo tanto el hecho de que este fenómeno mejora notablemente el funcionamiento del sistema, pero la mejora que podría alcanzarse es superior a los objetivos conseguidos. Finalmente, nótese que en el caso de este parámetro sí resultan representativos los resultados para temperaturas de entrada de $25^{\circ} \mathrm{C}$, ya que los valores de la temperatura de saturación adiabática difieren de éste y por lo tanto no se generan inestabilidades en el cociente de la expresión. 


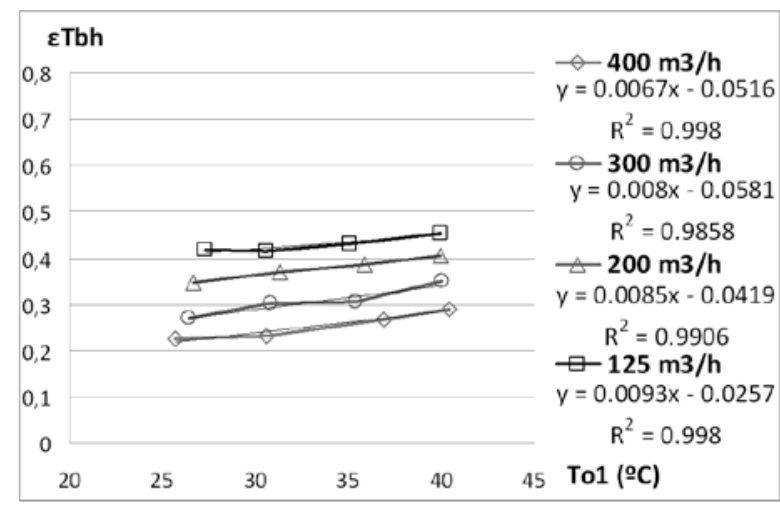

Figura V.10.- Efectividad térmica de bulbo húmedo del prototipo de paso estrecho en modo húmedo.

El indicador definido como capacidad de enfriamiento se muestra más interesante a la hora de reflejar el comportamiento del sistema de una forma más apropiada, ya que incluyendo en su expresión el caudal tratado por el sistema, refleja la cantidad de energía involucrada en el proceso. Por lo tanto, resultan previsibles los resultados recogidos en las figuras V.11.a y V.11.b, en las cuales se puede observar cómo este parámetro mejora con mayores caudales ensayados, al contrario que en el caso del salto térmico y de la eficiencia térmica. Sin embargo, al igual que los casos anteriores, el enfriamiento logrado por el sistema para cualquiera que sea el caudal tratado es mejor para mayores temperaturas de entrada del aire exterior, por las mismas razones ya expuestas.

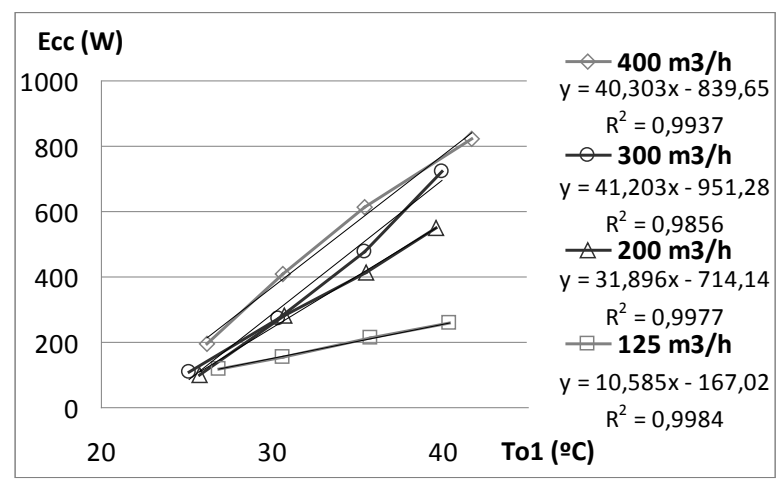

Figura V.11.a.- Capacidad de enfriamiento del prototipo de paso estrecho en modo seco.

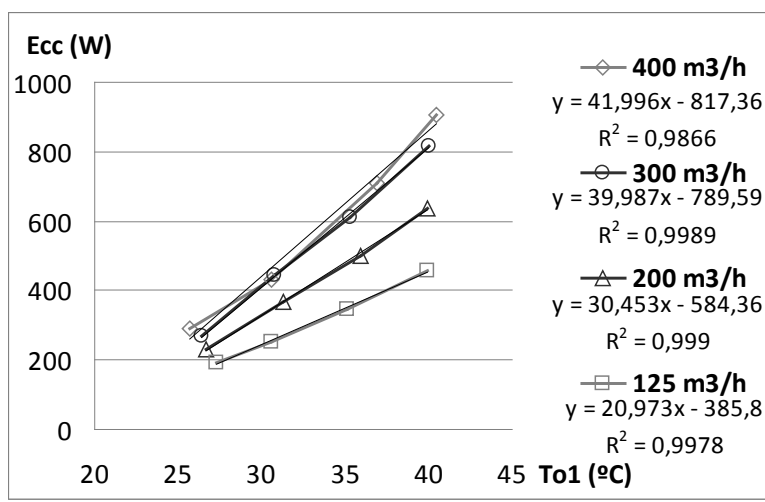

Figura V.11.b.- Capacidad de enfriamiento del prototipo de paso estrecho en modo húmedo.

En lo que concierne al modo húmedo de operación, el estudio de este parámetro refleja cómo la implementación del fenómeno de enfriamiento evaporativo mejora la capacidad del mismo para acondicionar la corriente de aire de ventilación requerida.

Finalmente, se ha abordado el estudio de la conductancia térmica a fin de analizar la efectividad obtenida en el intercambio sensible de calor entre corrientes a través de las paredes de policarbonato. Dado que la expresión del coeficiente global de transmisión de calor encierra 
en sí mismo a la capacidad de enfriamiento, pero compensada por la relación dada por la diferencia media logarítmica de temperaturas, el valor de la conductancia térmica va a mantenerse aproximadamente constante con la temperatura de entrada del aire exterior, como se comprueba atendiendo a las Figuras V.12.a y V.12.b.

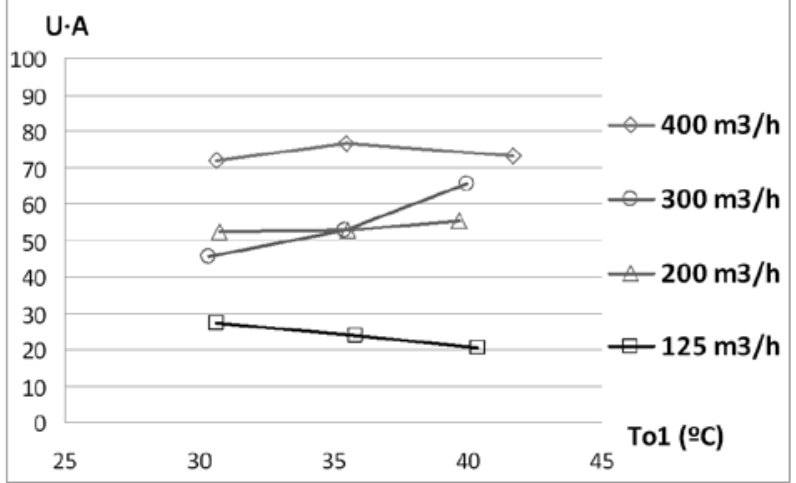

Figura V.12.a.- Conductancia térmica del prototipo de paso estrecho en modo seco.

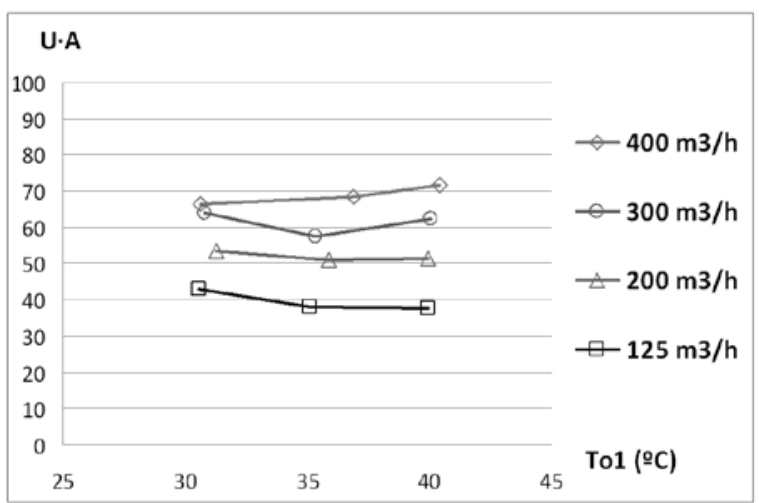

Figura V.12.b.- Conductancia térmica del prototipo de paso estrecho en modo húmedo.

Uno de los puntos de interés en el aporte de agua en uno de los lados del intercambiador reside en la creación de una película de agua sobre la superficie de intercambio, que generara una mejora en el coeficiente de película en ese lado del intercambiador. Sin embargo, comparando los resultados obtenidos entre ambos modos de operación, se comprueba que esta mejora no se ve generada en el funcionamiento en modo húmedo del sistema, posiblemente debido a que el agua no se adhiere en una película uniforme en las paredes como era esperado y deseable al realizar el diseño del sistema. Esto podría ser debido a que el contacto en contracorriente entre el aire de retorno y el agua aportada impide su distribución idealmente uniforme sobre la superficie. Para acatar este problema se replantea el diseño del sistema recurriendo a la utilización de paneles de policarbonato de mayor espesor que permitan un paso del aire más libre. A partir de esta idea se decide construir el prototipo de paso ancho.

En cualquier caso, resulta interesante comprobar cómo las medidas experimentales presentan unas tendencias más definidas en el caso del sistema operando como enfriador evaporativo indirecto. Puede observarse también que los resultados obtenidos para los ensayos realizados a menor caudal de aire exterior, $125 \mathrm{~m}^{3} / \mathrm{h}$, no muestran un comportamiento tan ajustado a las tendencias del resto de ensayos. Esto se debe, como se ha visto, a las inestabilidades registradas en el caudal de retorno para un caudal de aporte tan reducido, por las limitaciones del control de caudales en el dispositivo experimental ya descritas.

\section{Resultados del EEI de policarbonato de paso ancho}

Como se acaba de presentar, se planteó el rediseño del sistema recurriendo a paneles de policarbonato de mayor paso, a fin de permitir una correcta distribución del agua en el lado del aire de extracción en el intercambiador, y de esta forma que se generara adecuadamente la 
esperada película de agua que permitiera obtener mejores coeficientes de convección en ese lado del intercambio sensible de calor a través de las paredes de policarbonato.

Sin embargo, la construcción del dispositivo con iguales dimensiones pero con paneles de policarbonato de mayor espesor, supone una menor área de intercambio. El objetivo en este punto es estudiar los resultados experimentales obtenidos en este caso, para a continuación poder determinar cómo afectan estos dos puntos, variación del diámetro hidráulico y del área de intercambio, en el funcionamiento de un intercambiador de policarbonato, comparando ambos sistemas.

La evolución del salto de temperaturas alcanzado en la corriente de ventilación tratada con el sistema ancho presenta igual tendencia con las distintas temperaturas y caudales de entrada ensayados que el sistema de paso estrecho. Esta correspondencia de tendencias es en todo caso previsible, ya que ambos sistemas basan su funcionamiento en los mismos principios. Los resultados quedan recogidos en las figuras V.13.a y V.13.b.

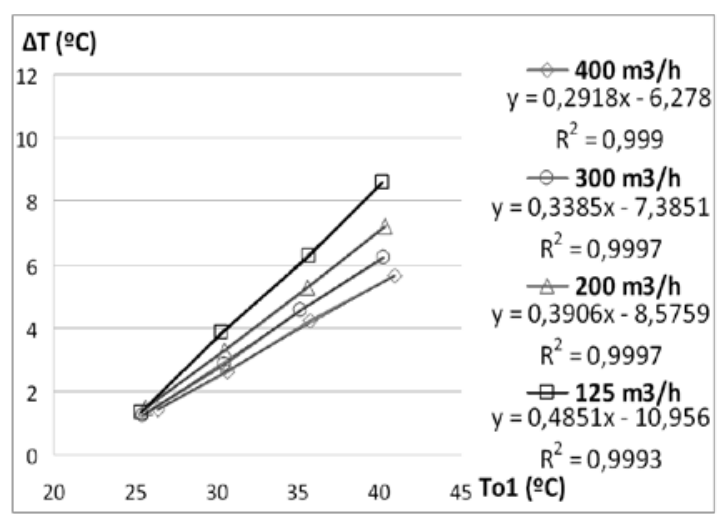

Figura V.13.a.- Salto térmico de temperaturas logrado con el prototipo de paso ancho en modo seco.

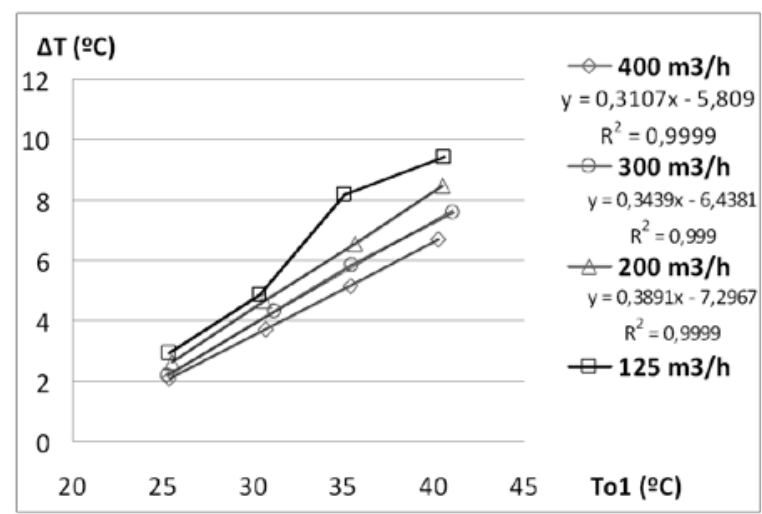

Figura V.13.b.- Salto térmico de temperaturas logrado con el prototipo de paso ancho en modo húmedo.

Asimismo, también en este caso se obtiene un comportamiento mejorado del sistema cuando este trabaja en modo húmedo, previsiblemente debido en su mayor parte a la mayor diferencia de temperaturas entre las corrientes de intercambio al efectuarse el fenómeno evaporativo en la de extracción.

Es notoria la desviación respecto a toda tendencia del resultado obtenido a $35^{\circ} \mathrm{C}$ y $125 \mathrm{~m}^{3} / \mathrm{h}$ para el sistema operando en modo húmedo. Esto es debido a la elevada humedad relativa registrada en el ambiente del laboratorio el día de realización de dicho ensayo, la cual afectó a las condiciones de operación en el interior de la cámara climática y a las condiciones del aire de aporte al sistema. Esta desviación se va a ver reflejada en todos los índices considerados para el análisis.

En lo que respecta a la efectividad térmica (figuras V.14.a y V.14.b), también para este sistema las tendencias reflejadas ante variaciones en la temperatura seca y caudal volumétrico 
del aire a la entrada son similares al sistema de paso estrecho. Este hecho es también argumentable en este caso mediante el mismo razonamiento que el expresado para el sistema de paso estrecho, puesto que como se ha indicado los principios básicos de operación son idénticos.

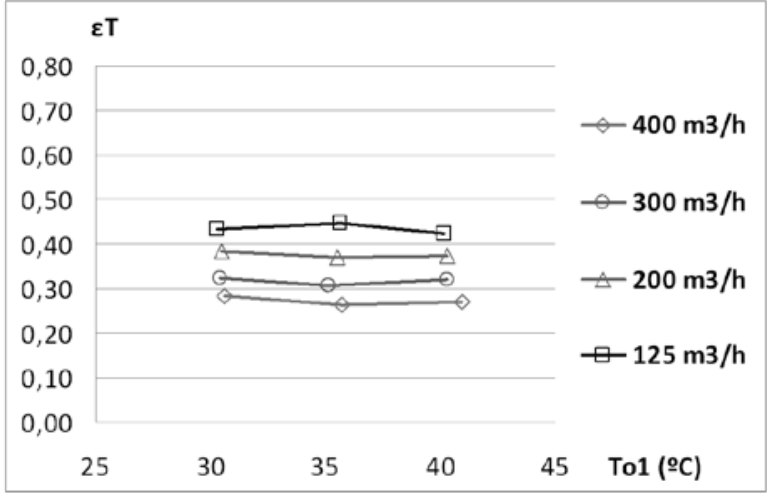

Figura V.14.a.- Efectividad térmica del prototipo de paso ancho en modo seco.

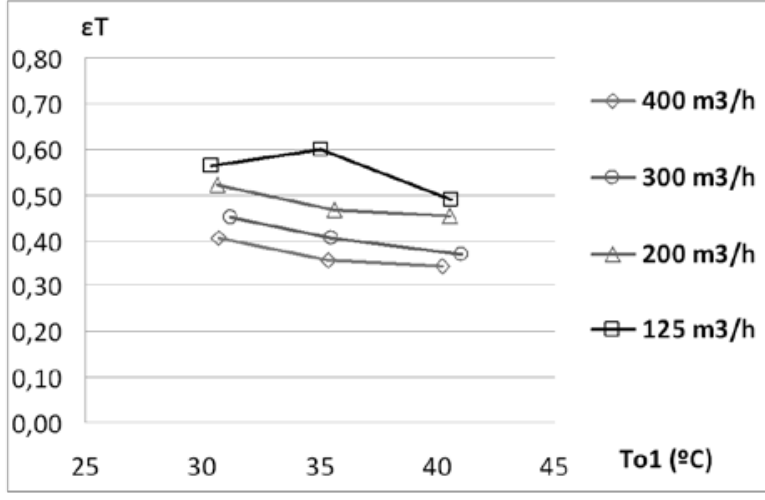

Figura V.14.b.- Efectividad térmica del prototipo de paso ancho en modo húmedo.

Los resultados para temperaturas secas del aire exterior a la entrada de $25^{\circ} \mathrm{C}$ no son representativos, ya que suponen inestabilidades en la expresión matemática del parámetro, como ya se presentó.

De manera semejante, se puede observar cómo el funcionamiento mejora en modo húmedo. Sin embargo, y dado que el máximo salto de temperaturas obtenible en este segundo modo de operación es mayor, atendiendo a los valores obtenidos de la efectividad térmica de bulbo húmedo (figura V.15) se comprueba que la mejora obtenida no es tan elevada como podría desearse; es decir, el rendimiento en el preacondicionamiento del aire mejora, pero no el del proceso de intercambio en sí.

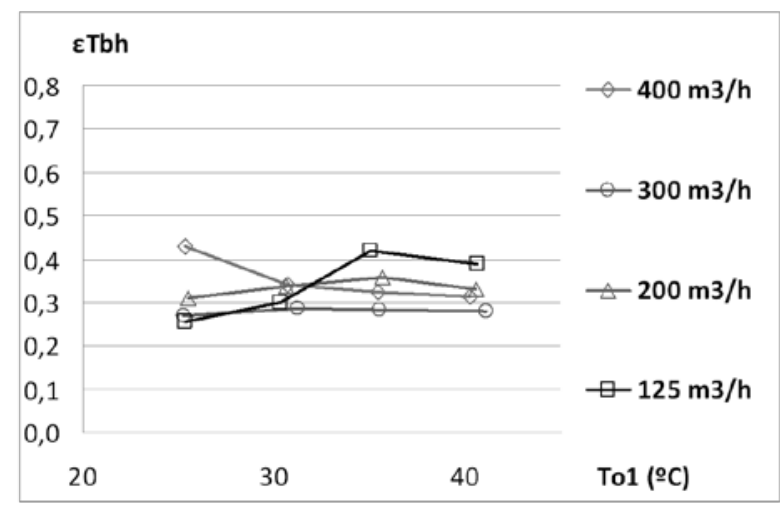

Figura V.15.- Efectividad térmica de bulbo húmedo del prototipo de paso ancho en modo húmedo. 
Por otro lado, estudiando la capacidad de enfriamiento, presentada como parámetro más representativo en términos de estudio de la energía real involucrada en el proceso, se puede observar unas claras tendencias lineales con la temperatura de entrada, correspondientes con los resultados obtenidos para el sistema de paso estrecho. Asimismo, también en este caso los resultados mejoran con el caudal tratado, al estar este directamente recogido en la expresión del parámetro (figuras V.16.a y V.16.b). También para este sistema operando como enfriador evaporativo indirecto, los valores de la capacidad de enfriamiento alcanzados son mayores.

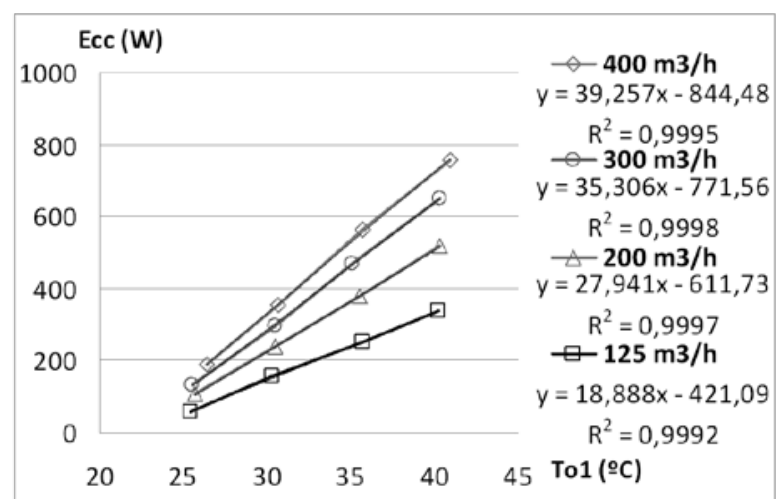

Figura V.16.a.- Capacidad de enfriamiento del prototipo de paso ancho en modo seco.

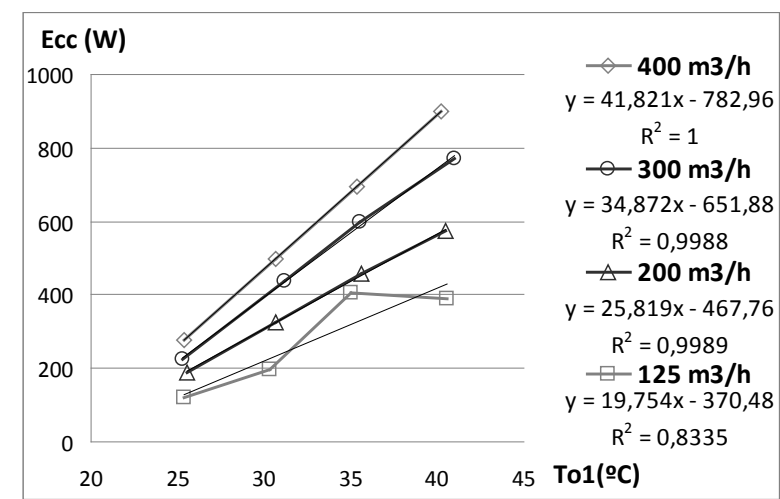

Figura V.16.b.- Capacidad de enfriamiento del prototipo de paso ancho en modo húmedo.

Finalmente, el análisis del propio intercambio de calor sensible en el sistema, realizado a través del parámetro de conductancia térmica (figuras V.17.a y V.17.b), demuestra que es independiente de la temperatura seca del aire exterior a la entrada, y que mejora con el caudal impulsado al incurrir esto último en la mejora del coeficiente de película del lado del intercambiador del aire exterior.

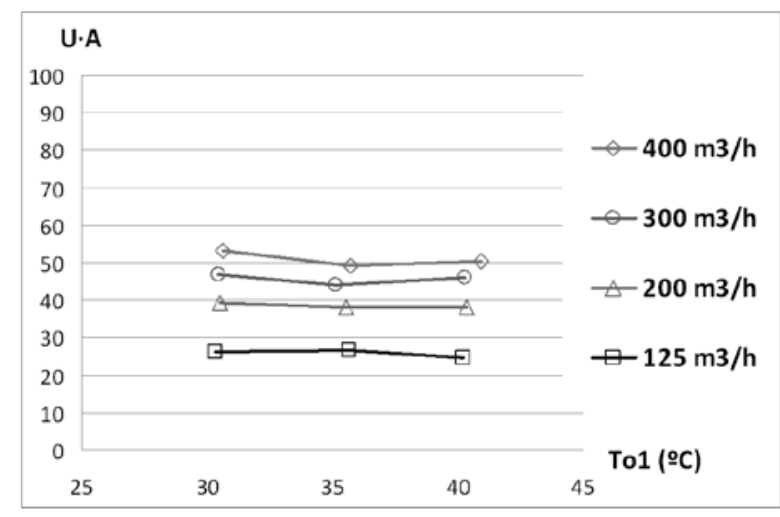

Figura V.17.a.- Conductancia térmica del prototipo de paso ancho en modo seco.

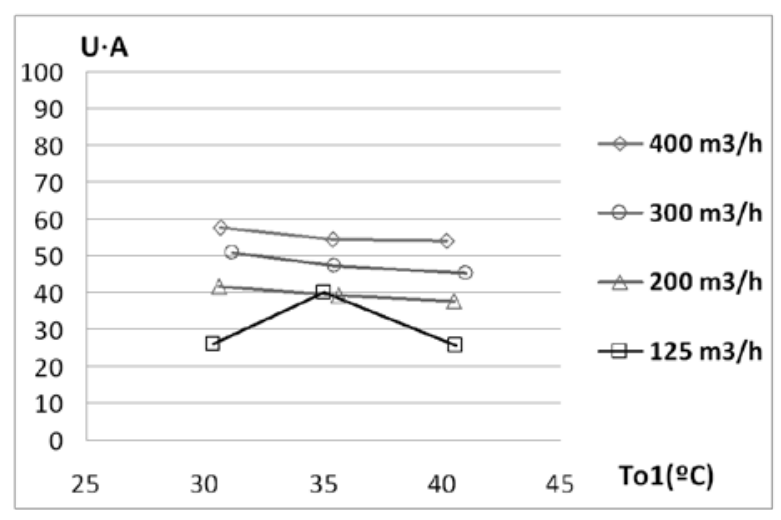

Figura V.17.b.- Conductancia térmica del prototipo de paso ancho en modo húmedo.

Sin embargo, la supuesta mejora en el coeficiente de película en el lado del intercambiador del aire de extracción por la creación en el modo de operación húmedo de una película de agua sobre la superficie de intercambio, no supone una mejora tan notoria como la esperada en el parámetro conductancia térmica entre los dos modos de operación. Es de suponer, por lo tanto, 
que tal película no se produce de forma uniforme, posiblemente debido a la distribución del flujo de agua a contracorriente con el aire impulsado, incluso habiéndose aumentado el paso del aire mediante paneles de policarbonato más anchos.

Es interesante destacar en este sistema el hecho de que todas las tendencias presentadas son especialmente claras, atendiendo a las regresiones obtenidas, tanto en modo seco como en modo húmedo. Sin embargo, como se ha visto en las figuras anteriores, los resultados obtenidos para el sistema ensayado en modo húmedo al menor caudal de ventilación y $35^{\circ} \mathrm{C}$ de temperatura de entrada no son representativos, debido a la variabilidad del proceso experimental. En este caso particular, se registraron condiciones de ensayo de la cámara con una humedad inusualmente elevada, debido a la elevada humedad relativa del ambiente del laboratorio en el día del ensayo.

\section{Comparación de resultados entre equipos}

Como ya se ha presentado, las dos únicas diferencias constructivas destacables entre ambos sistemas son el área de intercambio y el diámetro hidráulico de los canales de paso del aire, siendo esta última favorecida en detrimento de la primera en el nuevo diseño planteado con el sistema de paso ancho. A continuación se analizan detenidamente las diferencias operacionales obtenidas extraídas de los resultados de los dos sistemas ensayados, a fin de poder caracterizar cómo estos dos factores afectan al funcionamiento del sistema. Las tablas V.3 a V.6 recopilan todos los resultados obtenidos de los parámetros analizados para clarificar este planteamiento, representados con anterioridad a través de las figuras V.8 a V.17.

Tabla V.3.- Recopilación de los resultados de los saltos térmicos.

\begin{tabular}{|c|c|c|c|c|c|}
\hline \multirow[b]{2}{*}[\begin{array}{c}{Q}\\
{[m^{\frac{3}{3}}/\mathrm{h}}\end{array}]{} & \multirow[b]{2}{*}{$\begin{array}{l}T_{01} \\
\text { [C] }\end{array}$} & \multicolumn{2}{|c|}{ M1 } & \multicolumn{2}{|c|}{ M2 } \\
\hline & & $\begin{array}{c}\text { Estrecho } \\
\Delta \mathrm{T}[\mathrm{C}]\end{array}$ & $\begin{array}{l}\text { Ancho } \\
\Delta \mathrm{T}[\mathrm{C}]\end{array}$ & $\begin{array}{c}\text { Estrecho } \\
\Delta \mathrm{T}[\mathrm{C}]\end{array}$ & $\begin{array}{l}\text { Ancho } \\
\Delta T[C]\end{array}$ \\
\hline \multirow{4}{*}{400} & 40 & 6,18 & 5,62 & 6,81 & 6,70 \\
\hline & 35 & 4,53 & 4,23 & 5,37 & 5,16 \\
\hline & 30 & 3,03 & 2,61 & 3,30 & 3,72 \\
\hline & 25 & 1,47 & 1,41 & 2,13 & 2,07 \\
\hline \multirow{4}{*}{300} & 40 & 7,19 & 6,23 & 8,29 & 7,60 \\
\hline & 35 & 4,79 & 4,55 & 6,20 & 5,86 \\
\hline & 30 & 2,73 & 2,87 & 4,46 & 4,30 \\
\hline & 25 & 1,07 & 1,25 & 2,67 & 2,20 \\
\hline \multirow{4}{*}{200} & 40 & 8,07 & 7,21 & 9,28 & 8,47 \\
\hline & 35 & 6,04 & 5,28 & 7,22 & 6,54 \\
\hline & 30 & 4,06 & 3,29 & 5,27 & 4,64 \\
\hline & 25 & 1,43 & 1,48 & 3,25 & 2,63 \\
\hline \multirow{4}{*}{125} & 40 & 6,37 & 8,58 & 11,11 & 9,42 \\
\hline & 35 & 5,18 & 6,24 & 7,97 & 8,18 \\
\hline & 30 & 3,70 & 3,83 & 5,72 & 4,87 \\
\hline & 25 & 2,82 & 1,33 & 4,31 & 2,93 \\
\hline
\end{tabular}


Tabla V.4.- Recopilación de los resultados de las efectividades térmicas.

\begin{tabular}{|c|c|c|c|c|c|c|c|}
\hline \multirow[b]{2}{*}{$\left.\stackrel{\frac{Q}{3}}{\left[\mathrm{~m}^{3} / \mathrm{h}\right.}\right]$} & \multirow[b]{2}{*}{$\begin{array}{l}T_{\text {o1 }} \\
\text { [C] }\end{array}$} & \multicolumn{2}{|c|}{ M1 } & \multicolumn{2}{|c|}{ M2 } & \multicolumn{2}{|c|}{ M2 } \\
\hline & & $\begin{array}{l}\text { Estrecho } \\
\qquad \varepsilon_{\mathbf{T}}\end{array}$ & $\begin{array}{c}\text { Ancho } \\
\varepsilon_{\mathrm{T}}\end{array}$ & $\begin{array}{c}\text { Estrecho } \\
\varepsilon_{\mathrm{T}}\end{array}$ & $\begin{array}{c}\text { Ancho } \\
\varepsilon_{\mathbf{T}}\end{array}$ & $\begin{array}{c}\text { Estrecho } \\
\varepsilon_{\text {WBT }}\end{array}$ & $\begin{array}{c}\text { Ancho } \\
\varepsilon_{\mathrm{WBT}}\end{array}$ \\
\hline \multirow{4}{*}{400} & 40 & 0.33 & 0.27 & 0.42 & 0.34 & 0.29 & 0.31 \\
\hline & 35 & 0.34 & 0.26 & 0.41 & 0.36 & 0.27 & 0.32 \\
\hline & 30 & 0.32 & 0.28 & 0.43 & 0.41 & 0.23 & 0.34 \\
\hline & 25 & 0.32 & 0.31 & 0.61 & 1.08 & 0.23 & 0.43 \\
\hline \multirow{4}{*}{300} & 40 & 0.38 & 0.32 & 0.46 & 0.37 & 0.35 & 0.28 \\
\hline & 35 & 0.34 & 0.31 & 0.45 & 0.40 & 0.30 & 0.28 \\
\hline & 30 & 0.30 & 0.32 & 0.51 & 0.45 & 0.30 & 0.29 \\
\hline & 25 & 0.47 & 0.36 & 0.66 & 0.70 & 0.27 & 0.27 \\
\hline \multirow{4}{*}{200} & 40 & 0.46 & 0.37 & 0.52 & 0.45 & 0.40 & 0.33 \\
\hline & 35 & 0.44 & 0.37 & 0.53 & 0.47 & 0.39 & 0.36 \\
\hline & 30 & 0.43 & 0.38 & 0.57 & 0.52 & 0.37 & 0.34 \\
\hline & 25 & 0.42 & 0.43 & 0.82 & 0.91 & 0.35 & 0.31 \\
\hline \multirow{4}{*}{125} & 40 & 0.36 & 0.42 & 0.61 & 0.49 & 0.45 & 0.39 \\
\hline & 35 & 0.38 & 0.45 & 0.61 & 0.58 & 0.43 & 0.57 \\
\hline & 30 & 0.41 & 0.43 & 0.68 & 0.56 & 0.41 & 0.30 \\
\hline & 25 & 0.55 & 0.46 & 0.86 & 1.02 & 0.42 & 0.26 \\
\hline
\end{tabular}

Tabla V.5.- Recopilación de los resultados de la capacidad de enfriamiento.

\begin{tabular}{|c|c|c|c|c|c|}
\hline \multirow[b]{2}{*}{$\begin{array}{c}Q \\
{\left[\mathrm{~m}^{3} / \mathrm{h}\right]}\end{array}$} & \multirow[b]{2}{*}{$\begin{array}{l}T_{01} \\
{[C]}\end{array}$} & \multicolumn{2}{|c|}{ M1 } & \multicolumn{2}{|c|}{ M2 } \\
\hline & & $\begin{array}{c}\text { Estrecho } \\
\text { CC [W] }\end{array}$ & $\begin{array}{l}\text { Ancho } \\
\text { CC [W] }\end{array}$ & $\begin{array}{c}\text { Estrecho } \\
\text { CC [W] }\end{array}$ & $\begin{array}{l}\text { Ancho } \\
\text { CC [W] }\end{array}$ \\
\hline \multirow{4}{*}{400} & 40 & 822.3 & 759.2 & 906.7 & 900.3 \\
\hline & 35 & 612.1 & 565.1 & 710.9 & 694.3 \\
\hline & 30 & 407.8 & 351.9 & 432.6 & 498.4 \\
\hline & 25 & 195.6 & 190.9 & 290.3 & 278.0 \\
\hline \multirow{4}{*}{300} & 40 & 724.5 & 651.1 & 817.7 & 771.1 \\
\hline & 35 & 477.3 & 469.3 & 612.5 & 596.7 \\
\hline & 30 & 274.8 & 297.9 & 444.7 & 437.0 \\
\hline & 25 & 109.4 & 130.2 & 268.2 & 224.0 \\
\hline \multirow{4}{*}{200} & 40 & 548.9 & 517.1 & 637.4 & 572.6 \\
\hline & 35 & 412.7 & 379.1 & 501.2 & 457.7 \\
\hline & 30 & 279.9 & 237.2 & 367.7 & 327.2 \\
\hline & 25 & 101.4 & 107.0 & 230.3 & 186.8 \\
\hline \multirow{4}{*}{125} & 40 & 260.0 & 337.4 & 456.1 & 388.0 \\
\hline & 35 & 213.4 & 250.8 & 344.2 & 313.0 \\
\hline & 30 & 153.5 & 156.2 & 252.1 & 197.4 \\
\hline & 25 & 119.5 & 55.6 & 191.6 & 120.7 \\
\hline
\end{tabular}


Tabla V.6.- Recopilación de los resultados de la conductancia térmica.

\begin{tabular}{|c|c|c|c|c|c|}
\hline \multirow[b]{2}{*}{ 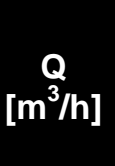 } & \multirow[b]{2}{*}{$\begin{array}{l}T_{01} \\
{[C]}\end{array}$} & \multicolumn{2}{|c|}{ M1 } & \multicolumn{2}{|c|}{ M2 } \\
\hline & & $\begin{array}{l}\text { Estrecho } \\
U \cdot A[W / C]\end{array}$ & $\begin{array}{c}\text { Ancho } \\
U \cdot A[W / C]\end{array}$ & $\begin{array}{l}\text { Estrecho } \\
U \cdot A[W / C]\end{array}$ & $\begin{array}{c}\text { Ancho } \\
U \cdot A[W / C]\end{array}$ \\
\hline \multirow{4}{*}{400} & 40 & 73,17 & 50,38 & 71,66 & 53,97 \\
\hline & 35 & 76,53 & 49,04 & 68,57 & 54,28 \\
\hline & 30 & 71,90 & 52,99 & 66,32 & 57,74 \\
\hline & 25 & 72,24 & 59,19 & 91,87 & 101,70 \\
\hline \multirow{4}{*}{300} & 40 & 65,45 & 46,15 & 62,25 & 45,08 \\
\hline & 35 & 52,60 & 43,88 & 57,39 & 47,27 \\
\hline & 30 & 45,59 & 46,77 & 63,82 & 50,69 \\
\hline & 25 & 84,28 & 53,85 & 80,08 & 76,03 \\
\hline \multirow{4}{*}{200} & 40 & 55,11 & 37,99 & 51,47 & 37,46 \\
\hline & 35 & 52,84 & 38,01 & 50,93 & 39,26 \\
\hline & 30 & 52,45 & 39,47 & 53,39 & 41,71 \\
\hline & 25 & 40,90 & 44,65 & 79,69 & 73,15 \\
\hline \multirow{4}{*}{125} & 40 & 20,62 & 24,78 & 37,71 & 25,70 \\
\hline & 35 & 23,70 & 26,63 & 38,05 & 39,82 \\
\hline & 30 & 27,18 & 26,17 & 42,84 & 25,94 \\
\hline & 25 & 43,86 & 30,48 & 68,19 & 44,07 \\
\hline
\end{tabular}

Comparando ambos sistemas en relación al descenso de la temperatura seca logrado en la corriente de ventilación (tabla V.3), y exceptuando los resultados poco fiables ya indicados (resultados para $125 \mathrm{~m}^{3} / \mathrm{h}$ en el sistema estrecho en modo seco, y para $35^{\circ} \mathrm{C}$ a $125 \mathrm{~m}^{3} / \mathrm{h}$ para el ancho en modo húmedo) estos son ligeramente mayores en el sistema de paso estrecho, siendo además las pendientes con la temperatura seca a la entrada también mayores en ese caso, de forma que la diferencia a menores temperaturas de ensayo no es tan notoria. Esto está claramente asociado a la mayor área de intercambio existente en el primer caso, de superficie total de cercanamente el doble.

Asimismo, la comparativa de ambos sistemas en cuanto a efectividad térmica nos lleva a la misma conclusión de que el sistema con mayor superficie de intercambio proporciona, lógicamente, mejores resultados, ya que este parámetro simplemente relaciona el salto térmico obtenido con el máximo alcanzable, el cual es idéntico en ambos casos ya que las condiciones ensayadas son semejantes (tabla V.4).

En lo que concierne a la efectividad térmica de bulbo húmedo, no es posible determinar una comparativa especialmente clara, ya que las tendencias presentadas por los resultados obtenidos de la caracterización del sistema de paso ancho no están tan definidas como las del sistema de paso estrecho (tabla V.4).

Al igual que las tendencias observadas entre sistemas en cuanto a saltos térmicos, la capacidad de enfriamiento también se ve mejorada al aumentar la superficie de intercambio en 
el sistema de paso estrecho, y la pendiente de la tendencia lineal con la temperatura es en ese caso más acentuada, por lo que para las menores temperaturas de ensayo los resultados son bastante similares (tabla V.5).

En cualquier caso, la diferencia más destacable entre sistemas debe plantearse en términos de intercambio de calor (tabla V.6). Las ya indicadas dos únicas diferencias constructivas consideradas en el diseño de los dos sistemas van a ser determinantes en los resultados de su funcionamiento. Se muestra obvio el hecho de que el factor área de intercambio prácticamente duplicado en el equipo de "paso estrecho" va a ser clave en la mejora de la transferencia de calor entre corrientes, reflejada en el coeficiente global de transmisión, y por lo tanto en la eficacia del sistema para recuperar la energía residual de la corriente de aire expulsada. Pero por otro lado, un mayor diámetro hidráulico del paso del aire en contracorriente con el agua aportada, objetivo del diseño el sistema de "paso ancho", también favorece a la transferencia de calor en cuanto a que permite mejores coeficientes de película gracias a la distribución más uniforme del agua sobre la pared de intercambio, como ya se ha indicado. Por lo tanto, puede observarse en la tabla V.6 que la conductancia térmica obtenida en el sistema de "paso estrecho" es notablemente superior al del sistema de "paso ancho" cuando ambos operan en modo seco, debido a la mayor superficie de intercambio en el primer caso; mientras que atendiendo a los resultados de los equipos en modo húmedo, la transmisión de calor en el segundo equipo se ve mejorada frente a la menos claramente alterada conductancia térmica registrada en el primero, al entorpecerse la distribución de agua sobre la superficie de intercambio por la estrechez de los paneles utilizados. Luego los resultados obtenidos del parámetro conductancia térmica resultan explicables por la posible compensación entre los dos efectos buscados con las dos particularidades constructivas planteadas en el diseño de los prototipos.

\section{V.6. ANÁLISIS DE VARIANZA}

Se ha observado que las variaciones en los distintos factores considerados en el diseño de experimentos afectan al comportamiento del equipo de forma más o menos notoria, y distinta en función de cada parámetro abordado para estudiar dicho comportamiento. Resulta pues interesante realizar un análisis de varianza que nos permita determinar la medida relativa en que cada factor influye en los resultados obtenidos para estos parámetros (apéndice A).

Del análisis realizado, los valores medios obtenidos de los parámetros abordados (salto térmico, efectividad térmica, efectividad térmica de bulbo húmedo, capacidad de enfriamiento y conductancia térmica) para los distintos ensayos realizados habiéndose mantenido constante un determinado nivel de un factor, son los recopilados en la tabla V.7 y representados en las figuras V.18 a V.22. 
Tabla V.7.- Recopilación de los valores medios de los ensayos realizados para cada nivel de los factores mantenido constante.

\begin{tabular}{ccccccc} 
& $\mathbf{P}_{\mathbf{N}}$ & $\mathbf{P}_{\mathbf{W}}$ & $\mathbf{V 1}$ & $\mathbf{V 2}$ & $\mathbf{V 3}$ & $\mathbf{V 4}$ \\
\hline $\boldsymbol{\Delta} \mathbf{T}$ & 5,062 & 4,728 & 4,021 & 4,516 & 5,258 & 5,784 \\
$\boldsymbol{\varepsilon}_{\mathbf{T}}$ & 0,482 & 0,471 & 0,406 & 0,426 & 0,507 & 0,567 \\
$\boldsymbol{\varepsilon}_{\mathbf{T B H}}$ & 0,266 & 0,257 & 0,233 & 0,232 & 0,279 & 0,300 \\
$\mathbf{E}_{\mathrm{CC}}$ & 411,795 & 420,272 & 538,522 & 456,655 & 366,510 & 302,447 \\
$\mathbf{U} \cdot \mathbf{A}$ & 207,296 & 167,605 & 241,095 & 207,263 & 177,407 & 124,036 \\
& $\mathbf{M 1}$ & $\mathbf{M 2}$ & $\mathbf{T 1}$ & $\mathbf{T 2}$ & $\mathbf{T 3}$ & $\mathbf{T 4}$ \\
$\mathbf{\Delta} \mathbf{T}$ & 4,207 & 5,583 & 7,695 & 5,833 & 3,900 & 2,152 \\
$\boldsymbol{\varepsilon}_{\mathbf{T}}$ & 0,375 & 0,577 & 0,412 & 0,431 & 0,438 & 0,625 \\
$\boldsymbol{\varepsilon}_{\mathbf{T B H}}$ & 0,188 & 0,335 & 0,302 & 0,285 & 0,249 & 0,209 \\
$\mathbf{E}_{\mathrm{CC}}$ & 349,039 & 483,028 & 629,398 & 539,985 & 319,766 & 174,985 \\
$\mathbf{U} \cdot \mathbf{A}$ & 171,994 & 202,907 & 170,764 & 171,969 & 172,118 & 234,951 \\
\hline
\end{tabular}
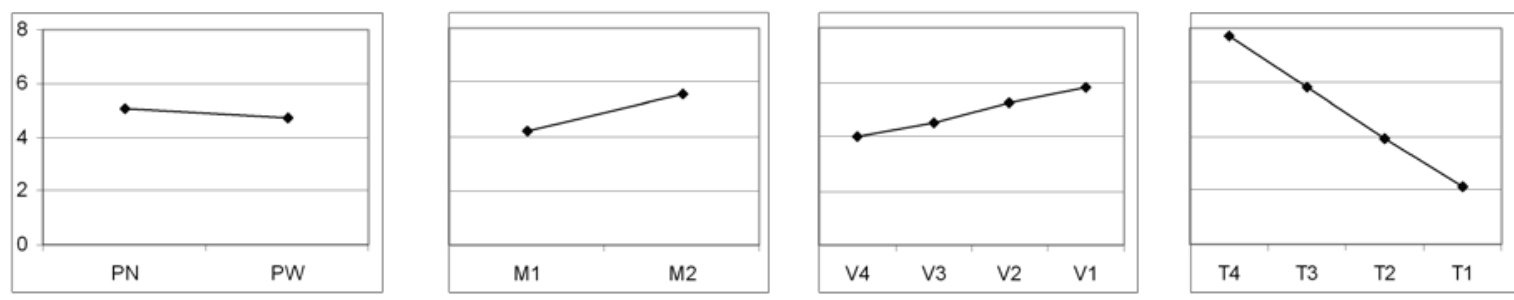

Figura V.18.- Gráficas factoriales para el salto de temperaturas.
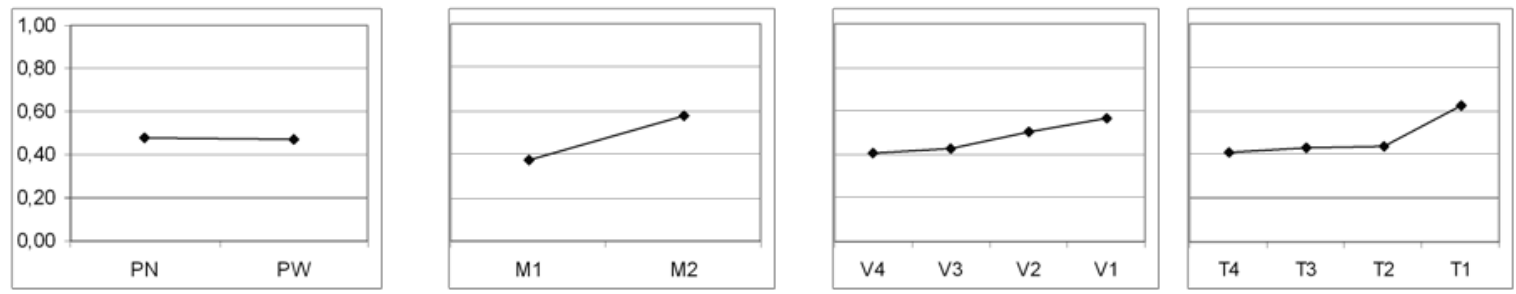

Figura V.19.- Gráficas factoriales para la efectividad térmica.
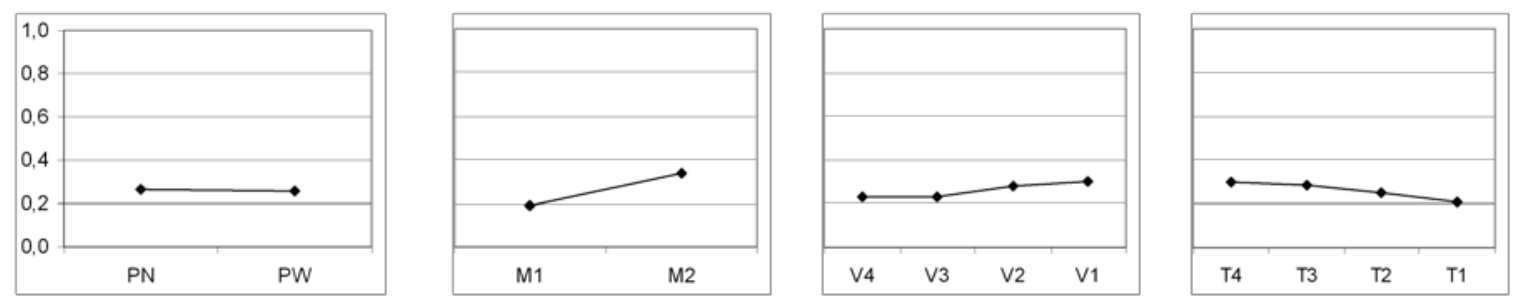

Figura V.20.- Gráficas factoriales para la efectividad térmica de bulbo húmedo. 

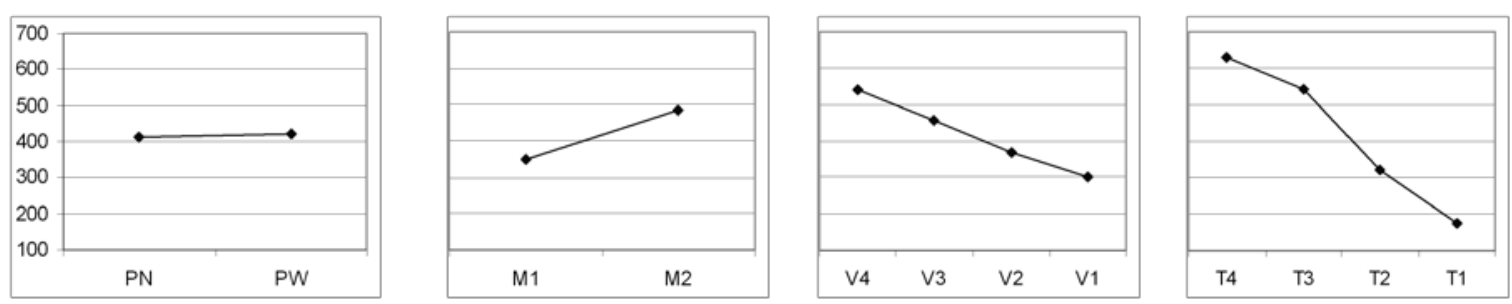

Figura V.21.- Gráficas factoriales para la capacidad de enfriamiento.
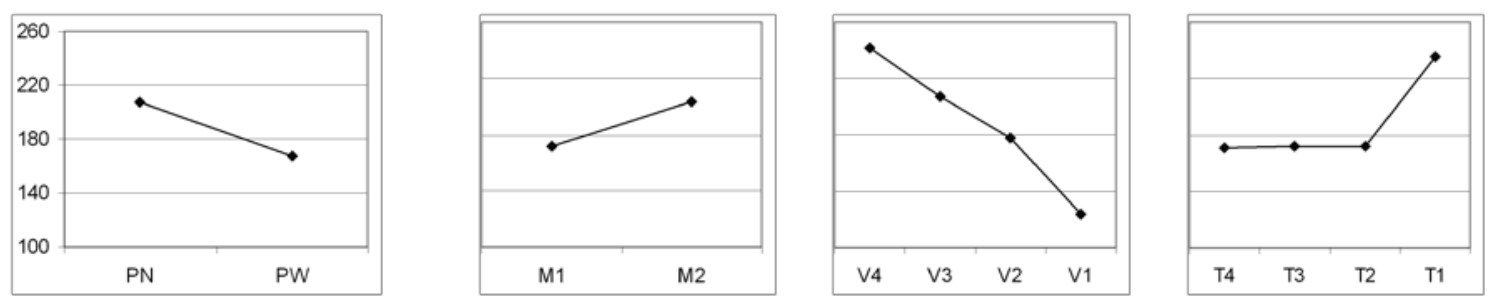

Figura V.22.- Gráficas factoriales para la conductancia térmica.

Analizando cómo varían los resultados medios entre niveles de cada factor, se comprueba que los niveles del factor prototipo sólo resultan ligeramente relevantes en lo que concierne a la conductancia térmica, ya que sí afecta a los resultados de este parámetro la modificación del área de transferencia de calor y la posible influencia de la configuración sobre los coeficientes de película convectivos obtenidos.

Por su parte, la modificación del modo de operación afecta en todo caso mejorando los resultados al implementarse el enfriamiento evaporativo, si bien los ligeros incrementos generados en los saltos térmicos, capacidad de enfriamiento y conductancia térmica (entre un 20 y un 30\%) se contraponen con el importante peso de este factor sobre las efectividades térmicas (más del 50\% para la de bulbo seco y hasta un 78\% para la de bulbo húmedo).

Finalmente, se aprecia que en todo caso el caudal volumétrico afecta a los parámetros, aun suponiendo un incremento en la capacidad de enfriamiento y la conductancia térmica y una disminución en el salto térmico y las efectividades, por las razones ya argumentadas con anterioridad. Por otro lado, la temperatura exterior no afecta apenas sobre las efectividades y la conductancia térmica, si bien influye notablemente en el salto térmico y la capacidad de enfriamiento.

Resta estudiar la posible interacción entre factores. Para ello se han obtenido los valores medios de los ensayos realizados para cada par de factores establecidos en un nivel dado, como se muestra en las tablas V.8 a V.12, cuyos datos se representan en las figuras V.23 a V.27. Las interacciones triples no se presentan aquí por poder considerarse despreciables. 
Tabla V.8.- Valores medios de las interacciones dobles para el salto térmico.

\begin{tabular}{|c|cc|}
\hline & $\mathbf{P}_{\mathbf{N}}$ & $\mathbf{P}_{\mathbf{w}}$ \\
\hline M1 & 4,125 & 4,289 \\
M2 & 5,331 & 5,834 \\
\hline
\end{tabular}

\begin{tabular}{|c|cc|}
\hline & $\mathbf{P}_{\mathbf{N}}$ & $\mathbf{P}_{\mathrm{w}}$ \\
\hline V4 & 3,940 & 4,102 \\
V3 & 4,358 & 4,675 \\
V2 & 4,941 & 5,576 \\
V1 & 5,673 & 5,895 \\
\hline
\end{tabular}

\begin{tabular}{|c|cc|}
\hline & $\mathbf{P}_{\mathrm{N}}$ & $\mathbf{P}_{\mathrm{w}}$ \\
\hline T4 & 7,479 & 7,910 \\
T3 & 5,753 & 5,912 \\
T2 & 3,766 & 4,033 \\
T1 & 1,913 & 2,392 \\
\hline
\end{tabular}

\begin{tabular}{|c|cc|}
\hline & M1 & M2 \\
\hline V4 & 3,634 & 4,407 \\
V3 & 3,833 & 5,199 \\
V2 & 4,605 & 5,912 \\
V1 & 4,756 & 6,812 \\
\hline
\end{tabular}

\begin{tabular}{|c|cc|}
\hline & M1 & M2 \\
\hline T4 & 6,931 & 8,458 \\
T3 & 5,103 & 6,563 \\
T2 & 3,263 & 4,536 \\
T1 & 1,531 & 2,774 \\
\hline
\end{tabular}

\begin{tabular}{|c|cc|cc|} 
& V4 & V3 & V2 & V1 \\
T4 & 6,326 & 7,328 & 8,255 & 8,869 \\
T3 & 4,823 & 5,349 & 6,267 & 6,892 \\
T2 & 3,164 & 3,590 & 4,316 & 4,529 \\
T1 & 1,770 & 1,798 & 2,195 & 2,846 \\
\hline
\end{tabular}
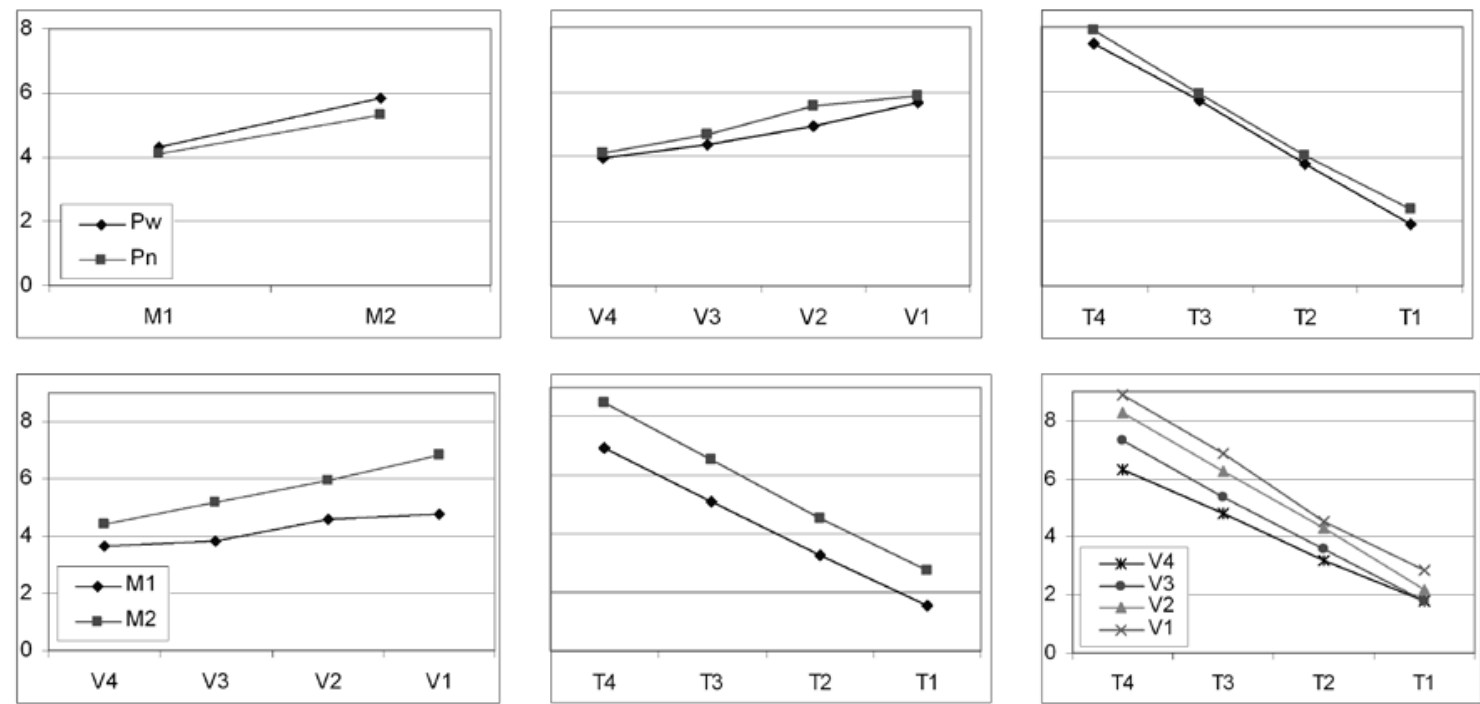

Figura V.23.- Gráficas de las interacciones factoriales para el salto de temperaturas. 
Tabla V.9.- Valores medios de las interacciones dobles para la efectividad térmica.

\begin{tabular}{|c|cc|} 
& $\mathbf{P}_{\mathbf{N}}$ & $\mathbf{P}_{\mathbf{w}}$ \\
\hline M1 & 0,360 & 0,391 \\
M2 & 0,582 & 0,573 \\
\hline
\end{tabular}

\begin{tabular}{|c|cc|}
\hline & $\mathbf{P}_{\mathbf{N}}$ & $\mathbf{P}_{\mathrm{w}}$ \\
\hline V4 & 0,415 & 0,397 \\
V3 & 0,405 & 0,447 \\
V2 & 0,488 & 0,525 \\
V1 & 0,577 & 0,558 \\
\hline
\end{tabular}

\begin{tabular}{|c|cc|}
\hline & $\mathbf{P}_{\mathbf{N}}$ & $\mathbf{P}_{\mathrm{w}}$ \\
\hline T4 & 0,380 & 0,443 \\
T3 & 0,424 & 0,438 \\
T2 & 0,420 & 0,456 \\
T1 & 0,660 & 0,590 \\
\hline
\end{tabular}

\begin{tabular}{|c|cc|}
\hline & M1 & M2 \\
\hline V4 & 0,304 & 0,507 \\
V3 & 0,351 & 0,501 \\
V2 & 0,413 & 0,600 \\
V1 & 0,433 & 0,701 \\
\hline
\end{tabular}

\begin{tabular}{|c|cc|}
\hline & M1 & M2 \\
\hline T4 & 0,364 & 0,459 \\
T3 & 0,360 & 0,502 \\
T2 & 0,361 & 0,516 \\
T1 & 0,416 & 0,834 \\
\hline
\end{tabular}

\begin{tabular}{|c|cc|cc|} 
& V4 & V3 & V2 & V1 \\
T4 & 0,340 & 0,384 & 0,452 & 0,470 \\
T3 & 0,342 & 0,373 & 0,454 & 0,555 \\
T2 & 0,359 & 0,396 & 0,477 & 0,521 \\
T1 & 0,581 & 0,551 & 0,645 & 0,723 \\
\hline
\end{tabular}
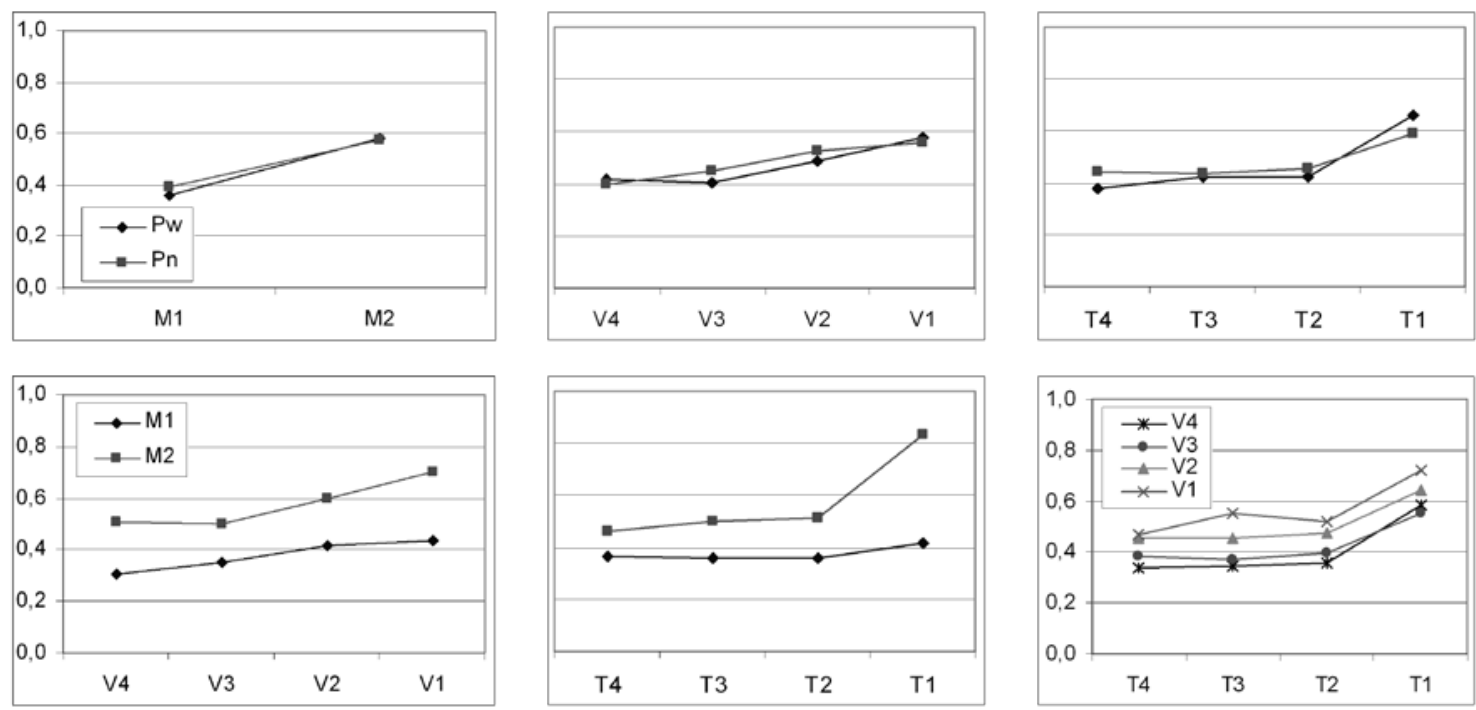

Figura V.24.- Gráficas de las interacciones factoriales para la efectividad térmica. 
Tabla V.10.- Valores medios de las interacciones dobles para la efectividad de bulbo húmedo.

\begin{tabular}{|c|cc|} 
& $\mathbf{P}_{\mathbf{N}}$ & $\mathbf{P}_{\mathrm{w}}$ \\
\hline M1 & 0,185 & 0,190 \\
M2 & 0,328 & 0,341 \\
\hline
\end{tabular}

\begin{tabular}{|c|cc|} 
& $\mathbf{P}_{\mathbf{N}}$ & $\mathbf{P}_{\mathrm{w}}$ \\
$\mathbf{V 4}$ & 0,255 & 0,211 \\
V3 & 0,226 & 0,239 \\
V2 & 0,264 & 0,295 \\
V1 & 0,282 & 0,318 \\
\hline
\end{tabular}

\begin{tabular}{|c|cc|}
\hline & $\mathbf{P}_{\mathbf{N}}$ & $\mathbf{P}_{\mathbf{w}}$ \\
\hline T4 & 0,284 & 0,320 \\
T3 & 0,285 & 0,285 \\
T2 & 0,247 & 0,250 \\
T1 & 0,211 & 0,207 \\
\hline
\end{tabular}

\begin{tabular}{|c|cc|}
\hline & M1 & M2 \\
V4 & 0,163 & 0,303 \\
V3 & 0,172 & 0,293 \\
V2 & 0,204 & 0,355 \\
V1 & 0,212 & 0,388 \\
\hline
\end{tabular}

\begin{tabular}{|c|cc|}
\hline & M1 & M2 \\
\hline T4 & 0,254 & 0,351 \\
T3 & 0,220 & 0,350 \\
T2 & 0,174 & 0,323 \\
T1 & 0,103 & 0,315 \\
\hline
\end{tabular}

\begin{tabular}{|c|cc|cc|} 
& $\mathbf{V 4}$ & $\mathbf{V 3}$ & $\mathbf{V 2}$ & $\mathbf{V 1}$ \\
T4 & 0,258 & 0,279 & 0,324 & 0,348 \\
T3 & 0,241 & 0,249 & 0,307 & 0,343 \\
T2 & 0,220 & 0,224 & 0,274 & 0,277 \\
T1 & 0,213 & 0,177 & 0,213 & 0,233 \\
\hline
\end{tabular}
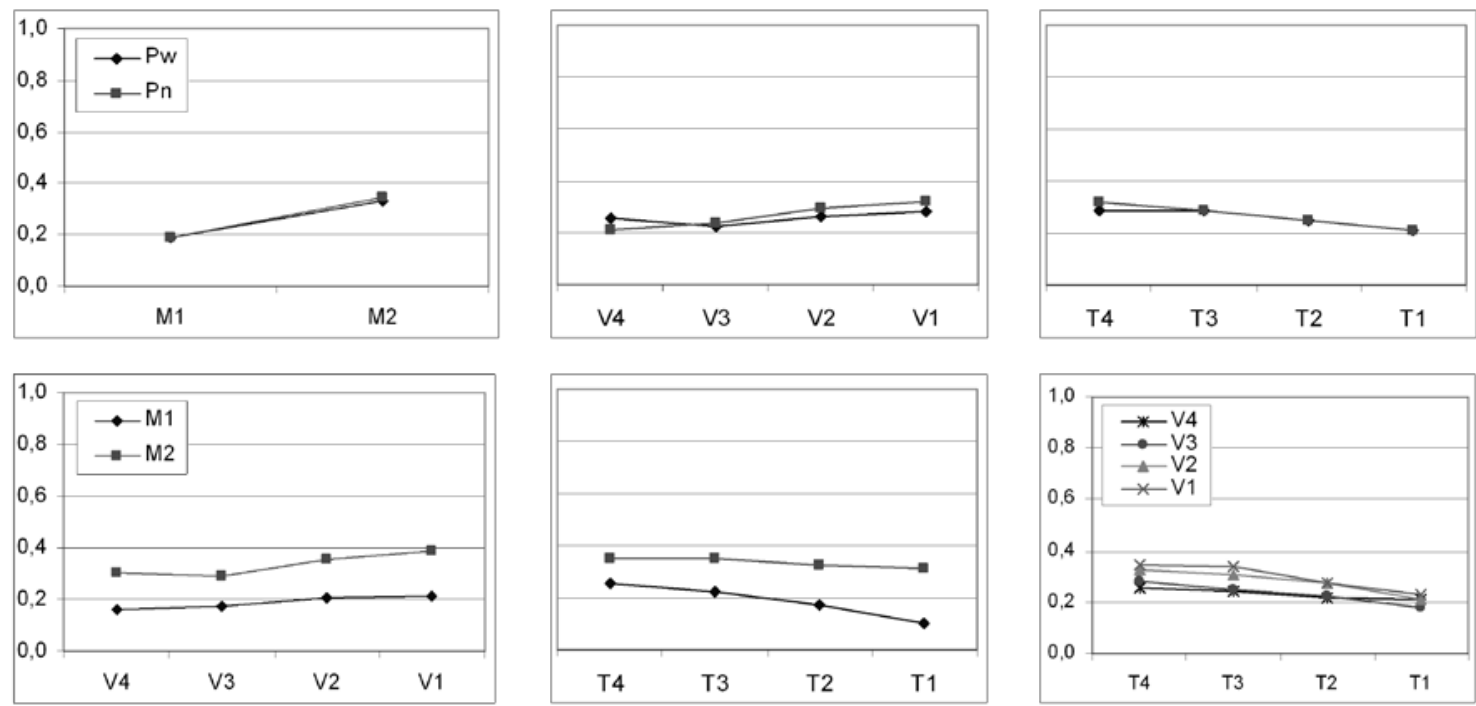

Figura V.25.- Gráficas de las interacciones factoriales para la efectividad térmica de bulbo húmedo. 
Tabla V.11.- Valores medios de las interacciones dobles para la capacidad de enfriamiento.

\begin{tabular}{|c|cc|} 
& $\mathbf{P}_{\mathbf{N}}$ & $\mathbf{P}_{\mathrm{w}}$ \\
\hline M1 & 341,002 & 357,076 \\
M2 & 499,542 & 466,514 \\
\hline
\end{tabular}

\begin{tabular}{|c|cc|}
\hline & $\mathbf{P}_{\mathbf{N}}$ & $\mathbf{P}_{\mathbf{w}}$ \\
\hline V4 & 529,752 & 547,292 \\
V3 & 447,169 & 466,141 \\
V2 & 348,084 & 384,937 \\
V1 & 356,083 & 248,812 \\
\hline
\end{tabular}

\begin{tabular}{|c|cc|}
\hline & $\mathbf{P}_{\mathbf{N}}$ & $\mathbf{P}_{\mathrm{w}}$ \\
\hline T4 & 612,102 & 646,694 \\
T3 & 594,437 & 485,532 \\
\hline T2 & 312,875 & 326,656 \\
T1 & 161,672 & 188,299 \\
\hline
\end{tabular}

\begin{tabular}{|ccc|} 
& M1 & M2 \\
V4 & 488,110 & 588,934 \\
V3 & 391,826 & 521,484 \\
V2 & 322,905 & 410,115 \\
V1 & 193,315 & 411,579 \\
\hline
\end{tabular}

\begin{tabular}{|ccc|} 
& M1 & M2 \\
\hline T4 & 577,561 & 681,236 \\
T3 & 422,465 & 657,504 \\
T2 & 269,909 & 369,623 \\
T1 & 126,221 & 223,749 \\
\hline
\end{tabular}

\begin{tabular}{|c|cc|cc|} 
& $\mathbf{V 4}$ & $\mathbf{V 3}$ & $\mathbf{V 2}$ & $\mathbf{V 1}$ \\
\hline T4 & 847,127 & 741,075 & 569,009 & 360,382 \\
T3 & 645,584 & 538,952 & 437,650 & 537,752 \\
T2 & 422,658 & 363,610 & 302,989 & 189,806 \\
T1 & 238,718 & 182,981 & 156,393 & 121,848 \\
\hline
\end{tabular}
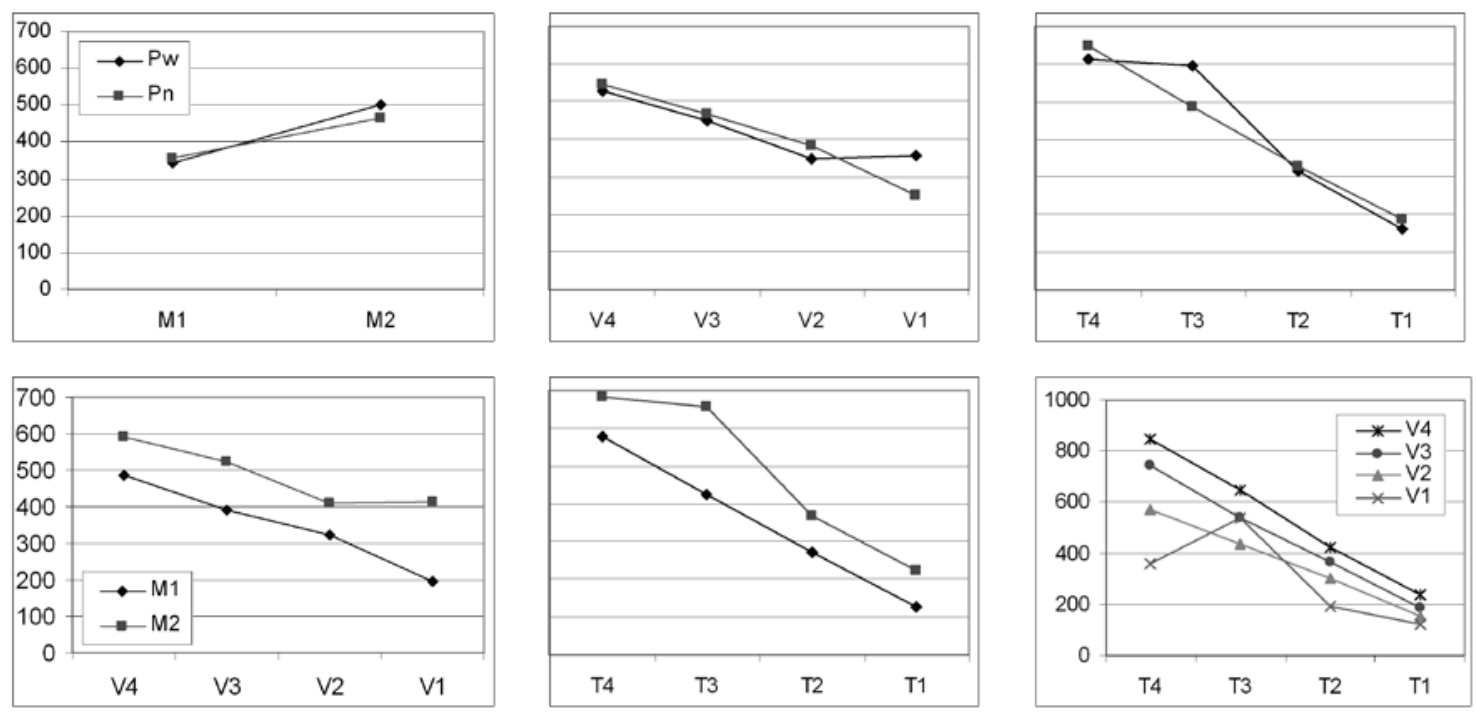

Figura V.26.- Gráficas de las interacciones factoriales para la capacidad de enfriamiento. 
Tabla V.12.- Valores medios de las interacciones dobles para la conductancia térmica.

\begin{tabular}{|c|cc|} 
& $\mathbf{P}_{\mathbf{N}}$ & $\mathbf{P}_{\mathbf{w}}$ \\
\hline M1 & 150,846 & 193,142 \\
M2 & 184,364 & 221,450 \\
\hline
\end{tabular}

\begin{tabular}{|c|cc|}
\hline & $\mathbf{P}_{\mathbf{N}}$ & $\mathbf{P}_{\mathbf{w}}$ \\
\hline V4 & 215,681 & 266,509 \\
V3 & 184,370 & 230,157 \\
V2 & 158,267 & 196,547 \\
V1 & 112,100 & 135,972 \\
\hline
\end{tabular}

\begin{tabular}{|ccc|} 
& $\mathbf{P}_{\mathbf{N}}$ & $\mathbf{P}_{\mathbf{w}}$ \\
\hline T4 & 144,678 & 196,850 \\
T3 & 154,666 & 189,272 \\
T2 & 153,670 & 190,565 \\
T1 & 217,404 & 252,498 \\
\hline
\end{tabular}

\begin{tabular}{|c|cc|} 
& M1 & M2 \\
\hline V4 & 227,446 & 254,745 \\
V3 & 197,352 & 217,175 \\
V2 & 162,639 & 192,176 \\
V1 & 100,539 & 147,534 \\
\hline
\end{tabular}

\begin{tabular}{|c|cc|}
\hline & M1 & M2 \\
\hline T4 & 168,145 & 173,383 \\
\hline T3 & 163,449 & 180,489 \\
T2 & 163,126 & 181,109 \\
\hline T1 & 193,255 & 276,648 \\
\hline
\end{tabular}

\begin{tabular}{|c|cc|cc|} 
& V4 & V3 & V2 & V1 \\
\hline T4 & 224,263 & 197,033 & 163,831 & 97,927 \\
T3 & 223,572 & 181,027 & 162,928 & 120,350 \\
T2 & 224,047 & 186,176 & 168,321 & 109,926 \\
T1 & 292,499 & 264,817 & 214,548 & 167,941 \\
\hline
\end{tabular}
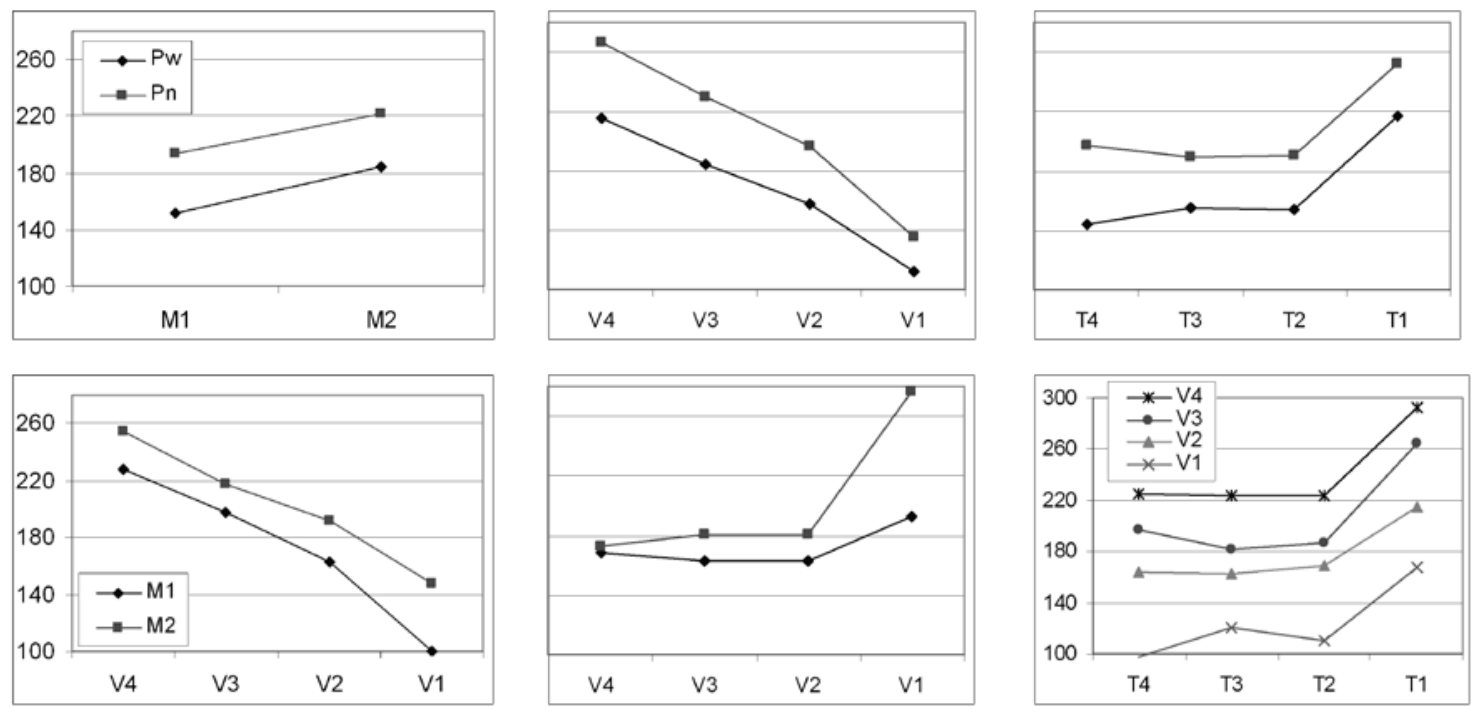

Figura V.27.- Gráficas de las interacciones factoriales para la conductancia térmica. 
Se comprueba que las interacciones entre factores son despreciables en prácticamente todos los casos, ya que las irregularidades en las tendencias de las interacciones de cualquier factor con la temperatura exterior para los parámetros de efectividad térmica y de la conductancia térmica se deben a las inestabilidades en la propia expresión de estos parámetros para las temperaturas más bajas ensayadas, como ya se apreció en el análisis de resultados. De igual forma, la tendencia de los valores medios para la interacción caudal volumétrico-temperatura no son muy representativos, al no serlo los ensayos para el menor caudal y el tercer nivel de temperatura.

Las distintas contribuciones de los factores analizados son las recopiladas en la tabla V.13, mostrándose el error desglosado en las correspondientes contribuciones de las posibles interacciones dobles en la tabla V.14.

Tabla V.13.- Recopilación de los coeficientes de contribución derivados del ANOVA realizado sobre los factores del diseño de experimentos.

\begin{tabular}{cccccc} 
& $\mathbf{S S}_{\mathbf{P}}$ & $\mathbf{S S}_{\mathbf{M}}$ & $\mathbf{S S}_{\mathbf{V}}$ & $\mathbf{S S}_{\mathbf{T}}$ & $\begin{array}{c}\mathbf{S S}_{\text {Error }} \\
{[\%]}\end{array}$ \\
& {$[\%]$} & {$[\%]$} & {$[\%]$} & {$[\%]$} & 4,69 \\
$\boldsymbol{\Delta} \mathbf{T}$ & 0,50 & 8,56 & 8,28 & 77,96 & $4,69,23$ \\
$\boldsymbol{\varepsilon}_{\mathbf{T}}$ & 0,09 & 33,48 & 13,70 & 24,50 & 28,23 \\
$\boldsymbol{\varepsilon}_{\mathrm{TBH}}$ & 0,21 & 55,23 & 8,91 & 13,03 & 22,62 \\
$\mathbf{E}_{\mathrm{CC}}$ & 0,03 & 7,37 & 13,13 & 52,63 & 26,84 \\
U.A & 9,91 & 6,01 & 46,49 & 18,93 & 18,67 \\
\hline
\end{tabular}

Tabla V.14.- Desglose del porcentaje de error en los coeficientes de contribución de las interacciones entre factores.

\begin{tabular}{cccccccc} 
& $\begin{array}{c}\mathbf{S S}_{\mathrm{PM}} \\
{[\%]}\end{array}$ & $\begin{array}{c}\mathbf{S S}_{\mathrm{PV}} \\
{[\%]}\end{array}$ & $\begin{array}{c}\mathbf{S S}_{\mathrm{PT}} \\
{[\%]}\end{array}$ & $\begin{array}{c}\mathbf{S S}_{\mathbf{M V}} \\
{[\%]}\end{array}$ & $\begin{array}{c}\mathbf{S S}_{\mathbf{M T}} \\
{[\%]}\end{array}$ & $\begin{array}{c}\mathbf{S S}_{\mathrm{VT}} \\
{[\%]}\end{array}$ & $\begin{array}{c}\mathbf{S S}_{\mathrm{RError}} \\
{[\%]}\end{array}$ \\
$\mathbf{\Delta \mathbf { T }}$ & 0,13 & 0,15 & 0,07 & 0,94 & 0,07 & 1,02 & 2,31 \\
$\boldsymbol{\varepsilon}_{\mathbf{T}}$ & 0,34 & 0,68 & 2,03 & 1,51 & 13,16 & 1,01 & 9,50 \\
$\boldsymbol{\varepsilon}_{\mathrm{TBH}}$ & 0,05 & 2,64 & 0,64 & 1,03 & 4,47 & 1,71 & 12,08 \\
$\mathbf{E}_{\mathrm{CC}}$ & 0,25 & 1,36 & 1,40 & 1,07 & 1,40 & 6,82 & 14,54 \\
$\mathbf{U} \cdot \mathbf{A}$ & 0,04 & 0,65 & 0,33 & 0,62 & 5,93 & 1,12 & 9,97 \\
\hline
\end{tabular}

Como puede observarse, el factor determinante en el salto térmico alcanzado en el aire exterior tratado es la temperatura seca exterior a la cual se encuentra dicho aire a la entrada, ya que contribuye en un $78 \%$ a la variabilidad de dicho parámetro de estudio. Puede comprobarse también que en este caso no se identifican interacciones entre los distintos factores.

En cuanto a la efectividad térmica, la temperatura no resultaba ser un factor tan determinante, sí siéndolo sin embargo el hecho de introducir el enfriamiento evaporativo en el 
segundo modo de operación. Esto queda también reflejado en los resultados recogidos en la tabla V.7. Por otro lado, la efectividad térmica de bulbo húmedo varía también principalmente debido al modo de operación, habiéndose calculado esta en este análisis para ambos modos de operación. Este resultado obtenido en ambos parámetros resulta obvio, considerando que el máximo salto de temperaturas obtenible en los modos de operación seco y húmedo es el reflejado por la expresión de la efectividad térmica y el de la efectividad térmica de bulbo húmedo respectivamente, y en ningún caso al contrario. Asimismo, la influencia del factor temperatura de entrada le sigue en relevancia, como es lógico por afectar también este directamente a la expresión de ambos parámetros. Sin embargo, para los dos parámetros el considerable error correspondiente indica que las interacciones entre factores no serían en principio despreciables, pudiéndose destacar frente al resto de contribuciones la de la interrelación entre el modo de operación y la temperatura, si bien es más notoria en el caso de la efectividad térmica.

En lo que concierne a la capacidad de enfriamiento, al igual que sucedía con el salto térmico, es la temperatura exterior el factor de mayor peso en la variabilidad del parámetro en cuestión, lo cual es esperable por estar ambos parámetros directamente relacionados a través del caudal volumétrico del aire exterior. Sin embargo, la variabilidad con este último factor no resulta tan destacable. En cualquier caso, el porcentaje de contribución restante es elevado también en este caso, aunque las interacciones dobles posibles no son especialmente relevantes. Dado que es esperable que las interacciones triples tengan una relevancia reducida, se espera que el porcentaje de error sea debido a las propias variabilidades inherentes al proceso experimental.

Finalmente, es el caudal volumétrico el factor determinante en la variación de la conductancia térmica, por su influencia en los coeficientes de película convectivos del proceso de intercambio térmico en el sistema. Sin embargo, como se vio, los prototipos no resultan en alteraciones de los resultados tan importantes como se hubiera esperado, posiblemente debido a la ya discutida compensación entre los efectos de la modificación en el área de intercambio y del coeficiente de película convectivo del lado del aire de extracción por la distribución del agua sobre la superficie de intercambio. Las interacciones entre factores no son especialmente destacables para este parámetro, por ser en todo caso menores que el error restante obtenido. 


\section{REFERENCIAS}

[1] Schibuola, L.; "High-efficiency recovery for air-conditioning applications in a mild climate: a case study". Revista: Applied Thermal Engineering 17, N05 (pp.: 447-454). 1997.

[2] Rey Martínez, F.J.; Velasco Gómez, E.; Álvarez Guerra, M.; Molina Leyva, M.; "Refrigeración Evaporativa". Suplemento de la revista El Instalador, n³60, enero 2000.

[3] Rey Martínez F.J.; Álvarez-Guerra Plasencia, M.A.; Velasco Gómez, E.; Varela Díez, F.; Herrero Martín, R.; "Design and experimental study of a mixed energy recovery system, heat pipes and indirect evaporative equipment for air conditioning". Revista: Energy and Buildings, $\mathrm{n}^{\mathrm{o}}$ 35 (pp.: 1021-1030). 2003.

[4] Velasco, E.; Rey, F.J.; Varela, F.; Molina, M.J.; Herrero R.. "Description and experimental results of a semi-indirect ceramic evaporative cooler." International Journal of Refrigeration 28 (pp. 654-662). 2005.

[5] Velasco Gómez, E.; Rey Martínez, F.J.; Tejero González, A., Flores Murrieta, F.E. "Performance of three different evaporative cooling systems". Comunicaciones del ExHFT-7, 7th World Conference on Experimental Heat Transfer, Fluid Mechanics and Thermodynamics. Cracovia, Polonia, 2009.

[6] Velasco Gómez, E.; Rey Martínez, F.J.; Tejero González, A. "Experimental characterisation of the operation and comparative study of two semi-indirect evaporative systems." Revista: Applied Thermal Engineering, No 30 (pp. 1447-1454). 2010.

[7] Rey Martínez, F.J.; Velasco Gómez, E.; Herrero Martín, R.; Martínez Gutiérrez, J.; Varela Diez, F. "Comparative study of two different evaporative systems: an indirect evaporative cooler and a semi-indirect ceramic evaporative cooler". Revista: Energy and Buildings, № 36 (pp.: 696-708). 2004.

[8] Pescod D., "An evaporative air cooler using a plate heat exchanger", CSIRO Division of Mechanical Engineering Transactions, Tech. Rep. No. 2. Highett, Victoria (Australia), 1974.

[9] Zhao, X.; Shuli Liu; Riffat, S.B. "Comparative study of heat and mass exchanging materials for indirect evaporative cooling systems". Revista: Building and Environment, n'43 (pp.: 1902-1911). 2008.

[10] Joen, C.T.; Park, Y.; Wang, Q.; Sommers, A.; Han, X.; Jacobi, A. "A review on polymer heat exchangers for HVAC\&R applications". Revista: International Journal of Refrigeration, No 32 (рр.: $763-779), 2009$.

[11] Delfani S., Esmaeelian J., Pasdarshahrib H., Karamia M., "Energy saving potential of an indirect evaporative cooler as a pre-cooling unit for mechanical cooling systems in Iran". Revista: Energy and Buildings, 42, pp.: 2169-2176. 2010.

[12] Heidarinejad G., Bozorgmehr M., Delfani S., Esmaeelian J., "Experimental investigation of two-stage indirect/direct evaporative cooling system in various climatic conditions". Revista: Building and Environment, 44, pp.: 2073-2079. 2009. 
[13] Wang S.K., "Incorporating Evaporative Cooling with Other Coolers", Handbook of AirConditioning and Refrigeration, McGraw Hill, New York, 1994.

\section{NORMATIVA}

[N-1] Ministerio de Industria, Turismo y Comercio y Ministerio de Vivienda de España, "Real Decreto 1027/2007: Reglamento de Instalaciones Térmicas en Edificios". 


\section{RELACIÓN DE FIGURAS}

- Figura V.1.- Paneles de policarbonato de paso ancho y estrecho utilizados en la fabricación de los prototipos.

- Figura V.2.a.- Esquema de la disposición de los paneles de policarbonato.

- Figura V.2.b.- Vista del prototipo de paso ancho durante su construcción.

- Figura V.2.c.- Vista del prototipo de paso estrecho durante su construcción.

- Figura V.3.- Vista esquemática del funcionamiento del prototipo de policarbonato en modo húmedo.

- Figura V.4.- Adaptación del sistema a la estructura de conexión a la instalación.

- Figura V.5.- Conexión de la estructura al dispositivo experimental del laboratorio.

- Figura V.6.- Esquema del dispositivo experimental completo.

- Figura V.7.- Evolución registrada de las medidas de las sondas de temperatura durante la realización del ensayo del sistema estrecho en modo húmedo, a $300 \mathrm{~m}^{3} / \mathrm{h}$ de caudal y $30^{\circ} \mathrm{C}$ de temperatura seca a la entrada.

- Figura V.8.a.- Salto térmico de temperaturas logrado con el prototipo de paso estrecho en modo seco.

- Figura V.8.b.- Salto térmico de temperaturas logrado con el prototipo de paso estrecho en modo húmedo.

- Figura V.9.a.- Efectividad térmica del prototipo de paso estrecho en modo seco.

- Figura V.9.b.- Efectividad térmica del prototipo de paso estrecho en modo húmedo.

- Figura V.10.- Efectividad térmica de bulbo húmedo del prototipo de paso estrecho en modo húmedo.

- Figura V.11.a.- Capacidad de enfriamiento del prototipo de paso estrecho en modo seco.

- Figura V.11.b.- Capacidad de enfriamiento del prototipo de paso estrecho en modo húmedo.

- Figura V.12.a.- Conductancia térmica del prototipo de paso estrecho en modo seco.

- Figura V.12.b.- Conductancia térmica del prototipo de paso estrecho en modo húmedo.

- Figura V.13.a.- Salto térmico de temperaturas logrado con el prototipo de paso ancho en modo seco.

- Figura V.13.b.- Salto térmico de temperaturas logrado con el prototipo de paso ancho en modo húmedo.

- Figura V.14.a.- Efectividad térmica del prototipo de paso ancho en modo seco.

- Figura V.14.b.- Efectividad térmica del prototipo de paso ancho en modo húmedo.

- Figura V.15.- Efectividad térmica de bulbo húmedo del prototipo de paso ancho en modo húmedo.

- Figura V.16.a.- Capacidad de enfriamiento del prototipo de paso ancho en modo seco.

- Figura V.16.b.- Capacidad de enfriamiento del prototipo de paso ancho en modo húmedo.

- Figura V.17.a.- Conductancia térmica del prototipo de paso ancho en modo seco.

- Figura V.17.b.- Conductancia térmica del prototipo de paso ancho en modo húmedo. 
- Figura V.18.- Gráficas factoriales para el salto de temperaturas.

- Figura V.19.- Gráficas factoriales para la efectividad térmica.

- Figura V.20.- Gráficas factoriales para la efectividad térmica de bulbo húmedo.

- Figura V.21.- Gráficas factoriales para la capacidad de enfriamiento.

- Figura V.22.- Gráficas factoriales para la conductancia térmica.

- Figura V.23.- Gráficas de las interacciones factoriales para el salto de temperaturas.

- Figura V.24.- Gráficas de las interacciones factoriales para la efectividad térmica.

- Figura V.25.- Gráficas de las interacciones factoriales para la efectividad térmica de bulbo húmedo.

- Figura V.26.- Gráficas de las interacciones factoriales para la capacidad de enfriamiento.

- Figura V.27.- Gráficas de las interacciones factoriales para la conductancia térmica.

\section{RELACIÓN DE TABLAS}

- Tabla V.1.- Características geométricas de los dos prototipos de policarbonato.

- Tabla V.2.- Diseño de Experimentos planteado para la caracterización de los dos prototipos de policarbonato.

- Tabla V.3.- Recopilación de los resultados de los saltos térmicos.

- Tabla V.4.- Recopilación de los resultados de las efectividades térmicas.

- Tabla V.5.- Recopilación de los resultados de la capacidad de enfriamiento.

- Tabla V.6.- Recopilación de los resultados de la conductancia térmica.

- Tabla V.7.- Recopilación de los valores medios de los ensayos realizados para cada nivel de los factores mantenido constante.

- Tabla V.8.- Valores medios de las interacciones dobles para el salto térmico.

- Tabla V.9.- Valores medios de las interacciones dobles para la efectividad térmica.

- Tabla V.10.- Valores medios de las interacciones dobles para la efectividad térmica de bulbo húmedo.

- Tabla V.11.- Valores medios de las interacciones dobles para la capacidad de enfriamiento.

- Tabla V.12.- Valores medios de las interacciones dobles para la conductancia térmica.

- Tabla V.13.- Recopilación de los coeficientes de contribución derivados del ANOVA realizado sobre los factores del diseño de experimentos.

- Tabla V.14.- Desglose del porcentaje de error en los coeficientes de contribución de las interacciones entre factores. 


\section{CAPÍTULO VI \\ CARACTERIZACIÓN DE LOS EQUIPOS DE ENFRIAMIENTO EVAPORATIVO DIRECTOS}

ABSTRACT. 197

VI.1. INTERÉS Y PROBLEMÁTICA DE LOS EQUIPOS DE ENFRIAMIENTO EVAPORATIVO DIRECTOS. 201

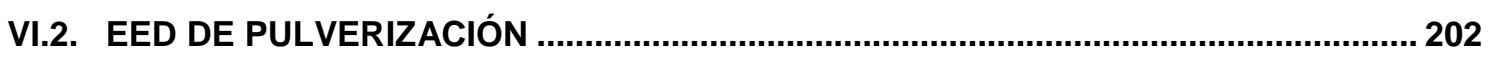

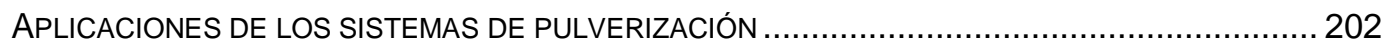

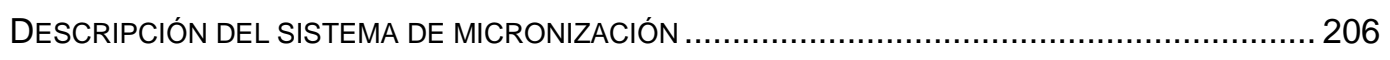

CARACTERIZACIÓN DEL SISTEMA DE MICRONIZACIÓN.................................................. 208

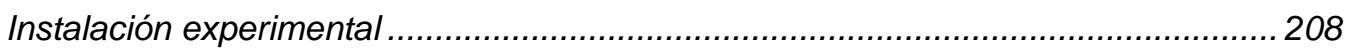

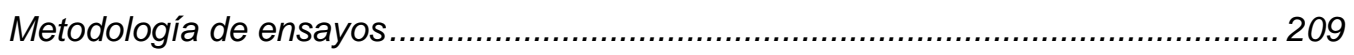

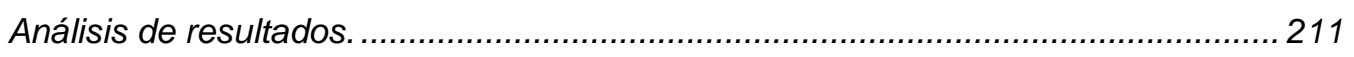

APLICACIÓN AL REFRESCAMIENTO DE UN ESPACIO EXTERIOR. .......................................... 215

APLICACIÓN AL REFRESCAMIENTO DE UN ESPACIO INTERIOR. .......................................... 217

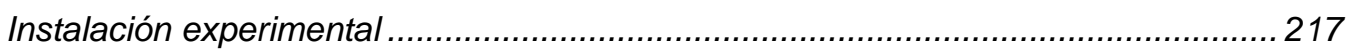

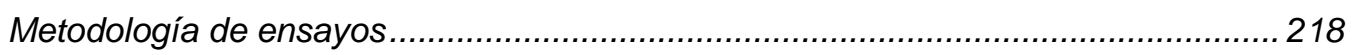

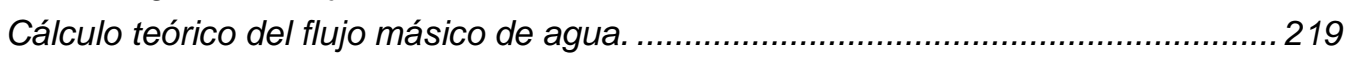

Selección del número y tipo de boquillas. ........................................................... 221

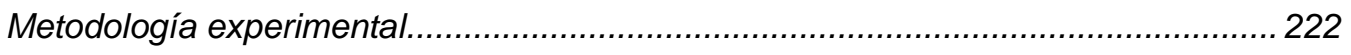

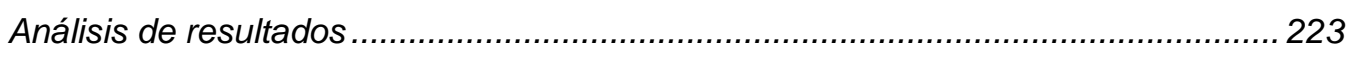

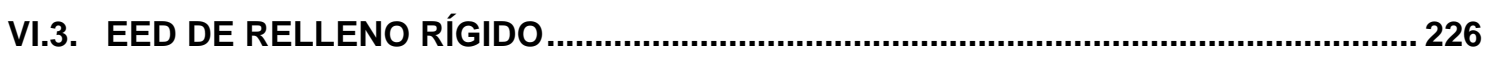

DESCRIPCIÓN DEL SISTEMA COMERCIAL DE RELLENO RÍGIDO FA6 ...................... 227

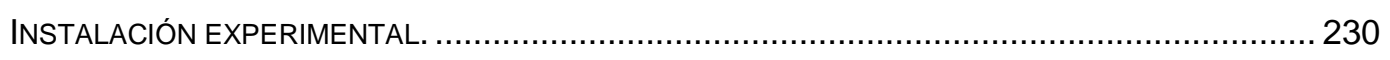

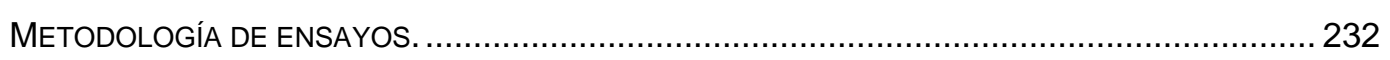

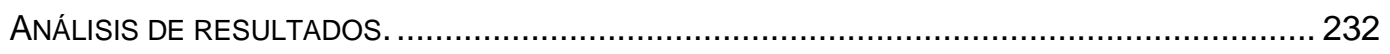

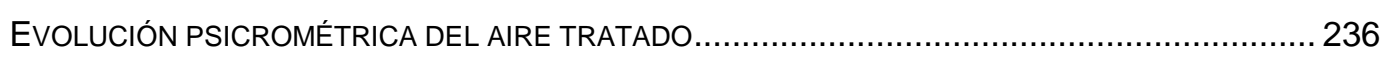

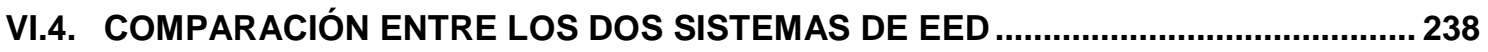




\section{CHAPTER VI: \\ CHARACTERIZATION OF THE DIRECT EVAPORATIVE COOLERS}

\section{ABSTRACT}

In this chapter, two commercial direct evaporative coolers are experimentally characterized. These two systems are based on the technologies described in chapter III of water pulverization and the evaporation from humid surface known as Rigid Media Pad Systems, respectively.

In the first case, a misting system widely used for refreshing outdoor occupied spaces is acquired. It is composed of a high-pressure water pump and a series of nozzles whose diameter is varied from $0.2 \mathrm{~mm}$ to $0.5 \mathrm{~mm}$, as well as their number and the pressure at the heat pump (from 20 to 70 bar), which are the factors established in the experimental tests.

Both the experimental setup and the results obtained from the tests developed are shown. The main target of the study is to optimize the power consumption of the system, considering as criteria the sensible cooling capacity achieved by the system and the power consumption of the heat pump for the different operation cases established, as well as that required by the lamp of UV disinfection. Once characterized, its installation to refresh an outdoor space is studied. Then a further step is proposed by studying the feasibility of its installation in indoor spaces.

The second device corresponds to the commercial Rigid Media Pad FA6 ${ }^{\mathrm{TM}}$, consisting of an inorganic inflammable pad which is humidified by an upper water distributor fed by a pump connected to a lower water tank. Supplied air flows through the pad, being thus humidified. Psychrometric evolution of treated air is studied.

Finally, both systems are compared in terms of applicability, performance and humidification effectiveness. 


\section{SimBología del CAPÍTULO}

$\dot{\mathrm{m}}_{\text {agua }}$ : Caudal másico de agua proporcionado al aire por el sistema $[\mathrm{g} / \mathrm{s}]$

$\mathrm{m}_{\text {agua }}$ : Masa de agua pulverizada en un período de tiempo $[\mathrm{g}]$

t: tiempo $[\mathrm{s}]$

$\dot{\mathrm{W}}:$

Potencia eléctrica $[\mathrm{W}]$

V: Tensión [V]

I: Intensidad $[A]$

COP: Coefficient of Performance

$\dot{Q_{F}}:$ Potencia de enfriamiento [W]

$\lambda$ : Calor latente de vaporización $[\mathrm{kJ} / \mathrm{kg}]$

$\mathrm{m}_{\mathrm{as}}$ : flujo másico de aire seco tratado por el sistema $[\mathrm{g} / \mathrm{s}]$

$\mathrm{X}$ : humedad específica del aire $\left[\mathrm{g}_{\mathrm{agua}} / \mathrm{kg}_{\mathrm{as}}\right]$

$\mathrm{X}_{\text {ent }}$ : humedad específica del aire a la entrada al sistema $\left[\mathrm{g}_{\mathrm{agua}} / \mathrm{kg}_{\mathrm{as}}\right]$

$\mathrm{X}_{\text {sal }}$ : humedad específica del aire a la salida del sistema $\left[\mathrm{g}_{\mathrm{agua}} / \mathrm{kg}_{\mathrm{as}}\right]$

$\dot{Q}$ : caudal volumétrico de aire $\left[\mathrm{m}^{3} / \mathrm{h}\right]$

$\mathrm{m}_{\mathrm{as}}:$ masa de aire seco $[\mathrm{g}]$

Ve: volumen específico del aire húmedo $\left[\mathrm{m}^{3} / \mathrm{kg}\right]$

R: constante de los gases ideales

$\mathrm{T}$ : temperatura seca del aire $[\mathrm{K}]$

Ts: temperatura seca del aire $\left[{ }^{\circ} \mathrm{C}\right]$

v: volumen de aire seco $\left[\mathrm{m}^{3}\right]$

Mas: Peso molecular del aire seco $[\mathrm{g} / \mathrm{mol}]$

Pas: Presión parcial del aire seco en el aire húmedo [Pa]

$\mathrm{P}_{\mathrm{T}}$ : Presión total del aire húmedo $[\mathrm{Pa}]$ 
$\mathrm{P}_{\mathrm{V}}$ : Presión parcial de vapor en el aire húmedo $[\mathrm{Pa}]$

$\mathrm{P}_{\mathrm{Vsat}}$ : Presión parcial de vapor de saturación del aire a la entrada $[\mathrm{kPa}]$

HR: humedad relativa del aire húmedo [\%]

$\mathrm{N}$ : Número de boquillas.

$\mathrm{m}_{\mathrm{b}, \mathrm{i}}$ : flujo másico de agua pulverizado por una boquilla de diámetro i [g/s]

$\dot{\mathrm{M}}_{\mathrm{as}}$ : Caudal másico de aire seco $\left(\mathrm{kg}_{\mathrm{as}} / \mathrm{s}\right)$

c: Velocidad del aire $(\mathrm{m} / \mathrm{s})$

A: Área de la sección de paso del aire $\left(\mathrm{m}^{2}\right)$

$\mathrm{T}_{\text {bh }}$ : temperatura de bulbo húmedo del aire $\left[{ }^{\circ} \mathrm{C}\right]$

h: entalpía específica del aire $[\mathrm{kJ} / \mathrm{kg}]$

$\rho:$ densidad del aire $\left(\mathrm{kg} / \mathrm{m}^{3}\right)$

$\varepsilon:$ eficiencia de humidificación [\%]

$H R_{i}$ : Humedad Relativa del aire al comienzo del proceso [\%]

$H R_{f}$ : Humedad Relativa del aire al final del proceso [\%]

$\Delta \mathrm{P}:$ pérdida de carga $[\mathrm{Pa}]$

$\Delta \mathrm{T}$ : salto de temperaturas alcanzado en la corriente de aire tratado $[\mathrm{PC}]$ 


\section{VI.1. INTERÉS Y PROBLEMÁtICA DE LOS EQUIPOS DE ENFRIAMIENTO EVAPORATIVO DIRECTOS}

Se ha visto que los sistemas evaporativos indirectos permiten aprovechar el potencial enfriador de este fenómeno sin alterar el contenido en humedad ni suponer riesgos de contaminación bacteriológica en la corriente de impulsión al local. Sin embargo, no por ello estos sistemas pueden prescindir de los debidos procesos de mantenimiento y limpieza, ya que debe cuidarse la salubridad del aire secundario expulsado al exterior [N-1].

En aquellos procesos en los que no es estrictamente necesario mantener la humedad presente en el aire tratado, y particularmente en aquellas aplicaciones en las que precisamente su aumento es deseable o aconsejable, recurrir a sistemas de enfriamiento evaporativo directos no sólo permite simplificar la instalación, sino también alcanzar mayores eficiencias, al realizarse la evaporación del agua en el mismo seno del aire a tratar, y consecuentemente sufriendo dicha corriente directamente el enfriamiento, suprimiéndose el paso intermedio del intercambio de calor sensible a una segunda corriente en el que se basan los sistemas indirectos [1, Rey et al., 2000].

Otra consideración de gran relevancia a la hora de abordar el funcionamiento de los sistemas directos son las condiciones del aire a exterior sobre las que se realizará el proceso, ya que por los propios principios del enfriamiento evaporativo, la eficiencia de estos equipos depende de los niveles de temperatura y humedad del aire objeto [2, El-Refaie\&Kaseb, 2009].

En el presente capítulo se describen dos sistemas de enfriamiento evaporativo directos (EED), ambos comerciales, que permitirán profundizar en la descripción y comprensión del funcionamiento de este tipo de equipos, y en particular de las subcategorías a las que los dos sistemas pertenecen, escogidas por tratarse de las más usuales: los de relleno rígido y los de pulverización [3, ASHRAE, 2000]. Su caracterización experimental nos va a permitir prever las opciones y optimizaciones que brinda su instalación en una aplicación real.

A pesar de que por las condiciones de operación de los sistemas de enfriamiento evaporativo la contaminación por Legionela es improbable, tanto el diseño como el mantenimiento de estas instalaciones debe ser cuidado [4, Puckorious et al., 1995]. Por ello, siempre serán preferibles aquéllos sistemas que eviten la generación de aerosoles que puedan ser portadores de las bacterias, lo cual hará prevalecer la instalación de aquéllos en los que se trabaje desde superficie húmeda a los basados en pulverización de agua. En trabajos previos del Grupo de Termotecnia de Valladolid ya se realizó el estudio de prototipos de enfriadores evaporativos directos desde superficie húmeda textil [5, Rey et al., 2009], y cerámica, trabajando estos últimos según las condiciones de operación como sistemas directos o indirectos [6, Velasco et al., 2010]. 
Sin embargo, como se verá, esta caracterización del funcionamiento de los equipos será una tarea delicada, ya que el proceso seguido de control y registro de los distintos parámetros de interés en el análisis es complejo y susceptible de generar ambigüedades.

\section{VI.2. EED DE PULVERIZACIÓN}

En los sistemas de enfriamiento evaporativo directo mediante pulverización de agua, la evaporación se potencia disminuyendo el tamaño de gota, gracias a la consiguiente disminución de las fuerzas de enlace intermoleculares, mediante micronización del agua de aporte. Esto se realiza aumentando la presión del agua hasta 60-100 bares mediante un sistema de bombas y haciéndola atravesar seguidamente unos orificios especiales (boquillas) de forma que se nebuliza en gotas de aproximadamente 10 micras (grosor inferior al de un cabello).

Aunque las aplicaciones más usuales de este tipo de sistemas son en exteriores, también pueden verse instalaciones orientadas al acondicionamiento de espacios cerrados, aunque en esos casos debe cuidarse que toda el agua aportada se evapore de manera que no se produzcan condensaciones o existan aerosoles en el aire portadores de posibles bacterias [1, Rey et al., 2000]. Previamente a la descripción de la caracterización experimental del sistema, se introducen aquí algunas de estas aplicaciones prácticas.

\section{Aplicaciones de los sistemas de pulverización}

Los sistemas de pulverización de agua se pueden utilizar en gran variedad de aplicaciones, en especial en ciertos casos donde el uso de los aparatos de aire acondicionado convencionales no resultarían ser soluciones factibles o supondrían un coste elevado, como es el caso de grandes espacios, o en espacios exteriores en los cuales la normativa restringe las alternativas recurribles a aquéllas renovables o de aprovechamiento de energías residuales [N2]. Algunas de estas aplicaciones se describen a continuación.

Quizás sea el refrescamiento de espacios exteriores la aplicación más extendida, o al menos la más evidente, de los sistemas de micronización de agua. Esta alternativa es especialmente interesante en los lugares donde el clima es árido y caliente, ya que permite suavizar las severas condiciones climáticas para los transeúntes y ocupantes de las zonas en las que se instala, al permitir disminuir las temperaturas hasta $7-11^{\circ} \mathrm{C}$ además de humidificar el ambiente seco.

Se trata de un recurso interesante para acondicionar zonas urbanas, situando los dispositivos aprovechando el inmobiliario urbano, como las marquesinas de los autobuses, en los edificios, estaciones de metro... Algunos ejemplos de esta aplicación en ciudades Españolas especialmente calurosas y secas en período estival, como es el caso de Mérida o Sevilla, se muestran en las figuras VI.1 y VI.2 respectivamente. 


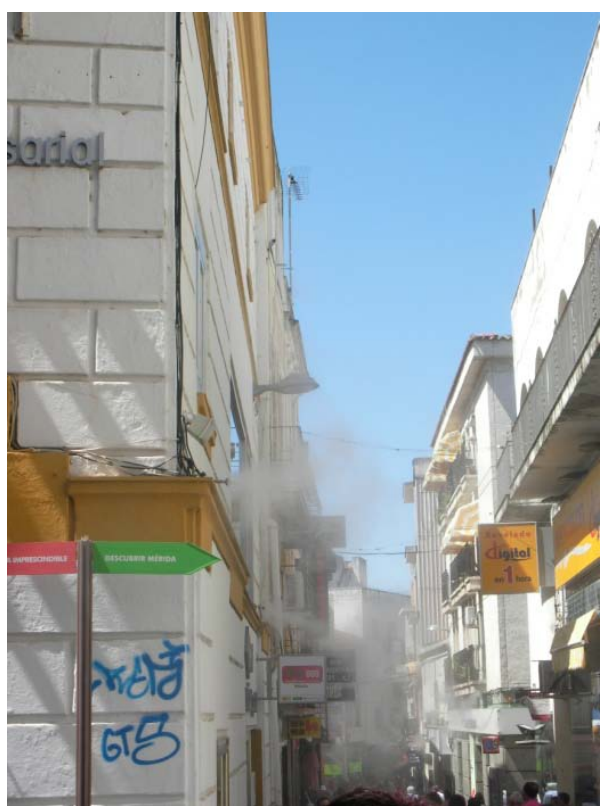

Figura VI.1.- Sistemas de pulverización de agua operando para refrescamiento de una calle en Mérida.

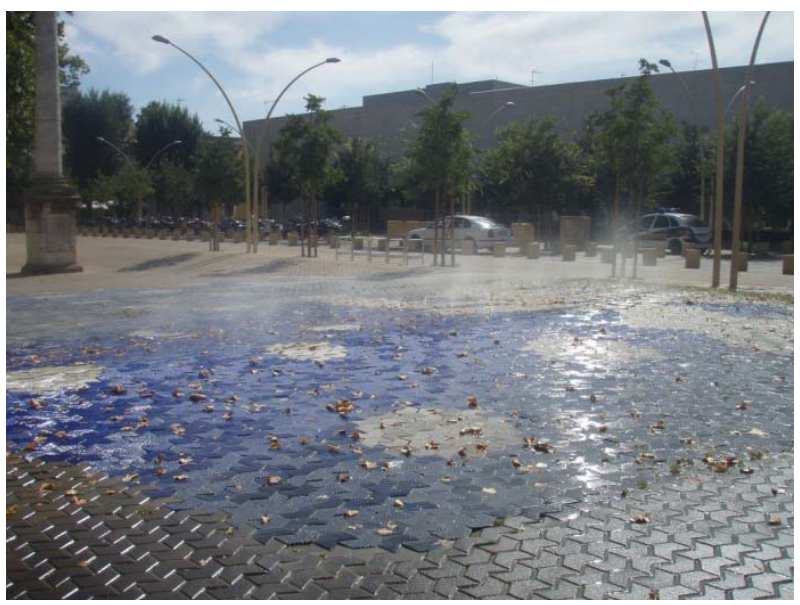

Figura VI.2.- Sistemas de pulverización de agua instalados en los adoquines de una plaza para refrescamiento en Sevilla.

Es también usual su instalación en terrazas de establecimientos de restauración, como se muestra en las figuras VI.3 y VI.4, correspondientes a terrazas de Toledo y Madrid, respectivamente.

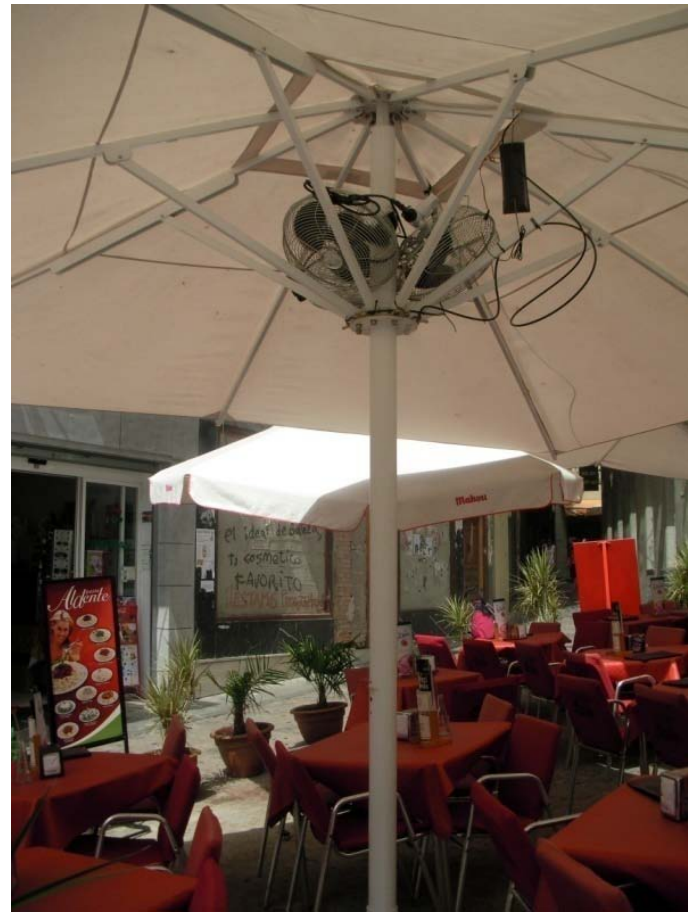

Figura VI.3.- Sistemas de pulverización de agua con ventiladores, para refrescamiento de una terraza en Toledo.

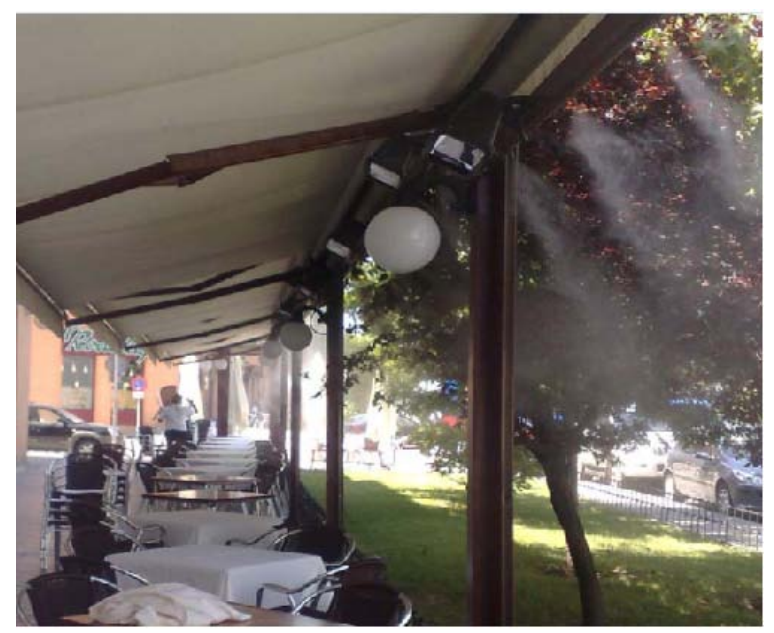

Figura VI.4.- Sistemas de pulverización de agua para refrescamiento de una terraza en el RTE de Madrid. 
Generalmente, los sistemas se disponen a una cierta altura para permitir que la el agua pulverizada se evapore en el aire y no moje a las personas. En las figuras VI.5.a, VI.5.b y VI.5.C se muestran algunas boquillas utilizadas para pulverización de agua en exteriores.

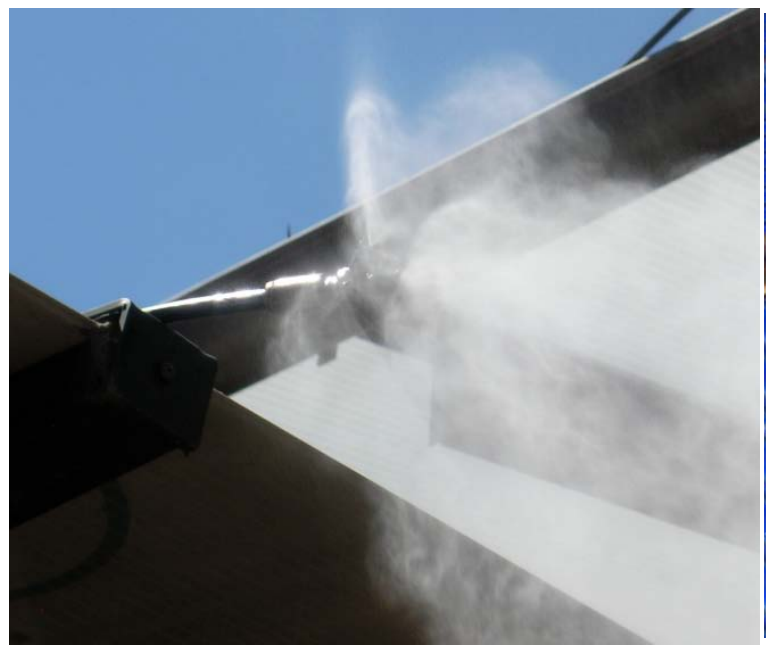

Figura VI.5.a.- Boquilla para pulverización de agua en espacios exteriores urbanos.

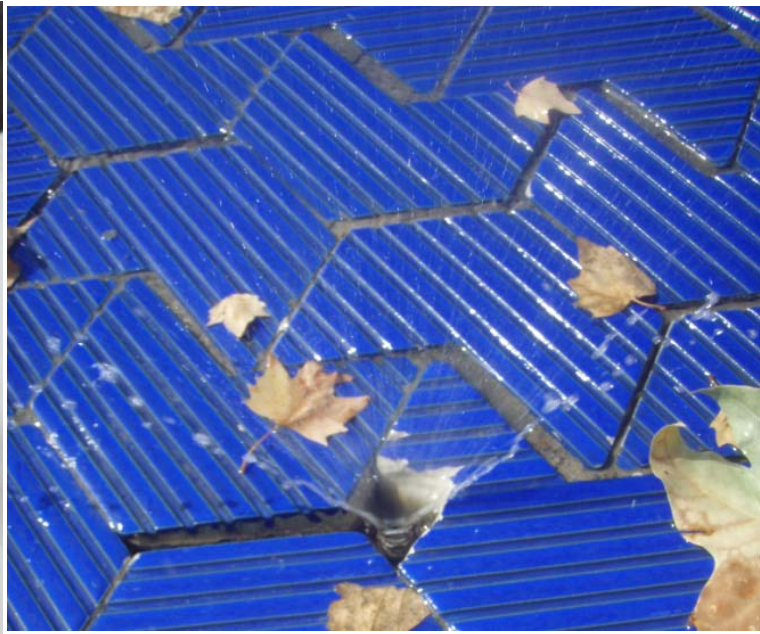

Figura VI.5.b.- Boquilla instalada en el adoquinado.

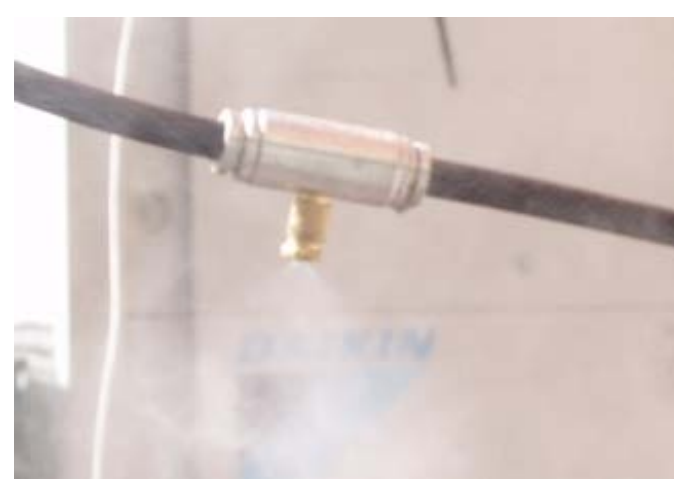

Figura VI.5.c.- Boquilla para pulverización de agua en terrazas.

Es también usual encontrar este tipo de sistemas para en el acondicionamiento de ambientes exteriores en parques temáticos como Terra Mitica, Terra Natura, Selwo Park, L'Oceanografic; o eventos de gran afluencia como la Expo Sevilla 92 o la Expo Zaragoza 2008, caracterizados por sus elevadas temperaturas en las épocas estivales, condiciones que se ven agravadas por la concentración de gente. En las figuras VI.6 y VI.7 se muestran ejemplos de los sistemas de acondicionamiento de este tipo recurridos en la Expo Sevilla 1992 y Expo Zaragoza 2008 en las zonas de mayor acumulación de visitantes. 


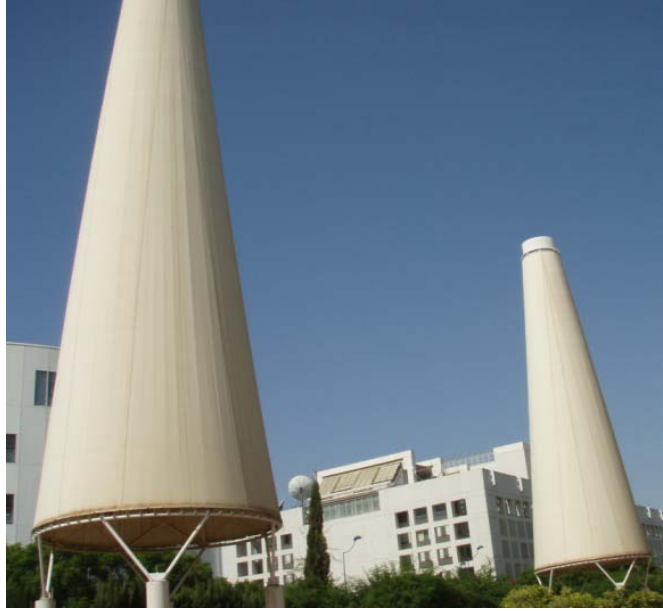

Figura VI.6.- Torres de tiro invertido con pulverizadores interiores para acondicionamiento del aire exterior en la Expo Sevilla 92.

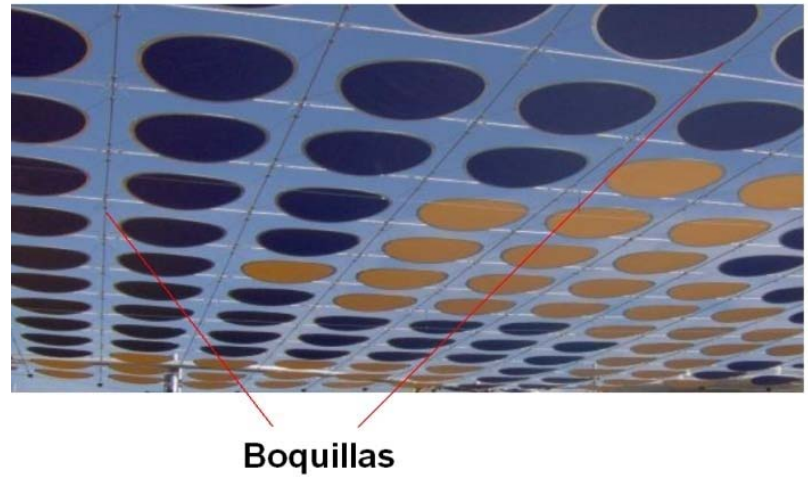

Figura VI.7.- Pérgola provista de pulverizadores para refrescamiento de una zona de gran afluencia de personas en la Expo Zaragoza 2008.

Sin embargo, a la aplicación como refrescamiento de espacios puede complementarse las posibilidades que ofrece la pulverización de agua como recurso paisajístico. La ya citada Alameda de Hércules en Sevilla mostrado en la figura VI.2. podría también ser ejemplo de esto. En el caso de jardines, como los mostrados en la figura VI.8, este recurso paisajístico alcanza una utilidad superior al actuar como complemento del riego.
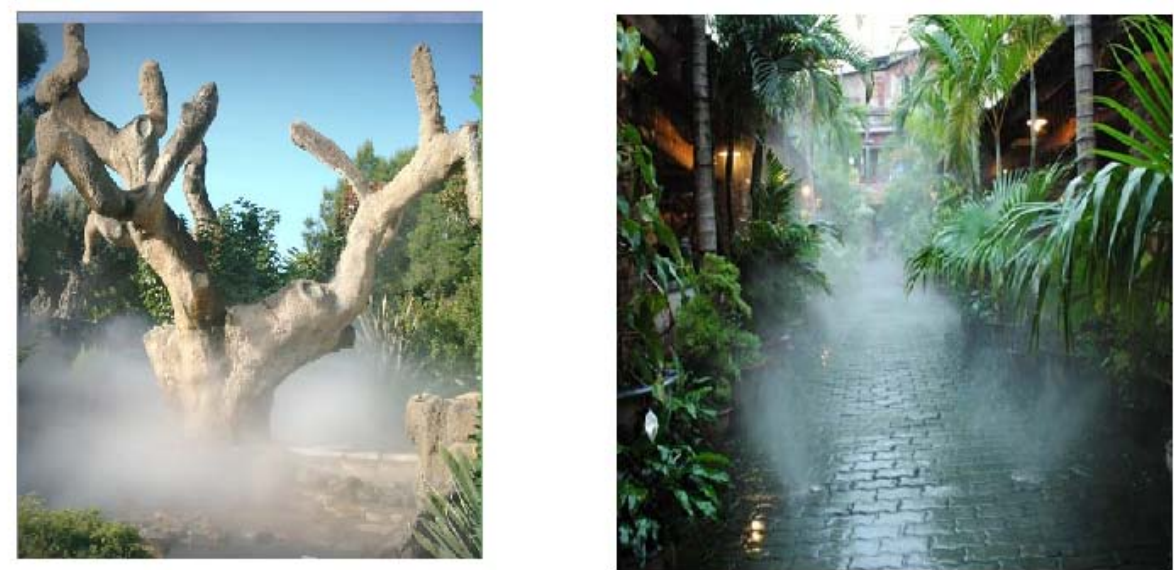

Figura VI.8.- Ejemplos de aplicación de la pulverización de agua con utilidad paisajística.

No obstante su aplicación predominante en espacios exteriores cuando está orientado al acondicionamiento térmico, también son posibles las instalaciones en interiores, requiriéndose en estos casos un cuidadoso diseño que asegure que toda el agua aportada se evapora en el aire sin generar condensaciones ni permanencia de aerosoles. 
Asimismo puede ser también interesante la pulverización de agua en invernaderos, ya que este sistema es muy apropiado para el riego de planteles, semilleros y plantas en macetas de pequeño formato, que precisen de un fino tamaño de gota, bien debido a la fragilidad de la planta o por el escaso volumen de sustrato con el que cuentan. También son muy útiles en aquellas situaciones en las que la anchura del riego no deba de superar los dos metros (riego individual por mesa).

A la hora de acondicionar térmicamente espacios en el sector industrial, podemos encontrarnos con que las alternativas convencionales no resultan rentables o incluso factibles, debido al gran volumen de los locales. Por ello, la pulverización de agua puede resultar una solución interesante para el enfriamiento de ambientes en estos casos. Además, este recurso puede cumplir requisitos superiores de calidad del aire al actuar como retenedor de partículas suspendidas y de posibles olores.

En el ámbito industrial puede también recurrirse a estos sistemas para el pre-enfriamiento de maquinaria cuyo sobrecalentamiento podría generar daños o paradas indeseadas, o para la humidificación de ambientes en los cuales interesa mantener humedades relativas superiores a las disponibles, como es el caso de las bodegas, para reducir las pérdidas de producto; en la conservación de alimentos vegetales o frutas, reduciendo el consumo energético y las pérdidas en peso del producto; mantenimiento de flores y plantas, etc.

\section{Descripción del sistema de micronización}

El equipo caracterizado es un sistema comercial de micronización de agua, compuesto por [2, Mist\&Fog]:

- Bomba que proporciona un caudal de un litro por minuto a presión controlada entre 0 y 80 bar.

- Boquillas de latón con dispositivo antigoteo de diámetro de orificio 0,2mm, 0,3mm, $0,4 \mathrm{~mm}$ y $0,5 \mathrm{~mm}$ (se dispone de 2 boquillas de cada diámetro).

- 1 Filtro de desinfección por radiación ultravioleta 5 litros por minuto

- 1 Carcasa para filtro de $25 \mathrm{~cm}$ de alto

- 1 Cartucho de filtro de 1 micrón para carcasa de $25 \mathrm{~cm}$

- Tubo de nylon de diámetro exterior 9,53 mm (3/8 pulgadas)

- Conectores con orificio para cada boquilla de diámetro exterior 9,53 mm (3/8 pulgadas) con unión Slip Lok.

- Conector tapón terminal de diámetro exterior

La pulverización del agua se realiza gracias a la bomba, que proporciona agua a presión de forma controlada entre 0 y 80 bar (figura VI.9). 

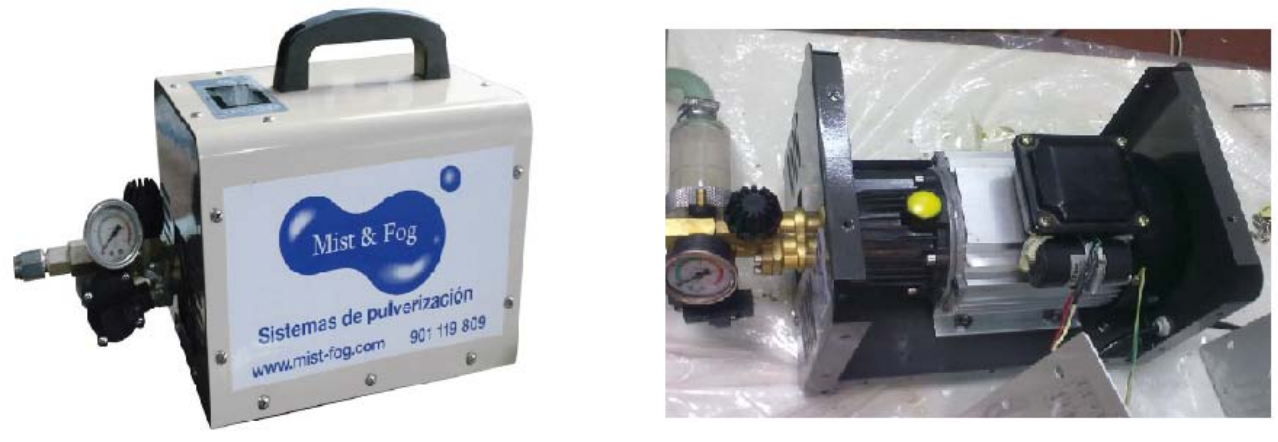

Figura VI.9.- Vista exterior de la bomba y detalle del interior

Disponemos de distintos tamaños de boquillas que permiten suministrar distintos valores de caudal y diferentes tamaños de gota en función de los requerimientos de la aplicación particular a la que se destine el sistema. La relación de boquillas disponibles se muestra en la tabla VI.1.

Tabla Vl.1.- Información técnica de dimensiones y flujos

\begin{tabular}{|ccccc|}
\hline Diámetro & Descripción & $\begin{array}{c}\text { Caudal (LPM) } \\
\mathbf{1 1} \text { bar }\end{array}$ & $\begin{array}{c}\text { Caudal (LPM) } \\
\mathbf{7 0} \text { bar }\end{array}$ \\
\hline $\mathbf{0 , 2} \mathbf{~ m m}$ & Roja & 0,030 & 0,076 \\
\hline $\mathbf{0 , 3} \mathbf{~ m m}$ & & Negra & 0,045 & 0,114 \\
\hline $\mathbf{0 , 4} \mathbf{~ m m}$ & Marrón & 0,057 & 0,150 \\
\hline $\mathbf{0 , 5} \mathbf{~ m m}$ & Verde & 0,075 & 0,190 \\
\hline
\end{tabular}

El tamaño de la boquilla de $0,2 \mathrm{~mm}$ es ideal para las aplicaciones que requieren menos flujo con un menor tamaño de gota, humedad mínima y garantizar una evaporación completa, ya que es el orificio estándar más pequeño disponible. Se puede utilizar para la humidificación de interiores o para refrescar espacios exteriores. Este tamaño de boquilla no está diseñado para ser utilizado a presiones por debajo de 17,5 bar.

La boquilla de 0,3 mm (figura VI.10) es la más común y se puede utilizar para la mayoría de las aplicaciones, ya que proporciona resultados comparables a las boquillas de $0,2 \mathrm{~mm}$ pero con un caudal mayor. La boquilla de $0,4 \mathrm{~mm}$ se utiliza sobre todo para las aplicaciones al aire libre, donde la circulación de aire es suficiente, se requieren flujos de agua más altos y la separación permite la evaporación completa. El uso de boquillas de $0,5 \mathrm{~mm}$ se restringe a 
aplicaciones al aire libre que requieren de caudales muy altos, y en las que la evaporación completa del agua no sea un requisito especialmente grave.

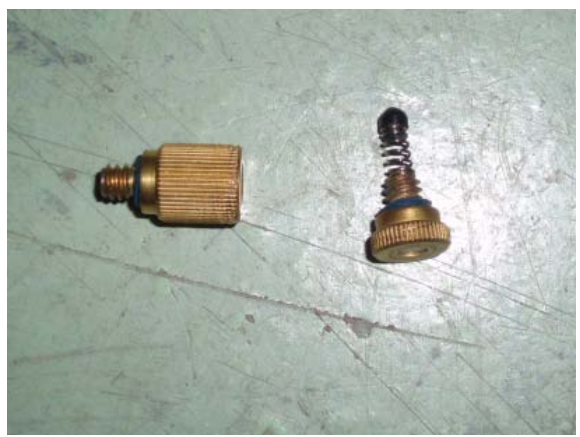

Figura VI.10.- Detalle de una boquilla de $0,3 \mathrm{~mm}$.

El uso del filtro es necesario debido a que el tratamiento de agua es crítico, por las tolerancias extremadamente pequeñas de las boquillas, por lo que hay que eliminar todo posible sedimento y partículas existentes en el agua antes de su entrada al sistema. El cartucho de filtro es de polifosfatos, que no eliminan los sólidos disueltos sino que rodearán las moléculas sólidas disueltas para evitar que se adhieran a las boquillas y causen una obstrucción prematura.

\section{Caracterización del sistema de micronización}

\section{Instalación experimental}

Existen diversas formas de montaje del dispositivo, más o menos adecuadas según la aplicación a la que se destinan y del espacio del que se disponga.

El sistema montado en superficie mediante la ayuda de elevadores, cuya configuración típica se muestra en la figura VI.11.a, se recurre principalmente para crear efectos de brumas naturales y nieblas decorativas.

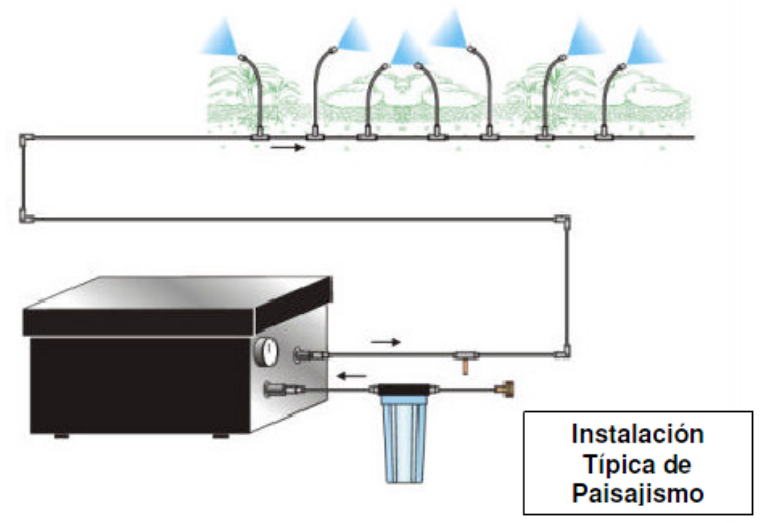

Figura VI.11.a.- Esquema de la configuración en suelo para paisajismo.

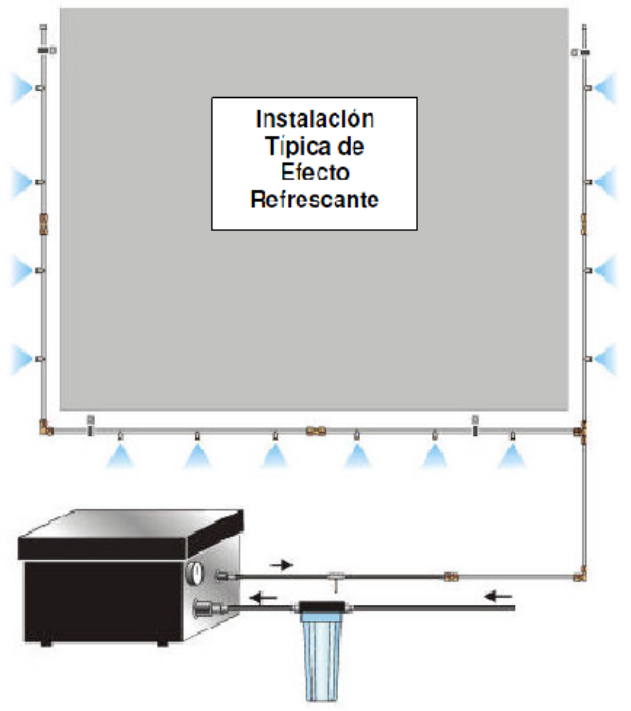

Figura VI.11.b.- Esquema de la configuración en línea para refrescamiento de espacios. 
La instalación en línea (figura VI.11.b) cubre normalmente un cierto perímetro pulverizando agua a una altura superior a dos metros y medio de altura. Es el montaje más habitual cuando se dispone de espacio suficiente y se busca refrescar ambientes, humidificar invernaderos o para ciertas aplicaciones industriales, entre otras.

Si en las aplicaciones anteriores las condiciones de operación hacen que la configuración en línea no sea efectiva, a causa de techos demasiado elevados por ejemplo, se puede apoyar el sistema con ventiladores. Un ejemplo de esto se mostraba en la aplicación ilustrada por la figura VI.3.

Se puede también reducir el impacto visual de la instalación disponiendo ésta en inflables o postes.

La caracterización del sistema se va a realizar siguiendo la configuración en línea descrita, por ser la más apropiada para el tipo de aplicaciones de interés en este trabajo de Tesis Doctoral. Para la consecución del proceso experimental descrito en el apartado siguiente, en dicha configuración en línea se irán modificando el tipo, número y disposición de las distintas boquillas según queda establecido en el procedimiento de ensayo.

Además de los propios elementos del dispositivo conectados según las especificaciones del fabricante [2, Mist\&Fog], para realizar la medición del caudal de agua aportado y de la potencia de la bomba, se dispondrá de los siguientes elementos:

- 7 botellas de plástico de 0,5 I, con tapón roscado perforado para ajustar a las boquillas.

- 1 garrafa de plástico de 5 I para el desagüe.

- 1 báscula.

- 1 cronómetro.

\section{Metodología de ensayos}

Se dispone de 4 tamaños distintos de boquillas que permitirán obtener distintos tamaños de gota en función de los requerimientos de la aplicación particular a la que se destine el sistema. Además, existe la posibilidad de trabajar con distinto número de boquillas y de regular la presión de trabajo del sistema. Dado que el parámetro de interés en la caracterización del funcionamiento del equipo es el caudal de agua pulverizada proporcionado, por ser éste el valor determinante de su capacidad de enfriamiento, se establecerán los tres factores anteriores (número y tamaño de boquilla, y presión de trabajo) como parámetros a controlar en la realización de los ensayos. En función del caudal de agua proporcionado y del consumo de la bomba, que será el segundo parámetro a registrar durante los ensayos, se va a poder calcular el COP característico del equipo enfriador en función de los factores en estudio [8, Velasco et al., 2010].

Los ensayos realizados se han establecido considerando los parámetros de estudio en los niveles indicados en la tabla VI.2. 
Tabla VI.2.- Ensayos realizados con el sistema micronizador de agua

\begin{tabular}{|c|c|c|}
\hline $\begin{array}{l}\text { Grupo de ensayos } \\
\text { ( } n^{\circ} \text { boquillas) }\end{array}$ & $\begin{array}{l}\text { Niveles de presión } \\
\text { ensayados [bar] }\end{array}$ & $\begin{array}{c}\text { Tamaños de boquillas } \\
\text { ensayados* }[\mathrm{mm}]\end{array}$ \\
\hline A- 1 boquilla & $20 / 30 / 40 / 50 / 60 / 70 * *$ & $0,2 / 0,3 / 0,4 / 0,5$ \\
\hline B- 2 boquillas & $20 / 30 / 40 / 50 / 60 / 70$ & $0,2 / 0,3 / 0,4 / 0,5$ \\
\hline C- 3 boquillas & $20 / 30 / 40 / 50 / 60 / 70$ & $\begin{array}{c}0,2-0,3-0,4 / 0,2-0,3-0,5 / \\
0,2-0,4-0,5 / 0,3-0,4-0,5\end{array}$ \\
\hline D- 4 boquillas & $20 / 30 / 40 / 50 / 60 / 70$ & $0,2-0,3-0,4-0,5$ \\
\hline E- 6 boquillas & $20 / 30 / 40 / 50 / 60 / 70$ & $\begin{array}{c}(2 \times) 0,2-0,3-0,4 I \\
(2 \times) 0,3-0,4-0,5\end{array}$ \\
\hline F- 7 boquillas & $20 / 30 / 40 / 50 / 60 / 70$ & $\begin{array}{c}0,5-(2 \times) 0,2-0,3-0,4 I \\
0,4-(2 \times) 0,2-0,3-0,5 I \\
0,3-(2 \times) 0,2-0,4-0,5 I \\
0,2-(2 \times) 0,3-0,4-0,5\end{array}$ \\
\hline
\end{tabular}

*Se han realizado ensayos para las boquillas indicadas, reordenándolas.

**Los ensayos no se han podido realizar a 70 bar para una boquilla de 0,2 , por problemas de recalentamiento.

A la hora de establecer la metodología de ensayos a seguir, debe tenerse presente que las variables de interés a medir en los distintos ensayos planteados son el consumo de la bomba y el flujo másico proporcionado por las boquillas.

En cada ensayo realizado, una vez configurado el sistema en número y tipo de boquillas, se establece la presión a la que se va a trabajar nada más arrancar la bomba, para procurar que todo el caudal suministrado lo sea en las mismas condiciones de presión. Sin embargo, este pequeño margen de tiempo entre el arranque de la bomba y el ajuste de las condiciones de operación del ensayo supondrá una cierto error en los valores registrados.

Para poder determinar el flujo másico pulverizado por cada boquilla, se han colocado los recipientes disponibles ajustados a las boquillas, de forma que toda el agua pulverizada por ellas quede retenida en su interior. Se determina el valor del flujo másico de agua proporcionado en cada boquilla pesando cada recipiente en un intervalo de tiempo dado (figura VI.12). El caudal de agua proporcionado se obtendrá a partir de la expresión (E-VI.1):

$$
\dot{\mathrm{m}}_{\text {agua }}=\frac{\mathrm{m}_{\text {agua }}}{\mathrm{t}}
$$

El valor de la tensión se considera constante y con el valor medido mediante la pinza amperimétrica, aproximamos el valor de la potencia eléctrica consumida por la bomba, según la expresión:

$$
\stackrel{\bullet}{\mathrm{W}}=\mathrm{V} \times \mathrm{I}
$$




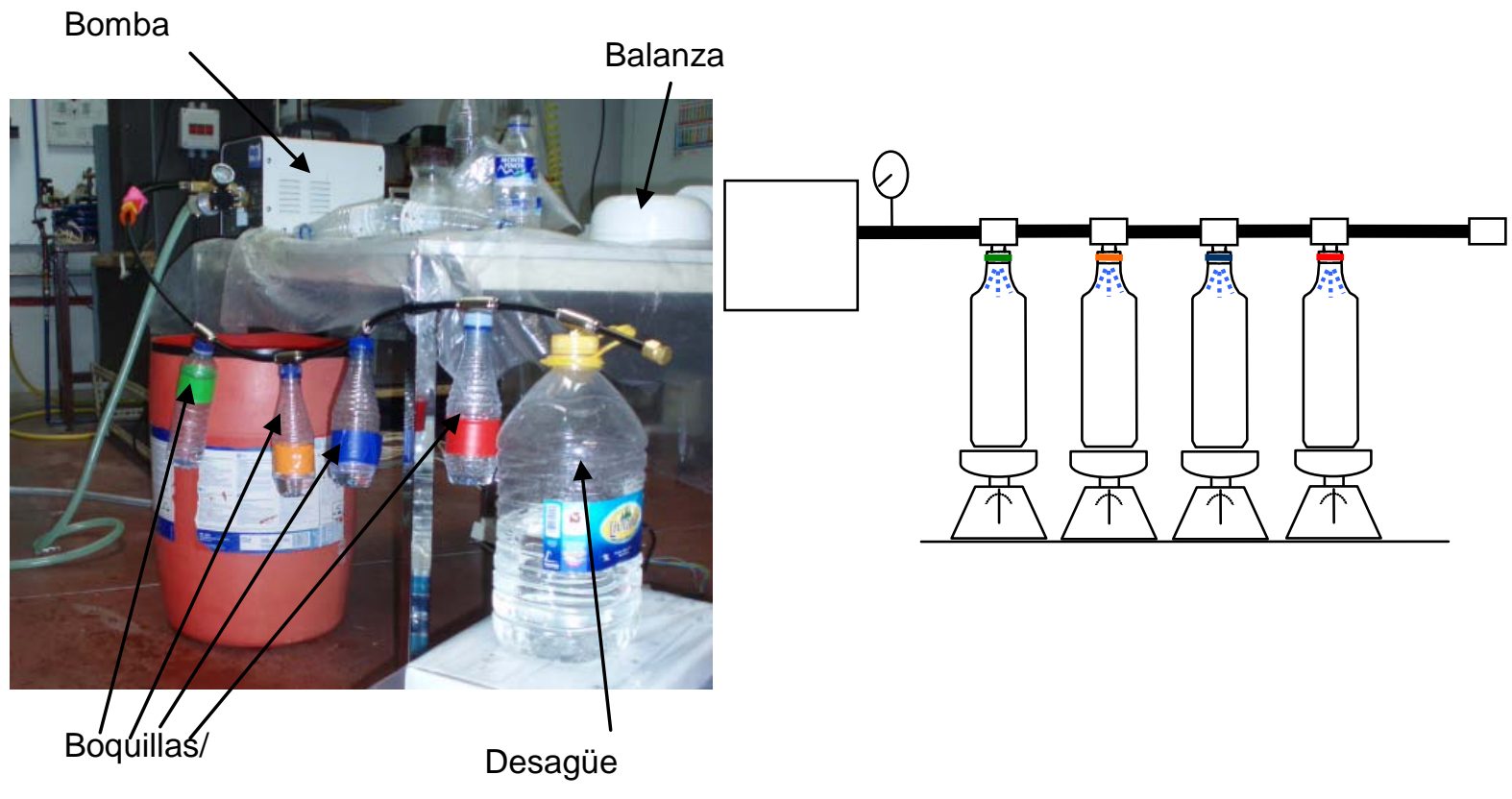

recipientes

Figura VI.12.- Esquema e imagen de la instalación y medida de flujos másicos de agua

Durante la realización de algunos ensayos especialmente extremos, como en el caso de pocas boquillas de pequeño tamaño sometidas a altas presiones, ha sido necesario refrigerar el sistema humedeciendo las zonas críticas en las que había riesgo de producirse sobrecalentamientos.

\section{Análisis de resultados.}

De los ensayos realizados anteriormente expuestos, no todos han proporcionado información de utilidad para la determinación de los consumos y caudales proporcionados por el equipo, si bien igualmente han arrojado luz sobre ciertos aspectos del funcionamiento del equipo.

Por ejemplo, en los ensayos realizados con número de boquillas bajo, y de forma más destacable a mayores presiones de trabajo, la bomba no opera dentro de su rango nominal. Este funcionamiento fuera de curva supone un recalentamiento del sistema debido al importante incremento de temperatura ocasionado por la fracción de la potencia suministrada disipada en forma de calor al no ser toda ella aprovechable como trabajo, de forma que, de no refrigerarse el sistema durante su funcionamiento, se incurre en daños en los elementos de canalización y conexión. Por lo tanto, los resultados obtenidos a partir de estos ensayos no son extrapolables a la hora de estudiar la variación de los parámetros de interés con respecto a los factores establecidos; sin embargo sí permite determinar que el funcionamiento del sistema no 
es factible con menos de cierto número de boquillas, dependiente de la presión de trabajo, ya que no aseguran un caudal mínimo de pulverización.

Un resultado destacado en la medida de los caudales proporcionados por las distintas boquillas es el hecho de que existe cierta variabilidad en este parámetro entre boquillas de igual diámetro, más acusada a mayores diámetros de boquilla. Este hecho se asocia a variaciones dentro de tolerancia en el diámetro de boquilla, generadas en la manufacturación, y deberá tenerse en cuenta a la hora de estudiar la variabilidad global del análisis experimental.

El resultado más destacable ha sido, sin embargo, el hecho de que los consumos parecen depender exclusivamente del nivel de presión proporcionado, y no del número de boquillas ni su ordenación, como podría esperarse a priori. Es por lo tanto clave analizar la correlación caudal - presión, puesto que nos relacionará los caudales proporcionados con el consumo de la bomba. En la figura VI.13 se puede observar cómo los caudales proporcionados por cada boquilla presentan una dependencia claramente lineal con respecto a la presión suministrada por la bomba. Este resultado nos permite por lo tanto caracterizar los caudales proporcionados por el sistema en las distintas condiciones de trabajo.

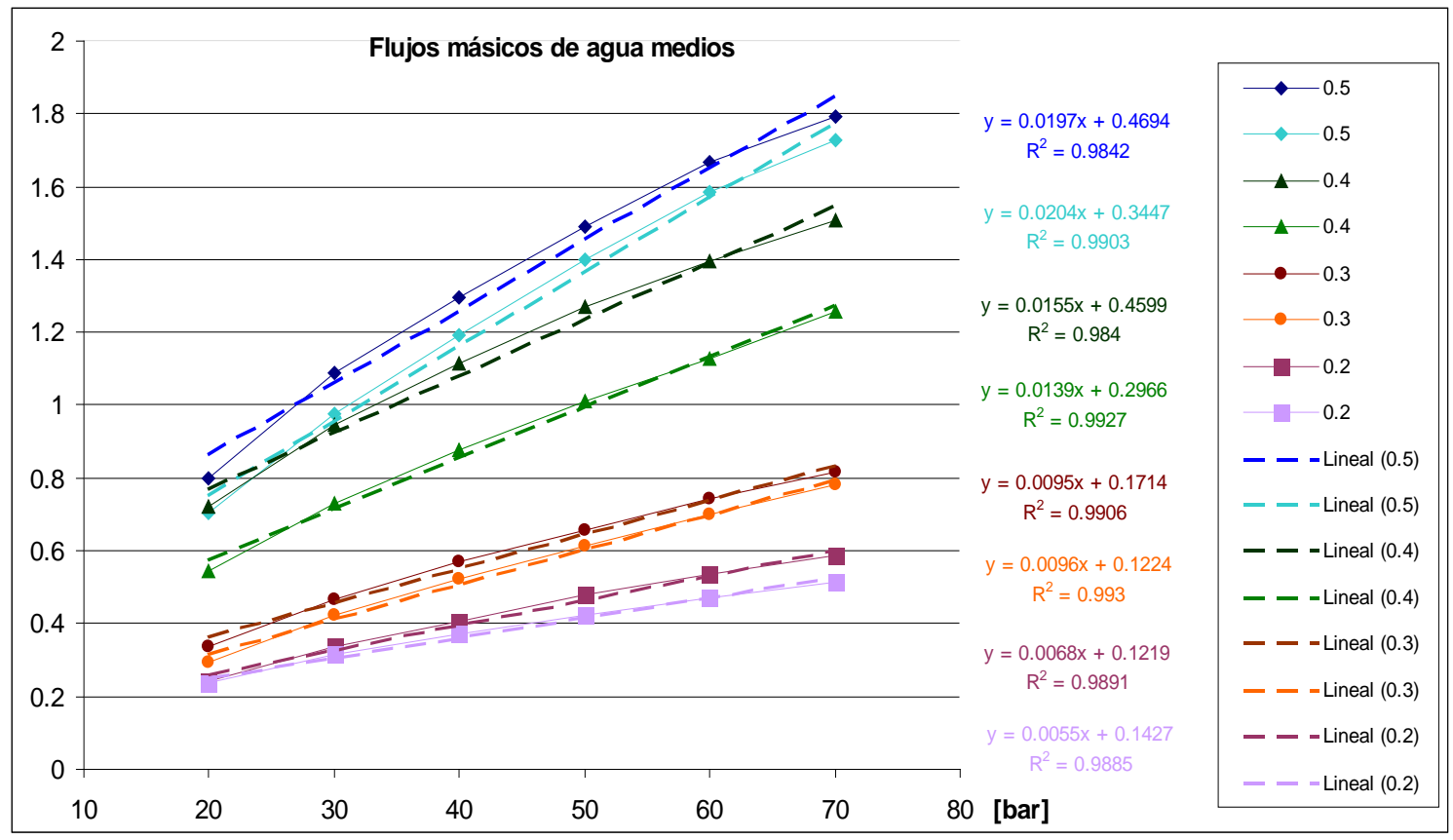

Figura VI.13.- Correlación flujo másico de agua-presión.

Si se comparan los flujos másicos obtenidos en el ensayo de la máquina con los datos proporcionados por el fabricante, dados para unas condiciones de presión de 70 bar, se comprueba que los valores experimentales resultan mucho menores que los especificados (tabla VI.3). Estas diferencias son del orden del 50\%, ligeramente más acusadas en el caso de las dos boquillas de menor tamaño. Esto puede deberse a las distintas condiciones en las que se haya determinado el caudal teórico respecto a las ensayadas, además de a la variabilidad en el proceso experimental y en los elementos reales particulares. Un ejemplo de esta última 
posible causa es la ya mentada variabilidad en el caudal proporcionado por boquillas de igual diámetro, debida posiblemente a tolerancias en la manufacturación.

Tabla VI.3.- Comparación entre flujos másicos experimentales y teóricos a 70 bar.

\begin{tabular}{|c|c|c|c|}
\hline $\begin{array}{c}\text { Tamaño de } \\
\text { boquilla [mm] }\end{array}$ & $\begin{array}{c}\text { Flujo másico } \\
\text { experimental medio } \\
\text { (70 bar) [g/s] }\end{array}$ & $\begin{array}{c}\text { Flujo másico } \\
\text { teórico (70 bar) } \\
\text { [g/s] }\end{array}$ & Desviación \\
\hline 0,2 & 0.6 & 1.3 & $54 \%$ \\
0,3 & 0.8 & 1.9 & $58 \%$ \\
0,4 & 1.5 & 2.5 & $40 \%$ \\
0,5 & 1.8 & 3.2 & $44 \%$ \\
\hline
\end{tabular}

No obstante es importante determinar el COP que proporcionaría el sistema, actuando como equipo de enfriamiento del aire interior, ya que es el dato que permitiría su confrontación con otros sistemas convencionales. Por la propia definición del COP, éste va a estar determinado por la relación entre la potencia frigorífica suministrada, dependiente a su vez del caudal de agua aportado por estar basado en el fenómeno del enfriamiento evaporativo; y el consumo de la bomba, según la ecuación E-VI.3. Dado que, como se ha visto, el consumo de la bomba depende sólo de la presión, y que el caudal depende a su vez de ésta y de las boquillas conectadas, el COP óptimo va a depender del nivel de presión y del tipo y número de boquillas conectado.

$$
\text { COP }=\frac{\dot{Q}_{F}}{\dot{W}}=\frac{\dot{m}_{\text {agua }} \cdot \lambda}{\dot{W}}
$$

Según lo anterior, se esperaría que el COP mejorara a mayor número de boquillas, Sin embargo, el número de éstas se va a ver limitado no ya por condiciones de operación o diseño, sino por las propias limitaciones del fenómeno de enfriamiento evaporativo asociadas al caudal de agua proporcionado y a las condiciones del ambiente, ya que no se debe alcanzar saturación, además de que debe evitarse la formación de gotas no evaporadas.

En la figura VI.14 se muestra la correlación entre este parámetro y la presión suministrada, para cada grupo de ensayos de interés. Se comprueba aquí que el COP del sistema es mayor a mayor número de boquillas ensayadas simultáneamente, además de a mayores tamaños de boquilla, ya que este parámetro es directamente proporcional al caudal suministrado y este depende precisamente del número y tamaño de boquillas instaladas.

Se aprecia además cómo, para un mismo número de boquillas instaladas, como son los casos de 3 y 7 boquillas totales, el COP es mayor cuanto menor es el tamaño de la boquilla no instalada en el grupo de ensayos; ya que, como es previsible, el caudal suministrado es mayor. 


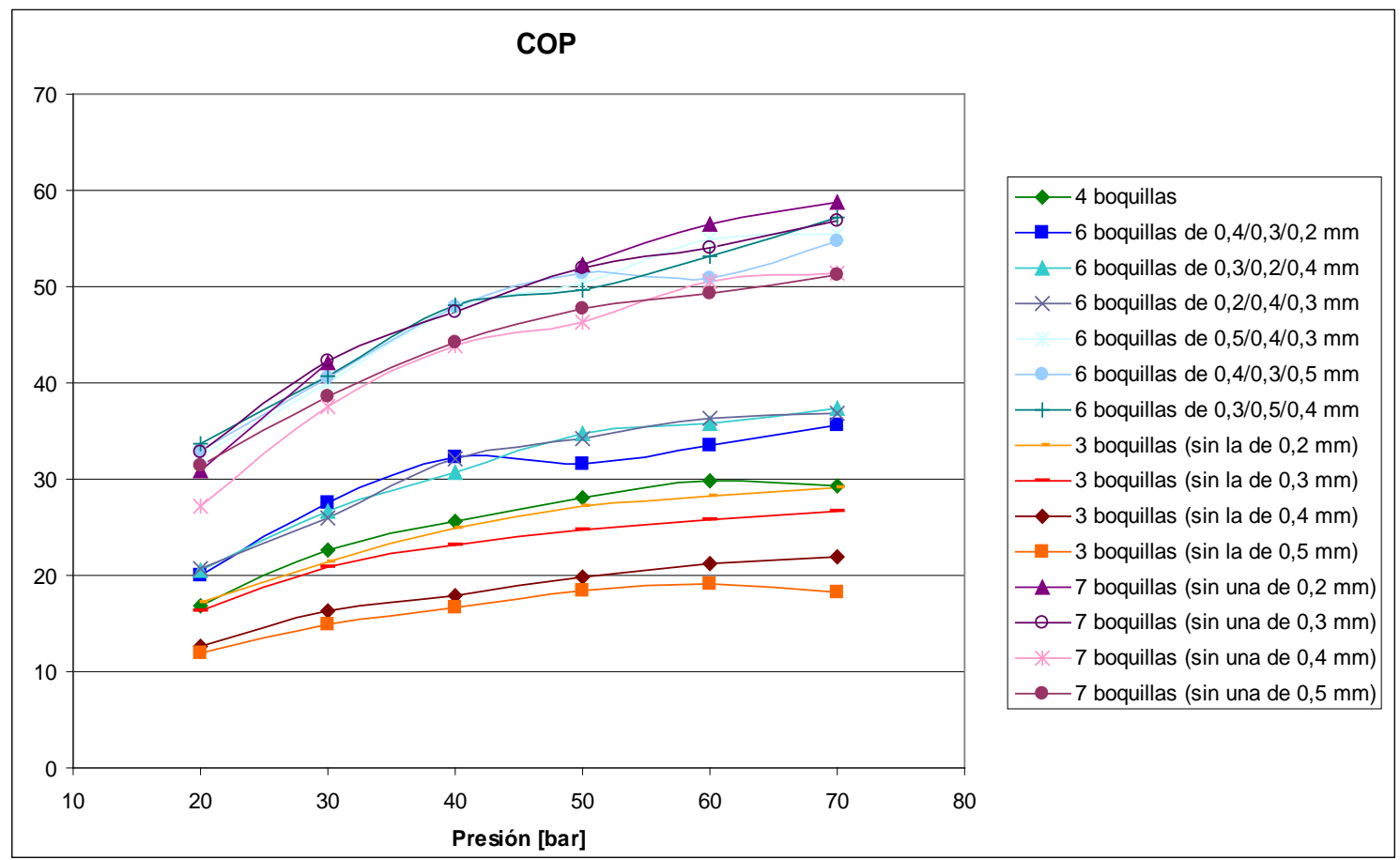

Figura VI.14.- Correlación COP- presión.

Se puede observar también cómo el orden de las boquillas no influye, ya que para los ensayos con 6 boquillas totales, de 0,2 mm, 0,3 mm y 0,4 $\mathrm{mm}$ de diámetro dispuestas en distintos órdenes, los COP obtenidos son muy próximos a cada valor de la presión. Lo mismo ocurre con los ensayos realizados con 6 boquillas de $0,3 \mathrm{~mm}, 0,4 \mathrm{~mm}$ y $0,5 \mathrm{~mm}$.

Asimismo el COP aumenta con la presión. Sin embargo, se muestra un punto de inflexión cerca de la presión máxima ensayada en algunos casos, como el de 3 boquillas sin la de diámetro $0,5 \mathrm{~mm}$; y el de 4 boquillas. Por ello es previsible que el COP no aumente indefinidamente con la presión, sino que exista un máximo para cierto valor de ésta. En cualquier caso, para los rangos de presión ensayados no puede asegurarse que se haya alcanzado dicho máximo exceptuando para los dos grupos de ensayos en los que se percibe el punto de inflexión.

El máximo error experimental obtenido se observa para el caso de la boquilla de mayor tamaño $(0,5 \mathrm{~mm})$ trabajando a la mínima presión (20 bar), y resulta ser del 15\%. Este error estará en gran parte influido por las causas ya mentadas de variabilidad en la manufacturación de las boquillas, más acusada a mayor tamaño de boquilla. Sin embargo, la variabilidad del estudio experimental en sí mismo, no evitable, como puede ser la debida a desviaciones en la presión establecida para el ensayo, produce un error inevitable en todas las medidas que no obstante es admisible por mantenerse entorno al $6,8 \%$. 


\section{Aplicación al refrescamiento de un espacio exterior.}

Como complemento a la caracterización del sistema, se ha planteado y realizado el estudio de su comportamiento real en dos aplicaciones prácticas, en particular una de ellas centrada en el refrescamiento de un espacio exterior en condiciones estivales, por ser ésta la aplicación más usual de este tipo de sistemas.

Para la realización de este segundo tipo de ensayo experimental, orientado a la evaluación de la funcionalidad del equipo, primeramente se ha realizado una toma de medidas de temperatura y humedad relativa en diversos puntos del espacio exterior a acondicionar, para caracterizar la distribución en el espacio de estos parámetros y su evolución a lo largo de un día tipo.

Una vez realizada esta caracterización inicial del ambiente a acondicionar, se procede a plantear el refrescamiento de dicho ambiente. Para ello se toma una única configuración de 5 boquillas, de tamaños $0,3 \mathrm{~mm}$ (una boquilla), 0,4 $\mathrm{mm}$ (dos boquillas) y 0,5 $\mathrm{mm}$ (dos boquillas), operando a presión de 40 bar. Se escogieron estos tamaños de boquilla, porque las aplicaciones en un espacio exterior requieren mayores flujos de agua, y además es más fácil que se produzca evaporación completa. Se colocan las boquillas de forma equidistante, con la finalidad de asegurar uniformidad en la pulverización y por lo tanto del efecto de enfriamiento producido (figura VI. 15). Cuando se monta la línea de pulverización hay que dejar una pequeña caída hacia la bomba de presión, para asegurar el drenaje completo cada vez que el sistema se apaga. El segundo paso del estudio consiste entonces en realizar una nueva toma de medidas de temperatura seca y humedad relativa en los puntos ya caracterizados del espacio exterior objeto durante el funcionamiento del sistema.

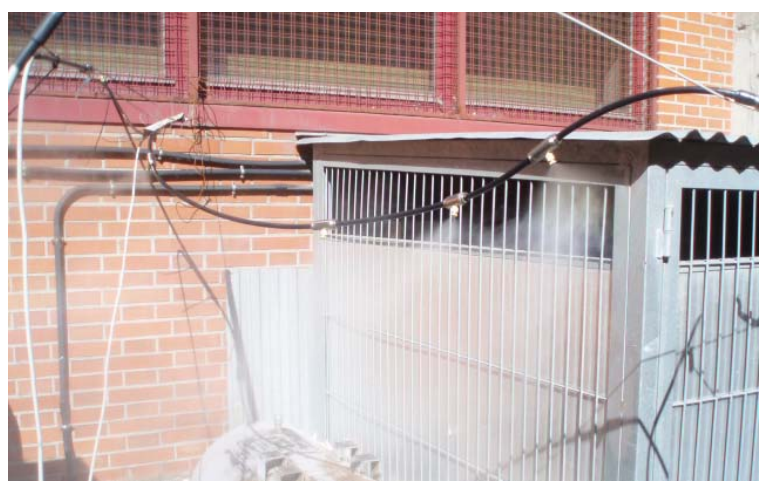

Figura VI.15.- Vista de la instalación para ensayo del refrescamiento de espacios exteriores.

Los resultados obtenidos en el primer muestreo de las condiciones exteriores sin refrescamiento mostraron un aumento de la temperatura durante las horas de ensayo desde aproximadamente $20^{\circ} \mathrm{C}$ en todos los puntos, medida a las 8:45 de la mañana, hasta valores medios de entre 27 y $30^{\circ} \mathrm{C}$ según el punto de medida, a las 13:45 horas. En cuanto a la 
humedad relativa, esta sufrió una disminución en el período considerado del orden del $20 \%$, hasta rondar un $45 \%$, similar en todos los puntos.

Los ensayos se realizaron al día siguiente del primer barrido planteado en el párrafo anterior, siendo las condiciones climáticas previstas para ese día muy similares a las del día del muestreo sin operación del sistema. Los resultados en temperatura mostraron un aumento de esta desde el valor inicial de $20^{\circ} \mathrm{C}$ ya previsto, hasta valores medios entre 25 y $27^{\circ} \mathrm{C}$. Se comprueba por lo tanto que la temperatura medida en los distintos puntos cuando el sistema está en funcionamiento, la temperatura seca oscila en torno a valores ligeramente más confortables que los que se alcanzarían en ese espacio exterior a medida que avanza la mañana en un día primaveral relativamente cálido.

Por su parte, los valores de humedad relativa medidos en los distintos puntos difieren mucho entre sí, lo cual es esperable dada la falta de uniformidad del ambiente del espacio acondicionado, por estar pulverizándose el agua que genera el efecto de enfriamiento evaporativo en 5 puntos discretos. Para tener una idea más fiable de la evolución de la humedad relativa sería necesario disponer de medidas en un gran número de puntos del espacio de interés. La evolución temporal de las condiciones del aire durante el día del muestreo original y durante el de ensayo del equipo se muestran en las figuras VI.16 y VI.17.

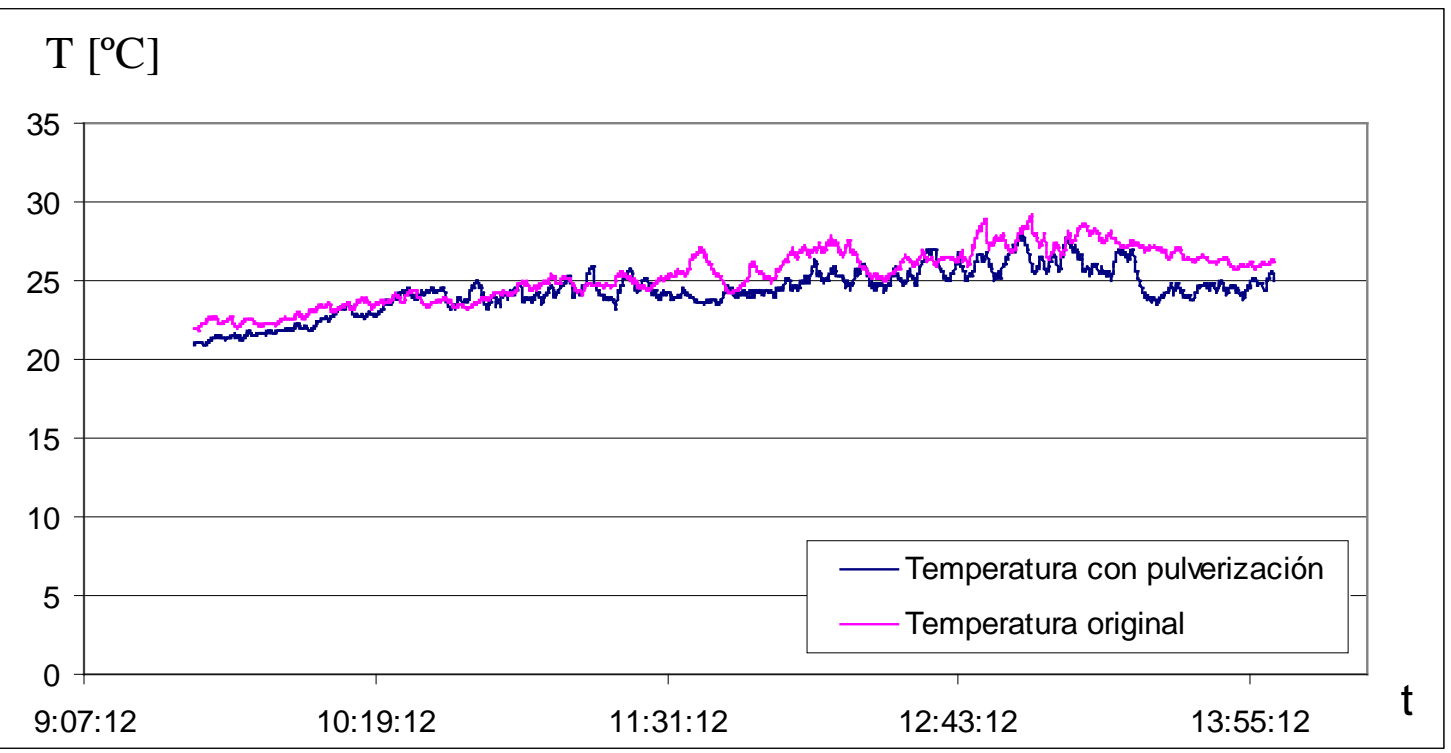

Figura VI.16.- Evolución temporal de la temperatura seca durante el día de muestreo previo frente a la evolución durante el de ensayo del sistema.

Se observa sin embargo una gran oscilación en las medidas de temperatura. Esto es debido a perturbaciones debidas a la variabilidad de las condiciones ambientales en el espacio exterior, como por ejemplo debido a la proyección de sombras por nubes o movimientos del aire, estas últimas ocasionadas por el propio viento o por la operación de equipos situados en el patio donde se realizaron los ensayos. 


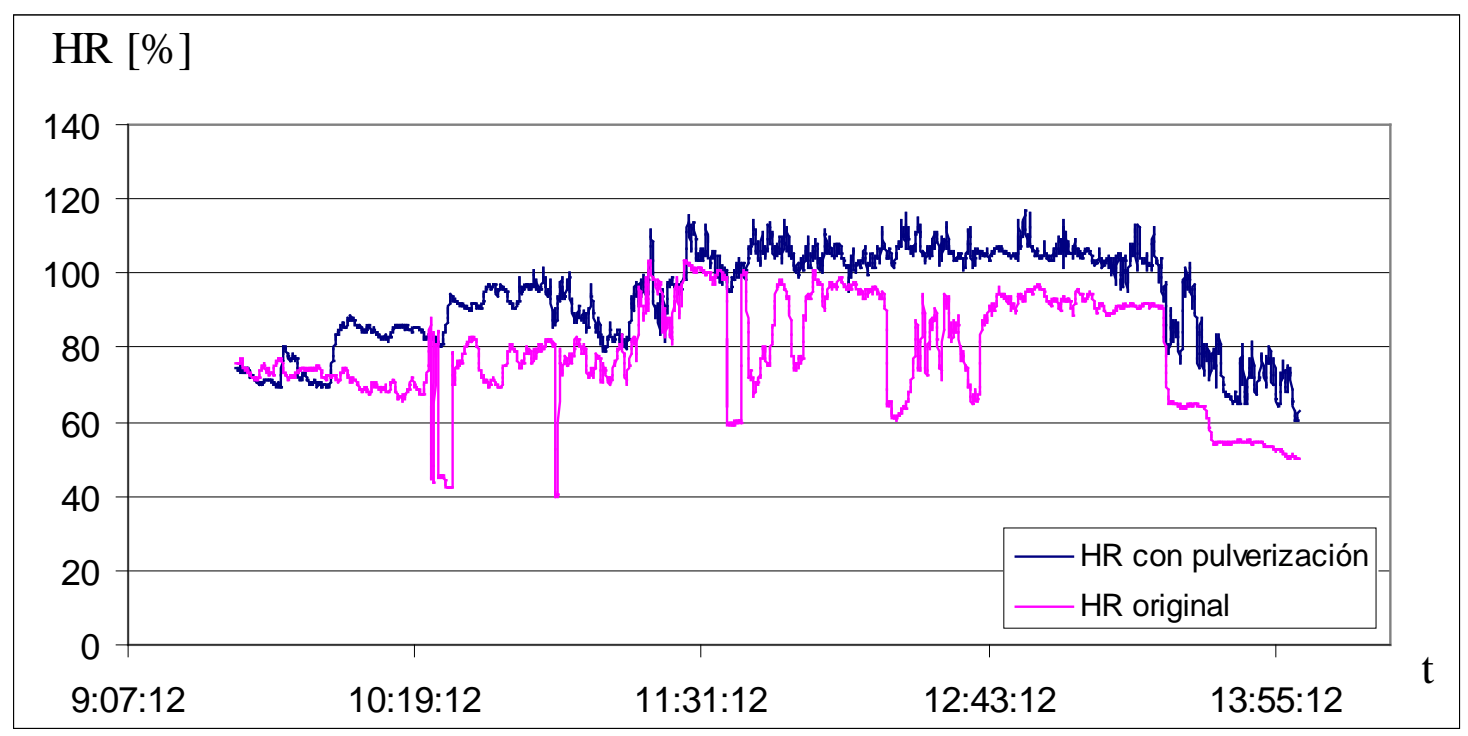

Figura VI.17.- Evolución temporal de la humedad relativa durante el día de muestreo previo frente a la evolución durante el de ensayo del sistema.

\section{Aplicación al refrescamiento de un espacio interior.}

Como segunda aplicación práctica, se va a caracterizar el proceso de humidificación del aire en un espacio interior. El espacio interior en cuestión consistirá en la cámara climática del propio laboratorio, en la cual se dispondrá el sistema en igual configuración de línea que la recurrida tanto para su caracterización experimental como para la aplicación práctica anterior.

La particularidad de especial cuidado en este caso es que, al tratarse de una aplicación en interiores, la selección del tipo y número de boquillas es tarea delicada al tener que poderse asegurar que todo el agua pulverizada está siendo evaporada en el aire, sin que se produzcan condensaciones ni se alcancen niveles excesivos de humedad en el espacio cerrado.

Además, previamente a la realización de las medidas experimentales deben determinarse qué valores se van a ensayar de los parámetros de interés a la entrada; y dicha determinación debe hacerse precisamente bajo la consideración de la cantidad de agua pulverizada por el sistema, y consecuentemente del número y tamaño de las boquillas que se coloquen en el dispositivo, en función de los resultados obtenidos de la caracterización del sistema ya realizada.

\section{Instalación experimental}

Para analizar el funcionamiento del equipo en el acondicionamiento de un espacio interior, se precisa disponer tanto de un espacio controlado en el que disponer el equipo, como de un sistema de tratamiento de aire que permita simular las condiciones del aire impulsado a ensayar y de los elementos de conexión entre estos. Además serán también precisos todos los elementos de control y medida requeridos para la realización y monitorización de los ensayos. 
Con este objeto, se recurre al dispositivo experimental disponible en el laboratorio de Termotecnia de la Universidad de Valladolid, ya recurrido para la caracterización de los sistemas evaporativos indirectos de policarbonato y descrito en el capítulo IV. La instalación particular sigue el esquema mostrado en la figura VI.18.

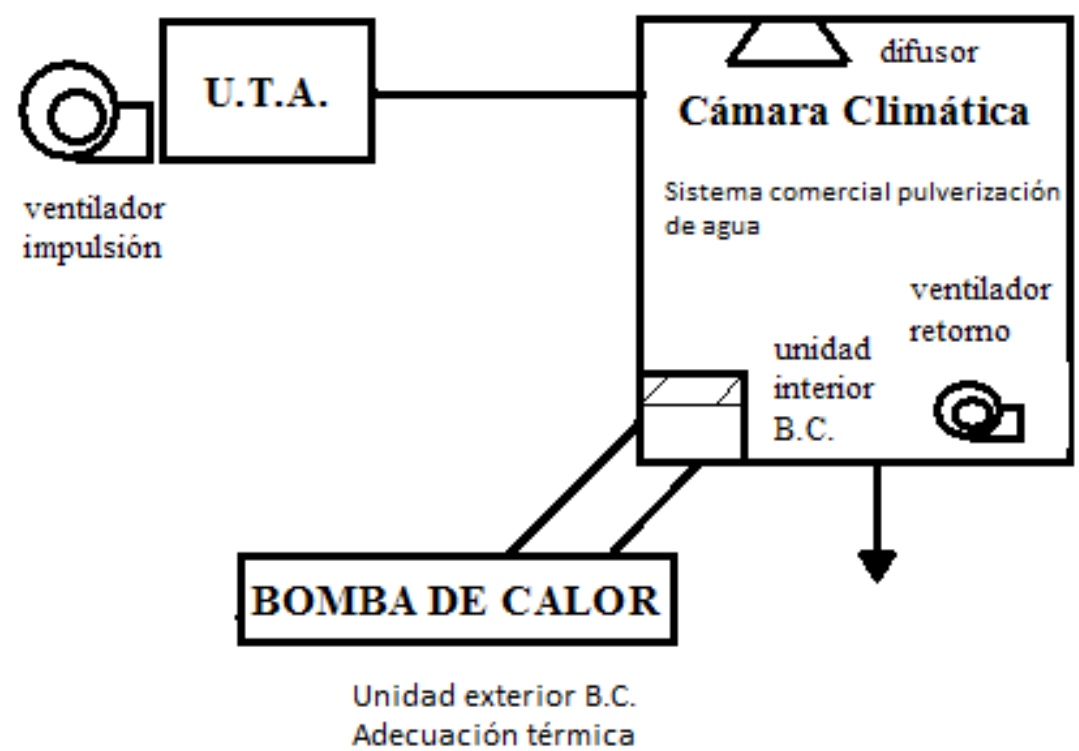

Figura VI.18.- Instalación experimental para la caracterización del funcionamiento del sistema de micronización en el acondicionamiento de un espacio interior.

\section{Metodología de ensayos}

Se presentan inicialmente las variables consideradas de interés para realizar la caracterización del proceso, las cuales deben poderse controlar en el banco de ensayos.

A la hora de establecer dichas variables, hay que tener en cuenta las limitaciones impuestas por el sistema experimental. Por su parte, el valor de la humedad relativa del aire de entrada no será susceptible de ser controlado debido a que la UTA no dispone de un deshumidificador, y por lo tanto su valor su corresponderá a la humedad relativa del aire del laboratorio, comprendido entre 20-25\%.

Por lo tanto, a la hora de determinar las condiciones de los ensayos a realizar se consideran sólo los cuatro factores siguientes para cada configuración ensayada: caudal volumétrico del aire a la entrada, temperatura seca del aire a la entrada, presión de trabajo de la bomba y orientación de las boquillas.

El caudal volumétrico que la UTA puede enviar a los difusores rotacionales que se encuentran en la cámara de ensayos está limitado entre 100 y $1100 \mathrm{~m}^{3} / \mathrm{h}$. Cuando se analizan los resultados obtenidos en el cálculo teórico para ver el número de boquillas que es necesario instalar en el sistema, procedimiento que será presentado a continuación, se observa que para 
los valores de caudal comprendidos entre 0 y $600 \mathrm{~m}^{3} / \mathrm{h}$, el número de boquillas de diámetro 0,2 $\mathrm{mm}$ y $0,3 \mathrm{~mm}$ es menor a la unidad. Debido a esto, se han considerado dos únicos niveles de caudal: $800 \mathrm{~m}^{3} / \mathrm{h}$ y $1000 \mathrm{~m}^{3} / \mathrm{h}$.

La presión de trabajo de la bomba sólo afecta a la cantidad de agua pulverizada por las boquillas y al consumo eléctrico, que como ya se analizó en apartados anteriores, aumenta con la presión. Por lo tanto, y para minimizar el consumo, sólo se considera un nivel de presión, 20 bar.

La temperatura del aire a la entrada establece la cantidad de agua que hay que pulverizar, ya que cuanto mayor es la temperatura, para una humedad relativa y caudal de aire constante, mayor es la cantidad de agua a evaporar en el seno del aire para disminuir su temperatura hasta condiciones de confort. Como la humedad del aire está fijada y el caudal de aire de renovación es pequeño debido al reducido volumen de la cámara climática, va a ser preciso ensayar valores de temperatura elevados para que sea factible realizar los ensayos, ya que en otro caso las condiciones de confort se alcanzarían con caudales menores de los que proporcionaría una única boquilla. Por lo tanto, los niveles de temperatura ensayados se encuentran dentro del rango de $43^{\circ} \mathrm{C}$ a $46^{\circ} \mathrm{C}$.

Otro factor a tener en cuenta es la orientación de las boquillas, ya que el dardo de la boquilla varía en función de la posición de la misma. Se analizan dos orientaciones: con la boquilla paralela al suelo o perpendicular (figura VI.19).

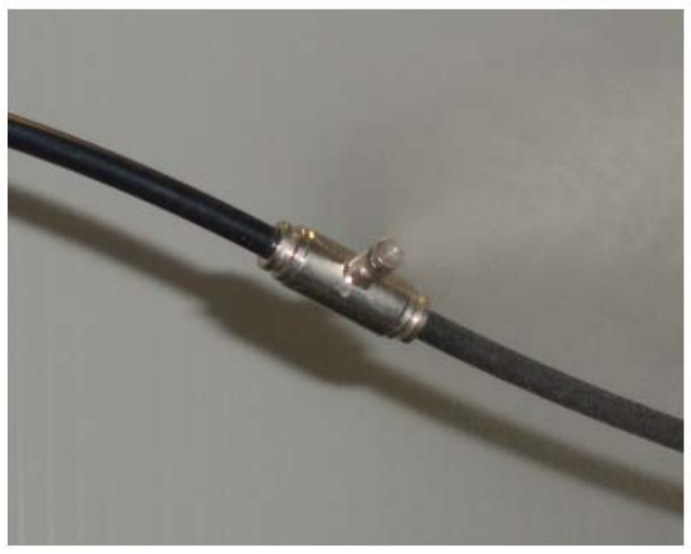

Figura VI.19.a- Orientación de las boquillas en paralelo al suelo.

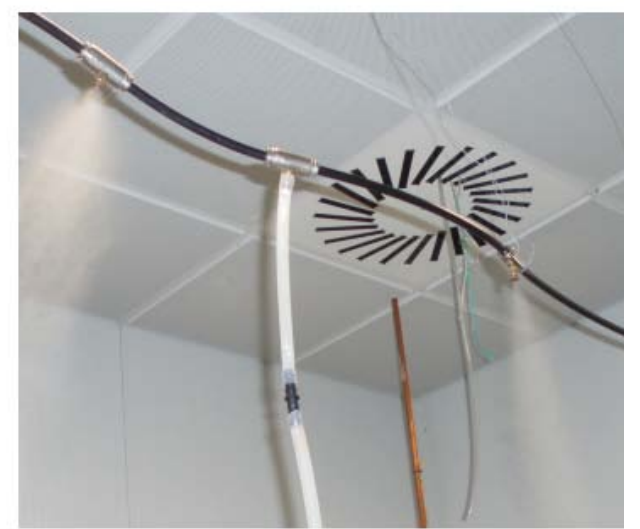

Figura VI.19.b- Orientación de las boquillas en perpendicular al suelo.

Sin embargo, como ya se ha indicado, para la determinación de las especificaciones de los parámetros ensayados va a ser necesario calcular el flujo másico de agua a pulverizar en cada caso, y a partir de este cálculo teórico, seleccionar las boquillas para la correspondiente configuración experimental. A continuación se describe este proceso.

\section{Cálculo teórico del flujo másico de agua.}

El cálculo teórico del flujo másico de agua que se puede evaporar en cada caso de ensayo, se realiza considerando una eficacia de humidificación del $70 \%$ para una cierta 
corriente de aire a temperatura y humedad relativa dadas. Con el valor del flujo másico de agua que hay que pulverizar y el flujo másico que proporciona cada boquilla, determinado experimentalmente cuando se caracterizó el equipo de pulverización de agua, se calcula el número de boquillas necesarias que hay que montar en el sistema para enfriar el caudal de aire establecido.

Para calcular la cantidad de agua necesaria, se plantea un balance de materia al sistema en términos de aire húmedo, sabiendo que en el proceso de humidificación el flujo másico de aire seco se mantendrá constante. Por lo tanto, el flujo de agua evaporado puede calcularse a partir del producto del caudal másico de aire seco de renovación de la cámara multiplicado por la diferencia de las humedades específicas a la entrada y a la salida:

$$
\dot{\mathrm{m}}_{\text {agua }}=\dot{\mathrm{m}}_{a s} \cdot\left(X_{\text {sal }}-X_{\text {ent }}\right)
$$

Considerando las propiedades del agua constantes, se determina el flujo másico de aire seco a partir del caudal volumétrico de renovación establecido $(\dot{Q})$ y en función del volumen específico del aire húmedo. El volumen específico del aire húmedo (Ve), se define como el volumen que ocupa el aire húmedo por unidad de masa de aire seco $\left(\mathrm{m}^{3} / \mathrm{kg}\right.$ as), por tanto haciendo uso de la ley de los gases perfectos, resulta:

$$
V_{e}=\frac{v}{m_{a s}}=\frac{R T}{M_{a s} P_{a s}}=\frac{8314,4 \cdot T}{28,9645 \cdot P_{a s}}=287,055 \cdot \frac{T}{P_{T}-P_{V}}
$$

Donde la presión total del aire en Valladolid, situada a $750 \mathrm{~m}$ sobre el nivel del mar, puede establecerse en aproximadamente 92600Pa.

Para el cálculo de la humedad específica del aire a la entrada y a la salida de la cámara de ensayos, se toman los valores de temperatura seca y humedad relativa en estos puntos.

Mediante la ecuación de Antoine (ecuación E-VI.6), y con la temperatura del aire a la entrada, se determina la presión de vapor de saturación para las condiciones a la entrada:

$$
P_{V s a t}=e^{\left(a-\frac{b}{c+T}\right)}
$$

Donde las constantes empleadas se corresponden con los siguientes valores:

$$
\begin{aligned}
& a=16,262 \\
& b=3799,89 \\
& c=226,31
\end{aligned}
$$


Con la presión de saturación calculada y los datos registrados de las medidas de la humedad relativa del aire, se determina la presión de vapor para el aire (ecuación E-VI.7), y a partir de ésta la humedad específica del aire a la entrada y a la salida de la cámara (E-VI.8).

$$
\begin{aligned}
& \mathrm{P}_{\mathrm{V}}=\frac{H R}{100} \times P_{V s a t} \\
& X=0,62198 \times \frac{P_{V}}{P_{T}-P_{V s a t}}
\end{aligned}
$$

\section{Selección del número y tipo de boquillas.}

Como se ha comprobado en la caracterización del sistema en apartados anteriores, el flujo másico pulverizado por cada tipo de boquilla depende únicamente de la presión. Para este estudio particular se va a considerar la mínima presión disponible (20 bar).

Asimismo, en la determinación del caudal proporcionado por cada tipo de boquilla, se observó que existe cierta variabilidad entre resultados obtenidos para boquillas de igual tamaño, hecho más acusado a medida que aumenta el diámetro. En el cálculo del número de boquillas necesarias para pulverizar el flujo másico de agua determinado según el apartado anterior, para cada caudal de aire ensayado se van a considerar los valores medios de los datos experimentales del flujo másico proporcionado por cada tipo de boquilla, correspondientes con los indicados en la tabla VI.4.

Tabla VI.4.- Valores medios del flujo másico

\begin{tabular}{|cc|}
\hline Diámetro [mm] & $\begin{array}{c}\text { Flujo másico medio [g/s] } \\
\text { a presión 20 bar }\end{array}$ \\
\hline 0,5 & 0,75 \\
0,4 & 0,63 \\
0,3 & 0,31 \\
0,2 & 0,24 \\
\hline
\end{tabular}

Se determina el número de boquillas a partir del cociente entre el flujo másico de agua a pulverizar y el que pulveriza una boquilla del tipo considerado:

$$
\mathrm{N}=\frac{\dot{\mathrm{m}}_{\text {agua }}}{\dot{\mathrm{m}}_{\mathrm{b}, \mathrm{i}}}
$$

Una vez determinado el número de boquillas por la expresión anterior, se escoge el tamaño y número de éstas, teniendo en cuenta que debido a los reducidos caudales de aire ensayados, en la mayor parte de los casos una única boquilla del tipo 0,4 ó $0,5 \mathrm{~mm}$ ya va a exceder por sí sola el caudal de agua requerido; además de que no se dispone de un número 
ilimitado de boquillas de cada tipo ( 2 boquillas de $0,5 \mathrm{~mm}$ y $0,4 \mathrm{~mm}$; y 3 boquillas de 0,3 $\mathrm{mm}$ y $0,2 \mathrm{~mm}$ ). Por ello, si el número de boquillas teórico requerido excede el máximo de boquillas del que se dispone, se considera el flujo másico que proporcionarían el número límite de boquillas de ese tamaño, y se resta al flujo total de agua necesario, soportando el exceso de caudal de agua requerido recurriendo a boquillas de menor diámetro, y procediendo para realizar el cálculo de éstas de forma análoga a la anterior.

Este hecho también da lugar a que existan varias configuraciones posibles, de las que tan sólo se ensayarán las más representativas, o en su caso simplemente aquellas posibles en función del caudal de aire que proporciona la UTA, el cual está limitado por la pérdida de carga o por las condiciones de humedad relativa y temperatura de aire que proporciona, dependientes del ambiente del laboratorio. Por otro lado, las boquillas de 0,2 $\mathrm{mm}$ y 0,3 $\mathrm{mm}$ no sólo pulverizan menos caudal, sino que también el tamaño de gota es menor, favoreciéndose en estos casos que el agua pulverizada se evapore más fácilmente en el aire, de ahí que se conceda preferencia a las boquillas de ese diámetro para la aplicación en espacios interiores. Por esta razón, en el estudio particular se van a realizar los ensayos únicamente con las boquillas de diámetro $0,3 \mathrm{~mm}$ y $0,2 \mathrm{~mm}$.

En la tabla VI.5 se recogen las configuraciones seleccionadas para ensayo, resultantes del estudio planteado.

Tabla VI.5.- Ensayos realizados con el sistema de micronización para adecuación de un espacio interior.

\begin{tabular}{|c|c|c|c|c|}
\hline $\begin{array}{l}N^{0} \text { de } \\
\text { ensayo }\end{array}$ & $\mathrm{N}^{0} \mathrm{y}$ tipo de boquillas & $\begin{array}{c}\text { Orientación de las } \\
\text { boquillas }\end{array}$ & $\begin{array}{c}\text { Caudal } \\
\text { volumétrico de } \\
\text { aire a la entrada } \\
{\left[\mathrm{m}^{3} / \mathrm{h}\right]}\end{array}$ & $\begin{array}{c}\text { Temperatura } \\
\text { seca del aire a } \\
\text { la entrada } \\
\mathrm{T}\left[{ }^{\circ} \mathrm{C}\right]\end{array}$ \\
\hline 1 & 2 boquillas de $0,2 \mathrm{~mm}$ & Paralelas al suelo & $800 \mathrm{~m}^{3} / \mathrm{h}$ & $42^{\circ} \mathrm{C}$ \\
\hline 2 & $\begin{array}{l}1 \text { boquilla de } 0,2 \mathrm{~mm} \\
1 \text { boquilla de } 0,3 \mathrm{~mm}\end{array}$ & Paralelas al suelo & $1030 \mathrm{~m}^{3} / \mathrm{h}$ & $44^{\circ} \mathrm{C}$ \\
\hline 3 & 3 boquillas de $0,2 \mathrm{~mm}$ & $\begin{array}{l}\text { Perpendiculares } \\
\text { al suelo }\end{array}$ & $1050 \mathrm{~m}^{3} / \mathrm{h}$ & $45^{\circ} \mathrm{C}$ \\
\hline 4 & 1 boquilla de $0,3 \mathrm{~mm}$ & Paralelas al suelo & $1050 \mathrm{~m}^{3} / \mathrm{h}$ & $46^{\circ} \mathrm{C}$ \\
\hline 5 & 2 boquillas de $0,3 \mathrm{~mm}$ & $\begin{array}{l}\text { Perpendiculares } \\
\text { al suelo }\end{array}$ & $1050 \mathrm{~m}^{3} / \mathrm{h}$ & $43^{\circ} \mathrm{C}$ \\
\hline 6 & 2 boquillas de $0,3 \mathrm{~mm}$ & Paralelas al suelo & $1050 \mathrm{~m}^{3} / \mathrm{h}$ & $46^{\circ} \mathrm{C}$ \\
\hline
\end{tabular}

\section{Metodología experimental}

En primer lugar, hay que tener en cuenta que cuando el número de boquillas es pequeño, como ocurre en todos los casos ensayados debido a las limitaciones de caudal de aire y del espacio empleado, se produce recalentamiento del sistema. Para evitar posibles daños por 
esta causa, se monta el sistema de pulverización en la cámara con una disposición de 7 conectores para las distintas boquillas. Como el número de boquillas que se emplean en cada ensayo es menor que 7, el agua pulverizada por las boquillas restantes se canaliza hacia un desagüe, como se apreciaba en la figura VI.19.b. En una aplicación real este gasto innecesario de agua no sería necesario, ya que tanto por el mayor tamaño de los espacios reales a acondicionar como el mayor caudal de aire requerido para su ventilación, sería necesario disponer de mayor número de boquillas para su acondicionamiento.

La forma de proceder en todos los ensayos es la misma. En primer lugar se coloca la distribución de boquillas a ensayar. Se acciona la UTA y se fijan el caudal y la temperatura a la entrada. Se espera hasta que se estabilizan los valores establecidos y a continuación se acciona el sistema de pulverización de agua. Una vez en estado estacionario, se registran los valores de la temperatura seca y humedad relativa del aire a la entrada y a la salida de la cámara durante el período de tiempo de ensayo establecido.

\section{Análisis de resultados}

Con los valores de caudal volumétrico de aire, temperatura y humedad relativa a la entrada y las alcanzadas en el ambiente del habitáculo se calcula la cantidad de agua que se evapora realmente en la corriente de aire, así como la eficacia de humidificación del proceso y la cantidad de agua que se evaporaría en esas mismas condiciones bajo la hipótesis inicial de eficacia de humidificación del $70 \%$.

La eficacia de humidificación se define como la relación entre la diferencia de humedades generada y la máxima que podría obtenerse, de alcanzarse saturación, suponiendo que el proceso seguido es puramente adiabático. Esta relación queda expresada en términos de humedad relativa como:

$$
\varepsilon=\frac{H R_{f}-H R_{i}}{100-H R_{i}} \times 100
$$

Como se ha planteado en el subapartado correspondiente, las condiciones de ensayo se determinaron bajo la suposición de una humedad relativa del aire a la entrada del local de ensayo fija e igual aproximadamente a un 20-25\%, al no ser susceptible de ser controlada mediante la UTA disponible en la instalación. Asimismo, en el estudio teórico inicial desarrollado para la determinación de las distintas configuraciones a ensayar se ha supuesto una eficacia de humidificación teórica del sistema del 70\% Se observa no obstante que las distintas condiciones particulares de ensayo afectan a la cantidad de agua evaporada, y en particular la disposición paralela o perpendicular al suelo de las boquillas.

Cuando se compara la cantidad de agua evaporada de forma experimental y la determinada teóricamente, se observa que se pueden producir tres situaciones distintas, que se describirán a continuación. Debe notarse sin embargo en la representación de estos ensayos la aparición de picos apreciables en la evolución del flujo de agua experimental, 
debidos a perturbaciones en el ambiente de la cámara de ensayos por la entrada de personas para vaciar las botellas instaladas como desagüe.

El valor del flujo de aqua evaporada determinado experimentalmente resulta mayor que el teórico calculado para una eficacia de humidificación del 70\%:

(Figura VI.20). A partir de estos resultados, la eficacia de humidificación real del proceso en el ensayo número 4 se muestra muy elevada, comprendida entre 94 y $97 \%$, lo cual deriva en un importante salto térmico en las condiciones del aire, de en torno a $17^{\circ} \mathrm{C}$.

El valor del flujo de agua evaporada determinado experimentalmente resulta menor que el teórico calculado

(Figura VI.21). Este caso refleja que no toda el agua aportada llega a evaporarse en la corriente de aire, lo cual se comprueba por las condensaciones producidas en el suelo de la cámara de ensayos. Esto se produce para las configuraciones de los ensayos número 1, 2, 3 y 5 (véase la tabla VI.5). En este caso la eficacia de humidificación que se consigue es elevada, entre el 70 y el $80 \%$, y consecuentemente el salto térmico que se obtiene también es importante, variando en torno a los $15^{\circ} \mathrm{C}$.

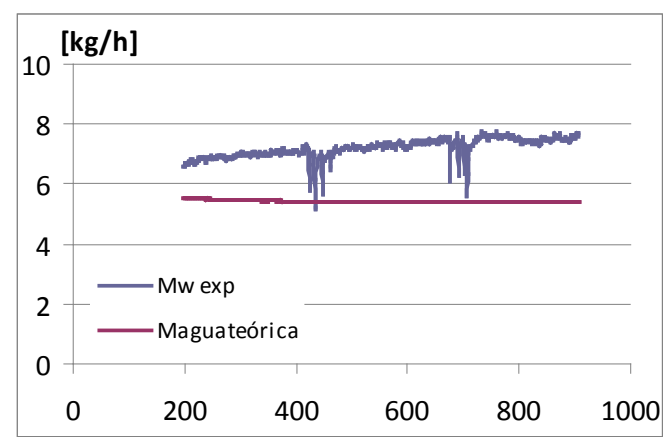

Figura Vl.20.- Comparación del flujo másico de agua evaporado para el ensayo número 4.

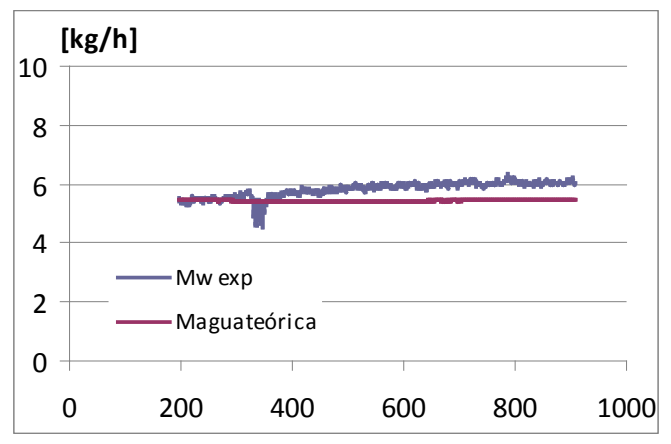

Figura VI.22.- Comparación flujo másico para el ensayo número 6.

\section{Efecto by-pass:}

En el ensayo número 6, y como se observa en la gráfica de la figura VI.22, al principio la cantidad de agua evaporada de forma experimental es menor que la teórica para luego
Figura VI.21.- Comparación del flujo másico de agua evaporado para el ensayo número 2. 
aumentar por encima de ésta. En este caso, es previsible que una parte del flujo de aire aportado a la cámara se extraiga sin haber sufrido apenas humidificación; es decir: esté siendo by-pasado. Las eficiencias de humidificación alcanzadas en este caso son también altas, del orden del 80 al 90\%.

Por otro lado, por la diversidad de ensayos realizados, es posible abordar el estudio de cómo influye la disposición de las boquillas, en paralelo o en perpendicular al suelo, en la eficacia de humidificación del sistema. Estas dos disposiciones supondrán distinta penetración del agua micronizada en el interior de la sala, siendo necesario analizar el efecto del dardo de las boquillas en la cantidad de agua evaporada en la corriente de aire.

Atendiendo al flujo másico de agua real evaporado obtenido de forma experimental para la configuración de 2 boquillas de $0,2 \mathrm{~mm}$ en las 2 posiciones ensayadas: paralelas y perpendiculares al suelo, correspondientes a los ensayos 5 y 6 (figura VI.23), se observa que cuando las boquillas están en posición paralela al suelo la cantidad de agua evaporada es mayor que cuando se encuentran en posición perpendicular al suelo. Esto es debido a que como en dicha posición el dardo es mayor, el agua pulverizada permanece más tiempo en contacto con el aire, y por lo tanto tiene más posibilidades de evaporarse.

Asimismo, representado las diferencias de temperatura alcanzadas para los dos casos entre la entrada y a la salida (figura VI.24), el salto térmico cuando las boquillas están en la posición paralelas al suelo es mayor que cuando tenemos las boquillas en posición perpendicular al suelo, caso este último en el que el dardo de la boquilla es menor, siendo la diferencia en el incremento de temperatura entre las distintas posiciones de la boquilla desde 4 ${ }^{\circ} \mathrm{C}$ a casi $7^{\circ} \mathrm{C}$.

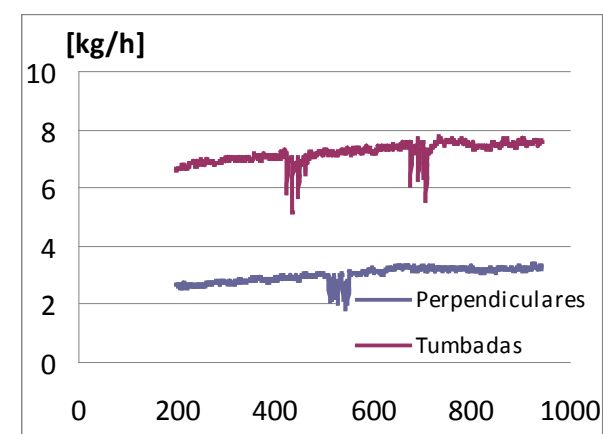

Figura VI.23.- Flujo másico de agua evaporada en las dos posiciones de las boquillas posibles (ensayos 5 y 6).

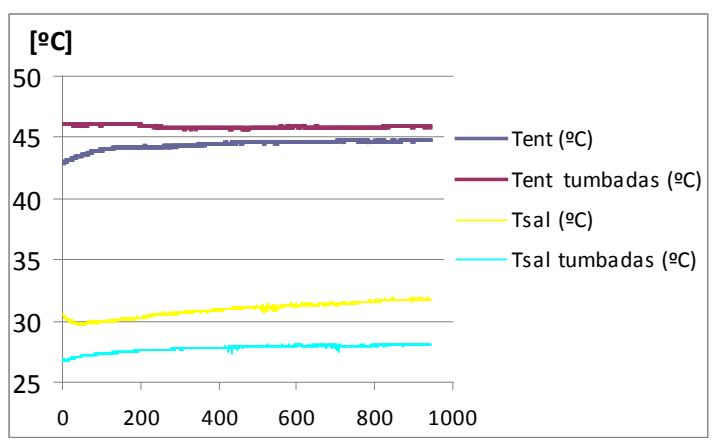

Figura VI.24.- Salto térmico alcanzado en las dos posiciones de las boquillas posibles (ensayos 5 y 6).

De esto se deduce que cuanto mayor sea el dardo de las boquillas, mayor es la cantidad de agua evaporada en el aire y consecuentemente el efecto enfriador generado, por lo que es más interesante la disposición de las boquillas para pulverización en paralelo al suelo, siempre 
y cuando el espacio a acondicionar sea suficientemente grande para que las boquillas puedan disponerse alejadas de obstáculos donde se puedan producir condensaciones.

Estos resultados muestran que en todo caso la eficacia de humidificación real supera el valor esperado, como se puede observar en los valores recogidos en la tabla VI. 6 para los 6 ensayos realizados.

Tabla VI.6.- Eficacias de humidificación medias obtenidas en los distintos ensayos realizados para el micronizador de agua en un espacio cerrado

\begin{tabular}{|c|c|c|c|c|c|c|}
\hline$N^{0}$ de ensayo & 1 & 2 & 3 & 4 & 5 & 6 \\
\hline$\varepsilon[\%]$ & $71,0 \%$ & $81,2 \%$ & $80,8 \%$ & $95,2 \%$ & $74,6 \%$ & $87,6 \%$ \\
\hline
\end{tabular}

\section{VI.3. EED DE RELLENO RÍGIDO}

Como se ha visto en la descripción proporcionada en el capítulo III, los enfriadores evaporativos directos de relleno rígido están conformados por placas rígidas y corrugadas que pueden estar fabricadas en diversos materiales, bien plástico, celulosa impregnada, fibra de vidrio, etc. Las corrientes de aire y agua circulan generalmente en flujo cruzado en el relleno, de modo que los canales horizontales correspondan al aire y los verticales al agua [3, ASHRAE, 2000] [1, Rey et al, 2000].

Los sistemas higrométricos de medio rígido no necesitan estructuras de soporte, no emiten partículas y tienen una vida útil prolongada; además comparativamente permiten una velocidad de flujo más alta, menor caída de presión y una eficacia ligeramente mayor que los enfriadores evaporativos directos con paneles evaporativos o los rotativos.

El atractivo del estudio de estos tipos de enfriadores radica en las ventajas que suponen su economía y efectividad, así como en el hecho de que permiten una gran versatilidad de aplicaciones dentro de los sectores residencial, comercial e industrial. La efectividad de estos equipos viene predeterminada por los siguientes factores:

- La velocidad del flujo del aire a través de los paneles.

- La absorción del relleno (panel).

- La superficie de los paneles en contacto con el caudal de aire.

A continuación se describe más detalladamente el equipo de relleno rígido comercial adquirido para la caracterización de este tipo de sistemas. 


\section{Descripción del sistema comercial de relleno rígido FA6.}

El refrigerador evaporativo FA6 puede utilizarse como un refrigerador directo, para refrigerar y humidificar el aire suministrado, configuración que se utiliza el presente estudio; o como un refrigerador indirecto en conjunto con un rotor de recuperación de calor, para refrigerar el aire suministrado sin añadir humedad.

Como enfriador evaporativo directo, va a permitir preacondicionar el aire en el interior de un local de modo que se reduzcan las necesidades energéticas de los equipos higrotérmicos convencionales destinados a alcanzar las condiciones de confort en el ambiente interior. Se considera además una fuente de energía semi-gratuita, ya que como todo equipo de enfriamiento evaporativo aprovecha el potencial calórico de la evaporación del agua para acondicionar el aire, y su consumo energético externo asociado se reduce al funcionamiento de la bomba de impulsión del agua, siendo éste en el equipo particular de 0,057 kW (potencia medida en el laboratorio de experimentación para una tensión de corriente de $397 \mathrm{~V}$ y una intensidad de la red de suministro de 0,082 A), y al del ventilador centrífugo que permite la circulación del aire a tratar.

También al igual que el resto de equipos evaporativos, su inconveniente principal se encuentra asociado a los riesgos de generación de aerosoles que porten bacterias como la legionella dentro del aire que se impulsa al local, lo que obliga a realizar un tratamiento bactericida eficaz con las implicaciones de control que esto supone. Sin embargo, la generación de aerosoles se minimiza en este caso gracias a la actuación como separador de gotas de una parte del relleno rígido (aunque esto también incurrirá en mayores pérdidas de carga que las estrictamente necesarias para la efectividad de su funcionamiento).

El equipo de enfriamiento evaporativo FA6 adquirido; es adecuado para su instalación en sistemas de tratamiento de aire tanto de edificios residenciales como industriales. El modelo particular elegido para su caracterización y análisis experimental es de dimensiones 60 x $60 \mathrm{~cm}$ (anchura $x$ altura). Está formado por un panel evaporativo de material inorgánico GLASdek (figuras VI.25.a y VI.25.b), el cual ha sido probado contra incendios y está clasificado como material no combustible de acuerdo con ISO 1182 [N-3], [9, Munters].

El agua puede ser suministrada directamente de la red o mediante una bomba (figura VI.26) que permita su circulación desde un depósito de acero inoxidable hacia la parte superior del panel a través de un sistema de distribución (figura VI.27). Desde allí, el agua desciende hacia la superficie corrugada del panel. El esquema del funcionamiento se muestra en la figura VI.28. 


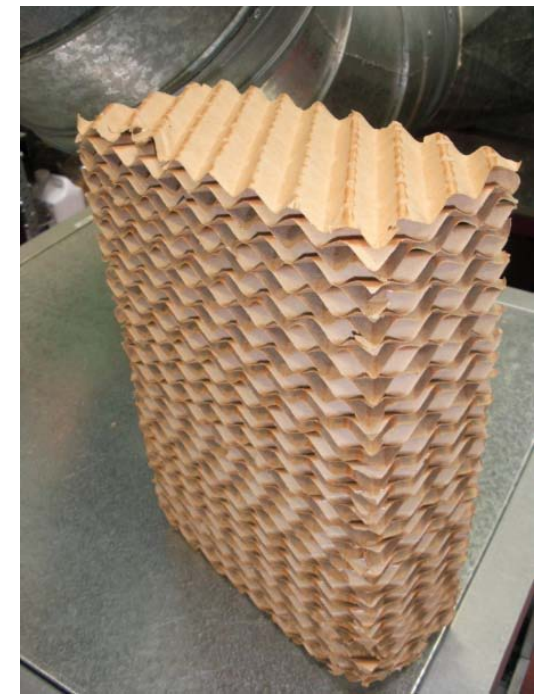

Figura VI.25.a.- Relleno rígido inorgánico GLASdek.

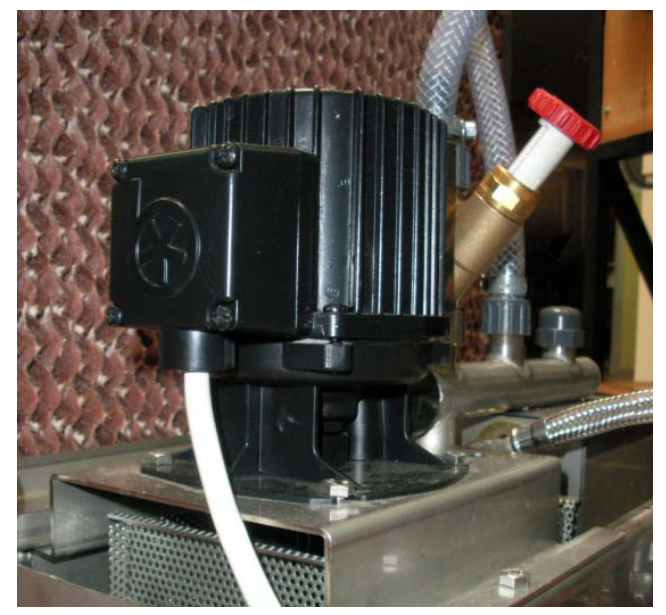

Figura VI.26.- Bomba de circulación del equipo FA6.

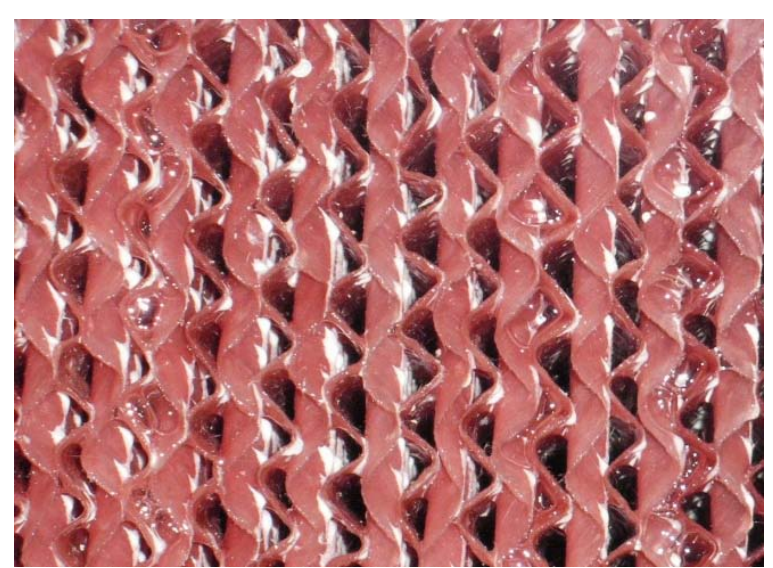

Figura VI.25.b.- Detalle del relleno durante el funcionamiento del equipo.

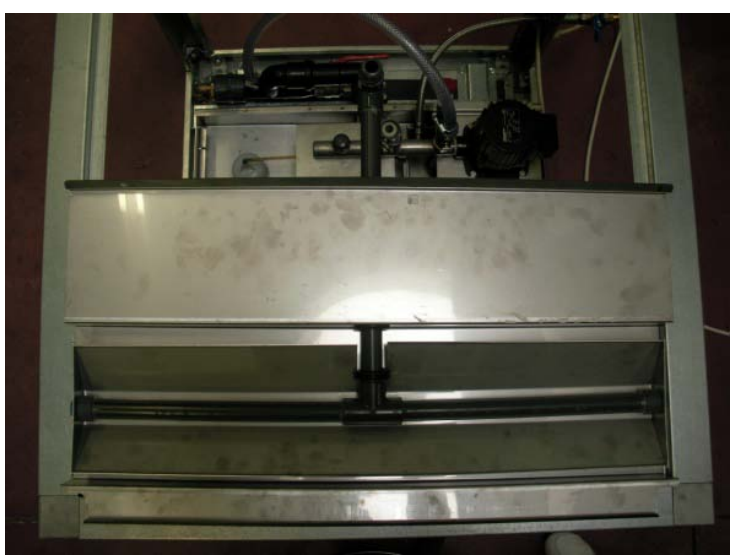

Figura VI.27.- Vista superior del equipo: sistema de distribución.

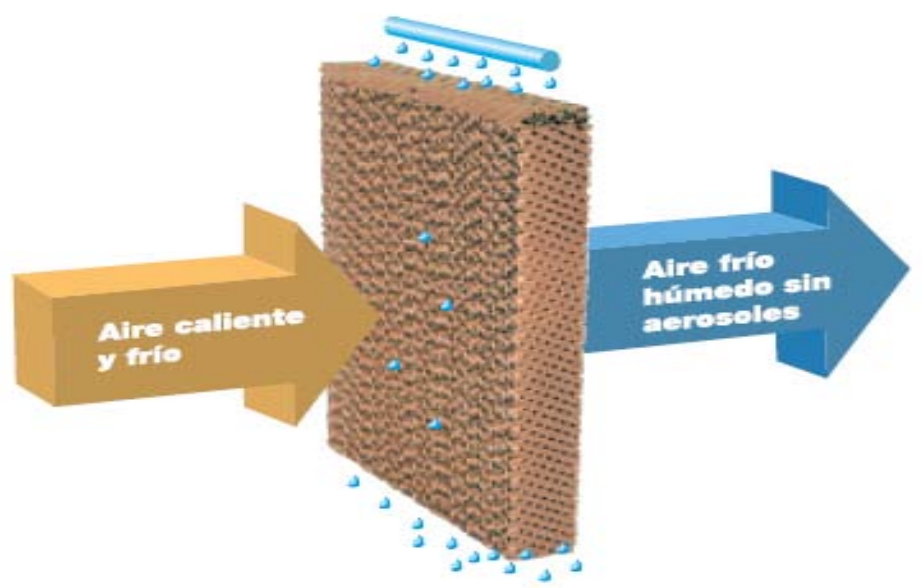

Figura VI.28.- Esquema del funcionamiento del equipo FA6. 
A medida que pasa aire caliente y seco por el panel, se evapora parte del agua, obteniéndose aire frío y humidificado. El resto del agua ayuda a lavar el panel y se vacía de nuevo en el depósito.

El agua utilizada es agua de red, y no precisa de ningún tipo de tratamiento, como plantas de desmineralización. Los minerales, sales y contaminantes se retiran del panel evaporativo a través del propio agua mediante las debidas purgas, lo que mantiene la pureza del proceso de humidificación. Como se ha dicho, el agua puede aportarse directamente de la red, o mediante una bomba de circulación del agua recogida en el depósito. Estos dos sistemas de distribución de agua se describen a continuación:

\section{Sistema de distribución de agua corriente}

Cuando se requiere el funcionamiento del equipo, el agua de la red se suministra directamente a los sistemas de distribución a través de válvulas de flujo constante. El exceso de agua que no se evapora limpia el panel antes de descargarse, como ya se ha indicado con anterioridad.

\section{Sistema de distribución de agua de recirculación:}

El funcionamiento particular se corresponde con esta última opción. En este caso, el depósito se llena con agua procedente de la red principal (5) y el nivel del agua se mantiene gracias a la válvula flotador de control (4). Cuando hay una demanda de humidificación, la bomba (10) se pone en funcionamiento y proporciona agua al conjunto de distribución (8), desde donde se envía a la cabecera de distribución de agua. La cabecera de distribución de agua (2) suministra suficiente agua al panel del humidificador. Los distintos elementos pueden identificarse en la figura esquemática VI.29.

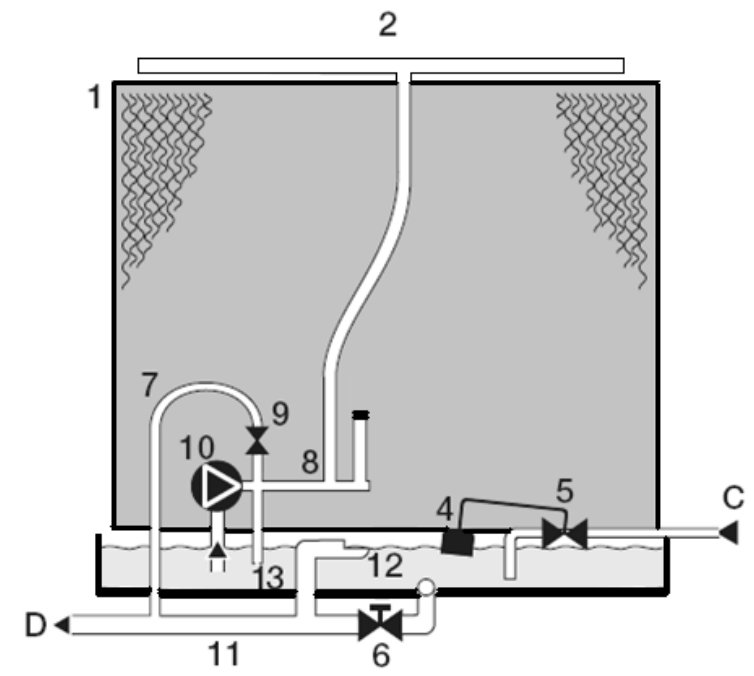
C: Red principal de agua corriente
D: Agua de descarga

Figura VI.29.- Vista esquemática del conjunto de elementos del equipo FA6. 
A continuación, el agua fluye descendiendo a través de la superficie corrugada del panel del humidificador. Parte del agua es absorbida por el relleno rígido y el resto baja hasta la balsa inferior. A medida que el suministro de aire (A) pasa a través del humidificador, una proporción del agua absorbida por el mismo se evapora al entrar en contacto con el aire, produciendo así aire húmedo (B).

Durante el proceso de evaporación, el aire se carga de agua pura. Los minerales y sales quedan en el agua, y por tanto, vuelven al depósito. Como consecuencia, la concentración en el agua del depósito es mayor que en el agua de suministro. Si la concentración de mineral (especialmente el calcio) es muy elevada, puede que se depositen incrustaciones en la superficie del material hasta que finalmente se atasque el humidificador. Para combatir el problema, una proporción del agua debe extraerse del depósito y ser reemplazada con agua nueva. El agua que se drena por la válvula de control de purga continua (9) pasando por la tubería de purga (7) hasta llegar a la tubería de descarga (11) recibe el nombre de caudal de purga continua. La tasa del caudal de purga continua se regula mediante la válvula de control, de manera que la concentración del mineral se mantiene a un nivel aceptable. Antes de que se pueda poner en marcha el humidificador, la tasa de flujo de la purga continua debe calcularse y ajustarse siguiendo las instrucciones [9, Munters].

\section{Instalación experimental.}

El análisis se lleva a cabo en las instalaciones de la Escuela de Ingenierías Industriales de la Universidad de Valladolid, en el laboratorio de Termotecnia del departamento de Ingeniería Energética y Fluidomecánica.

Para caracterizar el equipo se hará uso de la toma de aire exterior disponible en el laboratorio y ya descrita en el capítulo IV, a la que se conecta el equipo FA6 mediante tubo calorifugado flexible. El aire impulsado al sistema se encontrará por lo tanto en las condiciones climatológicas de Valladolid existentes durante los días de ensayo. Del mismo modo se coloca la tubería de salida del aire una vez ha atravesado el equipo, bajo las mismas consideraciones. Debido a la elevada pérdida de carga generada en el relleno rígido, la conexión se realiza dentro del espacio disponible en el laboratorio evitando posibles zonas de pérdidas de carga locales adicionales.

Se instalan las sondas de temperatura y humedad, dos a la entrada y dos a la salida, de modo que nos permita obtener valores medios de dichas propiedades del aire, siempre teniendo en cuenta que las medidas en aquellas sondas que se encuentran justo a la entrada y salida del equipo pueden verse influidas por el sistema, distorsionando la medida.Las medidas obtenidas en Voltios se convierten directamente del equipo de registro de datos al sistema internacional de medida, haciendo uso de las regresiones obtenidas en su calibración.

El caudal máximo de aire aportado al sistema desde la UTA, se calcula haciendo uso de la expresión E-VI.11, para lo cual se debe determinar el valor de la velocidad y el área de paso 
del aire. El valor de la velocidad se obtiene con un anemómetro, promediando el valor medido en diversos puntos de la sección atravesada por el aire.

Se obtiene un valor para la velocidad del aire a su paso por el equipo de $14,3 \mathrm{~m} / \mathrm{s}$. La sección del tubo conector corresponde a $0,053 \mathrm{~m}^{2}$.

$$
\dot{m}_{a s}=c \cdot \mathrm{A}
$$

Aplicando la expresión E-VI.11 se obtiene un caudal de aire de $2728,4 \mathrm{~m}^{3} / \mathrm{h}$.

Se comprueba así que la pérdida de carga media del equipo es elevada, alcanzando entorno a los $160 \mathrm{~Pa}$, de forma que se espera que incluso el caudal efectivo máximo obtenido con esta UTA no sea suficiente para el aire no salga saturado al atravesar el panel.

En la figura VI.30 se muestra una vista de la instalación experimental completa.

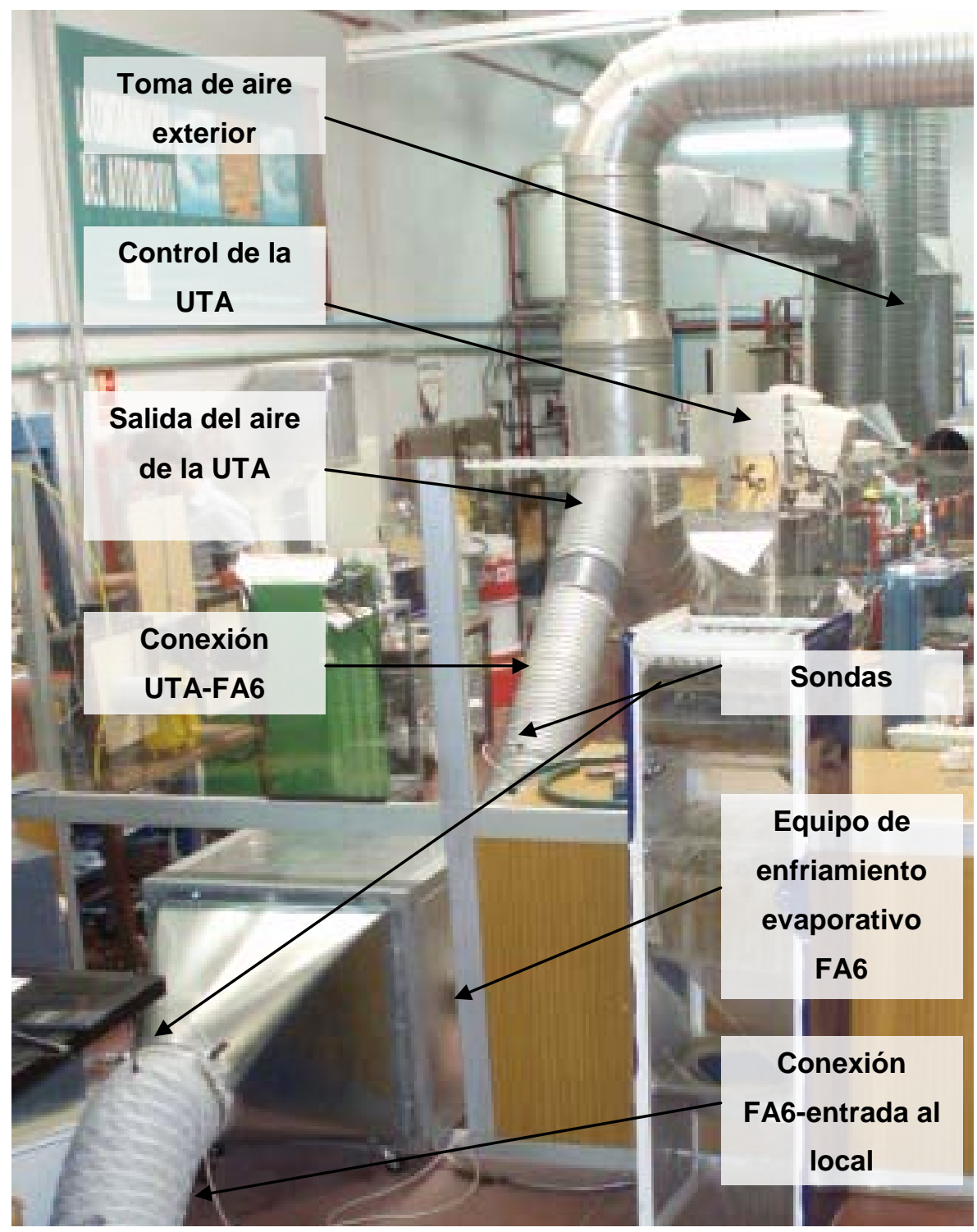

Figura VI.30.- Vista de la instalación experimental del equipo FA6. 


\section{Metodología de ensayos.}

Para la realización de los ensayos que permitan la caracterización del enfriador evaporativo directo de relleno rígido adquirido, se han considerado como factores a establecer: el caudal volumétrico de entrada, la temperatura seca y la humedad relativa de entrada.

Sin embargo, existen una serie de limitaciones en el propio dispositivo experimental que no van a permitir ensayar los rangos deseados de caudal y humedad a la entrada, ya que incluso el máximo caudal proporcionable por el ventilador centrífugo (véase el capítulo IV) se muestra insuficiente para que el sistema opere sin alcanzar en todo caso condiciones de saturación del aire a su salida. Por esta razón, y como se presentará a continuación, los únicos ensayos efectuados en la caracterización de la evolución psicrométrica del aire en el equipo han sido en las condiciones mínimas posibles de humedad relativa (20\%) y máximas de caudal $\left(780 \mathrm{~m}^{3} / \mathrm{h}\right)$, ya que incluso en estas condiciones de máxima desfavorecimiento de la humidificación, la alta eficiencia de humidificación característica del equipo comercial adquirido (95\%) va a suponer siempre saturación del aire a la salida del mismo.

En cuanto al rango ensayado de temperatura seca, se abordan 5 niveles: 25, 30, 35, 40 y $45^{\circ} \mathrm{C}$.

Como se ha indicado en la descripción de la instalación experimental, para realizar la caracterización experimental del sistema, se ha conectado la entrada de aire a éste directamente a la toma de aire exterior del mismo. Se instala por lo tanto en configuración convencional, sin recurrirse a ningún ciclo regenerativo o recuperativo. Las condiciones específicas de temperatura seca y humedad relativa de cada ensayo se corresponderán de esta forma con las particulares de las condiciones climáticas del día de realización.

El ensayo se realiza accionando el ventilador del sistema de toma de aire exterior para que comience a aportar el caudal requerido, aguardando previamente a la toma de medidas para que se alcance un régimen estacionario de funcionamiento. Una vez en régimen, se registran las medidas de temperatura seca y humedad relativa a entrada y salida del equipo enfriador evaporativo directo durante períodos de 1 hora. Las medidas de temperatura y humedad tomadas mediante dos sondas en cada punto de interés son promediadas para la obtención de los valores de las condiciones del aire en dichos puntos.

Para reflejar la repetitividad de los ensayos realizados bajo condiciones únicas de caudal de aire tratado, se han realizado varias tomas de datos durante varios días consecutivos, proporcionándose en el análisis planteado en el apartado siguiente un resumen de los resultados promediados para los diversos ensayos repetidos.

\section{Análisis de resultados.}

Como se adelantaba ya en el planteamiento de los ensayos realizados, para el primer conjunto de éstos, correspondientes precisamente a las condiciones más desfavorables para la 
eficiencia de humidificación (máximo caudal volumétrico y mínima humedad relativa de entrada), los resultados obtenidos mostraron en todos los casos de temperatura seca de entrada que se producía saturación en la corriente de aire de salida. Resultaba por lo tanto falto de interés la consecución del resto de ensayos inicialmente concebidos, que por ser más favorables a la eficiencia de humidificación era ya previsible que se alcanzara saturación. A continuación se van a analizar los resultados obtenidos para este único caudal de ensayo.

Es interesante especialmente comprobar cómo este sistema de simple funcionamiento permite alcanzar importantes saltos térmicos en el aire tratado, como puede verse en la figura VI.31, en la cual se recogen los resultados medios obtenidos en los saltos térmicos para cada temperatura del aire a la entrada ensayada. Como resulta previsible por el propio aumento de la capacidad de admisión de agua evaporada en el seno del aire al aumentarse su temperatura seca ante niveles fijos de humedad específica, estos saltos térmicos obtenidos se incrementan con el aumento de las temperaturas secas ensayadas a la entrada del sistema.

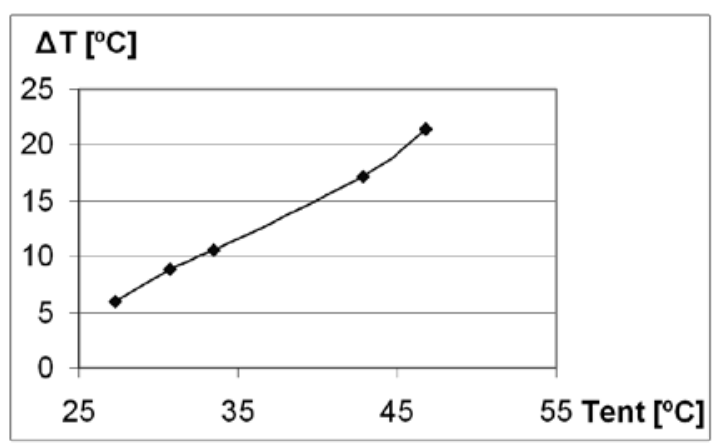

Figura VI.31.- Evolución promedio de los saltos térmicos alcanzados con el equipo FA6 frente a la temperatura de entrada.

Es destacable que, para temperaturas exteriores típicas en verano en una localidad de climatología similar a la de Valladolid durante el período de funcionamiento de los equipos de acondicionamiento de aire, de entorno a $33^{\circ} \mathrm{C}$, el enfriador evaporativo directo estudiado permitiría disminuir esta temperatura seca del aire impulsado hasta los $23{ }^{\circ} \mathrm{C}$. Al corresponderse estos valores de temperatura próximos con los de las condiciones de confort establecidas para el interior de los locales (véase el capítulo II), los consumos energéticos de los sistemas convencionales de acondicionamiento de aire se verían reducidos a lo estrictamente requerido para soportar las cargas internas del local, y no a la adecuación térmica del caudal de ventilación.

Sin embargo, debe estudiarse más detenidamente cómo evoluciona la humedad relativa en el interior del local ante un aporte de aire de ventilación en condiciones previsibles de elevada humedad. De hecho, estudiando la evolución de la humedad relativa en el aire a la salida del sistema, aire a ser impulsado al local, se observan valores muy elevados, en torno al $93 \%$ de valor promedio, registrándose valores mínimo y máximo de 73 \% y $97 \%$ respectivamente. En la figura VI.32 se muestra la evolución del incremento en la HR del aire al 
atravesar el sistema durante la realización de uno de los ensayos. Esta humedad elevada rozando la saturación no permitiría al aire aportado al local compensar las cargas latentes generadas en el mismo e incluso incurriría en mayores requerimientos, precisándose de sistemas adicionales de acondicionamiento que compensaran este efecto.

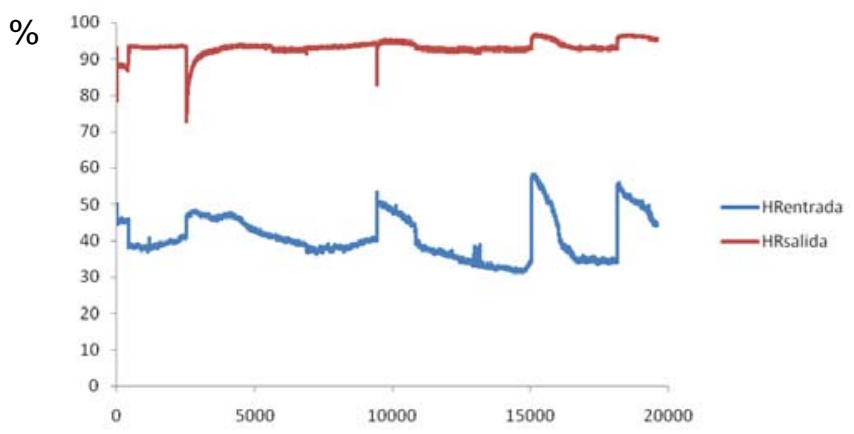

Figura VI.32.- Evolución de la HR del aire a la entrada y a la salida del sistema durante la realización de un ensayo ejemplo.

Al igual que en el caso del sistema de pulverización, y como se extiende a todos los sistemas de enfriamiento evaporativo directos, la eficiencia obtenida en el enfriamiento irá intrínsecamente relacionada con la cantidad de agua evaporada en el seno del aire. Por ello, es de interés analizar el flujo de agua distribuido sobre el relleno rígido que llega a evaporarse a su contacto con el aire circulante.

La masa de agua evaporada en el seno del aire puede obtenerse a partir de la expresión E-VI.3 planteada con anterioridad.

En la figura siguiente VI.33 correspondiente a la evolución de un ensayo ejemplo, se observa que la humedad específica del aire permanece casi constante tanto a la entrada como a la salida siguiendo en ambos casos la misma evolución, por tanto la masa de agua evaporada será la misma independientemente de las condiciones de temperatura seca a la entrada del aire al equipo. Esto es precisamente debido a que la humedad relativa, que es el parámetro determinante de la capacidad del aire de admisión de vapor de agua adicional, es mantenida entorno al 20\% para todos los ensayos.

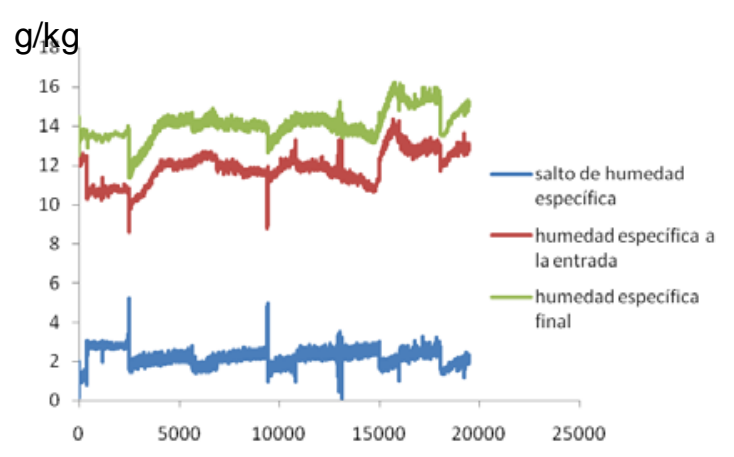

Figura VI.33.- Evolución de la humedad específica del aire a la entrada y a la salida del sistema durante la realización de un ensayo ejemplo. 
Planteando el promedio de los datos recogidos experimentalmente, el flujo de agua evaporada alcanza un valor promedio de $16 \mathrm{~kg} / \mathrm{h}$.

Según datos del fabricante para el equipo en cuestión el consumo total de agua directa es de 3,5 I/min [9, Munters]. Este consumo total comprende tanto la cantidad de agua evaporada como la purga continua, correspondiéndose este último con el flujo de descarga constante que es necesario para mantener la concentración de minerales en la balsa a un nivel óptimo para asegurar la máxima vida útil del relleno.

Para esbozar una idea de cómo de eficiente resulta ser este sistema como equipo de acondicionamiento del ambiente en base a las condiciones particulares de los ensayos puntuales realizados para su caracterización, es preciso atender al COP obtenido. Como ya se definió, este parámetro relaciona el enfriamiento alcanzado con la energía requerida para la operación del sistema. Por otro lado, por tratarse de un sistema de funcionamiento basado en el fenómeno de enfriamiento evaporativo de principios ya introducidos, al igual que en el caso del micronizador de agua el potencial de enfriamiento se encuentra directamente ligado a la cantidad de agua evaporada en el aire. En este caso, la energía eléctrica consumida se corresponde con la de la bomba de recirculación del agua y el incremento en el consumo del ventilador de impulsión debido a la instalación del equipo de relleno rígido en la impulsión de aire de renovación. Por los datos proporcionados por el fabricante, la bomba de recirculación tiene una potencia de $57 \mathrm{~W}$, mientras que el sistema adquirido genera una pérdida de carga de $160 \mathrm{~Pa}$ en la corriente de impulsión, correspondiente a un caudal de $780 \mathrm{~m}^{3} / \mathrm{h}$ en todos los ensayos realizados [9, Munters]. Según la ecuación E-VI.12, el incremento del consumo en el ventilador en términos de potencia será por lo tanto de 34,67 W.

$$
\Delta \dot{W}=\dot{M}_{\text {aire }} \times \Delta P
$$

El COP medio obtenido por la ecuación VI.3 para este sistema operando en las condiciones de los ensayos particulares realizados es de 121.

Los altos saltos térmicos logrados y las condiciones de saturación registradas para el máximo caudal de ensayo demuestran que este sistema se trata de un equipo de alta potencia de enfriamiento, excesiva para las condiciones de trabajo de nuestro caso particular, en las que el caudal de aire a tratar no es suficientemente grande respecto al especificado por el fabricante. Debe tenerse presente que este tipo de sistemas se comercializan para grandes instalaciones de acondicionamiento de aire en industrias ganaderas, aplicaciones en la cuales además no importa que se alcancen excesivas humedades relativas a la salida.

En el análisis de la eficiencia del sistema, se muestra también interesante el estudio de su eficacia de humidificación, al ser esto la clave del potencial de enfriamiento del equipo. La eficacia de humidificación se define como la relación entre la diferencia de humedades generada y la máxima que podría obtenerse de alcanzarse saturación (ecuación E-VI.10), 
suponiendo que el proceso seguido es puramente adiabático, lo que por otro lado resulta bastante acertado como queda demostrado en el apartado siguiente.

En la caracterización del funcionamiento del equipo FA6 de relleno rígido se partió para todos los ensayos de condiciones de humedad relativa del aire a la entrada del sistema del $20 \%$, ya que en todo caso se alcanzaba saturación, incluso tomándose estas mínimas condiciones de humedad a la entrada y trabajándose con el máximo caudal de aire suministrable por la UTA de mayor tamaño del laboratorio, debido precisamente a la insuficiencia de dicho caudal respecto a los de diseño indicados por el fabricante. Por este hecho de alcanzarse saturación en todos los ensayos, no es posible determinar la eficacia de humidificación que puede alcanzar este equipo en circunstancias reales de operación con caudales mayores. Sin embargo, es esperable que sea alta, por los resultados obtenidos y si nos guiamos por las especificaciones del fabricante, el cual indica para el modelo en particular eficacias de humidificación del $95 \%$ para caudales de aire de $0,9 \mathrm{~m}^{3} / \mathrm{s}\left(3240 \mathrm{~m}^{3} / \mathrm{h}\right)[9$, Munters].

\section{Evolución psicrométrica del aire tratado}

Un estudio interesante sobre el funcionamiento de los enfriadores evaporativos directos, es el análisis de la pureza de la evolución adiabática seguida en el proceso psicrométrico sufrido por el aire. Como se vio en el capítulo III en la descripción del proceso del enfriamiento evaporativo, en la evaporación del agua en el seno del aire se produce una transformación de calor sensible en calor latente, de forma que idealmente el aire evoluciona hacia unas condiciones psicrométricas de menor temperatura seca pero mayor humedad específica, y por lo tanto manteniendo su entalpía constante en todo momento.

En el caso experimental práctico de refrescamiento de un espacio exterior mediante el sistema de micronización de agua, la disposición discreta de las boquillas y de las sondas de medida no permite registrar unos valores reales de las condiciones del aire iniciales, tomadas con el equipo fuera de funcionamiento, y alcanzadas gracias al mismo. Por lo tanto, en ese caso no resultaba posible estudiar la evolución psicrométrica real seguida de forma fiable a partir de los datos disponibles.

Sin embargo, mediante los datos experimentales medios de un ensayo tipo realizado sobre el sistema directo de relleno rígido sí es posible plantear de forma sencilla el estudio de cómo de leal se muestra a la evolución adiabática la variación en las condiciones psicrométricas del aire tratado por el sistema. Estos resultados podrán extenderse de forma aproximada a los sistemas directos de este tipo.

En la figura VI.34 se muestra la evolución seguida por las condiciones del aire en el diagrama psicrométrico para uno de los ensayos realizados en particular, mientras que los valores numéricos se recogen en la tabla VI.7. Como se observa en esta tabla, la temperatura de bulbo húmedo coincide en los dos puntos inicial y final de la evolución, registrándose un salto térmico medio de $7^{\circ} \mathrm{C}$ con un aumento de $2,9 \%$ de humedad relativa. Esto explica el 
hecho de que el valor de la entalpía permanezca casi constante, debiéndose la pequeña diferencia observada a la carga térmica introducida por la bomba de alimentación al agua, produciéndose un calentamiento del fluido que se traduce en un ligero desviamiento de la evolución puramente adiabática.

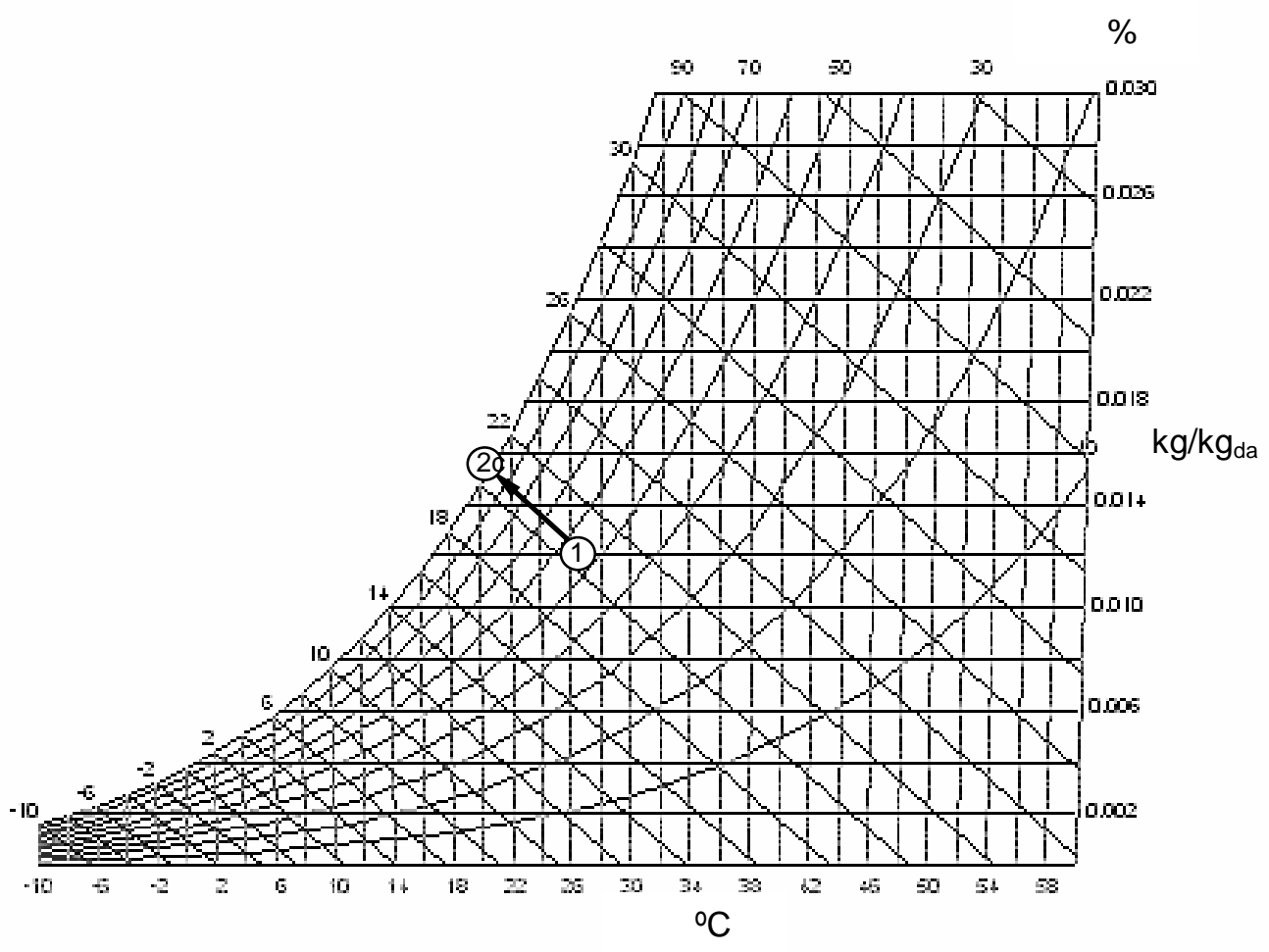

Figura VI.34.- Representación en el diagrama psicrométrico de la evolución del aire en el equipo FA6.

Tabla VI.7.- Valores de la evolución psicrométrica del aire tratado en el FA6.

\begin{tabular}{|c|c|c|c|c|c|c|c|c|c|}
\hline Punto & $\begin{array}{c}\text { Ts } \\
\left({ }^{\circ} \mathrm{C}\right)\end{array}$ & \multicolumn{1}{|c|}{$\mathrm{HR}(\%)$} & $\mathrm{X}(\mathrm{g} / \mathrm{kg})$ & $\mathrm{Tbh}\left({ }^{\circ} \mathrm{C}\right)$ & $\begin{array}{c}\mathrm{h} \\
(\mathrm{kJ} / \mathrm{kg})\end{array}$ & $\mathrm{Pv}(\mathrm{Pa})$ & $\begin{array}{c}\rho \\
\left(\mathrm{kg} / \mathrm{m}^{3}\right)\end{array}$ & $\mathrm{Ve}\left(\mathrm{m}^{3} / \mathrm{kg}\right)$ & $\begin{array}{c}\mathrm{Q} \\
\left(\mathrm{m}^{3} / \mathrm{h}\right)\end{array}$ \\
\hline 1 & 26,6 & 53,15 & 12,69 & 19,53 & 58,95 & 1852 & 1,0549 & 0,948 & 2728 \\
\hline 2 & 19,63 & 99,12 & 15,6 & 19,53 & 59,19 & 2266 & 1,0751 & 0,9302 & 2677 \\
\hline
\end{tabular}

De estos resultados puede extraerse que el comportamiento del sistema se aproxima fielmente a la evolución adiabática ideal del proceso de enfriamiento evaporativo. 


\section{VI.4. COMPARACIÓN ENTRE LOS DOS SISTEMAS DE EED}

Como se viene planteando a lo largo de todo el capítulo, en los sistemas directos el enfriamiento logrado en la corriente de aire tratada está intrínsecamente relacionado con la cantidad de agua que se evapora en el mismo, por los propios principios del fenómeno del enfriamiento evaporativo. Por lo tanto, el primer punto en la comparativa de dos sistemas de enfriamiento evaporativo directo basados en diferentes mecanismos de favorecer la evaporación del agua en la corriente de aire radica en la propia eficacia de humidificación.

Se ha visto que el micronizador de agua proporciona elevadas eficacias de humidificación, dependientes no obstante de la configuración de la instalación, como demostraba por ejemplo la preferencia de la disposición de las boquillas para pulverización horizontal frente a perpendicular al suelo, por la penetración del dardo de agua pulverizada. La elevada cantidad de agua que se consigue evaporar con este sistema junto con el mínimo consumo energético precisado para su funcionamiento resulta en interesantes COPs, de cerca de 60 en los casos más favorables.

Por otro lado, se ha comentado que el sistema de relleno rígido se comercializa para aplicaciones con exigencias de enfriamiento mucho más elevadas que las ensayadas. Esto queda reflejado en la altísima eficacia de humidificación que presenta, alcanzándose saturación en el aire tratado incluso para los máximos caudales ensayados. Esto, junto con el también en este caso reducido consumo energético requerido para su funcionamiento, resulta en importantes COPs, llegando en valor medio a duplicar los máximos obtenidos para el sistema de micronización en el caso óptimo.

Asimismo, el dispositivo de relleno rígido resulta más interesante en términos de seguridad frente a posibles contaminaciones bacteriológicas como la legionela, ya que además de disponer el relleno del sistema de tratamiento antibacteriológico, por realizarse en él la evaporación del agua desde superficie húmeda y actuar parte del relleno como separador de gotas, se minimiza el riesgo de generación de aerosoles que puedan actuar como portadores de bacterias. Esto último en el caso del sistema de micronización es inevitable, si no se puede asegurar que toda el agua pulverizada se evapora íntegra y rápidamente en el seno del aire.

Sin embargo, y aún considerando las ventajas del sistema de relleno rígido, debe tenerse presente que incluso siendo el equipo más pequeño de la gama comercializada, se encuentra diseñado para proporcionar potencias de enfriamiento mucho mayores que las que podrían requerirse en las aplicaciones abordadas en el presente estudio. Por lo tanto, no sería factible su instalación simple para el acondicionamiento de los ambientes estudiados, puesto que en todo caso se alcanzaría saturación, condiciones no admisibles para el confort térmico y salubridad en los espacios. Para ello, debería considerarse la instalación de equipos con menores superficies de intercambio, o conectar el equipo en paralelo a una impulsión directa 
de una corriente de aire de ventilación que sea mezclada con el aire tratado para reducir el nivel de humedad relativa de la corriente de aire.

Finalmente, la elevada pérdida de carga generada por el sistema de relleno rígido y las particularidades que limitan su instalación, hacen que este sistema sea de instalación preferible en espacios cerrados, mientras que el sistema de micronización se adecua especialmente al acondicionamiento de espacios exteriores, donde además la evaporación de los aerosoles generados es más segura. 


\section{REFERENCIAS}

[1] Rey Martínez, F.J.; Velasco Gómez, E.; Álvarez Guerra, M.; Molina Leyva, M.; "Refrigeración Evaporativa". Suplemento de la revista El Instalador, n³60, enero 2000.

[2] El-Refaie, M.F.; Kaseb, S. "Speculation in the feasibility of evaporative cooling". Revista: Building and Environment, № 44 (pp.: 826-838). 2009.

[3] ASHRAE, "Systems and Equipment. Chapter 19: Evaporative air cooling equipment". Handbook. 19.1-19.8. 2000.

[4] Puckorious, P.R.; Thomas, P.T.; Augspurger, R.L. "Why evaporative coolers have not caused Legionnaires' disease”. Revista: ASHRAE Journal, (pp.: 29-33). Enero, 1995.

[5] Rey Martínez, F.J.; Velasco Gómez, E.; Tejero González, A.; Gobernado Arribas, I. "Caracterización de un sistema de enfriamiento evaporativo utilizando una superficie húmeda textil". Comunicaciones del CYTEF-2009 V Congreso Ibérico y III Congreso Iberoamericano de Ciencias y Técnicas del Frío. Castellón, España, 2009.

[6] Velasco Gómez, E.; Rey Martínez, F.J.; Tejero González, A. “Experimental characterisation of the operation and comparative study of two semi-indirect evaporative systems." Revista: Applied Thermal Engineering, No 30 (pp. 1447-1454). 2010.

[7] Cuaderno técnico de instalación, sistema Mist\&Fog, Termigo Microclimas.

[8] Velasco Gómez, E.; Rey Martínez, F.J.; Villafruela Díez, M.; Tejero González, A. "Characterization of a misting system for applications of evaporative cooling in air-conditioning". Comunicaciones del congreso: I European Conference on Energy Efficiency and Sustainability in Architecture and Planning. San Sebastián, España. 2010.

[9] Catálogo del equipo humidificador/ enfriador FA6TM, de la empresa Munters.

\section{Normativa}

[N-1] Real Decreto 865/2003, de 4 de julio, por el que se establecen los criterios higiénicosanitarios para la prevención y control de la legionelosis. 2003

[N-2] Ministerio de Industria, Turismo y Comercio y Ministerio de Vivienda de España, "Real Decreto 1027/2007: Reglamento de Instalaciones Térmicas en Edificios".

[N-3] UNE-EN ISO 1182:2011 Ensayos de reacción al fuego de productos. Ensayo de no combustibilidad. (ISO 1182:2010). 


\section{RELACIÓN DE FiguRAS}

- Figura VI.1.- Sistemas de pulverización de agua operando para refrescamiento de una calle en Mérida.

- Figura VI.2.- Sistemas de pulverización de agua instalados en los adoquines de una plaza para refrescamiento en Sevilla.

- Figura VI.3.- Sistemas de pulverización de agua con ventiladores, para refrescamiento de una terraza en Toledo

- Figura VI.4.- Sistemas de pulverización de agua para refrescamiento de una terraza en el RTE de Madrid.

- Figura VI.5.a.- Boquilla para pulverización de agua en espacios exteriores urbanos.

- Figura VI.5.b.- Boquilla instalada en el adoquinado.

- Figura VI.5.c.- Boquilla para pulverización de agua en terrazas.

- Figura VI.6.- Torres de tiro invertido con pulverizadores interiores para acondicionamiento del aire exterior en la Expo Sevilla 92.

- Figura VI.7.- Pérgola provista de pulverizadores para refrescamiento de una zona de gran afluencia de personas en la Expo Zaragoza 2008.

- Figura VI.8.- Ejemplos de aplicación de la pulverización de agua con utilidad paisajística.

- Figura VI.9.- Vista exterior de la bomba y detalle del interior

- Figura VI.10.- Detalle de una boquilla de 0,3 mm.

- Figura VI.11.a.- Esquema de la configuración en suelo para paisajismo.

- Figura VI.11.b.- Esquema de la configuración en línea para refrescamiento de espacios.

- Figura VI.12.- Esquema e imagen de la instalación y medida de flujos másicos de agua

- Figura VI.13.- Correlación flujo másico de agua-presión.

- Figura VI.14.- Correlación COP- presión.

- Figura VI.15.- Vista de la instalación para ensayo del refrescamiento de espacios exteriores.

- Figura VI.16.- Evolución temporal de la temperatura seca durante el día de muestreo previo frente a la evolución durante el de ensayo del sistema.

- Figura VI.17.- Evolución temporal de la humedad relativa durante el día de muestreo previo frente a la evolución durante el de ensayo del sistema.

- Figura VI.18.- Instalación experimental para la caracterización del funcionamiento del sistema de micronización en el acondicionamiento de un espacio interior.

- Figura VI.19.a- Orientación de las boquillas en paralelo al suelo.

- Figura VI.19.b- Orientación de las boquillas en perpendicular al suelo.

- Figura VI.20.- Comparación del flujo másico de agua evaporado para el ensayo número 4.

- Figura VI.21.- Comparación del flujo másico de agua evaporado para el ensayo número 2.

- Figura VI.22.- Comparación flujo másico para el ensayo número 6.

- Figura VI.23.- Flujo másico de agua evaporada en las dos posiciones de las boquillas posibles (ensayos 5 y 6 ). 
- Figura VI.24.- Salto térmico alcanzado en las dos posiciones de las boquillas posibles (ensayos 5 y 6 ).

- Figura VI.25.a.- Relleno rígido inorgánico GLASdek.

- Figura VI.25.b.- Detalle del relleno durante el funcionamiento del equipo.

- Figura VI.26.- Bomba de circulación del equipo FA6.

- Figura VI.27.- Vista superior del equipo: sistema de distribución.

- Figura VI.28.- Esquema del funcionamiento del equipo FA6.

- Figura VI.29.- Vista esquemática del conjunto de elementos del equipo FA6.

- Figura VI.30.- Vista de la instalación experimental del equipo FA6.

- Figura VI.31.- Evolución promedio de los saltos térmicos alcanzados con el equipo FA6 frente a la temperatura de entrada.

- Figura VI.32.- Evolución de la HR del aire a la entrada y a la salida del sistema durante la realización de un ensayo ejemplo.

- Figura VI.33.- Evolución de la humedad específica del aire a la entrada y a la salida del sistema durante la realización de un ensayo ejemplo.

- Figura VI.34.- Representación en el diagrama psicrométrico de la evolución del aire en el equipo FA6.

\section{RELACIÓN DE TABLAS}

- Tabla VI.1.- Información técnica de dimensiones y flujos

- Tabla VI.2.- Ensayos realizados con el sistema micronizador de agua

- Tabla VI.3.- Comparación entre flujos másicos experimentales y teóricos a 70 bar.

- Tabla VI.4.- Valores medios del flujo másico

- Tabla VI.5.- Ensayos realizados con el sistema de micronización para adecuación de un espacio interior.

- Tabla VI.6.- Eficacias de humidificación medias obtenidas en los distintos ensayos realizados para el micronizador de agua en un espacio cerrado

- Tabla VI.7.- Valores de la evolución psicrométrica del aire tratado en el FA6. 


\section{CAPÍTULO VII \\ CARACTERIZACIÓN DEL SISTEMA DE ENFRIAMIENTO GRATUITO POR AGUA}

ABSTRACT

VII.1. INTRODUCCIÓN 251

VII.2. DESCRIPCIÓN DEL SISTEMA DE TORRE CON BATERÍA. 251

DISEÑO Y CONSTRUCCIÓN DEL SISTEMA. 252

VII.3. INSTALACIÓN EXPERIMENTAL. 254

CONFIGURACIÓN RECUPERATIVA 254

CONFIGURACIÓN CONVENCIONAL 255

Diseño de EXPERIMENTOS. METOdología de ENSAYOS. 256

VII.4. ANÁLISIS DE RESULTADOS. 258

PARÁMETROS CONSIDERADOS EN LA CARACTERIZACIÓN EXPERIMENTAL .............................2 258

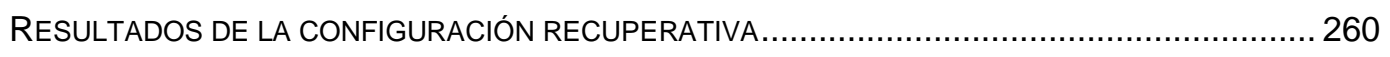

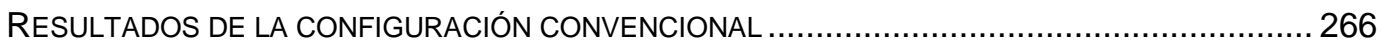

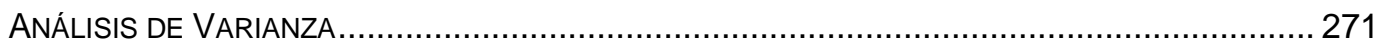

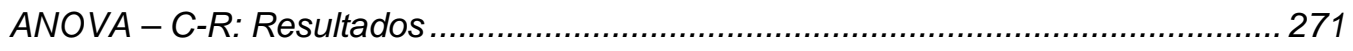

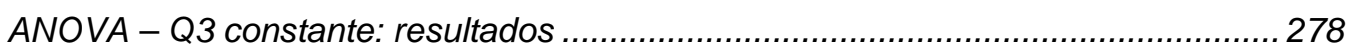




\section{CHAPTER VII: \\ CHARACTERIZATION OF THE FREE- COOLING BY WATER SYSTEM}

\section{ABSTRACT}

Chapter VII describes the manufacturing and experimental characterization of a system consisting of a cooling tower and a coil, whose design permits its operation either as a traditional free-cooling by water system or implemented into a heat-recovery cycle, depending on its connection possibilities. These two operation modes are called "conventional-mode" and "recovery-mode".

A Design of Experiments is developed to determine the operating conditions for the experimental tests. These factors varied for both configurations are: volume flow and temperature of air supplied to the coil, and water flow through it. However, a simplification is introduced in the second operation mode by omitting the factor "water flow supplied", thanks to some initial results that permit predicting its low importance. The parameters studied from the results for these different conditions performed are the same as the ones proposed in chapter $V$ for the indirect evaporative coolers: temperature drop, thermal effectiveness and wet-bulb thermal effectiveness; cooling capacity and thermal conductance.

Results permit comparing both operation modes, as well as the influence of the remaining factors: air dry bulb temperature and volume flow. The acceptability of the simplification on the factor "water flow supplied" is checked in an Analysis of Variance proposed to determine the factors' relative weight on obtained results for the parameters studied. 


\section{SimBología deL CAPÍTULO}

ETa: Entrada de aire a la torre.

STa: Salida de aire de la torre.

ETw: Entrada de agua a la torre.

STw: Salida de agua de la torre.

EBw: Entrada de agua a la batería.

SBw: Salida de agua de la batería.

Tw: Temperatura del agua en el depósito.

EBa: Entrada de aire a la batería.

SBa: Salida de aire de la batería.

Q: caudal de agua aportado a la torre [I/min]

$\dot{V}: \quad$ caudal volumétrico de aire $\left[\mathrm{m}^{3} / \mathrm{h}\right]$

m : $\quad$ Flujo másico de aire seco [ $\left.\mathrm{kg}_{\mathrm{as}} / \mathrm{s}\right]$

$X_{i}$ : humedad específica en el punto i del sistema $[\mathrm{g} / \mathrm{kg}]$

$T_{i}$ : Temperatura de bulbo seco del aire en el punto i del sistema $\left[{ }^{\circ} \mathrm{C}\right.$ ]

$\Delta T$ : salto térmico de temperaturas alcanzado en la corriente de aire de ventilación (batería) [ $\left.{ }^{\circ} \mathrm{C}\right]$

$\varepsilon_{T}$ : Efectividad térmica.

$\varepsilon_{T B H}$ : Efectividad térmica de Bulbo Húmedo.

$T_{B H i}: \quad$ Temperatura de bulbo húmedo del aire en el punto i del sistema $\left[{ }^{\circ} \mathrm{C}\right]$

$\Delta T_{L M}:$ Diferencia Media Logarítmica de Temperaturas [K]

$E_{C c}:$ Capacidad de enfriamiento [W]

$h_{E B a:}$ entalpía del aire de ventilación a la entrada de la batería $\left[\mathrm{kJ} / \mathrm{kg}_{\text {as }}\right]$

$h_{S B a}$ : entalpía del aire de ventilación a la salida de la batería $\left[\mathrm{kJ} / \mathrm{kg}_{\text {as }}\right]$

$C p_{a}$ : Calor específico del aire a presión constante [kJ/kgC]

U: Coeficiente Global de Transmisión de Calor $\left[\mathrm{W} / \mathrm{m}^{2} \mathrm{~K}\right]$

A: Área $\left[\mathrm{m}^{2}\right]$ 
SS $S_{c}$ Porcentaje de contribución de la suma de cuadrados del factor "configuración" [\%]

$S_{Q}$ : Porcentaje de contribución de la suma de cuadrados del factor "caudal de agua aportado a la torre" [\%]

$S_{\text {V: }}$ Porcentaje de contribución de la suma de cuadrados del factor "flujo de aire de ventilación" [\%]

$\mathrm{SS}_{T}$ : Porcentaje de contribución de la suma de cuadrados del factor "temperatura seca exterior" [\%]

SS $_{\text {Error: }}$ Porcentaje de contribución de la suma de cuadrados del error restante de las contribuciones de los factores [\%]

$\mathrm{SS}_{\mathrm{CV}}$ : Porcentaje de contribución de la suma de cuadrados de la interacción configuración flujo de aire [\%]

$\mathrm{SS}_{C T}$ : Porcentaje de contribución de la suma de cuadrados de la interacción configuracióntemperatura [\%]

$\mathrm{SS}_{V T}$ : Porcentaje de contribución de la suma de cuadrados de la interacción flujo de airetemperatura [\%]

$S_{Q}$ : Porcentaje de contribución de la suma de cuadrados de la interacción caudal de aguaflujo de aire [\%]

$\mathrm{SS}_{Q T}$ : Porcentaje de contribución de la suma de cuadrados de la interacción caudal de aguatemperatura[\%]

SS $S_{\text {Error: }}$ Porcentaje de contribución de la suma de cuadrados del error restante de las contribuciones de los factores y sus interacciones [\%] 


\section{VII.1. INTRODUCCIÓN}

El enfriamiento gratuito se muestra como una alternativa de ahorro energético de gran potencial, ya que permite acondicionar térmicamente los locales asegurando simultáneamente la calidad del aire interior, con un mínimo consumo de energía, limitado a los sistemas de circulación de fluidos [1, Ghiaus\&Allard, 2006]. Esta solución es especialmente interesante como sustitución en época estival de la recuperación de energía, sobre todo durante las horas nocturnas [2, Adnot, 2003], [3, IEA, 2000], [4, Hughes et al., 2010].

Como se ha presentado en el capítulo III de este trabajo de tesis doctoral, el enfriamiento gratuito puede realizarse en su forma más simple, por aire exterior; o por agua, recurriendo a una torre de enfriamiento aprovechando las características del aire exterior cuando estas sean adecuadas para enfriar el agua, que después mediante una batería permita acondicionar el aire exterior impulsado [5, ATECYR, 2010]. En este trabajo se aborda el análisis de un sistema compuesto por una torre de enfriamiento y una batería, destinado a trabajar según esta segunda opción.

Asimismo, existe la posibilidad de optimizar la eficiencia energética del proceso, recurriendo al aprovechamiento del potencial de enfriamiento residual de la corriente de aire expulsado por requerimientos de ventilación, combinando este proceso con el planteado de enfriamiento gratuito por agua. En este caso, se alcanzarían ahorros energéticos aditivos correspondientes a los dos procesos [2, Adnot, 2003].

A continuación se describe el sistema diseñado y construido en el laboratorio de Termotecnia de la Universidad de Valladolid de free-cooling por agua.

\section{VII.2. DESCRIPCIÓN DEL SISTEMA DE TORRE CON BATERÍA.}

El sistema de enfriamiento gratuito por agua consta de una torre de enfriamiento y de una batería por la cual circula el agua previamente enfriada en la primera. El agua procedente de la torre puede ser idealmente enfriada hasta la temperatura de bulbo húmedo del aire exterior que atraviesa la torre, y en las condiciones alcanzadas se lleva a una batería que permita enfriar la corriente de aire utilizada para acondicionar los locales.

Como se veía en la figura III.22 del capítulo III, el sistema permitirá alcanzar las condiciones requeridas en la corriente de aire de impulsión cuando las condiciones psicrométricas del aire exterior se encuentren dentro de un cierto rango. En el resto de condiciones, el sistema sólo permitirá preacondicionar la corriente de aire seguidamente enviada a una batería convencional de enfriamiento mecánico. Por ello, para que en todo caso puedan asegurarse condiciones de confort en el ambiente controlado, será necesario instalar el sistema junto con un sistema de apoyo, además de los requeridos conductos y compuertas que 
permitan regular los pasos de los distintos flujos de aire, y dispuesto el conjunto según se ha mostrado previamente en la figura III.21.

\section{Diseño y construcción del sistema.}

Se diseña y construye una torre de enfriamiento (figura VII.1) y una batería de agua (figuras VII.2 y VII.3).

La torre de enfriamiento se construye en chapa metálica recubierta con pintura hidrófuga y relleno de policarbonato. Dispone de un depósito de agua en el que se recoge el agua enfriada en ella para su canalización hacia la batería, y en el cual existe un visor del nivel de agua almacenado. La entrada del aire exterior a la torre se realiza a través del mismo depósito de agua, por lo que se practica en éste un orificio preparado para la conexión del tubo flexible disponible en el laboratorio. Asimismo, dispone de un circuito de agua accionado por una bomba hidráulica, que recircula el agua del depósito hacia la torre, regulado el flujo mediante válvula de compuerta y medido utilizando un caudalímetro.

A la salida de la corriente de aire se dispone de un sistema de separación de gotas para evitar pérdidas de agua innecesarias y salida de aerosoles al ambiente.

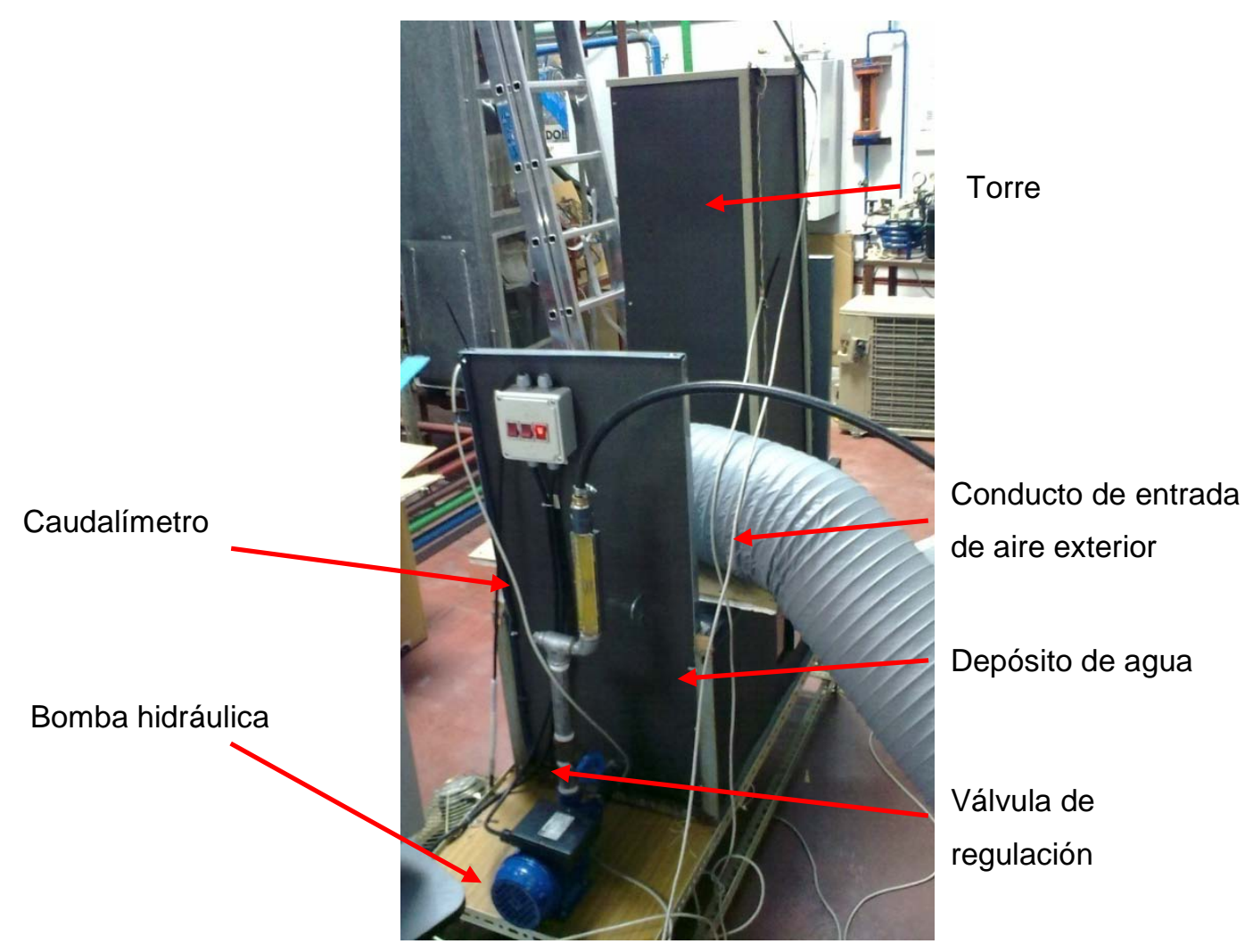

Figura VII.1.- Vista de la torre de enfriamiento. 


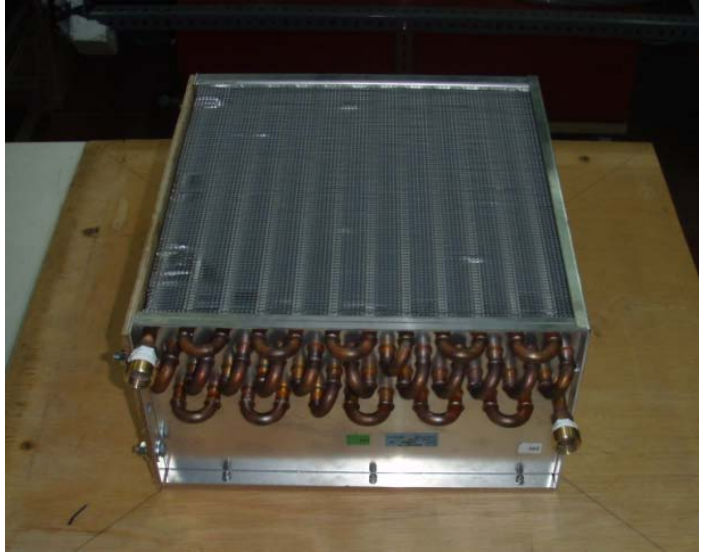

Figura VII.2. - Vista de la batería adquirida.

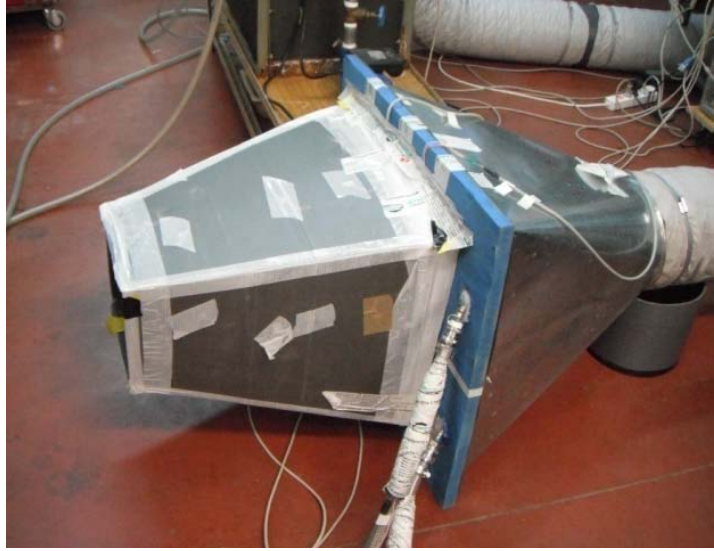

Figura VII.3.- Vista de la batería montada en el sistema.

La batería empleada fue adquirida como batería para recuperación de energía en sistemas aire-aire, con tubería de cobre y aleta de aluminio, modelo AT-48N y disposición al tresbolillo, 25 22, con aleta de alta efectividad; tubo de 3/8“; separación entre aletas de 3,2 mm y conexiones a 1/2". Esta batería (figura VII.2) se instaló sobre una placa a la cual se ajustan los colectores que soportan los conductos de aire (figura VII.3) [W-1].

En la figura VII.4 se muestra una vista superior de la torre y la batería dentro de la instalación global descrita en el apartado siguiente.

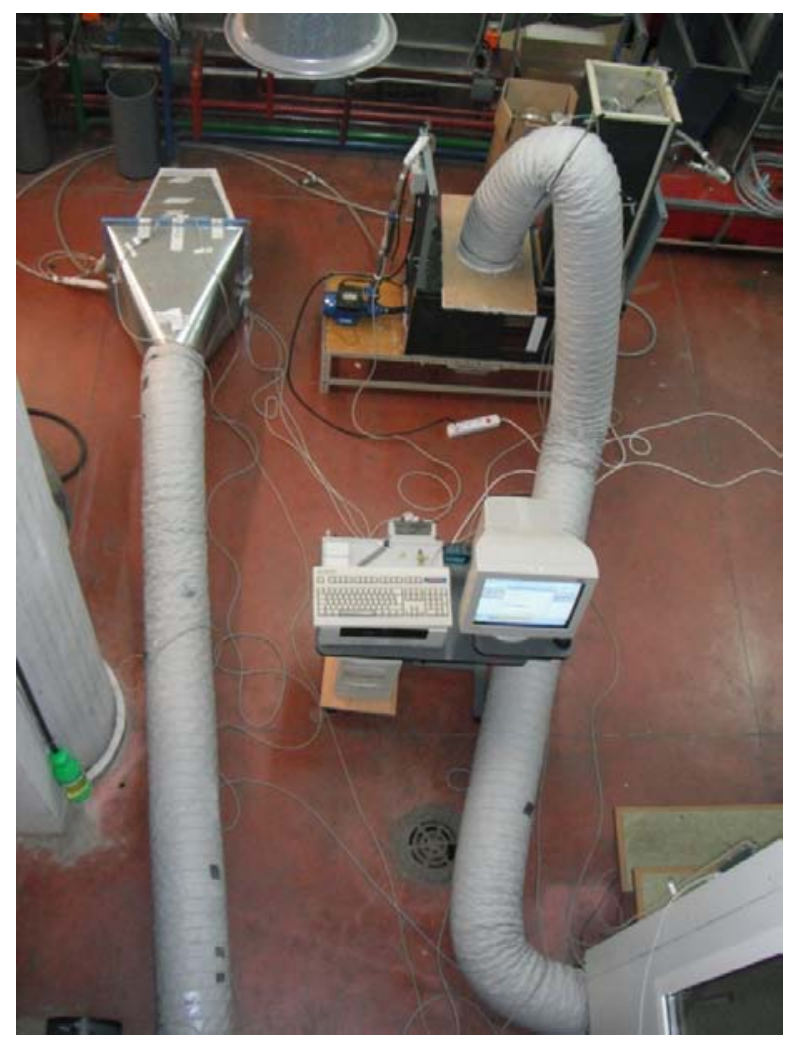

Figura VII.4.- Vista superior de la instalación de torre con batería. 


\section{VII.3. INSTALACIÓN EXPERIMENTAL.}

Para la caracterización del sistema, se dispone de la instalación experimental existente en el laboratorio y ya descrita con anterioridad en el capítulo IV de esta tesis. La UTA permite proporcionar los flujos de aire requeridos en las condiciones ambientales del aire exterior que se desean ensayar, mientras que el interior de la cámara climática se adecua hasta condiciones de confort mediante una bomba de calor para permitir la recirculación del aire hacia la torre en la configuración recuperativa. Asimismo se dispone de los necesarios sistemas de medida de caudales, temperatura y humedad relativa, y de los equipos de adquisición de datos requeridos para su monitorización y registro, todos ellos ya presentados en el capítulo IV. En las corrientes de aire, tanto la temperatura seca como la humedad relativa son medidas para poder proporcionar información completa sobre las condiciones psicrométricas, considerando que los ensayos están realizados en Valladolid (a $715 \mathrm{~m}$ sobre el nivel del mar); mientras que en el circuito de agua sólo se mide la temperatura de ésta. Sin embargo, ha de tenerse presente que el aire al atravesar la batería no verá modificado su nivel de humedad específica.

El circuito de agua, además de conectar el depósito de la torre con la batería para permitir la circulación del agua enfriada por los tubos aleteados en los cuales se realiza el intercambio de calor sensible con la corriente de aire de ventilación, permite también la recirculación de agua conduciéndola desde la salida de la batería hasta la torre de enfriamiento.

Como se verá en el diseño de experimentos planteado sobre el sistema en estudio, su caracterización se plantea en dos configuraciones en función de la procedencia del aire utilizado para el enfriamiento del agua en la torre en el conjunto de la instalación: en configuración recuperativa (el aire procede del espacio climatizado) y en configuración convencional (aire procedente del exterior).

\section{Configuración recuperativa}

Los primeros ensayos del sistema se realizaron en configuración recuperativa. En este caso, el sistema no puede considerarse como de enfriamiento gratuito puro: el hecho de optimizar el proceso introduciendo un aprovechamiento de la energía residual del aire viciado que es expulsado al exterior en condiciones de confort confiere al sistema el carácter de recuperación de energía. En la figura VII.5 se muestra un esquema de la conexión de los diversos elementos en esta configuración.

En este caso, el aire que circula por la torre de enfriamiento (ETa) proviene del interior del espacio acondicionado térmicamente, por lo que sus condiciones psicrométricas son más favorables para potenciar el efecto de enfriamiento del agua generado en la torre. El aire a la salida de la torre (STa) es expulsado al ambiente, aunque cabría la posibilidad de reconducirlo hacia la unidad exterior de la bomba de calor de la cámara climática, para aprovechar su bajo nivel térmico en el enfriamiento de dicha unidad actuando como condensadora. 
Por su parte, el aire proporcionado por la UTA en las condiciones del ambiente exterior particulares para cada ensayo es canalizado hacia la batería (EBa) para ser preenfriado antes de aportarse (SBa) al espacio acondicionado.

Nótese que la temperatura del agua a la entrada a la batería (EBw) coincidirá teóricamente con aquélla a la salida de la torre (STw), mientras que la temperatura del agua a la entrada a la torre (ETw) puede considerarse que será la misma que tenía a la salida de la batería (SBw).

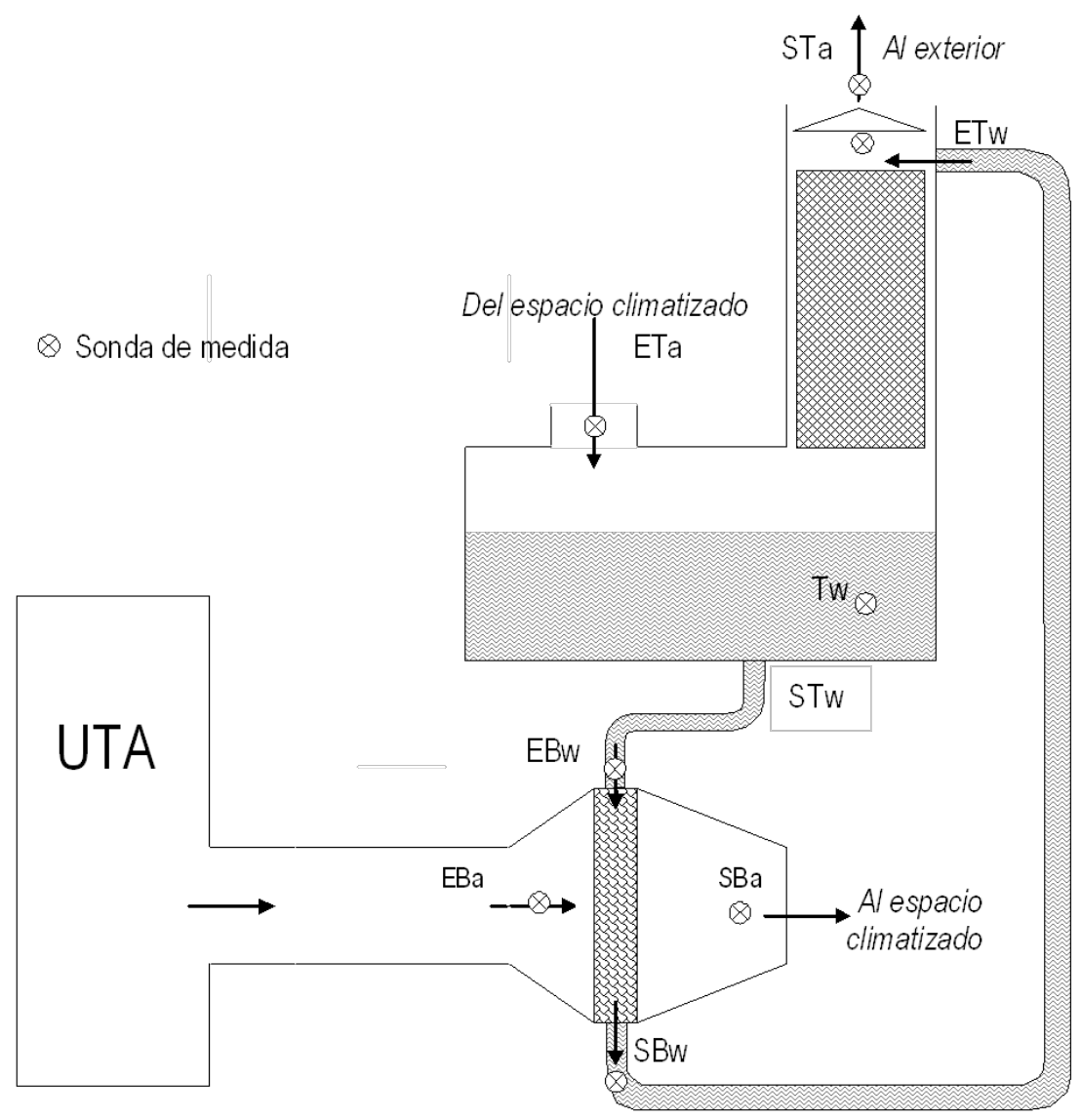

Figura VII.5.- Esquema de la instalación experimental en configuración recuperativa, con indicaciones de los puntos de toma de medidas.

\section{Configuración convencional}

En el modo de funcionamiento llamado como "configuración convencional", el sistema trabaja en un proceso de free-cooling por agua convencional. La conexión entre los distintos elementos de la instalación se esquematiza en la figura VII.6.

El plenum de distribución que se mostraba en el capítulo IV en la figura IV.10 permite canalizar en dos flujos independientes el aire en las condiciones de ensayo, para su respectiva conexión a la torre y a la batería, como se mostraba en el esquema de la figura VII.6.

El aire a la entrada de la torre (ETa) y de la batería (EBa) se encontrará en las condiciones del aire exterior proporcionadas por la UTA para cada ensayo particular. El aire a la salida de la 
torre (STa) es expulsado al ambiente, mientras que el aire saliente de la batería (SBa) será el que se impulsaría al local a climatizar.

También en este caso teóricamente la temperatura del agua a la entrada a la batería (EBw) será la misma que la que posee a la salida de la torre (STw), mientras que la temperatura del agua a la entrada a la torre (ETw) coincidirá con la que tenía a la salida de la batería (SBw).

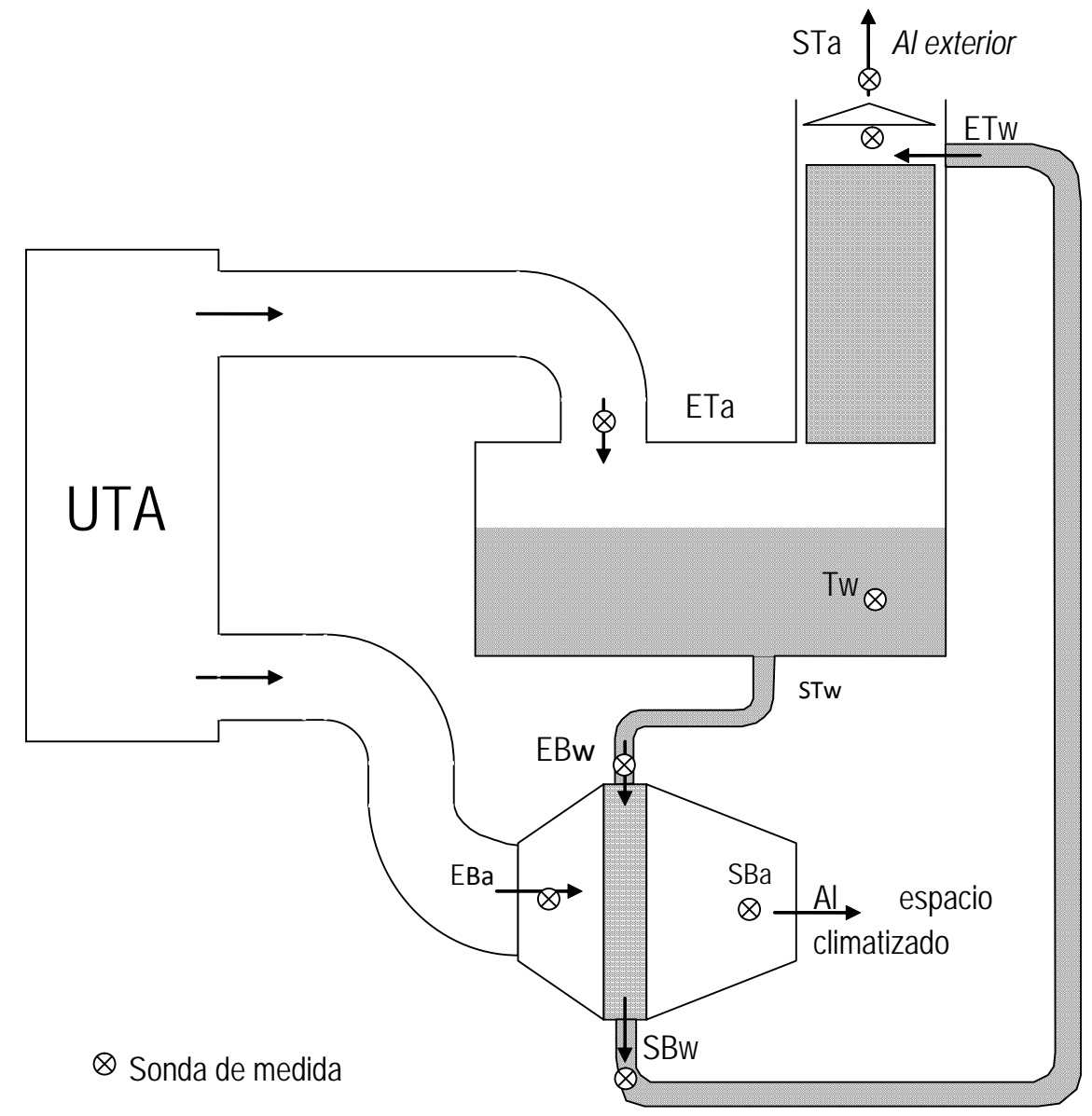

Figura VII.6.- Esquema de la instalación experimental en configuración convencional, con indicaciones de los puntos de toma de medidas.

\section{Diseño de Experimentos. Metodología de ensayos.}

Para asegurar que el conjunto de ensayos realizados proporciona información representativa sobre el funcionamiento y rendimiento del sistema, se realiza previamente un Diseño de Experimentos para determinar qué variables son de interés, y qué niveles de éstas son suficientes para disponer de un abanico completo de resultados (véase el anexo A). Los factores y niveles determinados en dicho estudio se proporcionan en la tabla VII.1. 
Tabla VII.1.- Diseño de Experimentos

\begin{tabular}{|c|c|c|c|}
\hline Configuración & $\begin{array}{l}\text { Caudal de agua } \\
\text { [1/min] }\end{array}$ & $\begin{array}{c}\text { Caudal volumétrico } \\
\text { de aire a la batería } \\
\qquad\left[\mathrm{m}^{3} / \mathrm{h}\right]\end{array}$ & $\begin{array}{l}\text { Temperatura del } \\
\text { aire de entrada a la } \\
\text { batería } \mathrm{T}_{\mathrm{EBa}}\left[{ }^{\circ} \mathrm{C}\right]\end{array}$ \\
\hline $\begin{array}{l}\text { C-R: Recuperativa } \\
\text { C-C: Convencional }\end{array}$ & $\begin{array}{l}\text { Q1: } 4 \\
\text { Q2: } 6 \\
\text { Q3: } 8\end{array}$ & $\begin{array}{l}\text { V1: } 125 \\
\text { V2: } 200 \\
\text { V3: } 300 \\
\text { V4: } 400\end{array}$ & $\begin{array}{l}\text { T1: } 20 \\
\text { T2: } 25 \\
\text { T3: } 30 \\
\text { T4: } 35 \\
\text { T5: } 40 \\
\text { T6: } 45\end{array}$ \\
\hline
\end{tabular}

Como puede verse, para cada una de las configuraciones de la instalación del sistema ensayadas, se han realizado ensayos modificando, por un lado, el caudal del agua aportado a la torre, el cual se ha establecido en 3 niveles entre 4 y $8 \mathrm{l} / \mathrm{min}$. Por su parte, en relación al aire de aporte a la batería se han estudiado dos únicos factores: el caudal aportado, establecido en los 4 niveles indicados; y su temperatura de entrada, variada entre 20 y $45^{\circ} \mathrm{C}$.

Sin embargo, no resultó necesaria la realización de todas las combinaciones de ensayos. Como se verá durante el análisis de resultados, un estudio provisional de los resultados obtenidos en configuración recuperativa proporcionará información que permitirá simplificar la caracterización de la otra configuración limitándola a un único nivel de caudal de agua de aporte, y tan sólo algunas combinaciones de condiciones de caudal-temperatura del aire de entrada a la batería de agua. Asimismo, los resultados realizados sobre la configuración recuperativa en el primer caso de caudal de agua, de $8 \mathrm{l} / \mathrm{min}$, permiten reducir el número de ensayos con el resto de caudales a tan sólo algunos flujos de aire tratado por la batería.

También fue necesario realizar la medida y registro de ciertas variables en puntos clave del funcionamiento del sistema. Las medidas de especial relevancia consideradas para la determinación de los parámetros que permitan la caracterización del equipo, son:

- La temperatura seca y humedad relativa del aire a la salida de la batería.

- Las temperaturas del agua a entrada y salida de la batería.

- Las temperaturas del agua a entrada y salida de la torre.

- Las temperaturas y humedades del aire a entrada y salida de la torre de enfriamiento.

Nótese que el proceso sufrido por el aire a su paso por la batería es puramente sensible, por lo que es previsible que no se registren variaciones en la humedad específica entre la entrada y la salida de este sistema. Por ello, la medida de la humedad relativa a la salida de la batería no sería necesaria, pudiéndose calcular a partir del resto de variables. El flujo de aire aportado a la torre se mantendrá en todo caso constante, establecido en de $300 \mathrm{~m}^{3} / \mathrm{h}$.

Las figuras VII.7 y VII.8 muestran la evolución de las variables medidas durante la realización de un ensayo, a modo de ejemplo; en particular el realizado en configuración recuperativa para $400 \mathrm{~m}^{3} / \mathrm{h}$ de aire entrando a $30^{\circ} \mathrm{C}$ y con un aporte de agua de $8 \mathrm{l} / \mathrm{min}$. Las 
medias de las variables registradas durante todo el ensayo serán los valores considerados en el análisis de los resultados del estudio experimental expuesto en el apartado siguiente.

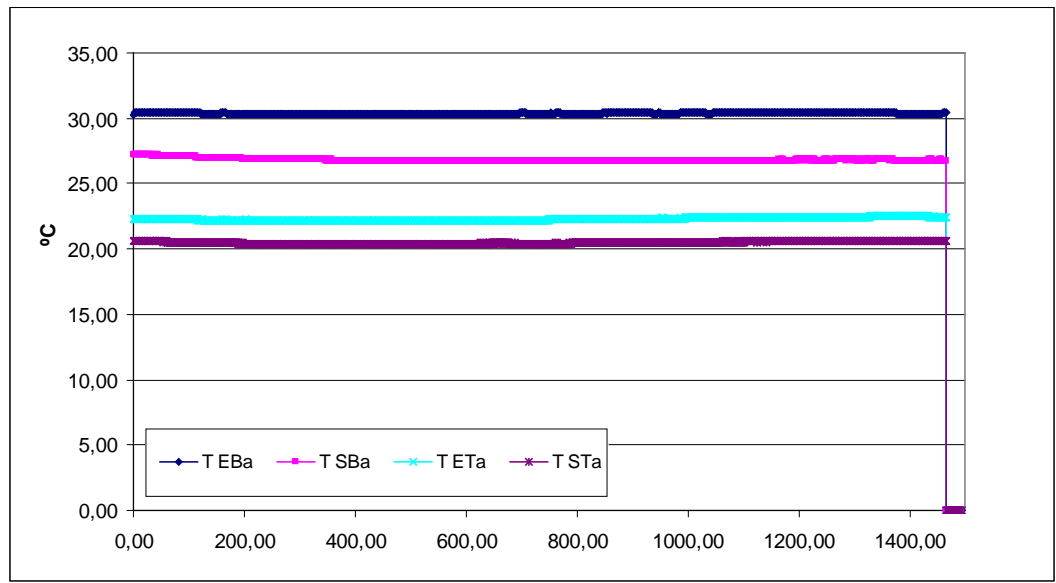

FiguraVII.7.- Evolución de las temperaturas del aire a entrada y salida de la torre y de la batería durante el ensayo del sistema en modo recuperativo a $400 \mathrm{~m}^{3} / \mathrm{h}$ de aire entrando a $30^{\circ} \mathrm{C}$, y con un caudal de agua de aporte de $8 \mathrm{I} / \mathrm{min}$.

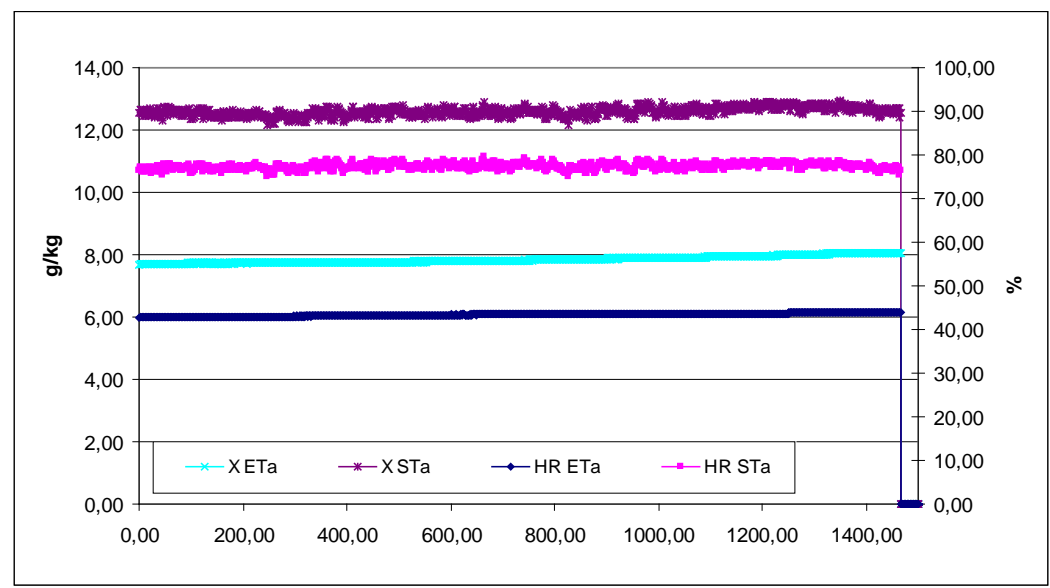

FiguraVII.8.- Evolución de la humedad específica y relativa del aire a su paso por la torre durante el ensayo del sistema en modo recuperativo a $400 \mathrm{~m}^{3} / \mathrm{h}$ de aire entrando a $30^{\circ} \mathrm{C}$, y con un caudal de agua de aporte de $8 \mathrm{I} / \mathrm{min}$.

\section{VII.4. ANÁLISIS DE RESULTADOS.}

\section{Parámetros considerados en la caracterización experimental}

Como se acaba de indicar, la caracterización del sistema trabajando en las distintas combinaciones de factores planteadas en el Diseño de Experimentos se ha realizado a partir de los valores medios de las medidas de interés registradas durante la realización de los ensayos. El análisis se aborda trasponiendo estas medidas a la definición de una serie de parámetros que nos permiten estudiar el comportamiento experimental del dispositivo. Estos 
parámetros son los mismos que los introducidos para el estudio de los sistemas evaporativos indirectos de policarbonato estudiados en el capítulo $\mathrm{V}$, planteados a continuación para las particularidades del sistema analizado en este capítulo.

El salto de temperaturas se define de forma análoga a la ecuación E-V.1, como la diferencia entre la temperatura seca alcanzada en el aire a la salida de la batería y la que tenía a su entrada, según la ecuación VII.1.

$$
\Delta T=T_{E B a}-T_{S B a}
$$

Por su parte, las efectividades de bulbo seco y de bulbo húmedo definidas por las expresiones E-V.2 y E-V.3 quedan para el caso particular como se indica en las ecuaciones EVII.2 y E-VII.3. La efectividad térmicas de bulbo seco se encuentra referida al salto térmico entre la temperatura seca del aire de ventilación a la entrada del sistema (es decir, la de entrada del aire a la batería) y la temperatura seca del aire a la entrada a la torre de enfriamiento [6, Wang, 1994]:

$$
\varepsilon_{T}=\frac{T_{E B a}-T_{S B a}}{T_{E B a}-T_{E T a}}
$$

De igual manera, la efectividad de bulbo húmedo se plantea en este caso en términos de la temperatura de saturación adiabática, o por aproximación de bulbo húmedo, del aire aportado a la torre [6, Wang, 1994]::

$$
\varepsilon_{T B H}=\frac{T_{E B a}-T_{S B a}}{T_{E B a}-T_{B H-E T a}}
$$

Se ha visto que, en configuración recuperativa, el aire impulsado a la torre procede del espacio climatizado con ayuda del aire tratado por la batería. Por su parte, en configuración convencional el aire a la entrada de la torre se corresponderá con el mismo aire exterior en iguales condiciones que el impulsado a través de la batería. Por ello, la efectividad de bulbo seco no será susceptible de análisis en el estudio de los resultados para esta última configuración, por la propia definición de su expresión matemática (ecuación E-VII.3).

La capacidad de enfriamiento (E-V.4 y E-V.5) queda en términos del flujo másico de aire involucrado en este caso como se muestra en la ecuación E-VII.4:

$$
E_{C C}=\dot{m} \cdot\left(h_{E B a}-h_{S B a}\right)
$$

Simplificada por trabajarse exclusivamente con intercambio sensible a través de la expresión E-VII.5:

$$
E_{C C}=\dot{m} \cdot C p_{a} \cdot\left(T_{E B a}-T_{S B a}\right)
$$


Asimismo, la diferencia media logarítmica de temperaturas dada en la expresión E-V.7 para el cálculo de la conductancia térmica de la batería (E-V.6) queda en este caso como:

$$
\Delta T_{L M}=\frac{\left(T_{E B a}-T_{S B w}\right)-\left(T_{S B a}-T_{E B w}\right)}{\ln \left(\frac{\left(T_{E B a}-T_{S B w}\right)}{\left(T_{S B a}-T_{E B w}\right)}\right)}
$$

Donde las diferencias de temperaturas se corresponden con las del aire y el agua entre las entradas y salidas de la batería aire-agua.

\section{Resultados de la configuración recuperativa}

Para la comprensión del funcionamiento del conjunto del sistema en el preacondicionamiento del aire exterior tomado en condiciones estivales, se ha comenzado analizando el salto térmico alcanzado por éste a su paso por la batería, según se definía en la ecuación E-VII.1. Los resultados obtenidos son los dados en la figura VII.9:

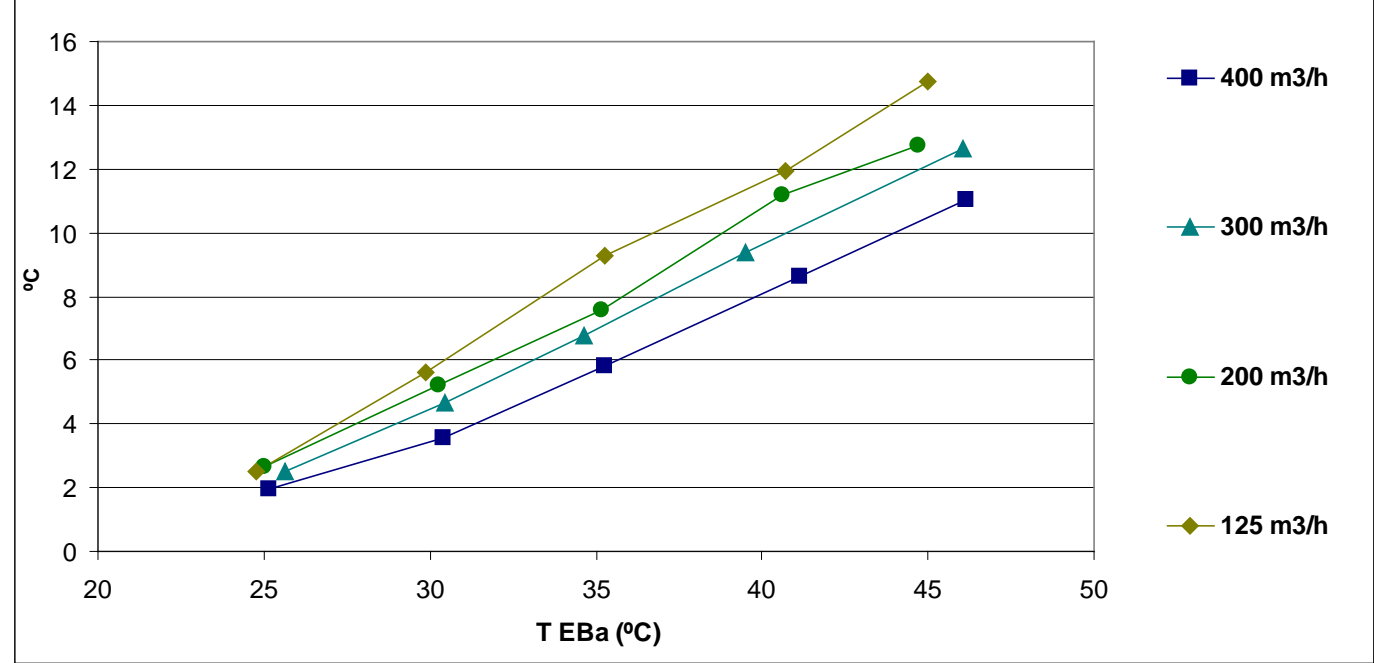

FiguraVII.9.- Saltos térmicos de temperaturas del aire a su paso por la batería, con un caudal de agua en la torre de $8 \mathrm{I} / \mathrm{min}$ (sistema en configuración recuperativa).

Se puede observar cómo el enfriamiento logrado en la corriente de aire de ventilación está linealmente relacionado con la temperatura de ésta a su entrada a la batería, lo cual es lógico considerando los mayores intercambios de calor permitidos por mayores diferencias de temperaturas entre el agua y el aire en la batería. Además, mayores caudales de aire sufren menos disminución de temperatura, dado que el tiempo de residencia del aire en la batería se ve reducido, y consecuentemente el tiempo durante el cual se trata. En cualquier caso, los comportamientos con la temperatura de los resultados para los distintos flujos muestran pendientes muy similares. Estos saltos térmicos en el aire llegan a alcanzar los $13^{\circ} \mathrm{C}$. 
La figura VII.10 muestra los saltos térmicos de temperatura del aire tratado para flujos de aire de 400 y $300 \mathrm{~m}^{3} / \mathrm{h}$, aportándose distintos caudales de agua a la torre de enfriamiento (8, 6 y $4 \mathrm{l} / \mathrm{min})$ :

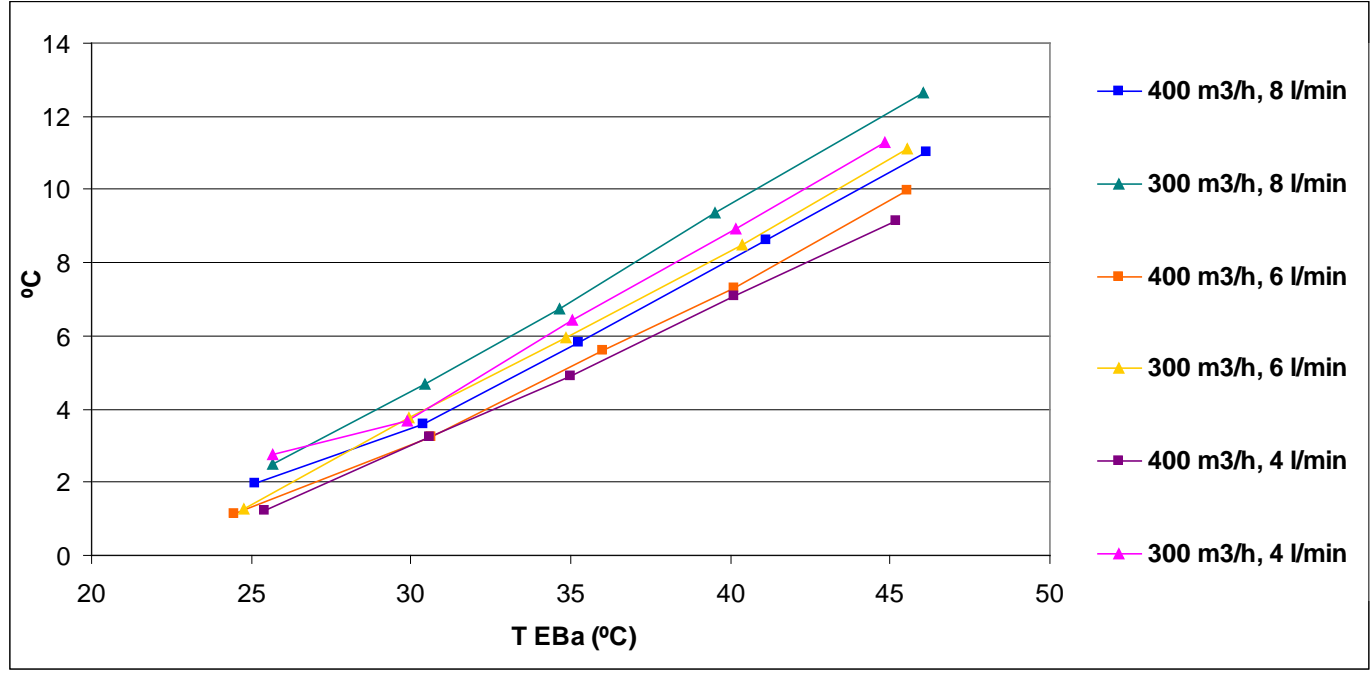

FiguraVII.10.- Saltos térmicos de temperaturas del aire a su paso por la batería, fluyendo a razón de 400 y $300 \mathrm{~m}^{3} / \mathrm{h}$ (sistema en configuración recuperativa).

A partir de estos resultados se puede concluir que el comportamiento observado para un caudal de agua aportado a la torre de $8 \mathrm{l} / \mathrm{min}$ se extiende al resto de casos de caudales de agua. Sin embargo, analizando la influencia del factor caudal de agua aportado a la torre, las diferencias entre resultados no son destacables ni se ajustan a ninguna tendencia observable, por lo que su influencia es despreciable. Esto es así porque en todo caso se trabaja con exceso de agua respecto al flujo de agua evaporada en la torre de enfriamiento, por lo que su modificación no afecta de forma importante al comportamiento del sistema [6, Wang, 1994].

La figura VII.11 muestra los resultados de la efectividad de bulbo seco para un caudal de agua en la torre de $8 \mathrm{l} / \mathrm{min}$.

Los resultados se mantienen prácticamente constantes para cada caudal de aire con la temperatura seca de éste a la entrada de la batería, variando para distintos caudales entre 0,45 y 0,8 , ya que aunque mayores temperaturas supongan mayores saltos térmicos, también los máximos saltos térmicos alcanzables son mayores. Se observa que mayores caudales de aire tratados suponen menores efectividades del proceso, al reducirse el tiempo de residencia del aire tratado dentro del sistema, y por disponer de mayor flujo de aire para la potencia intercambiada con el agua en la batería. 


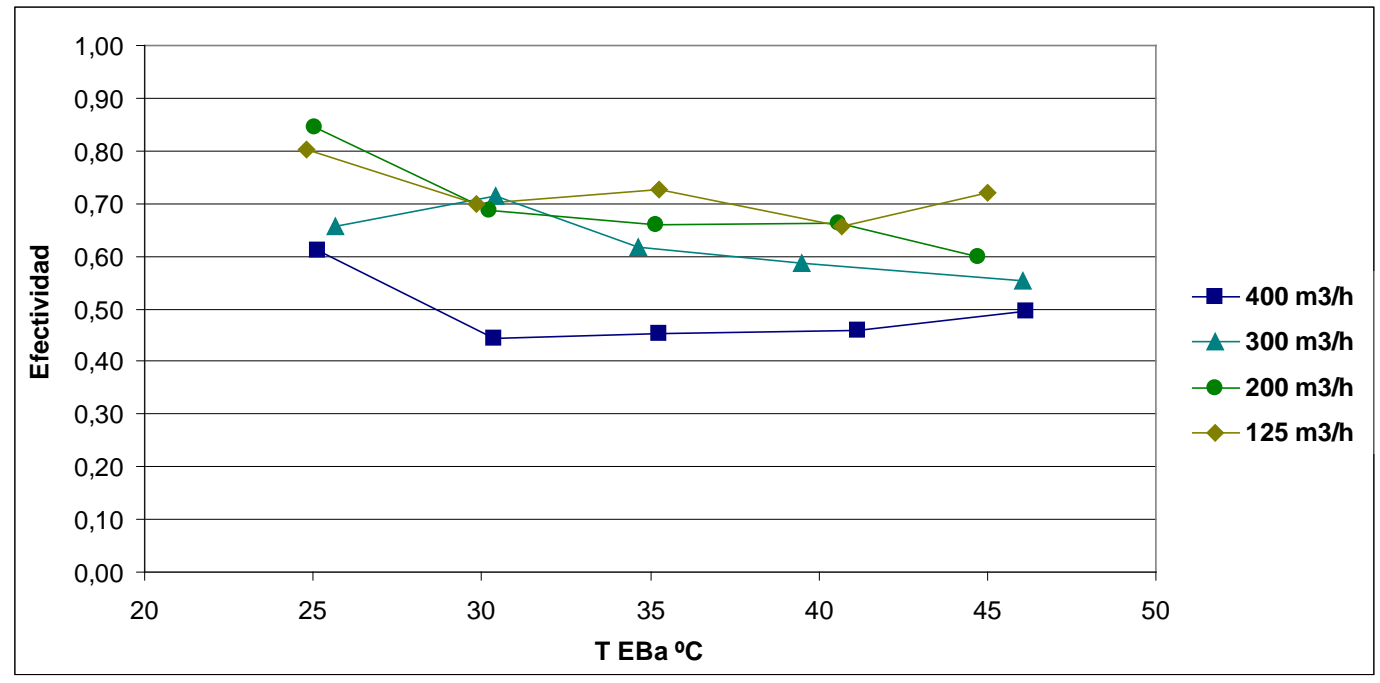

FiguraVII.11.- Efectividad de bulbo seco del sistema, con un caudal de agua en la torre de 8 I/min (sistema en configuración recuperativa).

Comparando los resultados ante distintos caudales de agua de aporte, mostrados en la figura VII.12, se comprueba que también para este factor las conclusiones derivadas para el caudal de $8 \mathrm{l} / \mathrm{min}$ son extrapolables al resto de casos. Asimismo, también en este caso la proximidad de los resultados indica que el factor caudal de agua de aporte no es de especial relevancia.

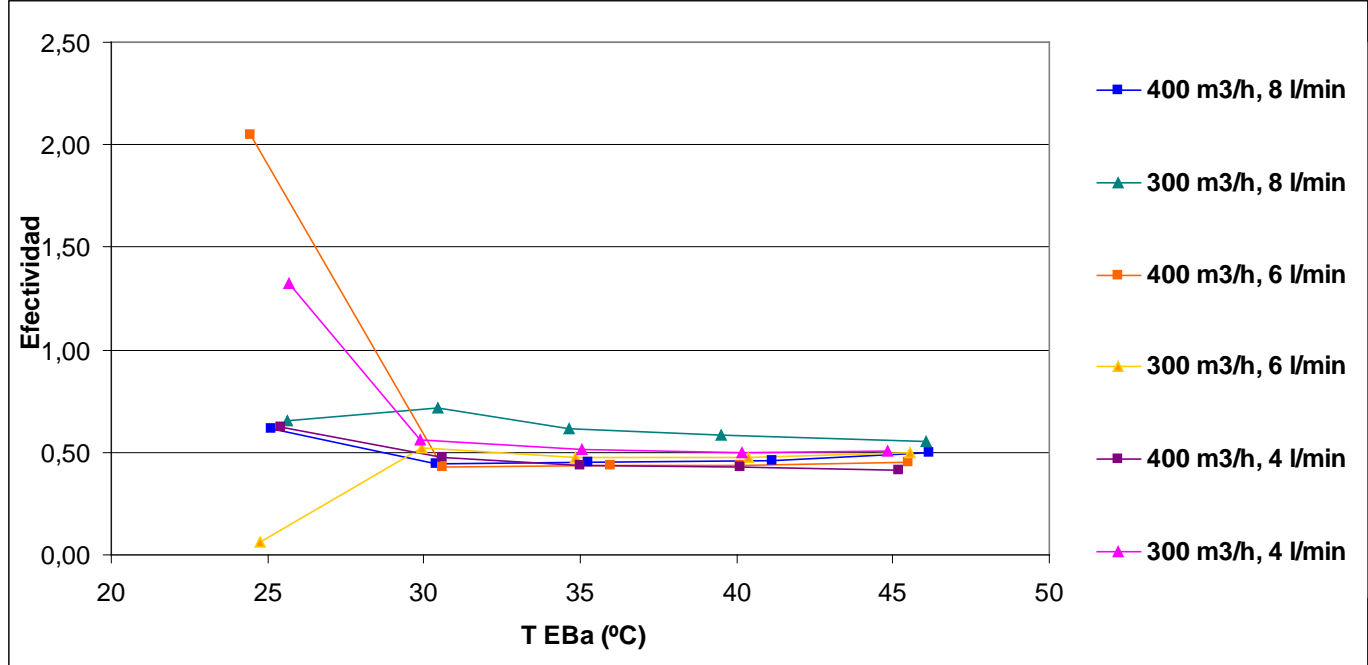

FiguraVII.12.- Efectividad de bulbo seco del sistema para varios caudales de agua, con caudales de aire de 400 y $300 \mathrm{~m}^{3} / \mathrm{h}$ (sistema en configuración recuperativa).

Cabe destacarse no obstante la desviación de los resultados de algunos de los ensayos realizados a $25^{\circ} \mathrm{C}$ de temperatura de entrada, en particular para los ensayos a $400 \mathrm{~m}^{3} / \mathrm{h}$ y 6 $\mathrm{l} / \mathrm{min}$, y a $300 \mathrm{~m}^{3} / \mathrm{h}$ y 4 y $6 \mathrm{l} / \mathrm{min}$. Comprobando las medidas registradas durante estos ensayos, se observa un aumento no controlado en la temperatura seca del aire dentro de la cámara climática, teóricamente establecida en condiciones de confort y por lo tanto entorno aproximadamente $22^{\circ} \mathrm{C}$, llegándose incluso en cierto período del ensayo a $300 \mathrm{~m}^{3} / \mathrm{h}$ y $6 \mathrm{l} / \mathrm{min}$ a 
superar la temperatura de entrada del aire a la batería. Este aumento genera inestabilidades en el denominador de la ecuación E-VII.3, derivando en valores de este parámetro medios durante el ensayo inusualmente elevados o reducidos que no serían representativos del comportamiento del sistema.

Nótese además que los ensayos planteados para temperaturas de entrada del aire de $20^{\circ} \mathrm{C}$ no se muestran en ningún caso. Esto es así porque se corresponden con temperaturas del aire exterior de ventilación inferiores a las de confort establecidas en el espacio a climatizar, y por lo tanto no resulta lógico el cálculo de la efectividad térmica de bulbo seco en esos casos. Asimismo, inicialmente sólo se realizaron para el caudal de agua de aporte de 8 I/min cuando se tenían flujos de aire de ventilación de 400 y $300 \mathrm{~m}^{3} / \mathrm{h}$, en los que se comprueba que por la suavidad de las condiciones exteriores del aire de trabajo no era interesante el estudio del comportamiento del sistema en esos casos a través de los parámetros definidos. En dichas condiciones sería más recomendable trabajar directamente con Free-cooling por aire.

La figura VII.13. refleja los resultados de la efectividad de bulbo húmedo obtenidos de los ensayos realizados con caudal de agua de aporte a la torre constante a $8 \mathrm{l} / \mathrm{min}$ y diferentes caudales de aire aportados.

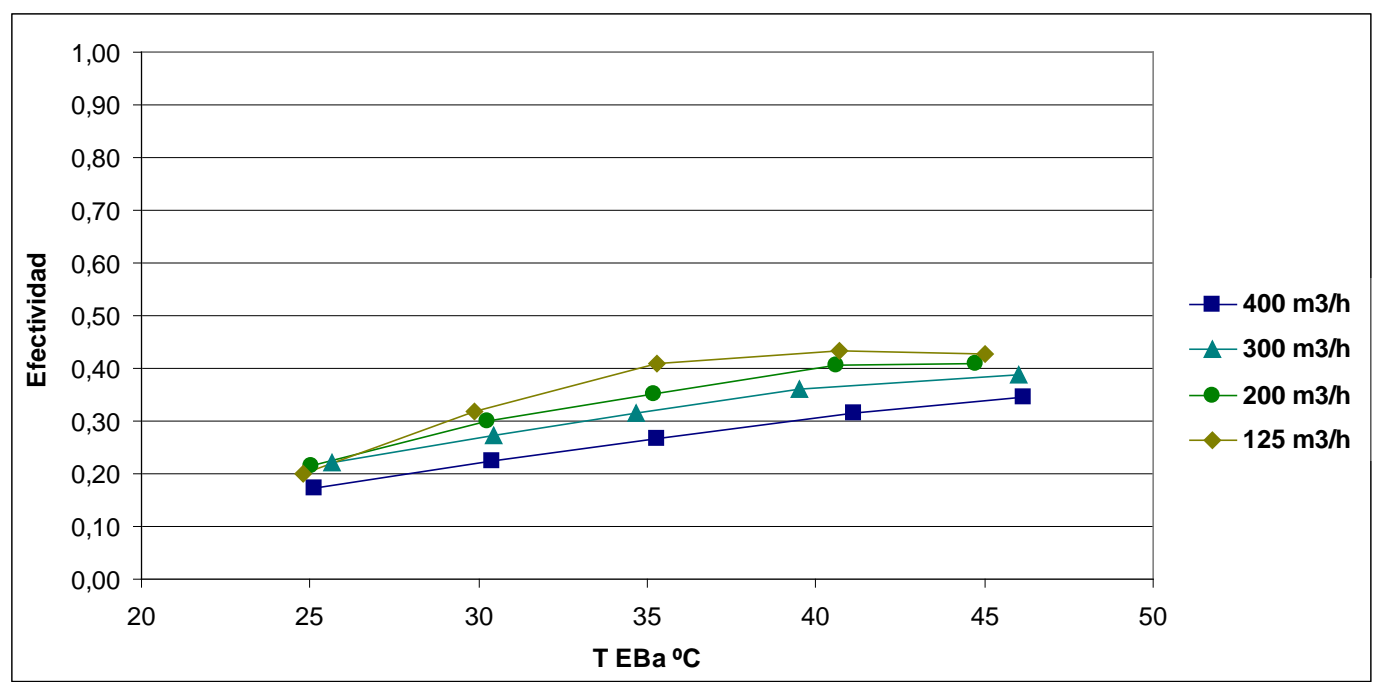

FiguraVII.13.- Efectividad de bulbo húmedo del sistema, con un caudal de agua en la torre de 8 I/min (sistema en configuración recuperativa).

Se puede observar cómo la efectividad de bulbo húmedo mejora claramente con la temperatura seca del aire a la entrada de la batería, si bien la tendencia no es muy lineal. Por otro lado, mayores caudales de aire suponen menores tiempos de residencia y consecuentemente peores efectividades. Puede observarse además que los valores de la efectividad térmica de bulbo húmedo resultan bastante menores que los de la efectividad térmica de bulbo seco. Esto es así porque la diferencia de temperaturas en el denominador de la expresión E-VII.2 está referida a la temperatura seca del aire a la entrada de la torre, y no a la de bulbo húmedo, como es el caso de la ecuación E-VII.3, la cual es precisamente la mínima 
teórica hasta la que podría estar enfriándose realmente el agua. De esta forma, para el parámetro efectividad de bulbo seco se obtiene un denominador menor, y por lo tanto mayores valores, aunque la efectividad de bulbo húmedo sea más representativa de la verdadera efectividad del sistema.

Al igual que se ha observado para los parámetros estudiados anteriormente, y como refleja la figura VII.14, este comportamiento es extrapolable al resto de ensayos realizados con otros caudales de agua de aporte, si bien este factor no se muestra muy relevante, incluso a pesar de apreciarse en este caso una leve mejora en el parámetro al aumentar los caudales de agua aportados a la torre, como posteriormente se pondrá de manifiesto con el análisis de varianza (ANOVA).

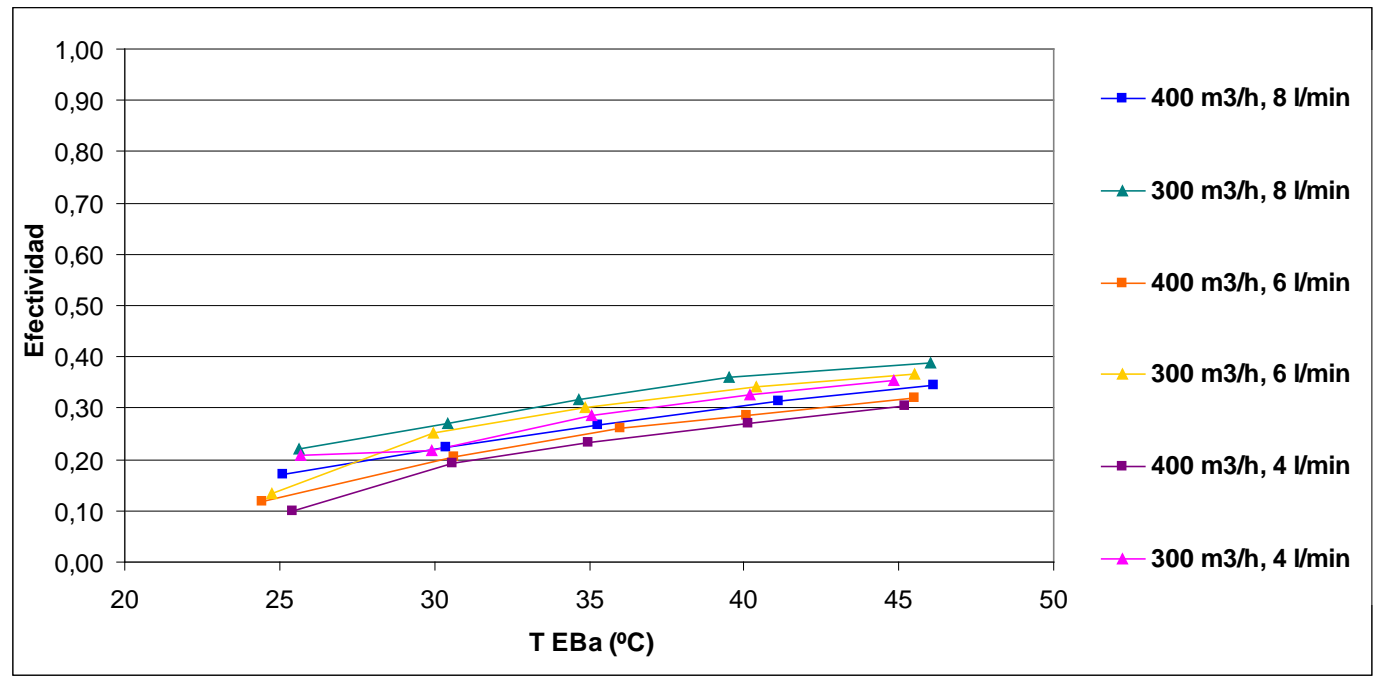

FiguraVII.14.- Efectividad de bulbo húmedo del sistema para varios caudales de agua, con caudales de aire de 400 y $300 \mathrm{~m}^{3} / \mathrm{h}$ (sistema en configuración recuperativa).

En lo que concierne a la capacidad de enfriamiento, dado que esta queda definida en función del caudal de aire tratado por el sistema además del salto de temperaturas, los resultados de la figura VII.15 serían predecibles. Se observa cómo, al igual que sucedía con el salto de temperaturas, los resultados mejoran de forma lineal con la temperatura a la entrada, tendiendo a confluir para temperaturas menores. Sin embargo, en este caso mayores caudales de aire tratado suponen mejores capacidades de enfriamiento, por el mero hecho de que este factor se vea incluido, en este caso, en la determinación del parámetro.

El sistema planteado trabajando en la configuración particular resulta interesante considerando su simplicidad frente a las potencias de enfriamiento proporcionadas, las cuales alcanzan para el mayor caudal tratado los $1500 \mathrm{~W}$ a $40^{\circ} \mathrm{C}$ de temperatura seca exterior, y asegurando $300 \mathrm{~W}$ de potencia de enfriamiento de ese mismo caudal en el caso de menor exigencia correspondientes a condiciones exteriores de $25^{\circ} \mathrm{C}$. Para el menor caudal ensayado, la potencia de enfriamiento alcanzada varía entre 100 y $600 \mathrm{~W}$. 


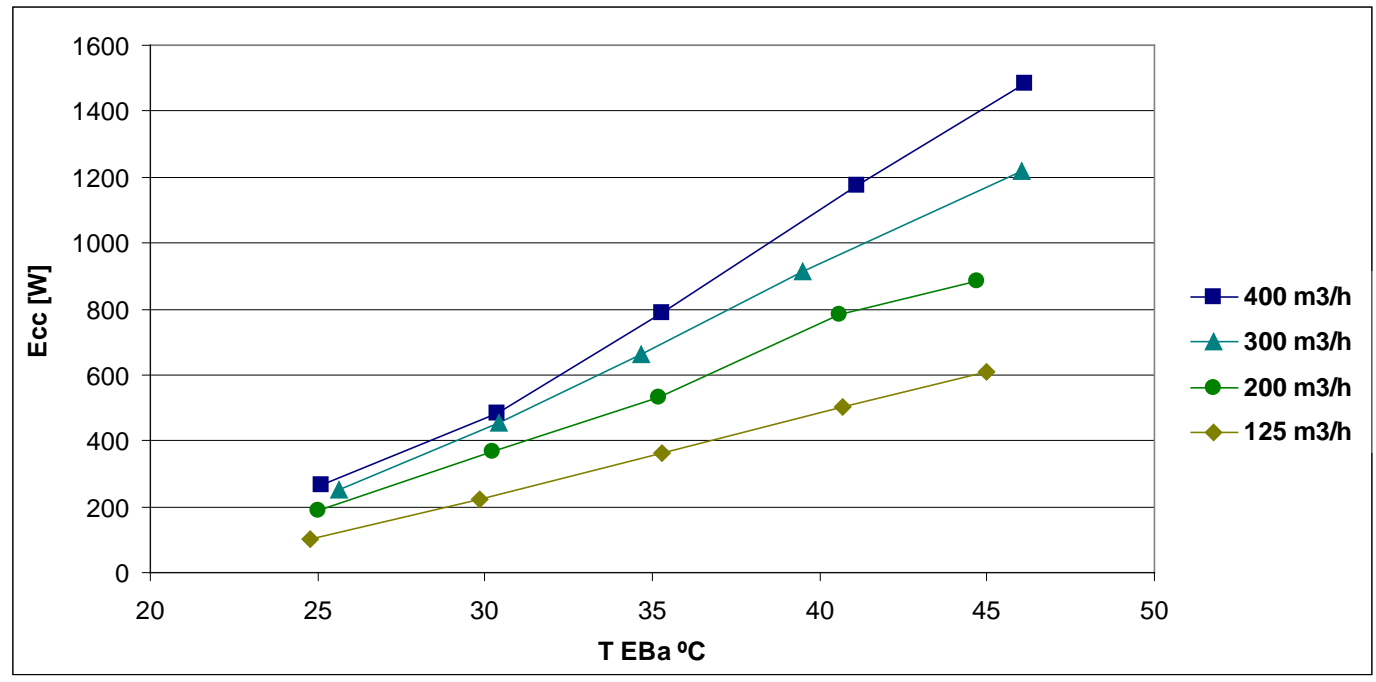

FiguraVII.15.- Capacidad de enfriamiento del sistema, con un caudal de agua en la torre de 8 I/min (sistema en configuración recuperativa).

Al igual que sucedía con los casos anteriores, el estudio realizado sobre los resultados de los ensayos a caudales de aire establecidos en 400 y $300 \mathrm{~m}^{3} / \mathrm{h}$ variando el caudal de agua aportado a la torre de enfriamiento, muestra que los resultados serían extrapolables para el resto de ensayos no realizados (figura VII.16). Además, la práctica invariabilidad entre resultados demuestra la baja influencia del factor caudal de agua.

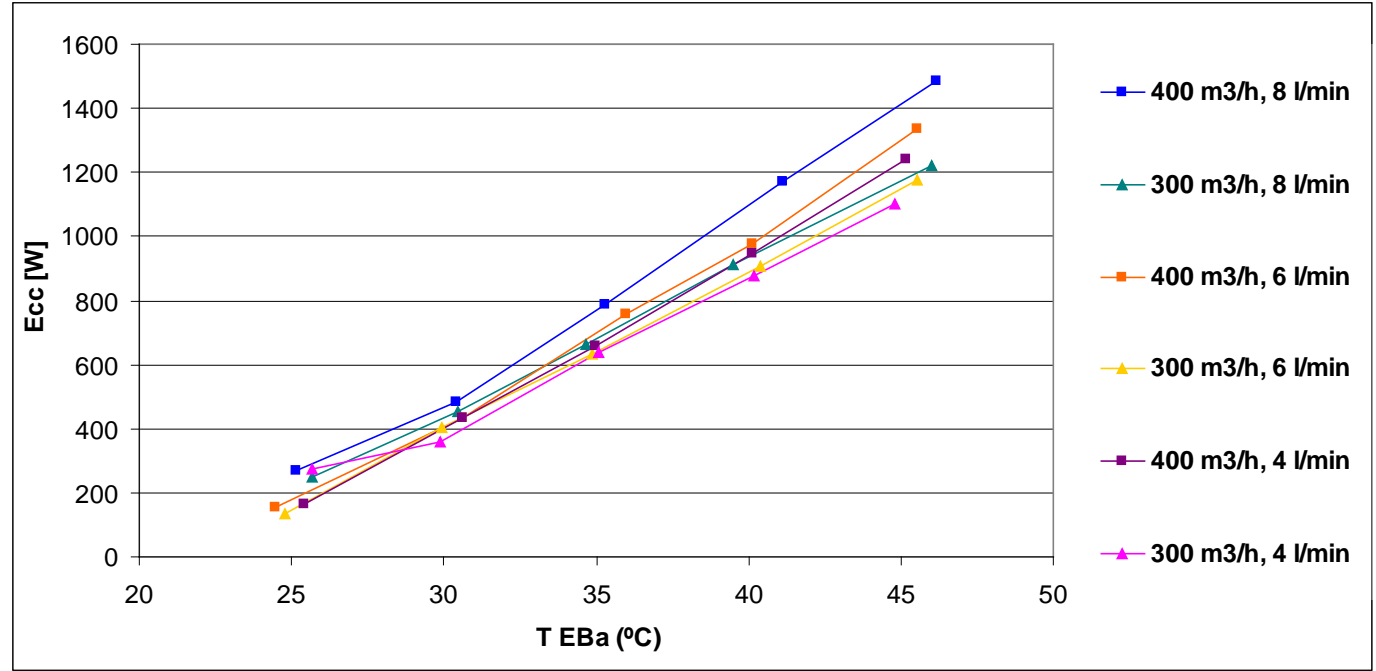

FiguraVII.16.- Capacidad de enfriamiento del sistema para varios caudales de agua, con caudales de aire de 400 y $300 \mathrm{~m}^{3} / \mathrm{h}$ (sistema en configuración recuperativa).

Finalmente, queda analizar la conductancia térmica de la batería para analizar su comportamiento como intercambiador de calor. De la figura VII.17 se extrae que este parámetro aumenta levemente con la temperatura del aire exterior a la entrada, aunque no se puede identificar un modelo de comportamiento que se ajuste a los datos obtenidos; mientras que incrementos en el caudal de aire que atraviesa la batería suponen mejoras más notables en el coeficiente global de transmisión de la misma. Esto es así porque, en el intercambio aire- 
agua, un aumento del caudal del fluido gaseoso, limitante del proceso de transmisión de calor por los menores coeficientes convectivos de película asociados, mejora dichos coeficientes, y consecuentemente dicho intercambio de calor.

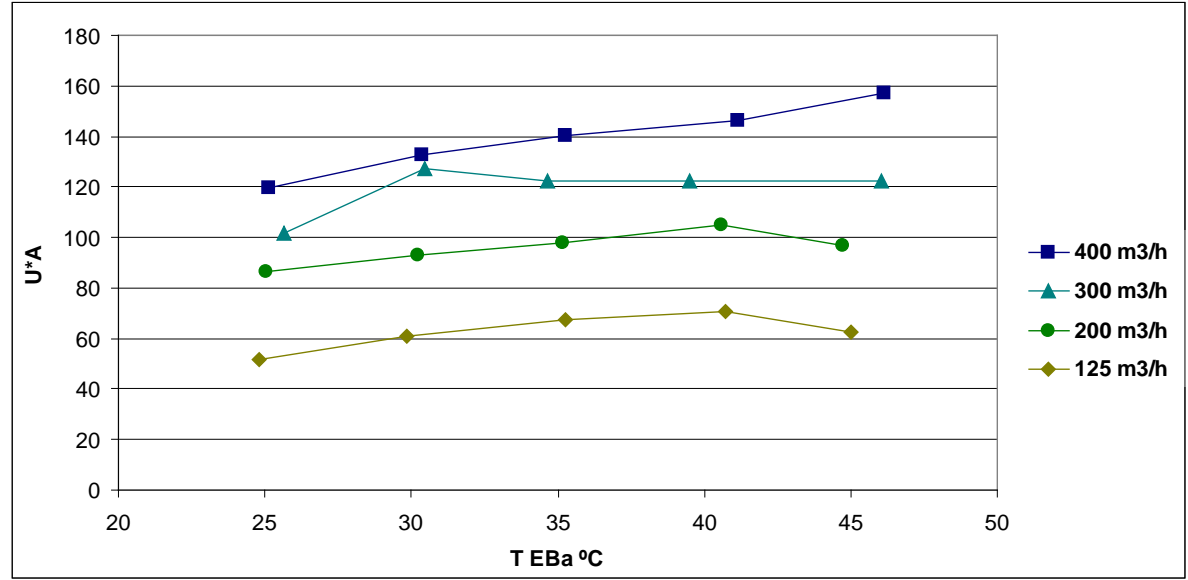

FiguraVII.17.- Conductancia térmica de la batería, con un caudal de agua en la torre de 8 I/min (sistema en configuración recuperativa).

Para este mismo parámetro a distintos caudales de agua de aporte a la torre (figura VII.18), se cumplen los mismos comportamientos observados. Aunque parece apreciarse una ligera mejora en el parámetro con el aumento del caudal de agua aportada, dado que no hay diferencia especialmente notable al modificarse ese factor, tampoco en este caso el caudal de agua de aporte sería relevante. Nótese que para los caudales de aire de 300 y $400 \mathrm{~m}^{3} / \mathrm{h}$, las conductancias térmicas varían entorno a aproximadamente los 120 y los $140 \mathrm{~W} \cdot \mathrm{m}^{2} /{ }^{\circ} \mathrm{C}$.

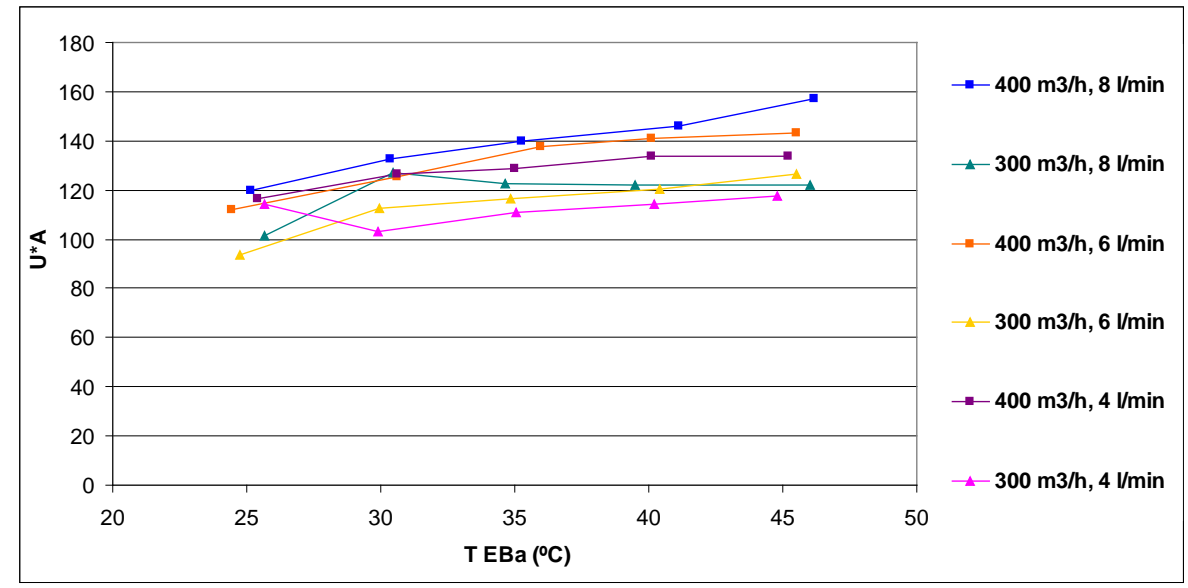

FiguraVII.18.- Conductancia térmica de la batería para varios caudales de agua, con caudales de aire de 400 y $300 \mathrm{~m}^{3} / \mathrm{h}$ (sistema en configuración recuperativa).

\section{Resultados de la configuración convencional}

La caracterización del sistema operando en configuración convencional se ha planteado simplificando el procedimiento experimental a partir de algunas de las conclusiones derivadas del análisis sobre la configuración recuperativa ya abordada. De esta forma, el Diseño de 
Experimentos planteado inicialmente no se ha seguido estrictamente, sino que los ensayos se han realizado para un único caudal de agua de aporte, $8 \mathrm{l} / \mathrm{min}$, al haberse comprobado que la influencia de este factor es prácticamente despreciable; y el rango de temperaturas estudiado se ha recortado a 5 niveles entre 25 y $45^{\circ} \mathrm{C}$, ya que no resulta interesante el funcionamiento del equipo en condiciones de temperatura por debajo de las de confort establecidas en el espacio acondicionado, en cuyo caso se utilizaría Free-cooling por aire.

Asimismo, dado que se pudo observar la existencia de tendencias claras en los valores obtenidos al modificarse la temperatura seca del aire exterior y entre caudales de aire impulsados, tan sólo se realizaron ensayos para el rango completo de temperaturas a un determinado caudal volumétrico establecido, específicamente de $200 \mathrm{~m}^{3} / \mathrm{h}$, mientras que para el resto de caudales se realizaron ensayos para un único nivel de temperatura del aire exterior establecido en $35^{\circ} \mathrm{C}$, extrapolando las tendencias de los resultados observadas en el sistema operando en configuración recuperativa para comprobar la correspondencia de tendencias con la configuración ahora analizada.

Esta semejanza observada en las tendencias de los resultados experimentales recopilados en las figuras VII.9, VII.13, VII.15 y VII.17permite prever que los resultados en configuración convencional mostrarían también comportamientos similares. Para realizar el cálculo de los valores no ensayados, se obtuvieron las pendientes esperables de estos conjuntos de ensayos a caudal fijo a partir de las obtenidas de las regresiones realizadas para los valores ya obtenidos en configuración recuperativa.

Los coeficientes de estas tendencias obtenidas de la regresión de los resultados experimentales de la configuración recuperativa, se recogen en la tabla VII.2. Nótese que, para la conductancia térmica, la aproximada estabilidad del parámetro con la temperatura del aire hace considerar una pendiente nula de la regresión lineal.

Tabla VII.2.- Coeficientes de las regresiones respecto a la temperatura de los resultados experimentales en configuración recuperativa.

\begin{tabular}{cccccccccc}
\hline & \multicolumn{2}{c}{$\Delta T$} & \multicolumn{3}{c}{$\boldsymbol{\varepsilon}_{\mathrm{TBH}}$} & \multicolumn{2}{c}{$\mathrm{Ecc}$} & $\mathrm{U} \cdot \mathrm{A}$ \\
$\mathbf{\text { V) }}$ & $\mathbf{b} \cdot(\mathbf{T})^{\mathbf{1}}$ & $\mathbf{a} \cdot(\mathbf{T})^{\mathbf{0}}$ & $\mathbf{c} \cdot(\mathbf{T})^{\mathbf{2}}$ & $\mathbf{b} \cdot(\mathbf{T})^{\mathbf{1}}$ & $\mathbf{a} \cdot(\mathbf{T})^{\mathbf{0}}$ & $\mathbf{b} \cdot(\mathbf{T})^{\mathbf{1}}$ & $\mathbf{a} \cdot(\mathbf{T})^{\mathbf{0}}$ & $\mathbf{a} \cdot(\mathbf{T})^{\mathbf{0}}$ \\
V4 & 0,440 & $-9,45$ & $-0,0001$ & 0,017 & $-0,17$ & 59,254 & $-1269,8$ & 501,09 \\
V3 & 0,501 & $-10,5$ & $-0,0002$ & 0,025 & $-0,27$ & 48,127 & $-997,07$ & 428,98 \\
V2 & 0,526 & $-10,6$ & $-0,0009$ & 0,071 & $-1,03$ & 36,294 & $-724,06$ & 344,59 \\
V1 & 0,601 & $-12,3$ & $-0,0004$ & 0,039 & $-0,49$ & 25,222 & $-525,18$ & 225,41 \\
\hline
\end{tabular}

La efectividad de bulbo seco no es un parámetro a considerar en esta configuración, puesto que por su propia definición entraría en conflicto con el hecho de que las condiciones del aire a la entrada de la torre son en este caso coincidentes con las del aire de ventilación a la entrada de la batería. 
Una vez obtenidos estos coeficientes, es preciso estudiar cómo están interrelacionados en función de los caudales. Estas correlaciones se plantearán para los flujos másicos de aire, al ser éstos los que se mantienen aún variando las condiciones del aire impulsado. Las interrelaciones identificadas se supondrán válidas para los coeficientes correspondientes a las tendencias, por calcular, para el sistema en configuración convencional. Las interrelaciones esperadas entre coeficientes en función del caudal para la configuración convencional obtenidas son las dadas en la tabla VII.3.

El coeficiente asociado al término independiente en la correlación frente al caudal se obtiene imponiendo en la función del caudal las condiciones obtenidas de la propia regresión de los únicos datos experimentales realizados en configuración convencional para el rango de temperaturas completo (nivel de caudal V2).

Obsérvese por lo tanto que, dado que con excepción de la pendiente de la regresión a la que se ajusta la capacidad de enfriamiento, no parecía existir una relación aceptable en función de los caudales entre los coeficientes de las regresiones de la tabla VII.2, en esos casos se consideraron como coeficientes de las regresiones respecto a la temperatura para configuración recuperativa las medias de éstos para los distintos caudales, que por lo tanto en configuración convencional se corresponderán, a falta de más datos, con los datos de la regresión realizada a los ensayos al nivel de caudal V2.

Tabla VII.3.- Coeficientes de las regresiones respecto al flujo másico de aire de los coeficientes de las regresiones respecto a la temperatura esperadas para los resultados para configuración convencional.

\begin{tabular}{|c|c|cc|c|c|}
\hline & $\Delta \mathbf{T}$ & \multicolumn{2}{c}{$\boldsymbol{\varepsilon}_{\mathrm{TBH}}$} & Ecc & $\mathbf{U} \cdot \mathbf{A}$ \\
& $\mathbf{b} \cdot(\mathbf{T})^{\mathbf{1}}$ & $\mathbf{b} \cdot(\mathbf{T})^{\mathbf{1}}$ & $\mathbf{c} \cdot(\mathbf{T})^{\mathbf{2}}$ & $\mathbf{b} \cdot(\mathbf{T})^{\mathbf{1}}$ & $\mathbf{b} \cdot(\mathbf{T})^{\mathbf{1}}$ \\
\hline $\mathbf{N} \cdot(\boldsymbol{m})^{\mathbf{1}}$ & 0 & 0 & 0 & 0,3745 & 0 \\
\hline $\mathbf{P} \cdot(\boldsymbol{m})^{\mathbf{0}}$ & 0,430 & 0,0461 & $-0,0005$ & $-63,6$ & 0 \\
\hline
\end{tabular}

Aplicados a cada flujo másico de aire tratado, correspondiente a 150, 250, 350 y 480 kg/h para los niveles de caudal volumétrico V1 a V4, los coeficientes calculados para estimar las tendencias de la configuración convencional quedan como se muestra en la tabla VII.4.

Tabla VII.4.- Coeficientes de las regresiones respecto a la temperatura en configuración convencional, experimentales y calculados.

\begin{tabular}{cccc|c|c|}
\hline & $\Delta T$ & \multicolumn{2}{c}{$\varepsilon_{\mathrm{TBH}}$} & \multicolumn{1}{c}{ Ecc } & U.A \\
(V) & $\mathrm{b} \cdot(\mathrm{T})^{1}$ & $\mathrm{~b} \cdot(\mathrm{T})^{1}$ & $\mathrm{c} \cdot(\mathrm{T})^{2}$ & $\mathrm{~b} \cdot(\mathrm{T})^{1}$ & $\mathrm{~b} \cdot(\mathrm{T})^{1}$ \\
V4 & 0,430 & 0,0461 & $-0,0005$ & 116,1 & 0 \\
V3 & 0,430 & 0,0461 & $-0,0005$ & 67,43 & 0 \\
V2 & 0,430 & 0,0461 & $-0,0005$ & 29,98 & 0 \\
V1 & 0,430 & 0,0461 & $-0,0005$ & $-7,466$ & 0 \\
\hline
\end{tabular}


Los resultados experimentales de los saltos térmicos para el nivel V2 del factor caudal de aire se muestran en la figura VII.19 confrontados con los previsibles para el resto de caudales a partir de las regresiones calculadas por el procedimiento de cálculo explicado anteriormente, y de los valores experimentales de los ensayos realizados a dichos caudales para la temperatura de $35^{\circ} \mathrm{C}$. Puede extraerse de estos resultados que las tendencias esperables serían adecuadas.

Tomando estos resultados, de forma general los saltos térmicos alcanzados en el aire tratado por el sistema operando en configuración convencional disminuyen del orden de $2^{\circ} \mathrm{C}$ respecto a los obtenidos en configuración recuperativa.

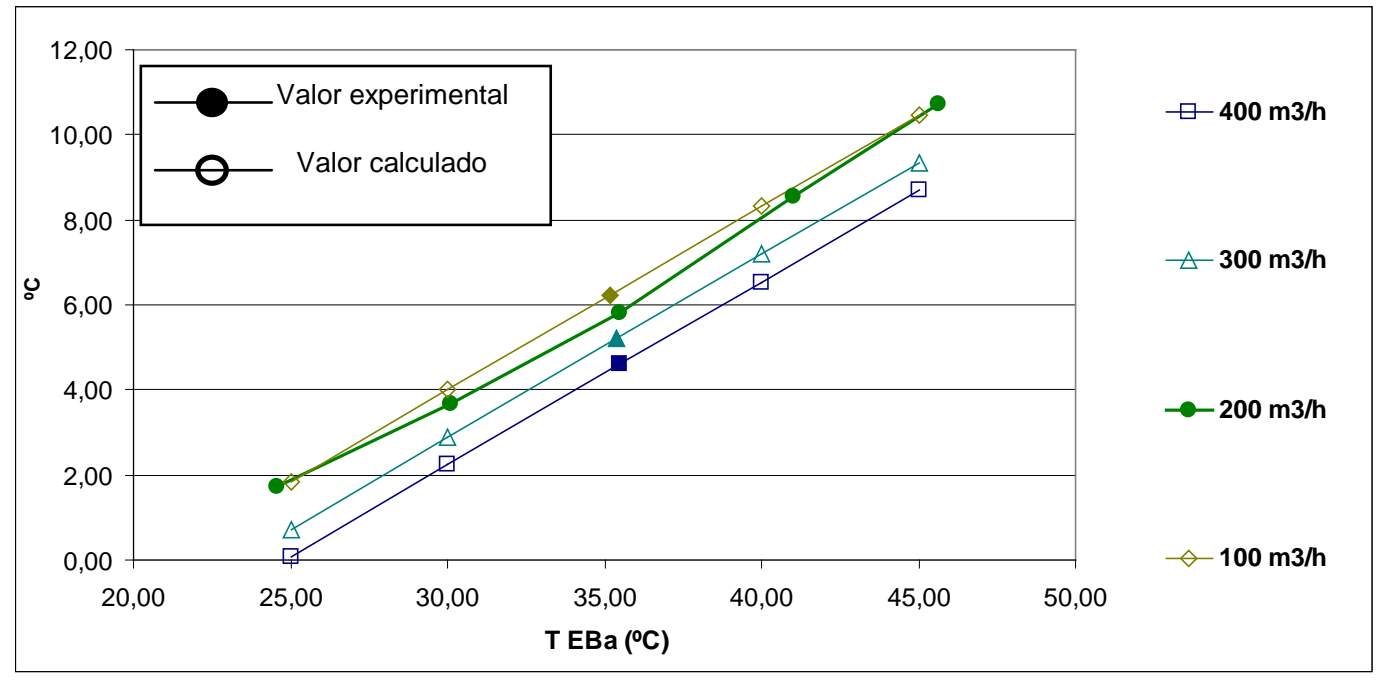

Figura VII.19.- Salto térmico de temperaturas del aire en la batería: resultados experimentales y previstos (sistema en configuración recuperativa).

En cuanto a la efectividad de bulbo húmedo, los resultados experimentales completados con los valores estimados se muestran en la figura VII.20.

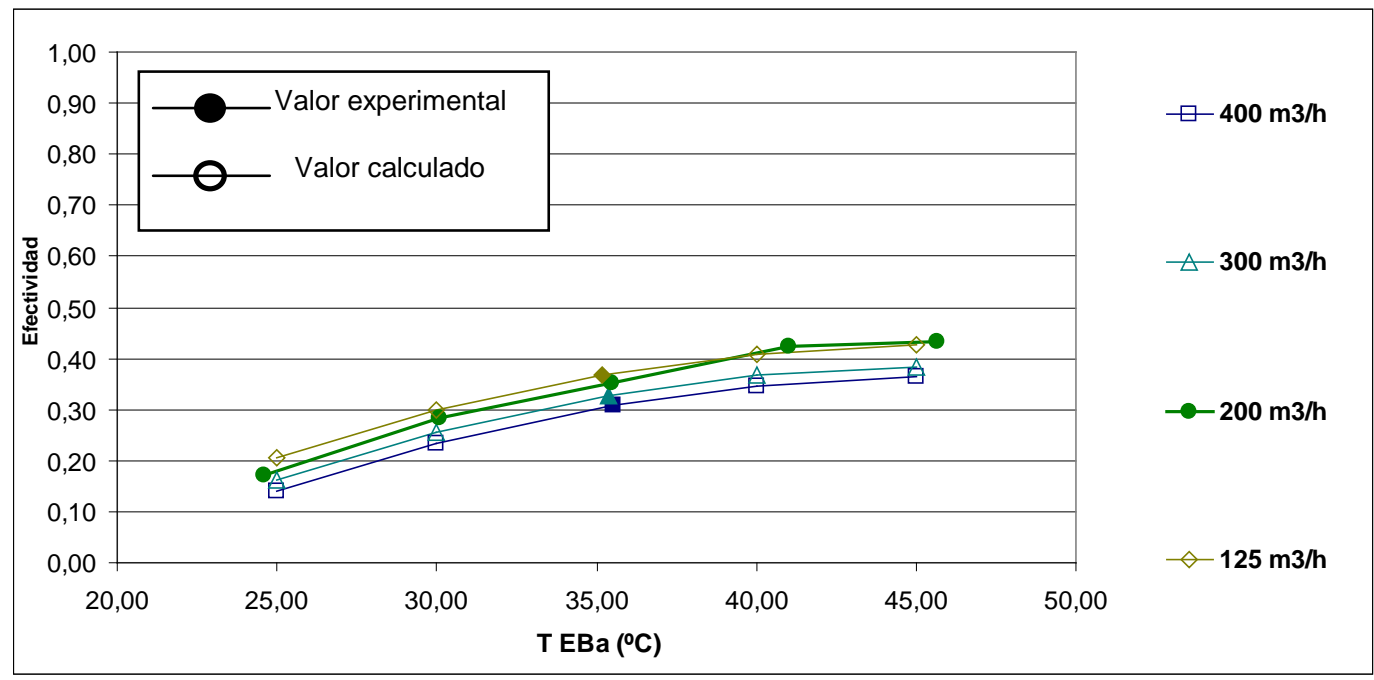

Figura VII.20.- Efectividad térmica de bulbo húmedo: resultados experimentales y previstos (sistema en configuración recuperativa). 
En este caso, los resultados experimentales obtenidos para $200 \mathrm{~m}^{3} / \mathrm{h}$ también se corresponden con las tendencias previstas para el resto de ensayos. Asimismo, para este parámetro se observa una disminución respecto a los resultados obtenidos en configuración recuperativa, si bien no es muy destacable, pues apenas se ven desplazados hacia valores inferiores entorno a 0,05.

Los resultados experimentales y estimados de la capacidad de enfriamiento se presentan en la figura VII.21. Aunque los resultados son interesantes en cuanto a la aplicabilidad del sistema de forma efectiva, como era de esperar en configuración convencional el enfriamiento alcanzado en la corriente no es tan alto, llegando como máximo a alcanzar casi los 1200 W frente a los $1500 \mathrm{~W}$ obtenidos en configuración recuperativa trabajando en las mismas condiciones. Por ejemplo para el único caso experimental a $45^{\circ} \mathrm{C}$, a caudal $200 \mathrm{~m}^{3} / \mathrm{h}$ en configuración recuperativa se alcanzaban entorno a los $900 \mathrm{~W}$, mientras que en este caso tan sólo llega a 750 W. Asimismo, en los casos más desfavorables tan sólo se aseguran 50 W de potencia, si bien siguen siendo resultados interesantes dada la simplicidad del sistema.

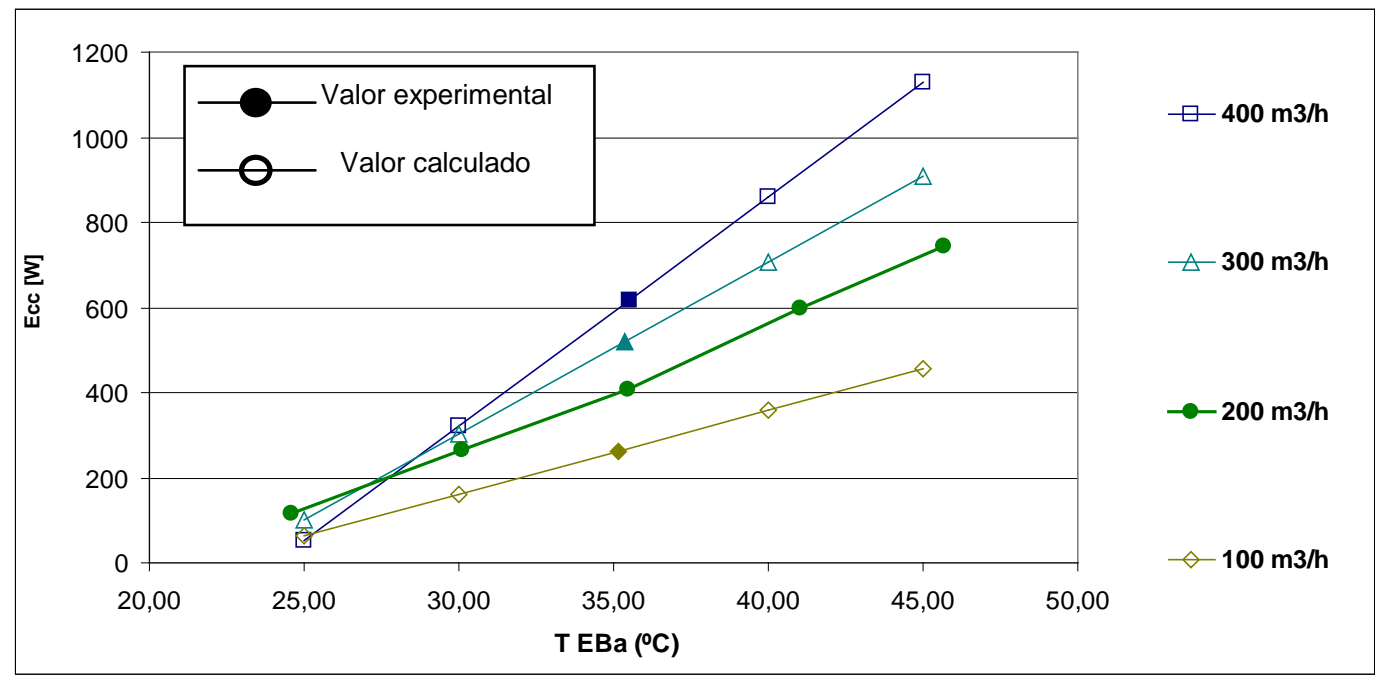

Figura VII.21.- Capacidad de enfriamiento: resultados experimentales y previstos (sistema en configuración recuperativa).

Finalmente, la conductancia térmica experimental obtenida para los $200 \mathrm{~m}^{3} / \mathrm{h}$ de caudal muestra una ligera tendencia ascendente con la temperatura que no se corresponde con lo previsto. Sin embargo, como la variabilidad del parámetro con la temperatura no es tan destacada como la que sufre en función del caudal, puede ser suficiente este cálculo aproximado para ofrecer una idea de su comportamiento. En ese caso, los valores de la conductancia térmica pueden considerarse estables entorno a $125,100,80$ y $55 \mathrm{~W} /\left(\mathrm{m}^{2}{ }^{\circ} \mathrm{C}\right)$ para caudales de 400, 300, 200 y $125 \mathrm{~m}^{3} / \mathrm{h}$. Sí es interesante observar aquí, sin embargo, el hecho de que los resultados de forma global no se alejan demasiado de los obtenidos en configuración recuperativa. Esto se justifica por el hecho de que el comportamiento de la batería como intercambiador de calor no se ve afectado por la configuración del funcionamiento. 


\section{Análisis de Varianza}

Dado que el Diseño de Experimentos original no se ha seguido estrictamente en este estudio experimental, por haberse refutado a partir de los resultados de los primeros ensayos el posible interés inicialmente considerado en la consecución de algunos de los ensayos restantes, el Análisis de Varianza a seguir en este caso ha de plantearse de forma particular. Un ejemplo de esto ha sido, directamente observable a partir de los resultados, la baja influencia del factor caudal de agua aportado a la torre. Asimismo, se dedujo que el primer nivel de temperatura $\mathrm{T} 1=20^{\circ} \mathrm{C}$ no era ilustrativo para el funcionamiento del equipo por no corresponderse con condiciones exteriores adversas para el confort térmico en el interior del espacio acondicionado en verano.

Para verificar los resultados expuestos, se han realizado dos ANOVA sobre los resultados (según el anexo A), planteados de forma independiente. En el primer análisis de varianza tan sólo la configuración recuperativa es objeto de interés, limitándose también el flujo de aire tratado a los dos niveles más elevados. Este análisis se denominará a partir de ahora como "ANOVA - C-R". Por su parte, el segundo análisis de varianza se planteó para ambas configuraciones pero para un único caudal de agua de aporte a la torre, manteniendo el resto de factores y niveles iguales al planteamiento original del diseño de experimentos. Este ANOVA será referido como "ANOVA - Q3". Los resultados de estos análisis se muestran por separado a continuación, y permitirán corroborar las conclusiones observadas en el análisis de resultados desarrollado anteriormente.

\section{ANOVA - C-R: Resultados}

Los valores medios de los resultados experimentales para cada nivel mantenido constante, para la configuración recuperativa trabajando a tan sólo dos niveles de flujo de aire de ventilación y los tres niveles de agua de aporte a la torre, están recopilados en la tabla VII.5, y representados en las figuras VII.22 a VII.26.

Se observa cómo, sobre el parámetro salto térmico, el factor caudal de agua no afecta mientras que el factor configuración afecta tan sólo levemente; si bien la temperatura del aire exterior influye notoriamente sobre este parámetro. Por otro lado, ningún factor parece determinar el comportamiento de la efectividad térmica seca, el valor medio de este parámetro para el menor nivel de temperatura se dispara, debido a las inestabilidades en el parámetro por la falta de control sobre la temperatura de confort del aire de retorno del espacio climatizado, como se observó en la figura VII.12. En lo que concierne a la efectividad térmica de bulbo húmedo, por su parte, el parámetro se ve ligeramente influido, de forma no destacable, por los factores caudal de agua y de aire, y de forma algo más destacable por el factor temperatura, aunque no tanto como afectaba dicho factor al salto térmico.

De igual forma, la capacidad de enfriamiento sólo se ve afectada de manera importante por la temperatura seca del aire, aunque en este caso la influencia es mucho más notable. 
El hecho de que no se observe influencia destacable del flujo de aire puede deberse simplemente a la reducción a dos niveles del rango de flujos de aire considerados en este ANOVA. Finalmente, la conductancia térmica parece verse influida por los tres factores, pero por ninguno de manera importante.

Tabla VII.5.- Valores medios de los factores (ANOVA-CR).

\begin{tabular}{c|ccc|} 
& $\mathbf{Q 3}$ & $\mathbf{Q 2}$ & $\mathbf{Q 1}$ \\
\hline $\boldsymbol{\Delta T}$ & 6,69 & 5,79 & 5,87 \\
$\boldsymbol{\varepsilon}_{\mathbf{T}}$ & 0,56 & 0,58 & 0,58 \\
$\boldsymbol{\varepsilon}_{\mathrm{TBH}}$ & 0,29 & 0,26 & 0,25 \\
$\mathbf{E}_{\mathrm{CC}}$ & 770,12 & 691,64 & 669,87 \\
$\mathbf{U} \cdot \mathbf{A}$ & 465,04 & 442,33 & 431,69 \\
\hline
\end{tabular}

\begin{tabular}{|c|cc|}
\hline & $\mathbf{V 4}$ & $\mathbf{V} \mathbf{3}$ \\
\hline $\mathbf{T}$ & 5,60 & 6,64 \\
$\boldsymbol{\varepsilon}_{\mathbf{T}}$ & 0,58 & 0,57 \\
$\boldsymbol{\varepsilon}_{\mathrm{TBH}}$ & 0,24 & 0,29 \\
$\mathbf{E}_{\mathrm{CC}}$ & 753,85 & 667,24 \\
$\mathbf{U} \cdot \mathbf{A}$ & 478,70 & 414,01 \\
\hline
\end{tabular}

\begin{tabular}{cccc|ccc|} 
& T6 & T5 & T4 & T3 & T2 \\
\hline $\boldsymbol{\Delta T}$ & 10,86 & 8,31 & 5,91 & 3,69 & 1,81 \\
$\boldsymbol{\varepsilon}_{\mathbf{T}}$ & 0,49 & 0,48 & 0,49 & 0,52 & 0,89 \\
$\boldsymbol{\varepsilon}_{\mathbf{T B H}}$ & 0,35 & 0,32 & 0,28 & 0,23 & 0,16 \\
$\mathbf{E}_{\mathrm{CC}}$ & 1260,58 & 966,36 & 690,14 & 427,91 & 207,73 \\
$\mathbf{U} \cdot \mathbf{A}$ & 480,50 & 466,46 & 453,89 & 436,46 & 394,46 \\
\hline
\end{tabular}
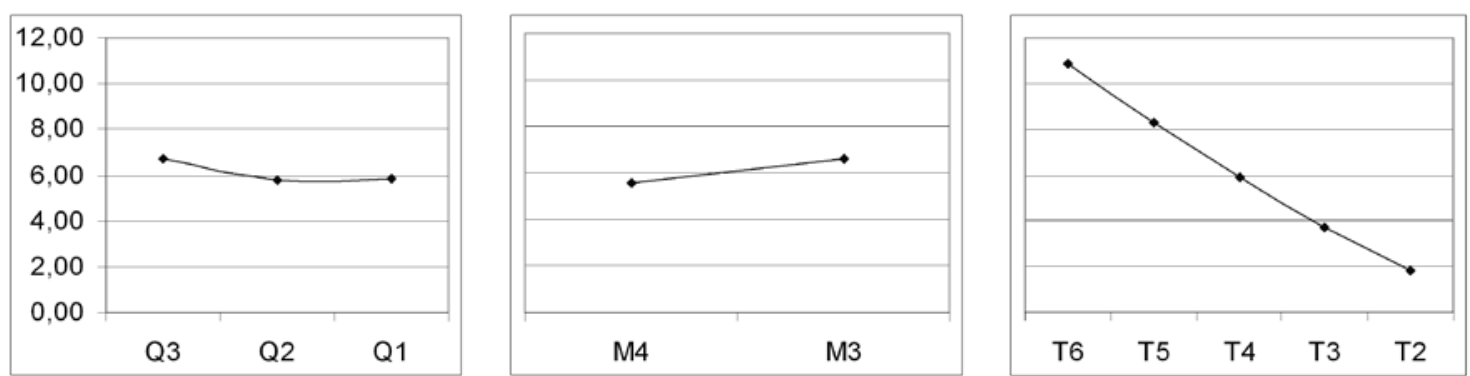

Figura VII.22.- Gráficas factoriales para el salto de temperaturas.
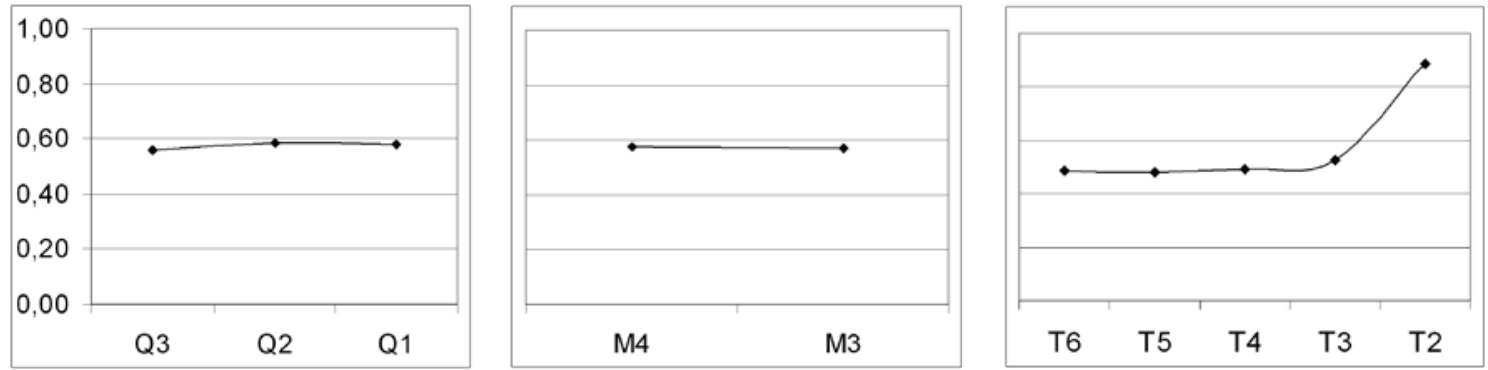

Figura VII.23.- Gráficas factoriales para la efectividad térmica. 

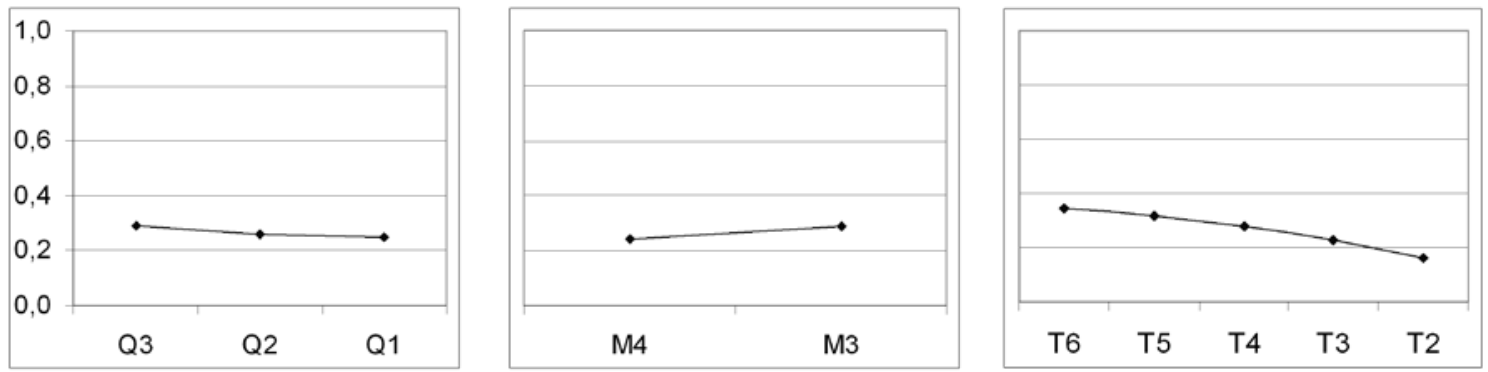

Figura VII.24.- Gráficas factoriales para la efectividad térmica de bulbo húmedo.
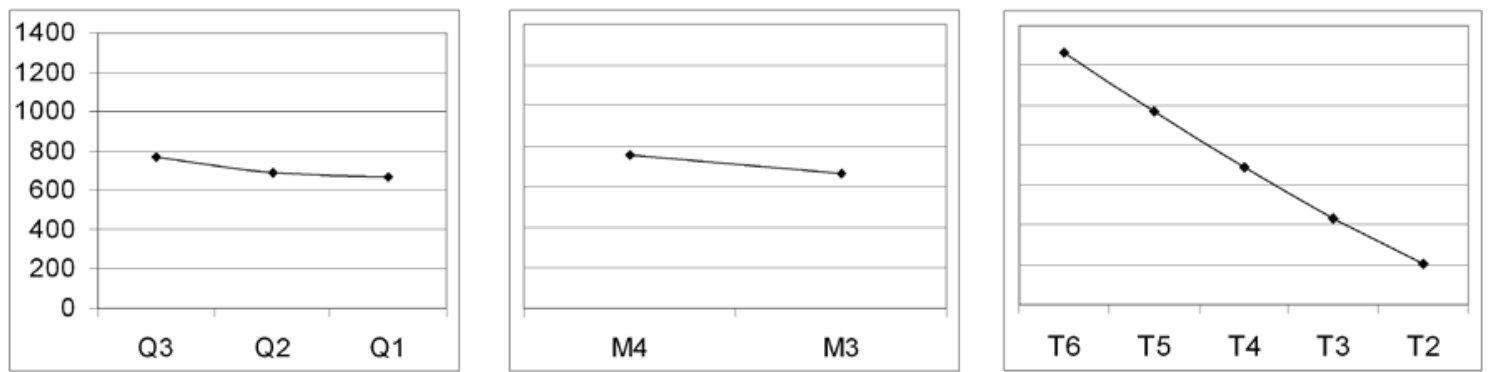

Figura VII.25.- Gráficas factoriales para la capacidad de enfriamiento.
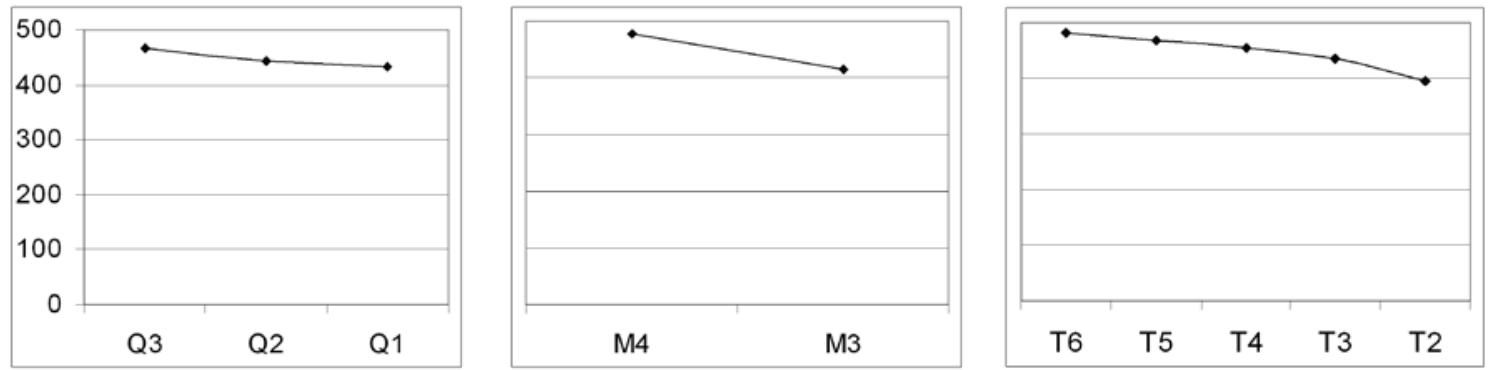

Figura VII.26.- Gráficas factoriales para la conductancia térmica.

Observando las figuras VII.27 a VII.31, correspondientes a los valores recopilados en las tablas VII.6 a VII.10, se observa que la interacción entre factores no parece relevante sobre ningún parámetro, con excepción de una leve influencia de la interacción flujo -temperatura sobre la capacidad de enfriamiento. Sí existe, sin embargo, una influencia importante de las distintas interacciones de factores posibles sobre el factor efectividad seca, pero esta es debida a los ya estudiados resultados desviados respecto a la tendencia esperada por inestabilidades en la expresión del parámetro en cuestión.
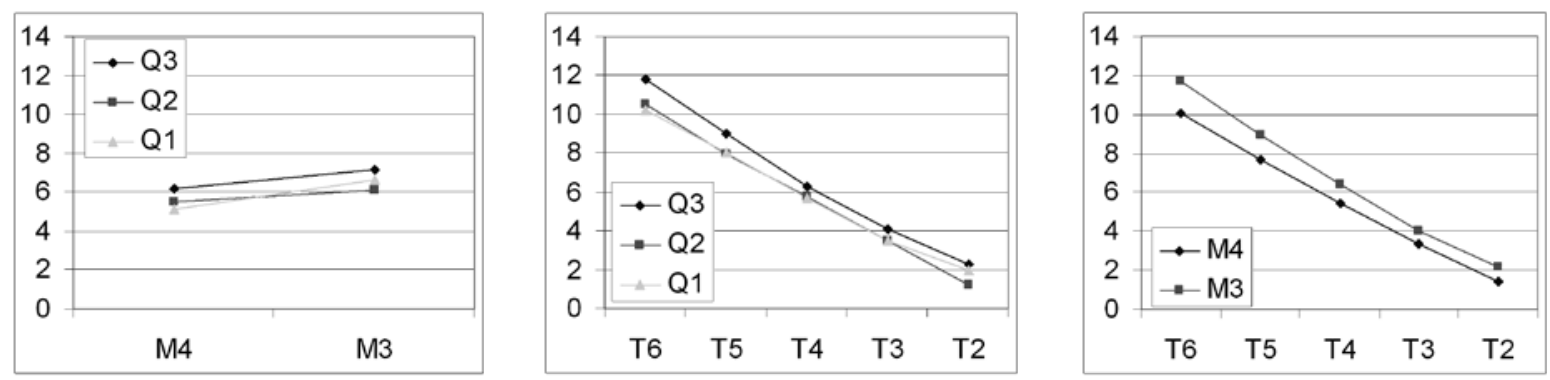

Figura VII.27.- Gráficas de las interacciones factoriales para el salto de temperaturas. 

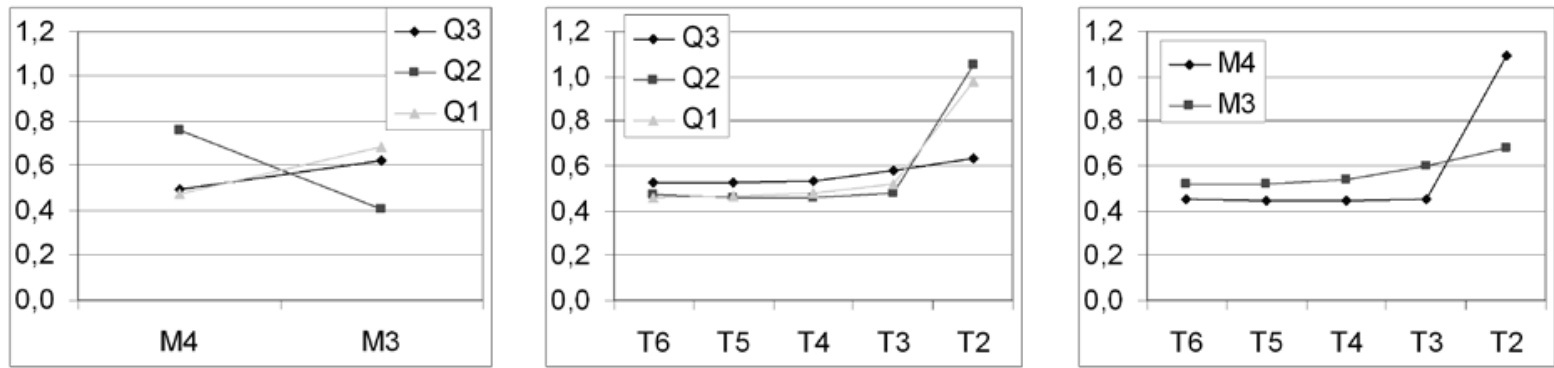

Figura VII.28.- Gráficas de las interacciones factoriales para la efectividad térmica.
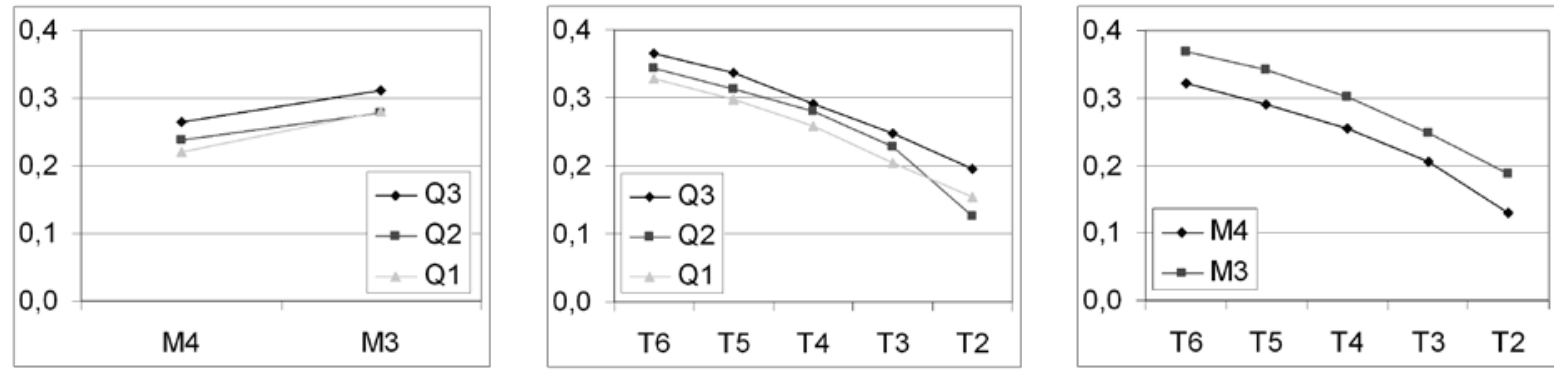

Figura VII.29.- Gráficas de las interacciones factoriales para la efectividad térmica de bulbo húmedo.
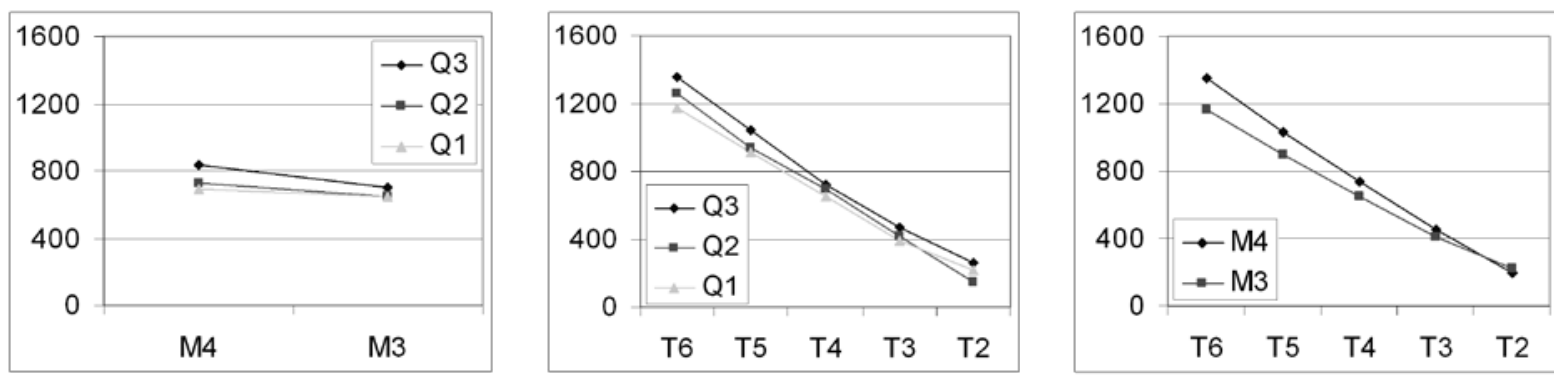

Figura VII.30.- Gráficas de las interacciones factoriales para la capacidad de enfriamiento.
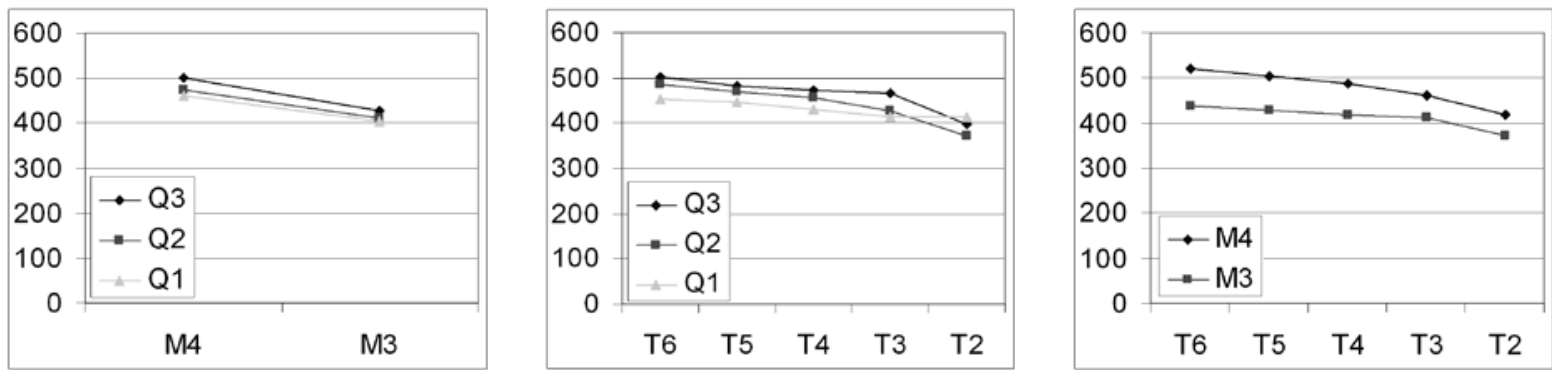

Figura VII.31.- Gráficas de las interacciones factoriales para la conductancia térmica. 
Tabla VII.6.- Valores medios de las interacciones dobles para el salto térmico (ANOVACR).

\begin{tabular}{|c|c|c|}
\hline & V4 & V3 \\
\hline Q3 & 6,21 & 7,18 \\
\hline Q2 & 5,47 & 6,11 \\
\hline Q1 & 5,12 & 6,61 \\
\hline
\end{tabular}

\begin{tabular}{|cccccc|}
\hline \multicolumn{7}{c|}{ Interacción caudal de agua - temperatura } \\
\hline Q3 & T6 & T5 & T4 & T3 & T2 \\
Q2 & 11,83 & 9,00 & 6,28 & 4,12 & 2,24 \\
Q1 & 10,55 & 7,92 & 5,78 & 3,50 & 1,20 \\
& 10,22 & 8,02 & 5,67 & 3,45 & 1,99 \\
\hline
\end{tabular}

Interacción flujo de aire - temperatura

\begin{tabular}{|cccccc} 
& T6 & T5 & T4 & T3 & T2 \\
V4 & 10,05 & 7,69 & 5,45 & 3,35 & 1,45 \\
V3 & 11,68 & 8,94 & 6,37 & 4,03 & 2,16 \\
\hline
\end{tabular}

Tabla VII.7.- Valores medios de las interacciones dobles para la efectividad seca (ANOVA-CR).

Interacción caudal de agua - flujo de aire

\begin{tabular}{|ccc|} 
& V4 & V3 \\
\hline Q3 & 0,49 & 0,63 \\
Q2 & 0,76 & 0,41 \\
Q1 & 0,48 & 0,68 \\
\hline
\end{tabular}

Interacción caudal de agua - temperatura

\begin{tabular}{|cccccc|}
\hline & T6 & T5 & T4 & T3 & T2 \\
Q3 & 0,53 & 0,52 & 0,54 & 0,58 & 0,63 \\
Q2 & 0,47 & 0,46 & 0,46 & 0,48 & 1,05 \\
Q1 & 0,46 & 0,47 & 0,48 & 0,52 & 0,98 \\
\hline
\end{tabular}

Interacción flujo de aire - temperatura

\begin{tabular}{|ccccccc} 
& T6 & T5 & T4 & T3 & T2 \\
V4 & 0,45 & 0,44 & 0,44 & 0,45 & 1,09 \\
V3 & 0,52 & 0,52 & 0,54 & 0,60 & 0,68 \\
\hline
\end{tabular}


Tabla VII.8.- Valores medios de las interacciones dobles para la efectividad de bulbo húmedo (ANOVA-CR).

Interacción caudal de agua - flujo de aire

\begin{tabular}{|ccc|} 
& $\mathbf{V 4}$ & $\mathbf{V 3}$ \\
$\mathbf{Q} 3$ & 0,26 & 0,31 \\
$\mathbf{Q} 2$ & 0,24 & 0,28 \\
$\mathbf{Q 1}$ & 0,22 & 0,28 \\
\hline
\end{tabular}

Interacción caudal de agua - temperatura

\begin{tabular}{|cccccc|} 
& T6 & T5 & T4 & T3 & T2 \\
Q3 & 0,37 & 0,34 & 0,29 & 0,25 & 0,20 \\
Q2 & 0,34 & 0,31 & 0,28 & 0,23 & 0,13 \\
Q1 & 0,33 & 0,30 & 0,26 & 0,20 & 0,15 \\
\hline
\end{tabular}

Interacción flujo de aire - temperatura

\begin{tabular}{ccccccc} 
& T6 & T5 & T4 & T3 & T2 \\
V4 & 0,32 & 0,29 & 0,25 & 0,21 & 0,13 \\
V3 & 0,37 & 0,34 & 0,30 & 0,25 & 0,19 \\
\hline
\end{tabular}

Tabla VII.9.- Valores medios de las interacciones dobles para la capacidad de enfriamiento (ANOVA-CR).

Interacción caudal de agua - flujo de aire

\begin{tabular}{|ccc|} 
& V4 & V3 \\
\hline Q3 & 840,43 & 699,80 \\
Q2 & 732,51 & 650,78 \\
Q1 & 688,61 & 651,14 \\
\hline
\end{tabular}

Interacción caudal de agua - temperatura

\begin{tabular}{|cccccc|} 
& T6 & T5 & T4 & T3 & T2 \\
Q3 & 1352,61 & 1043,85 & 725,98 & 469,47 & 258,67 \\
Q2 & 1257,60 & 941,59 & 695,97 & 418,67 & 144,40 \\
Q1 & 1171,53 & 913,65 & 648,46 & 395,60 & 220,13 \\
\hline
\end{tabular}

Interacción flujo de aire - temperatura

\begin{tabular}{|ccccccc|}
\hline & T6 & T5 & T4 & T3 & T2 \\
\cline { 2 - 7 } V4 & 1354,90 & 1033,22 & 734,47 & 451,03 & 195,63 \\
V3 & 1166,26 & 899,50 & 645,80 & 404,80 & 219,83 \\
\hline
\end{tabular}


Tabla VII.10.- Valores medios de las interacciones dobles para la conductancia térmica (ANOVA-CR).

\begin{tabular}{|ccc|}
\multicolumn{2}{c|}{ Interacción caudal de agua - flujo de aire } \\
\hline Q3 & V4 & V3 \\
Q2 & 401,09 & 428,98 \\
Q1 & 464,73 & 409,93 \\
\hline
\end{tabular}

\begin{tabular}{|cccccc|}
\hline \multicolumn{7}{c|}{ Interacción caudal de agua - temperatura } \\
\hline & T6 & T5 & T4 & T3 & T2 \\
\hline Q3 & 503,26 & 482,84 & 472,71 & 467,67 & 398,71 \\
Q2 & 485,36 & 470,31 & 457,28 & 428,53 & 370,18 \\
Q1 & 452,87 & 446,22 & 431,69 & 413,20 & 414,49 \\
\hline
\end{tabular}

Interacción flujo de aire - temperatura

\begin{tabular}{ccccccc} 
& T6 & T5 & T4 & T3 & T2 \\
\cline { 2 - 6 } V4 & 521,43 & 505,04 & 488,01 & 461,24 & 417,76 \\
V3 & 439,56 & 427,87 & 419,77 & 411,69 & 371,16 \\
\hline
\end{tabular}

La tabla VII.11 recoge las contribuciones de los distintos factores a la varianza de cada parámetro, en porcentaje.

Tabla VII.11.- Coeficientes de contribución derivados del ANOVA-CR realizado sobre los factores del diseño de experimentos.

\begin{tabular}{cccccccccc} 
& $\begin{array}{c}\mathbf{S S}_{\text {total }} \\
{[\%]}\end{array}$ & $\begin{array}{c}\mathbf{S S}_{\mathbf{Q}} \\
{[\%]}\end{array}$ & $\begin{array}{c}\mathbf{S S}_{\mathbf{V}} \\
{[\%]}\end{array}$ & $\begin{array}{c}\mathbf{S S}_{\mathbf{T}} \\
{[\%]}\end{array}$ & $\begin{array}{c}\mathbf{S S}_{\text {Error }} \\
{[\%]}\end{array}$ & $\begin{array}{c}\mathbf{S S}_{\mathrm{QV}} \\
{[\%]}\end{array}$ & $\begin{array}{c}\mathbf{S S}_{\mathrm{QT}} \\
{[\%]}\end{array}$ & $\begin{array}{c}\mathbf{S S}_{\mathrm{VT}} \\
{[\%]}\end{array}$ & $\begin{array}{c}\mathbf{S S}_{\mathrm{RE}} \\
{[\%]}\end{array}$ \\
$\mathbf{\Delta T}$ & 100 & 1,53 & 2,46 & $\mathbf{9 4 , 7 9}$ & 1,22 & 0,27 & 0,45 & 0,29 & 0,21 \\
$\boldsymbol{\varepsilon}_{\mathbf{T}}$ & 100 & 0,10 & 0,01 & 22,87 & $\mathbf{7 7 , 0 3}$ & 14,18 & 6,83 & 9,74 & $\mathbf{4 6 , 2 8}$ \\
$\boldsymbol{\varepsilon}_{\mathrm{TBH}}$ & 100 & 5,01 & 11,13 & $\mathbf{8 0 , 4 4}$ & 3,42 & 0,26 & 1,68 & 0,14 & 1,34 \\
$\mathbf{E C C}$ & 100 & 1,26 & 1,28 & $\mathbf{9 5 , 4 7}$ & 1,99 & 0,30 & 0,48 & $\mathbf{0 , 9 0}$ & 0,30 \\
$\mathbf{U} \cdot \mathbf{A}$ & 100 & 7,83 & $\mathbf{4 2 , 3 3}$ & $\mathbf{3 5 , 7 5}$ & 14,09 & 0,38 & $\mathbf{6 , 8 6}$ & 2,07 & 4,79 \\
\hline
\end{tabular}

El factor temperatura se muestra como la variable clave en la definición del comportamiento de los parámetros salto térmico, efectividades y capacidad de enfriamiento, mientras que la conductancia térmica debe abordarse además en función del flujo de aire tratado, por su influencia sobre los coeficientes de película convectivos.

Los porcentajes de error son aceptables para todos los casos, si acaso ligeramente elevado para la conductancia térmica, pero resulta excesivo para el parámetro efectividad seca. Por lo tanto, la efectividad seca no sería un parámetro válido para la caracterización del sistema. 
Desglosando los porcentajes de error en las distintas contribuciones de las interacciones entre factores, tan sólo se muestran notables, por su magnitud y comparadas frente al porcentaje de error restante, las de la interacción caudal de agua-temperatura en la conductancia térmica, y si acaso la interacción flujo -temperatura para la capacidad de enfriamiento. El efecto de la interacción caudal de agua- temperatura sobre la conductancia térmica puede deberse a la variación en las propiedades de los fluidos a causa de la temperatura, y consecuentemente sobre los coeficientes convectivos de película. Por su parte, la influencia de la interacción entre flujo de aire y temperatura en la capacidad de enfriamiento se muestra evidente atendiendo a la propia definición de ésta (ecuación E-VII.5).

\section{ANOVA - Q3 constante: resultados}

Del análisis realizado desconsiderando el factor caudal de agua, los valores medios obtenidos de los parámetros abordados (salto térmico, efectividad térmica de bulbo húmedo, capacidad de enfriamiento y conductancia térmica) para los distintos ensayos realizados habiéndose mantenido constante un determinado nivel de un factor, son los recopilados en la tabla VII.12 y representados en las figuras VII.32 a VII.35. El factor efectividad térmica de bulbo seco no se considera en este ANOVA, por estar incluyéndose la configuración convencional para la cual la definición de dicho parámetro no es posible.

Tabla VII.12.- Valores medios de los factores (ANOVA-Q3).

\begin{tabular}{|ccc|} 
& $\mathbf{C}-\mathbf{C}$ & $\mathbf{C}-\mathbf{R}$ \\
\hline $\boldsymbol{\Delta T}$ & 7,52 & 5,44 \\
$\boldsymbol{\varepsilon}_{\mathrm{TBH}}$ & 0,32 & 0,32 \\
$\mathbf{E}_{\mathrm{CC}}$ & 613,14 & 448,25 \\
$\mathbf{U} \cdot \mathbf{A}$ & 375,02 & 327,69 \\
\hline
\end{tabular}

\begin{tabular}{cccccc} 
& $\mathbf{V 4}$ & $\mathbf{V 3}$ & $\mathbf{V 2}$ & $\mathbf{V 1}$ \\
\cline { 2 - 5 } $\boldsymbol{\Delta}$ & 5,32 & 6,12 & 6,99 & 7,50 \\
$\boldsymbol{\varepsilon}_{\mathbf{T B H}}$ & 0,27 & 0,31 & 0,33 & 0,35 \\
$\mathbf{E}_{\mathrm{CC}}$ & 718,75 & 604,55 & 488,82 & 310,66 \\
$\mathbf{U} \cdot \mathbf{A}$ & 474,39 & 401,29 & 316,84 & 212,89 \\
\hline
\end{tabular}

\begin{tabular}{cccccc} 
& T6 & T5 & T4 & T3 & T2 \\
\hline $\boldsymbol{\Delta}$ & 11,30 & 8,96 & 6,41 & 3,99 & 1,75 \\
$\boldsymbol{\varepsilon}_{\text {TBH }}$ & 0,40 & 0,38 & 0,34 & 0,28 & 0,20 \\
$\mathbf{E}_{\text {CC }}$ & 930,15 & 737,35 & 519,66 & 323,11 & 143,21 \\
U·A & 364,07 & 366,84 & 356,55 & 347,87 & 321,44 \\
\hline
\end{tabular}



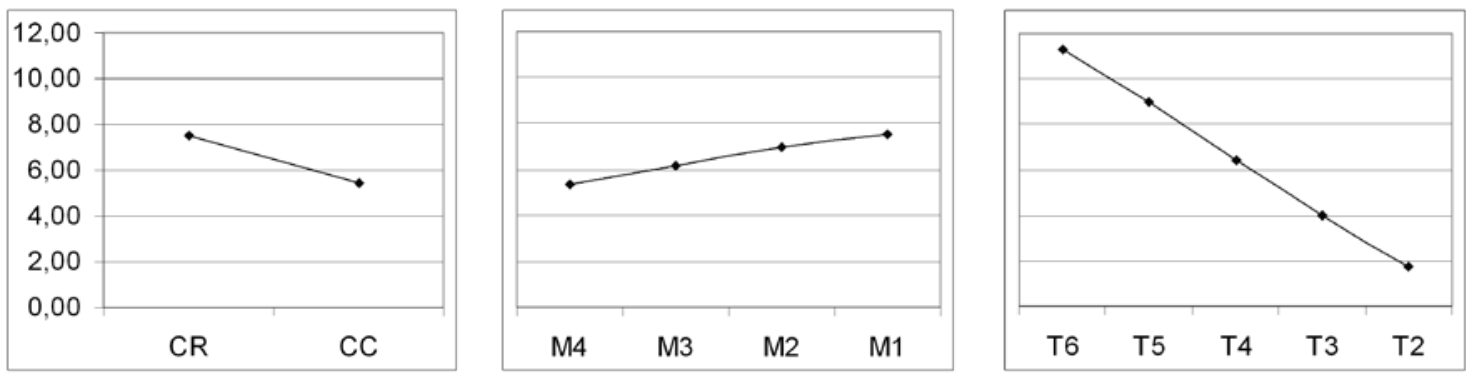

Figura VII.32.- Gráficas factoriales para el salto de temperaturas.
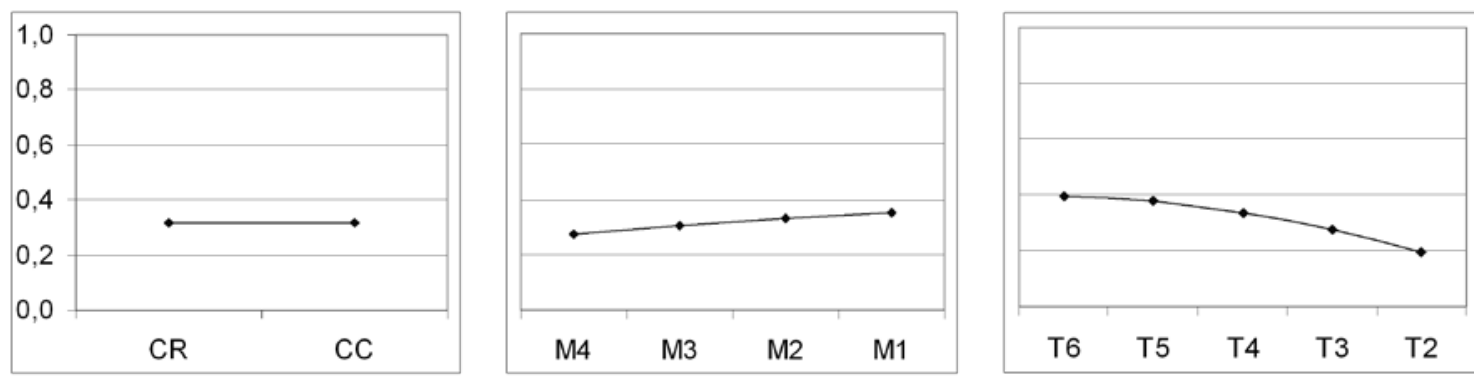

Figura VII.33.- Gráficas factoriales para la efectividad térmica.
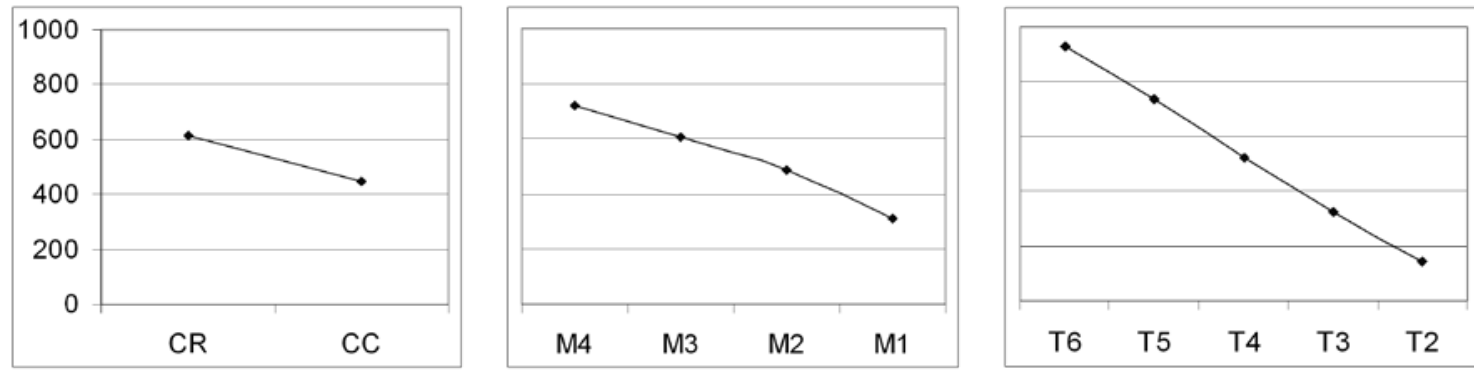

Figura VII.34.- Gráficas factoriales para la capacidad de enfriamiento.
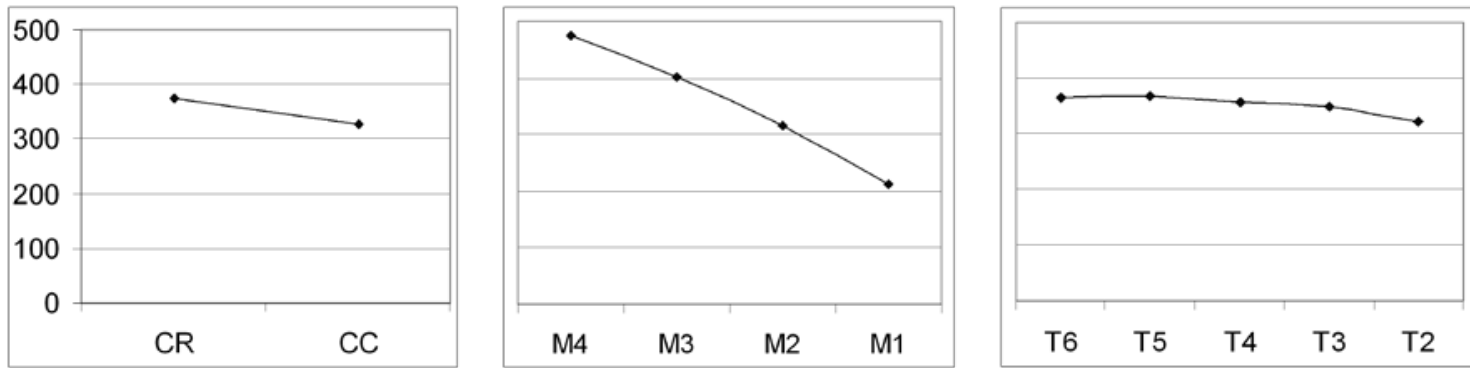

Figura VII.35.- Gráficas factoriales para la conductancia térmica.

De estos resultados recogidos en la tabla VII.12 y mostrados en las figuras anteriores puede extraerse que el factor configuración afecta sólo suavemente al parámetro salto térmico, capacidad de enfriamiento y conductancia térmica, y de forma prácticamente nula a la efectividad de bulbo húmedo.

Por otro lado, el factor flujo de aire también afecta de forma poco notoria a los dos primeros parámetros, mientras que en resulta especialmente relevante su influencia en los resultados de la capacidad de enfriamiento y en la conductancia térmica. 
Finalmente, el factor temperatura aparece como el factor más interesante en la variación de todos los parámetros, con excepción de la conductancia térmica, sobre la que apenas afecta.

Las tablas VII.13 a VII.16 y las correspondientes figuras VII. 36 a VII.39 muestran los valores medios obtenidos de los distintos parámetros para las interacciones dobles entre factores.

Los comportamientos de los saltos térmicos no se ven afectados por la interacción entre factores de forma relevante, puesto que como se muestra en la figura VII.36 (tabla VII.13), los valores medios de los resultados para cada par de factores a las distintas combinaciones de niveles mantenidos constantes siguen tendencias paralelas.
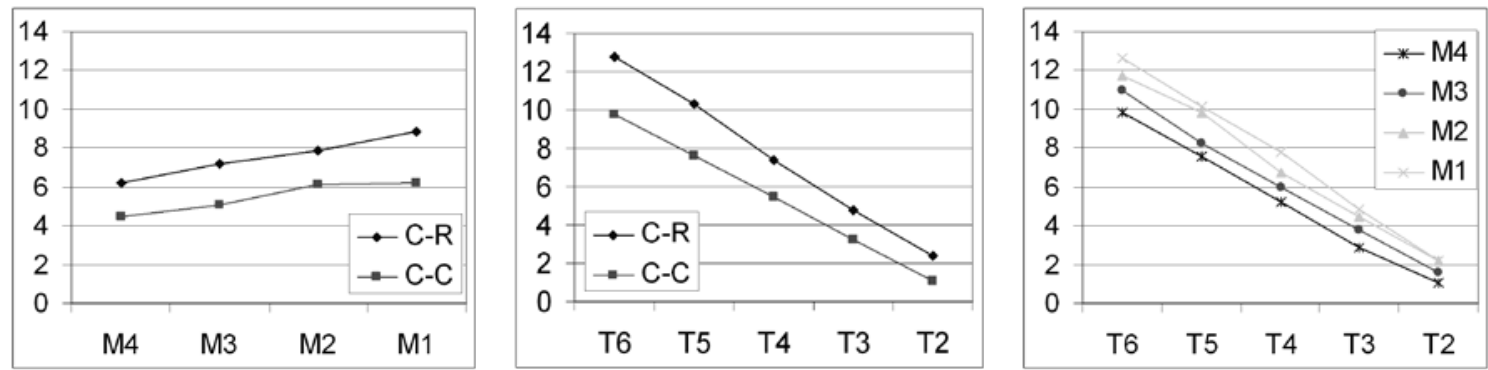

Figura VII.36.- Gráficas de las interacciones factoriales para el salto de temperaturas.

Tabla VII.13.- Valores medios de las interacciones dobles para el salto térmico (ANOVA- Q3).

Interacción caudal de agua - flujo de aire

\begin{tabular}{|ccccc|} 
& V4 & V3 & V2 & V1 \\
C-C & 6,21 & 7,18 & 7,88 & 8,83 \\
C-R & 4,43 & 5,07 & 6,09 & 6,17 \\
\hline
\end{tabular}

Interacción configuración-temperatura

\begin{tabular}{|c|ccccc|}
\hline & T6 & T5 & T4 & T3 & T2 \\
C-C & 12,80 & 10,28 & 7,36 & 4,77 & 2,41 \\
C-R & 9,80 & 7,65 & 5,47 & 3,20 & 1,09 \\
\hline
\end{tabular}

Interacción flujo de aire - temperatura

\begin{tabular}{|cccccc} 
& T6 & T5 & T4 & T3 & T2 \\
V4 & 9,86 & 7,59 & 5,21 & 2,91 & 1,03 \\
V3 & 10,98 & 8,27 & 5,97 & 3,78 & 1,62 \\
V2 & 11,73 & 9,85 & 6,71 & 4,46 & 2,18 \\
V1 & 12,62 & 10,13 & 7,77 & 4,81 & 2,19 \\
\hline
\end{tabular}


Por lo que respecta a la efectividad de bulbo húmedo, y como se muestra en la figura VII.37 (tabla VII.14), las tendencias de las interacciones de cada par de factores son también semejantes en todos los casos, debiéndose despreciarse por lo tanto también aquí el posible efecto de las interacciones sobre los valores obtenidos de este parámetro.
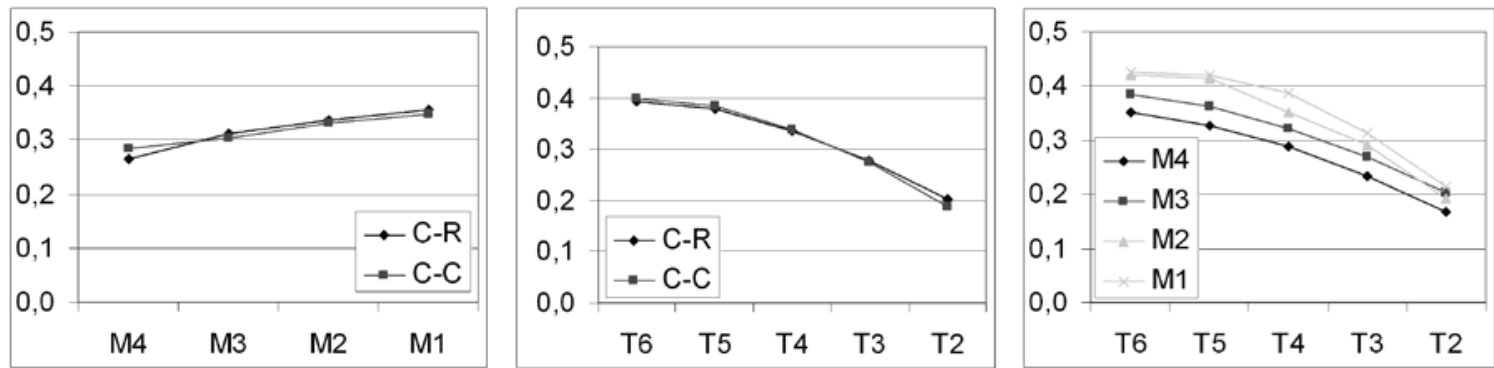

Figura VII.37.- Gráficas de las interacciones factoriales para la efectividad térmica de bulbo húmedo.

Tabla VII.14.- Valores medios de las interacciones dobles para la efectividad de bulbo húmedo (ANOVA- Q3).

Interacción caudal de agua - flujo de aire

\begin{tabular}{c|cccc|} 
& $\mathbf{V 4}$ & $\mathbf{V 3}$ & $\mathbf{V 2}$ & $\mathbf{V 1}$ \\
$\mathbf{C}-\mathbf{C}$ & 0,26 & 0,31 & 0,34 & 0,36 \\
$\mathbf{C}-\mathbf{R}$ & 0,28 & 0,30 & 0,33 & 0,35 \\
\hline
\end{tabular}

Interacción configuración-temperatura

\begin{tabular}{|cccccc|} 
& T6 & T5 & T4 & T3 & T2 \\
C-C & 0,39 & 0,38 & 0,34 & 0,28 & 0,20 \\
C-R & 0,40 & 0,38 & 0,34 & 0,27 & 0,19 \\
\hline
\end{tabular}

Interacción flujo de aire - temperatura

\begin{tabular}{|cccccc} 
& T6 & T5 & T4 & T3 & T2 \\
V4 & 0,35 & 0,33 & 0,29 & 0,23 & 0,17 \\
V3 & 0,38 & 0,36 & 0,32 & 0,27 & 0,20 \\
V2 & 0,42 & 0,41 & 0,35 & 0,29 & 0,19 \\
V1 & 0,43 & 0,42 & 0,39 & 0,31 & 0,22 \\
\hline
\end{tabular}

Al igual que se observaba en el ANOVA-CR, la interacción entre los factores flujo de aire tratado y temperatura seca sí parece influir sobre los resultados del parámetro capacidad de enfriamiento, como se extrae de la tabla VII.15 (figura VII.38), lo cual se muestra lógico, dado que dicho parámetro está definido en función de esos dos mismos factores. 

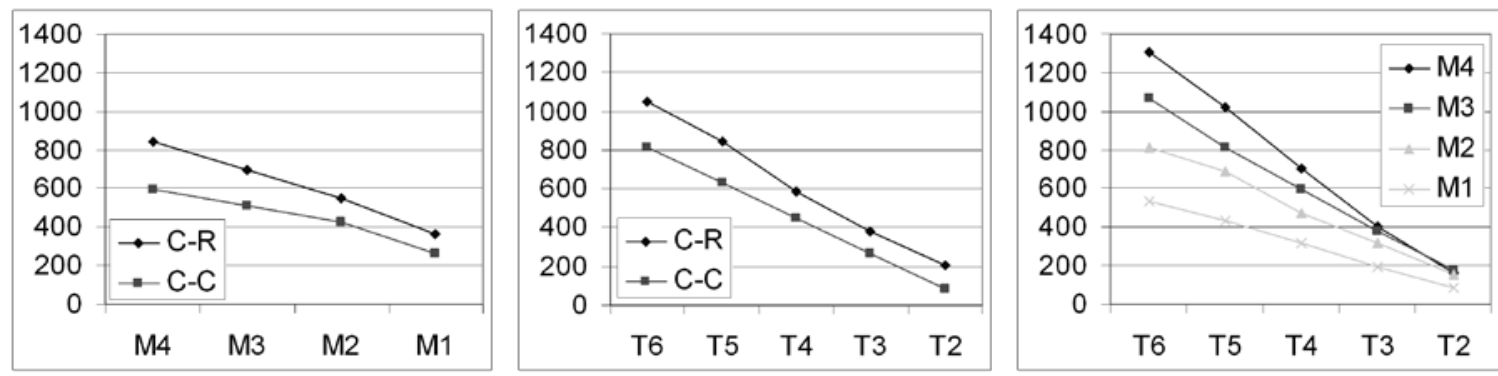

Figura VII.38.- Gráficas de las interacciones factoriales para la capacidad de enfriamiento.

Tabla VII.15.- Valores medios de las interacciones dobles para la capacidad de enfriamiento (ANOVA- Q3).

Interacción caudal de agua - flujo de aire

\begin{tabular}{|c|cccc|} 
& V4 & V3 & V2 & V1 \\
\hline C-C & 840,43 & 699,80 & 551,69 & 360,65 \\
C-R & 597,07 & 509,30 & 425,96 & 260,66 \\
\hline
\end{tabular}

Interacción configuración-temperatura

\begin{tabular}{|cccccc|}
\hline & T6 & T5 & T4 & T3 & T2 \\
\hline C-C & 1049,81 & 843,42 & 586,79 & 383,11 & 202,59 \\
C-R & 810,49 & 631,29 & 452,53 & 263,10 & 83,82 \\
\hline
\end{tabular}

Interacción flujo de aire - temperatura

\begin{tabular}{|cccccc} 
& T6 & T5 & T4 & T3 & T2 \\
\cline { 2 - 6 } V4 & 1308,57 & 1017,31 & 704,16 & 403,60 & 160,11 \\
V3 & 1064,49 & 811,25 & 591,84 & 379,11 & 176,06 \\
V2 & 814,76 & 690,42 & 469,03 & 316,59 & 153,31 \\
V1 & 532,80 & 430,43 & 313,60 & 193,11 & 83,36 \\
\hline
\end{tabular}

Finalmente, en el caso de la conductancia térmica (tabla VII.16, figura VII.39) tampoco parece afectar especialmente el efecto de ninguna interacción entre factores. Tan sólo se muestra una pequeña desviación al menor nivel de temperatura considerado respecto a la tendencia prácticamente paralela de las variaciones con la temperatura de los resultados medios para las dos configuraciones, que probablemente sea debida a variabilidades del proceso experimental ajenas a los factores controlados. 

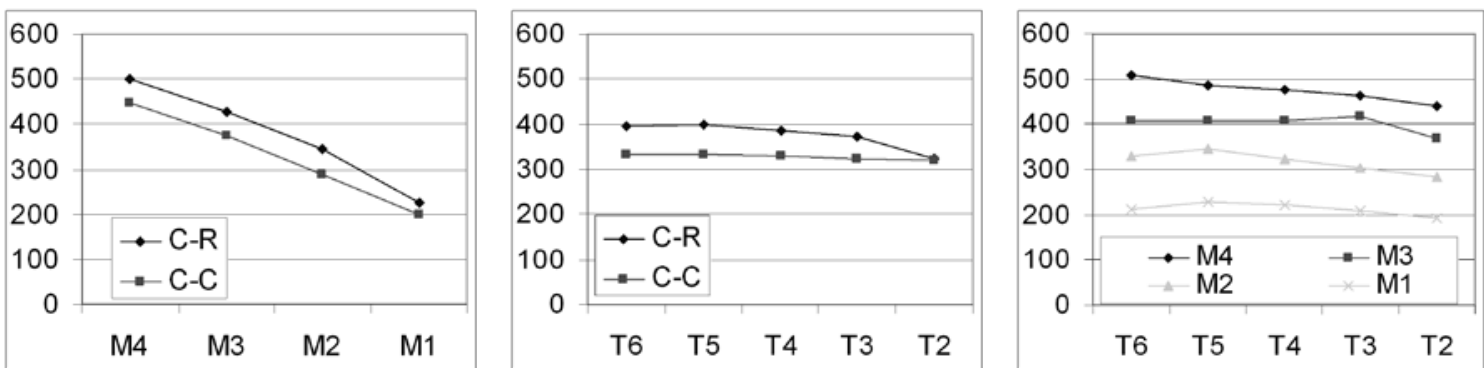

Figura VII.39.- Gráficas de las interacciones factoriales para la conductancia térmica.

Tabla VII.16.- Valores medios de las interacciones dobles para la conductancia térmica (ANOVA- Q3).

Interacción caudal de agua - flujo de aire

\begin{tabular}{cccccc|} 
& V4 & V3 & V2 & V1 \\
C-C & 501,09 & 428,98 & 344,59 & 225,41 \\
C-R & 447,69 & 373,59 & 289,10 & 200,37 \\
\hline
\end{tabular}

Interacción configuración-temperatura

\begin{tabular}{|cccccc|}
\hline & T6 & T5 & T4 & T3 & T2 \\
\hline C-C & 394,91 & 399,44 & 384,78 & 372,15 & 323,81 \\
C-R & 333,23 & 334,24 & 328,31 & 323,60 & 319,06 \\
\hline
\end{tabular}

Interacción flujo de aire - temperatura

\begin{tabular}{|cccccc|}
\hline & T6 & T5 & T4 & T3 & T2 \\
V4 & 507,13 & 486,89 & 475,98 & 462,42 & 439,52 \\
V3 & 406,77 & 406,58 & 407,37 & 415,88 & 369,83 \\
V2 & 329,48 & 346,68 & 321,66 & 303,38 & 283,01 \\
V1 & 212,89 & 227,20 & 221,18 & 209,80 & 193,39 \\
\hline
\end{tabular}

Las conclusiones analizadas anteriormente quedan corroboradas atendiendo a los resultados obtenidos de los porcentajes de contribución sobre la varianza de los distintos factores, recogidos en la tabla VII.17. Como puede observarse en dicha tabla, el factor con más peso sobre los parámetros salto térmico, efectividad de bulbo húmedo y capacidad de enfriamiento es, con diferencia, la temperatura, de lo que se deduce que sería factible el análisis del comportamiento de estos tres parámetros tan sólo atendiendo a la variable temperatura del aire exterior. Por otro lado, el flujo de aire aportado se muestra como factor clave sobre la conductancia térmica, lo cual parece esperable por la influencia del flujo de aire sobre los coeficientes de película convectivos, por lo que dicho parámetro podría estudiarse en función exclusivamente de esta variable. 
Tabla VII.17.- Coeficientes de contribución derivados del ANOVA-Q3 realizado sobre los factores del diseño de experimentos.

\begin{tabular}{cccccccccc} 
& $\begin{array}{c}\mathbf{S S}_{\text {total }} \\
{[\%]}\end{array}$ & $\begin{array}{c}\mathbf{S S}_{\mathbf{C}} \\
{[\%]}\end{array}$ & $\begin{array}{c}\mathbf{S S}_{\mathbf{V}} \\
{[\%]}\end{array}$ & $\begin{array}{c}\mathbf{S S}_{\mathbf{T}} \\
{[\%]}\end{array}$ & $\begin{array}{c}\mathbf{S S}_{\text {Error }} \\
{[\%]}\end{array}$ & $\begin{array}{c}\mathbf{S S}_{\mathbf{C V}} \\
{[\%]}\end{array}$ & $\begin{array}{c}\mathbf{S S}_{\mathrm{CT}} \\
{[\%]}\end{array}$ & $\begin{array}{c}\mathbf{S S}_{\mathbf{V T}} \\
{[\%]}\end{array}$ & $\begin{array}{c}\mathbf{S S}_{\mathrm{RError}} \\
{[\%]}\end{array}$ \\
$\mathbf{\Delta T}$ & 100 & 7,95 & 5,09 & $\mathbf{8 5 , 0 2}$ & 1,94 & 0,24 & 0,74 & 0,48 & 0,48 \\
$\boldsymbol{\varepsilon}_{\mathrm{TBH}}$ & 100 & 0,00 & 13,19 & $\mathbf{8 3 , 1 3}$ & 3,68 & 0,53 & 0,21 & 1,62 & 1,32 \\
$\mathbf{E C C}$ & 100 & 5,71 & 19,12 & $\mathbf{6 6 , 5 1}$ & 8,66 & 0,66 & 0,54 & $\mathbf{7 , 3 0}$ & 0,16 \\
$\mathbf{U} \cdot \mathbf{A}$ & 100 & 5,24 & $\mathbf{8 8 , 9 3}$ & 2,50 & 3,33 & 0,39 & 1,13 & 0,75 & 1,05 \\
\hline
\end{tabular}

En cualquier caso, el porcentaje de error asociado a cada parámetro es bajo, y su desglose en las distintas contribuciones de las posibles interacciones no es muy importante en casi ningún caso, con excepción de la interacción flujo -temperatura sobre la capacidad de enfriamiento, ya ilustrada en los resultados de la tabla VII.15. Por su parte, la leve repercusión de la interacción configuración-temperatura observada en la tabla VII.16 no resulta notable cuando se estudia comparada a la contribución del error restante una vez desglosadas las contribuciones de las distintas interacciones.

En resumen, se comprueba a partir de los resultados de los dos ANOVA realizados, que las conclusiones derivadas del análisis de resultados sobre el sistema en las dos configuraciones, en el que se observaba la baja influencia del factor caudal de agua y el no interés del nivel de temperatura menor, serían válidas. Esto, junto con el resto de ideas extraídas en el análisis de la varianza, supone por un lado que los parámetros salto térmico, efectividad de bulbo húmedo y capacidad de enfriamiento pueden caracterizarse exclusivamente en función de la temperatura de forma aceptable; y por el otro que dicho factor de temperatura junto con el flujo de aire tratado serían suficientes por su parte para caracterizar el parámetro conductancia térmica. Finalmente, se concluye que el parámetro efectividad seca no sería una característica válida en el análisis del comportamiento del sistema. 


\section{REFERENCIAS}

[1] Ghiaus, C.; Allard, F.; "Potential for free-cooling by ventilation". Revista: Solar Energy, n80 (pp.402-413). 2006.

[2] Adnot, J. et al.; "Energy Efficiency and Certification of Central Air Conditioners (EECCAC) FINAL REPORT - APRIL 2003", Volumen 3. Paris, 2003.

[3] International Energy Agency - Energy Conservation in Buildings and Community Systems. Technical Synthesis Report - Annex 28: Low Energy Cooling. Coventry, U.K.: ESSU (ExCo Support Services Unit); 2000.

[4] Hughes, B.R.; Chaudhry, H.N.; Ghani, S.A. "A review of sustainable cooling technologies in buildings". Revista: Renewable and Sustainable Energy Reviews, № 15 (pp.: 3112- 3120). 2010.

[5] Asociación Técnica Española de Climatización y Refrigeración (ATECYR), "Guía técnica de ahorro y recuperación de energía en instalaciones de climatización". Serie: "Ahorro y Eficiencia Energética en la Climatización", Guía nº 9. Instituto para la Diversificación y Ahorro de la Energía (IDAE), Madrid, 2010.

[6] Wang S.K., "Incorporating Evaporative Cooling with Other Coolers", Handbook of AirConditioning and Refrigeration, McGraw Hill, New York, 1994.

\section{Páginas web}

[W-1] http://www.pecomark.com/ Página del fabricante Pecomark, donde se puede descargar la información técnica sobre las baterías de tubos aleteados modelo AT48N (Consultada en octubre de 2011). 


\section{RELACIÓN DE FIGURAS}

- Figura VII.1.- Vista de la torre de enfriamiento.

- Figura VII.2. - Vista de la batería adquirida.

- Figura VII.3.- Vista de la batería montada en el sistema.

- Figura VII.4.- Vista superior de la instalación de torre con batería.

- Figura VII.5.- Esquema de la instalación experimental en configuración recuperativa, con indicaciones de los puntos de toma de medidas.

- Figura VII.6.- Esquema de la instalación experimental en configuración convencional, con indicaciones de los puntos de toma de medidas.

- FiguraVII.7.- Evolución de las temperaturas del aire a entrada y salida de la torre y de la batería durante el ensayo del sistema en modo recuperativo a $400 \mathrm{~m}^{3} / \mathrm{h}$ de aire entrando a $30^{\circ} \mathrm{C}$, y con un caudal de agua de aporte de $8 \mathrm{l} / \mathrm{min}$.

- FiguraVII.8.- Evolución de la humedad específica y relativa del aire a su paso por la torre durante el ensayo del sistema en modo recuperativo a $400 \mathrm{~m}^{3} / \mathrm{h}$ de aire entrando a $30^{\circ} \mathrm{C}$, y con un caudal de agua de aporte de $8 \mathrm{l} / \mathrm{min}$.

- FiguraVII.9.- Saltos térmicos de temperaturas del aire a su paso por la batería, con un caudal de agua en la torre de $8 \mathrm{l} / \mathrm{min}$ (sistema en configuración recuperativa).

- FiguraVII.10.- Saltos térmicos de temperaturas del aire a su paso por la batería, fluyendo a razón de 400 y $300 \mathrm{~m}^{3} / \mathrm{h}$ (sistema en configuración recuperativa).

- FiguraVII.11.- Efectividad de bulbo seco del sistema, con un caudal de agua en la torre de 8 I/min (sistema en configuración recuperativa).

- FiguraVII.12.- Efectividad de bulbo seco del sistema para varios caudales de agua, con caudales de aire de 400 y $300 \mathrm{~m}^{3} / \mathrm{h}$ (sistema en configuración recuperativa).

- FiguraVII.13.- Efectividad de bulbo húmedo del sistema, con un caudal de agua en la torre de 8 l/min (sistema en configuración recuperativa).

- FiguraVII.14.- Efectividad de bulbo húmedo del sistema para varios caudales de agua, con caudales de aire de 400 y $300 \mathrm{~m}^{3} / \mathrm{h}$ (sistema en configuración recuperativa).

- FiguraVII.15.- Capacidad de enfriamiento del sistema, con un caudal de agua en la torre de $8 \mathrm{l} / \mathrm{min}$ (sistema en configuración recuperativa).

- FiguraVII.16.- Capacidad de enfriamiento del sistema para varios caudales de agua, con caudales de aire de 400 y $300 \mathrm{~m}^{3} / \mathrm{h}$ (sistema en configuración recuperativa).

- FiguraVII.17.- Conductancia térmica de la batería, con un caudal de agua en la torre de 8 I/min (sistema en configuración recuperativa).

- FiguraVII.18.- Conductancia térmica de la batería para varios caudales de agua, con caudales de aire de 400 y $300 \mathrm{~m}^{3} / \mathrm{h}$ (sistema en configuración recuperativa).

- Figura VII.19.- Salto térmico de temperaturas del aire en la batería: resultados experimentales y previstos (sistema en configuración recuperativa). 
- Figura VII.20.- Efectividad térmica de bulbo húmedo: resultados experimentales y previstos (sistema en configuración recuperativa).

- Figura VII.21.- Capacidad de enfriamiento: resultados experimentales y previstos (sistema en configuración recuperativa).

- Figura VII.22.- Gráficas factoriales para el salto de temperaturas.

- Figura VII.23.- Gráficas factoriales para la efectividad térmica.

- Figura VII.24.- Gráficas factoriales para la efectividad térmica de bulbo húmedo.

- Figura VII.25.- Gráficas factoriales para la capacidad de enfriamiento.

- Figura VII.26.- Gráficas factoriales para la conductancia térmica.

- Figura VII.27.- Gráficas de las interacciones factoriales para el salto de temperaturas.

- Figura VII.28.- Gráficas de las interacciones factoriales para la efectividad térmica.

- Figura VII.29.- Gráficas de las interacciones factoriales para la efectividad térmica de bulbo húmedo.

- Figura VII.30.- Gráficas de las interacciones factoriales para la capacidad de enfriamiento.

- Figura VII.31.- Gráficas de las interacciones factoriales para la conductancia térmica.

- Figura VII.32.- Gráficas factoriales para el salto de temperaturas.

- Figura VII.33.- Gráficas factoriales para la efectividad térmica.

- Figura VII.34.- Gráficas factoriales para la capacidad de enfriamiento.

- Figura VII.35.- Gráficas factoriales para la conductancia térmica.

- Figura VII.36.- Gráficas de las interacciones factoriales para el salto de temperaturas.

- Figura VII.37.- Gráficas de las interacciones factoriales para la efectividad térmica de bulbo húmedo.

- Figura VII.38.- Gráficas de las interacciones factoriales para la capacidad de enfriamiento.

- Figura VII.39.- Gráficas de las interacciones factoriales para la conductancia térmica. 


\section{RELACIÓN DE TABLAS}

- Tabla VII.1.- Diseño de Experimentos

- Tabla VII.2.- Coeficientes de las regresiones respecto a la temperatura de los resultados experimentales en configuración recuperativa.

- Tabla VII.3.- Coeficientes de las regresiones respecto al flujo másico de aire de los coeficientes de las regresiones respecto a la temperatura esperadas para los resultados para configuración convencional.

- Tabla VII.4.- Coeficientes de las regresiones respecto a la temperatura en configuración convencional, experimentales y calculados.

- Tabla VII.5.- Valores medios de los factores (ANOVA-CR).

- Tabla VII.6.- Valores medios de las interacciones dobles para el salto térmico (ANOVA-CR).

- Tabla VII.7.- Valores medios de las interacciones dobles para la efectividad seca (ANOVACR).

- Tabla VII.8.- Valores medios de las interacciones dobles para la efectividad de bulbo húmedo (ANOVA-CR).

- Tabla VII.9.- Valores medios de las interacciones dobles para la capacidad de enfriamiento (ANOVA-CR).

- Tabla VII.10.- Valores medios de las interacciones dobles para la conductancia térmica (ANOVA-CR).

- Tabla VII.11.- Coeficientes de contribución derivados del ANOVA-CR realizado sobre los factores del diseño de experimentos.

- Tabla VII.12.- Valores medios de los factores (ANOVA-Q3).

- Tabla VII.13.- Valores medios de las interacciones dobles para el salto térmico (ANOVAQ3).

- Tabla VII.14.- Valores medios de las interacciones dobles para la efectividad de bulbo húmedo (ANOVA- Q3).

- Tabla VII.15.- Valores medios de las interacciones dobles para la capacidad de enfriamiento (ANOVA- Q3).

- Tabla VII.16.- Valores medios de las interacciones dobles para la conductancia térmica (ANOVA- Q3).

- Tabla VII.17.- Coeficientes de contribución derivados del ANOVA-Q3 realizado sobre los factores del diseño de experimentos. 


\section{CAPÍTULO VIII CARACTERIZACIÓN DEL SISTEMA DE RECUPERACIÓN DE ENERGÍA MEDIANTE DOS BATERÍAs CON BOMBA}

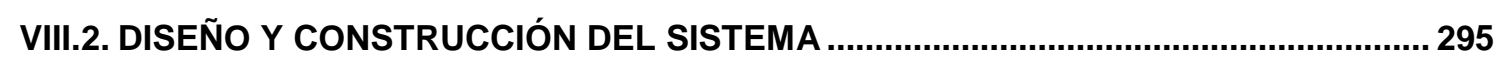

VIII.3. DISEÑO DE EXPERIMENTOS. METODOLOGÍA DE ENSAYOS................................. 299

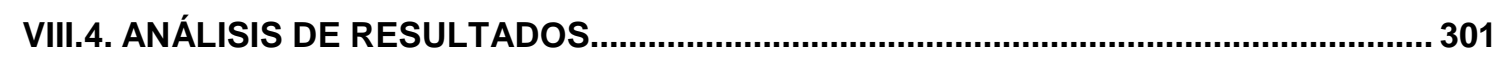

PARÁMETROS CONSIDERADOS EN LA CARACTERIZACIÓN EXPERIMENTAL ............................... 301

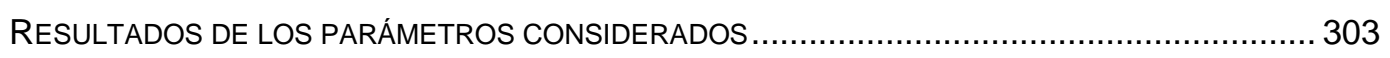

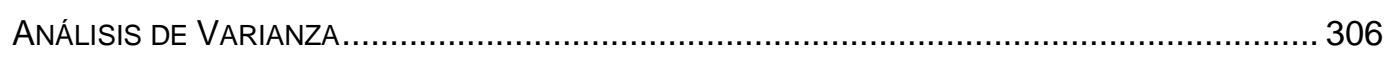


Capítulo Vill: Caracterización del Sistema de Recuperación de Energía Mediante dos baterías CON BOMBA 


\section{CHAPTER VIII: \\ CHARACTERIZATION OF THE RUN-AROUND LOOP HEAT RECOVERY SYSTEM}

\section{ABSTRACT}

The system studied in chapter VIII is a Run-around Loop Heat Recovery device, consisting of two coils operating with outdoor and exhaust air respectively, through whose pipes it flows water which is continuously recirculated with the aid of two pumps. For being also in this case a prototype manufactured in the laboratory, the chapter starts with a description of the design and constructive characteristics.

With the aim of experimentally characterize its behaviour, specific operating conditions have been tested, determined from a Design of Experiments. Factors varied among different tests are: air volume flow through the first coil (operating with outdoor air) and dry bulb temperature of this same entering airstream.

Parameters studied in this case are the same as the ones proposed for previous systems: temperature drop, thermal effectiveness, cooling capacity and thermal conductance. Notice nonetheless that wet bulb thermal effectiveness has no sense in this particular analysis.

An Analysis of Variance is developed to study how the different factors considered in the tests affect the performance of the Run-around system. 
Capítulo VIII: Caracterización del Sistema de Recuperación de Energía MEdiante dos Baterías CON BOMBA 


\section{SiMBOLOGÍA DEL CAPÍTULO}

EB1w: Entrada de agua a la batería 1

SB1w: Salida de agua de la batería 1.

EB2w: Entrada de agua a la batería 2.

SB2w: Salida de agua de la batería 2.

EB1a: Entrada de aire a la batería 1.

SB1a: Salida de aire de la batería 1.

EB2a: Entrada de aire a la batería 2.

SB2a: Salida de aire de la batería 2.

m : $\quad$ Flujo másico de aire seco $\left[\mathrm{kg}_{a s} / \mathrm{s}\right]$

$\dot{V}: \quad$ Caudal volumétrico de aire $\left[\mathrm{m}^{3} / \mathrm{h}\right]$

$X_{i}$ : humedad específica en el punto i del sistema [g/kg]

$T_{i}$ : Temperatura de bulbo seco del aire en el punto i del sistema [ $\left.{ }^{\circ} \mathrm{C}\right]$

$\Delta T$ : salto térmico de temperaturas alcanzado en la corriente de aire de ventilación (batería) [ ${ }^{\circ} \mathrm{C}$ ]

$\varepsilon_{T}:$ Efectividad térmica.

$\Delta T_{L M}:$ Diferencia Media Logarítmica de Temperaturas [K]

$E_{C c}:$ Capacidad de enfriamiento [W]

$h_{E B 1 a:}$ entalpía del aire de ventilación a la entrada de la batería[kJ/kg $\left.{ }_{a s}\right]$

$h_{S B 1 a}$ : entalpía del aire de ventilación a la salida de la batería $\left[\mathrm{kJ}^{\mathrm{k}} / \mathrm{kg}_{\text {as }}\right]$

$C p_{a}$ : Calor específico del aire a presión constante [kJ/kgC]

$U_{1}$ : Coeficiente Global de Transmisión de Calor de la batería $1\left[\mathrm{~W} / \mathrm{m}^{2} \mathrm{~K}\right]$

$U_{2}$ : Coeficiente Global de Transmisión de Calor de la batería 2[W/m $\left.{ }^{2} \mathrm{~K}\right]$

A: Área $\left[\mathrm{m}^{2}\right]$

$\dot{Q}_{\text {sensi }}$ : calor sensible intercambiado en la batería i [W]

n: Término independiente en las regresiones de los parámetros respecto a la temperatura de entrada del aire a la batería 1. 
m: Coeficiente del término de la primera potencia de la temperatura de entrada del aire a la batería 1 en las regresiones de los parámetros respecto a ésta.

SS $S_{V}$ Porcentaje de contribución de la suma de cuadrados del factor "caudal de aire de ventilación" [\%]

$\mathrm{SS}_{T}$ : Porcentaje de contribución de la suma de cuadrados del factor "temperatura seca exterior" [\%]

SS Error: Porcentaje de contribución de la suma de cuadrados del error restante de las contribuciones de los factores [\%]

$\mathrm{SS}_{V T}$ : Porcentaje de contribución de la suma de cuadrados de la interacción caudal de airetemperatura [\%]

SS $S_{\text {Error: }}$ Porcentaje de contribución de la suma de cuadrados del error restante de las contribuciones de los factores y sus interacciones [\%] 


\section{VIII.1. INTRODUCCIÓN}

En el capítulo III se presentaban los sistemas de recuperación de energía como alternativas capaces de hacer uso de la energía residual de los caudales de aire expulsados al exterior en condiciones de confort, necesarios para cumplir con los requisitos de renovación de aire, para preacondicionar el aire de ventilación impulsado a los locales con el mismo objeto [1, ATECYR, 2010], [2, Rey et al., 1996]. Además, en España la recuperación de energía en la actualidad se trata no sólo de una alternativa de ahorro energético, sino que su implantación queda impuesta por la normativa [N-1].

De entre los múltiples sistemas existentes de recuperación de energía, los Heat Pipes resultan una solución interesante por su ausencia de partes móviles y su independencia de fuente de alimentación alguna [3, Hughes, 2010]. Desde el Grupo de Termotecnia de Valladolid se han desarrollado con anterioridad estudios experimentales de sistemas basados en esta tecnología [4, Rey et al., 2003].

Por otro lado, los equipos de dos baterías con bomba o run-around, permitían el transvase energético desde la corriente de extracción hacia la corriente de ventilación gracias a la circulación en un circuito cerrado de un fluido caloportador que en las condiciones habituales de trabajo intercambia sólo calor sensible con estas corrientes [5, ASHRAE, 2000]. A pesar de su ligeramente menor rendimiento frente a otros sistemas de recuperación de energía en sistemas de acondicionamiento de aire por requerir de varios procesos intermedios, al contrario que éstos, los equipos Run-around no precisan que los conductos de aire de expulsión e impulsión sean adyacentes, lo que se traduce en una gran ventaja cuando existen limitaciones en la instalación o cuando resulta de especial relevancia la posible contaminación entre flujos en las tomas de entrada/ salida [6, Adnot et al., 2003], [7, Mardiana-Idayu\&Riffat, 2011]. Es en consideración a estas ventajas por lo que se escoge esta tecnología de recuperación de energía para su estudio en este trabajo de Tesis Doctoral.

A continuación se realiza la descripción experimental del sistema particular diseñado y construido en el laboratorio de Termotecnia de la Universidad de Valladolid siguiendo esta misma idea de recuperación de energía mediante dos baterías con bomba.

\section{VIII.2. Diseño Y CONSTRUCCIÓN DEL SISTEMA}

El sistema diseñado en particular consta de dos baterías de tubos de cobre aleteadas para intercambio aire - líquido, conectadas por el circuito del líquido caloportador, agua en este caso, con el cual las corrientes de aire que atraviesan cada batería intercambian energía y que es accionado por dos bombas hidráulicas de potencia $380 \mathrm{~W}$ conectadas en serie.

A su paso por las baterías, el agua toma energía de la que es atravesada por la corriente de aire más cálida (aire exterior en verano e interior en invierno) para luego cederla al flujo de 
aire a menor temperatura (aire interior en verano y exterior en invierno), como se mostraba en la figura III.26; realizándose así el aprovechamiento del nivel térmico del aire interior expulsado cuando éste sea más adecuado que el del introducido para ventilación. En caso contrario, se recurriría a alternativas de free-cooling por aire o por agua, como se explicó en los capítulos III y VII [1, ATECYR, 2010], [2, Rey et al., 1996].

Las baterías empleadas son similares a la utilizada en el sistema de enfriamiento gratuito por agua del capítulo VII (figura VII.2). Se trata de baterías para recuperación de energía en sistemas aire-aire, con tubería de cobre y aleta de aluminio, modelo AT-48N y disposición al tresbolillo, 25 22, con aleta de alta efectividad; tubo de 3/8“; separación entre aletas de 3,2 mm y conexiones a 1/2". Ambas baterías se montaron sobre placas acopladas a los colectores que soportan los conductos de aire (figuras VIII.1 y VIII.2).

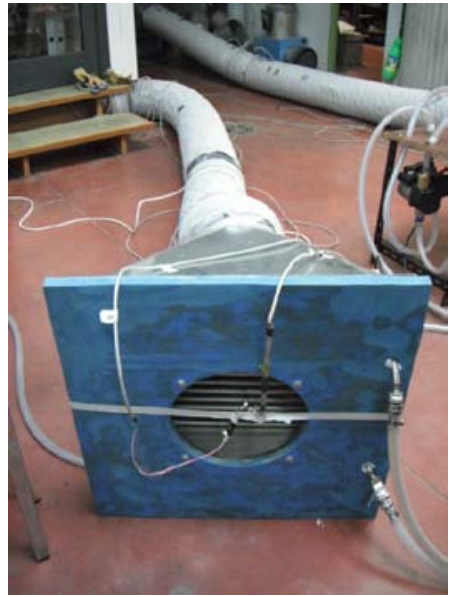

Figura VIII.1. - Vista frontal del montaje de una batería.

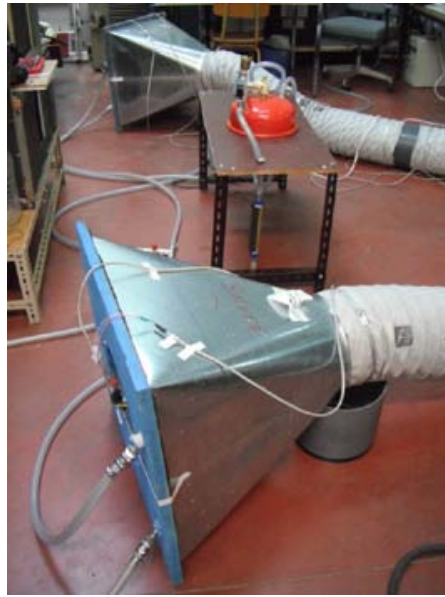

Figura VIII.2.- Vista global de las baterías instaladas en el sistema.

Una vez montadas las baterías y conectadas a los conductos de aire, se conectaron al circuito de agua, el cual consta además de las dos bombas de circulación Salmson (ya descritas en el capítulo IV) de un depósito de expansión para amortiguar variaciones en la densidad del fluido, junto a un purgador, un manómetro de presión y un caudalímetro para medir la presión y caudal del agua circulante (figura VIII.3).

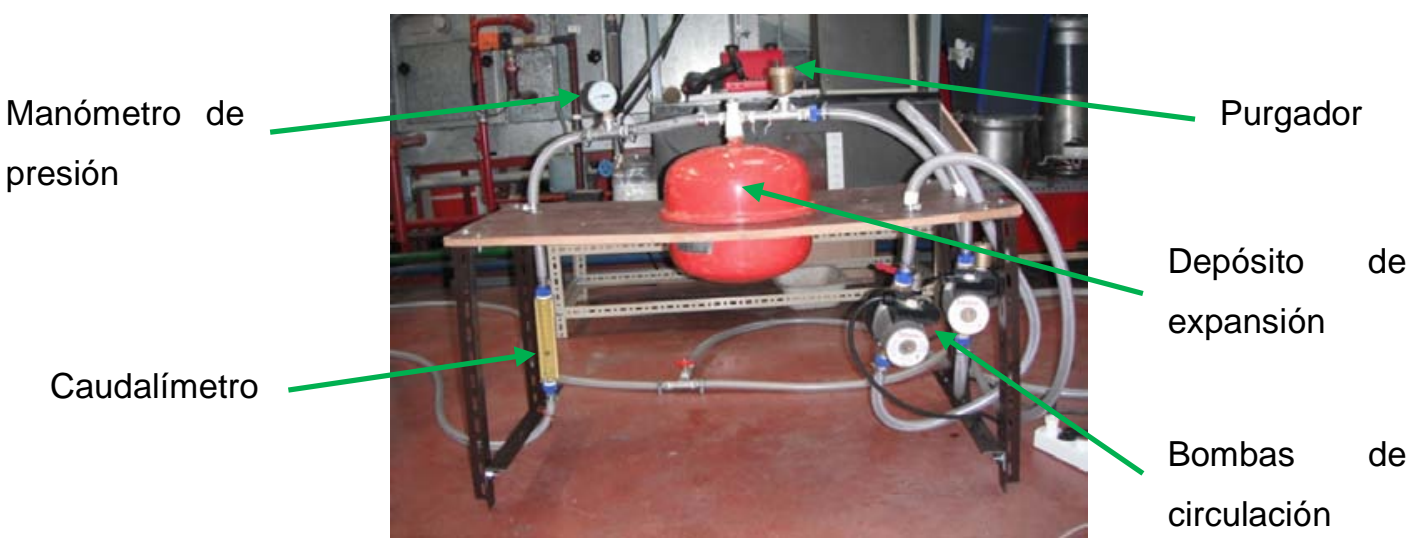

Figura VIII.3.- Elementos de circulación, regulación y control del sistema. 
Para poder realizar la caracterización del funcionamiento del sistema, fue necesario conectar el circuito de aire al dispositivo experimental disponible en el laboratorio y ya descrito en el capítulo IV. El conducto de aire exterior está conectado a la Unidad de Tratamiento de Aire, mientras que el conducto de aire de expulsión conecta la correspondiente batería a la salida de aire de la cámara climática. La UTA permite aportar el caudal de aire de ventilación requerido, en las condiciones estivales del ambiente exterior a ensayar. Por su parte, el ambiente interior de la cámara climática está adecuado en condiciones de confort (mantenidas aproximadamente entorno a $22^{\circ} \mathrm{C}$ de temperatura seca y $50 \%$ de humedad relativa), gracias a la bomba de calor de la que dispone dicho espacio (véase el capítulo II).

La figura VIII.4 muestra un dibujo de la instalación global descrita. En una aplicación real, la salida de la batería del aire de ventilación se encontraría conectada a la cámara climática para la impulsión de dicha corriente de aire preacondicionado al interior del espacio climatizado, reduciendo así el consumo del equipo convencional de acondicionamiento de aire. Sin embargo, por simplicidad del dispositivo experimental y por ser innecesaria para la caracterización del sistema, dicha conexión se obvió en la instalación.

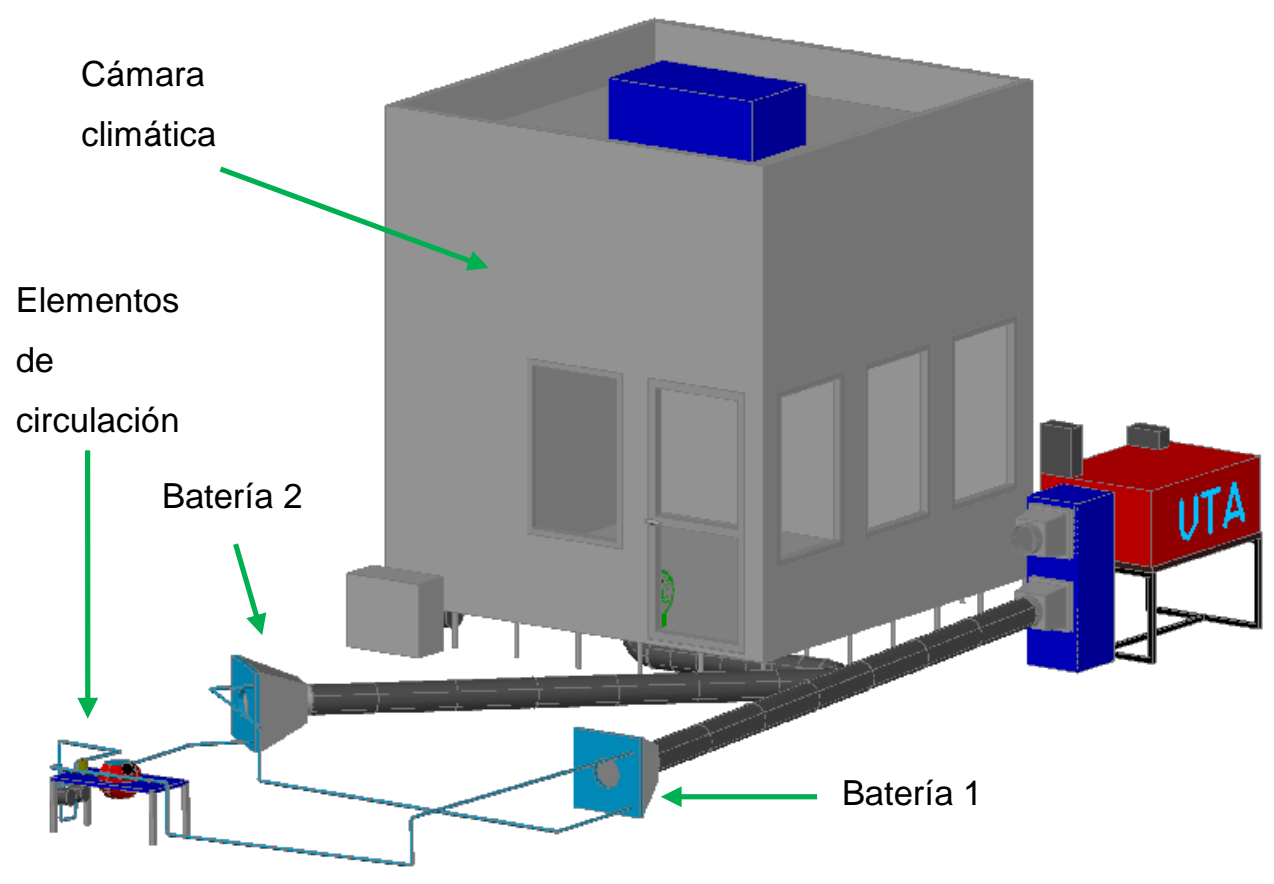

Figura VIII.4.- Dibujo de la instalación global.

Por claridad, de ahora en adelante se referirán las baterías de aire exterior e interior como batería 1 y batería 2 respectivamente, según se identifican en la figura VIII.4.

Las baterías 1 y 2 están además conectadas entre sí a través del circuito cerrado de agua que actúa como portador de la energía recuperada. Como se ha indicado en el apartado anterior, este circuito consta de un depósito de expansión, un purgador y dos bombas de agua 
conectados en serie entre la batería 1 y la batería 2, que van a permitir la circulación de un caudal de agua constante de $4 \mathrm{l} / \mathrm{min}$.

En el esquema de la instalación global mostrado en la figura VIII.5, se indica la conexión de los distintos elementos, además de la posición de las sondas de medida de temperatura seca y humedad relativa de las corrientes de aire, y de medida de temperatura del agua en los distintos puntos de interés dentro del circuito cerrado. Asimismo, se miden los caudales de aire exterior y de expulsión mediante placas orificio; y el caudal de agua circulante mediante un caudalímetro. La nomenclatura utilizada en el estudio para denominar a los distintos puntos de interés de las condiciones del aire y del agua se corresponde con la indicada en el esquema de la figura VIII.5.

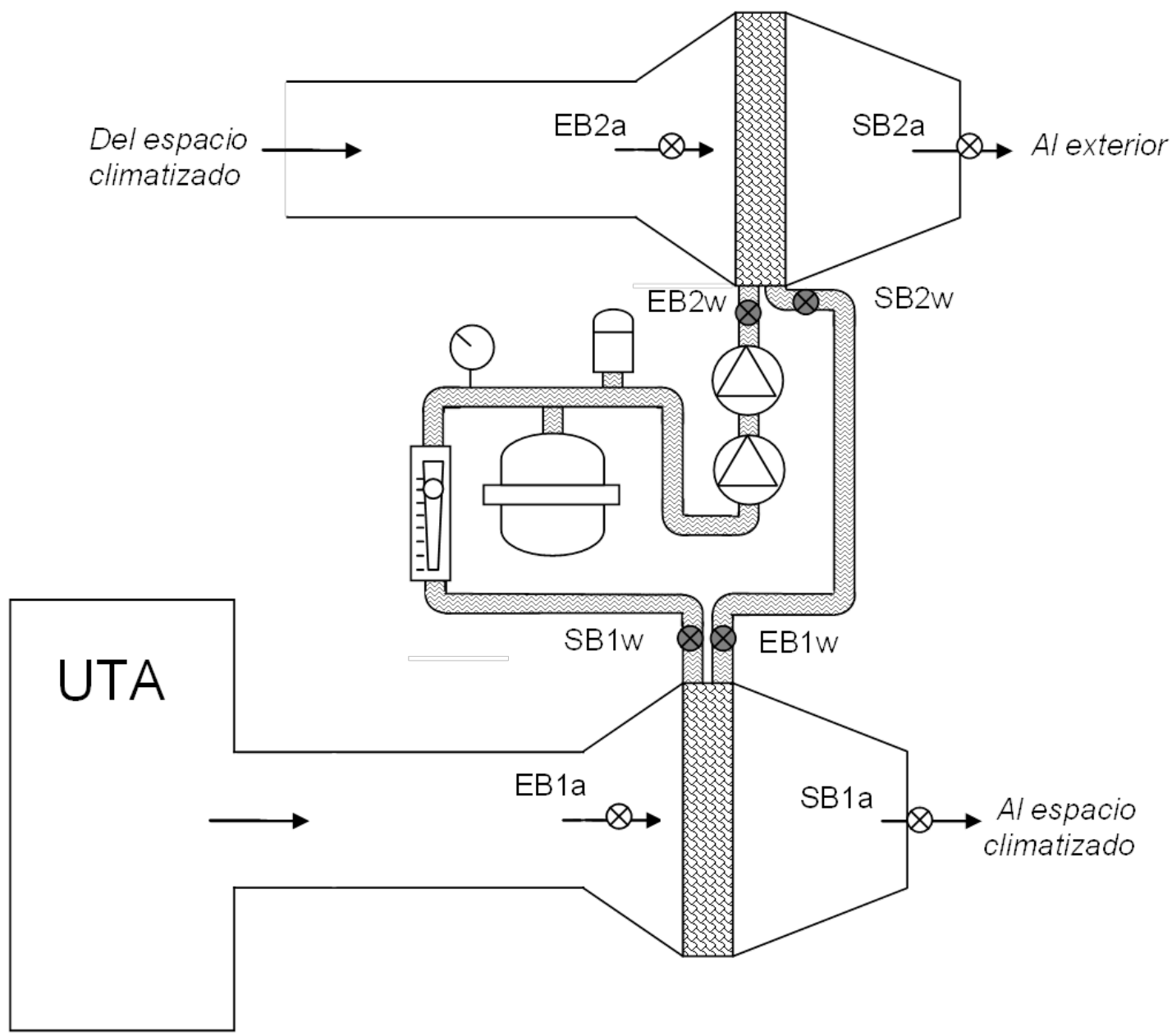

$\otimes$ Sonda de medida de temperatura y humedad

Q Sonda de medida de temperatura

Figura VIII.5.- Esquema de la instalación global. 


\section{VIII.3. DISEÑO DE EXPERIMENTOS. METOdología de ENSAYOS.}

La selección de las variables de interés a controlar para la caracterización del funcionamiento del equipo, así como los niveles en los que variar estas, se determinan a partir de un Diseño de Experimentos (anexo A). De dicho estudio, se concluyen dos variables como determinantes del comportamiento del sistema, ambas relacionadas con el aire exterior aportado a la batería 1: el caudal de aire tratado y su temperatura seca. Los niveles controlados de éstas son los mostrados en la tabla VIII.1.

Tabla VIII.1.- Diseño de Experimentos.

\begin{tabular}{|c|c|}
\hline $\begin{array}{c}\text { Caudal volumétrico de aire a } \\
\text { la batería } 1 \mathrm{~V}_{1}\left[\mathrm{~m}^{3} / \mathrm{h}\right]\end{array}$ & $\begin{array}{c}\text { Temperatura del aire de } \\
\text { entrada a la batería } 1 \mathrm{~T}_{\mathrm{EB} 1 \mathrm{a}} \\
{\left[{ }^{\circ} \mathrm{C}\right]}\end{array}$ \\
\hline V1: 125 & $\mathrm{~N} 1: 25$ \\
V2: 200 & N2: 30 \\
V3: 300 & N3: 35 \\
V4:400 & N4: 40 \\
N5: 45 \\
\hline
\end{tabular}

El caudal de aire de ventilación se analiza en 4 niveles entre 125 y $400 \mathrm{~m}^{3} / \mathrm{h}$, mientras que la temperatura seca se establece en un total de 5 niveles, en un rango de 25 a $45^{\circ} \mathrm{C}$. Sin embargo, la proximidad del primer nivel de temperatura ensayado a las condiciones de confort establecidas en el espacio interior acondicionado, justificarán la limitación del rango de aplicación del sistema, siendo preferible recurrir a alternativas de free-cooling por aire en dichas condiciones.

Como se ha indicado en el apartado anterior en la descripción de la instalación, se dispusieron elementos de medida en puntos clave de los circuitos de aire y de agua para medir las temperaturas de estas corrientes a entrada y salida de ambas baterías, así como los caudales de aire y de agua, y las humedades relativas de los flujos de aire.

El flujo de aire de extracción, conducido hacia la batería 2, se establece para todos los ensayos entorno a $450 \mathrm{~m}^{3} / \mathrm{h}$, en condiciones de confort (aproximadamente $22^{\circ} \mathrm{C}$ de temperatura seca y $50 \%$ de humedad relativa). De esta forma se elimina la posibilidad de que esta sea la corriente limitante en el intercambio de calor.

Como el intercambio en las baterías es puramente sensible, se puede prever que no exista variación de la humedad específica entre la entrada y salida de las baterías, por lo que la medida de las humedades relativas a la salida se podría obviar, calculándose directamente a partir del resto de variables medidas. La medida de humedad relativa del aire a la salida de la 
batería 2 ha servido por tanto para corroborar la fiabilidad de las medidas realizadas de la temperatura seca del aire.

Las figuras VIII.6 a VIII.8 muestran, a modo de ejemplo, la evolución de las variables registradas durante la realización del ensayo a $300 \mathrm{~m}^{3} / \mathrm{h}$ de aire entrando a $30^{\circ} \mathrm{C}$. Para el análisis de los resultados experimentales a la hora de caracterizar el equipo, se recurrirá a las medias de estas variables registradas para cada ensayo. Este procedimiento se desarrolla en el apartado siguiente.

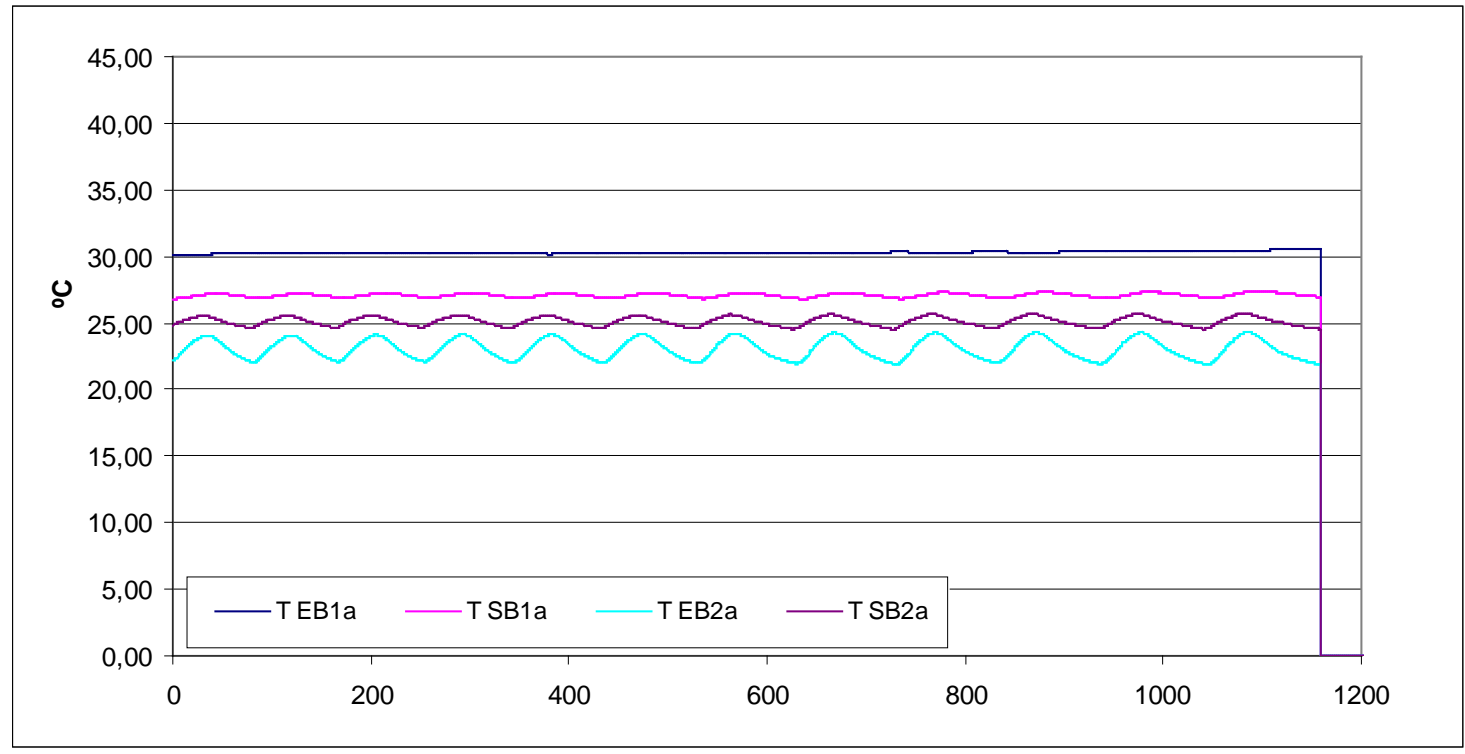

FiguraVIII.6.- Evolución de las temperaturas del aire a entrada y salida de las baterías durante el ensayo del sistema a $300 \mathrm{~m}^{3} / \mathrm{h}$ de aire entrando a $30^{\circ} \mathrm{C}$.

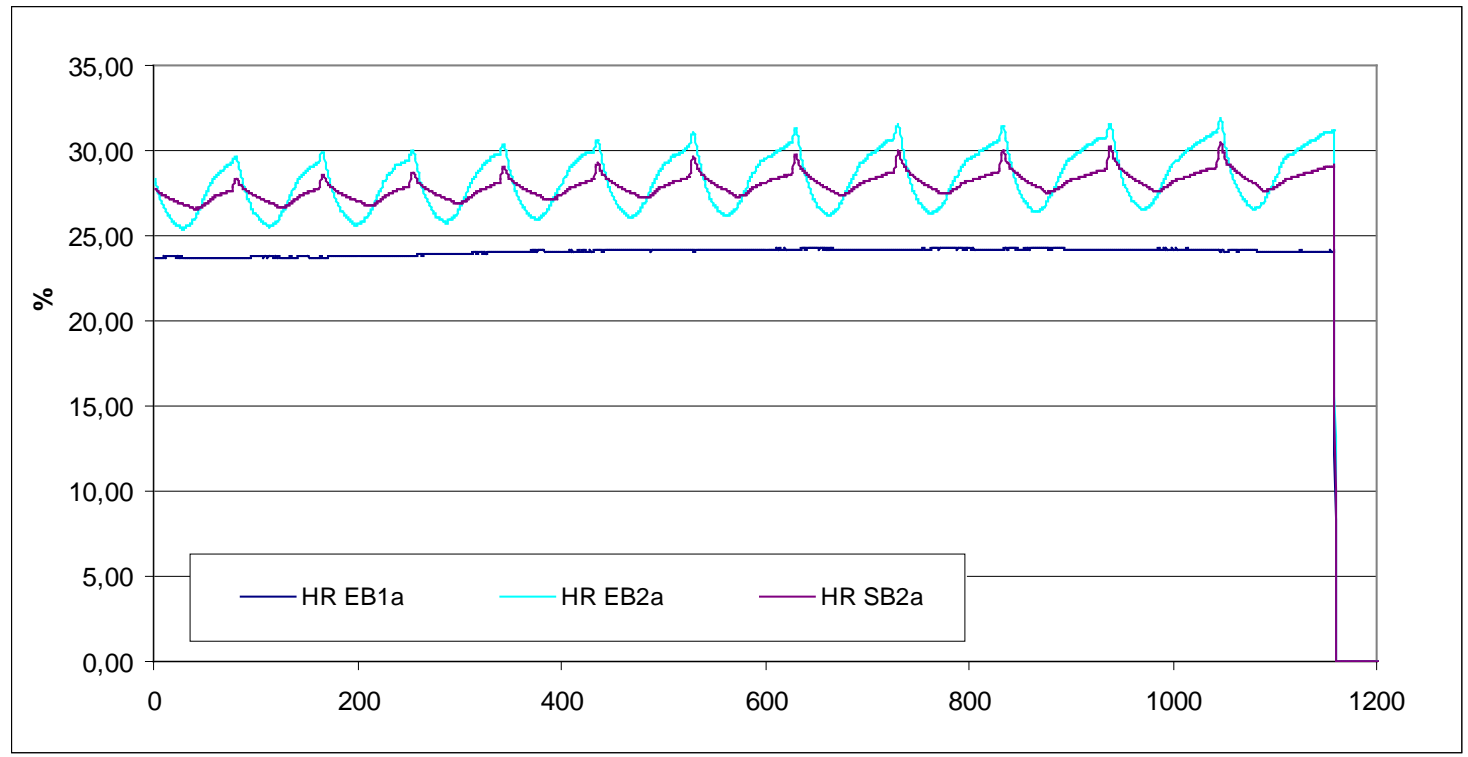

FiguraVIII.7.- Evolución de las humedades relativas del aire a entrada y salida de las baterías durante el ensayo del sistema a $300 \mathrm{~m}^{3} / \mathrm{h}$ de aire entrando a $30^{\circ} \mathrm{C}$. 


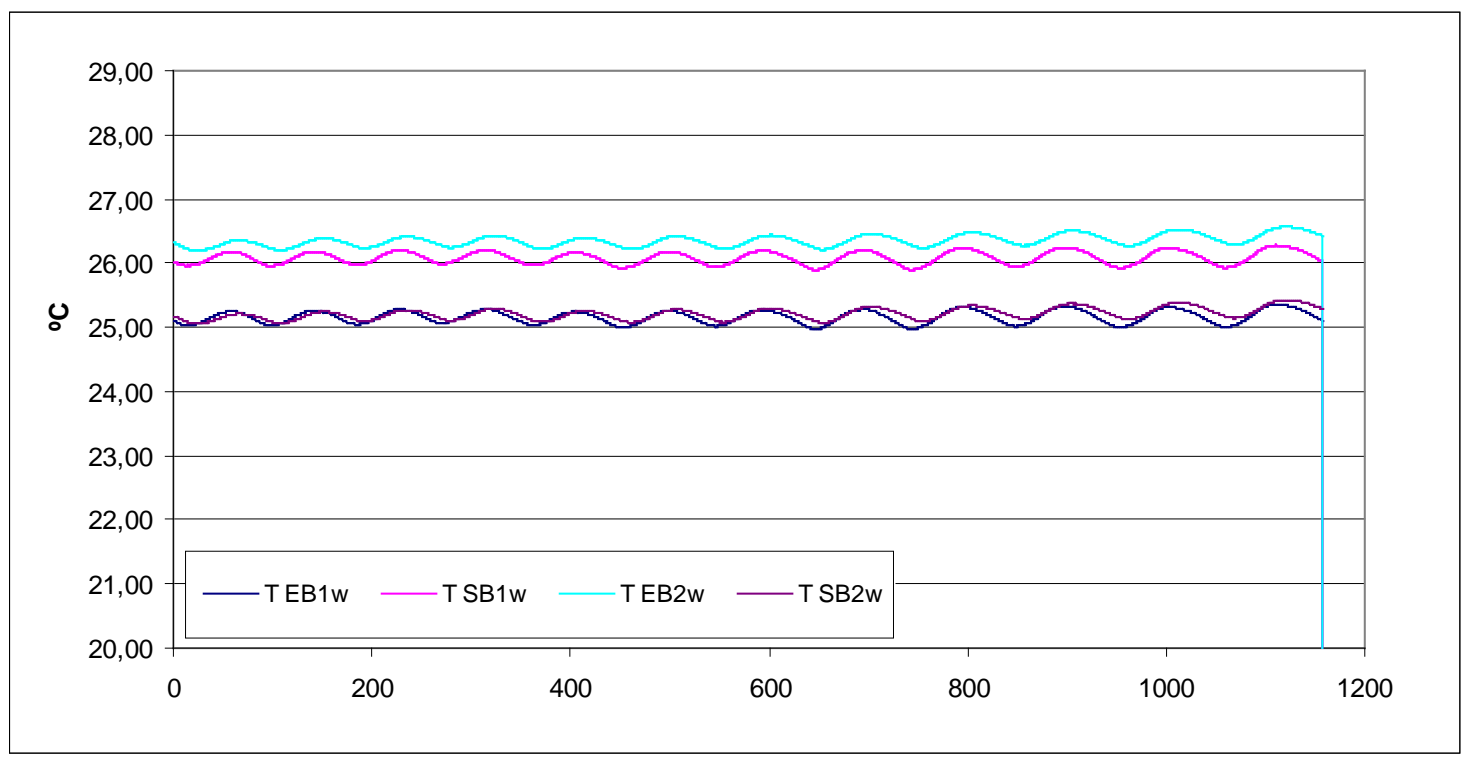

FiguraVII.8.- Evolución de las temperaturas del agua a entrada y salida de las baterías durante el ensayo del sistema a $300 \mathrm{~m}^{3} / \mathrm{h}$ de aire entrando a $30^{\circ} \mathrm{C}$.

\section{VIII.4. ANÁLISIS DE RESULTADOS}

\section{Parámetros considerados en la caracterización experimental}

Los resultados experimentales obtenidos se van a estudiar a partir de la definición de algunos parámetros que permiten la caracterización del funcionamiento del equipo, sustituyendo en sus expresiones los valores medios obtenidos de las variables de interés registradas. Estos parámetros se definen a continuación.

En primer lugar, y al igual que como se procedió en los capítulos $V$ y VII, se va a analizar el salto de temperaturas alcanzado en la corriente de aire exterior que atraviesa la batería 1, y cuyo preacondicionamiento previo a su impulsión como caudal de ventilación al local en condiciones de confort es precisamente el objetivo del funcionamiento del equipo. Este salto de temperaturas viene dado por la expresión E-VIII.1:

$$
\Delta T=T_{E B 1 a}-T_{S B 1 a}
$$

La efectividad térmica para el conjunto del sistema se define, en este caso, como este mismo salto de temperaturas referido a la diferencia entre la temperatura seca del aire exterior a la entrada de la batería 1 respecto a la temperatura seca del aire de expulsión procedente de la cámara en condiciones de confort (ecuación E-VIII.2), el cual sería el máximo salto térmico que podría haberse obtenido, de ser ideales ambas baterías y no existir pérdidas ni ganancias de calor en el circuito de agua [8, Wang, 1994]: 


$$
\varepsilon_{T}=\frac{T_{E B 1 a}-T_{S B 1 a}}{T_{E B 1 a}-T_{E B 2 a}}
$$

Al igual que en capítulos anteriores (capítulo $\mathrm{V}$ y capítulo VII), es interesante analizar la capacidad de enfriamiento, ya que esta considera la cantidad de aire exterior que es tratada por la batería 1, calculado en términos de flujo másico de aire. En este caso, este parámetro se define por la expresión E-VIII.3:

$$
E_{C C}=\dot{m} \cdot\left(h_{E B 1 a}-h_{S B 1 a}\right)
$$

Esta ecuación queda simplificada en términos de las temperaturas secas según la ecuación E-VIII.4, al darse sólo intercambio de calor sensible en la batería.

$$
E_{C C}=\dot{m} \cdot C p_{a} \cdot\left(T_{E B 1 a}-T_{S B 1 a}\right)
$$

El valor del calor específico del aire a presión constante se considera como un valor fijo por ser ésta una buena aproximación en el rango de temperaturas de trabajo.

Finalmente, el parámetro conductancia térmica para la batería 1 de aire exterior puede obtenerse a partir de la ecuación del coeficiente global de transmisión (E-VIII.5) despejando el área:

$$
U_{1}=\frac{E_{C C}}{A \cdot \Delta T_{L M 1}}
$$

La diferencia media logarítmica de temperaturas en este caso se correspondería con la expresión E-VIII.6.

$$
\Delta T_{L M 1}=\frac{\left(T_{E B 1 a}-T_{S B 1 w}\right)-\left(T_{S B 1 a}-T_{E B 1 w}\right)}{\ln \left(\frac{\left(T_{E B 1 a}-T_{S B 1 w}\right)}{\left(T_{S B 1 a}-T_{E B 1 w}\right)}\right)}
$$

Análogamente, para la batería 2, la conductancia térmica puede obtenerse de las expresiones E-VIII.7 y E-VIII.8.

$$
\begin{aligned}
& U_{2}=\frac{\dot{Q}_{\text {sens } 2}}{A \cdot \Delta T_{L M 2}} \\
& \Delta T_{L M 2}=\frac{\left(T_{E B 2 a}-T_{S B 2 w}\right)-\left(T_{S B 2 a}-T_{E B 2 w}\right)}{\ln \left(\frac{\left(T_{E B 2 a}-T_{S B 2 w}\right)}{\left(T_{S B 2 a}-T_{E B 2 w}\right)}\right)}
\end{aligned}
$$

Donde $\dot{Q}_{\text {sens2 }}$ sería el calor sensible intercambiado en la batería 2 de aire de expulsión. 


\section{Resultados de los parámetros considerados}

El comportamiento del sistema de dos baterías con bomba para el aprovechamiento energético residual del aire de extracción se caracteriza a partir de los resultados experimentales para obtener los parámetros planteados en el apartado anterior. En primer lugar, se ha comenzado analizando el salto térmico alcanzado por el aire exterior a acondicionar a su paso por la batería 1, según se definía en la ecuación E-VIII.1. Los resultados obtenidos son los dados en la figura VIII.9:

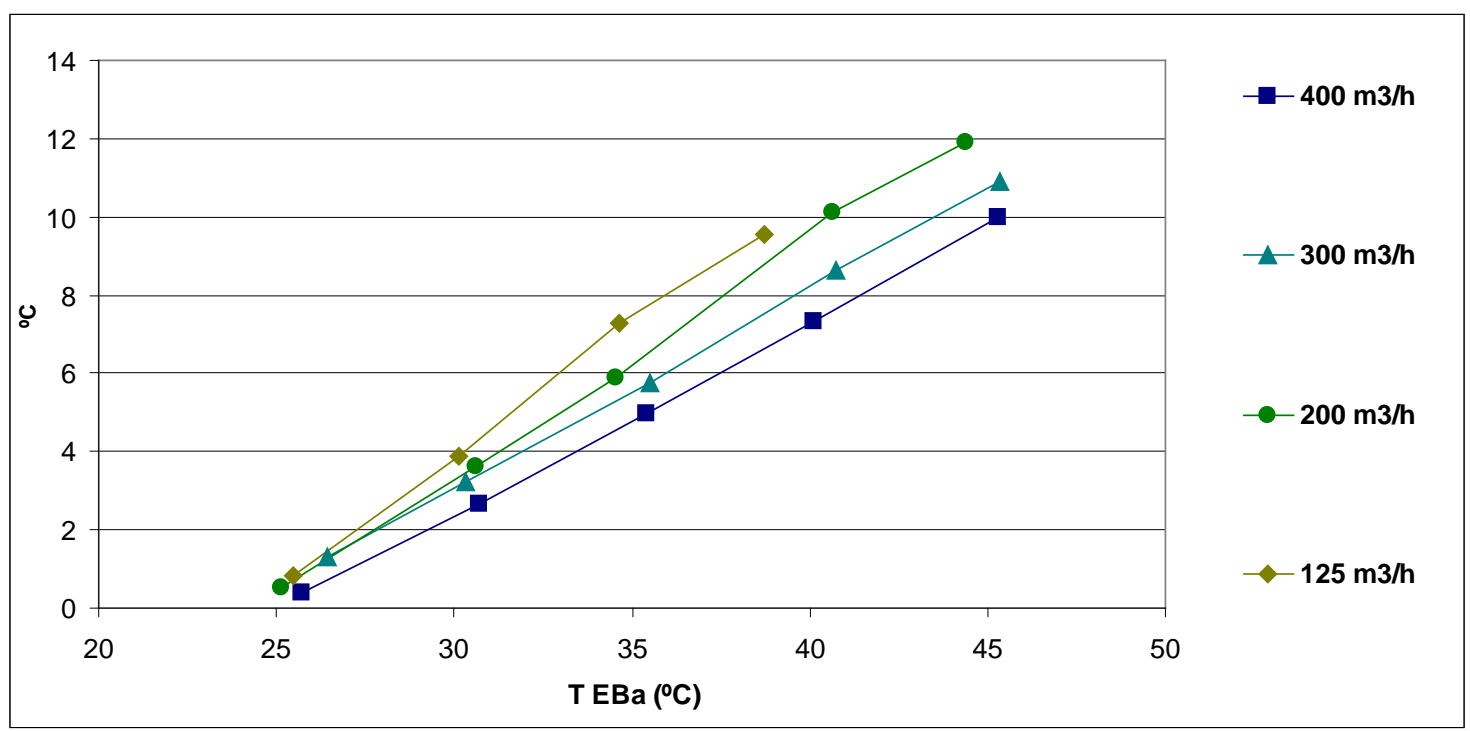

FiguraVIII.9.- Saltos térmicos de temperaturas del aire a su paso por la batería 1.

Se observa que el enfriamiento alcanzado en la corriente de aire exterior es directamente proporcional a su temperatura original (figura VIII.9), ya que mayores niveles térmicos suponen diferencias de temperatura entre ambos lados del intercambio de calor en la batería también mayores, y consecuentemente mayores enfriamientos, como se ha venido observando en los sistemas abordados en los capítulos $\mathrm{V}$ y VII de este trabajo de tesis doctoral. También en este caso se observan incrementos en los saltos térmicos al disminuir el caudal tratado por el sistema, al verse aumentado el tiempo de residencia a la vez que reducida la cantidad de aire a tratar por el mismo.

Para el menor nivel de temperatura ensayado, los saltos térmicos son prácticamente nulos, ya que la temperatura establecida en el interior de la cámara climática en condiciones de confort supera los $22^{\circ} \mathrm{C}$ esperados y llega casi a alcanzar los $25^{\circ} \mathrm{C}$, según se observa en los resultados reales registrados.

El ensayo a $125 \mathrm{~m}^{3} / \mathrm{h}$ y $45^{\circ} \mathrm{C}$ de temperatura de entrada no se pudo realizar, ya que al trabajar con caudales tan reducidos a temperaturas tan altas, el calor generado en la UTA no se disipaba convenientemente y por seguridad quedaban bloqueados los termostatos del equipo. 
Las tendencias observadas se ajustan a regresiones claras, como se aprecia en la tabla VIII.2.

Tabla VIII.2.- Regresiones de los resultados del salto térmico.

\begin{tabular}{|ccccc|}
\hline Parámetro & $\mathbf{V}$ & $\mathbf{m}$ & $\mathbf{n}$ & $\mathbf{R}^{\mathbf{2}}$ \\
\hline \multirow{4}{*}{$\Delta \mathbf{T}$} & $125 \mathrm{~m}^{3} / \mathrm{h}$ & 0,6689 & $-16,177$ & 0,9973 \\
& $200 \mathrm{~m}^{3} / \mathrm{h}$ & 0,6064 & $-14,862$ & 0,9979 \\
& $300 \mathrm{~m}^{3} / \mathrm{h}$ & 0,5102 & $-12,222$ & 0,9995 \\
& $400 \mathrm{~m}^{3} / \mathrm{h}$ & 0,4909 & $-12,33$ & 0,9994 \\
\hline
\end{tabular}

En lo que concierne a la efectividad térmica, los resultados obtenidos se muestran en la figura VIII.10.

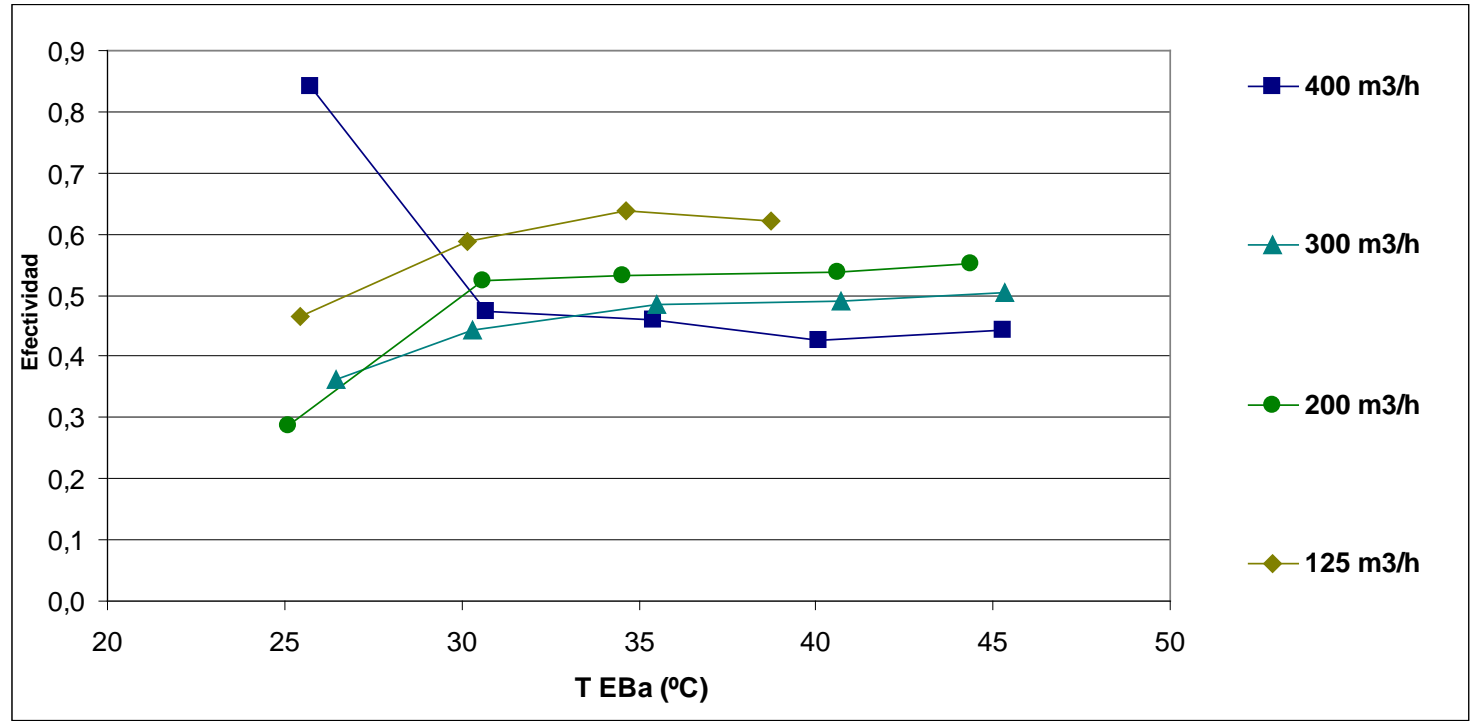

FiguraVIII.10.- Efectividad térmica del sistema.

Obviando los resultados obtenidos para el nivel de temperatura $\mathrm{T} 1=25^{\circ} \mathrm{C}$, el cual por ser tan próximo a la temperatura del aire de expulsión no proporciona resultados representativos, se comprueba que este parámetro se mantiene prácticamente constante con la temperatura exterior (figura VIII.10). Esto se debe a que, aunque el salto térmico alcanzado en la corriente de aire tratada mejora con la temperatura de ésta a la entrada, y como muestra la expresión EVIII.2, también el salto térmico máximo obtenible sería mayor.

Asimismo, los resultados mejoran para menores caudales de aire impulsados, por las mismas razones que las expuestas en el análisis del parámetro anterior.

Por su parte, la capacidad de enfriamiento se muestra en la figura VIII.11. Las regresiones a las que se ajustan las tendencias observadas se recogen en la tabla VIII.3. 


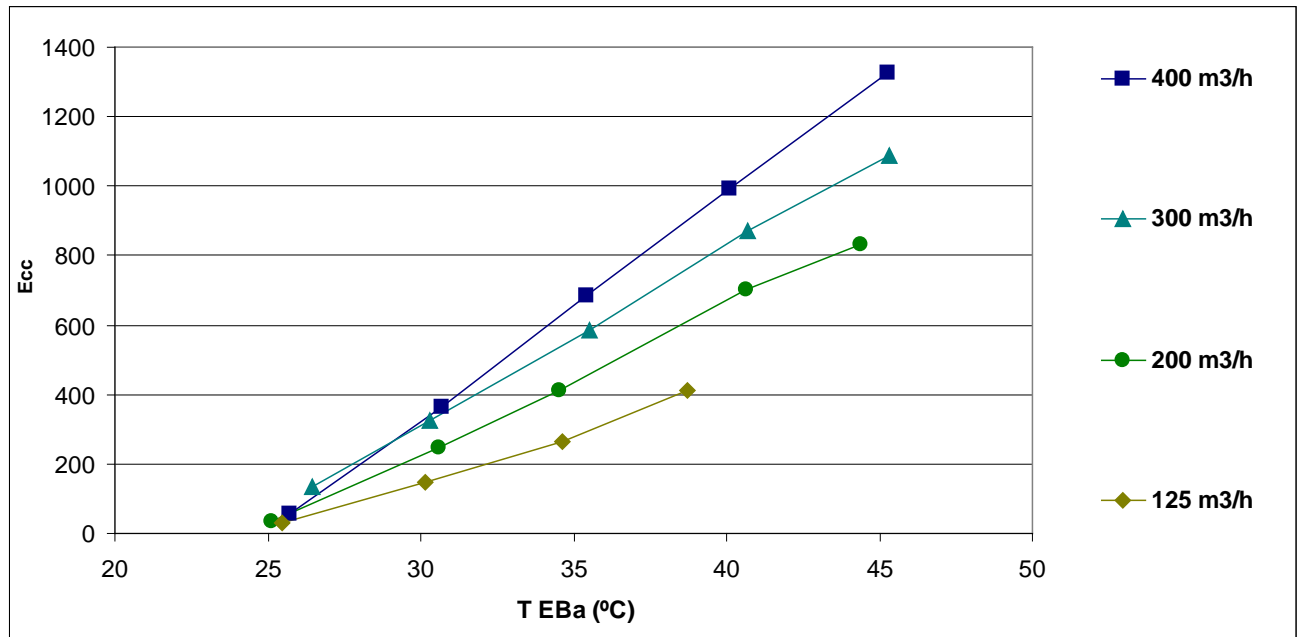

FiguraVIII.11.- Capacidad de enfriamiento del sistema alcanzada en la batería 1.

Tabla VIII.3.- Regresiones de los resultados de la capacidad de enfriamiento.

\begin{tabular}{|ccccc|}
\hline Parámetro & $\mathbf{V}$ & $\mathbf{m}$ & $\mathbf{n}$ & $\mathbf{R}^{\mathbf{2}}$ \\
\hline \multirow{4}{*}{ Ecc } & $125 \mathrm{~m}^{3} / \mathrm{h}$ & 28,365 & $-700,32$ & 0,991 \\
& $200 \mathrm{~m}^{3} / \mathrm{h}$ & 42,391 & $-1040,7$ & 0,9984 \\
& $300 \mathrm{~m}^{3} / \mathrm{h}$ & 50,921 & $-1215,5$ & 0,9995 \\
& $400 \mathrm{~m}^{3} / \mathrm{h}$ & 65,271 & $-1628,6$ & 0,9998 \\
\hline
\end{tabular}

Este parámetro característico del funcionamiento del sistema también mejora con la temperatura, aunque no en igual proporción para los distintos caudales. De hecho, al aumentar el caudal este parámetro mejora tanto en su valor como en la proporción en que lo hace con la temperatura. Esto se debe a que la capacidad de enfriamiento está intrínsecamente relacionada no sólo con el salto de temperaturas, sino también con el flujo de aire tratado por el sistema.

El parámetro conductancia térmica de la batería 1 se muestra en la figura VIII.12.

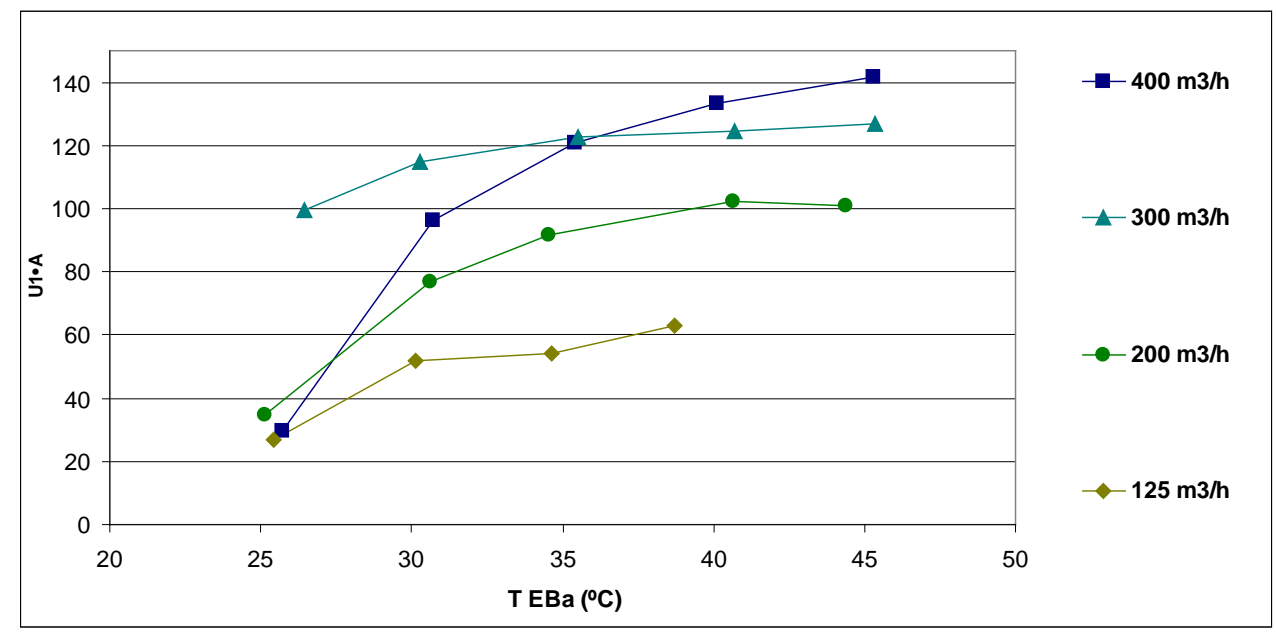

FiguraVIII.12.- Conductancia térmica de la batería 1. 
Los resultados para $25^{\circ} \mathrm{C}$ no serían representativos, por la proximidad de esta temperatura a la del aire expulsado, lo cual incurre en inestabilidades en el logaritmo neperiano del denominador de la expresión E-VIII.6. Ignorando por lo tanto el menor nivel de temperatura ensayado, se observa que la conductancia térmica disminuye ligeramente a menores niveles térmicos, sin seguir una tendencia clara, y con excepción del comportamiento obtenido para el mayor nivel de caudal de aire. Sí varía de forma más destacada con el caudal, ya que mayores caudales de aire suponen un mejor coeficiente de película convectivo del intercambiador del lado del aire, y por lo tanto mejor conductancia térmica.

Los resultados de la conductancia térmica para las dos baterías trabajando con caudales de aire similares, son los mostrados en la figura VIII:13.

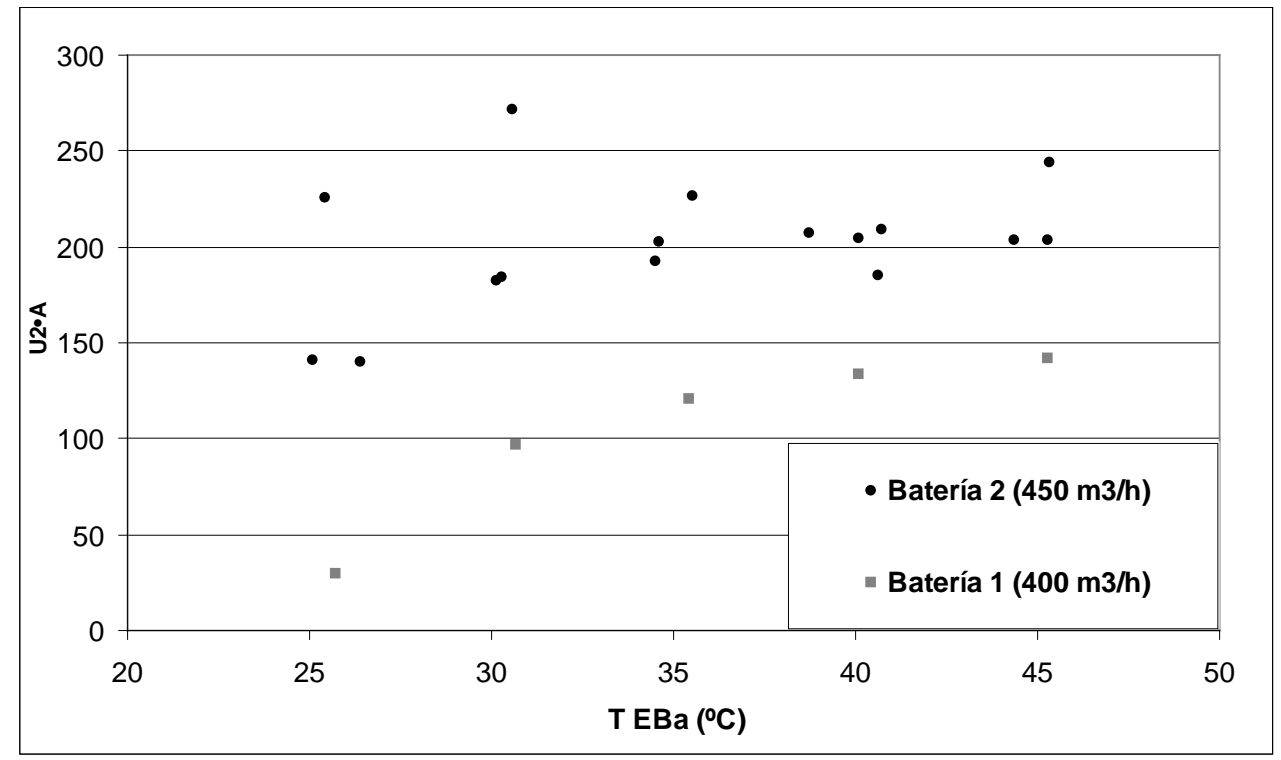

FiguraVIII.13.- Conductancias térmicas de las dos baterías.

Dado que ambas baterías son idénticas, las conductancias térmicas de ambas deberían coincidir trabajando en condiciones similares de caudal de aire, puesto que se ha visto que la temperatura no afecta de forma muy destacada. No es posible sin embargo realizar esta comparativa de forma estricta, al haberse mantenido el caudal de aire de expulsión a $450 \mathrm{~m}^{3} / \mathrm{h}$ fijo, y en todo caso superior a los caudales de aire tratados en la batería 1. Atendiendo a los resultados de la figura VIII.13 se observa precisamente que las conductancias térmicas obtenidas en la batería 2 para los ensayos realizados superan ligeramente las máximas alcanzadas para la batería 1 trabajando con $400 \mathrm{~m}^{3} / \mathrm{h}$ de aire.

\section{Análisis de Varianza}

Finalmente, se procede a realizar el análisis de varianza sobre los resultados experimentales obtenidos para los parámetros de interés abordados en los apartados anteriores (véase el anexo A). 
Para poder realizar convenientemente el ANOVA planteado, ha sido preciso obtener resultados aproximados para el ensayo a $125 \mathrm{~m}^{3} / \mathrm{h}$ y $45^{\circ} \mathrm{C}$, cuya realización no fue posible por limitaciones del dispositivo experimental, por extrapolación de los resultados obtenidos del resto de ensayos.

Como se indicaba en el diseño de experimentos descrito en la tabla VIII.1, se ha trabajado considerando dos factores, caudal volumétrico de aire exterior a la batería 1 y temperatura de bulbo seco de esta misma corriente de aire a la entrada, analizados en 4 y 5 niveles respectivamente. Los valores medios de los resultados de los parámetros para cada nivel del factor mantenido constante se recogen en la tabla VIII.5, quedando representados en las figuras VIII.14 a VIII.17.

Tabla VIII.4.- Valores medios de los factores.

\begin{tabular}{|ccccc} 
& $\mathbf{V 1}$ & $\mathbf{V 2}$ & $\mathbf{V 3}$ & $\mathbf{V 4}$ \\
\hline $\boldsymbol{\Delta} \mathbf{T}$ & 6,71 & 6,40 & 5,97 & 5,07 \\
$\boldsymbol{\varepsilon}_{\mathbf{T}}$ & 0,59 & 0,48 & 0,46 & 0,43 \\
$\mathbf{E}_{\mathrm{CC}}$ & 283,24 & 445,48 & 600,27 & 684,73 \\
$\mathbf{U}_{\mathbf{1}} \cdot \mathbf{A}$ & 51,45 & 76,99 & 107,80 & 97,48 \\
\hline
\end{tabular}

\begin{tabular}{ccc|ccc} 
& T5 & T4 & T3 & T2 & T1 \\
\hline $\boldsymbol{\Delta} \mathbf{T}$ & 0,76 & 3,34 & 5,98 & 8,91 & 11,19 \\
$\boldsymbol{\varepsilon}_{\mathbf{T}}$ & 0,35 & 0,51 & 0,53 & 0,52 & 0,53 \\
$\mathbf{E}_{\mathrm{Cc}}$ & 63,81 & 270,57 & 487,53 & 744,42 & 950,81 \\
$\mathbf{U}_{\mathbf{1}} \cdot \mathbf{A}$ & 42,88 & 78,97 & 91,10 & 100,09 & 104,10 \\
\hline
\end{tabular}
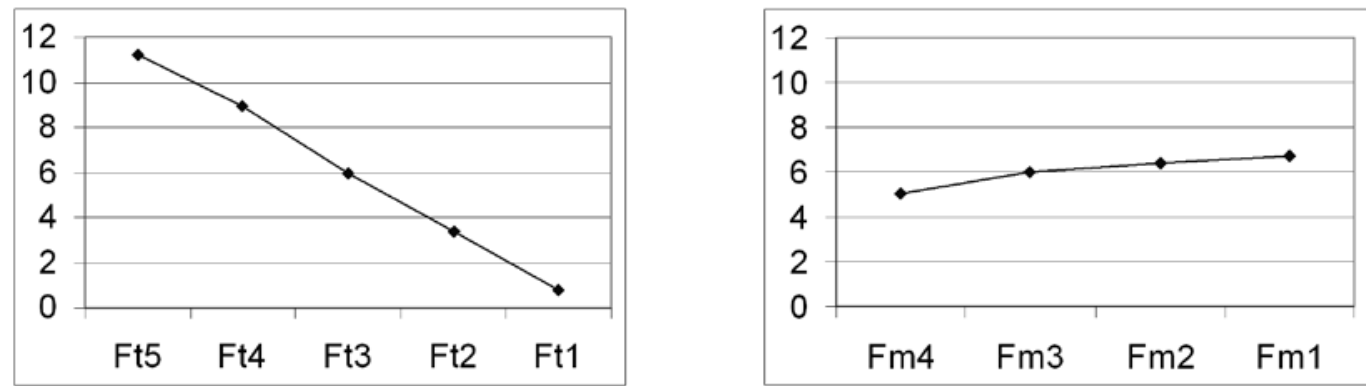

Figura VIII.14.- Gráficas factoriales para el salto de temperaturas.
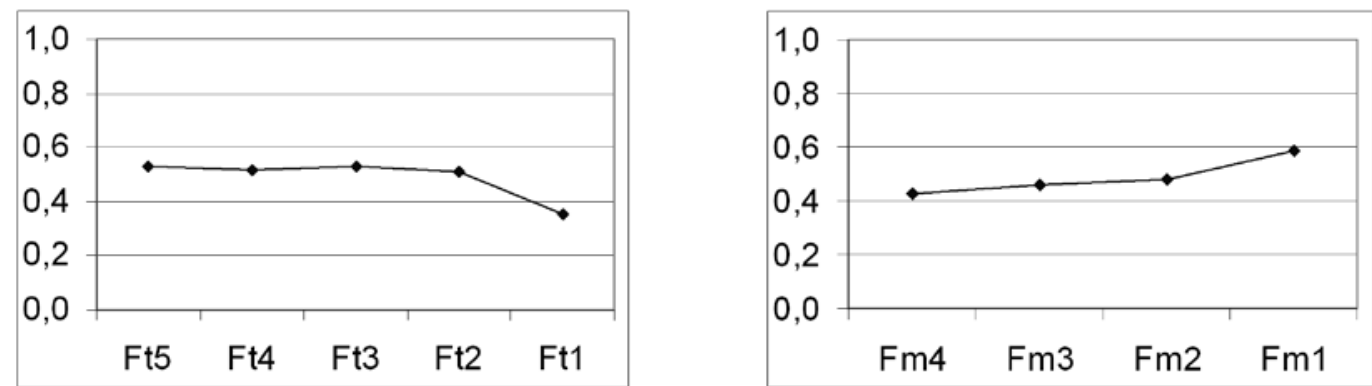

Figura VIII.15.- Gráficas factoriales para la efectividad térmica. 

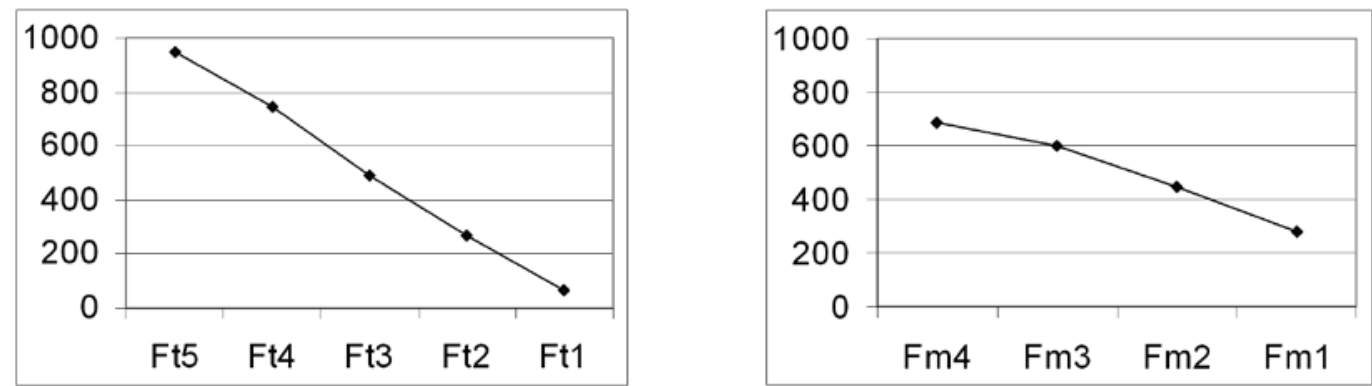

Figura VIII.16.- Gráficas factoriales para la capacidad de enfriamiento.
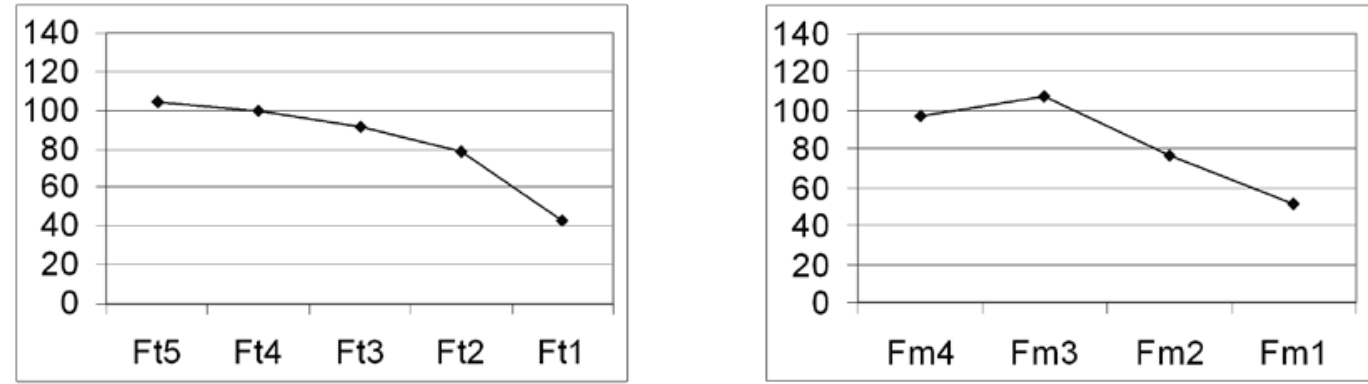

Figura VIII.17.- Gráficas factoriales para la conductancia térmica.

Observando la variación de los valores medios de los factores entre niveles, la repercusión del factor caudal de aire tan sólo aparece destacable para los parámetros capacidad de enfriamiento y conductancia térmica; si bien al menos en el primer caso el factor temperatura seca del aire parece repercutir más notoriamente. Este último factor también parece influir bastante sobre el salto térmico alcanzado en el aire exterior a su paso por la batería 1.

Por su parte, las gráficas de la figura VIII.25, cuyos resultados están recopilados en las tablas VIII.5 a VIII:8, parecen reflejar que la interacción entre los dos únicos factores estudiados no es relevante, con excepción tal vez de la capacidad de enfriamiento, al tender las evoluciones con la temperatura para los distintos caudales a confluir hacia valores inferiores de temperatura. En el resto de casos, las interacciones no muestran una identificación clara.

Salto de temperaturas

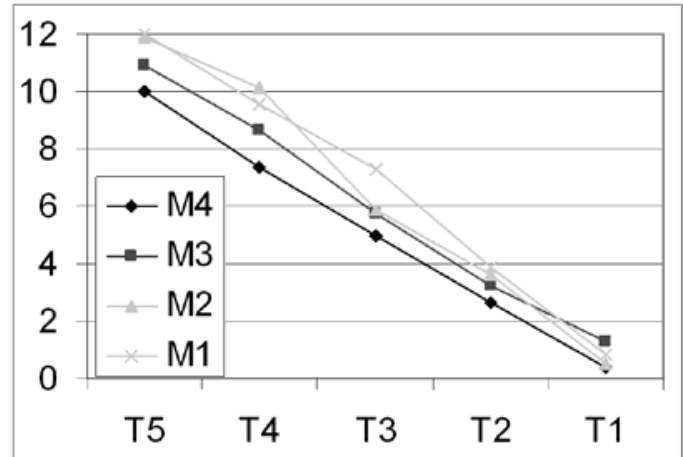

Efectividad térmica

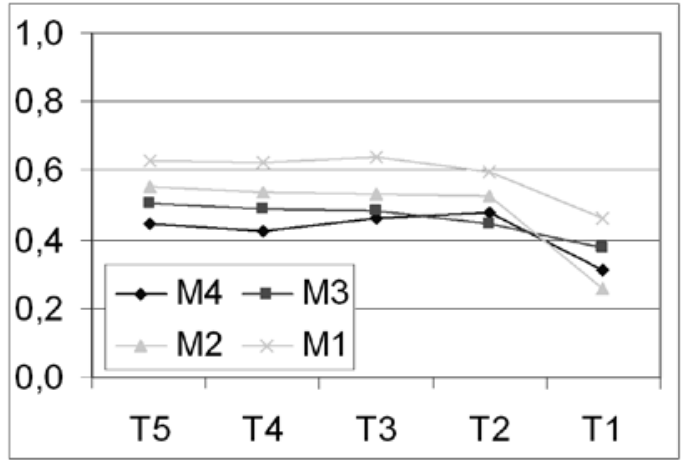

Figura VIII.18.a- Gráficas de las interacciones factoriales. 
Capacidad de Enfriamiento

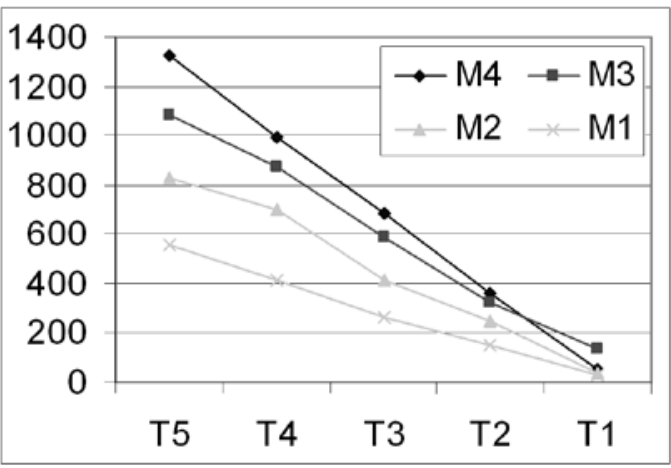

Conductancia Térmica

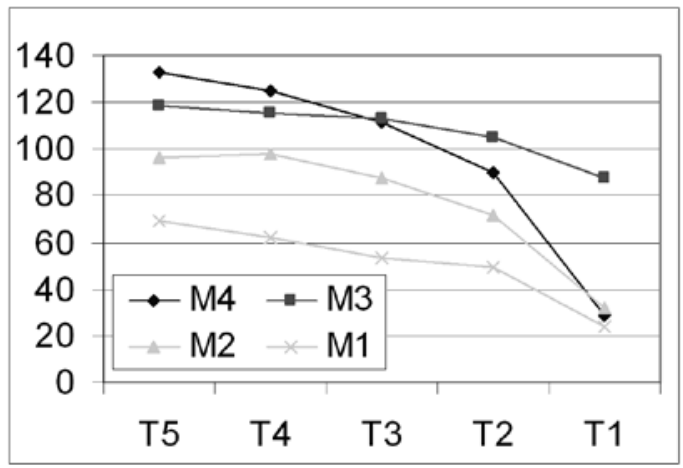

Figura VIII.18.b- Gráficas de las interacciones factoriales.

Tabla VIII.5.- Valores medios de la interacción doble entre factores para el salto térmico.

\begin{tabular}{|ccccc:c}
\hline & T5 & T4 & T3 & T2 & T1 \\
V4 & 9,98 & 7,33 & 4,97 & 2,66 & 0,40 \\
V3 & 10,89 & 8,66 & 5,77 & 3,22 & 1,32 \\
V2 & 11,89 & 10,11 & 5,89 & 3,61 & 0,50 \\
V1 & 12,00 & 9,56 & 7,27 & 3,89 & 0,82 \\
\hline
\end{tabular}

Tabla VIII.6.- Valores medios de la interacción doble entre factores para la efectividad térmica.

\begin{tabular}{|ccccc:c} 
& T5 & T4 & T3 & T2 & T1 \\
V4 & 0,44 & 0,43 & 0,46 & 0,48 & 0,31 \\
V3 & 0,50 & 0,49 & 0,49 & 0,45 & 0,38 \\
V2 & 0,55 & 0,54 & 0,53 & 0,52 & 0,26 \\
V1 & 0,63 & 0,62 & 0,64 & 0,59 & 0,46 \\
\hline
\end{tabular}

Tabla VIII.7.- Valores medios de la interacción doble entre factores para la capacidad de enfriamiento.

\begin{tabular}{|cccccc} 
& T5 & T4 & T3 & T2 & T1 \\
V4 & 1325,34 & 992,19 & 686,96 & 363,88 & 55,26 \\
V3 & 1086,51 & 871,33 & 585,51 & 324,74 & 133,26 \\
V2 & 831,40 & 700,82 & 413,81 & 246,83 & 34,53 \\
V1 & 560,00 & 413,33 & 263,83 & 146,84 & 32,19 \\
\hline
\end{tabular}

Tabla VIII.8.- Valores medios de la interacción doble entre factores para la conductancia térmica de la batería 1. 


\begin{tabular}{|ccccccc} 
& T5 & T4 & T3 & T2 & T1 \\
\cline { 2 - 6 } V4 & 132,62 & 125,23 & 111,08 & 90,10 & 28,35 \\
V3 & 118,30 & 115,62 & 112,82 & 104,81 & 87,45 \\
V2 & 96,48 & 97,58 & 87,31 & 71,57 & 32,05 \\
V1 & 69,00 & 61,94 & 53,21 & 49,42 & 23,68 \\
\hline
\end{tabular}

La tabla VIII.9. recopila los coeficientes de contribución calculados por las sumas de cuadrados sobre los resultados experimentales de los distintos parámetros analizados. Los valores proporcionados en esta tabla justifican las tendencias observadas anteriormente sobre las repercusiones en los resultados de la variación de los distintos factores. Para la capacidad de enfriamiento, el factor clave parece ser la temperatura, con poca influencia del caudal de aire. Por otro lado, en el caso del salto de temperatura es precisamente la temperatura seca el único factor de importancia destacable. Para los otros dos parámetros ambos factores influyen de manera similar sobre los resultados. La interacción entre ambos, no obstante, no parece importante en ningún caso.

Tabla VIII.9.- Coeficientes de contribución derivados del ANOVA realizado sobre los factores del diseño de experimentos.

\begin{tabular}{|c|c|c|c|c|c|c|}
\hline & $\begin{array}{c}\mathbf{S S}_{\text {total }} \\
{[\%]}\end{array}$ & $\begin{array}{l}\mathbf{S S}_{\mathrm{V}} \\
{[\%]}\end{array}$ & $\begin{array}{l}\mathbf{S S}_{\mathrm{T}} \\
{[\%]}\end{array}$ & $\begin{array}{c}\text { SS }_{\text {Error }} \\
{[\%]}\end{array}$ & $\begin{array}{c}\mathbf{S S}_{\mathrm{VT}} \\
{[\%]}\end{array}$ & $\begin{array}{c}\text { SS }_{\text {RError }} \\
{[\%]}\end{array}$ \\
\hline$\Delta \mathbf{T}$ & $100 \%$ & $2,62 \%$ & $96,15 \%$ & $1,24 \%$ & $1,24 \%$ & $0 \%$ \\
\hline$\varepsilon_{T}$ & $100 \%$ & $40,13 \%$ & $50,64 \%$ & $9,24 \%$ & $9,24 \%$ & $0 \%$ \\
\hline Ecc & $100 \%$ & $17,57 \%$ & $75,58 \%$ & $6,85 \%$ & $6,85 \%$ & $0 \%$ \\
\hline$U_{1} \cdot A$ & $100 \%$ & $44,02 \%$ & $46,08 \%$ & $9,91 \%$ & $9,91 \%$ & $0 \%$ \\
\hline
\end{tabular}




\section{REFERENCIAS}

[1] Asociación Técnica Española de Climatización y Refrigeración (ATECYR), "Guía técnica de ahorro y recuperación de energía en instalaciones de climatización". Serie: "Ahorro y Eficiencia Energética en la Climatización", Guía no 9. Instituto para la Diversificación y Ahorro de la Energía (IDAE), Madrid, 2010.

[2] Rey Martínez, F.J.; San José Alonso, J.F.; Velasco Gómez, E.; Álvarez-Guerra Plasencia, M.A.; "Recuperación de Energía en Sistemas de Climatización". Documentos Técnicos de instalacinoes en la Edficiación DTIE 8.01. Madrid, 1996.

[3] Hughes, B.R.; Chaudhry, H.N.; Ghani, S.A. "A review of sustainable cooling technologies in buildings". Revista: Renewable and Sustainable Energy Reviews, № 15 (pp.: 3112- 3120). 2010.

[4] Rey Martínez F.J.; Álvarez-Guerra Plasencia, M.A.; Velasco Gómez, E.; Varela Díez, F.; Herrero Martín, R.; "Design and experimental study of a mixed energy recovery system, heat pipes and indirect evaporative equipment for air conditioning". Revista: Energy and Buildings, $\mathrm{n}^{\circ}$ 35 (pp.: 1021-1030). 2003.

[5] ASHRAE "Systems and Equipment. Chapter 44: Air-to-air Energy Recovery". Handbook. 44.1-44.18. 2000.

[6] Adnot, J. et al.; "Energy Efficiency and Certification of Central Air Conditioners (EECCAC) FINAL REPORT - APRIL 2003", Volumen 3. Paris, 2003.

[7] Mardiana-Idayu, A.; Riffat, S.B.; "Review on heat recovery technologies for building applications". Revista: Renewable and Sustainable Energy Reviews, 2011 (publicación aceptada).

[8] Wang S.K., "Incorporating Evaporative Cooling with Other Coolers", Handbook of AirConditioning and Refrigeration, McGraw Hill, New York, 1994.

\section{Normativa}

[N-1] Ministerio de Industria, Turismo y Comercio y Ministerio de Vivienda de España, "Real Decreto 1027/2007: Reglamento de Instalaciones Térmicas en Edificios". 


\section{RELACIÓN DE FIGURAS}

- Figura II.1.- Balance térmico del cuerpo humano con el entorno.

- Figura II.2.- Porcentaje de Personas Insatisfechas (PPD) en función del Voto Medio Previsto (PMV).

- Figura VIII.1. - Vista frontal del montaje de una batería.

- Figura VIII.2.- Vista global de las baterías instaladas en el sistema.

- Figura VIII.3.- Elementos de circulación, regulación y control del sistema.

- Figura VIII.4.- Dibujo de la instalación global.

- Figura VIII.5.- Esquema de la instalación global.

- FiguraVIII.6.- Evolución de las temperaturas del aire a entrada y salida de las baterías durante el ensayo del sistema a $300 \mathrm{~m}^{3} / \mathrm{h}$ de aire entrando a $30^{\circ} \mathrm{C}$.

- FiguraVIII.7.- Evolución de las humedades relativas del aire a entrada y salida de las baterías durante el ensayo del sistema a $300 \mathrm{~m}^{3} / \mathrm{h}$ de aire entrando a $30^{\circ} \mathrm{C}$.

- FiguraVII.8.- Evolución de las temperaturas del agua a entrada y salida de las baterías durante el ensayo del sistema a $300 \mathrm{~m}^{3} / \mathrm{h}$ de aire entrando a $30^{\circ} \mathrm{C}$.

- FiguraVIII.9.- Saltos térmicos de temperaturas del aire a su paso por la batería 1.

- FiguraVIII.10.- Efectividad térmica del sistema.

- FiguraVIII.11.- Capacidad de enfriamiento del sistema alcanzada en la batería 1.

- FiguraVIII.12.- Conductancia térmica de la batería 1.

- FiguraVIII.13.- Conductancias térmicas de las dos baterías.

- Figura VIII.14.- Gráficas factoriales para el salto de temperaturas.

- Figura VIII.15.- Gráficas factoriales para la efectividad térmica.

- Figura VIII.16.- Gráficas factoriales para la capacidad de enfriamiento.

- Figura VIII.17.- Gráficas factoriales para la conductancia térmica.

- Figura VIII.18.a- Gráficas de las interacciones factoriales.

- Figura VIII.18.b- Gráficas de las interacciones factoriales. 


\section{RELACIÓN DE TABLAS}

- Tabla VIII.1.- Diseño de Experimentos.

- Tabla VIII.2.- Regresiones de los resultados del salto térmico.

- Tabla VIII.3.- Regresiones de los resultados de la capacidad de enfriamiento.

- Tabla VIII.4.- Valores medios de los factores.

- Tabla VIII.5.- Valores medios de la interacción doble entre factores para el salto térmico.

- Tabla VIII.6.- Valores medios de la interacción doble entre factores para la efectividad térmica.

- Tabla VIII.7.- Valores medios de la interacción doble entre factores para la capacidad de enfriamiento.

- Tabla VIII.8.- Valores medios de la interacción doble entre factores para la conductancia térmica de la batería 1.

- Tabla VIII.9.- Coeficientes de contribución derivados del ANOVA realizado sobre los factores del diseño de experimentos. 
Capítulo VIII: CaRActerización del Sistema de RECuperación de Energía MEdiante dos Baterías CON BOMBA 


\section{PART III: RESULTS AND CONCLUSIONS}

Chapter IX: Practical Study of Results Obtained.

ChAPTER X: CONCLUSiONS ANd Future WORK. 



\section{CHAPTER IX}

\section{PRACTICAL ANALYSIS OF RESULTS OBTAINED}

IX.1. INTRODUCTION.

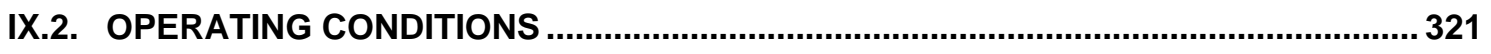

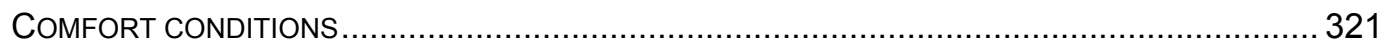

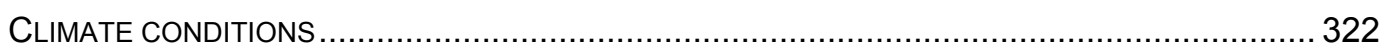

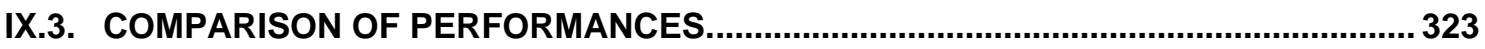

PERFORMANCE OF SYSTEMS OPERATING IN NATURALLY CONDITIONED SPACES ...................... 323

COOLING CAPACITIES OF SYSTEMS OPERATING INTO A HEAT RECOVERY MODE ....................... 324

IX.4. PRACTICAL APPLICATION

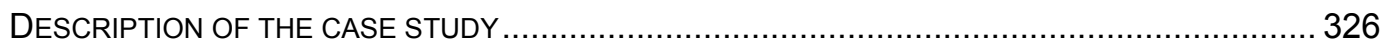

CONDITIONS ACHIEVED IN NATURALLY CONDITIONED SPACES ....................................... 327

ENERGY SAVINGS ESTIMATED IN A THERMAL CONDITIONED SPACE ............................. 329

$\mathrm{CO}_{2}$ EMISSIONS REDUCTION ESTIMATED IN A THERMAL CONDITIONED SPACE ........................ 334 


\section{NOMENCLATURE}

SCH: parameter of Summer Climate Harshness

V: Air volume flow $\left[\mathrm{m}^{3} / \mathrm{h}\right]$

Ecc: Cooling Capacity [W]

T: Outdoor air Dry Bulb Temperature $\left[{ }^{\circ} \mathrm{C}\right]$

$\Delta T$ : Dry Bulb Temperature drop achieved in treated air $\left[{ }^{\circ} \mathrm{C}\right]$

$\dot{W}:$ Total power consumption [kWh]

$\mathrm{COP}_{\text {seasonal: }}$ Seasonal Average Coefficient of Performance.

$\Delta M_{\mathrm{CO}_{2}:}: \mathrm{CO}_{2}$ emissions reduced $[\mathrm{g}]$

$\Delta W$ : Energy Saved [kWh] 


\section{IX.1. INTRODUCTION}

In part II of the present $\mathrm{PhD}$ project, it has been developed the experimental characterization of various equipment of air-conditioning, based on the fundamentals of the phenomena of evaporative cooling (policarbonate indirect evaporative coolers and misting and rigid media pad direct evaporative coolers, studied in chapters $V$ and $V I$ respectively), freecooling alternatives (free-cooling with water, in chapter VII), and energy recovery (coil energy recovery -runaround- loops, chapter VIII).

Once the behaviour of the systems is defined thanks to the experimental characterization developed, a more practical analysis of these equipments should be raised by studying their applicability in conditioning the required spaces. For this aim, it would be necessary to clearly determine the climate conditions in which they are expected to operate, as well as the comfort conditions to be achieved inside the spaces. This is tackled in the following subsection.

Finally, gathering all the information obtained from the analysis of the behaviour and operating conditions of the systems, it is possible to determine the conditions achieved by those among these devices that can be used to improve Indoor Climate Quality (ICQ) in buildings without thermal conditioning. Moreover, for thermal conditioned spaces, this information also permits us estimating the energy savings that could be achieved when installing the devices characterized into a heat-recovery mode to support the conventional systems that ensure comfort conditions.

\section{IX.2. OPERATING CONDITIONS}

When operating to improve the ICQ inside a building or to pre-condition the air treated by the conventional systems, the alternatives characterized must work in certain outdoor air conditions to face a certain quality of indoor climate required; and in those cases when heatrecovery mode is implemented, also these last conditions affect their performance.

\section{Comfort conditions}

Concerning thermal comfort conditions expected inside the spaces, they have been widely described in chapter II of the present work. It should be distinguished, however, between those cases which are simply naturally conditioned and those where some kind of conventional thermal conditioning is implemented. In the first case, ranges considered as comfort conditions are wider and depend on the average outdoor air effective temperature (figure II.4.b); whereas for the second case more strict requirements are established.

Some of the devices already characterized are susceptible of being installed to improve indoor climate conditions when no thermal conditioning is implemented: these are the two direct evaporative coolers and the tower-plus-coil device for free-cooling by water, this last only when operating in what was called conventional mode. The rest of the devices characterized could be 
installed to reduce the energy consumption of the conventional systems installed in thermal conditioned spaces. On the other hand, traditional free-cooling by air is an interesting option available in every case.

\section{Climate conditions}

Although climate conditions will vary depending on the particular sort of climate and the time of the year, in the particular case the study can be simplified because, on one hand, only summer season is of interest, and on the other, the selection of some different climates could serve as an example. Thus, taking advantage of the various climates existing in Spain, four Spanish cities have been considered for the study. Figure IX.1 shows the distribution of the different Spanish climates.

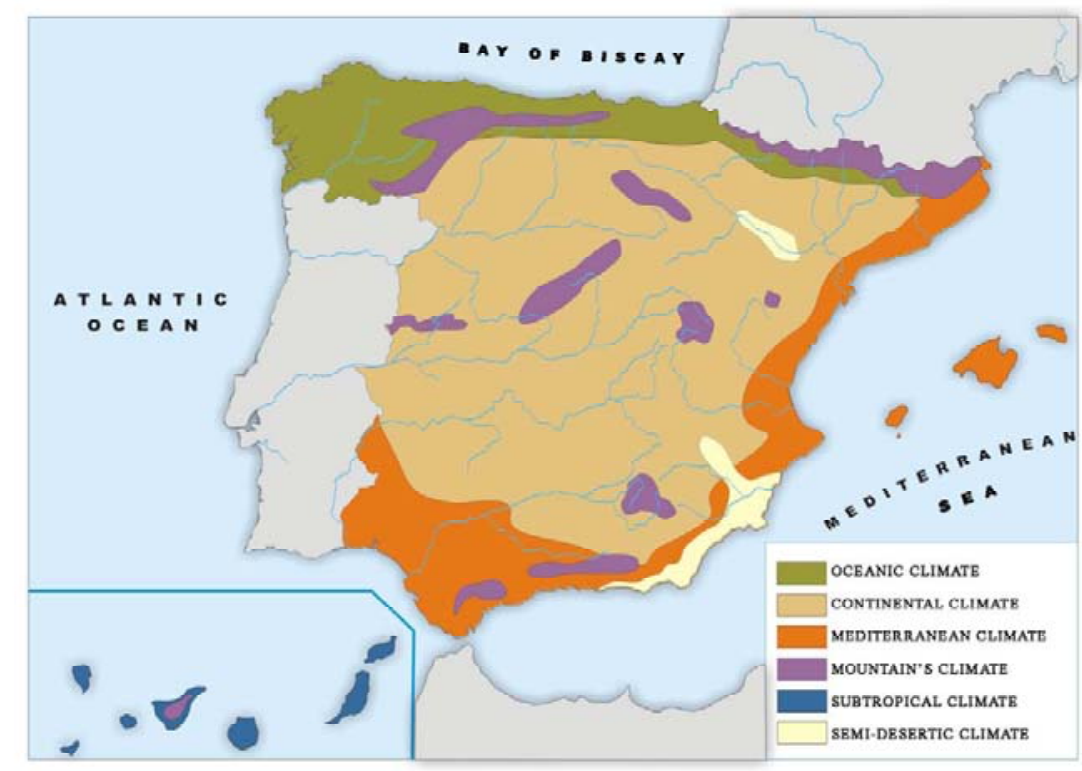

Figure IX.1.- Map of the different climates existing in Spain [1, Bermúdez, 2008].

As the dry bulb temperature is the only parameter of outdoor air considered in the designs of experiments developed, the climates can be chosen disregarding their humidity characteristic; even if relative humidity has been studied (but not controlled) for the direct evaporative coolers, which operate directly on the ventilation outdoor airstream and not in a heat-recovery mode.

Thus, the selection was made according to the classification set out by the appendix $D$ of the HE document (energy saving) of the Spanish building code, the CTE (Código Técnico de la Edificación) [N-1], in which Spanish cities are classified in categories from 1 to 4 simply considering their climate harshness during the summer. This parameter is defined in the text mentioned only considering dry bulb temperature and solar radiation, taking Madrid as reference. The cities chosen are classified as shown in table IX.1. 
Table IX.1.- Spanish cities selected according to the CTE classification for summer.

\begin{tabular}{|ccc|}
\hline City & \multicolumn{2}{c|}{ Summer (1/2/3/4) } \\
Classification & Climate Harshness \\
\hline BILBAO & 1 & $\mathrm{SCH} \leq 0.6$ \\
VALLADOLID & 2 & $0.6<\mathrm{SCH} \leq 0.9$ \\
MADRID & 3 & $0.9<\mathrm{SCH} \leq 1.25$ \\
SEVILLA & 4 & $\mathrm{SCH}>1.25$ \\
\hline
\end{tabular}

The analysis of the evolution of the climate conditions for the four cities will span 5 full months, from May to September, which are expected to correspond to the operating period of the systems.

\section{IX.3. COMPARISON OF PERFORMANCES.}

\section{Performance of systems operating in naturally conditioned spaces}

It has been seen in chapter II, that wider ranges of comfort should be considered for nonconditioned spaces in which occupants are expected to have control on easy-adaptable options such as opening of windows or clothing. Nonetheless, any improvement in these indoor conditions would be happily met by their occupants.

There are three systems characterized that could be conceived to be installed in naturally conditioned spaces in order to soften the indoor climate conditions faced by their occupants: the two direct evaporative coolers (Misting Direct Evaporative Cooler, MDEC; and the Rigid Media Pad Direct Evaporative Cooler, RMPDEC), and the device consisting of a cooling tower and a coil used to implement Free Cooling by Water, when operating in what was called Conventional Mode (FCW-CM).

The operation of these systems during harsh outdoor climate conditions, would enable a drop in the indoor temperature that would improve overall human sensation of thermal comfort. The actual temperature drops achievable by the devices were obtained in their characterization developed in previous chapters. Global results are gathered in table IX.2.

Table IX.2.- Results of temperature drops obtainable by systems susceptible of being installed in naturally conditioned spaces.

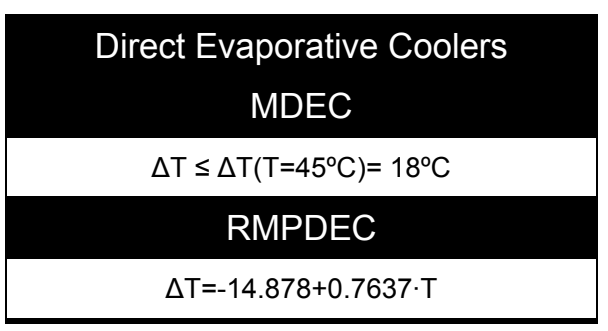

\begin{tabular}{cc|}
\hline$V$ & FCW-CM \\
\hline $125 \mathrm{~m}^{3} / \mathrm{h}$ & $\Delta T=-8.90-0.4304 \cdot \mathrm{T}$ \\
\hline $200 \mathrm{~m}^{3} / \mathrm{h}$ & $\Delta \mathrm{T}=-9.13+0.4304 \cdot \mathrm{T}$ \\
\hline $300 \mathrm{~m}^{3} / \mathrm{h}$ & $\Delta \mathrm{T}=-10.03+0.4304 \cdot \mathrm{T}$ \\
\hline $400 \mathrm{~m}^{3} / \mathrm{h}$ & $\Delta \mathrm{T}=-10.67+0.4304 \cdot \mathrm{T}$ \\
\hline
\end{tabular}


Notice that for the RMPDEC, only one regression is given. This is because, due to its constructive particularities described in chapter $\mathrm{VI}$, only one level of airflow could have been tested. On the other hand, it was seen in chapter VI that the MDEC presented risks of noncomplete evaporation of aerosols, which also restricted the operating conditions tested in terms of airflow supplied and dry bulb temperature. As only temperatures between 43 and $46^{\circ} \mathrm{C}$ were tested, only a maximum temperature drop is shown, to give an idea of its performance. In any case, its installation would require a careful design (notice that these systems are usually applied for outdoor spaces).

In section IX.4, a practical case study is proposed in order to illustrate the improvements introduced by installing these systems.

\section{Cooling capacities of systems operating into a heat recovery mode}

Four systems have been characterized operating in a heat-recovery configuration to precondition the air supplied to indoor thermal conditioned spaces, from which the exhaust airstream is used for improving the performance thanks to its more adequate psychrometric characteristics. These systems were: two polycarbonate indirect evaporative coolers of different total heat exchange area, named "narrow" (NPIEC) and "wide" (WPIEC); a cooling tower and a coil combined to permit free-cooling by water, which in one case was studied into a heatrecovery mode (FCW-HRM); and finally a run-around loop consisting on two coils for heatrecovery (RLHR).

As a summary of the results obtained in the previous chapters of part II, next table numbered IX.3 gathers the regressions obtained from the experimental results for the cooling capacity (Ecc) of the different devices.

Notice that both indirect evaporative coolers are considered here only in mode 2 (M2), for being the best operating mode observed.

Table IX.3.- Regressions for the systems cooling capacity.

\begin{tabular}{|c|c|c|c|c|}
\hline V & $\begin{array}{c}\text { NPIEC-M2 } \\
\text { [W] }\end{array}$ & $\begin{array}{c}\text { WPIEC-M2 } \\
\text { [W] }\end{array}$ & $\begin{array}{c}\text { FCW-HRM } \\
{[\mathrm{W}]}\end{array}$ & $\begin{array}{c}\text { RLHR } \\
\text { [W] }\end{array}$ \\
\hline $125 \mathrm{~m}^{3} / \mathrm{h}$ & $E c c=-358.8+20.97 \cdot T$ & $E c c=-370.48+19.75 \cdot T$ & $\mathrm{Ecc}=-525.18+25.222 \cdot \mathrm{T}$ & $E c c=-700.32+28.365 \cdot T$ \\
\hline $200 \mathrm{~m}^{3} / \mathrm{h}$ & $E c c=-584.36+30.45 \cdot T$ & $E c c=-467.76+25.82 \cdot T$ & $E c c=-724.06+36.294 \cdot T$ & $E c c=-1040.7+42.391 \cdot T$ \\
\hline $300 \mathrm{~m}^{3} / \mathrm{h}$ & $E c c=-789.59+39.99 \cdot T$ & $E c c=-651.88+34.87 \cdot T$ & $\mathrm{Ecc}=-997.07+48.127 \cdot \mathrm{T}$ & $\mathrm{Ecc}=-1215.5+50.921 \cdot \mathrm{T}$ \\
\hline $400 \mathrm{~m}^{3} / \mathrm{h}$ & $E c c=-817.36+42 \cdot T$ & $E c c=-782.96+41.821 \cdot T$ & $E c c=-1269.8+59.254 \cdot T$ & $E c c=-1628.6+65.271 \cdot T$ \\
\hline
\end{tabular}

When operating, all these systems are expected to be capable of preconditioning the ventilation air introduced in the space, needed for ensuring IAQ requirements. Thus, by introducing any of these devices, it will be possible to support part of the cooling demand of the 
conditioned space; specifically part of the contribution to the cooling demand associated to the ventilation rate.

In the next subsection, a practical case study is introduced in order to provide particular data for the analysis of the success of these systems in supporting the cooling demand due to ventilation.

\section{IX.4. PRACTICAL APPLICATION}

To propose a more practical comparison between the systems, a case study is defined consisting of a particular building where the different devices already characterized are supposed to be installed.

This building corresponds to the specifications about the building-type needed to accomplish with the requirements established by the Spanish Government through the programmes CALENER and LIDER, developed to determine the energy demand and efficiency in buildings. For the calculus of the cooling demand required in this building, the case study is implemented in an Excel spreadsheet already validated with CALENER and LIDER through the proceedings required [2, IDAE, 2009]. This alternative application has been used because CALENER does not provide demands hour by hour, which as will be seen later is necessary information for the study. As a probe of the validation performed, figure IX.2 provides results obtained for an example developed with the spreadsheet and the percentage of deviation from those obtained with CALENER. As in any case deviations exceed $15 \%$, which is the limit established for the validity of alternative proceedings.

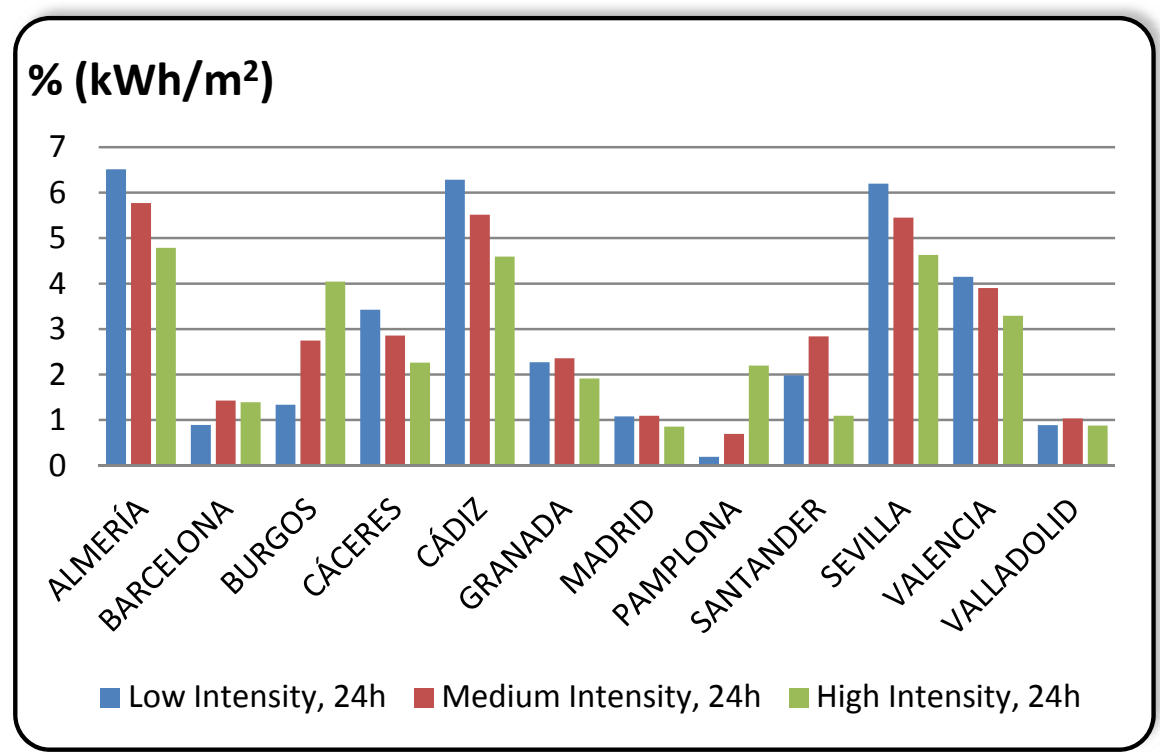

Figure IX.2.- Deviation percentage of demands calculated through the alternative process to results given by CALENER, for various cities.

The particular case study is defined following. 


\section{Description of the case study}

According to the annex I of the Spanish norm RD 47/2007 of 19 January [W-1], through which it is approved the basic proceedings for the certification of the energy efficiency in new buildings; and to subsection 3.3.1.1. of part HE1 of the Basic Code for Energy Saving (HE) of the Spanish building code (CTE) [N-1], the building-type considered as reference must adhere to certain points to be acceptable for verifying the energy efficiency certification on one hand, and the demand limits established in the CTE on the other.

For this study, it has been selected the building defined in cases 600 and 900 among the theoretical ones given as examples of BESTEST (Building Energy Simulation Test) of the International Energy Agency (IEA) [2, IDAE, 2009]. These cases can be defined as buildings of a unique zone, with two glass surfaces facing south of $6 \mathrm{~m}^{2}$ each. The dimensions of the selected building, of total floor area of $48 \mathrm{~m}^{2}$, are shown in figure IX.2.

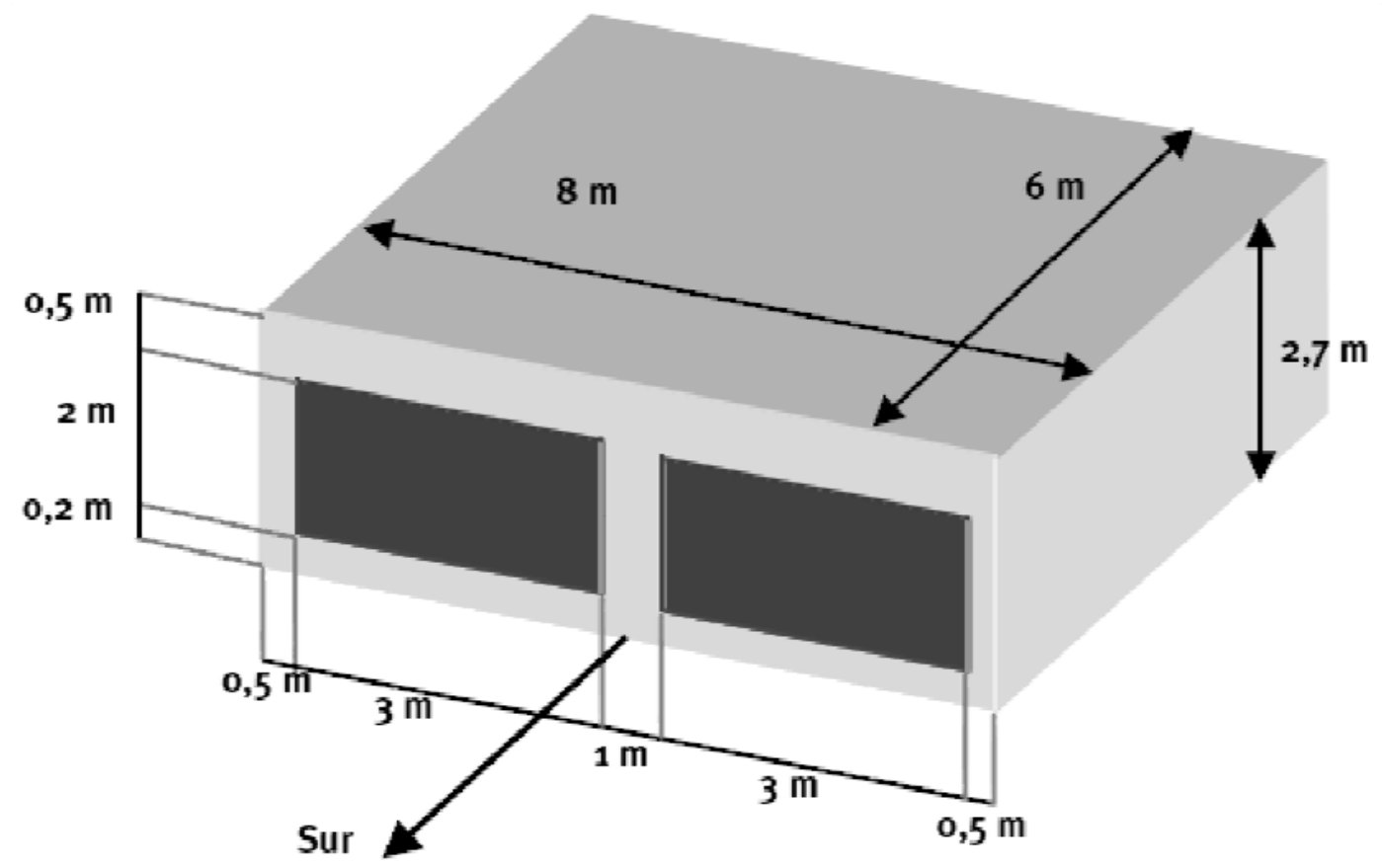

Figure IX.3.- General scheme of the building subject (geometry of cases 600 and 900).

To simplify the study, loads have been considered constant during $8 \mathrm{~h}$ operation periods (from 7 a.m. to 3 p.m.), only on weekdays and Saturdays. There are three cases distinguished according to the input data requirements for the acceptance of alternative proceedings to LIDER and CALENER, named low, medium and high-intensity loads. These loads are given in annex III of the same document [2, IDAE, 2009]. For the reference building of total area of $24 \mathrm{~m}^{2}$, operating conditions during working hours would correspond to the values gathered for each case in table IX.4. The high and low set temperatures would be of $25^{\circ} \mathrm{C}$ and $20^{\circ} \mathrm{C}$ respectively, in any case. 
However, for the particular study it is enough to consider only one of these three possibilities, as the cooling demand due to ventilation does not depend on the thermal loads established indoors, and only this part of the demand is considered for analysing the performance of the systems operating into a heat recovery mode. For the remaining systems, the exact demands are not tackled directly. Consequently, the programme is run only for the conditions corresponding to this case of medium intensity loads.

Table IX.4.- Operating conditions for the $48 \mathrm{~m}^{2}$-area building during summer, for an operating period of $8 \mathrm{~h}$.

\begin{tabular}{|c|c|c|c|}
\hline Load type & High intensity & Medium Intensity & Low intensity \\
\hline Sensible load due to occupancy [W] & 480 & 288 & 96 \\
\hline Latent load due to occupancy [W] & 302.88 & 181.92 & 60.48 \\
\hline Sensible load due to lighting [W] & 211.2 & 211.2 & 211.2 \\
\hline Sensible load due to systems [W] & 360 & 216 & 72 \\
\hline Latent load due to systems [W] & 0 & 0 & 0 \\
\hline Ventilation air volume flow $\left[\mathrm{m}^{3} / \mathrm{h}\right]$ & 200 & 200 & 200 \\
\hline Infiltration air volume flow $\left[\mathrm{m}^{3} / \mathrm{h}\right]$ & 0 & 0 & 0 \\
\hline
\end{tabular}

For the calculus, the building has been supposed to be in the four Spanish cities selected for their different characteristic summer climates. Then, the cooling demand in each particular case during the five months of interest (from May to September) is calculated through an application developed on Excel, previously validated by comparing results to those provided by CALENER, through the proceedings established in the Spanish norm.

\section{Conditions achieved in naturally conditioned spaces}

It was seen in chapter II that naturally ventilated buildings should show much wider opportunities for their occupants to adapt theirselves to the indoor climate conditions in order to achieve comfort, by opening windows, controlling clothing, etc. Consequently, also comfort ranges stretch in these cases. These cases should be dealt through particular models such as the one given by Dear y Brager or the adaptative model proposed in norm EN 15251 [3, deDear\&Brager, 1998] [N-2]. These models were already illustrated in figures II.4.b and II.5.b, which showed the acceptability ranges for indoor operative temperature in relation to outdoor air average effective temperature.

To simplify this brief analysis, radiant temperature of surfaces inside the considered space is considered uniform and equal to indoor air dry bulb temperature. Moreover, also outdoor air temperature of precedent days is considered to be similar to that of the present day, and thus the average effective temperature would also coincide.

Taking into account these considerations, results of the temperature drops obtained for the different systems applicable to naturally conditioned spaces can be represented as shown in 
figures IX.3 and IX.4. Notice however that results for the Misting system are not given. This is because the restrictions in its characterization for indoor spaces disable their comparison for the temperature ranges considered here. Consequently, this sort of systems is more adequate for their installation in outdoor spaces.

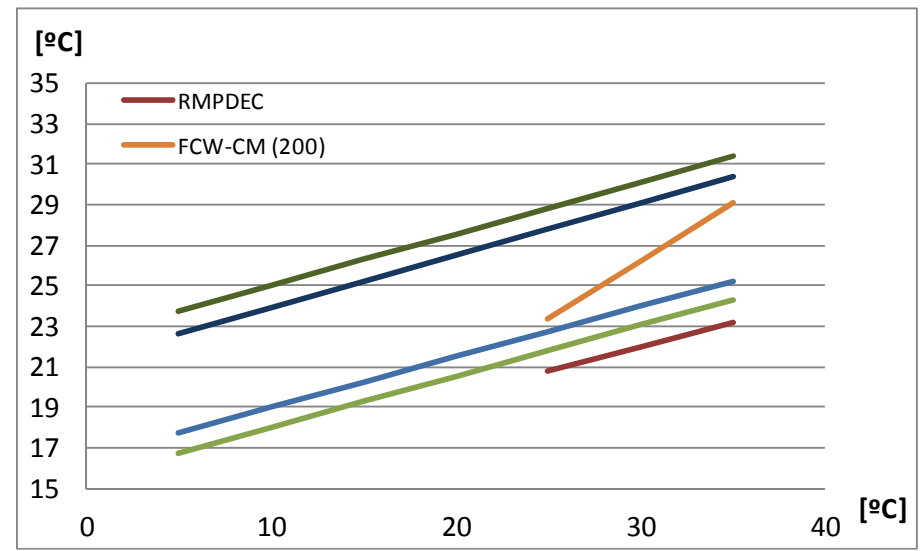

Figure IX.4.- Conditions achieved by the RMPDEC and the FCW-CM in naturally conditioned systems, according to the adaptative model given by Dear \& Brager [3, deDear\&Brager, 1998]

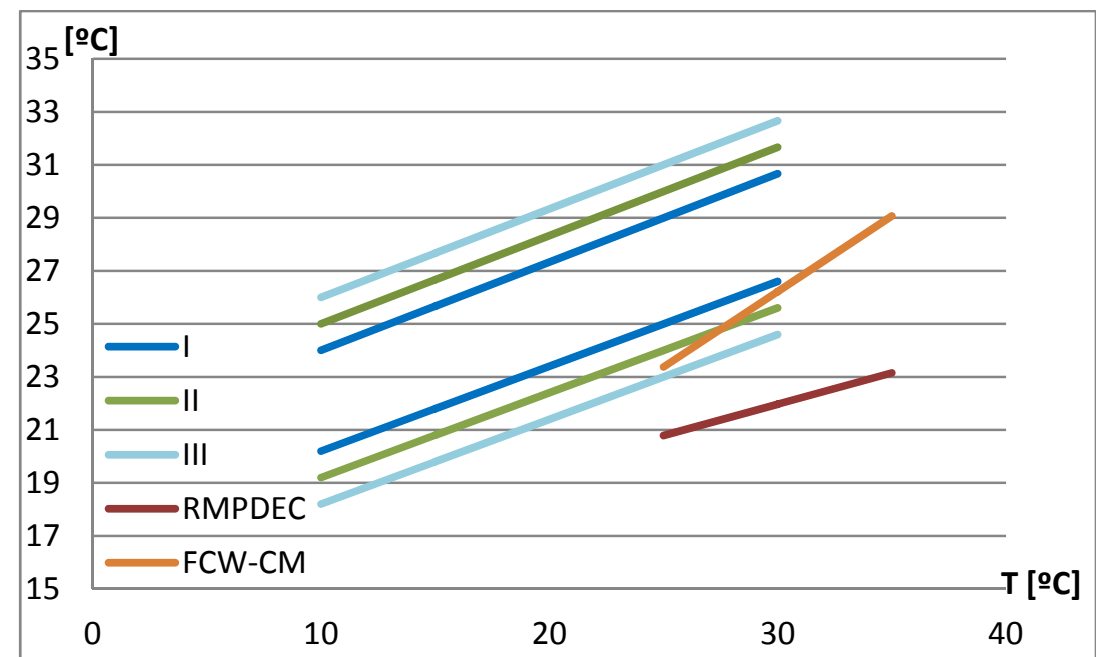

Figure IX.5.- Conditions achieved by the RMPDEC and the FCW-CM in naturally conditioned systems, according to the adaptative model in norm EN 15251 [N-2].

For low temperatures outdoors, occupants inside the non-conditioned space will tend to open windows to enter fresh air. Consequently, for temperatures under the ones tested for the systems, free-cooling can be expected to be a successful solution.

Temperatures given in the graphs for the two systems are not those that could be achieved in these cases inside the spaces, but those of air supplied indoors. Nevertheless, these systems can operate for various airflows, and consequently adjust it to the particular indoor thermal loads to achieve comfort indoors according to the limits given by the adaptative models. On the 
other hand, this increase in the airflows treated would be favourable for IAQ and air velocity (notice that this last point is not considered in the adaptative model).

Having this possibility of airflow control into consideration, the FCW-CM appears capable of providing acceptable conditions of comfort inside the spaces in the outdoor air temperature ranges were it was tested. The RMPDEC seems to provide quite low temperatures of supply air, so controlling treated airflow would provide wider possibilities of supporting thermal loads.

\section{Energy savings estimated in a thermal conditioned space}

Table IX.5 provides the annual results obtained through the developed spreadsheet for the building for medium intensity loads indoors, and the amount that could be supplied by traditional free-cooling by air. On the other hand, table IX.6 gives the total annual cooling demand due to ventilation, and the cooling capacities achievable by each system and the combination of all alternatives (this last option is called "optimum").

Table IX.5.- Total annual cooling demands for medium intensity loads, and total cooling potential through free-cooling by air.

\begin{tabular}{|c|c|c|}
\hline City & Total Cooling demand $[\mathrm{kWh}]$ & Free Cooling $[\mathrm{kWh}]$ \\
\hline BILBAO & $\mathbf{6 5 8 . 1 1}$ & 510.64 \\
VALLADOLID & $\mathbf{1 3 4 2 . 1 5}$ & 734.11 \\
MADRID & $\mathbf{1 7 4 7 . 2 7}$ & 876.65 \\
SEVILLA & $\mathbf{2 4 2 0 . 6 0}$ & 796.58 \\
\hline
\end{tabular}

Table IX.6.- Total ventilation cooling demands for medium intensity loads, and total cooling capacities achievable by different alternatives.

\begin{tabular}{|c|c|c|c|c|c|c|}
\hline City & $\begin{array}{c}\text { Ventilation } \\
\text { demand } \\
{[\mathrm{kWh}]}\end{array}$ & \multicolumn{4}{|c|}{ Cooling Capacity of alternative systems [kWh] } \\
& NPIEC-M2 & WPIEC-M2 & FCW-HRM & RLHR & Optimum \\
\hline BILBAO & $\mathbf{4 . 7 4}$ & 11.72 & 11.43 & 12.48 & 4.04 & 12.48 \\
VALLADOLID & $\mathbf{3 1 . 0 3}$ & 44.42 & 42.41 & 48.24 & 22.99 & 48.24 \\
MADRID & $\mathbf{4 9 . 0 8}$ & 66.29 & 63.09 & 72.18 & 35.94 & 72.18 \\
SEVILLA & $\mathbf{1 3 4 . 1 1}$ & 138.56 & 129.61 & 153.11 & 93.61 & 153.11 \\
\hline
\end{tabular}

Free-cooling by air has been considered during the working hours when outdoor air dry bulb temperature is below $20^{\circ} \mathrm{C}$. For every city studied, it can be observed that this option appears as a quite interesting alternative that should not be ignored, because mild outdoor air conditions can support indoor loads in many cases. Furthermore, less harsh climates such as Bilbao are characterised by a larger number of hours when outdoor air temperature goes below 
$20^{\circ} \mathrm{C}$ when having cooling demands; and thus the milder the climate is, the more powerful is the potential of the free-cooling.

Annual ventilation cooling demand has been calculated by summing, for all working hours during summer period, the products of the ventilation airflow and the temperature difference between outdoor and indoor air, considering the air density and specific heat capacity. Focusing on this demand, most alternatives seem to provide cooling capacities high enough to reach these demands comfortably, the better the milder the climate is. However, considering total annual demands does not give a fair view of real results. Actually, although the cooling capacities achieved go far beyond demands during some operation hours, they only succeed to supply the ventilation cooling demand completely when this demand is low. This can be appreciate in figure IX.5, which show as an example the evolution of outdoor and indoor air temperatures, as well as that of the ventilation demand and the cooling capacities supplied by each system, during the working hours of a day of July for the four cities studied.

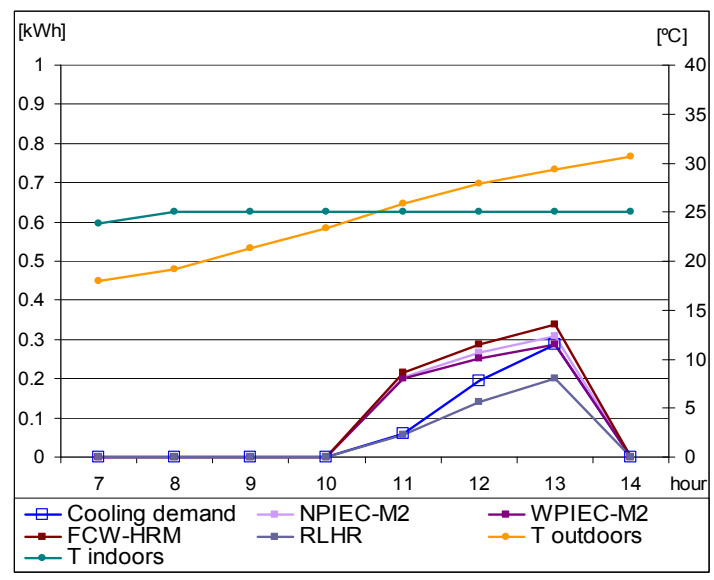

(BILBAO)

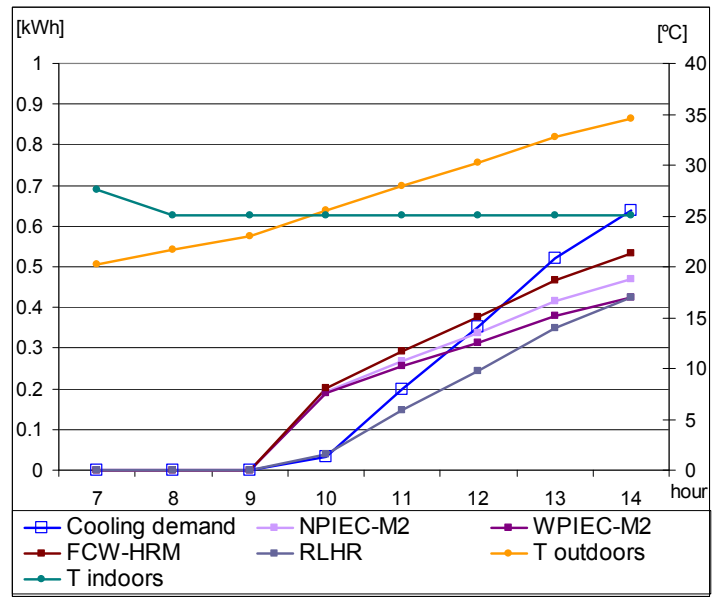

(MADRID)

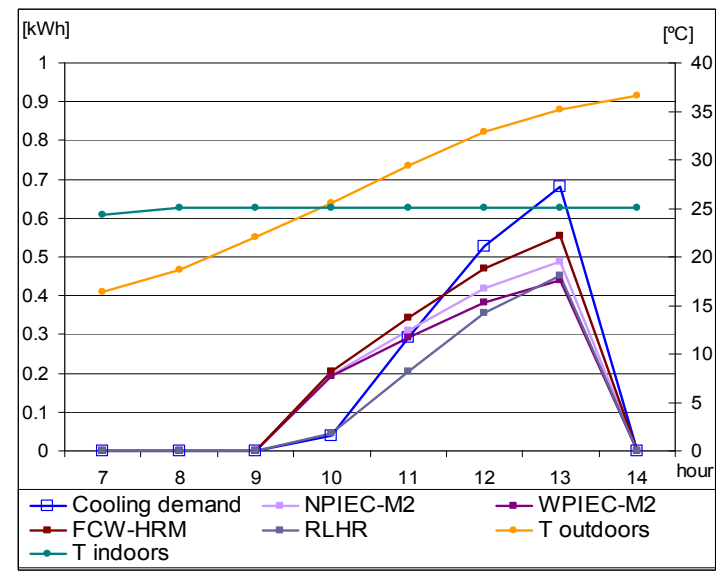

(VALLADOLID)

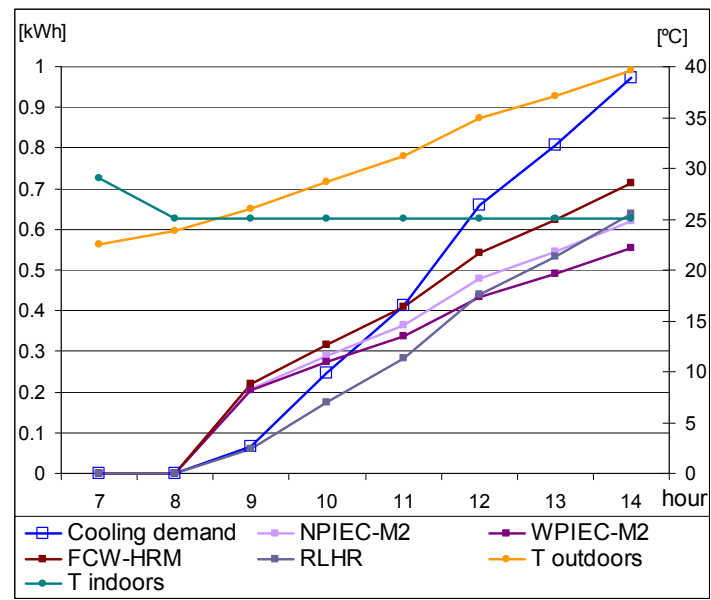

(SEVILLA)

Figure IX.6.- Evolution of temperatures and demands evolution during the working hours of a day in July.

From results shown in figures above given, it can be seen that most systems operating at temperatures below approximately $30^{\circ} \mathrm{C}$ succeed to support the ventilation cooling demand 
completely. On contrary, the Run-around Loop Heat-Recovery system (RLHR) scarcely supports all the demand for the milder cases. This fact is an important point to be taken into account when analysing the interest of installing the systems characterized.

Consequently, although extra cooling potential of the systems would be used to support part of other thermal loads, for the calculus of the energy savings achieved in comparison to the consumption of a conventional heat pump it will be considered the actual ventilation cooling demand supplied, disregarding this extra potential during hours of low ventilation cooling demand. Table IX.6 gathers the ventilation demand percentage supported by the alternative systems.

Table IX.7.- Annual total and ventilation cooling demands for medium intensity loads, and total cooling capacities achieved by different alternatives.

\begin{tabular}{|c|c|c|c|c|c|c|}
\hline \multirow{2}{*}{ City } & \multirow{2}{*}{$\begin{array}{c}\text { Ventilation } \\
\text { demand } \\
\text { [kWh] }\end{array}$} & \multicolumn{5}{|c|}{ Percentage of demand supported by alternative systems [kWh] } \\
\hline & & NPIEC-M2 & WPIEC-M2 & FCW-HRM & RLHR & Optimum \\
\hline BILBAO & 4.74 & $100.00 \%$ & $100.00 \%$ & $100.00 \%$ & $81.98 \%$ & $100.00 \%$ \\
\hline VALLADOLID & 31.03 & $95.90 \%$ & $93.08 \%$ & $98.66 \%$ & $73.30 \%$ & $98.66 \%$ \\
\hline MADRID & 49.08 & $93.47 \%$ & $90.11 \%$ & $97.43 \%$ & $72.19 \%$ & $97.43 \%$ \\
\hline SEVILLA & 134.11 & $86.13 \%$ & $81.13 \%$ & $92.60 \%$ & $69.52 \%$ & $92.60 \%$ \\
\hline
\end{tabular}

Once having calculated the cooling demand that could be supported by the different alternatives, it is possible to determine the energy savings that would be achieved thanks to their installation.

First of all, considering free-cooling by air to support indoor thermal loads when outdoor air conditions are favourable appears as an unavoidable option, for the energy consumption required in this case is negligible, as the fans required would be just the ones needed for ventilation. For the remaining systems, however, the consumption of the water pumps needs to be taken into account.

It is also interesting the fact that the optimum option among the four alternatives in terms of percentage of cooling demand supplied is in every case the Free Cooling by Water system operating in a Heat Recovery Mode (FCW-HRM). This can be explained considering the simplicity of the system, in which there are less intermediate steps than in the remaining cases, and thus the performance of the process can be expected to be better as well.

Table IX.8. gathers the number of operation hours of any of the systems installed in the cities studied, supposing that they operate whenever the outdoor air temperature exceeds $25^{\circ} \mathrm{C}$, which is the lowest temperature tested in the characterization of the devices. 
Table IX.8.- Annual total operating hours of the systems in the four cities studied.

\begin{tabular}{|c|c|}
\hline \multicolumn{1}{|c|}{ City } & $\begin{array}{c}\text { Operating hours } \\
\text { NPIEC-M2 }\end{array}$ \\
\hline BILBAO & 54 \\
VALLADOLID & 171 \\
\hline MADRID & 248 \\
SEVILLA & 437 \\
\hline
\end{tabular}

For the calculus of the energy consumed to support the ventilation cooling demands, it has only been considered the power consumed by the water pumps installed to enable the circulation of water in the systems, described in chapter IV. Power consumption of fans is disregarded, as it is not noticeably higher than the already required power consumption for ensuring the ventilation rates in the building. Powers are shown in table IX.9.

Table IX.9.- Power consumption associated to the systems operation.

\begin{tabular}{|cc|c|c|}
\hline \multicolumn{4}{|c|}{ Power consumption [kW] } \\
NPIEC-M2 & WPIEC-M2 & FCW-HRM & RLHR \\
\hline 0.020 & 0.020 & 0.053 & 0.120 \\
\hline
\end{tabular}

The actual power consumption of the water pumps has been calculated from the pump curves considering the pressure drop existing in the systems and the water volume flow circulating. In the case of the FCW-HRM, as the water pump is over-dimensioned for the particular requirements for operating in an open cycle and just covering the pressure drops associated to only one coil, the power associated is considered to be the product of these pressure drops (calculated in $4 \cdot 10^{4} \mathrm{~Pa}$ ) and the water flow in circulation $(8 \mathrm{l} / \mathrm{min}$ ).

On the other hand, it was seen in chapter VIII that in the case of the Run-around Loop Heat Recovery system two pumps were needed to permit water circulation through the two coils. When considering the pressure drops in the coils $\left(4 \cdot 10^{4} \mathrm{~Pa}\right.$ each $)$ in the water pumps, the total power summing both pumps has been estimated in $120 \mathrm{~W}$.

Table IX.10. gathers the kWh consumed by a heat pump to support the ventilation cooling demand, considering a COP of 2.5; and the energy consumptions associated to the alternative systems installed with the same aim as supporting systems to the conventional one, considering the power values in table IX.9 of the systems operating a number of hours during summer season (table IX.8). Thus, energy consumption of the alternatives considers both the energy required for their operation during the operating hours, plus the additional energy consumed by the heat pump during the periods when they fail in supplying demand completely. 
Table IX.10.- Energy consumptions associated to the systems operation.

\begin{tabular}{|c|c|c|c|c|c|}
\hline \multirow{2}{*}{ City } & \multicolumn{5}{c|}{ Total energy consumption [kWh] } \\
\hline BILBAO & 1.90 & 1.08 & 1.08 & 2.88 & 6.82 \\
VALLADOLID & 12.41 & 3.93 & 4.28 & 9.29 & 23.83 \\
MADRID & 19.63 & 6.24 & 6.90 & 13.73 & 35.22 \\
SEVILLA & 53.65 & 16.18 & 18.86 & 27.27 & 68.79 \\
\hline
\end{tabular}

Considering the cooling capacities achieved by the systems, given in table IX.6, and the electric energy consumptions (disregarding the additional energy consumed by the heat pump to achieve comfort conditions), the alternative systems seasonal average COP in each city can be obtained through the following equation [4, Rey\&Velasco, 2005]:

$$
\mathrm{COP}_{\text {Seasonal }}=\frac{\text { Total Cooling Capacity }}{\text { Total Energy Consumption }}=\frac{E c c}{\dot{W}}
$$

Being $\dot{W}$ the product of the power consumption (table IX.9) and the number of operating hours (table IX.8).

Values for the seasonal average Coefficient of Performance are gathered in table IX.11:

Table IX.11.- Systems seasonal average Coefficient of Performance for each city.

\begin{tabular}{|c|c|c|c|c|}
\hline \multirow{2}{*}{ City } & \multicolumn{4}{|c|}{ COP (Seasonal Average) } \\
\hline & NPIEC-M2 & WPIEC-M2 & FCW-HRM & RLHR \\
\hline BILBAO & 10.85 & 10.59 & 4.33 & 0.62 \\
\hline VALLADOLID & 12.99 & 12.40 & 5.29 & 1.12 \\
\hline MADRID & 13.36 & 12.72 & 5.46 & 1.21 \\
\hline SEVILLA & 15.85 & 14.83 & 6.57 & 1.79 \\
\hline
\end{tabular}

The indirect evaporative coolers show interestingly high performances, and although the free-cooling by water device provides much lower COPs, these are still better than the expected ones for a heat pump. On the other hand, the Run-around system is characterized by low COPs, because it consumes much more power through the water pumps installed.

The following energy savings would be thus obtained from installing the alternative systems to support cooling demand due to ventilation (table IX.11): 
Table IX.12.- Energy savings associated to the systems operation.

\begin{tabular}{|c|c|c|c|c|}
\hline \multirow{2}{*}{ City } & \multicolumn{4}{c|}{ Energy Savings [kWh] } \\
& NPIEC-M2 & WPIEC-M2 & FCW-HRM & RLHR \\
\hline BILBAO & 0.82 & 0.82 & -0.98 & -4.93 \\
VALLADOLID & 8.48 & 8.13 & 3.13 & -11.42 \\
MADRID & 13.39 & 12.73 & 5.90 & -15.59 \\
SEVILLA & 37.47 & 34.78 & 26.37 & -15.15 \\
\hline
\end{tabular}

Two key results can be highlighted from table given above. Firstly, that energy savings are more interesting for harsher climate conditions, up to the point that in mild climates such as Bilbao, the alternative might not be of interest, even though cooling demands could be supported completely in these cases. And secondly, that due to the considerable power of the water pumps required for the RLHR, plus their lower performance in comparison to other systems, in that case the system would be less interesting than the simple conventional heat pump. However, considering that the coils used for the construction of the device are not specifically made for this application of air conditioning, and consequently their pressure drops associated are much higher than expected, energy consumption would be considerably reduced and energy savings turned appealing. This point is further analysed in the following chapter $\mathrm{X}$ : Conclusions and Future Work.

\section{$\mathrm{CO}_{2}$ emissions reduction estimated in a thermal conditioned space}

Based on these energy savings, the reduction on the $\mathrm{CO}_{2}$ emissions generated by implementing the studied solutions can be estimated as indicated in chapter I, through the corresponding coefficient defined for electric energy consumption in the Spanish peninsula [W1]:

$$
\Delta M_{\mathrm{CO} 2}=649 \frac{g \mathrm{CO}_{2}}{k W h_{e}} \cdot \Delta W
$$

Figure IX.7. shows the differences on the $\mathrm{CO}_{2}$ emissions generated when supporting ventilation loads during the whole summer season, either if a heat pump is installed alone or if it the alternative systems studied are installed to reduce the cooling demand.

Emissions for the Run around loop are not given, because these results lack of interest without reconsidering the water pumps dimensioning.

It is interesting to highlight that better results are obtained when these alternatives are implemented in harsher climates. However, for mild climates such as Bilbao, there are not significant differences on the energy savings, and thus to better study whether the alternatives 
are preferable to the conventional solution or not, a deeper analysis including economical issues should be proposed.

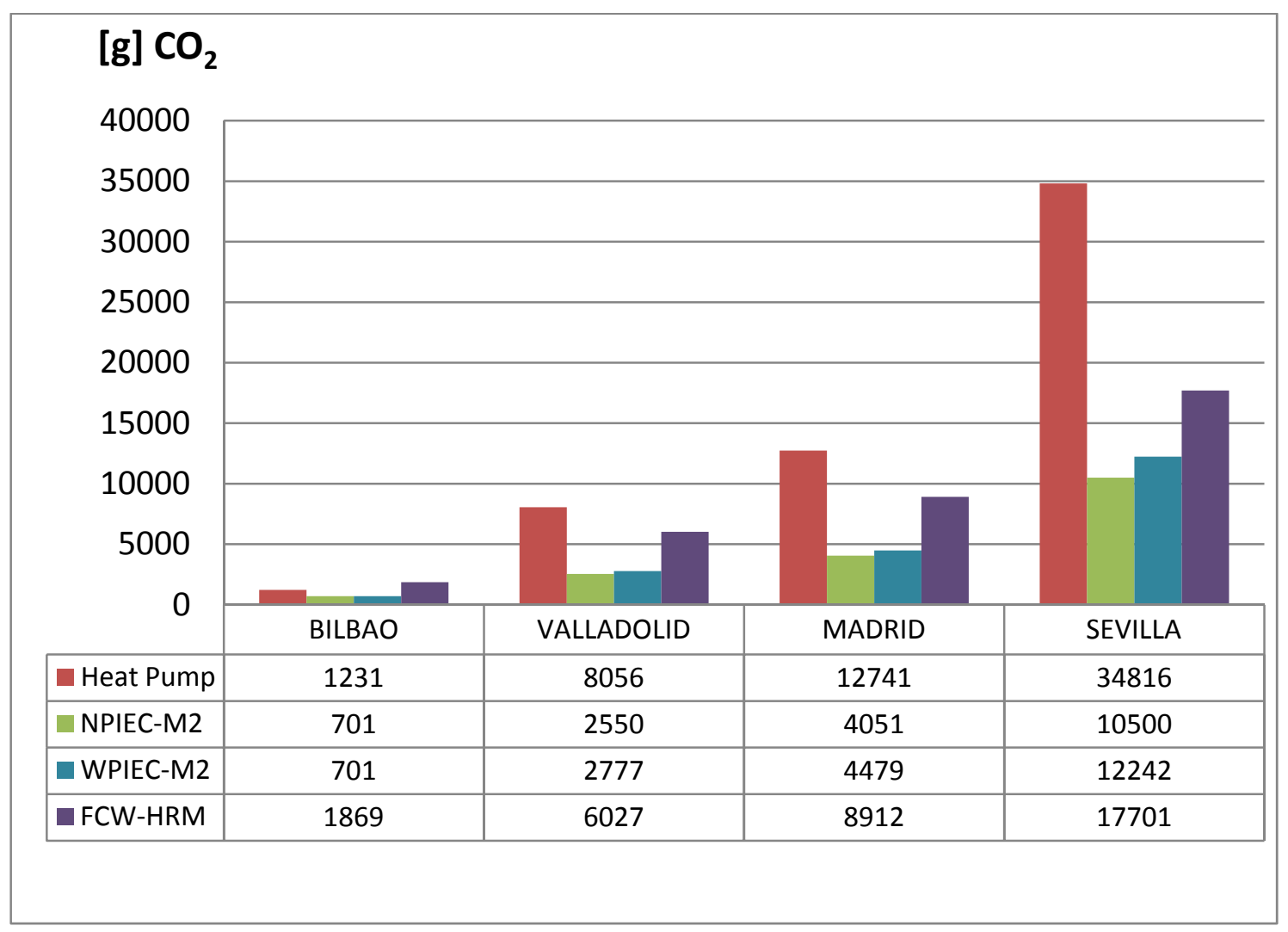

Figure IX.7.- $\mathrm{CO}_{2}$ emissions generated by a heat pump alone and through the implementation of the studied solutions.

From these results, savings in $\mathrm{CO}_{2}$ emissions given in table IX.13 can be inferred. Notice that also results for Free Cooling by air are given. These would be achieved through the amount of the total energy demand that could be supported simply introducing outdoor air, for being in adequate climate conditions. This has been calculated considering that otherwise that energy demand would be supported by a heat pump characterized by a COP of 2.5 .

Table IX.13.- $\mathrm{CO}_{2}$ emissions reduction achieved through the implementation of the studied solutions.

\begin{tabular}{|c|c|c|c|c|}
\hline \multirow{2}{*}{ City } & \multicolumn{4}{c|}{$\mathrm{CO}_{2}$ emissions reduction [g] } \\
& NPIEC-M2 & WPIEC-M2 & FCW-HRM & $\begin{array}{c}\text { Free } \\
\text { Cooling }\end{array}$ \\
\hline BILBAO & 530 & 530 & -639 & 1231 \\
VALLADOLID & 5506 & 5279 & 2029 & 8056 \\
\hline MADRID & 8690 & 8262 & 3829 & 12741 \\
SEVILLA & 24316 & 22574 & 17115 & 34816 \\
\hline
\end{tabular}




\section{REFERENCES}

[1] Bermúdez, J.A., Zonas climáticas de España, Banco de Imágenes y Sonidos del Ministerio de Educación, Política Social y Deporte (Gobierno de España), 2008.

[2] Instituto para la Diversificación y Ahorro Energético (IDAE), "Condiciones de aceptación de Procedimientos alternativos a LIDER y CALENER", Eficiencia y Ahorro energético em edifícios, Calificación de Eficiencia Energética en Edificios nº8 (2009).

[3] deDear, R. J.; Brager, G. S.; "Developing an Adaptive Model of Thermal Comfort and Preference", RP-884. ASHRAE Transactions: Research. (1998)

[4] Rey Martínez, F.J.; Velasco Gómez, E. "Bombas de Calor y Energías Renovables en Edificios". Editorial Thomson. ISBN: 84-9732-395-5. Madrid, 2005.

\section{Norms}

[N-1]. Ministerio de Vivienda de España, "Real Decreto 315/2006 de 17 de marzo: Código Técnico de la Edificación: Parte 1". 2006.

[N-2]. EN 15251: 2008. Criteria for the indoor environment including thermal, indoor air quality, light and noise.

\section{Websites}

[W-1] Instituto para la Diversificación y Ahorro Energético (IDAE) http://www.idae.es/ (Accessed on 11th March 2011). 


\section{INDEX OF FIGURES}

- Figure IX.1.- Map of the different climates existing in Spain [1, Bermúdez, 2008].

- Figure IX.2.- Deviation percentage of demands calculated through the alternative process to results given by CALENER, for various cities.

- Figure IX.3.- General scheme of the building subject (geometry of cases 600 and 900).

- Figure IX.4.- Conditions achieved by the RMPDEC and the FCW-CM in naturally conditioned systems, according to the model given by Dear \& Brager [3, deDear\&Brager, 1998].

- Figure IX.5.- Conditions achieved by the RMPDEC and the FCW-CM in naturally conditioned systems, according to the adaptative model [N-2].

- Figure IX.6.- Evolution of temperatures and demands evolution during the working hours of a day in July.

- Figure IX.7.- $\mathrm{CO} 2$ emissions generated by a heat pump alone and through the implementation of the studied solutions. 


\section{INDEX OF TABLES}

- Table IX.1.- Spanish cities selected according to the CTE classification for summer.

- Table IX.2.- Results of temperature drops obtainable by systems susceptible of being installed in naturally conditioned spaces.

- Table IX.3.- Regressions for the systems cooling capacity.

- Table IX.4.- Operating conditions for the $48 \mathrm{~m} 2$-area building during summer, for an operating period of $8 \mathrm{~h}$.

- Table IX.5.- Total annual cooling demands for medium intensity loads, and total cooling potential through free-cooling by air.

- Table IX.6.- Total ventilation cooling demands for medium intensity loads, and total cooling capacities achievable by different alternatives.

- Table IX.7.- Annual total and ventilation cooling demands for medium intensity loads, and total cooling capacities achieved by different alternatives.

- Table IX.8.- Annual total operating hours of the systems in the four cities studied.

- Table IX.9.- Power consumption associated to the systems operation.

- Table IX.10.- Energy consumptions associated to the systems operation.

- Table IX.11.- Systems seasonal average Coefficient of Performance for each city.

- Table IX.12.- Energy savings associated to the systems operation.

- Table IX.13.- CO2 emissions reduction achieved through the implementation of the studied solutions. 


\section{CHAPTER X}

\section{CONCLUSIONS AND FUTURE WORK}

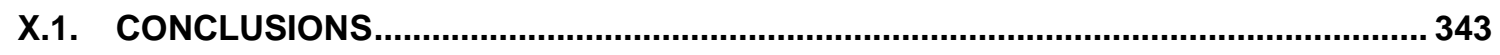

POLYCARBONATE INDIRECT EVAPORATIVE COOLERS................................................... 343

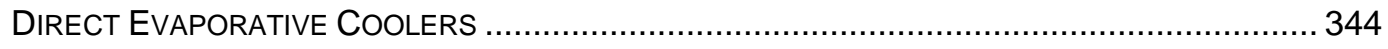

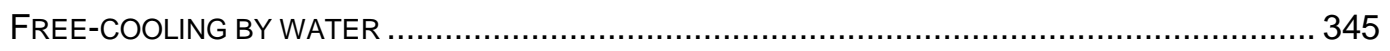

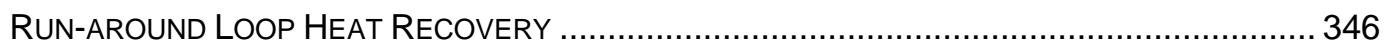

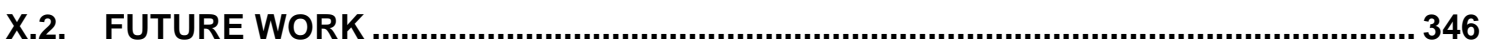




\section{X.1. CONCLUSIONS}

In the present chapter, the main conclusions derived from the analysis of the experimental characterization of the various systems studied are compiled. This will set the basis for the future work to be developed on the study of the applicability of the systems characterized, which is also dealt in subsection X.2.

On the overall, two main ideas can be extracted from the results obtained in this PhD project, in relation to its main objective of minimizing the energy demand required for cooling spaces ensuring thermal comfort during summer season; which constitutes a key potential working area on the reduction of the energy consumption and in particular on that associated to the building sector. Firstly, the great interest in making use of the adequate conditions of the exhaust airstreams required to ensure a certain level of Indoor Air Quality; which otherwise would constitute a residual source of energy directly discharged outdoors. This residual energy can be easily exploited through numerous ways: by a simple heat exchange with supplied air; or implementing a heat recovery mode on alternative systems, designed to reduce energy demand, in order to improve their performance. And secondly, the improvement on Indoor Climate Quality of naturally-ventilated spaces that could be achieved by implementing simple direct evaporative cooling systems that would not require complicate installations of airconditioning. Nevertheless, it must be considered that, for naturally-ventilated spaces, and despite the low consumptions of the systems susceptible of being installed in this case, there is an energy consumption generated and not considered. However, such small energy consumptions can be neglected and thus these systems considered "zero energy consumption".

These two ideas combine with the interest of taking advantage of the possibilities of the traditional free-cooling by air when outdoor air shows mild and consequently favourable climate characteristics for supporting indoor thermal loads. Thus, this option should be always taken into account.

Considering the various solutions proposed throughout the study, important energy savings can be achieved on the conventional heat pumps installed, and consequently reductions on the $\mathrm{CO}_{2}$ emissions related to indoor spaces cooling during summer season.

Some further more specific conclusions on each particular device characterized are highlighted following.

\section{Polycarbonate Indirect Evaporative Coolers}

Concerning the design and construction of the system, using a plastic material turned to be quite interesting due to both its lightness and low cost, additionally to its good behaviour in presence of water. This permits constructing more light and compact systems, reducing investing and maintenance costs. Furthermore, it had already been probed that the thermal 
conductivity did not constitute a determining factor when working with such small thicknesses of the heat exchange walls.

When studying their performance, both systems had their behaviour improved when operating as evaporative coolers instead of mere heat exchangers, because this phenomenon exploits better the cooling potential of the exhaust air used. They turned to behave better as well when treating hotter outdoor airstreams, which enhances the interest of their application in harsher climates.

Modifying the airflows treated permitted controlling the temperature of supplied air. Higher airflows permit supporting thermal loads by supplying air at lower temperatures and velocities, reducing risks of draughts and non-uniformity of the ambient indoors. Moreover, higher airflows improve the heat exchange process due to the increase in the convective coefficients. These coefficients are however not clearly modified due to the presence of a water film on the exchange walls.

The system constructed with narrower panels and thus characterized by a nearly doubled heat exchange area, provided slightly better results, but not as outstanding as could be expected. This was also observed on the energy savings that could be achieved on the ventilation cooling demand studied in chapter IX, as both systems gave similar results. Consequently, the selection of the optimum system would be based on constructive issues and not so founded on differences of performance.

One of the most important considerations for their implementation is, nonetheless, the near negligible power consumption of the water pumps which constitute the unique electric systems needed for their operation.

\section{Direct Evaporative Coolers}

It has been seen that, for their simple operating configuration, in which the phenomenon of evaporative cooling is directly implemented on the supplied airstream through simple methods (pulverization and evaporation from humid surface), they could be considered for being installed in naturally-ventilated spaces to soften indoor thermal conditions.

On one hand, the characterization of the misting system showed some interesting results on their operation, such as the necessity of providing a minimum water flow to avoid risks of overwarming in the system; and also that electric energy consumption depended exclusively on the pressure levels established. On the other hand, the COP turned to improve both with the pressure and the water flow, though high flows could incur in an incomplete evaporation of the mist, which would be inadmissible for the safety in their application.

However, misting systems are widely used to cool outdoor spaces and not very recommendable for their application in indoor spaces, due to the excessive airflow that would 
be required to support the increase in the humidity generated, which could lead to condensations. Furthermore, it worsens possible risks of generating aerosols that could be airborn porting harmful bacteria such as Legionnaire. Consequently, their characterization indoors required so high restrictions on working parameters that lead to the rejection of their practical implementation for this particular application.

Concerning the Rigid Media Pad system, aerosols generation was globally avoided, due to its operation from humid surface and existence of a drift elimination zone on the pad. This enables it use to cool ventilation air supplied indoors. However, this configuration incurred into high pressure drops that required the use of quite powerful fans, which would increase the global energy consumptions.

These two direct evaporative cooling systems could only be considered for application on dry climates, the hotter the better, as they operate directly on the outdoor airstream supplied for ventilation.

\section{Free-cooling by water}

The device consisting of a cooling tower and a coil to enable free-cooling by water, provides quite interesting results, mainly due to the simplicity of the process implemented, in which the intermediate steps are few and simple (there is a unique coil). Consequently, it is characterized by quite good performances with a minimum requirement of electric energy to move the water through the coil.

The system can be mounted into a conventional configuration, in which pure free-cooling by water is implemented by directly conducting outdoor air to the cooling tower; or into a heat recovery mode, in which the system makes use of the exhaust airstream from the space. In the first case, the system can be considered for application on naturally-ventilated systems, whereas the second option should be considered as an air-conditioning system itself.

It has been probed that performance improves for higher levels of dry bulb temperature of outdoor air treated, whereas the remaining factors do not constitute relevant influence on this performance. Particularly, varying the flow of water supplied, which is related to the water pump energy consumption, has a negligible effect on the parameters studied, for being in every case greater than the amount of water evaporated into the air.

Consequently, a wide range of airflows might be treated with this device maintaining the performance; and system's control is simplified as no variation of the supplied water flow is needed.

However, despite the simplicity of its configuration, it shows the main disadvantage of requiring wide space for its installation. Thus, its application in naturally-ventilated spaces would be always interesting, provided there are not space limitations in the building. Further 
complication would constitute the heat-recovery configuration. However, if supply and exhaust air ducts permit it, free-cooling by water into a heat-recovery cycle would also be recommendable as a supporting air-conditioning system to reduce energy demand.

Concerning the specific energy savings introduced with this system, it must be highlighted that a more adequately dimensioned water pump for a better designed coil of lower pressure drop would reduce the electric energy consumed, and thus improve the energy efficiency of the system. This idea is considered as further work to develop.

\section{Run-around Loop Heat Recovery}

Finally, the Run-around loop Heat Recovery system enables the exploitation of the residual energy associated to exhaust airstreams when the constructive configuration of supply and exhaust ducts do not permit simpler resources of heat recovery.

Like for previous devices, the performance of the run-around loop system improves when the outdoor conditions to be faced are harsher; which, on the other hand, will constitute the most demanding cases.

Operating with higher outdoor air volume flows do not only constitute a favourable condition to reduce the supplied air velocity and temperature difference to that of indoor air, but also improve the performance of the heat exchange process itself in the outdoor/supplied air coil.

However, for using an intermediate fluid between both airstreams, and consequently two heat exchangers, performance drops considerably. This, in addition to the power required by the water pumps to move the water through the two coils, spoils the energy savings that could be achieved by the heat recovery process. Future work should be raised on this issue.

Consequently, this sort of system is only recommended when the particular limitations of the installation do not enable other alternatives of heat recovery; and in every case a careful design should be firstly developed to ensure that its installation provides energy savings, actually.

\section{X.2. FUTURE WORK}

It has been seen that introducing some of the above systems would reduce the energy consumption for cooling indoor spaces during summer season. However, only the experimental characterization of the devices has been developed in detail, providing interesting results on their performances that nonetheless have only been briefly introduced on a simple practical case to illustrate the actual possibilities affordable through their installation. 
For a further wider and more detailed practical analysis, more extensive considerations on the operating conditions should be raised. Among these considerations is the fact that broader climate conditions should be studied for a complete practical analysis, in order to determine clearly for which particular climates each device (or combination of devices) would be of interest.

Concerning the proceedings followed to determine to what extent the systems succeed in supporting the ventilation cooling demand in conditioned spaces, the study has been done in terms of their characteristic Cooling Capacities. However, for some systems implementing evaporative cooling, a more precise analysis could be proposed in terms of Wet Bulb Thermal Effectiveness, as they operate in most cases implementing the phenomenon of evaporative cooling. However, it would complicate the analysis and difficult the comparison between systems for the cases where this parameter cannot be defined. Consequently, the Cooling Capacity appeared as a fair parameter for comparison.

Another possibly interesting point to be tackled could be the global analysis of a combination of the alternative systems to support air-conditioning demands. However, regarding the results of the ventilation cooling demand supplied by each system and by the optimum one in each moment, it was seen that the FCW-HR gave the maximum cooling power in most cases. Consequently, this step could be omitted.

A key point for the possibilities of improvement is the fact that the coils used in the FCW and RLHR are not specific devices for air-conditioning systems, but designed to cool water inside the pipes (water flow passes through all pipe's length), and consequently the pressure drop generated is excessive for the particular applications. If reduced, also water pumps required would be of low power, and thus the energy consumed by the system to operate. This would be a solution for the obtained negative energy savings when installing the RLHR, as well as a way to increase the ones obtained with the FCW-HR. Actually, power of $120 \mathrm{~W}$ consumed by the water pumps in the RLHR could be reduced up to around $36 \mathrm{~W}$, if the total of $12 \times 4$ pipes in the two coils (with a total of 47 elbows) would be divided in 12 or 24 paths of 4 or 2 pipes, respectively. (Notice from details given in chapter IV that the two pumps used for the RLHR range from 46 to $93 \mathrm{~W}$, and the one for the FCW has $370 \mathrm{~W}$. They were so overdimensioned initially to enable waterflow variation).

Finally, an unavoidable issue to rise is the economical analysis of the viability of the different systems, and the payback period of the investment associated. However, for being in most cases mere prototypes designed and constructed in the laboratory, there is not enough information to develop this analysis. Notice that man-hours in these cases are not representative, for having constituted such first prototypes a great workload not susceptible of being evaluated. Furthermore, improvisation already proposed on the prototypes' performances could be included in future research, and it could highly influence energy savings and thus payback periods. Concerning the two commercial direct evaporative coolers, no energy savings are considered for being installed just to improve indoor climate conditions but not to supply real 
demand; thus no payback could be considered in these cases. For all the reasons mentioned, the economical analysis is not developed in the present work.

In conclusion, the already justified potential of the studied technologies as alternatives for reducing the energy consumption in air-conditioning during summer season enhances the interest on pursuing the study of the options and viability of these devices, with special interest on the improvement of the design of the prototypes created in the laboratory. 


\section{ANEXOS \\ ANNEXES}

$\begin{array}{ll}\text { ANEXO A: } & \text { PROCEDIMIENTO DE DISEÑO DE } \\ & \text { EXPERIMENTOSYANÁLISIS DE VARIANZA }\end{array}$

ANEXO B: $\quad$ CALIBRACIONES 



\section{ANEXO A PROCEDIMIENTO DE DISEÑO DE EXPERIMENTOS Y ANÁLISIS DE VARIANZA}

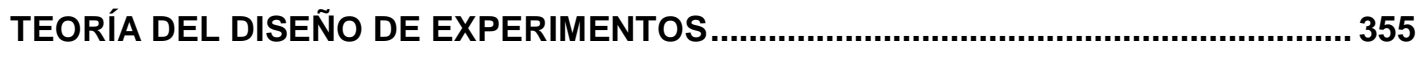

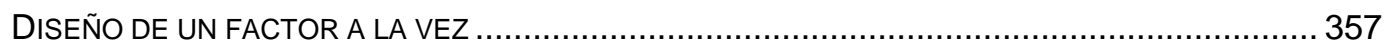

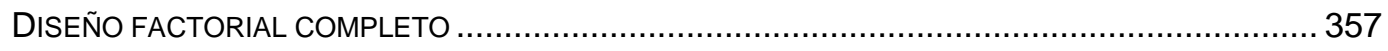

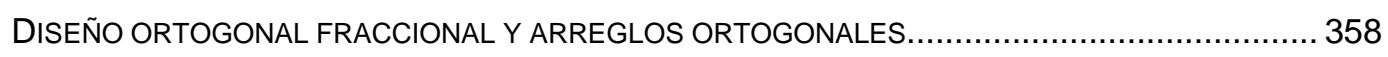

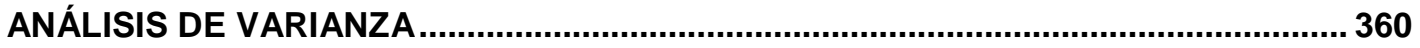




\section{SiMBOLOGÍA DEL CAPÍTULO}

$Y_{i}: \quad$ Medida i-ésima.

SS $S_{X}$ : Suma de cuadrados correspondiente a X (factor, interacción o error).

N: Número total de observaciones.

T: $\quad$ Suma de todas las medidas Yi.

$\bar{Y}: \quad$ Media de las medidas $Y$ i.

$A_{i}$ : $\quad$ Suma de todas las observaciones para el nivel i del factor $A$.

$(A \times B)_{j}$ : Suma de todos los valores de la interacción $A \times B$, en su cruce $j$.

$N_{A i}: \quad$ Número de observaciones bajo el nivel i del factor $A$.

$N_{(A \times B) j}$ : Número de valores de el cruce j, de la interacción $A x B$.

$k_{A}$ : Número de niveles del factor $A$.

$k_{A} x k_{B}$ : Número de cruces existentes en la interacción del factor $A$ con el factor $B$. 


\section{TEORÍA DEL DISEÑO DE EXPERIMENTOS}

En el presente anexo se describe la teoría del diseño de experimentos para justificar los estudios realizados previamente a la caracterización experimental de los equipos analizados en los capítulos de la memoria de este trabajo de tesis doctoral.

El objetivo de un diseño de experimentos es caracterizar el comportamiento de un proceso cuando se introducen cambios deliberados en aquellas variables que intervienen en el proceso.

Antes de realizar una descripción de la técnica experimental, que vamos a utilizar en la caracterización de la batería de tubos de calor, se van a definir algunos de los conceptos que se emplearán durante el desarrollo del presente capítulo, con el fin de precisar el significado que poseen en el contexto donde van a ser utilizados.

Factor: Aquella variable o circunstancia bajo la que se desarrolla el experimento, y que puede afectar de alguna manera a la característica seleccionada. Se definen dos tipos de factores dependiendo de cómo intervienen en el desarrollo del ensayo: factor de control y factor de ruido.

Factor de control.- Variable que podemos controlar durante el desarrollo de la experimentación.

Factor de ruido.- Variable que no podemos controlar durante el desarrollo de la experimentación [1, Stuart, 1995].

Niveles: Valores que adquieren los distintos factores que actúan sobre la característica de calidad.

Característica: Aquella propiedad o propiedades analizadas con cada uno de los experimentos realizados. Estos valores son los que permiten realizar el análisis de los experimentos, para obtener el resultado del diseño, determinar los índices de contribución de los diferentes factores analizados, los óptimos de papel o económicos, etc.

Efectos: Se entiende por efecto de un factor, al cambio de respuesta identificado en la característica que se mide, cuando se cambia de nivel al factor.

Interacción: Se dice que existe interacción cuando los efectos de los factores contemplados conjuntamente no son aditivos; o dicho de otra manera, cuando el efecto de un factor sobre una característica depende del nivel a que se encuentre otro factor.

Óptimos: Es la combinación de niveles de los factores que proporciona el mejor resultado sobre una determinada característica.

Grados de libertad: Se define como el número de comparaciones que hay que realizar para determinar el mejor nivel de un factor. Coincide con el número de niveles menos 1. 
Ortogonalidad: Cuando un conjunto de experimentos guardan entre sí ortogonalidad, al ensayar cada nivel de un factor el mismo número de veces con todos los niveles del resto de los factores, de tal manera que, aceptando que el comportamiento de los factores sobre una determinada característica es lineal, la contribución a la media del resto de los factores se anula. Esto facilita el análisis de los resultados obtenidos, pues el resultado para el nivel de un factor se obtiene como la media del conjunto de ensayos en los que interviene, pero obliga a realizar unas determinadas experiencias programadas previamente. En la Tabla A.1 se presenta un ejemplo de conjunto de experimentos que cumplen esta característica.

Tabla A.1.- Diseño factorial completo $L_{8}$.

\begin{tabular}{|l|c|c|c|c|c|c|c|}
\hline & Factor A & Factor B & Int. AxB & Factor C & Int. AxC & Int. BxC & Int.AxBxC \\
\hline Ensayo 1 & Nivel 1 & Nivel 1 & Nivel 1 & Nivel 1 & Nivel 1 & Nivel 1 & Nivel 1 \\
\hline Ensayo 2 & Nivel 1 & Nivel 1 & Nivel 1 & Nivel 2 & Nivel 2 & Nivel 2 & Nivel 2 \\
\hline Ensayo 3 & Nivel 1 & Nivel 2 & Nivel 2 & Nivel 1 & Nivel 1 & Nivel 2 & Nivel 2 \\
\hline Ensayo 4 & Nivel 1 & Nivel 2 & Nivel 2 & Nivel 2 & Nivel 2 & Nivel 1 & Nivel 1 \\
\hline Ensayo 5 & Nivel 2 & Nivel 1 & Nivel 2 & Nivel 1 & Nivel 2 & Nivel 1 & Nivel 2 \\
\hline Ensayo 6 & Nivel 2 & Nivel 1 & Nivel 2 & Nivel 2 & Nivel 1 & Nivel 2 & Nivel 1 \\
\hline Ensayo 7 & Nivel 2 & Nivel 2 & Nivel 1 & Nivel 1 & Nivel 2 & Nivel 2 & Nivel 1 \\
\hline Ensayo 8 & Nivel 2 & Nivel 2 & Nivel 1 & Nivel 2 & Nivel 1 & Nivel 1 & Nivel 2 \\
\hline
\end{tabular}

En la Tabla se observa como para cualquier nivel (nivel 1 o nivel 2) de un factor o interacción, siempre el resto de los factores o interacciones se ensayan el mismo número de veces en el nivel 1 que en el nivel 2. La importancia de estas técnicas ha proporcionado una gran documentación existente al respecto en la que se presentan varios métodos experimentales que tienen como característica común la ortogonalidad de sus diseños [1, Stuart, 1995], [2,Cochram\&Cox,1987], [3, Phadke], [4, Bendell et. al.,1989], [5, Roy,1990].

Los arreglos ortogonales han sido tradicionalmente relacionados con las técnicas experimentales utilizadas en metodología Taguchi, que es el que más ha difundido su uso, aunque no fue el que primero en desarrollarla [1, Stuart, 1995]. La principal contribución de la metodología Taguchi es que utiliza los denominados arreglos ortogonales fraccionales, que mantienen la ortogonalidad en el planteamiento del diseño, pero que no analizan las interacciones dobles entre factores que, a priori y derivado del conocimiento del proceso, se supone que no van a afectar al resultado de la experimentación. En la metodología Taguchi siempre se desprecian las interacciones superiores al segundo orden.

Las técnicas de diseño de experimentos, fueron propuestas ya por el profesor R. A. Fisher en la década de los años 1920 [3, Phadke], [5, Roy,1990], pero su principal desarrollo se ha derivado de su utilización como herramientas de calidad para conseguir mejores rendimientos de proceso. Su objetivo es conseguir la mayor cantidad de información de un proceso con pocas experiencias, permitiendo establecer los niveles de los factores que mejores resultados proporcionan al proceso, las zonas donde el proceso tiene un comportamiento estable, etc., 
pero siempre con un número de experiencias reducido, dado el coste asociado a su realización a nivel industrial.

De las técnicas más utilizadas en diseño de experimentos, anteriormente ya mencionada, es la metodología Taguchi, cuya principal contribución ha sido la forma en que relaciona los resultados obtenidos de los experimentos con la evaluación económica de los mismos. Por otra parte, introduce una nueva filosofía en el diseño, permitiendo perder parte de la información en favor de una reducción en el número de experimentos a realizar. Esta metodología es la más aplicada en la actualidad para optimizar los procesos productivos [6, Taguchi et al, 1989], [7, Ross, 1988].

Los diseños de experimentos permiten programar los ensayos que hay que realizar, para poder determinar cómo afectan los valores de los factores (niveles), sobre la característica (resultados) que se obtiene de un proceso. Las principales técnicas experimentales son las que se presentan a continuación.

\section{Diseño de un factor a la vez}

Se trata de la forma de experimentar más tradicional. De entre todos los factores seleccionados, sólo se cambia el nivel de uno de ellos permaneciendo el resto invariable, observando el efecto que ocasiona ese cambio de nivel. Una vez determinado el mejor nivel de ese factor, se mantiene fijo y se analiza otro factor de los que afectan a la característica seleccionada. Este método no permite contemplar interacciones entre factores.

\section{Diseño factorial completo}

Se trata de un diseño en el que se consideran todas las combinaciones posibles de los niveles de los factores. Con este método se obtiene toda la información posible de la influencia de los niveles de los factores analizados sobre el proceso objeto de estudio.

Este tipo de diseño es el utilizado durante la caracterización de los equipos planteados en la memoria de la presente tesis doctoral. La fórmula que determina el número de experimentos que se precisan es (A.1):

$$
N ” \text { de Experimentos }=\prod_{i=1}^{n} N_{i}
$$

Siendo Ni es el número de niveles del factor i.

Por ejemplo, para un diseño ortogonal completo de 2 factores a 2 niveles, 1 factor a 3 niveles y 2 factores a 4 niveles, el número de experiencias sería de: $2 \times 2 \times 3 \times 4 \times 4=192$ experimentos. 
Existe una regla, dada por Yates, que permite construir el diseño experimental. Su desarrollo sería similar al mostrado en la tabla A.1. Este tipo de diseño permite determinar si existen, entre los factores, interacciones importantes. Las interacciones se determinan como el número de combinaciones que se pueden realizar con los factores.

\section{Existe Interaccin}

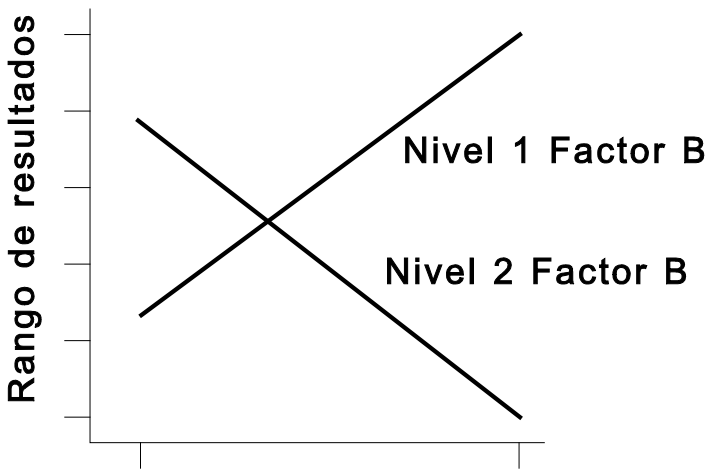

Nivel 1 Factor A Nivel 2 Factor A

\section{No Existe Interaccin}

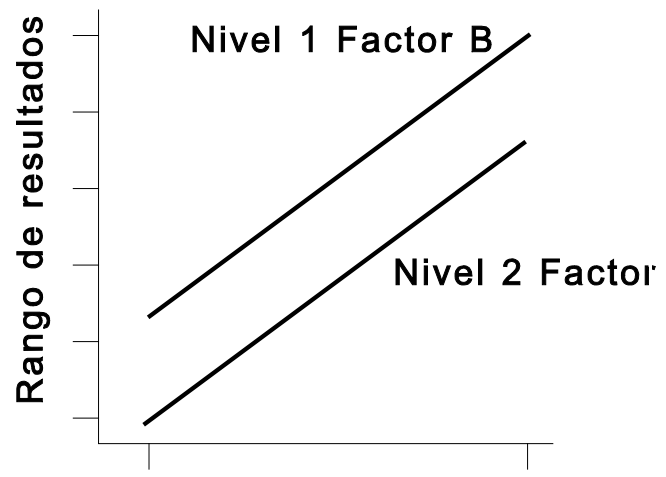

Nivel 1 Factor A Nivel 2 Factor

Figura A.1.- Posibles situaciones de interacción factorial.

Una interacción doble será aquella en la que intervienen dos factores, triple en la que intervienen tres, y así sucesivamente. La contribución de las interacciones triples o de orden superior al resultado se considera despreciable, y sólo se contemplan como significativas las interacciones dobles.

La existencia de interacción se manifiesta gráficamente con dos rectas no paralelas, y si esas rectas se cruzan se interpreta como que existe una interacción fuerte. En la figura A.1 se representan gráficamente las posibles situaciones que pueden presentar los niveles de dos factores analizados conjuntamente.

Dado que se han realizado los ensayos para todas las posibles combinaciones de los factores, y a todos sus niveles, los ensayos correspondientes a las combinaciones óptimas de niveles de los factores, se observa durante la experimentación.

\section{Diseño ortogonal fraccional y arreglos ortogonales}

El problema del diseño factorial completo es el elevado número de ensayos que hay que realizar cuando aumenta el número de factores o de niveles, por eso, se plantea reducir el número de experiencias manteniendo el máximo de información posible. Esto se logra con el diseño factorial fraccional y con los arreglos ortogonales.

Este tipo de diseño lo creó en 1934 Tippet, siendo desarrollados posteriormente por D.I. Finney, Yates, Placket \& Burman, C. R. Rao, S. Hunter y G. Taguchi [5, Roy, 1990]. 
Esto se consigue conociendo las interacciones que van a ser significativas y cuáles no lo van a ser, lo que siempre es consecuencia de la experiencia y el conocimiento del proceso. Cuando una interacción no va a contribuir al resultado final de un proceso, la columna asignada a esa interacción, o lo que es lo mismo, los grados de libertad que precisa su determinación, pueden ser empleados para determinar la contribución de otro factor. El número de grados de libertad determina la cantidad de información que puede obtenerse de un diseño de experimentos.

Cuando se investigan factores que se comportan de manera independiente respecto de los demás, luego no poseen interacciones con otros factores, puede asignarse un factor a cada columna del diseño de experimentos. Entonces se dice que tenemos un diseño factorial fraccional saturado. Una muestra esquemáticamente de las reglas para la asignación de los grados de libertad es:

a) Un diseño de experimentos que contemple 16 experimentos posee 15 grados de libertad (siempre 1 menos que el número de ensayos necesarios para realizar el diseño).

b) El análisis de un factor requiere un número de grados de libertad igual al número de niveles del factor menos 1 . Se necesitan 3 grados de libertad para determinar la influencia sobre el proceso de un factor a 4 niveles.

c) Cada columna de un diseño de experimentos está asociada a un grado de libertad, y puede soportar un factor a 2 niveles o una interacción de dos factores a dos niveles. Un factor a tres niveles requiere 2 columnas de 1 grado de libertad o 1 columna que soporte dos grados de libertad.

d) El número de grados de libertad asignados a una interacción se calcula como el producto de los grados de libertad de los factores que intervienen en la interacción. Ej. Una interacción de dos factores a 2 niveles precisa de 1 grado de libertad, mientras que si fueran a tres niveles necesita 4.

La utilización de este tipo de diseño es muy importante en procesos industriales, en los que existe ya un conocimiento del proceso elevado, en los cuales sólo se buscan óptimos de operación y donde la realización de un ensayo posee un coste económico muy elevado, por lo que no es muy importante el hecho de perder algo de información relativa a las interacciones.

En nuestro caso se va a desarrollar un diseño factorial completo, consecuencia de la necesidad de determinar cómo afectan todos los factores que vamos a considerar en la caracterización de los sistemas, así como sus posibles interacciones; además de ser posible gracias al bajo coste que lleva asociada cada una de las experiencias que hay que realizar, etc. 


\section{ANÁLISIS DE VARIANZA}

La variabilidad generada entre los resultados de la experimentación no se debe sólo al tipo y número de factores que entran en juego, si no también se debe a que existen causas desconocidas que influyen en ella. La técnica del Análisis de la Varianza (ANOVA) es una herramienta de amplia utilidad que va a permitir además estudiar la influencia de los distintos factores en la variabilidad del proceso.

Cuando se fijan todos los factores menos 1, la variabilidad se produce por multitud de causas que, teóricamente, es posible dividir en dos partes, la originada por el factor en estudio, y la variación producida por los restantes factores que entran en juego conocidos o no, controlables o no, que se conoce con el nombre de error experimental. Con el análisis de la varianza se mide la variación debida a los distintos niveles del factor estudiado, y también la originada por el error experimental. Si mediante los contrastes estadísticos adecuados la variación producida por el factor es mayor que la variación debida al error experimental, es aceptable la hipótesis de que los distintos niveles del factor actúan de forma distinta.

El análisis de varianza es un procedimiento basado en el método de mínimos cuadrados. Así la varianza debida al error, es el mínimo valor de la suma de cuadrados en torno a un valor de referencia, dividido por los grados de libertad del error. Esa suma de cuadrados es mínima cuando el valor de referencia coincide con la media.

El objetivo es el establecimiento de un modelo simple de comportamiento a partir de estas ideas, el cual se puede formalizar matemáticamente.

De la misma manera que se analiza el comportamiento de los niveles de un factor (como la temperatura del aire exterior), podemos estudiar el de dos o más (el segundo factor en los casos de estudio podría ser el caudal). En el caso de dos factores el modelo matemático es una extensión del establecido para uno, sin más que tener en cuenta la ampliación de la fuente de variación.

Dependiendo del número de factores controlados durante la experimentación, se precisarán análisis estadísticos diferentes que permitan determinar la contribución a la variación del error, los factores, sus interacciones dobles, triples, etc., y denominaremos a esos análisis de varianza como ANOVA de 0 vías, 1 vía, 2 vías, etc, dependiendo del número de factores controlados durante la experimentación y cuya contribución a la variación en los resultados se pretende determinar.

Puede plantearse la situación de que dos factores A y B, no actúen independientemente; en estas condiciones se dice que existe interacción entre ambos factores, no siendo el modelo aditivo.

Un ANOVA de 0 vías, nos permite determinar únicamente la contribución del error en la experimentación. El ANOVA de 1 vía, determina la contribución del error y la correspondiente al 
factor controlado. El de 2 vías, caracteriza las contribuciones del error, de dos factores y de su interacción doble.

En la presente tesis, se han tenido casos de trabajo con dos y tres cuatro factores controlados, luego se han realizado análisis de varianza (ANOVA) de 2 y 3 vías. Las contribuciones que podemos plantear son, en el primer caso, las correspondientes al error, los 2 factores y su interacción doble; y en el segundo a los 3 factores, las dos interacciones dobles posibles y la interacción triple, además de las del error. Los resultados proporcionados vendrán a certificar la validez de los obtenidos con los valores medios de los factores y sus interacciones.

Existen dos posibilidades de plantear el análisis de varianza (ANOVA), dependiendo de si se incluye o no la media. En ambos casos el resultado de la contribución a la variación para los factores, las interacciones y el error tienen que ser igual, pues la diferencia entre un método y otro es contemplar directamente los resultados obtenidos, o esos resultados menos la media. En el caso particular se utiliza el método de exclusión de la media.

La contribución a la variabilidad de las medidas se analiza calculando la suma de cuadrados asociada a cada uno de los factores y sus interacciones. A continuación se presentan las ecuaciones definidas para su evaluación.

Cada una de esas contribuciones pueden evaluarse por separado, y el valor obtenido del cálculo de su suma de cuadrados es proporcional a la variación que introducen sobre la media los cambios de nivel que experimentan los factores. En las ecuaciones A.2 a A.5, se muestra como se realizan los cálculos de las correspondientes sumas de cuadrados.

Suma de cuadrados del total de las medidas:

$$
S S_{\text {Total }}=\sum_{i=1}^{N} Y_{i}^{2}-\frac{T^{2}}{N}
$$

Los índices de contribución a la suma de cuadrados totales $\left(\mathrm{SS}_{\mathrm{T}}\right)$, se corresponderá con la suma de los de los factores, las interacciones y el error, obtenidos como:

Suma de cuadrados de un factor:

$$
S S_{A}=\sum_{j=1}^{k A} \frac{A_{j}^{2}}{N_{A_{j}}}-\frac{T^{2}}{N}
$$

Suma de cuadrados de una interacción doble:

$$
S S_{A x B}=\sum_{j=1}^{k A x k B} \frac{(A x B)_{j}^{2}}{N_{(A \times B)_{j}}}-\frac{T^{2}}{N}-\left(S S_{A}+S S_{B}\right)
$$

Suma de cuadrados de una interacción triple: 


$$
S S_{A x B x C}=\sum_{j=1}^{k A x k B x k C} \frac{(A x B x C)_{j}^{2}}{N_{(A x B x C)_{j}}}-\frac{T^{2}}{N}-\left(S S_{A}+S S_{B}+S S_{C}+S S_{(A x B)}+S S_{(A x C)}+S S_{(B x C)}\right)
$$

La suma de cuadrados del error se obtiene por diferencia entre la $\mathrm{SS}_{\text {Total }}$ y el resto de las contribuciones de los factores.

La contribución a la variabilidad de las interacciones siempre será inferior que la debida a los factores, y prácticamente nunca se evalúan las de orden superior a dos. En los casos particulares abordados en la presente tesis, por disponer de un número de datos tan elevado, se utiliza para cada experimento un solo valor que es la media de todos los obtenidos para cada ensayo, por lo que la suma de cuadrados del error de experimentación no se puede precisar, dado que no se contemplan repeticiones en los ensayos.

La contribución del error de experimentación a la variabilidad, en este caso, se puede asociar a la calculada con las interacciones de orden superior a dos, y aquellas dobles cuya suma de cuadrados sea pequeña, en comparación con los valores obtenidos para el resto de los factores e interacciones.

Cuando se estudia mediante análisis de varianza el comportamiento de los niveles de un factor fijo, no se persigue como única finalidad del análisis saber si los distintos niveles del factor son significativamente distintos entre sí; sino que interesa conocer, una vez contrastado que las diferencias son significativas, qué niveles producen un efecto superior a los otros. Para ello se precisa de las "pruebas de significación", que utilizan los valores medios de los ensayos y del ANOVA. Estas pruebas de significación son múltiples, como el Test F, el Test de Duncan, el de Student-Newman-Keuls (SNK), Test de Tukey (HSD), Test de la diferencia mínima significativa (LSD) o el Test de Scheffe.

Para evitar aumentar la complejidad del tratamiento de los resultados, en el presente trabajo no se presentan las pruebas de significación asociadas al tratamiento estadístico de los datos, puesto que el interés del diseño de experimentos es determinar cómo afectan los factores analizados sobre las diferentes características, y no tanto los valores numéricos obtenidos para esas características en los diferentes niveles. 


\section{REFERENCIAS}

[1] Stuart Peace, G.; "Taguchi methods, A hands-on approach to quality engineering". Ed. Addison-Wesley publishing company. ISBN 0-201-56311-8. Massachusetts. Marzo 1995.

[2] Cochram, W. G. y Cox, G. M.; "Diseños experimentales". Editorial Trillas, 10a edición. ISBN 968-24-0062-7. Méjico. Agostyo de 1987.

[3] Phadke, M. S.; "'Quality engineering using robust design". Ed. Prentice-Hall International Editions. AT\&T Bell Laboratories. England.

[4] Bendell, A.; Disney, J. y Pridmore, W. A.; "Taguchi methods, applications in world industry". Ed. IFS publications. ISBN 0-948507-92-6. United Kingdom. 1989.

[5] Roy, R. K.; "A primer on the Taguchi method". Ed. Van Nostrand Reinhold International Company Limited. ISBN 044223729 4. New York. 1990.

[6] Taguchi, G.; Elsayed, E. A. y Hsiang, T.; "Quality engieering in production systems". Ed. McGraw Hill Book Company. ISBN 0-07-062830-0. United States. 1989.

[7] Ross, P. J.; "Taguchi techniques for quality engineering. Loss function, orthogonald experiments, parameter and tolerance design". Ed. McGraw-Hill Book Company. ISBN 0 07053866-2. United States. 1988. 


\section{RELACIÓN DE FIGURAS}

- Figura A.1.- Posibles situaciones de interacción factorial.

\section{RELACIÓN DE TABLAS}

- Tabla A.1.- Diseño factorial completo L8. 


\section{ANEXO B CALIBRACIONES}

CALIBRACIÓN DE LAS SONDAS DE TEMPERATURA................................................ 367

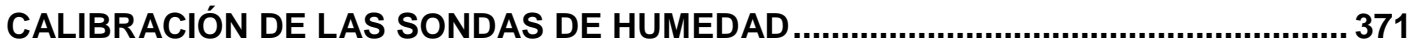

CALIBRACIÓN DE LOS MANÓMETROS DE PRESIÓN.................................................. 372

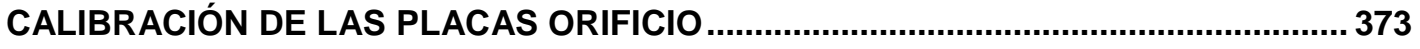




\section{CALIBRACIÓN DE LAS SONDAS DE TEMPERATURA}

A continuación se proporcionan las gráficas de las calibraciones de las sondas de temperatura desarrolladas mediante el horno de calibración FLUKE 9103 (rango de calibración entre -25 hasta $140^{\circ} \mathrm{C}$ ) utilizado como patrón primario.
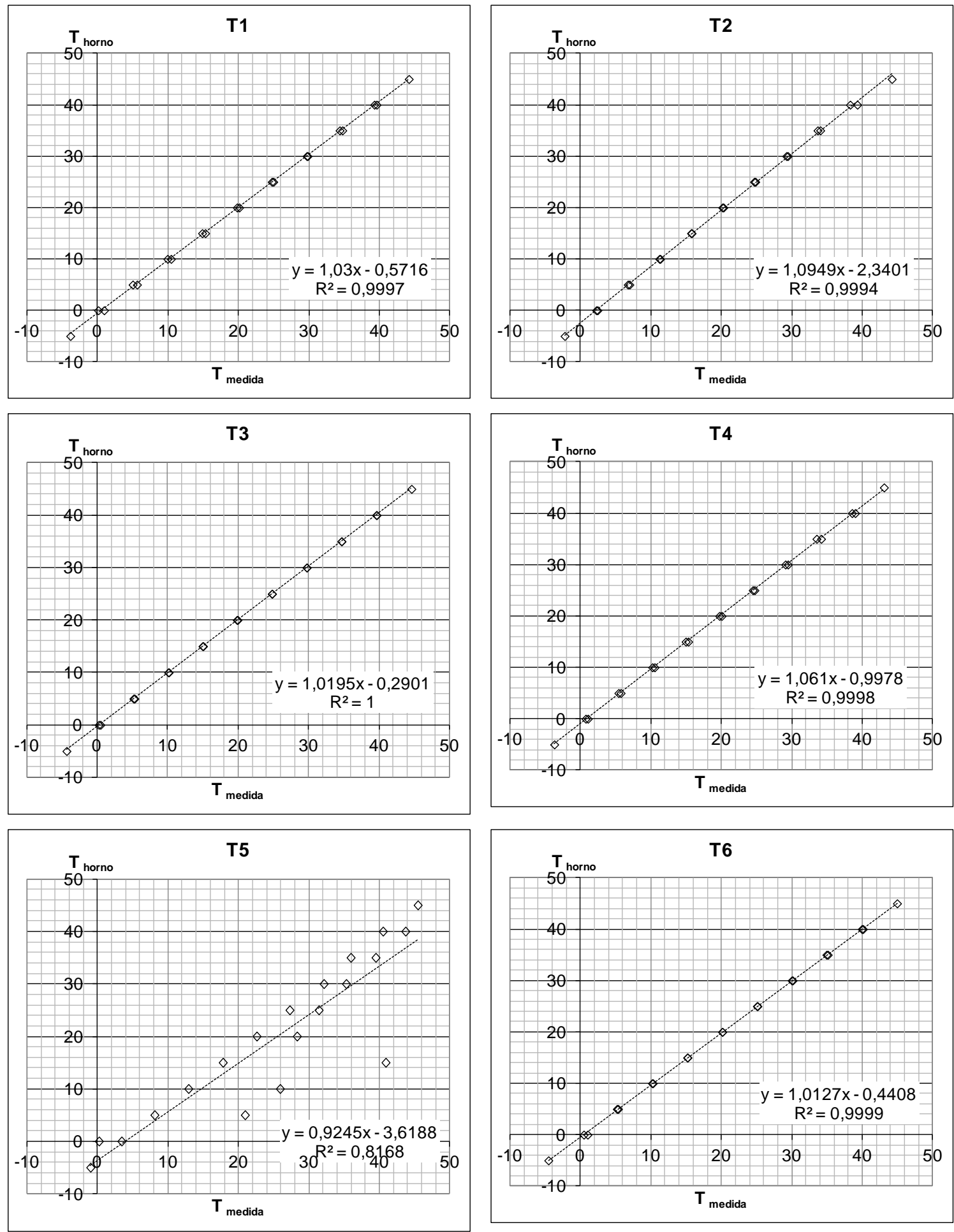

Figura B.1.a- Gráficas de las calibraciones de las sondas de temperatura. 

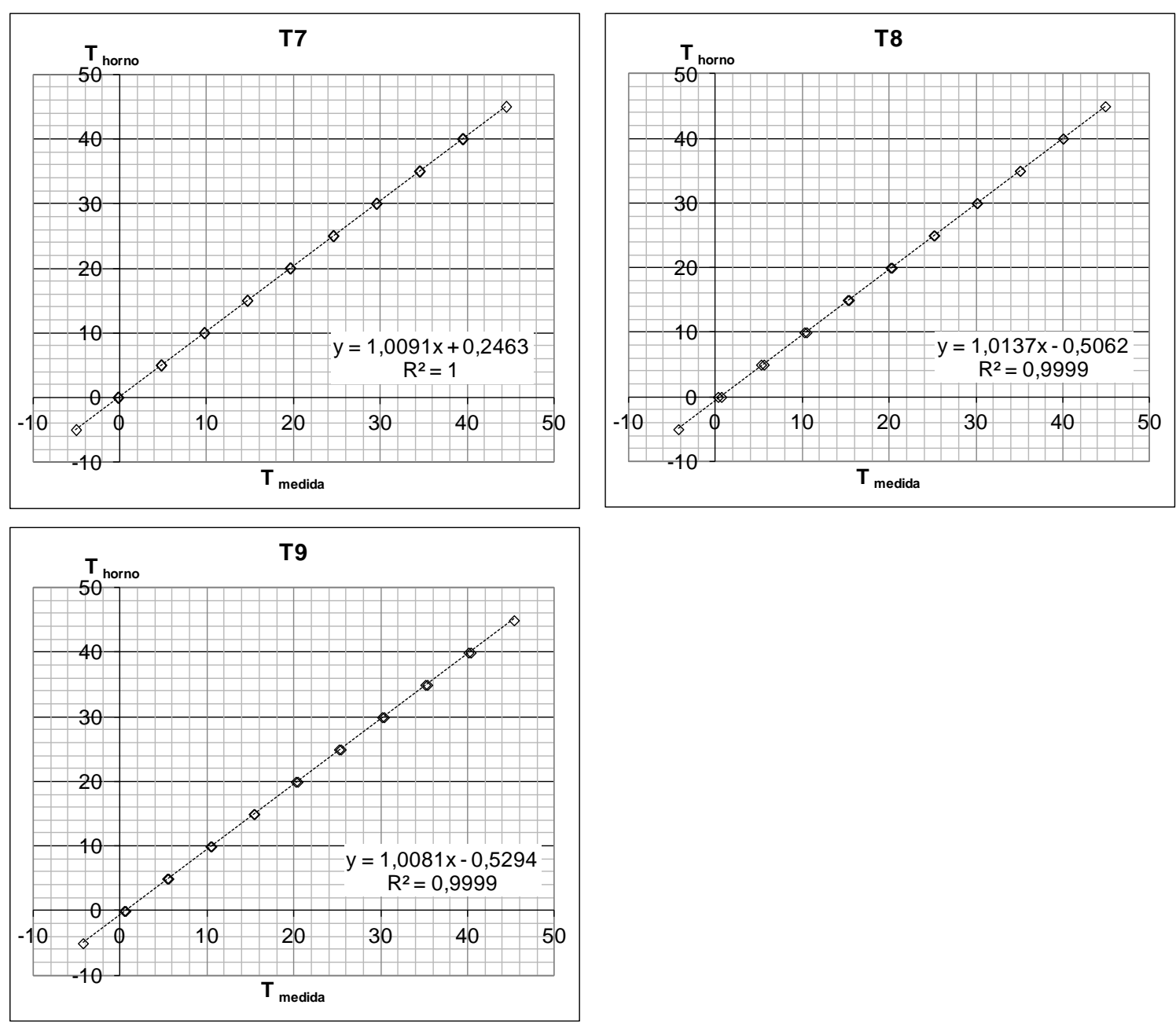

Figura B.1.b- Gráficas de las calibraciones de las sondas de temperatura (continuación).

En las páginas siguientes se proporciona el informe del fabricante sobre la calibración de dicho horno. 
Calibration Performed At:

Fluke Conporaticon

Hart Scientific Division

799 E Utah Valley Drive

Amerikan Fork, Uth 84003-9775

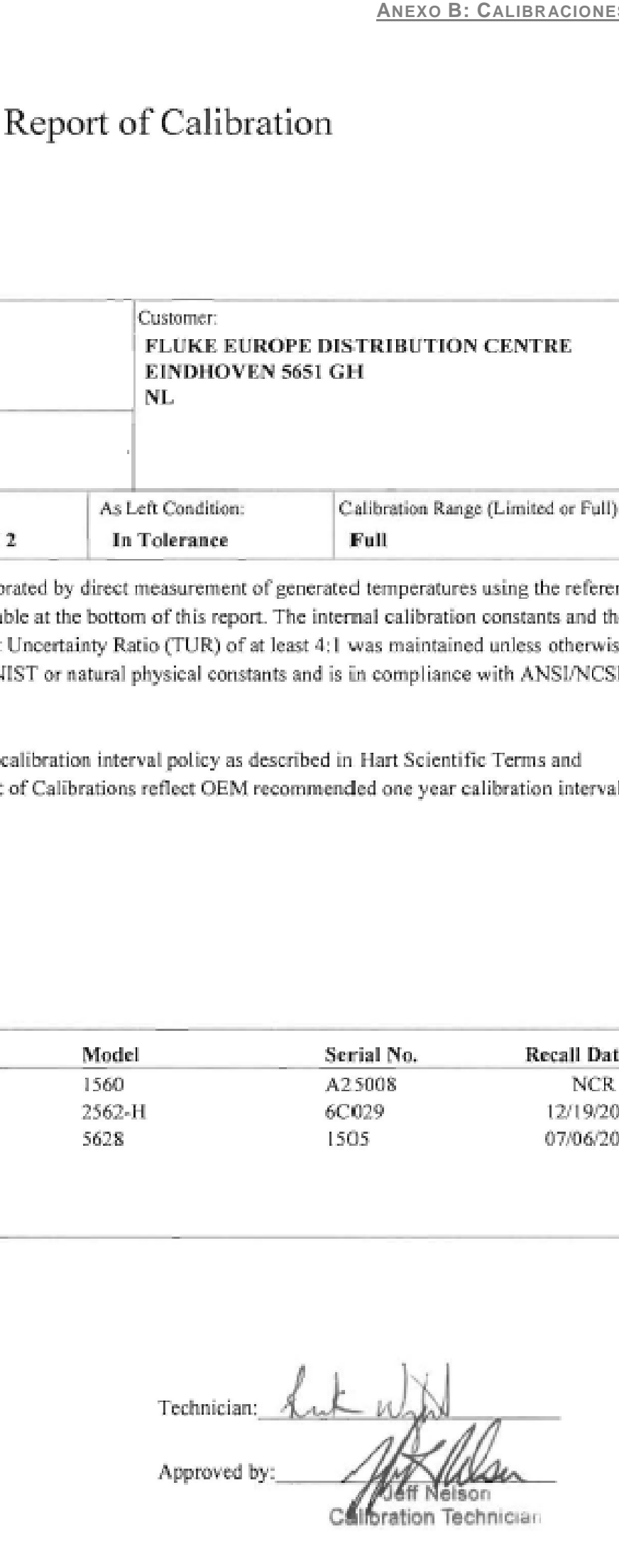

\begin{tabular}{|l|l|l|l|}
\hline $\begin{array}{l}\text { Model: } \\
9103\end{array}$ & $\begin{array}{l}\text { Serial No: } \\
\text { B06593 }\end{array}$ & $\begin{array}{l}\text { Customer: } \\
\text { FLUKE EUROPE DISTRIBUTION CENTRE } \\
\text { EINDHOVEN 5651 GH } \\
\text { NL }\end{array}$ \\
\hline $\begin{array}{l}\text { Description: } \\
\text { Drywell Calibrator }\end{array}$ & & \\
\hline $\begin{array}{l}\text { Received Condition: } \\
\text { New }\end{array}$ & $\begin{array}{c}\text { Procedure: } \\
\text { HST168 -2 }\end{array}$ & $\begin{array}{l}\text { As Left Condition: } \\
\text { In Tolerance }\end{array}$ & $\begin{array}{l}\text { Calibration Range (Limited or Full): } \\
\text { Full }\end{array}$ \\
\hline
\end{tabular}

The above referenced instrument was calibrated by direct measurement of generated temperatures using the reference standards listed in the "Test Equipment" table at the bottom of this report. The internal calibration constants and the data obtained are shown on page 2. A Test Uncertainty Ratio (TUR) of at least 4:1 was maintained unless otherwise indicated. This calibration is traceable to NIST or natural physical constants and is in compliance with ANSI/NCSL Z540-1 and MIL-STD 45662A.

NOTE: In accordance with recommended calibration interval policy as described in Hart Scientific Terms and Conditions of Sale, new instrument Report of Calibrations reflect OEM recommended one year calibration interval.

\begin{tabular}{lllc} 
Test Equipment & & & \\
Instrument & Model & Serial No. & Recall Date \\
\hline Digital Thermometer & 1560 & A25008 & NCR \\
Precision Digital Thermometer & $2562-\mathrm{H}$ & $6 \mathrm{C} 029$ & $12 / 19 / 2010$ \\
Platinum Resistance Thermometer & 5628 & 1505 & $07 / 06 / 2010$
\end{tabular}

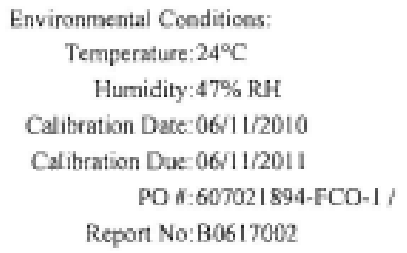

Report No:B0617002

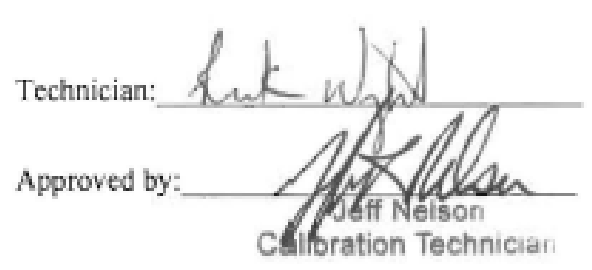

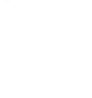




\section{Report of Calibration}

Model: 9103

Serial No: B06593

Report No:B0617002

-As Found Data

No As Found Data Required

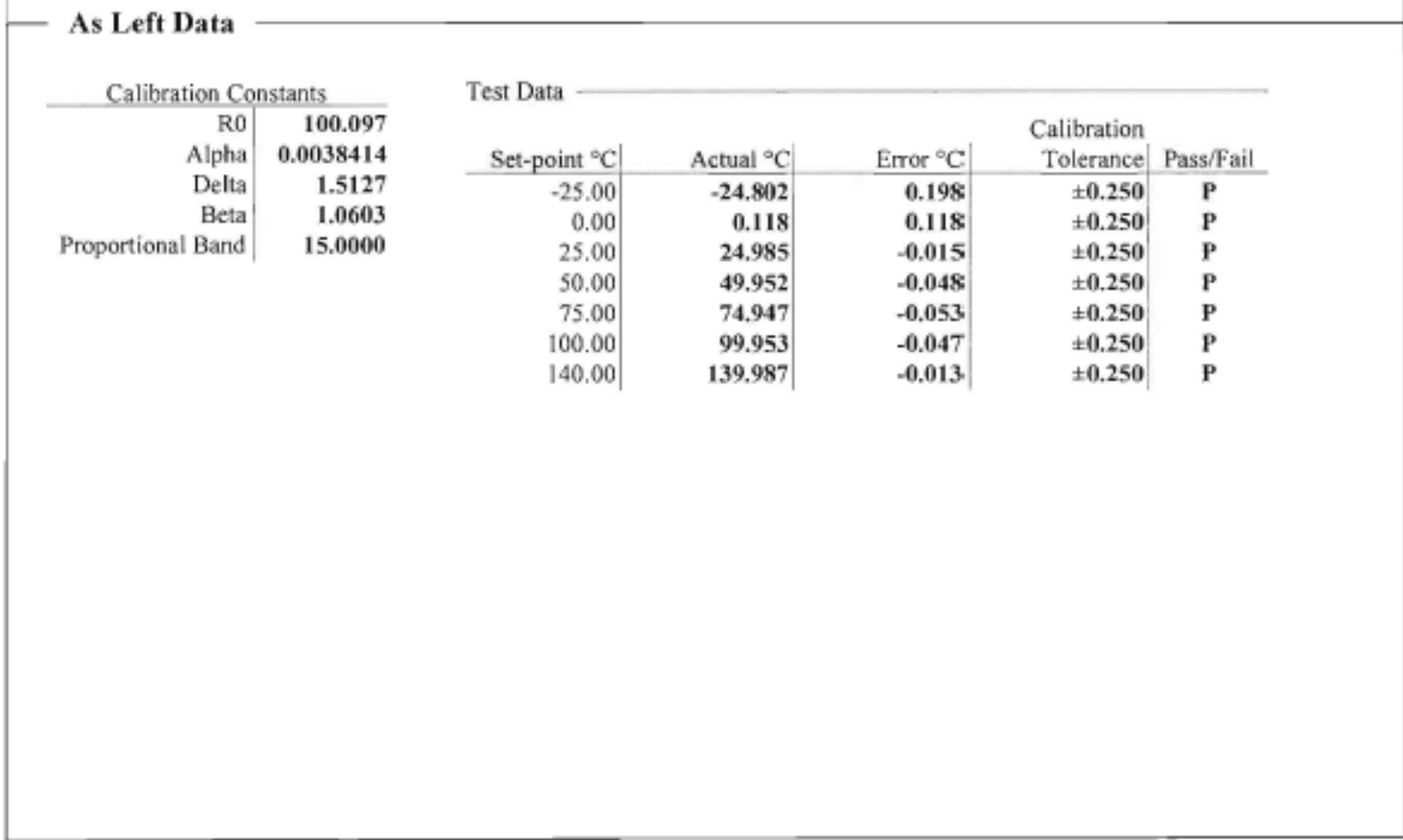

Figura B.2.b- Informe de calibración del horno (continuación). 


\section{CALIBRACIÓN DE LAS SONDAS DE HUMEDAD}

Las gráficas mostradas seguidamente se corresponden con las calibraciones de las sondas de humedad realizadas.
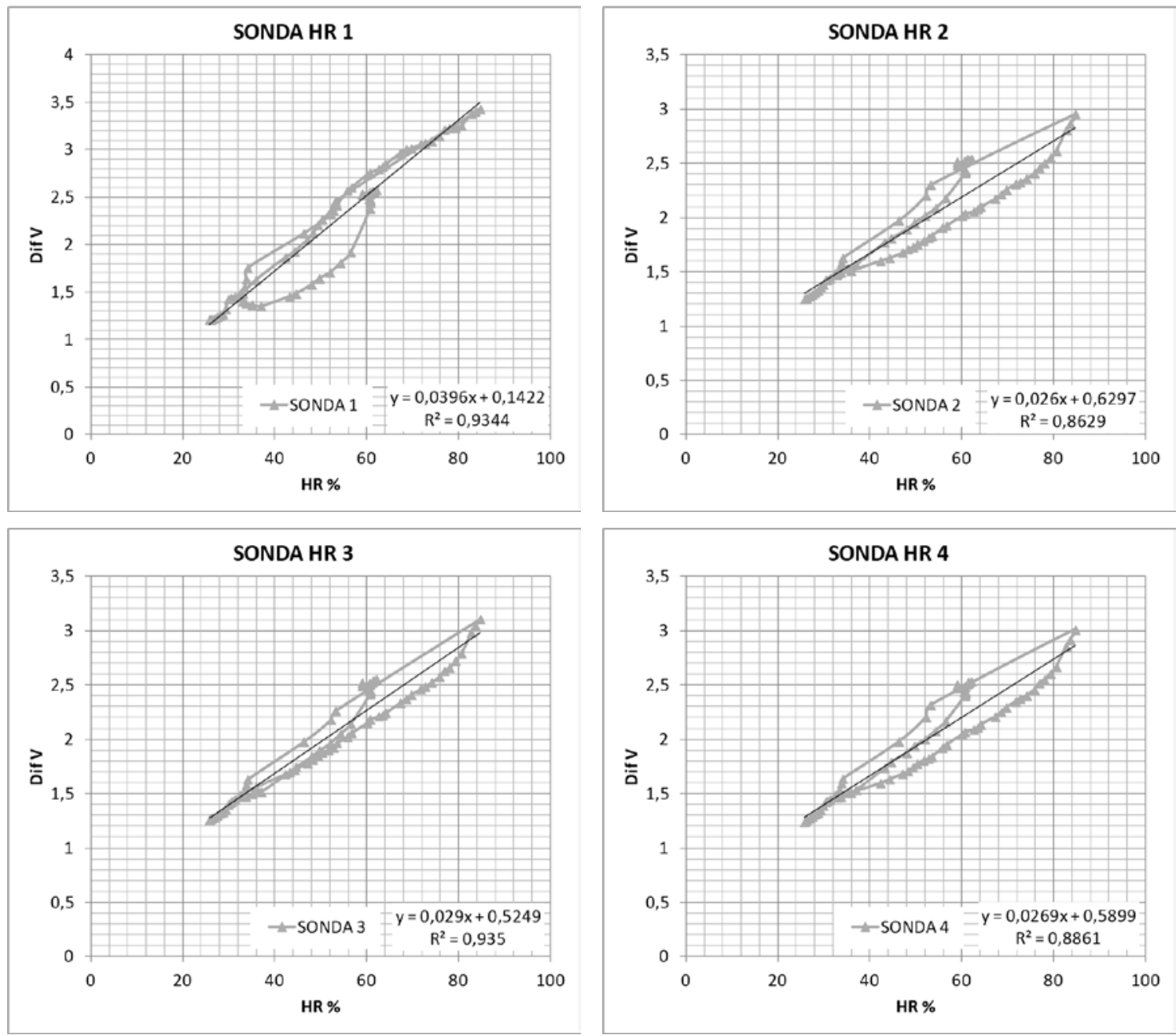

Figura B.3.- Gráficas de calibración de las sondas de humedad. 


\section{CALIBRACIÓN DE LOS MANÓMETROS DE PRESIÓN}

Los manómetros de presión utilizados en la determinación del caudal de aire circulante se han calibrado registrando su respuesta ante presiones manométricas del aire comprendidas entre 0 y 90 mmca. Las rectas de regresión resultan:
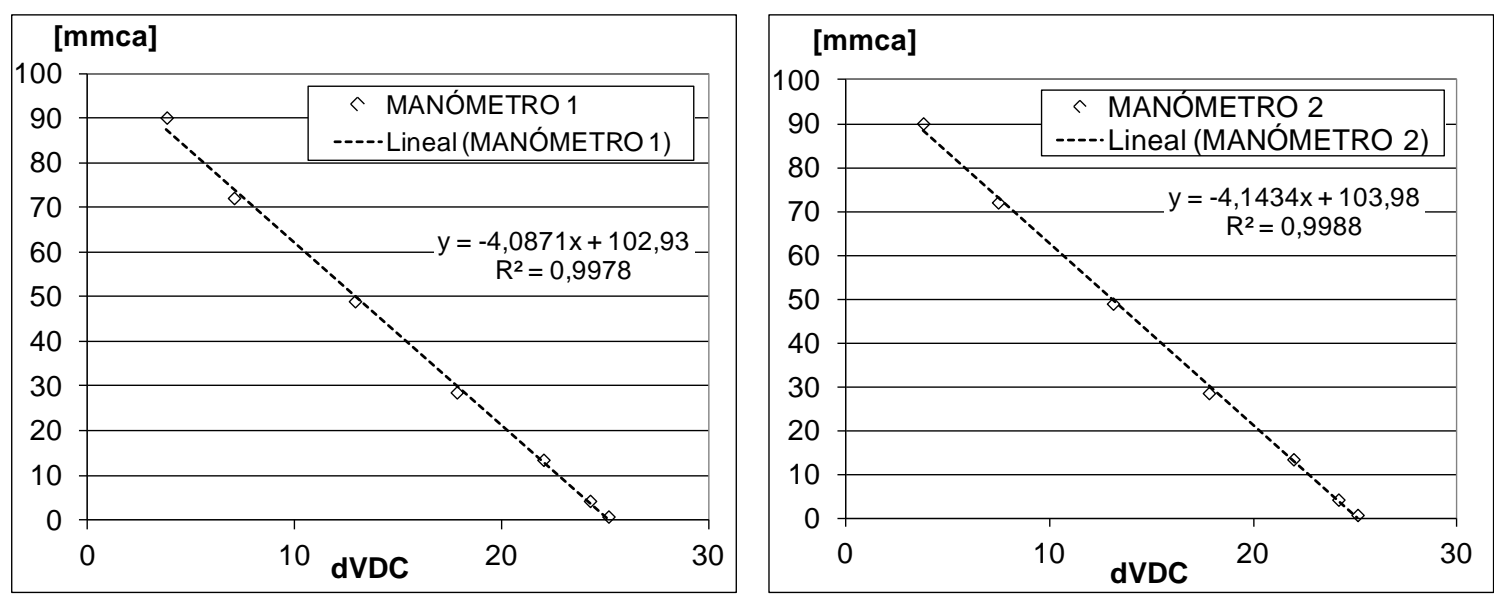

Figura B.4.- Gráficas de calibración de los manómetros de presión. 


\section{CALIBRACIÓN DE LAS PLACAS ORIFICIO}

Los resultados de las calibraciones de las placas orificio se muestran en las gráficas presentadas a continuación.
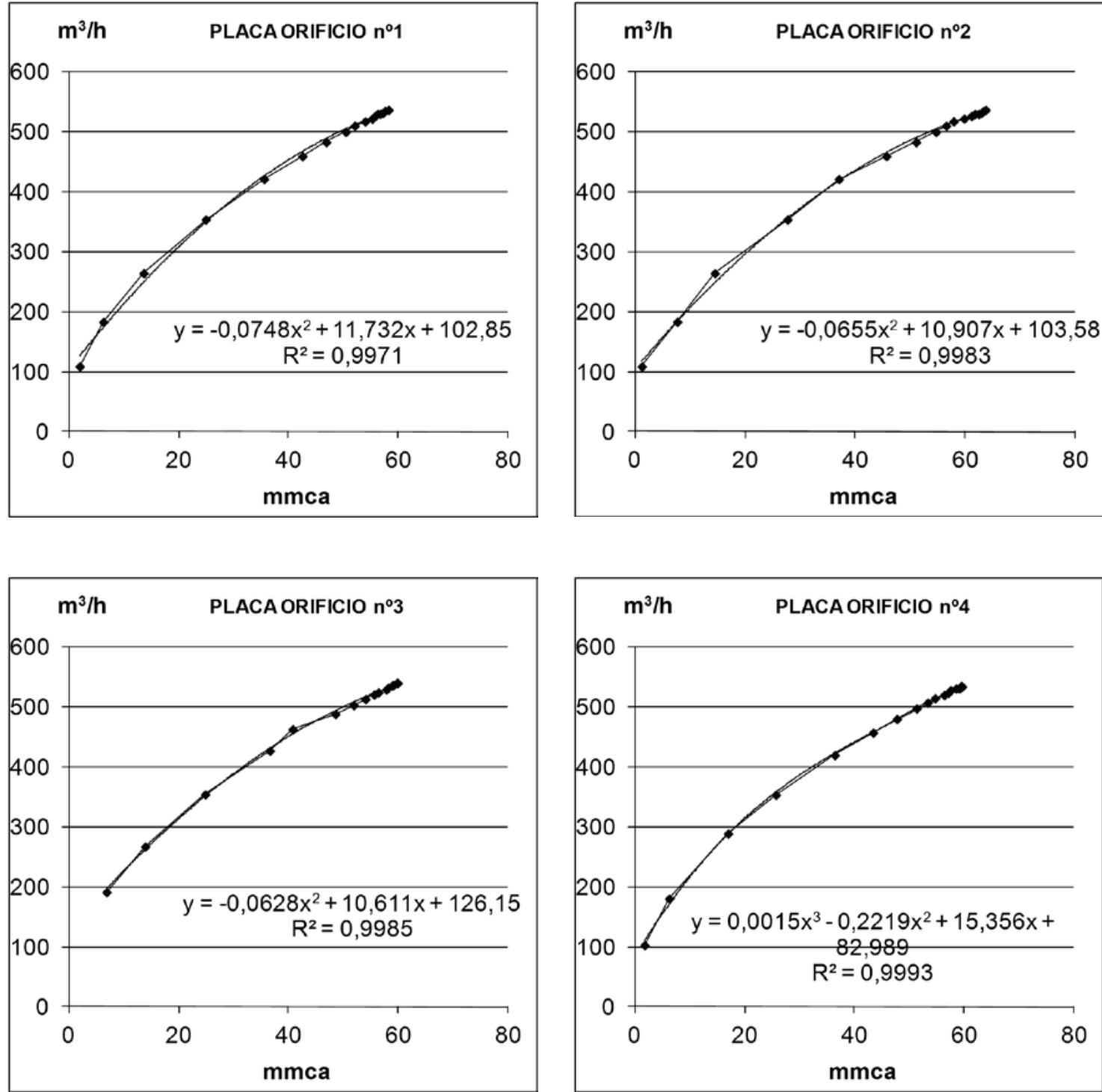

Figura B.5.- Gráficas de calibración de las placas orificio.

Estas calibraciones se han realizado en base a los datos de la tobera extraídos de la información dada por el fabricante, según la gráfica siguiente: 


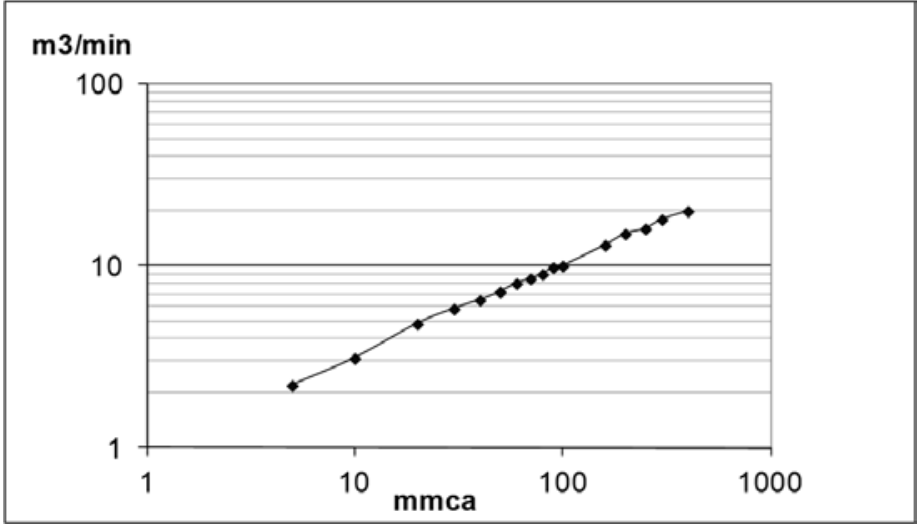

Figura B.6.- Datos del fabricante de la tobera TG50.

A continuación se muestra la gráfica original proporcionada por el fabricante: 

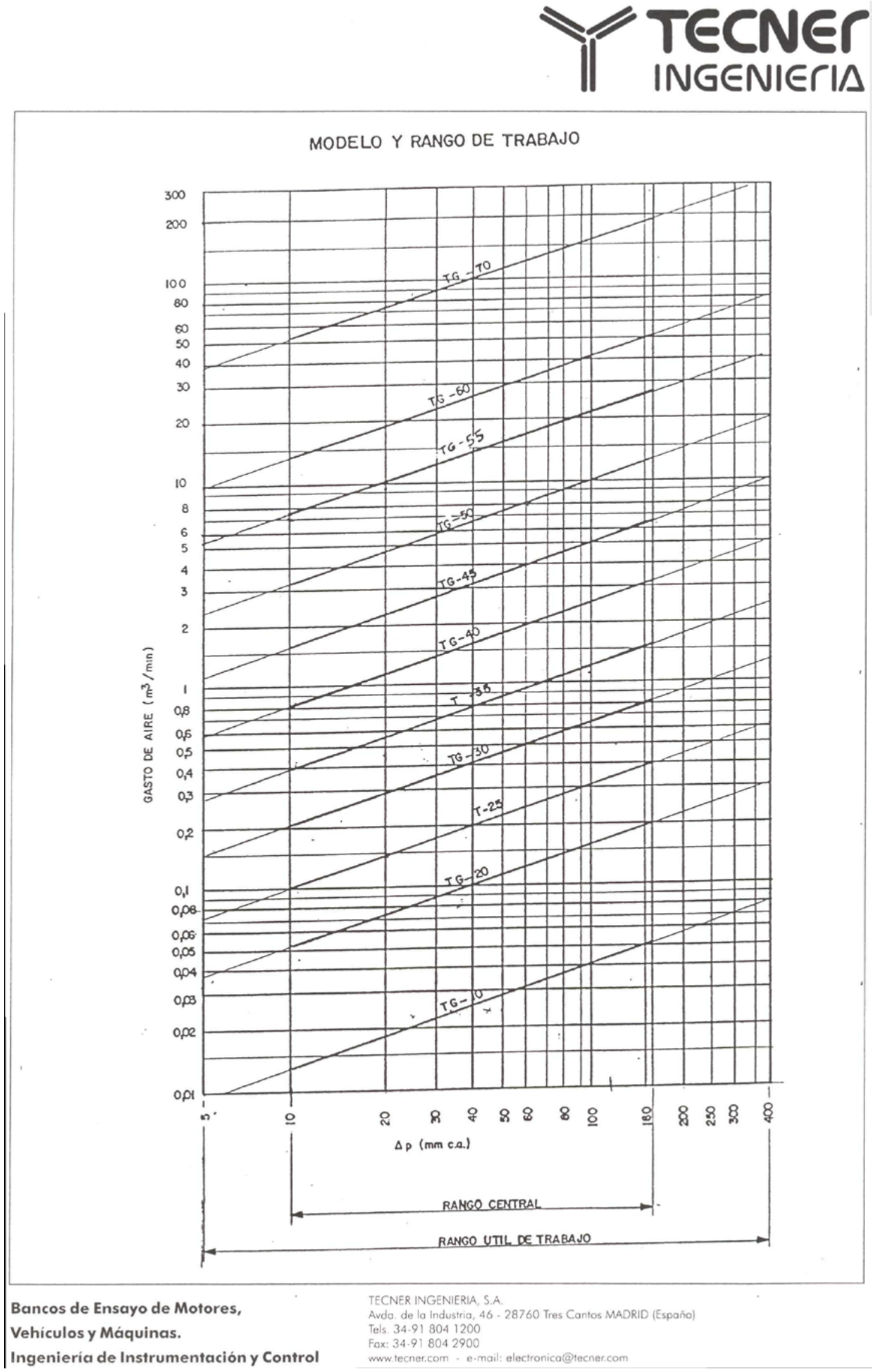

Figura B.7.- Datos de la gama de toberas TG del fabricante TECNER Ingeniería. 


\section{RELACIÓN DE FiguRAS}

- Figura B.1.a- Gráficas de las calibraciones de las sondas de temperatura.

- Figura B.1.b- Gráficas de las calibraciones de las sondas de temperatura (continuación).

- Figura B.2.a- Informe de calibración del horno.

- Figura B.2.b- Informe de calibración del horno (continuación).

- Figura B.3.- Gráficas de calibración de las sondas de humedad.

- Figura B.4.- Gráficas de calibración de los manómetros de presión.

- Figura B.5.- Gráficas de calibración de las placas orificio.

- Figura B.6.- Datos del fabricante de la tobera TG50.

- Figura B.7.- Datos de la gama de toberas TG del fabricante TECNER Ingeniería. 

